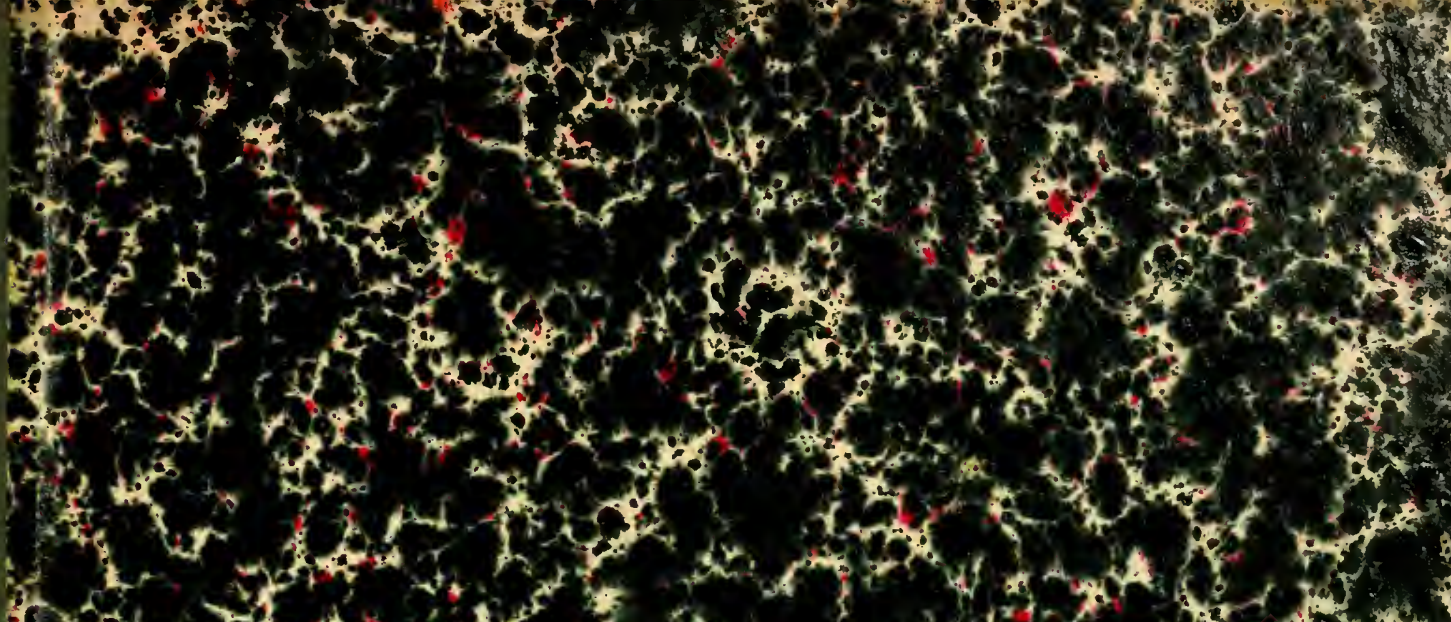

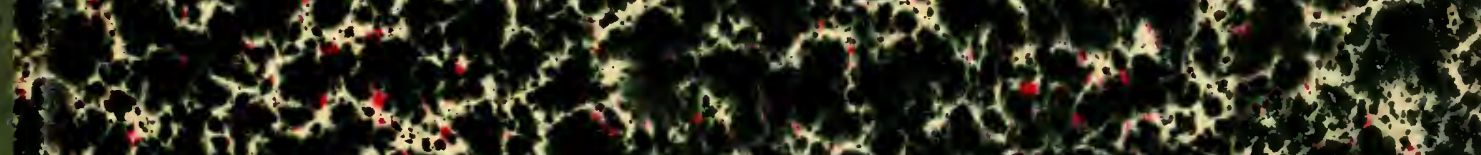

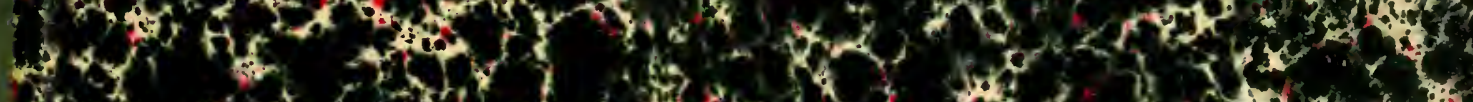

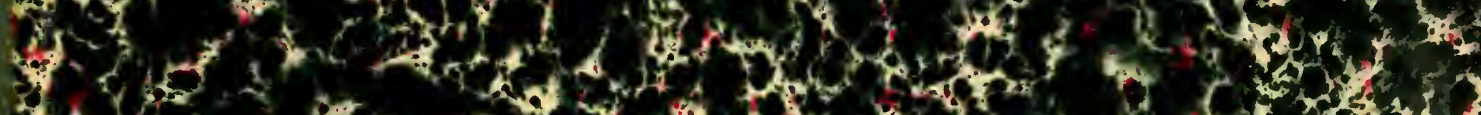

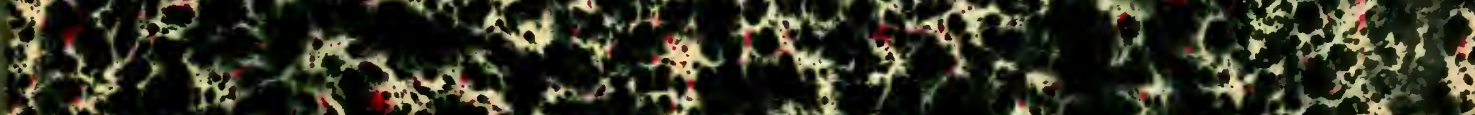

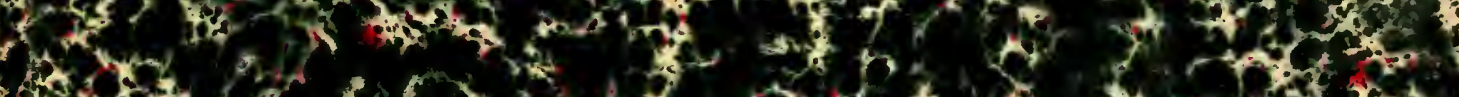

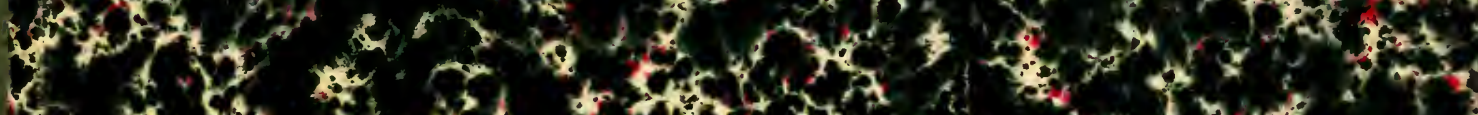

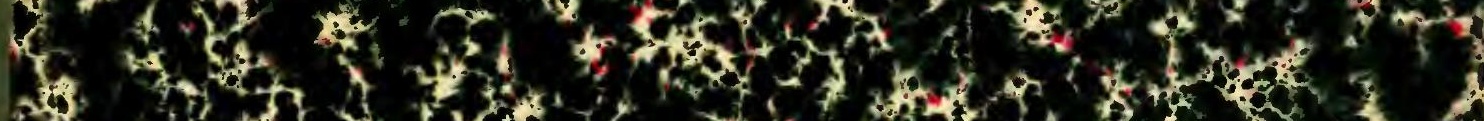

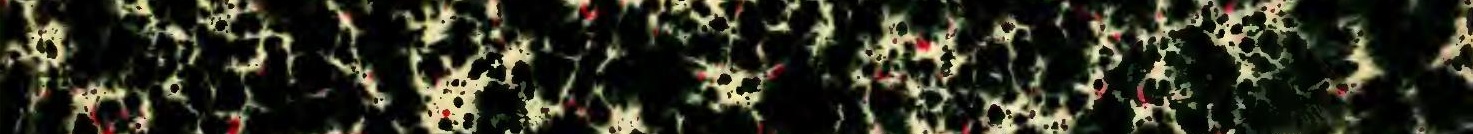

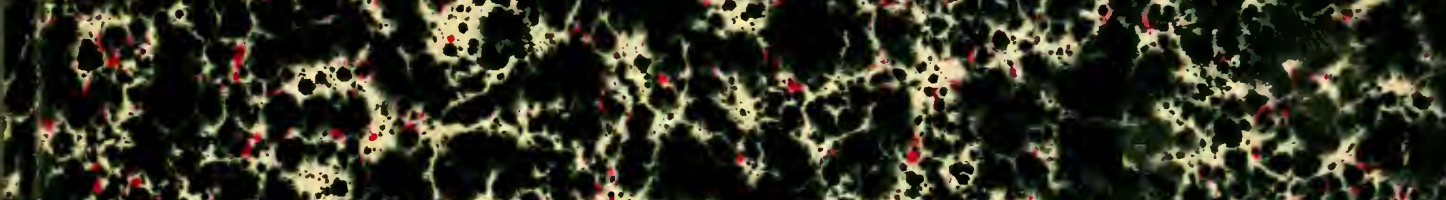
1

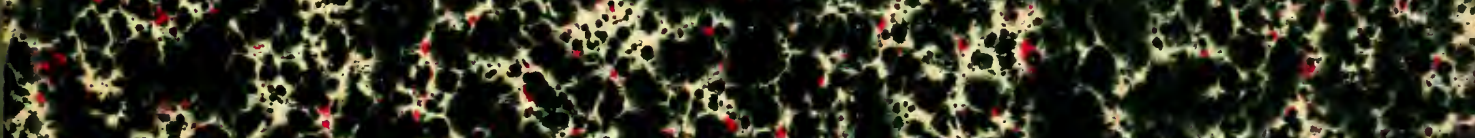

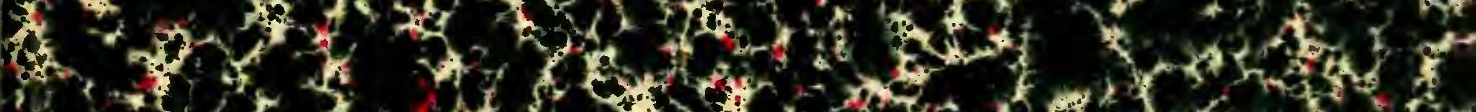
I. F t $x$.

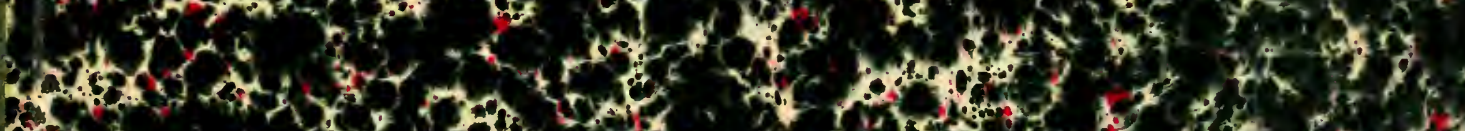
S

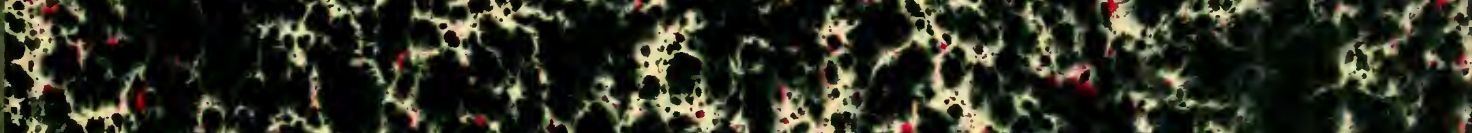

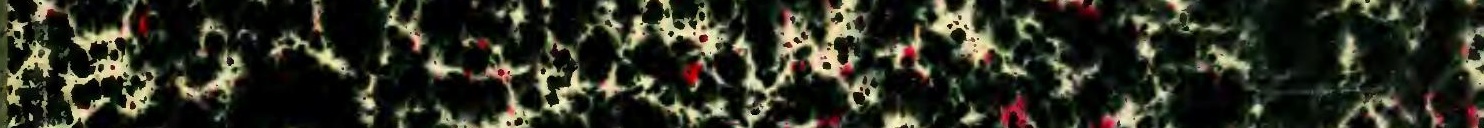

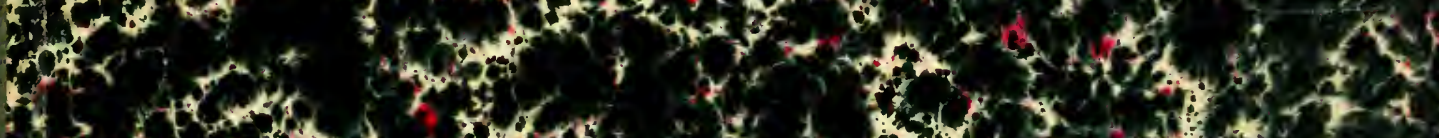

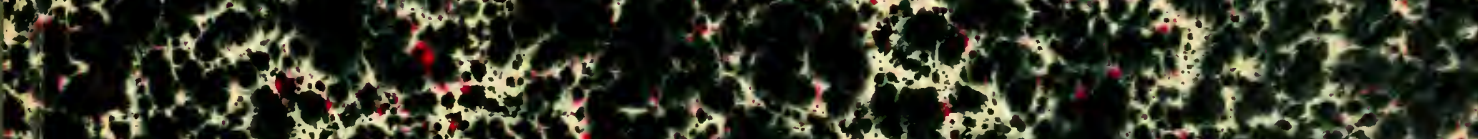

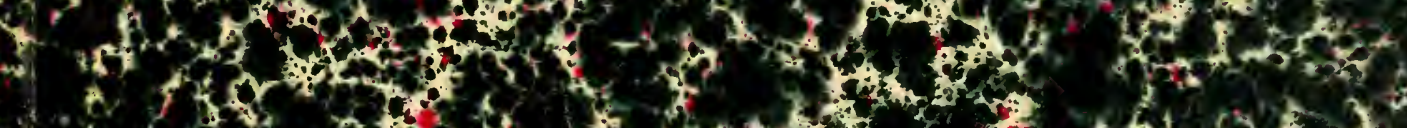

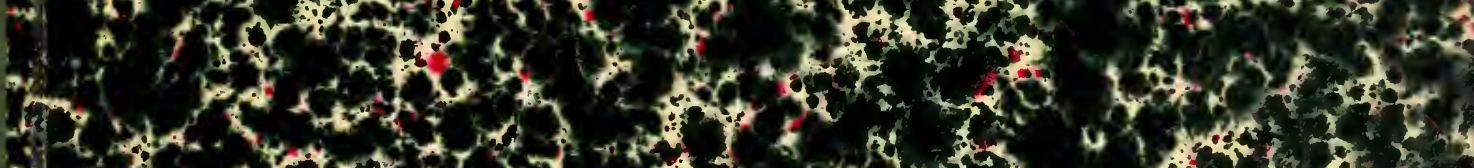

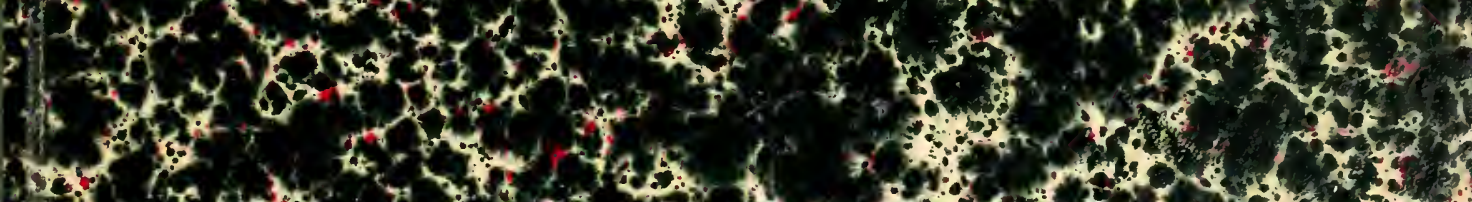
H.

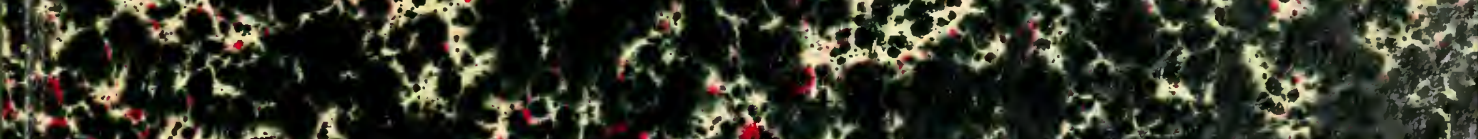

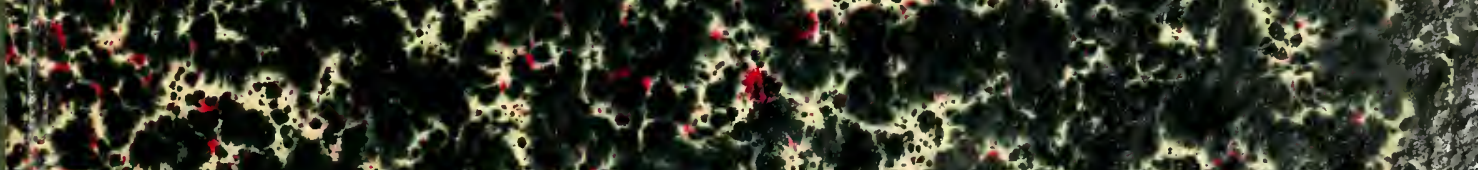

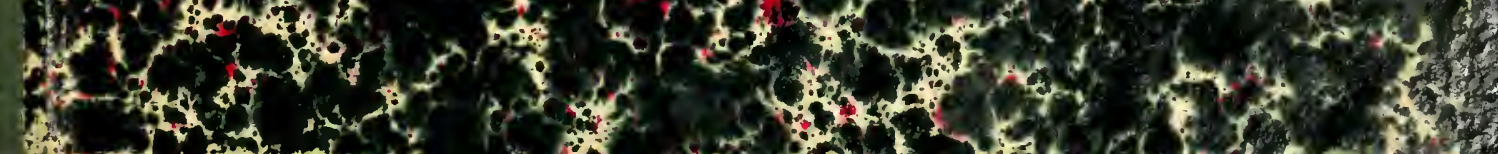









\section{Beiträge zur Kenntnis}

der

\section{Land- und Süßwasserfauna Deutsch-Südwestafrikas}

Ergebnisse der

Hamburger deutsch-südwestafrikanischen Studienreise 1911

Herausgegeben

Ton

\section{W. Michaelsen (Hamburg).}

\section{Band I.}

Mit $\delta$ Tafeln und 1 Karte. sowie 7 Kartenskizzen und os Abbildungen im 'Text

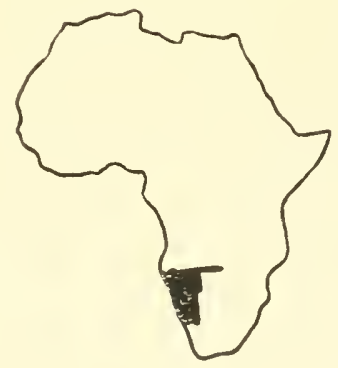

HAMBURG

L. FRIEUERICHSEN \& CO.

$1914-1916$. 
Alle Rechte rorbehalten.

1) ruck von .J. .I. Angustin in Glitckstadt und Hambure. 


\section{Inhaltsverzeichnis}

des I. Bandes.

Herallsgegeben 1914:

Vorwort des Herausgebers................. . . 1-4

IV. Michaelsex (Hamburg), Reisebericht (mit 1 Karte und

15 Abbildungen im Text) . . . . . . . . . . 5-53

K. Kraepelix (Hamburg), B ryozo a (mit 1 Tafel) . . . . . . 55-69

I. Sü̈steot (Stockholm), Isoptria (mit 1 Tafel und 2 Abbildungen $\mathrm{im}$ Text)................ $11-92$

('. vax Dowwe (München), Cop "poda mit l 'l'afol und 1 Kartenskizze in Text).................... . . . . . . . 13-103

K. Krafpelix (Hamburg), Skorpionosud solifugae (mit 6 Abbildungen im 'lext). . . . . . . . . 105-136;

IV. Michaelsex (Hamburg), ()liguehaeta (mit 1 'lafol, sowie

1 Abbildung und (i Kartenskizzen im 'T'ext).... . 137-182

Gr. Szépligetr (Budapest), Hymenoptera I: Braconidar. 183-191

G. Experier (Stettin), Hymenoptera II: Archiliymenidae

(mit 1 Tafel und 1 Abbildung im Text). . . . . 193-1!!

I. J. Kierrer (Bitsch), Hymenoptera IHI: Serplidac (Proc-

totropidae).................................. 07

(r. Exwerlew (Ntuttin), Hymonoptera IV: I chunumonida"

(mit 6 Abbildungen im Text) . . . . . . . . 209-233

N. Axaxdale (Calentta), Npongillida" mit 1 'Tafel) ... 235-244

I. Weise (Warmbrumu). C'oleoptera I: C'hrysomolidar

und coceinellidae......................

H. Bicknnom (Kassel), Colenptera II: Histeridar... . 277-282

M. Pic (Digoin), Coleoptera III: Malacodermata et

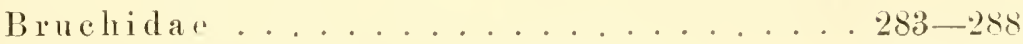

P. Lesie (Asuriere), Coleoptera IV: Lyetidae...... 289-292

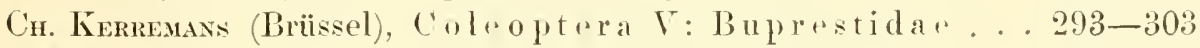

J. Moser (Berlin), ('olooptera Vt: cotonidar...... 305-309 
Herausgegeben 1915:

S.it"

Max Bersuaver (Horn in Niederiisterreich), ('oleoptera VII:

staplolinidae. . . . . . . . . . 311-321

Fis. Wersek (Wien), licptilia und Ampluibia (mit 1 Tafel und 1 Abbildung in Text . . . . . . . 323-376

Herausgegeben 1916:

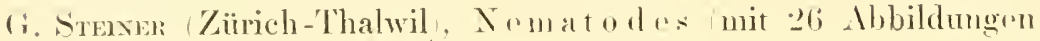

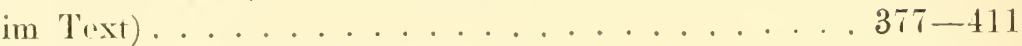

H. Frese (Schwerin i. 11. Hymonoptra Y': Apidar mit 1 Tafol . . . . . . . . . . . . . . . . . . . . 

Mrchaelsex: Land- and Sïßwasserfanna Deutsch-s̈̈dwestafrikas.

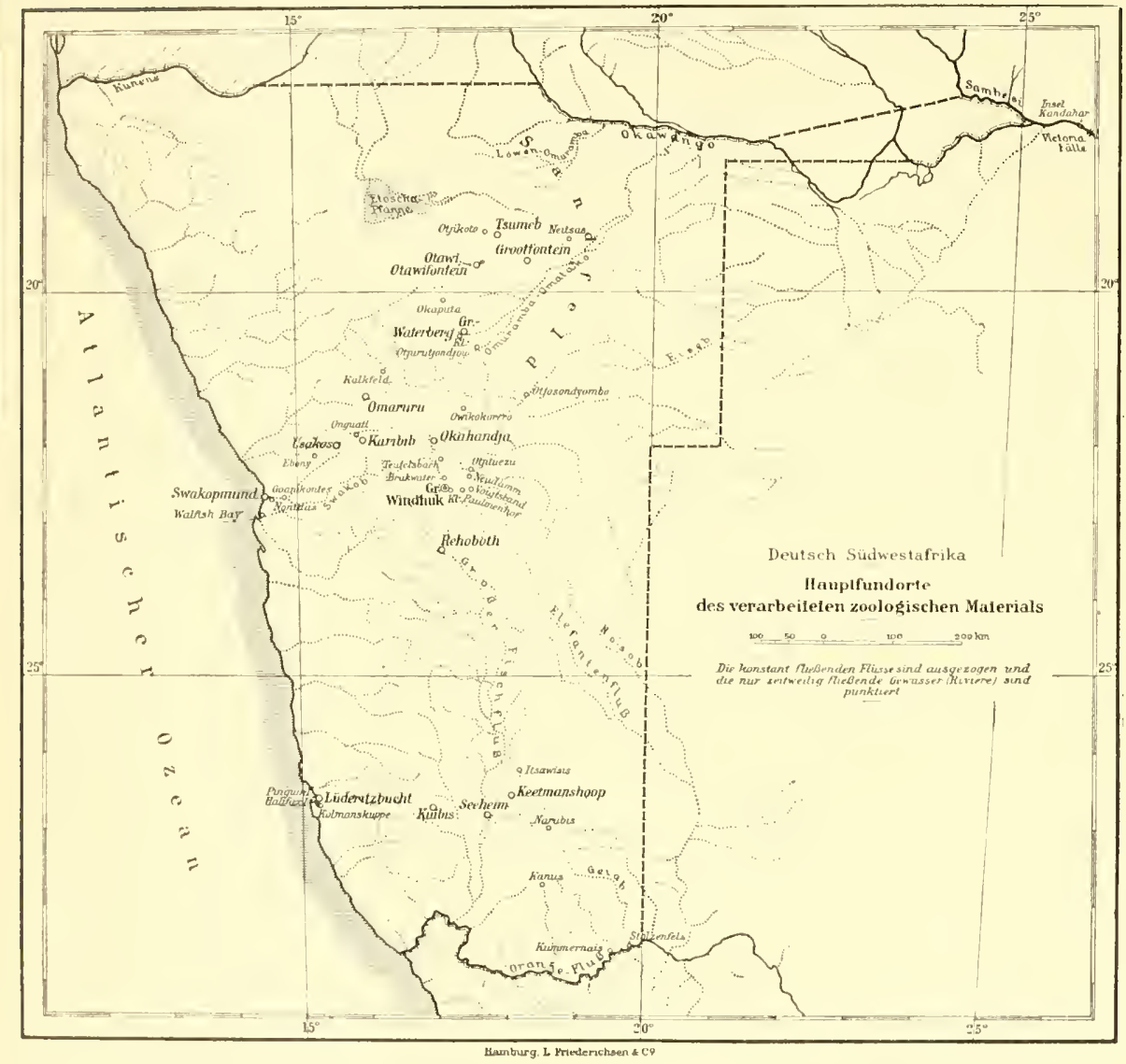




\section{Vorwort.}

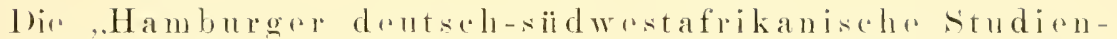

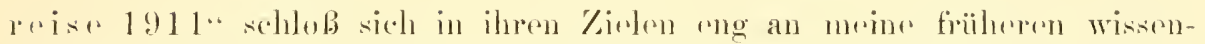

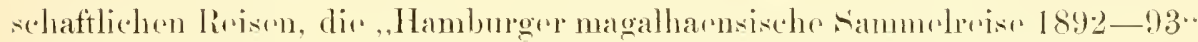
und dic ,Hamburger sïdwest-anstralische Forschungserise" 1905", an. sir.

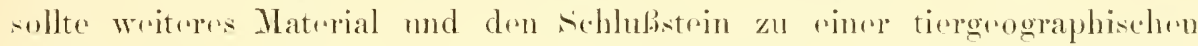

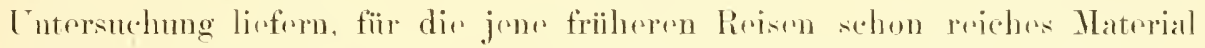

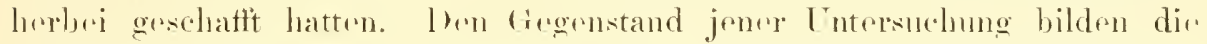
Faumen dor drei in die siidlichen Mrope hineinragenden Kontinentalspitzon. des sïdlichsten siidamerikas. Sïdanstraliens und siidafikas. Dio durch Jirstimmung und Beschreibung des gosammolten Matrials erweiterte systematische Kenntnis von diesen Fammen soll uns in den stand setzen, etwaig

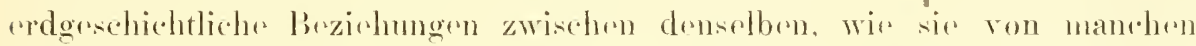
Forscheren vermuter oder als tatsächlich bustelend hingestellt worden, antzuklären.

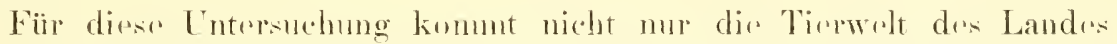

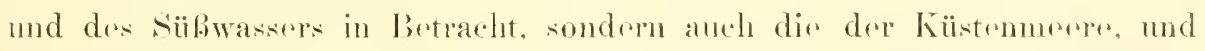

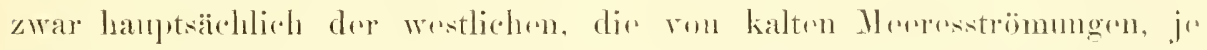

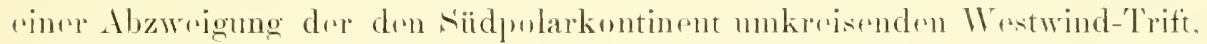

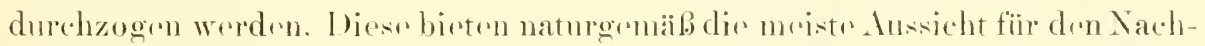

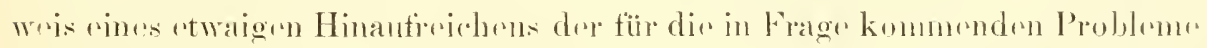

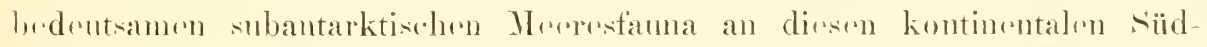

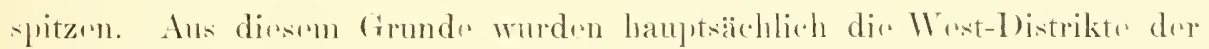

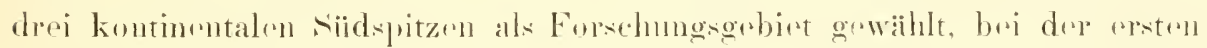

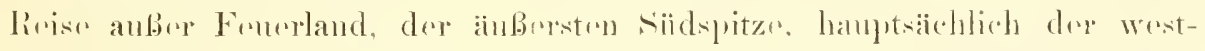

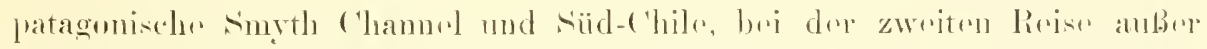

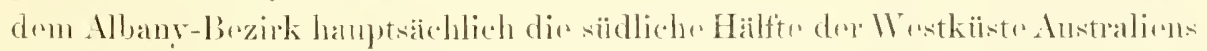

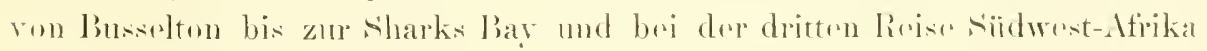
ron der Miindung dos ()ranju-Fluswes bis swaknjmund. 
Irahrend in den Veröflentlichungen iiber dis sammungen meiner beiden ersten Reisen") die Tierwelt von Kontinent und Jece nicht gesondert worden ist, soll in don Vorätiontlichungen ïber dir Ansbenter meiner afrikanischen lieise rine sondereung dieser beiden biologischen Abtrilungen arfolgen. Fis hat wich nämlich als ratsam herausgustellt, die in Betracht zu

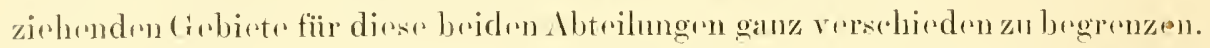
Fïr die Abtrilumg der Land- und siißwassertiore wird die politische Gernze

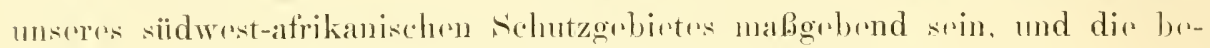

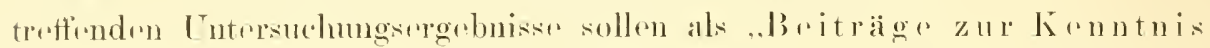
dor Land- und Sii Bwassorfauna lonutsch-siidwostafikas.

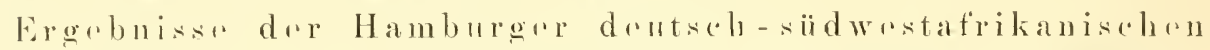
ベtudirn

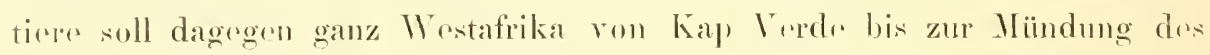

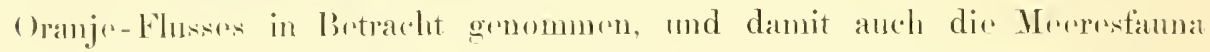

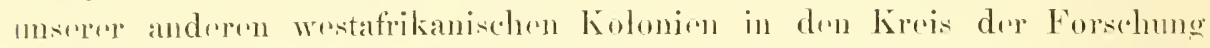
gezogen worden, und zwar aus folgendem (irunde. I as Hamburger Natur-

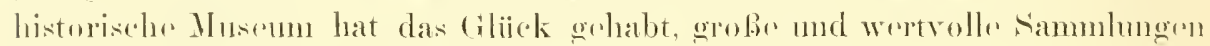

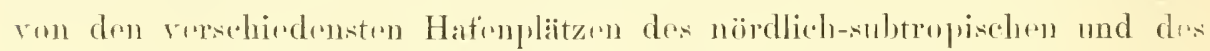

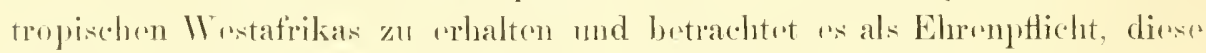

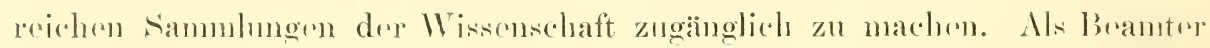

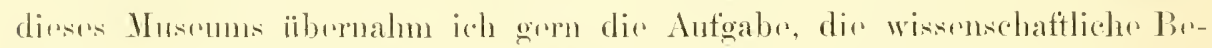
arbertung dieses Materials in die Wrege zu loiten. Kusammen mit den von

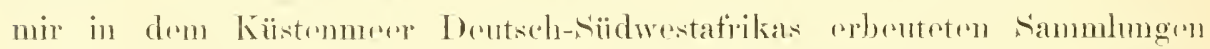

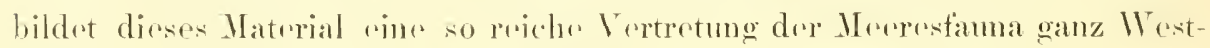

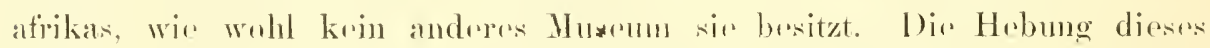

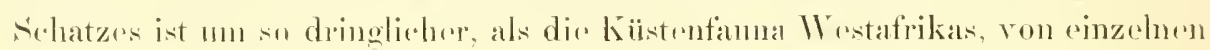

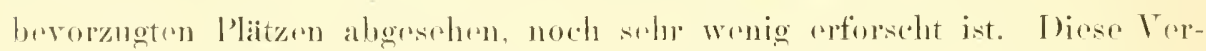
hailtnisser rechtfertigen es, dab ich dem Sammelwark iiber die Land- und

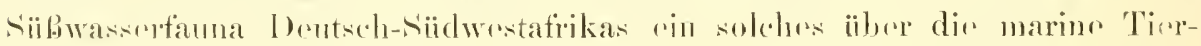

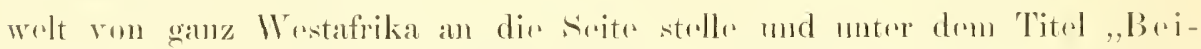

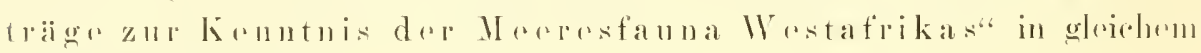
linlage loparigabe.

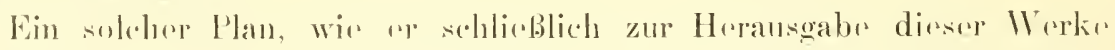

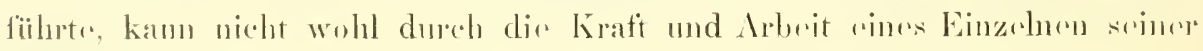

1) Ergebnisse der Iamburger Hagalhaensischen sammelreise 1592/93, herausgegelien vom Naturhistorischen Musenu zu Hamburg, Hauburg. L. Fubntancusax \& Co. (Abgeschlossen, \& bind $)$ Die Fama siodwest-Australiens, Ergebnisse der llamburger siidwert-

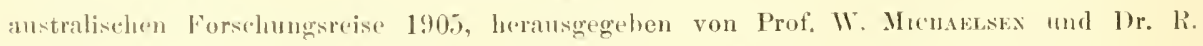

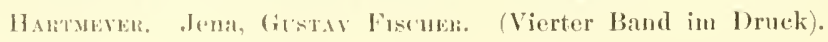


Vurvirklichung ontgegen gefiilut worden. Es bedarf daz11 der Beihilfi vieler. So habe jeh auch bri dirsem Lntremehmen vielen für Lnterstiitzungen

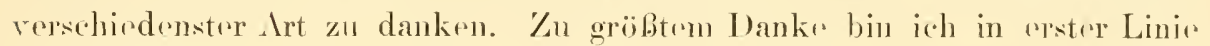

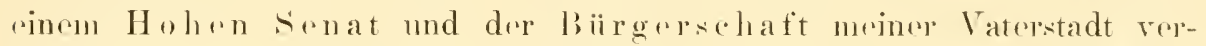

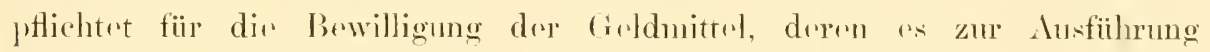

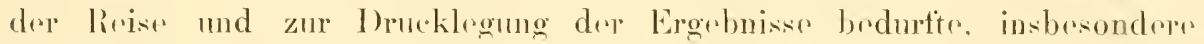

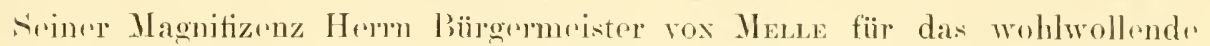

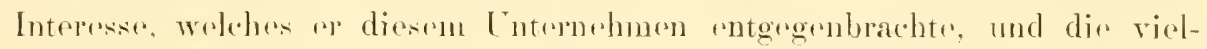

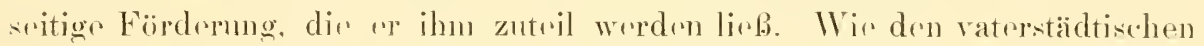
Rogierungstaktoren, so bin ich aurh dom (ionvernement des dentsch-

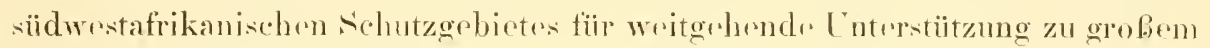

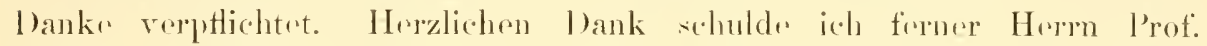

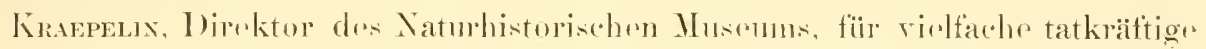

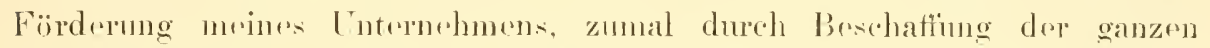
wissmsehaftlichon Anspiistung, sowir den Profissorentat des II amburgischen Kolonialinstituts für dio warme Bofürwortung bej dep

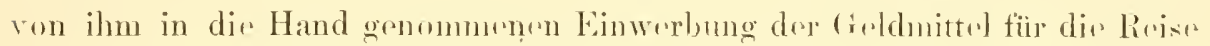

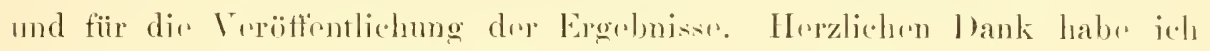
moch rielen, violen abzustatten, die als l'pivatpersonen hïbren und drüben das Lntremehmon durch liat und Tat gefördert und dir Rovise damit zu riner ersprieblichen and angenchmon gemacht haben. Es ist nicht angängig. dir. Namen all disser lrounde autzutïhrem, und as widerstrebt mir. durch rine bestimmte Auswahl das Maß der Fenndschaftedienste riner gervissen liritik zu unterziohen, war dirses Mab vielfarh derch lodigliell dureh den

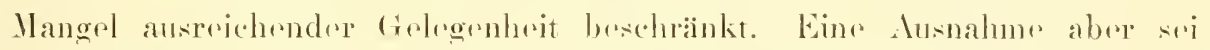

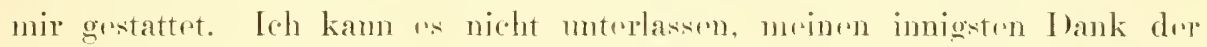

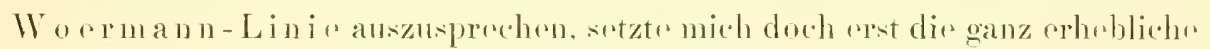

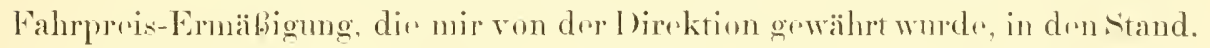

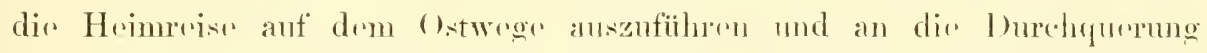

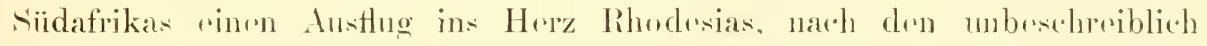
geobartigen und sehönen Victuria-Fälen anzuschlioben, und damit die Natur

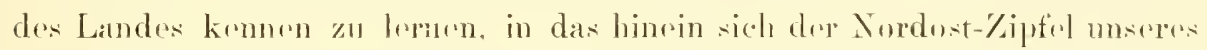

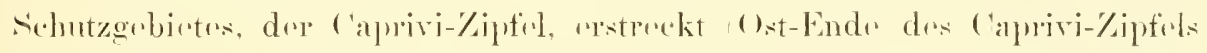

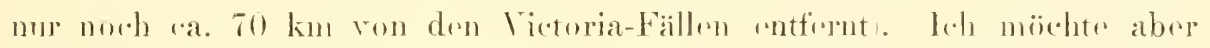

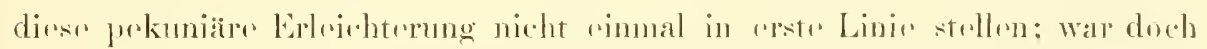
fiir den Hauptteil moines Lntremehmens viol wichtiger necle die tatkräftige

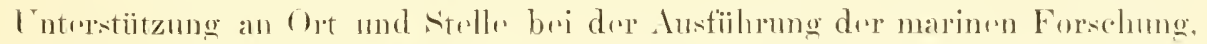

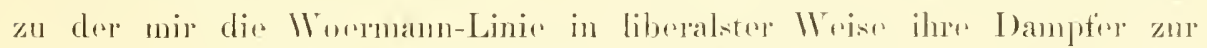

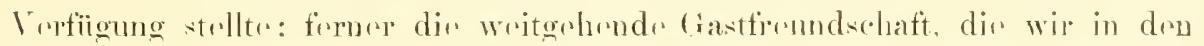


Häusern der Woermann-Linie genivbon durften, und die vielen wertrollon liatschläge und Empfehlungen. Untere letzteren waren besonders wichtig dir an dir befremender und mit der Wormante-Line Hand in Hand arberitende Firma

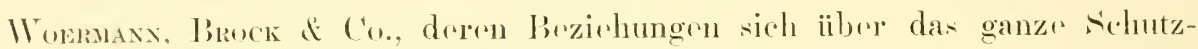
gebiet erstrecken, und deren Ciastferendlichkerit im lulande die dere auf dir Kïstenplätze beschrïnkten Wormann-Liniv verteat. Ich darf wohl moinn

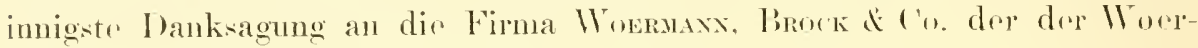
mann-Linie gewidmoten anschlieforn. 


\title{
Reisebericht
}

ron

\author{
IV. Michaelsen \\ (Hamburo.
}

Mit 15 Abbildungen im Text und 1 Kartenskizze. 

Cber kein auberemopäisches Land ist während der letzten llezennicn

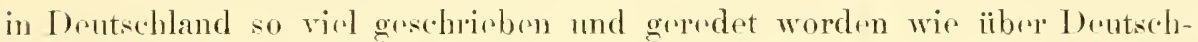
Siidwestafrika. Nicht nur Männere sondern auch Frauen und Jungframen haben sich rerpflichter gefïhlt, ihre Erlebnisse und Erfahrungen in diesem Lande einem weiteren Leser- und Hörerkreise vorzutragen. .Ja, nicht mur Lente, die dagewesen sind, anch Lesute, die das Land nie geserenn haben. wir Gicstar Frexsex, haben vorzügliche sachen darïber grseluriebrn. Bui dieser Sachlage ist es kaum möglich, viol Neurs ïbur dies Grebiont vorzu-

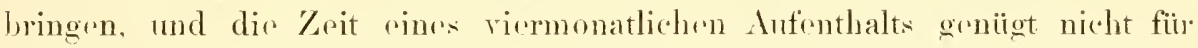

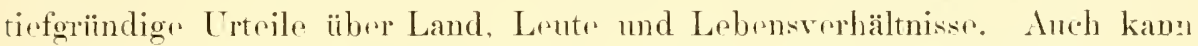
ich niclut ïber romantisehe Fahrten in bisher unbekannte Wildnisise berrichten. Es bedurfte nicht soleher kostspieliger Lnternehmmgen. Mein Forschungsobjekt, dir Fauna der Klointiore, lies sich oben so gut in der Nahe der lubturlinion rrlangen wies in kulturferneren Gebieren: demn so diek ist die Knltur hier noch nicht anfgetragen, daf sir den ursprünglichen Zustand dor Kleintiorwelt wesentlich boreinträchtigt hätte. Solbst in nächstor Xähe dor Städer, Eisenbahnen und Herestraben liegen Grebiete, die sich dis ganze Ursprünglichkoit im Charakter ihrer Flora und Klointirrwelt bor wahrt laben. Frejlich, dir Kulturfliichtor, zumal die gröberen säugetiere, waren fast ganz entwichen: aber auf dirse kam es mir anch nicht an. Mlan kann nicht zu ghrichor Zoit auf Grobwild pürschen und aut den Insekten-

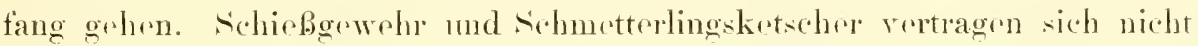
miteinander. So gern i.h als Zoolog" auch simmal das afrikanische Grobwild in freier. Wildnis beobachtet hätte. so mubte ich doch darauf rerzichten, meinen Arbeiteplan daraufhin zuzurichten. l)ie zeit war gemosen. und in dieser Zerit mubtr ich mögliehst viele weit auseinander liegende l)istrikte möglichst intensir durchforschen. Es galt also, schmoll und leicht rreoichbare Stationen zu wählen, und dirse Notwondigkeit fesselte mich an die Nachbarschaft der Eisenbahnlinien. Es kann sich demnach im vorliegenden Resisebericht hauptsächlich nur un die schilderung des Eindrucks handeln, den Dentsch-südwestafrika in biologischer und landsehaftlicher 


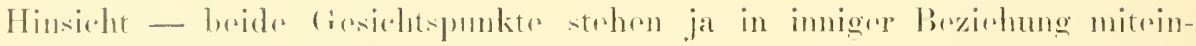
ander _ auf micls gemarelit bat.

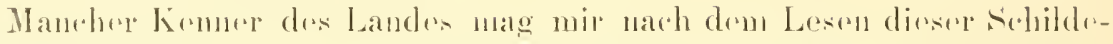

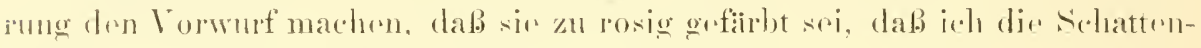

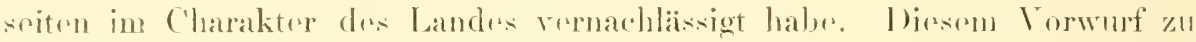

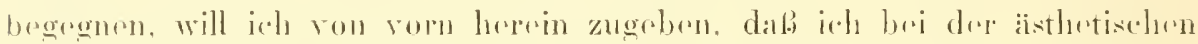

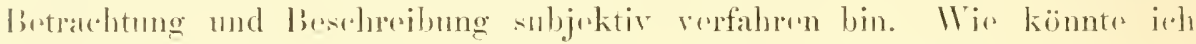

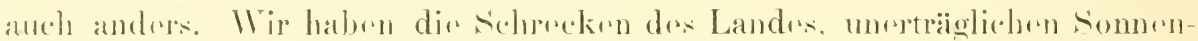

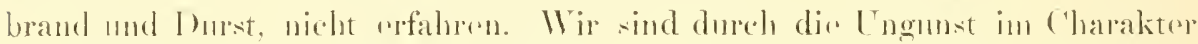

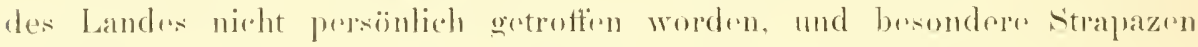

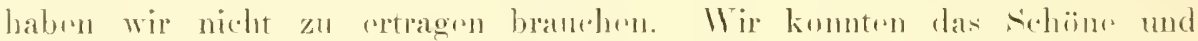

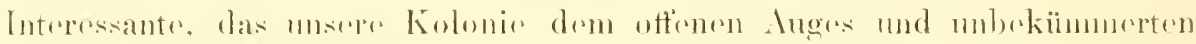

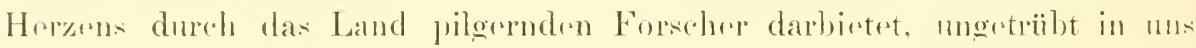

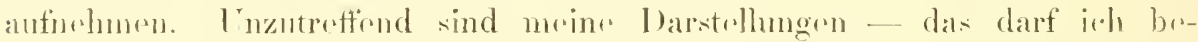
haupten - sieluedich nicht, werm anch dir Auswahl dep geschilderton

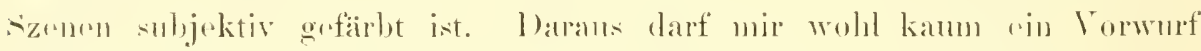

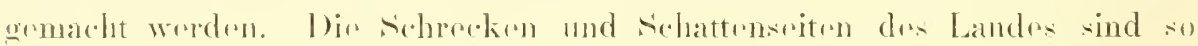

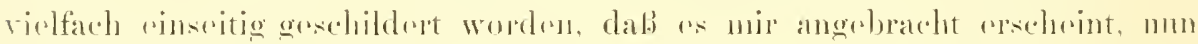

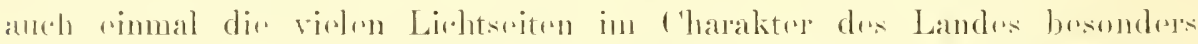

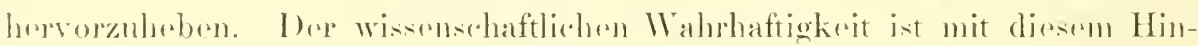

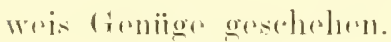

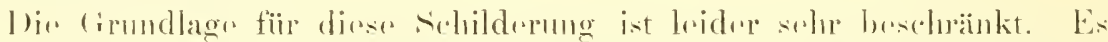

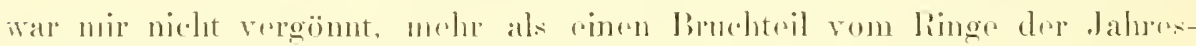

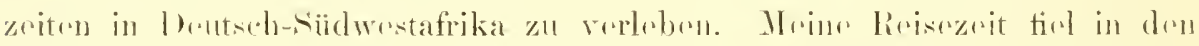

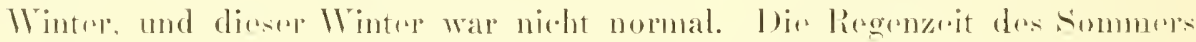

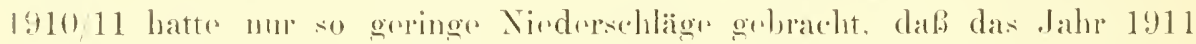

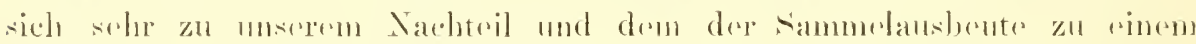

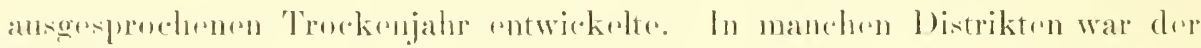

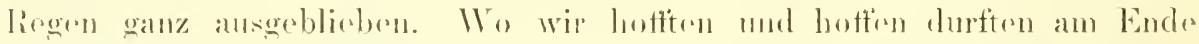

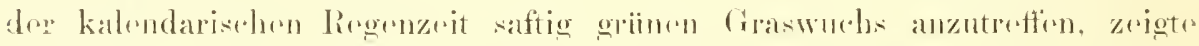

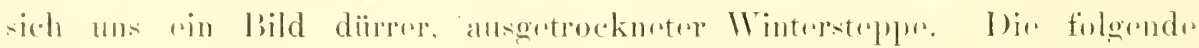

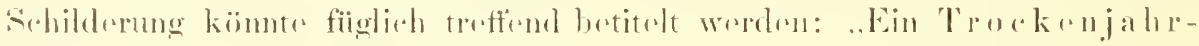
II inter in lentsole-siidwestatirika."

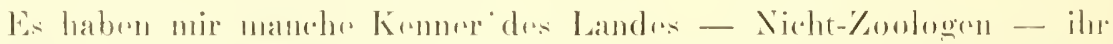

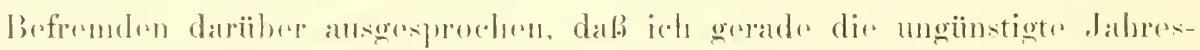

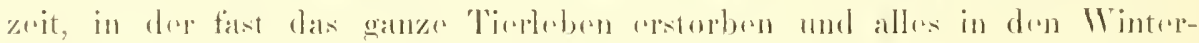

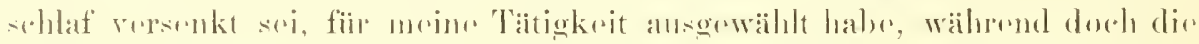

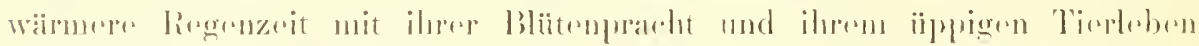

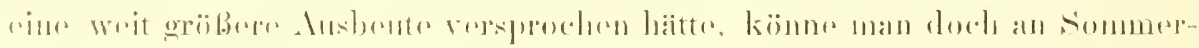


abenden der Lnsektenschwäme wegen kaum in Froirn beim Lampenschein sitzen und brauche nur immer zuzugereifen unter den Massen. dir einem

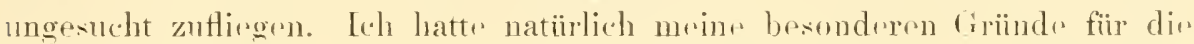
Wahl der nur scheinbar unginstigen winterlichon Jahreszeit. Joder Mlonat lat seine biologischen Besonderheiten. Die loichtre zugänglichen Fommen.

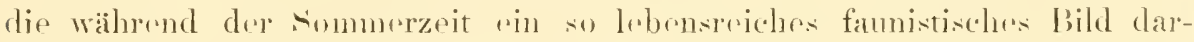
bieten, kïmen auch von Laien gesammelt werden und sind zum griißten Teil schon gexammelt worden. Wälmend dor scluinbar toten Winterzeit ist aber bisher nur wenig gesammelt worden. l)em Fachmann. der diu

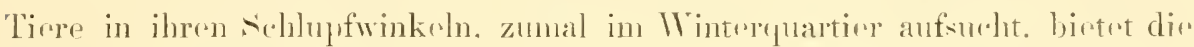
kältore Jahreszoit manches. was or in sommer kaum erbruten wiildr. Hanches Eidechseden, das bei seinex Hurtigkeit in der warmen Keit kaum

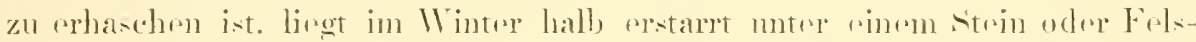
block und kam jetzt olme besondere M̈̈lue erefangen worders. Zumal fïr

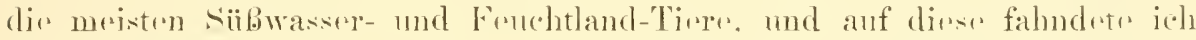

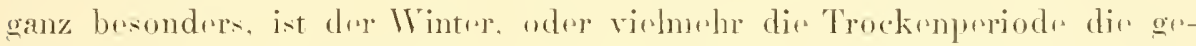

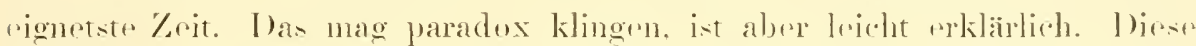
siißwasser- und Fruchtland-Tiere wir z. B. Qewisse selunecken und ()ligo(häten Regenwärmer und Verwandtr können nur dort lebrn, wo da 11 rend Wasser bezw. frucluter Boden vorlanden ist. Ninn sucher man abre während

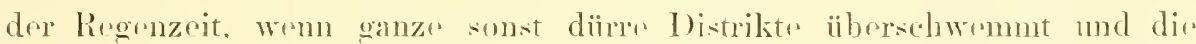
später bis auf geringe Masserlöclerer wiodter rintrocknenden Flubläufe in

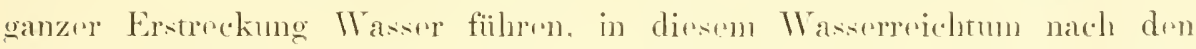
spärliclen stellen. an demen sicle das Wasser daurmd das ganze Jahr

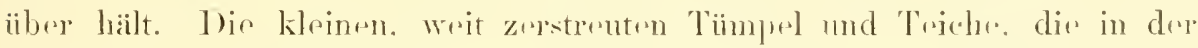
Trockenzert ausdaurerten. und dir dir Kempunkte und Reservoire der sïßrasserfauna darstellen, waren in Winter leicht aufzutindon mol boton

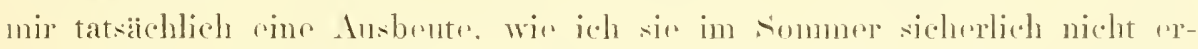
langt hätte. l)er Winterfeldzug bietert rine ganz andere. nur in gawisere

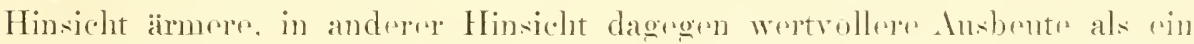
commerausthe. Ein anderes Bodenken kommt hinzu. In dem liesichtum der sommerlichen Tirrwelt peflegen ainzelno Tier-Arten seler zu äberwiegen und in enomen Massen aufzutreten. Es ist selbst für den Fachmann. der

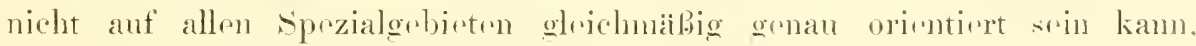
schwer, muter dimen Masion sogenannter gemeiner Arten, die den liblick

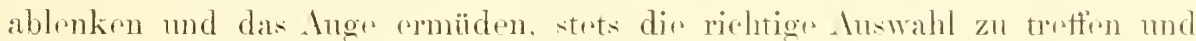

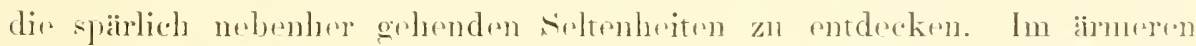
Winter kam er dagegen fast alles mituchmen, ohme sich mit lialast zu bu-

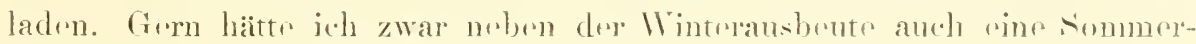


ansbeste mitgrnommen, und zn diesem Kaweke habe ich den Beginn der sammelperiode rer das Ende der kalendarischen liegenzeit golegt. Hier abre durehkrouzto höhres Gewalt, dir oben erwihnto klimatologisehr Abnormität des sommers 1910/11, moine Pläne. Jir Regenzeit, wromn von

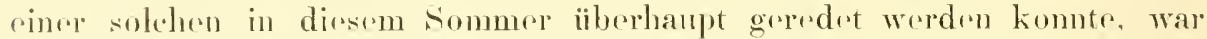

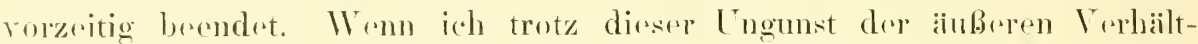
nisse mit dor Ausbente zufrieden suin darf, so verdanke ich dies ror allem

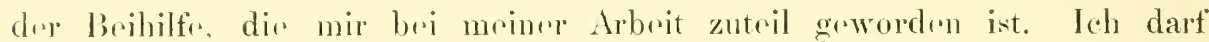
dirsen Hilfskräftrn, moiner lirisegenossensehaft, wohl rinen besonderen Abschnitt ,Personalirn" widnen.

I.h könnte diesen Abschnitt auch, die Käforehon-s ammlung g*

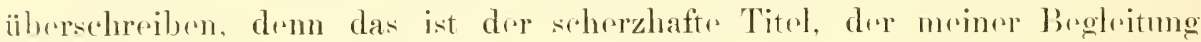
von humorvollen siadwestafrikanern gegeloen worden ist. Nachdem ieh bei meinel psten Reise dic Irwäldor Fenrelands habe rinsan durehschweifen nuiison, wal as rin hochgeschätzter Gewinn, dab sich mir bri der zweiten Forschungseise dureh siidwest-Australion ein tromer Gofahrte, Horr Dr.

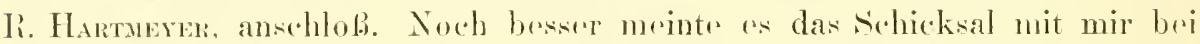

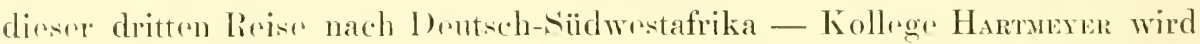

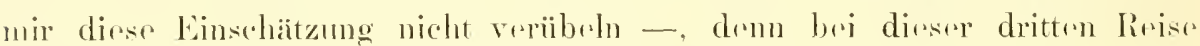
breghiteten mieh deri lisbenswärdige Danm, dis ihre Wanderlust in den l)ionst der Wissonschaft stehlen woilten, zunächst nuine Fran, den Kollegen von der Tunicaten-Forschung dureh dir interessanto Gattme Aguesia bekamnt, lusvorragend im Auffinden von Minution, damn ihro Freundiu Fräulein Henwe: Larkex ans Hamburg und doren Base, Fräulein Kanda Kentex ans Arusbereg i. Westf., bride den Minution mindor hold, aber vole

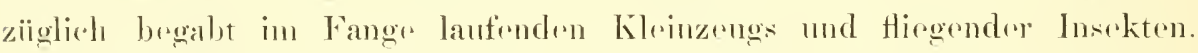

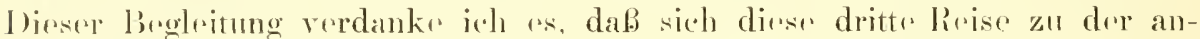

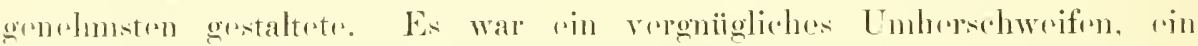
rifriges suchon und sammenn, ain intressiortes Buschtigen und Verghrichen

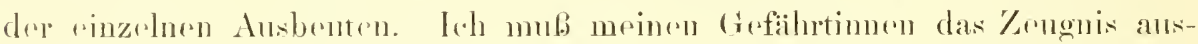

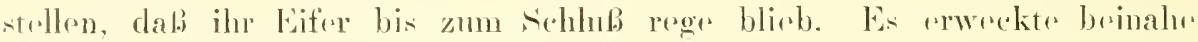

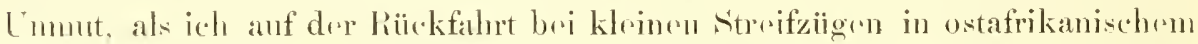

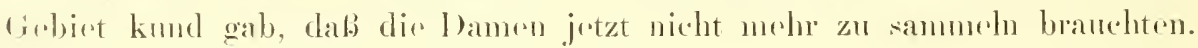




\section{Die Kiiste und das Meer.}

In wenigen stunden sollen wir nach langer Seopreses, die nur durels rinen kurzen Aufenthalt auf dem somnigen Eiland Gran Canaria unterbrochen worde. wieder festen Boden betreten, dentech-afrikanischen Boden! Fichon rasselt der Anker in die Tirefe. Fwakopmund in Sicht! Aber wo? Dort im (Jiten liegt oine dichte Nobelbank, sonst ringsum nur die unruhigen Mogen des Atlantisehen Ozeams und darïber der blaur Himnel. In jener Nobelbank muß das lang erselente Land liegen, und bald enthüllt rs sich anch unseren Blicken. J)ie höher strigendes Sonne besiegt den Küstrmmebel.

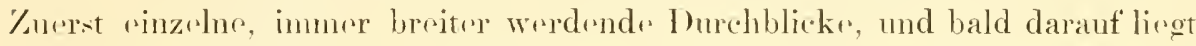
die Kiiste frei ror uns, ein wunderbares sommenbelenchtetes, farbenprächtiges l'anorama. In der jotzt kristallklaren Luft liegen die Häuser der stadt scheinbar regellos hineingestrent in den blendend weibgolben sand des Hachern, gen Osten sanft anstrigenden Landes, in der Jitte. zwischen der kloinen alten und der groben neurn Vole, dicht gedrängt. weiter anBon abor zorstrent. wis eino bunt zusammengewürfoltr schlecht zusammengehalteno Herde, kleine und gröbere selulplen und Häusere, zirrlichr Villen, Paläste und schlanke tumartigo fiebilde. lon Hinteromend des l'anoramas bildret linkerserits der scheinbar dicht hinter dor stadt anfsteigende, tatsächliell

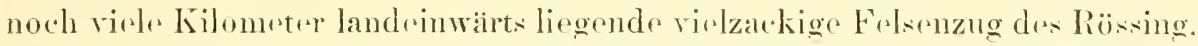
desion belonchtete Flächen sich in warmem Helleot scharf ron dem lenchtenden lilau des Himmels abhrben, während dir tiefen Fichluchten and dir

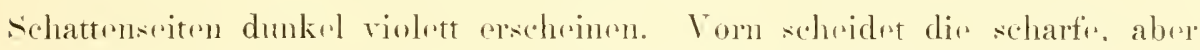
beweglicher Linie des schnereig weiben Brandumgegischtes das Land som Masser. Mber hiermit ist die Mannigfaltigkeit des Bildes nicht erschöpte Währond sich das Land links so weit der lilick reoleht in rinförmiger lileich-

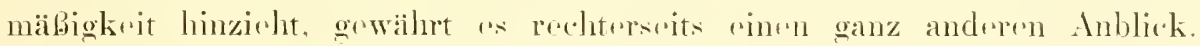
Hier treten die berïchtigten Wanderdïnen der Namil, bis an das Ilex heran und werfen durch ihr gegen das Himmelsblan schart abstechendes

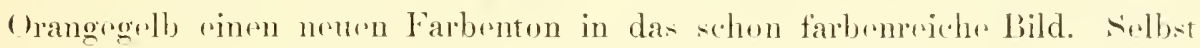

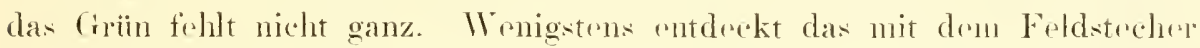
bewatthete suchende. Aluge hier und dort zwischen den Häuseren der stadt frisch-grïn. IB̈̈sche, augenseheinlich in künstlich beraissertrn fiartenanlagen. Lnd dort. der dunkelgrüne streif, der sich zwischen dir orangegelbe Inimenlandschatt und den wobgelben sand des Flachlandes rinschiobt, ist das nicht anch Buschwork? Wirklioh, der Foldstecher verrit auch hier im Freiland anscheinend ziemlieh üppigen Busclibestand. Das int das swakop- 


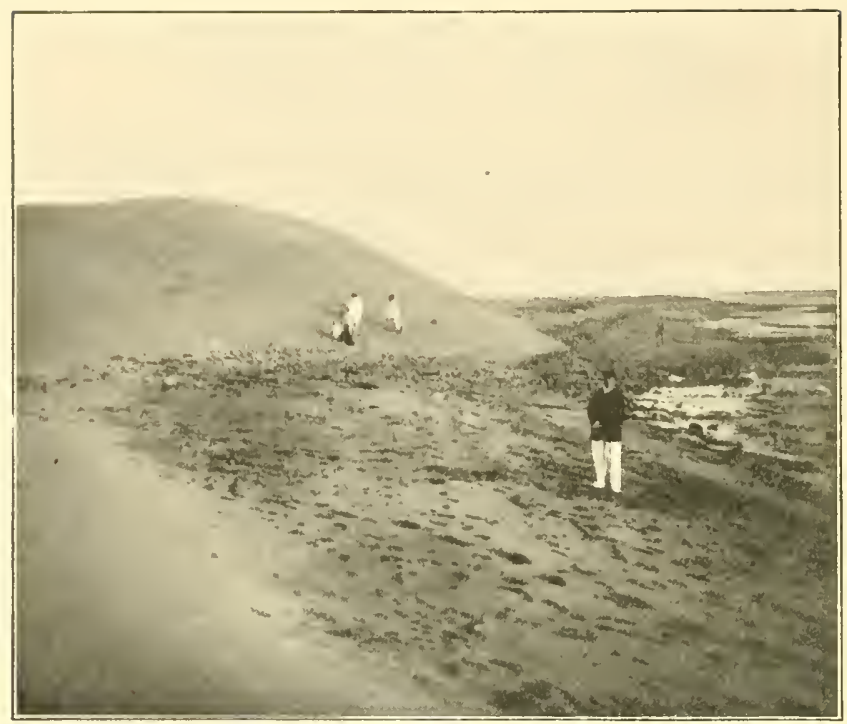

Fin. 1. Meeresstrand und Wanderdinen hei swakopmund.

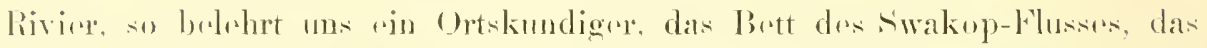

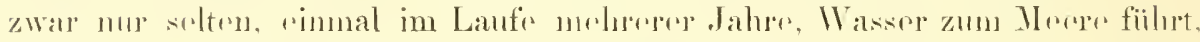

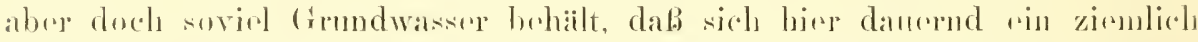

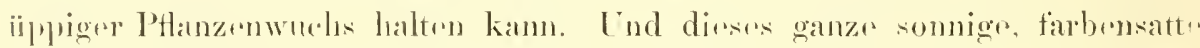

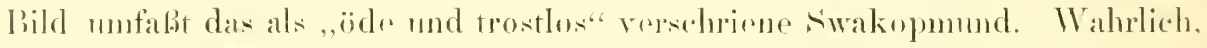

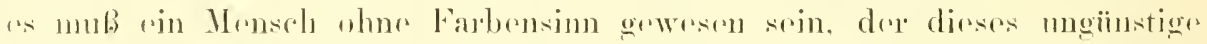

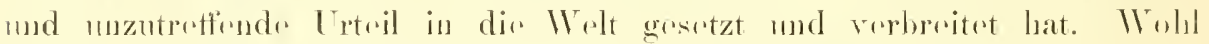

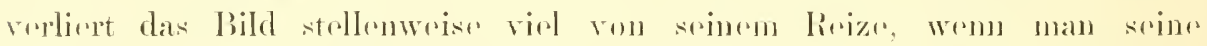

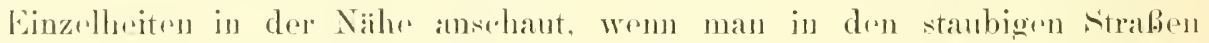

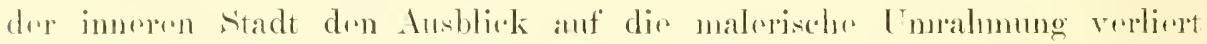
oder, im Schwoibre soines Angesiclits dureh den lockeren sand watend.

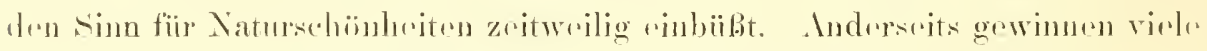

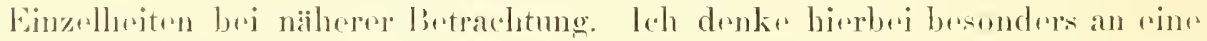

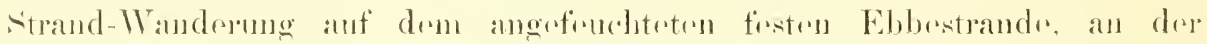

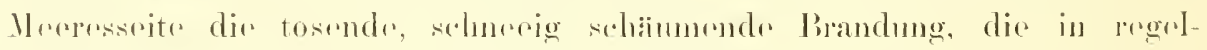

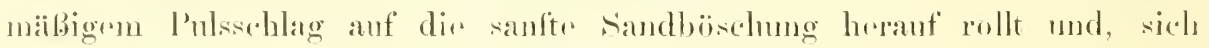

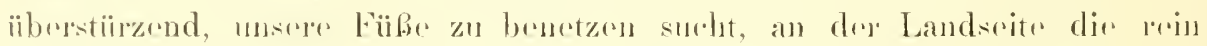

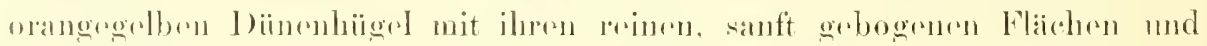

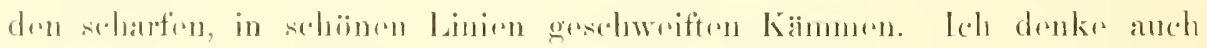

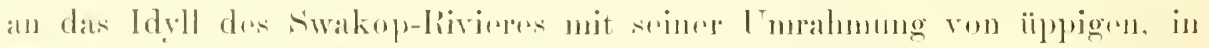

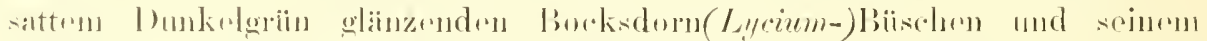

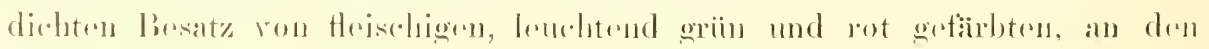




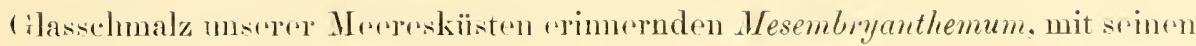
Lagunen, in deren glatter ()bertliche sich eine schar rosaroter Flamingos -pirgelt. Ich denke an rine Karrenfahet dieses hübsche swakop-Rivies

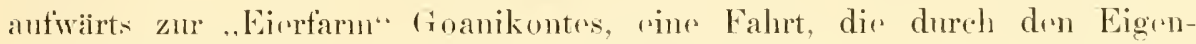
willen rines Maultieres recht seherzhafte Entrepbechungen und Verziogermegen mlitt. Fnd dazu das gesellige Loben im ()rt! Wahrlich, ich habe ijdere und langweiligere Orte auf dor Mrolt konuen gelernt, auch an der sidwestafrikanisclurn Küste (Waltisch-Bay ††').

Aber jeh bin mit meinen Gedanken der Schilderung ron unserer Ankmuft rorangereilt. Noch sind wir an Bord des...Adolf Woermann". Wohl streckt swakopmomd mit der langon neuren Molr gleichsam rerlangend seinen Arm nach uns ans, abore as oproicht uns bri woitem nicht, and rin Naher-

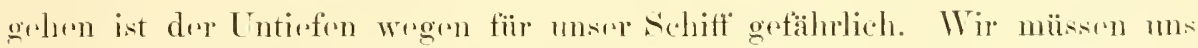
ako einem dor ron kloinen schleplern gezogenen Leichter anvertranen. Aber wio hineingolangen? Wuchtig hobt mod senkt or sich längsseits unseres 1)amptors auf den ozeanischen Wogen. Das sonst iibliche Einsteigen ibber das Fallerep ist ansgeschlosson. Dor Leichter würde as in don resten Hinuten zermalnen. Dir Wormann-Linis wrib anch hire liat. Eins der an Land zu betördernden l)anun wird höflichst aufgefordert, sich anf einen

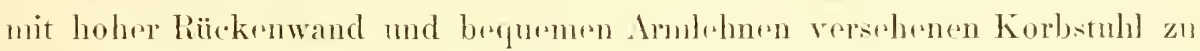

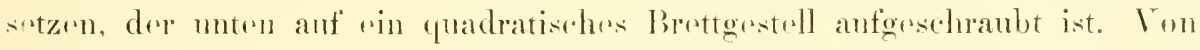

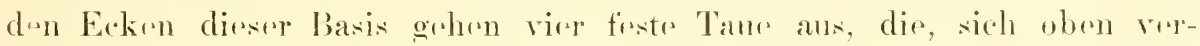

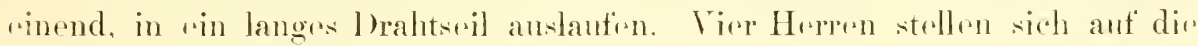
vien Burettere der Basis, sich an den Tanem festhaltend, und num wird dere

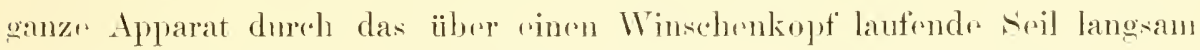
in die Hïhr gehoben. Mie Winselye droht sich rasselnd nach auben, und rinige sokunden solowelst die lobende. Fracht aubenbords frei in der Luft

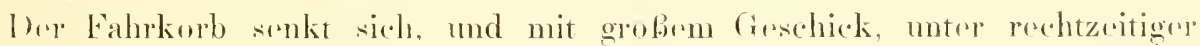

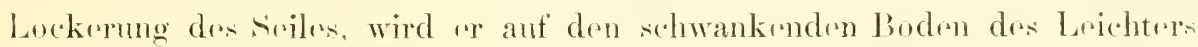

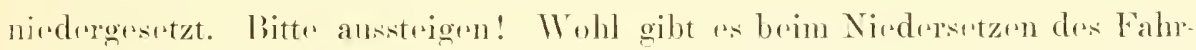
korbes auf den Leichter rinen kleinen stob, und manchere der Herpern hat

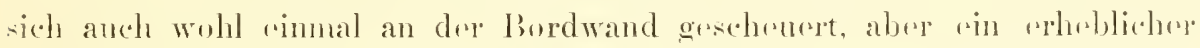
I nutall soll bei dirser Art des. Iusbontens noch nicht vergekemmens sein.

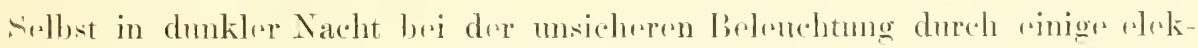
trische Lampen sahen wir eine Familie mit kleinen Kindern auf diens Meise

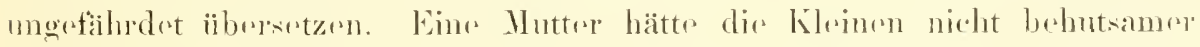

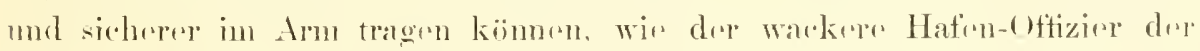
Hoermann-Linir. Narhdern wir on ainmal komnen golernt hatten, zogern

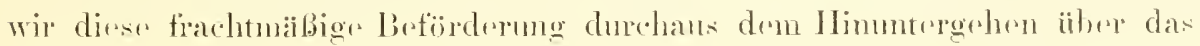


meler oder minder wacklige Fallreepl vor. Etwas woniges Lomstände macht man mit den dunkolfarbigon Passagiorn, Kou-Negern und Kapland-Katfirn,

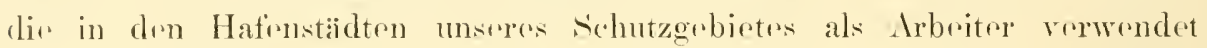
werden. Dirse werden dutzendweise in rims der groben Frachtnetze ge-

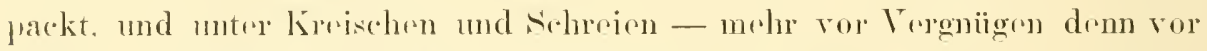
lngst - motleert sich das moten angekommeno Notz seines zappelnden, kollernden und balgenden Inhalts. Nur in selur seltemen Fällon ist das

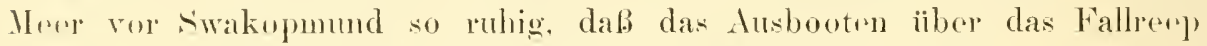
möglich ist. Selbst das Anlandsotzen an der Mole kann meist nur auf jeme Wrise ausgefülurt werden. D)er Ankonmende lernt bei diesem Landen

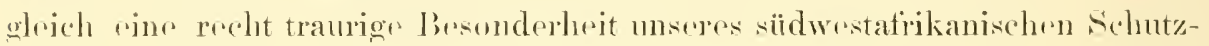

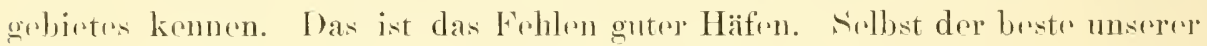

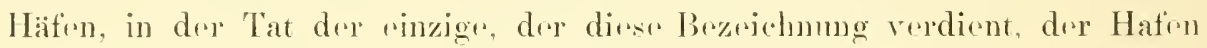
von Lïdrritzbucht, kam diser Ausbootumgsmethodr nicht ganz entraten. I) a l)ampfer mit gröborem Tirogange nicht in das Imnere dos Laideritzburchter Hafons rinlaufon kïnnon, mïssen sir dicht hinter den Hafen-Eingang zu Ankor golıen, wo sio drom noch kaum rorminderten Anprall der lureh den Fingang hrorinrollenden Wogen ausgesitzt sind.

In swakepmond tanden wir fireundliche Aufnahme in der ,Ritter-

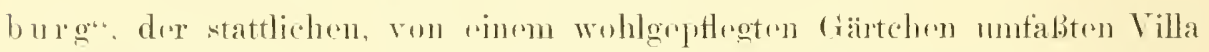
der Woemuann-Linir. Hier lornten wir zum ed'strn Mal dir berïlemte afrika-

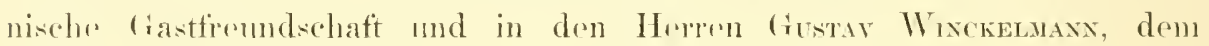

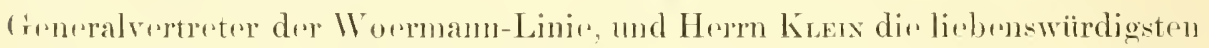
Ciastfreunde kennem. Mir kan diese Gastferundschaft 10 so muhr zu statten, als ieh gleich nach meinere Ankuntt in swakopmund rom Arzt ins Butt gisschickt woude. Iels hatte mir an Bord des , Adolf Worrmann", an deme die

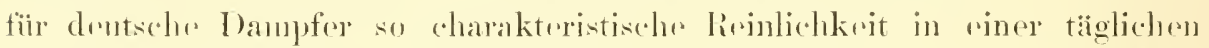
Interwassersetzung des l'romenadendereks zum Ausdenck kam, durch Aus-

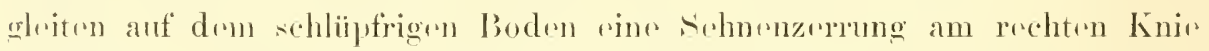
zugezogens. die nur dureh vollständige liuhe gröndlich und schonoll goherilt

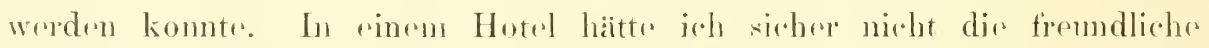

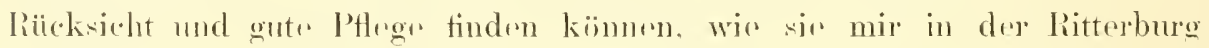

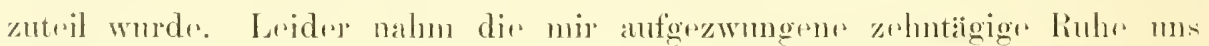

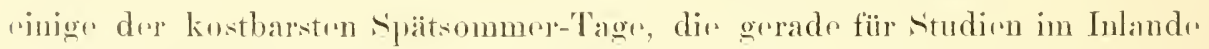

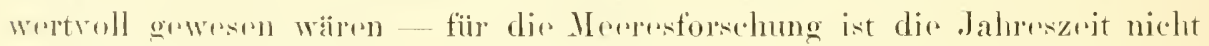

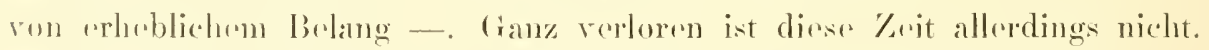

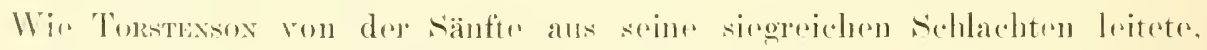

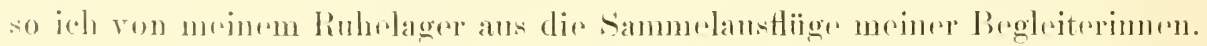
\%um P'räparioraal wordo das Lazarett. Dio ganze Ebbrostrand-Fauna von 
Swakopmund wurde mir zugetragen, sodaß ich genug zu sichten und zu konservieren hatte.

Stwakopmund bildete das Hanptquartior fiur die Erforselmug der marinen Kïstenfauna im mittleren Teil I)entsch-sïdwestafrikas. Auler drn Ftrandwanderungen ron swakopmund ans gaben mir zwei Fahrten anf dom Kästendampfer .,Linda Woermann". zu denen mich Herr Wixckemand in liebenswïrdigster Wrise einhd, Gelogenheit, anch andere Punkte der Kïstr. Walfisch-Bay und sandfisch-Hafen, kennen zu lernen.

Die Kiiste des nördlichen und mittleren Dentech-siidwratafrikas ist zum vorwiegenden Toile aine sogenannte Ansgleichskïste. I)is millionenjährige zerstörende. Wirkung der Brandung hat die meisten der ursprïnglich hervoragenden Trabe der Kïste abgetragen, die Felsen zu Bböckens. Kiesen nud sanden zermalmt und mit diesem Abban-Material die zurïckweichenden Buchten ansofiillt oder durch sandnehrungen abgeschlossin. bis sehlir.Blich rine einförmige, mohr odır woniger gradlinige sandstrandKïstr rntstand. Das pflanzliche, und infolgedessen auch das tierische Lebru an eincm solchren sandstrand ist sche ärmlich. Ihie lockeren, ron dire

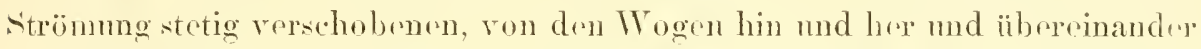
grwïlzten Sandmassen bieten den sich fistsetzenden Pflanzın nud Kïstrntieren keinen genügendon Anhaltspunkt und dahor anch den verschiedenen kriechenden und schwimmenden Tieren, die sich im Gowirr und Wurzelwerk von Pflanzon and zwischen festgewarhsenen Tiren zu vroberom pflegen, keine Wohngalegenheit.

An ringen stellen der Küste ist as den Brandungswogen abor nocll nicht gelungen, die Folsenvorsprïnge gänzlich abzutragun. Hier ragt das felsige skelett des Landes noch froi ins Jyer hinaus und bireter nit seinum festen Folswänden. mit den Klüften und Höhhungen dirser Felsen and din durch Block- und Stein-Anhäufungen gobildeten Vorstecken riner charaktrristischen Tirrwelt Gelegenheit zur Entfaltung. Ein solcher für den \%oologen gïnstiger Kïstrnpunkt findet sich gleich sïdlich ron swakopmund, jenserits

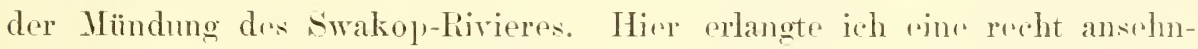
liche Ansbente. An der Lnterserite drer Strine, in dern Kilüten und spaltun der Felsen haften zierliche serrosen und mförmlich. Manteltiere (Ascidienı. deren von einex warzigen, bramnen, solllederartigen Hant (den Manted) umhïilter orangegelber Weichkörper der an der alten Mole angelnden Jugend ron swakopmund als rorzïglicher, bequem zu erlangender Fiseliküder dient. $\left.{ }^{1}\right)$ An don Folson sitzen rosarote serpocken und. sich fost

1) Dieselbe Ascidien-Art, Pyura stolonifera (Heller), wird in Kapstadt und Durban und vermutlich auch in anderen siidafrikanischen Feestädten massenhaft gesammelt, und die 


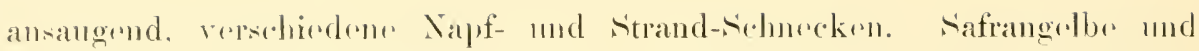

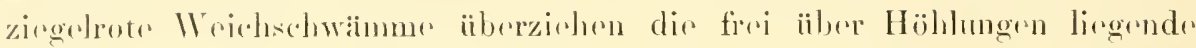
[ntersoite der steine. Sabullen mit purpurrot gobandertem Kiemenaplearat.

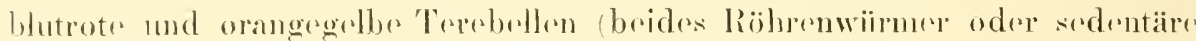

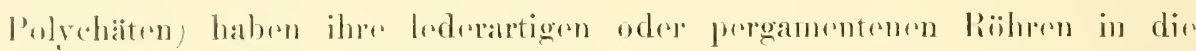

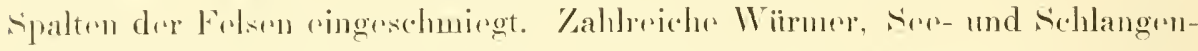

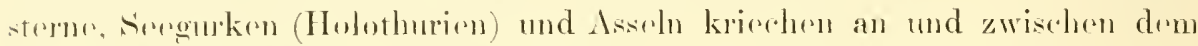

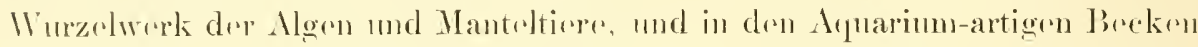

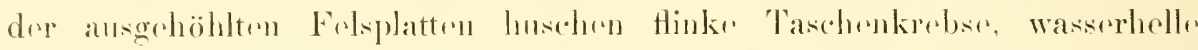

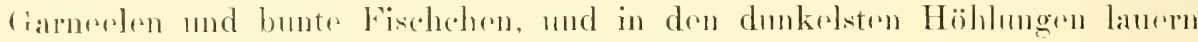

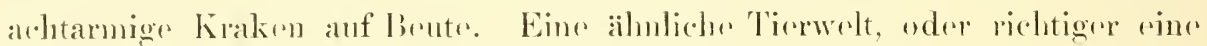

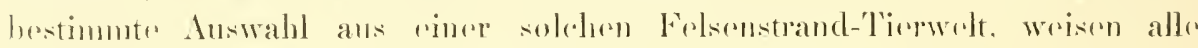

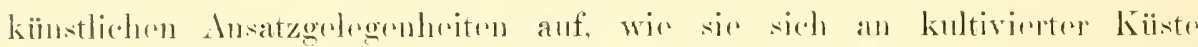

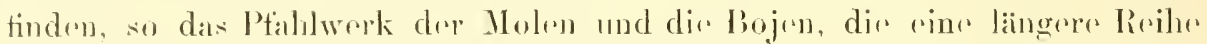

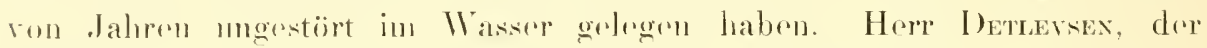
Kapitain der ..Linda Mormanm", war so lobenswiirdig, mir mit dor

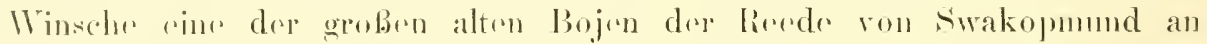

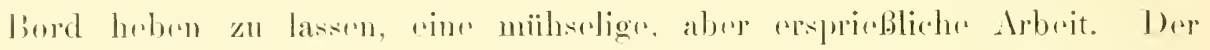

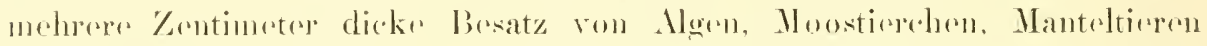
and serpocken, von dem ich mit rimem moibolartigen Instrument grobo

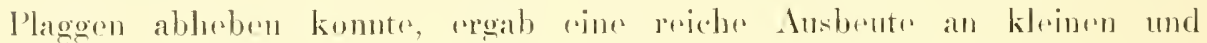

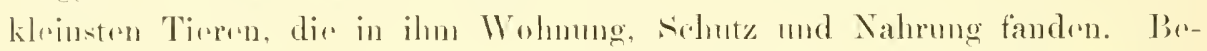

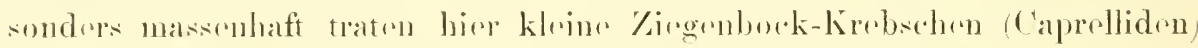

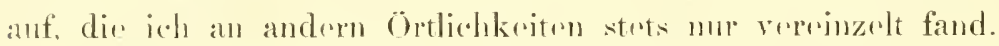

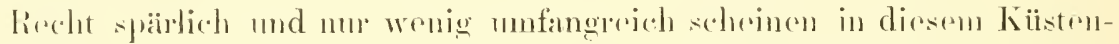

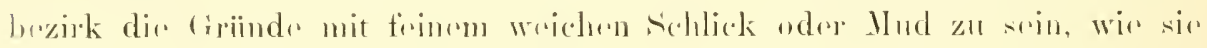

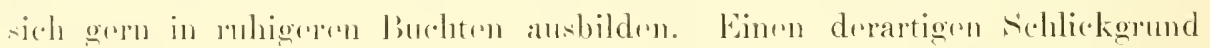

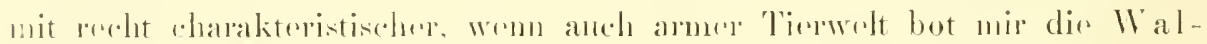

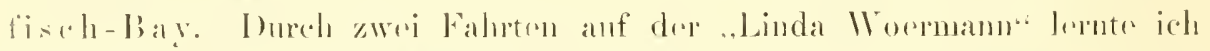

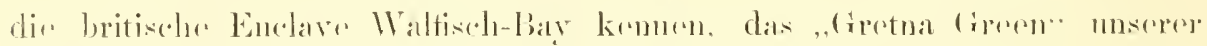

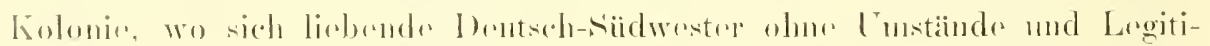

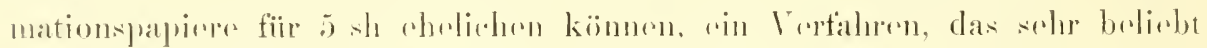

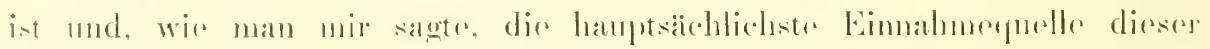

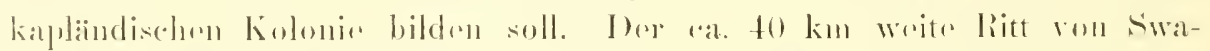

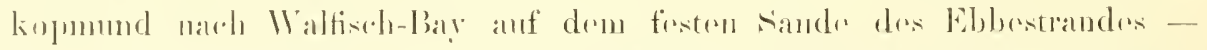

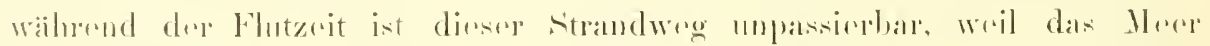

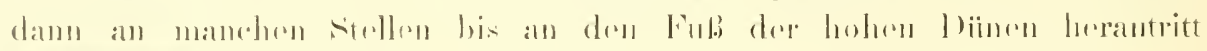

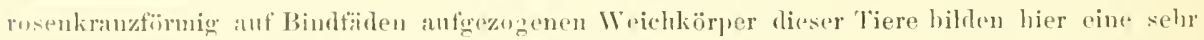

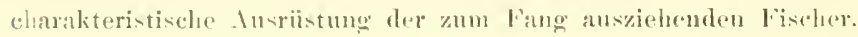


- ist allerdings ein recht zweifelhaftes Vorgniigen, und als Ausflugsont fiir Hochzeitsreisende will mir Walfiseh-Bay anch nicht recht gefallen. Ich kenne an der ganzen Küste kein äderes Nest. Die Dïnen, die besi Swakopmund das Landschaftsbild so interessant gestalten, treten hior weit zurïck, landwärts nur niedrige, einförmig,s sandwiiste, anf der man schutzlos dem sandgebläse, das der scharfe siidwestwind über die kahle Flächr hinfogt, ausgesetzt ist, auf diesen sand aufgesetzt virer oder fünf oraur Häuser, rin Landschaftsbild, (ran in Grau, in das nur Himmel und Meer manchmal cinen lenchenderen Farbenton rinfïgen. In dem durch rinu lange niedrige sandnehrung abgeschlossenen Hafen von Waltisch-bay führte ich versehiedene. Dredgezige aus, die cine zwar arme, aber sehr interessante sehlickfauna ergaben. Besonders interessant war der Fund eines nugenein charakteristischen Mud-Tireses, einer kleinen kugeligen, glashellen Ascidie mit langem, feinem und dichtrm Bart-Anhang zur Verankermo in weichen schlick. Ich namute sio zu Ehren der Rerderei, als deren Gast ich diese Fahrten machte, Eugyra Woermanmi.

Ilese ruhigen Buchten mit Schlick- und sandorund sind der bevor-

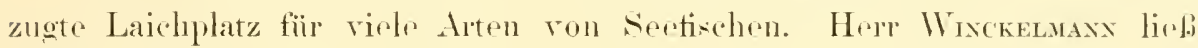
dureh die Bootsmannschaft unter Vorspann einiger zwanzig Kru-Neger vom strande aus rinige Fischziige nit dem Zngnetz (Wadr) ausfiiheren. I'berraschend reich war die Ausbeute. Fast hundert zappelnde und um sich schlagende Fische brachte jeder Fischzug an den strand, versehiedene Arten klimer Haitische. Seekatzen (Callorhynehes). Rochen, Rïisselrochen oder sandkruiper (Rhinobates). Panzerwelso (Arius), Knurhähur (Triqla), Ifreräschen (Mugil) und als edelste der Edeltische auch zwei Zumgen. ron denen ich allerdings mur die kteinere für meine sammhung reservieren durfte, denn - ich sah es an den ängstlich gespannten Blicken meinor Freunde - um das präehtige, fleischige gröbere Exrmplar waire es doch zu schade grwesen. Schweren Herzens habe ich sie unserem sichittikoch zur speziclleren Behandlung iibrerlasen. Es fiel zibrigons anch für die KruJungs, dis ihrersoits ganz besondere, rou uns Europäiern miBachtere Lieblinge unter den verschiedenen Fisch-Arten hatten, wine reiche Mahlzeit ab, und an ihrem Eifer bei dre Hantierung das Netzes, sowir ilnem fröhlichen Grojohle lieb sich erkennen, dab sie ron dieser Beuto ebruso befriedigt waren wie der Schiffskoch und ich. Bei der Nahrungsamut der pflanzen losen und tirrarmen sichlick- und sanderïnd, mus dieser rnome Fischreichtum auffallen. Die Fische kommen zwoifellos wenigstens zum gröbtru Tril nur zeitweilig, zum laichen, in disso seichteren Kiistongeraisser. Thre rigentliche Hemat ist dir offune ser. Dieser Fischreichtum ist ïbrigen.

2) Uichaelsen, Deutsch-Südwestatrika, 
für das ganze Gobiet des an der Kïste siidwestafrikas ron Süiden lıe rntlang streichenden kalten Benguela-Stromes charakteristisch. Er beruht anf den Reichtum dioses strömungsebietes an frei schwimmonder $\mathrm{Cr}$ nahrung, dem Plankton, und bildet seinerseits die (irmollage fïr dir üppige Entfaltung rines anderen, hïheren Tierlebens an dieser Kö̈ste, füir drn Reichtum an Fischfressem, nändich an Robben und viclen Srovögoln, wir Kormoranen, 'Tïlpeln, sieschwalben und lauptsächlich an P'inguinen, dir in Scharen ron Tausenden auf kleinen der Küsts vorgelagertron Inswh nisten, und rou denen weiter unten noch die Rede sein wird.

Eine der berden Fahrten nach Waltisch-Bay wurde noch etwas weiter südwärts ausgedelunt, bis nach siandfisch-H a fen, riner Bucht derselbrn Art we Maltisch-liay, abele bedeutend kleiner, und daher noch melu als jene der Voränderung durch Sand-Vorschiebungen ausgescetzt. Vor Jahren hatte sich hior oine Gesollschaft zur Ausbuntung des Fischreichtums niedorgelassen und aino Konsorvenfubrik gegriundet. Was [ntormohmen schlug jedoch fehl. Wir sahen das jetzt rorödetr Gobaiude der Konservenfabrik noch an Ifor des sandfisch-Hations stehen. Leider konnten wir anch nit Booten nicht in den sandfisch-Hafen rinlaufen. Eine nnunterbrochenr Linie wrib-schäumender Brandung zog sich von der Nehrumg bis zur Festlandskiiste hin, nirgends rine noch so kleine Luicke: Sandfisch-Hafen war geschlossen, wenn nicht durch vollständiges Auswachsen der Nehrung, so doch dureh eine barre, hoch genug, um eine brandumgswello zu arzengon und die Zufahrt ganz unmöglich zu machen, rin weiteres anschandiches

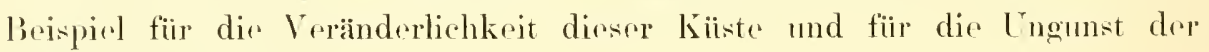
Landungsverhältnisso.

Für das Studium des sïdlicheren Küstendistriktes bildere L ï doritzbuelit maser Hanptquartior. Anch hior fanden wir wiedor gastliche Aufnahme im Hanso der Woermann-Linie, und auch hier versehatfite uns dere Vertroter der Woermann-Linie, Horr Heysesaxx, reiche Corlegenheit zul kleineren soefahrten. Mit der Jampfbarkasso führte or uns zul der l'inguin-Insal, wahrscheinlich so genannt, weil dort keine l'inguinr nisten, ferner nach dem von oiner furchtbaren Brandung umtosten D)iazFolsen, dem äubersten Vorpung des felsigen, die Lüderitzlucht im siiden abschliebenden Höhenzuges, bej dem vor Jahrhunderten der erste Europaier, der Portugine Diaz, mit seinen Scharen dieses damals ganz unwirtlicho Land botrat und als Denkmal soiner Landung ain grofors risolnes Keonz antricleste. Dieses Krenz, jetzt durch ain hölzornos resertzt, ist

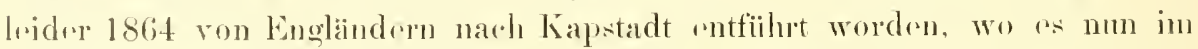

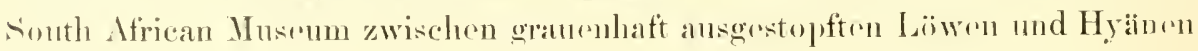




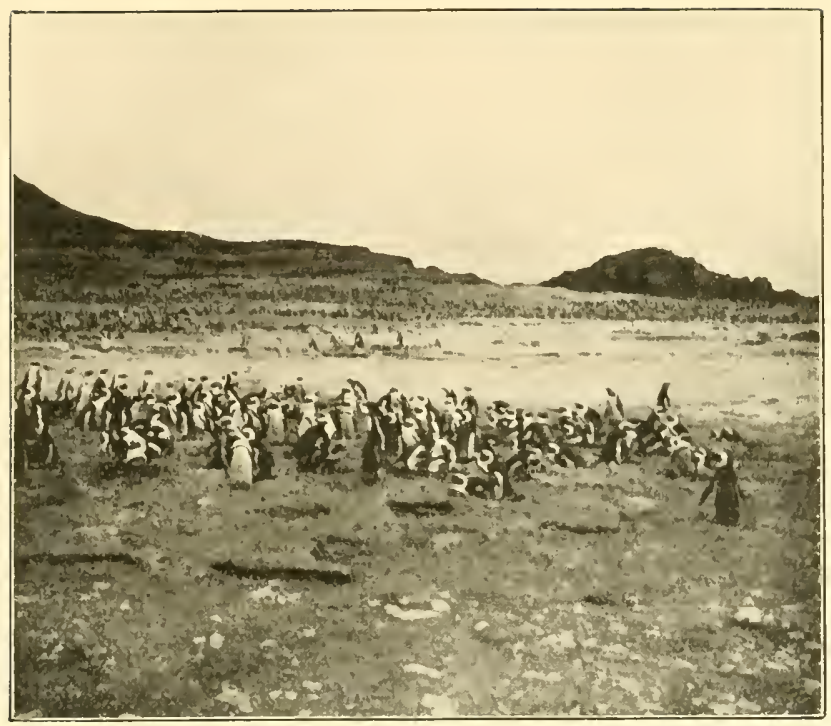

Fig. :- Pinguin-Kolonien auf der Halifax-Insel.

und anderen Kuriositaiten traurend seiner sturmumpeitschten Heimat mit dem woiten Ausblick anf die stahlblaur wogende sees gedenkt. Und weiter hinaus führte uns Herr Hexuendxx, nach der von den Engländern in Besitz genommenen Guano-Insel Halifax, der Insel der Pinguine. '/u 'Tausunden und aber Tausenden nisten lier diese nützlichen 'liere, durch rinen breiten Ieeresarm vor den rior- und brutraubenden schakalen geschützt, nicht gestört durch die kleine Schar der hier nit ihnen hausenden Jenschen. die ihnen nur das nehmen, was sie nicht mehr branchen, und zugleich für die Reinhaltung ihrer Nistplätze sorgen. Mjese Pinguine sind rine gar possierliche Gesellschaft, im Wasser flink und gerandt, auf dem Lande langsam und unbeholfen. Sie scheurn den Menschen durchaus nicht, und haben auch keinen Grund dazu: denn sie stehen unter besonderem sichutz der kapländischen Rogierung, dürfon nicht geschossen und nicht ihrer Eier und Brut beraubt wrorden. Kamal die brütenden Tirer crheben sich auch bei nächster Annährung des Menschen nicht vom Grelege. Einzelno Tiere scheinen otwas woniger phlrgmatisch zu sein: sic fauchen und knurren bei unserer Annäherung und hacken auch wohl wit dem schnabel nach unseren Fïßen. Lngemein komiseh sah zumal ein anscheinend allein strhender älterer Herr aus, als er sich knurrend und schnarend rom Nest rihob, offenbar mohr äber unsere Nongier geärgert als ornstlich beumruhigt, dann sein Bettzeng - wollte sagen dir zwei oder deri Fetzen sretang, mit denen ur soin Nest ausgepolstert hattr, in den sichnabel nahm und auszog, 
um sich eine andere Nisthöhle zu sucherl. Ab und zul warf or noch

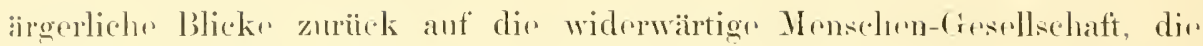
ihn in seimem Nachnittagssehlächen gestoint hatte. So watschelte or dahin - hopsa, alter Herr, stolpern Sie nicht! Sir treoten ja immer auf den serstang-Lappen. Nohmen sir den Lappen doch otwas kürzer in den Schmabel!

Bei diesen l)ampfor-Fahrton kounten auch ergiobigr Dredgezügu in

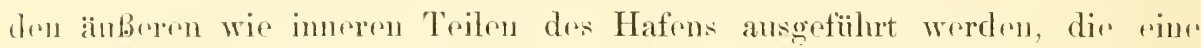

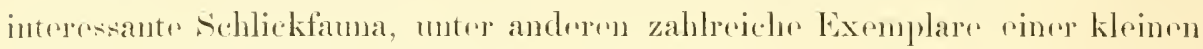
serfieder (Pommatulide) ergaben.

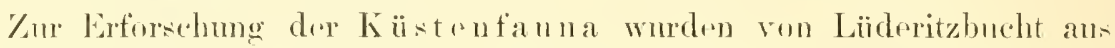
strandwanderungens untrenommon, sïdwärts nach dem schlickstrand der. liedford-Bucht und dem Lüderitzhafen, dem beliobtesten Aufenthaltsort dese nach S'chlammwïrmorn und -Musehehn suchonden Flamingos, nach Norden

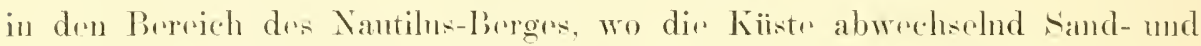
Folsonstrand darbot. Wie günstigsten Bedingungen für dic Entfaltumg riner Felsenstrand-Fama bot aber dir Haifisch-Insel, jene kleime mmittelbar

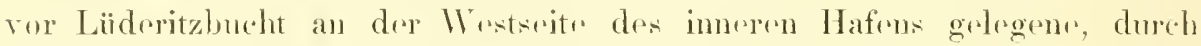

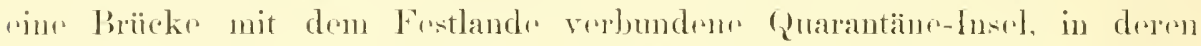

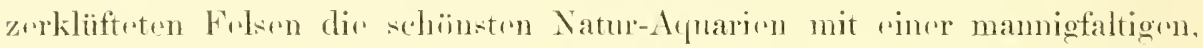
bunten Tierwelt zn tinden sind. Eine ganz besondere Faress zeigte dir.

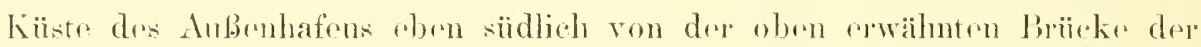
Haifisch-lnsel, nambleh ane rigentïnliche Kombination von Fels und

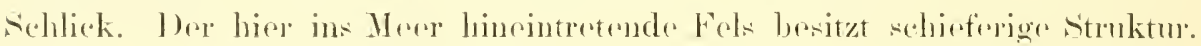
burch dir zorfressende Wirkung der Brandumg sind grobe schereferige

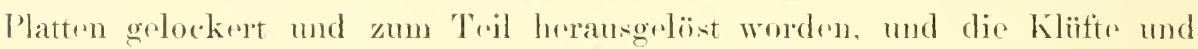

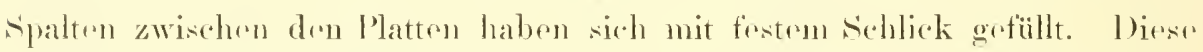

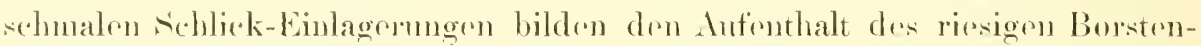
wurms Eunice Kinbergi, den ich liere narh mïhrowllem Losbrechen dere immerhin noch zientieh fixthaftenden Platten in lixmplaron von molne

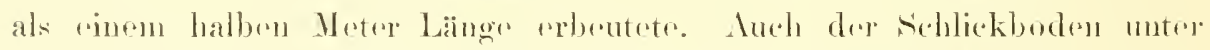
Hach liogenden derartigen l'lattron regab eine interessante Ausberute, untere

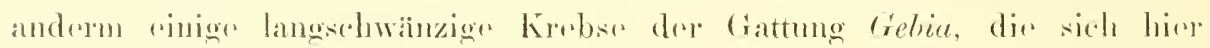

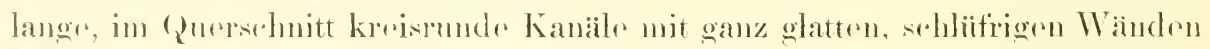
in don tonartig fisten s.hlamm gegraben hatten.

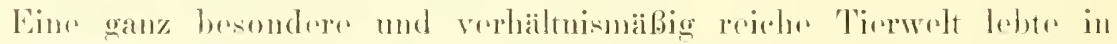

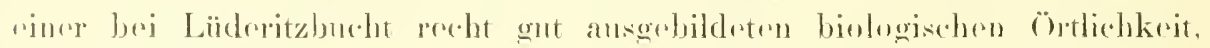
nämlich in dom Dotrituswall des hächston Flutstrandes, in und unter

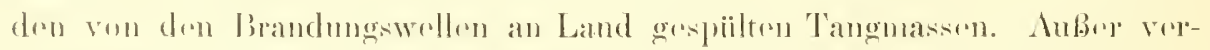

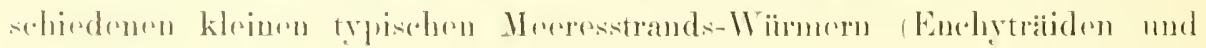


marinon Tubificiden), Flohkrebsen (Gammariden) und Meer-Assoln (Nphar-

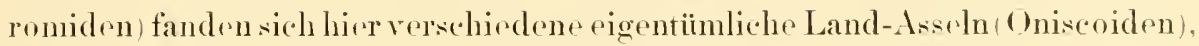
also Verwandte nnserer Kellerasseln. Dirse Tiere von Lüderitzbucht düifen rigentlich nicht mehr als Land-Asseln bezeichnot werden, denn sie haben ilele ganz dem Leben am Mereresstrande angepaßt. Es ist cine auffallend groBe Tylos-Art, rine mit sonderbarrm stacholapparat ausgeriistete Deto-Art (oder einige solchr?) und rine der flink hin huschenden Ligia-Arten. Diese Lebensgemeinschaft ist bei Lüdreritzbucht viel reicher und mannigfaltiger ausgebildet als im Bereich von swakopmund und Waltisch-lBay, wo ja dis Armut der Sandgriinde an Wasserptlanzen für die Bildung eines danernden und zusammenhängenden Detrituswalles am strande nicht ausreicht.

Wrann ich. die obigen Einzelsehilderungen zusammonfassend, mein Irteil iiber dir Mrerestirrwelt der Kiiste ron Drutsch-sïdwestafikika abgoben soll, so muB ich zunächst feststellen, dab dirsp Tirrwelt in rorwirgend felsigen Berejch ron Lüderitzbucht viel reicher und mannigfaltigur ist als im romiegend sandigen Bezirk ron Fwakopmund und IValfisch-Bay, dab also dir Tierarmut des letzteren Bezirks zweifollos vorwiegend anf dem Mangel an gïnstigen Ansatz- und Wohngelegenheiten borulst, nicht anf Verhältnissen der 'Temperatur dos Morerwassers und des Rerelutums an ['1'nahrung (Plankton) in der offenen soe ver dirson Küstendistrikten. Für rinen bedentsamen Untreschied in den letzteren Verhätnissen, die ins Bereich des ganzen Bengura-stromes annähernd gleich sind, liegen jenı versehiedenen Distrikte rinander zu nahe, und der Fischerehtum auch in jenen Distrikten mit vorwiogendem sandstrand zeigt geradrzu, dafo dir Charaktere der offenen sore vor beiden Küstendistrikten die eleichen sind.

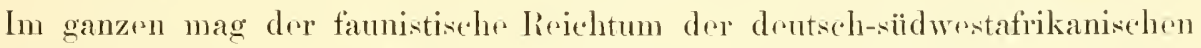
Kiisten otwa dem der Nordsos ainschlieslich der schottischon und westnorwegischen Kïste entsprecluen. Ihrem Charakter nach scheint sich dieso marine Tierwelt nnserer Kolonie, sownit ich es benrteilen kann, an dir

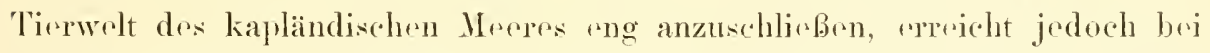
weitem nicht deren lieichtum, zu dem ja viele aus dem warmen Indischen Ozean mit der Agullas-strömung vordringende Warmwasser-Formen beitragen. Die Küstengewässer unseres siidwestafrikaniscluen schutzgebietes beherbergen dagegen angenscheinlich eine fast reine und daher ärmere Kaltwasser-Tirerwelt. Eine genaure und sicherere Frotstellung dieser faunistischen Verhälnisse mub aber bis zur Erledigung der wissenselaftlichen Bearbeitung des gesammelten Materials dahingestellt bleiben. 


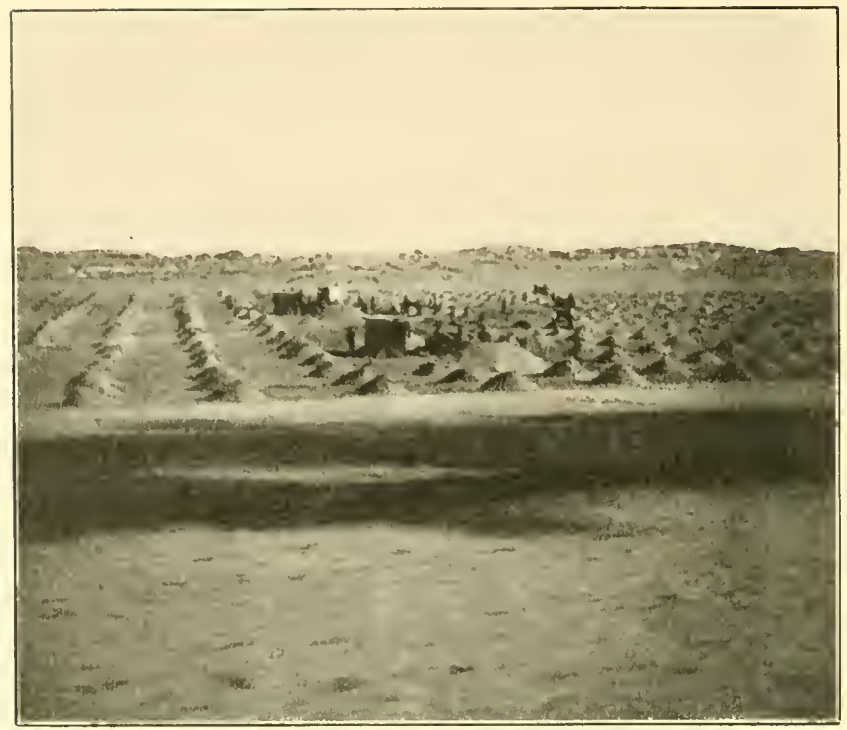

Fiw. .. Sandige Ntrecke der Tamih hei Kolmannskuple, unit Diamantwäischereien.

\section{Die Namil).}

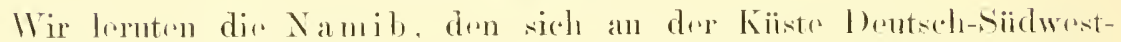

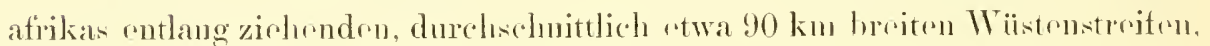
dor das zumal fiir Virhzucht so wertrolle Faramoenland des lonern lauger

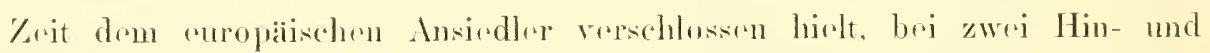

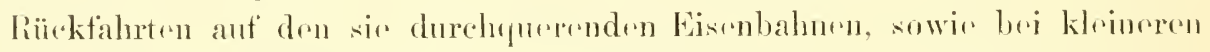
Insfligen von Swakopmund und Lïdreitzhucht ams kemmen, zumal beri rimmu Austug nach din Thamantfoldrem ron Kolmammkujpe.

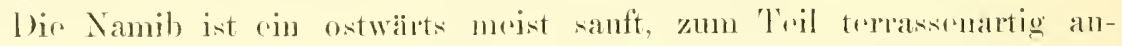

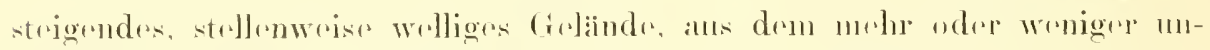

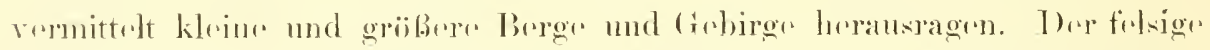

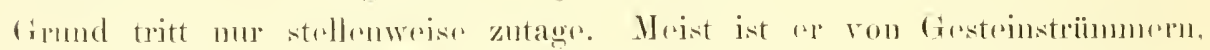

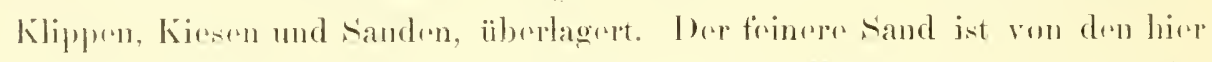

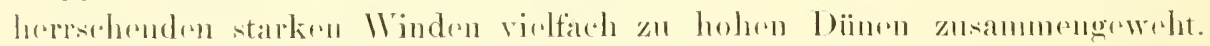

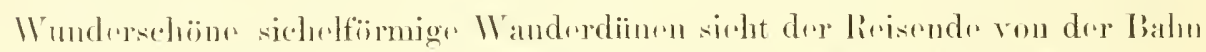

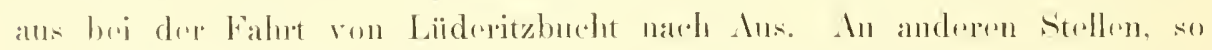

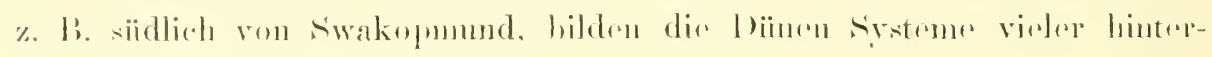

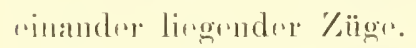

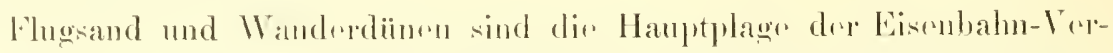

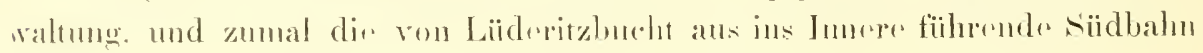


hat vicl unter dieser Landplage zu luiden. Es budart der unausgesotztru Arbeit melnerer Hunderter ron Orambos und Kaffern, um gowisse Bahustrecken freizuhalten. Jenerzeit sollte zum resten Mal der Versuch gemacht wrodın, dir lästigen Sandmassen, dir dir Bahustrecke zu verschüttrn droben. durch eine Maschine zu bewältigen. Diesu war gerade auf Station Grasplatz (nur im Volksmunde so wenig wüstenmäßig lautend, uffiziell , Grasabladeplatz" genaunt) angekommen, und dor Fisenbalınkommissar Herr listenex war so liebenswürdig, sir uns zu deunonstrieren. Lis ist rine grobr. ant rinem Eisenbahnwagen-Cntergestell montierte Maschine, dis dureh zwri Rirsenschläuchr den lockeren Sand auf dre siidseitr der Bahnstreckr anfsangen und auf der Nordseite wieder ausitoBen soll. Sir war aber noch nicht in Tätigkeit gesetzt und hatte ihre Abnahmeprifung noch vor sich. Lrider habe ich nicht erfahren kïmen, ob sio sich bewährt hat. Anch fïr den Wanderer, den Beruf oder wisensehaftliches Intreresse in diese Wiiste

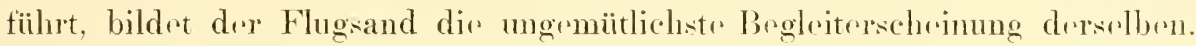
llit welcher Gewalt der Wind dir sandeilehen vor sich heretreibt, darom kann nur der sich eine Vorstellung machen, der rinmal rinem sandstum hat Stand halten mïssen. Wir ein sandgoblass wirkt or und spielt sichrerlich eine Hauptrolle bri der Ausziselierung der charakteristischen OberHächenformen und bei der Karstirung der Folsen und crobirge der Namib. Gleich in der Nähe von Lïderitzbucht, etwas nördlich von dor Stadt naho der Küste, hat man Gelegenlecit, an don zu Tage tretenden Felson die llirkung dieses Sandgobläses zu studieron. Es hat hior dir froi aufragenden Folsen zu den eigentiimlichsten Gestalten ausmodnlliert, dis weicheren T'rile und sichiehten weggeatzt, und dadureh Höhlungen und Kamneliorungen gobildet, die von den widerstandstïhigeren härteron Trilen gesimsartig überragt oder in Gestalt vou säulen und häutig von sonderbaren. Tirer- und Monschengestalten nachahmonden Formen ansorschnitickt sind.

Für mich als Tiergeograplen war natïrlich die Namib, in der rin fïu dir Verbreitung der Tierwelt im subtropischen siidafrika so bredentramer landschaftlicher und biologischer ('harakter das Maximum sriner Ausprägung finder, von besonderem Interesser. und zumal oine Verolojehung der Nanil,

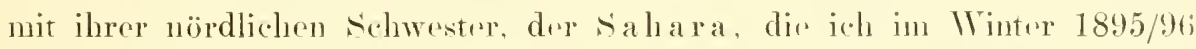
bei kleinen Streifziigen von Kairo. Luxos und Asman aus auch durch persönliche Anschanung krnnen Iernen konnte. In ihren landschaftlichen. wie auch in ihren faunistischern und floristischen Vorhälnissen unterseleded sich die Namib fundamental ron diesere nordafrikanisclen Wüstr. Die Namil, ist viel mehr Wiiste als dis sahara. In der Namib tinden sich tatsächlieh weite Strecken, in demen man vergeblich nach phanorogamen Phanzen sucht. 
Kumal otwa landeinwäls ven dem schmalen Küstrnstreifon, der noch unter dיm Einfub der Küstemmelbel stoht, liegen derartige ganz kahle Distriktr, $\therefore$ z. B. bri kolmannskuple, der beribmten J)iamant-Fundstätte. Hand in Hand mit dieser floristischen Armut geht natiolich anch eim famistischn Armut. Hinter dieser wïstesten Wüste beginnt dir charakteristische Wüstenregetation. im allgemeinen nach"osten mehr und mehr zunelumend, entsprechend der Annäherung an die östliche Quello der Niederschläge und mutsperelund dor Hebung des Landes, die rine Auscheidung des geringen Wassergehalts der Luft ermiiglicht.

Sowohl in der Fauna wie in der Flora zeigt die Namib beronders auffallende Frseheinungen. In dre Tierwelt ist vor allem dex sonderbare sandwatgerko, Palmatogecko Rangei, auftallend, rin Gecko mit IVatfüßen, mit denen or nun aber nicht im Wasser wates, sondern im lockrren Fande. Lntor den Pflanzen ist als eigentümlichste Form dio Welwitschia miralilis zu nemen. In der Vegetation der Namib sind ferner auch PHanzen mit Hrischigen Ntämmon, sogenannte Stammsukkulenten, bemerkenswert, wie die Nilchbusch-Euphorbie, die oinem ganzen Distrikt ihren Charakter aufdriickt. In der Sahara sucht man rergebrons nach solehen Figentïmlichkriten, nud ror allen charakteristisch ist für diese nordafrikanische Wüste das Fohlen trpischer stammsukkulenten. Dio Anpassung der Flora an die Masserarmut des Bodens und der Luft beschränkt sich hier auf die iibrigen Eimrichtungen zur Anfsaugung des geringsten Wassergehalts und seiner Aufstaumg in den

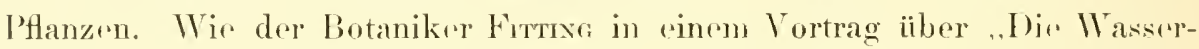
versorgung der Wüstemptlanzen"1) ausführte, spielt unter diesen Anpassungsrinrichtungen der Sahara-Pflanzen rine dem osmotischen Druck der Zellen rutsprechende ungrwöhnliche starke Saugkraft der Wurzeln eine Hauptrolle. Die Lrsache dieser besonderen Vegetationselaraktere der siahara, besonders des Fehlons der Ntammsukkulenten, sucht Frtwixa in besonderen Lebensrerhätnissen, in noch fraglichen physikalischen und chemischen Besonderleciten des Bodens, meint dagegen die Annahme historiseher Ursachen ablrhnen zu sollen. leh kamn mich hierin meinem botanischen kiollegen nicht

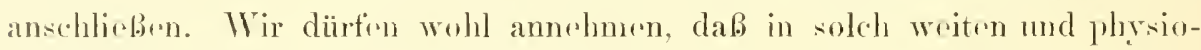
araphiseh so manuigfaltig ansgobildeten Gobioton wie die sabara und die Namib jede besondere Veranlagung der Wiistenptlanzen wenigstens in kleinen strecken ihr Auskommen fände. Meine tiorgeographischen studien haben

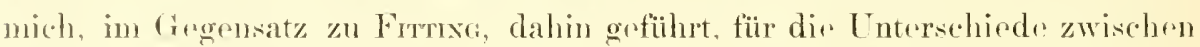
Namil und Saluara rine rein histopische trsache anzunehmen, und ieh

Gehalten zu Hambnrg am 10. Jan. 191:, kurzer bericht in: Verh. naturw. Ver. Hamburg, (i) XX, p. XXXVII. 
glaube, dab sich auch dir floristischen Lnterschiede in gheicher Wreise erklären lassen. Ich sehe die Ursache für die Verschiedenlenit in den Lebensformen der Namib und der Sahara in dem verschiedenen geologischen Alter dieser beiden Wiisten.

Dir Namib ist rine grborene Wüste. Siidafrika ist ein geologisele sehr alter, und in langen geologischenn Perioden nur wenig rerändertrr Klotz. So lange er. annährernd so wie jetzt, in das siddliche Iner vorragtr. muß er einen Teil der Wrstwind-Trift abgefangen und als Kaltwasserströmung an seiner Westkïste nordwairts geführt haben. Ebenso alt wie dieser Klot\% müssen also auch der noch durch den kalten Westkiisten-Auftrieb repstärkte Kältefilter an seiner Westkïste und demnach auch die hauptsächlichsten klimatischen Verhälnisse des ganzen Landes sein. Ebenso alt ist wahrscheinlich auch der Wüstenstreif an seiner Westseite, der hier ebenso zwingend auftreten muBte wir dir Kïstenwiiste an der Westsente der siudamerikanischen Kordillere im Bereich der Ostpassate und des kalten Küstrnauftriebes. Für das hohr geologische Alter der klimatischen V'rrhätnisso des westlichen siidafrikas, also nicht allein der Namib, sondern des ganzen Ciebiets bis zum Ostrande der Kalahari, spechen zunächst viele faunistische Tatsachen. Nicht nur das südlichste Afrika, Kapland, sondern auch das von Kalahari und Namib umschlossent Hochland Dentsch-siddwrstatrikas zeigt mancherlei Züge einer typischen Reliktematur. dir auf eine faunistischr Abgeschlossenherit in langer geologischer Periode hindeuten, und zwar zeigen diese Tatsachen, dab diese Abgeschlossenhreit nicht duch ein Meer, sondern durch Wüste oder wasserarmes firbiet rerursacht wurde. Sie finder sich nicht ausgeprägt in jenen Tiergruppen. für dir. Trockenland und Tüste kein Verbreitungshindernis sind, wohl aber bei Fenchtland-Tieren wie Landmollusken und terricolen ()ligochäten. Lntop den Landmollusken ist bersonders die lediglich ron der Namib bis in die Kalahari himein rerbreitere Schneckengattumg Jorcasia, dir primitiretr allex Holicinen, rine typeche Relikten-Gattung, zu erwähnen. Was die terricolen ()ligochäten anbetrift't. $\therefore 0$ bildet der breite streif Namib-Kahahari eine fundamentale trobietserenze: Im siiden, also im Kaplande, die archaischste aller Gattungen trericolre 1) ligochäten, Acanthodrilus (s. s.), rine typische Relikten-ciattung, durch 3 Arten vertreten, ferner die auch noch phyletisch meht alten Chilotacen und Microchätinen durch viels Arten, im Norden, also im äthiopischen fiebiet, die phyletisch jüngsten terricolen Oligochäten der Trigastrinen und Eudrilinen (außerdem allerdings auch sine Acanthodrilus-Art auf dem LamerunBerge, der ja aber auch sonst noch manchr Züge "iner lieliktenfauna aufweist). Für das hohe geologische Aler der Namib sprechen vor allem dir 
zwoifollos selur alten Anpassungen an das Wiistrenklima. wio sio unter dem Tieren rom Palmetogecko Rangei, unter den Pflanzen vou der vorwoltlich ammutrnden Whatschice mirabilis und den Stammsukkulenten dargustellt werden. Dreartign tiregüundige Anpassungen bilden sich nicht in kurzer geologischer Periodr.

In der Sahara liegen die Vorhälnisse ganz anders. Kwar, rine faunistiscles Grenze bildet auch die Sahara. Aber os läBt sich nachweisen. daß sir diese Grouzfinktionen nicht lodiglich als Wüste, sondern für lange goologischr Poriodern als Jurer ausgeribt hat. Die Sahara ist als Wüstr zweifrellos viol jünger als dir Namib. Iner grobte Teil des Crobietes der jetzigrn salıara war noch rom Meere iiberspült zu rinor Kerit, als südafrika schon lange seine jetzige frestalt anuähromd gewomnen hatte, und es ist firaglich, ob das Gobiot der sahara, als os landfost worde, sofort als Wiuste in die Erscheinung trat. Manche Tatsachens weisen darant hin. dab

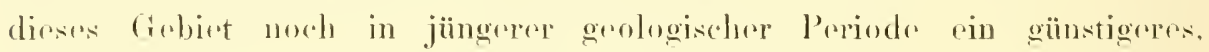
fouchoress Klima besals als zur Jetztzrit. Aus ihres relativen geologischen Jugendlichkreit rokkär ich dir Eigonart ihrer famistischen und floristischen Verhälnnisse und damit den Vuterschiod disser Ver-

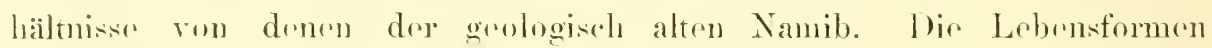

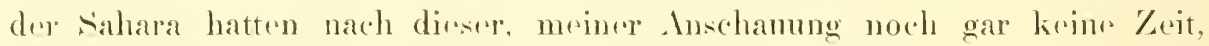

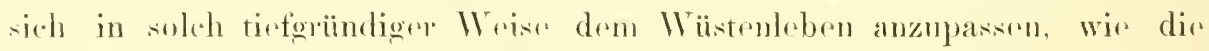
oben rewähnten kinder dep Nanib. Es kann wohl kaum rinom /weifol

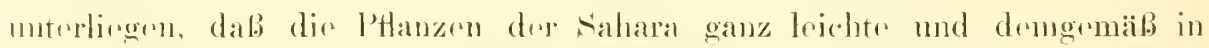

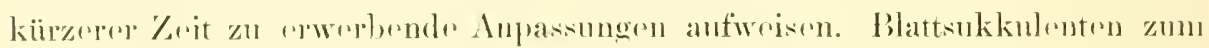
linispiol kommon doch anch in anderen klimatischen Bozirken vor. Kumal

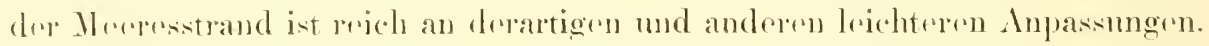

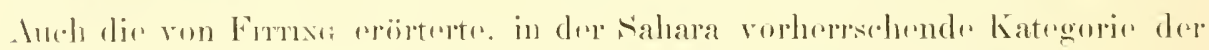

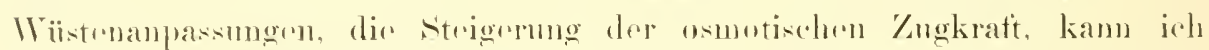

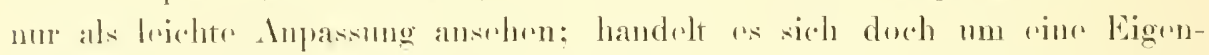

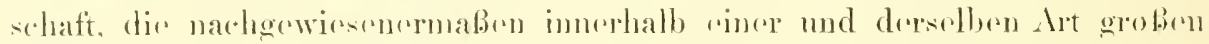

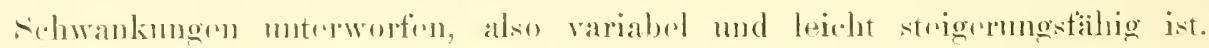

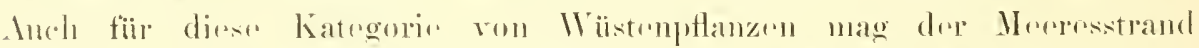

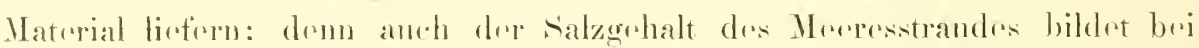

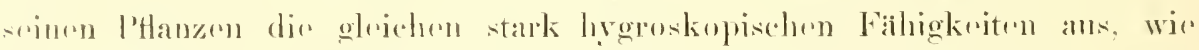

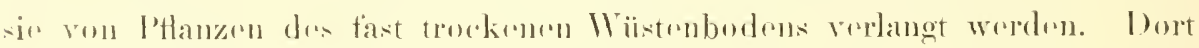

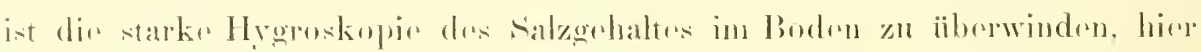

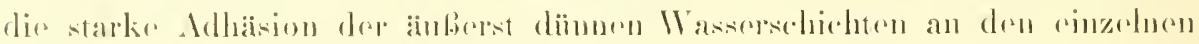
Kiomern des anseherinend staubtrocknene bodrus.

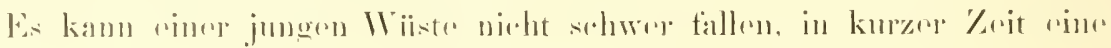


roiche Flora derartiger Mecrostrands-Anpasingen zu sich heranzuziohen. Es drängte sich mir die Frage auf, ob nicht äberhaupt der Mteresstrand al: Ausgangspunkt für dir Besiedelung riner jungen Wiiste eine wesentliche Rolle spiole. Die Brantwortung dieser Frage nußB ich aber den Botanik"ru ïborlassen, falls sie sie äberhaupt fïr disutiorbar halten. Selbst dem Laien auffallend ist jedenfalls ane gewisse Habitus-Mhnlichkreit zwisehen Jereresstrandepflanzen und gewissen Wüstenpflanzen.

In den meisten sichilderungen und lieiseberichten von lonutseh-side westafrika finder man die Namib als entsetzlich ödr und langweilig verschrien. So mag sir anch dem erscheinen, dem sie sich lodiglich als Hindernis auf dem Wrge nach dem resehnten fruchtbareren Buschwaldlande. des Innorn rntergenstellt, drm, der sie in mïhseliger mehrwächentlicher Manderung mit dom Oehsenwagen zu durchqueren hat und all ihre Grofahren und Ftraurazen, sand und sandsturm, sonnenbrand, Nachtfrost und Wassumangel, durchkosten mub. In rein landschaftlichor Hinsicht

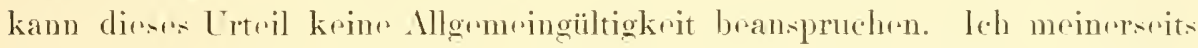
krono krine Landschaft. deren Eigenart mich so gepackt bäter. wie diese Miistr. Nicht ide ist sie, wohl starr: abrel gigantisch in ilerer startheit.

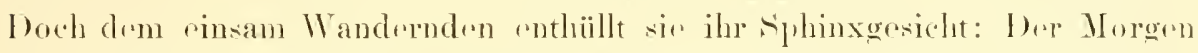
des dritten schojpfungstages, brvor liras und allorloi hräuter dem Boden

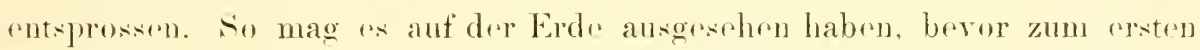
Mal Lobrewesen den Lrmeeres entstiegen und sich an ein Landleben gewïhnten. Nicht langweilig wirkt das Fohlen ainer firich-grinen Vegetation. Es wird voll auforwogen dureh die satte Farbensomphonie der nackten Felsen und sande. Vom hellsten Girau bis zum intensiven liraunrot und

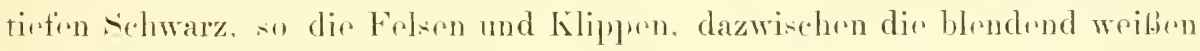
bis fahlgellyen, sich woit hinziohonden sand- und Kiesfolder und anf ihnon die glatten Dünen mit den schlönen Linisn ihrer scharf geschnittenen, grazil gachwohngenen Käumm, deren warmos, reines ()rangegelb sich von dems J)unkelblatu der. Himmels in schïnem Kontrast abhebt. Ich hatte hier stots das Gofïhl, als passe rin griiner stratuch oder ein bewaldeter Abhang gar nicht in dieses Landschaftshild hinein: wonigstens enthehrt man das firün

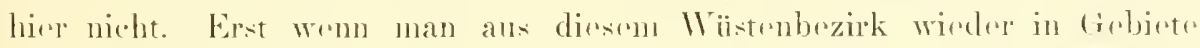

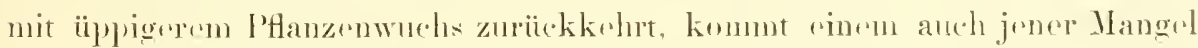

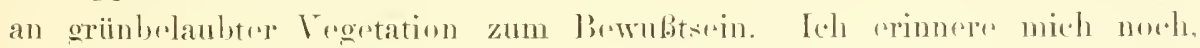
mit welchrem staunen wir bri der Fahrt von Lideritzbueht landerinwärts das

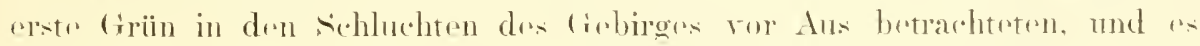

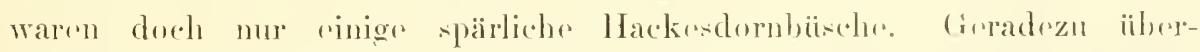
wältigend aber wirkt das smaragdene Kloid, in das die liolblielu Kapstadt 
ringohüllt ist, wemn man nach längurem Aufenthalt in Lüderitzbucht dorthin kommt.

Wrir aber wollen zunächst noch in Drutseh-siidwestafrika bloiben und nun writor ostwärts schreiten, dem savannenlande des Immern zu.

\section{Das Buschwald-Gebiet des Innern.}

Langsan anstrigend, trägt der Eisunbahnzug uns ron siwakopmund durch dir Namib, luider nicht auf dom interessanten, aber als Bahnliniro unginstigeren altun Weg an Swakol, rutlang iibre Jakalswater nach Karibib, sondern auf drm alle romantischen gebirgigen Partien vermeidenden Höhrenweg nördlich vom Khan-Rivier nach Lsakos. Zunächst ïde, in weiten strecken ganz jflanzenlose sand- und Klippenwiiste, deren linförmigkeit nur durch ainzelne in weitur, weiter Freme am Horizont anftanchendr Berokïmme gemildert. sowie manchmal durch rin kleines stationsgobäude gestört wird. Ilese stationsgebäud" wollen so gar nicht in das Landschaftsbild hineinpassen; sir seluen so puppenhaft, so hineingesetzt ans, $11 \mathrm{~m}$ so mehr, als auch ihre , Gärtehen" mit dem Rabatten aus zahlreichun in den sand ringrobohrten Flaschen und mit den 6,8 odor 10 in prinlicher symmetrie angeptlanzten glatt- und woißstämmigen Alö̈n, die geradezn ciner Nürnberger spielzengschachel antnommon zu soin schoimen, so soler an dio spolerisehen Produkte aus Kindrrland erinnern. Finen woit natiolicheren Findruck marhern die in riniger Entferumg vom stationsgebäude stelunden kuppelförmigen Eingelborenen-Hiitten, die wir Gruppen grobur Termitenhïgol ausseluru. Nur kurze liast ist uns an dirsen Stationen gegönnt, und writor goht dor Z/ug, langsam gonug, um uns dio Maglichkrit zu guben. interessante Finzolhoiten der vorberizielunden Landschaft wähend der Falurt

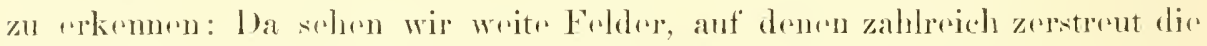

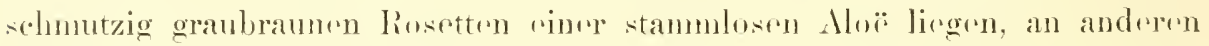

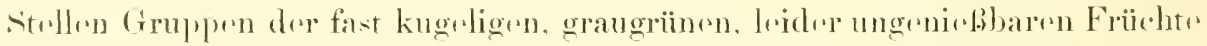

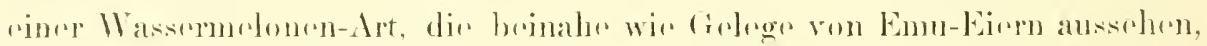
und bald auch dir sonderbaren, fiir dir Namib charaktristischen Milch-

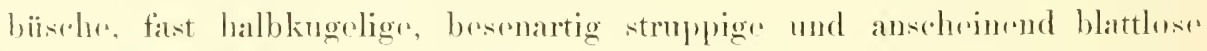

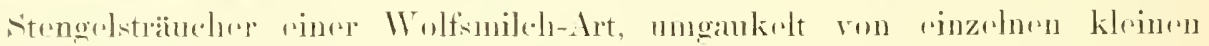
wriben sehmetterlingen, don rinzigen rom kisenbahnzug aus rrkenubaren Vortrotern dex Tireleberes der Namib.

Langsam ändert sich jotzt der Charakter dor Landichaft und der

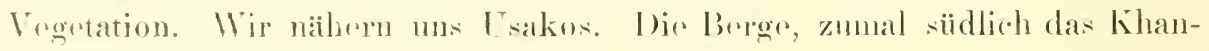


Gebirge, das der alten staatsbalm swakopmund-Karibib so vielo Schwierigkoiten bot. rücken näher heran. Spärliche lïschel trocknen Grases und kleine krüppelige Dornsträucher, die gegen die Wiiste rorgeschobenen Ausläutir der Buschwald-Vegetation des Hochlandes, die im eigentlichen (irbiet der Namib ganz auf die schmalen Gräbron drellivior hoschränkt waren. treten hire auf flachem Bodon auf und denten darauf him, dab wir uns drer Dornbusch-Landschaft des Innern nähern: abrer erst dicht vor Lakas gowiunt diese Buschwald-Vegetation die Voldurschaft. Dio Dornsträucher werden ansehnlicher, und zwischen ihnen dichtex sich dor Graswuchs zur steppes. Ein breites grïnes Band durchzieht siddleh ron drer Bahnstrecke die Landschaft. Berim Nährekommen shen wir. dab as rou groben, iippig bolaubten Bämon ron häutig cichenartigem Wnchs, von Akazion, gobildot mind, und dort, mittren in dirsem grünen Buschwaldstreifron, drm KhanRivier, erblicken wir einige wenigstens in der Fernsicht schmuck aussehende niedrige Hänser, oine kleine Farm. Auch der Himmel hat soin Aussehen goandert. Das reine blau des Wïstonhimmols hat sich allmählich vor-

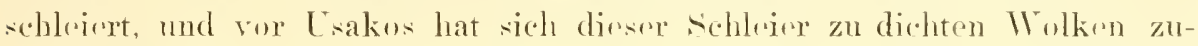
sammengeballt. aus denen strichweise ein kräftiger liegen heruntrerfällt, der letzte songen der spärlichon diesjährigen Reganzeit. die hiormit Abschiod nimmt, leider viel zu früh für don Farmer und fïr uns.

Es war ein würdiger Abschied, rersehönt durch rinen śonnonuntergang, we ihn nur die liegenzeit so grobartig hervorzubringen rermag. Niemals vorher, und anch nachher nicht, haben wir uine derartige Farbenpracht des Abendhimmels und der abendlichen Landschaft rolebt. wir sie sich uns beri dem Sonnenuntergang des o0. April rom dem froien Platz in Esakos mit soinem schönon linndblick darbot. In allen Farbentönen rom

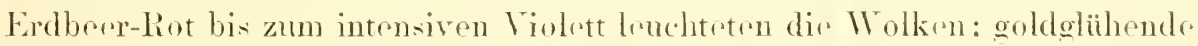

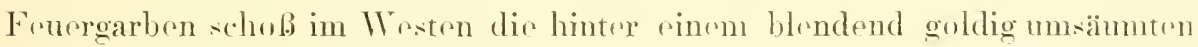
Wolkenrande stehende sonne strahlenförunig zum Horizont hernieder. und dre freir Himmel an der ()stseite glïhte in riner Farbe, wio wrom win helles Licht durch klaren Tokaire hindurehscheint. Lnd nun der Wiederschein dieser himmlischon Farbenpracht auf den Brrgon, dir Lakers wio in rinen Kessel rinschließen. Hire vermählte sich das hells Rot des tiesteins mit dem farbigen Licht. das dep Himmel ansistrahlte. zu fienhlaften Farbenwirkungen, whehe durch das tiof dunkle Violett der sahatten in schrïnden und Tieforn noch stärker hervorgehoben wurden und nur mit anem Apenglïhen vorglichen werden komnten. Alles, anch der Platz, auf dem wir standen, mit den hell gortïnchten Hänsern. und auch wir selbst waren wie gebadet in farbigem Licht, nirgends ain farbloses oder mibfarbenes 


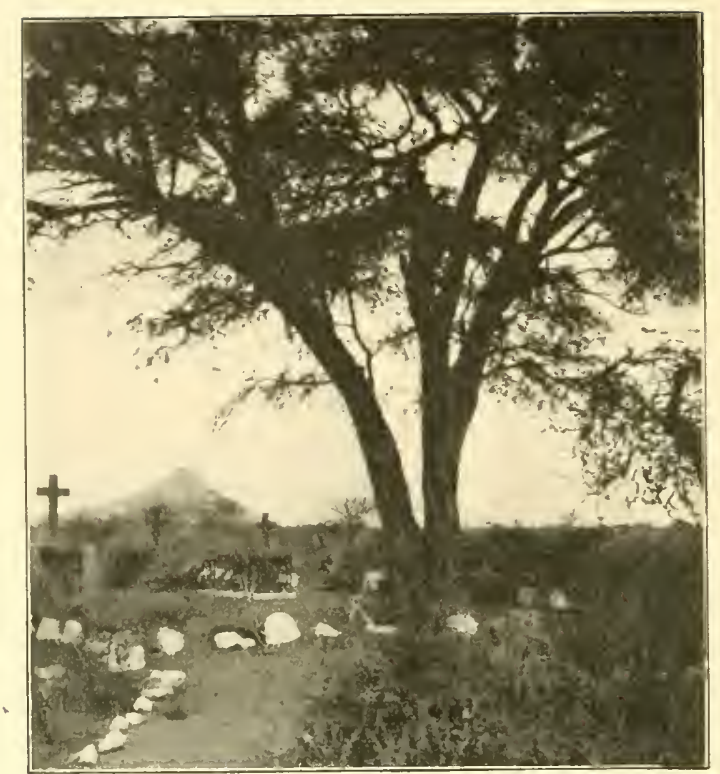

Fig. 4. Die (Mmaruru-kinjle (wihrend des Krieges Signalstation); im lordergrumle soldaten-friber.

Fleckchen. - Aucle während der winterlichen 'Trockenzoit haben wir oft schöne und prächtigr Dammerungserscherunteren in Dentsch-siidwestafrika beobachtet. Keine abes erreichte die Pracht dieses sommenunterganges an Ende der Regenzeit. lismerkenswert orschion mir auch dir für den Broitrngrad (Lsakos liegt noch etwas nördlich rom 22" sïdl. Brritr) auffallend lange Haner dieses Phänomens, das schon rinsetzte, als die sonne nech an Himmel stand, wenn auch sehon nahe dem Horizont. Aber auch beri nïchterner 'Tagesberleuchtung hat dir Landschaft dos sïdwestafrikanischen Hochlandes ihes lirize, solbst während dor winterlichen Trockenzeit, und nur ron dieser kann ich pedrom. Dop charakter der Landschaft ist aber in den versehiedenen Ringionen unseres schutzgobiotes nicht ganz gloichartig.

In der mittleren Region, dir wir in der Linir von Lsakos übur Karibib

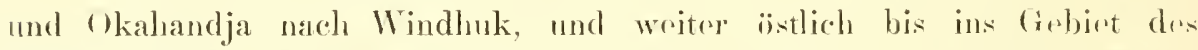
Wrißren Nosob (Otjiturzu) kennon lornten, zoigen die aus Irgestrin. Cimant und Gueis, bestrhenden Gobirge moist selur selurofter Formen mit zum

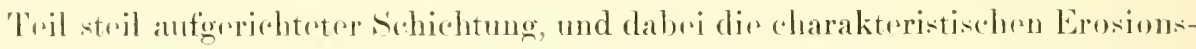

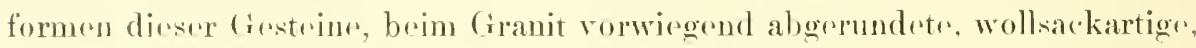
beim (incis mehr scharfkantige Blöcke. J)ir Verwitterungeprodukte des. Gobirgsmasirn sind, der rigenartigen klimatischon Natur des Landes rntsperelend, nicht weit fortgeselowroment, sondern bedecken als sehottermassen 


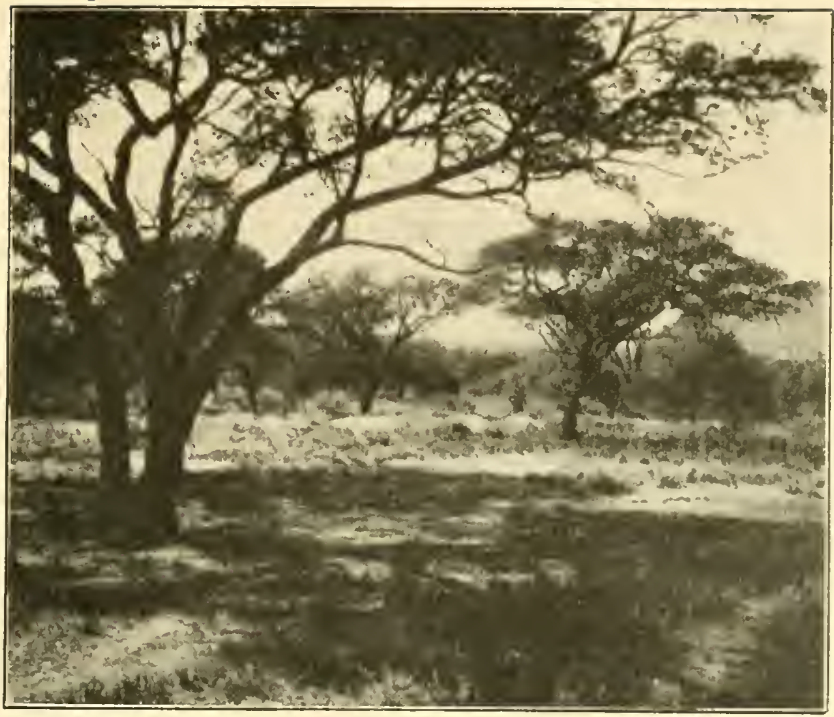

Fig. .). Was Osona-Wäldchen hei Okahandja.

die flachen Partien zwischron den Gobirgen and Bergen und umbiillen den Fub derselben. Vialfach erherben sich daher kleinere Berge - tatsäclslich nur die Gipfelpartion ron Burgen oder Grobergen, deren untere Partien von den Sichottermassen bedeckt sind - ganz unvermittelt ans der Ebrne und gewähren dir schönsten Fern- und Rundblicke, wio dir Onaruru-Kuppr, der Kaiser Wilhelm-Prop bei Okahandja und andere, dir daher auch während des Krieges als signalstationen eine bedentende liolle spieltrn. l)ies Kuppen laden geradezu zur Bustrigung rin, und we galt uns fast als lflicht, bei jeder unserer stationen zmächst von dem Gipfol riner nalue gelegenen Kuppr aus unser neues Jagdrevior zu rekognoszirun. Wreit hin dohnt sich zwischen diosen Bergen und Grebirgen die mit goldgelbem oder silberglänzendem Graso bodeckte Eb en n, dir nur ausnahmsweise von reiner Grassteppe eingenommen wird, moist aber sinen mehr oder weniger dichten Dornbusch-Brwuchs aufweist, und zwar vorwiegend ron Akazien, einzelnen zorstreuten Sträuchern oder größeren Bäumen von der Stattlichkeit nnsorer ruropäischen Waldbäume. An manchen stellen rüicken disse Bäume so "ng aneinander, daß sich iher Kronen zusammensehliofon und rin echter Wald rntsteht, so das berihmtr Osona-Wäldcleen beri Okahandja. Als shönster Baum der mittleren Rorgion ist wohl der besonders in cler Nähe ron Rivioren (ïber (irundwassor) manchmal in dichten bestainden anftrotende Anabaum (Acacia albida) zu bezeichnen, der nns durel seinen präalıtigen Muchs und durch den Lindrublüten-I)uft soinor gulblichen Kätzehen, die 


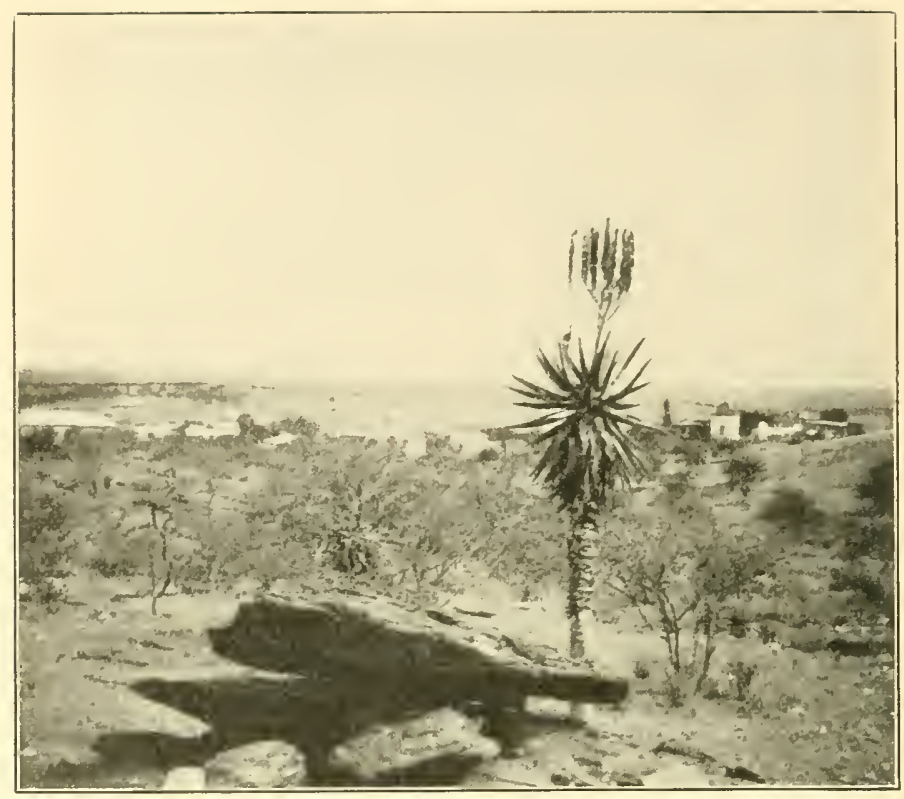

Fig. 6. Alo" rulvolutea bei Wirdhuk.

wir in winterlicher \%eit Ende Mai) beri ()kahandja in voller Blüte antrafen.

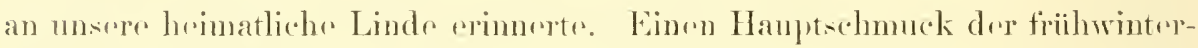
liehen Landsehaft bildet nicht nur in der mittleren Region, sondern anch in der südlichen und dor nördliehen dire rauhstäimmige Alö̈ (Aloë rubrolutea) mit ihren näichtigen liosettrukïpfin und den hoch aufragendens. von zahl-

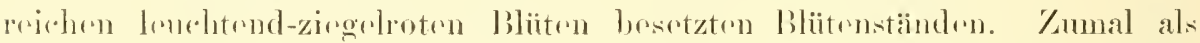
Krïung dor von bunten Flochton gofäbton und von niedrigem Krantwork rorbrämten wïst durelıinander geworfonen Klippen und Blockpackungen sir kommen anch im Hachen Buschfold ror - bildrn sie oft ungemoin malerische cirupen, bulobt durch das simmmen der ron iluren lBlïten angelocktrn Insektron und durels das foine Zirpon der sie Kolibri-artig umschwirenden bunt gefiederten Bhumensanger.

In geringem Mabu nolmon auch gewisse Tiere an der schaftumg

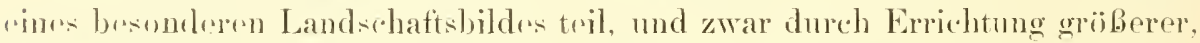
in dir Augen fallender bauten. Bosonders dir Banten dere Termiten mïison hior crwähnt worden, und zwar sowohl die in dor nördlichun Hälfte

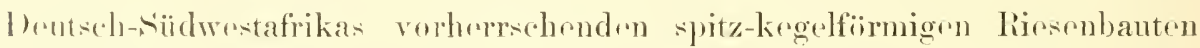

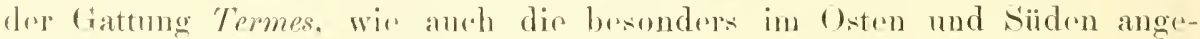

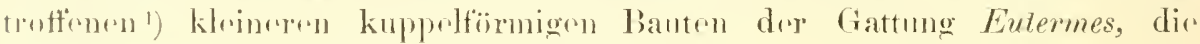

1) Im mituleren 'Teil unseres fiebietes, so bei Okahandja, kommen beide Formen vor. 


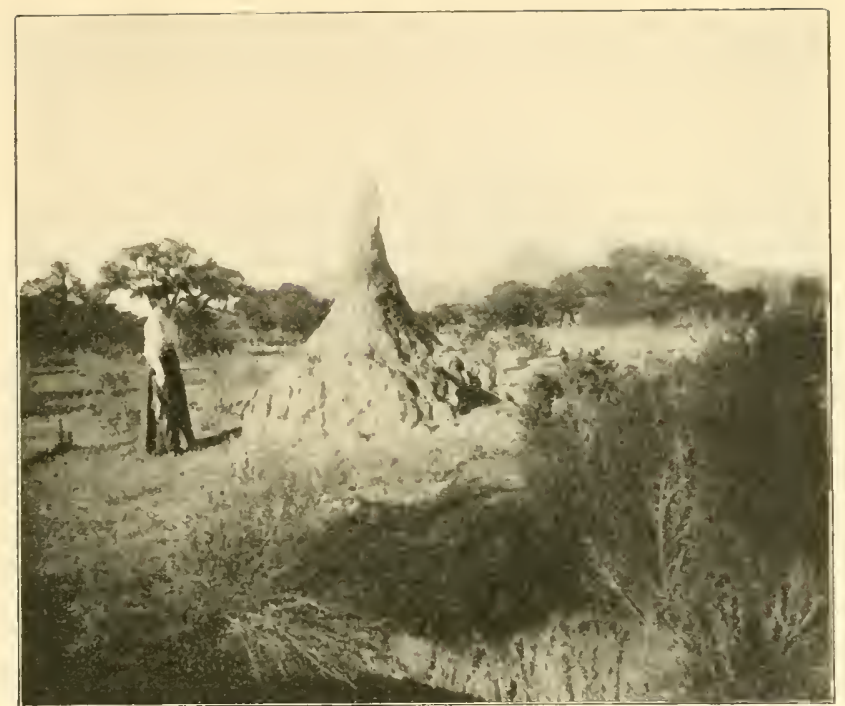

Fig. 7. Termiten-Bau der Gattung Termes, bei Okahandja: im Hintergrunde der Kaiser Wilhelm-Berg.

häutig ziemlich nahe und zahlreich beicinandre stehen und dadureh den (berflächen-Charakter ainer steppe beeinflusen kiinnen. Wenngleich ich sir nur in der spätor zu besprechenden nördlichen Region augetroffien habe. $\therefore$ will ich doch hier auch der spinuen einer Art ,Cyrtophora" Erwahmung tum. die. in individuenreichon Kolonien zusamminlebend. ganze trebüsches nit ihrem dichten weißen Gespinst ïbreziehen, ähnhlich den Gespinstrn gewisser Rampen in unserer Heimat. doeh in weit wröberem Mabstabe. so dafe das Gebüsch ron weitom aussieht, als sei es mit winterlichem Reif ïberzogen. $\left.{ }^{1}\right)$ Nicht unerwähnt dïrfen schlieflich dio grobon Nester gowisser Tögel bloiben, nämlich die rievigen, klumpigen Kolonie-Nester des siedelsperlings und dir kloineren. aber meist in gröberer /ahl an einzeln stehenden Bäumen angobrachten Noster gewiser Mebervägol, die von weitens don Eindruck machen, als trage jener baum eigentïmlichr grobe Frïchte.

Das Wasser spielt in diesem Landschaftsbilde nur eine geringe Rolle. Die Flubbetten oder Riviere sind in der wintrelichen Trockenzest wasserteer und durchzichen das Buschland als locker-sandige odre kiesige. meist nacktr. zum Teil von sogenannter unechter liaumwolle oder anderen schnell aufschiefornden Pflanzen lockre ïberwucherte straben. Aus der Vogelperspektive, von der Kuppe nahe liegender Höhen betrachete sehen

1) Siehe unten auf Seite 39 die Abbildnng Hig. 11 vom Otjikoto-See nit derartigen ron Cyrthophora übersponnenen sträuchen.

3 Michaelsen, Deutsch-Südwestafrika. 


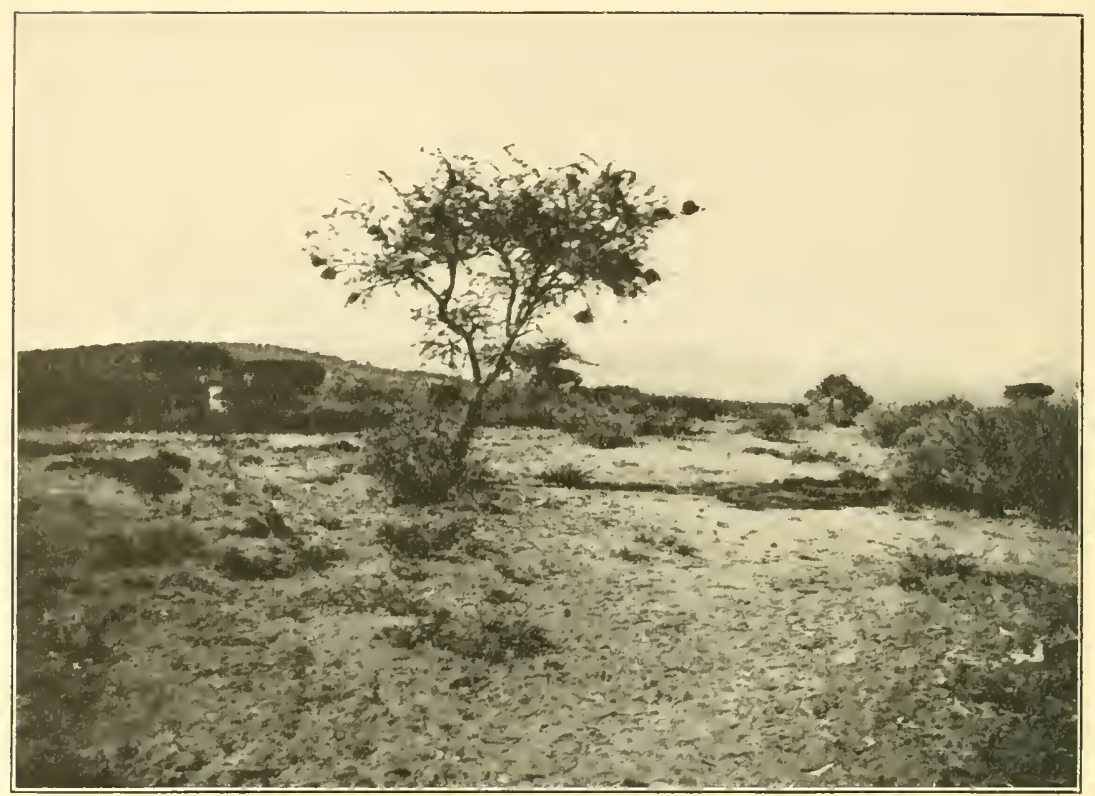

Fig. \&. Akazie mit Nestern ron Wehervögeln.

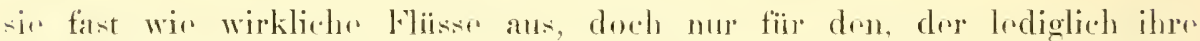
Linionfiilurung ins Ange fabt und nicht bordenkt, dab das Masser in Landsclaftsbilder rorwirgand den dunkteren 'Ton liefert und nur streckenweiser,

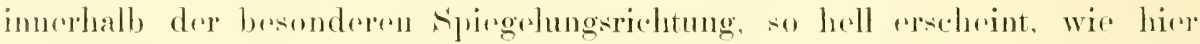
dir sand-liviere in joder beliobigen lichemne, in ihrom ganzen Vorlant.

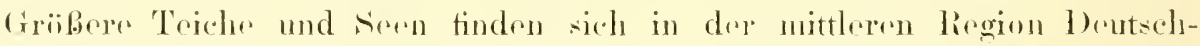

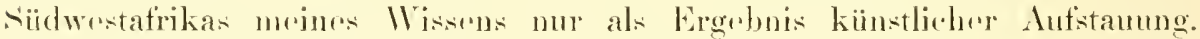
Die natiirliclern ausdaueruden, auch in dor Trockenzerit anzutroffenden Gre-

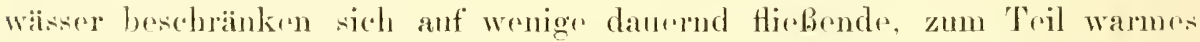
weler gar hrobers Wassere fiihrender Quellon und Bäche (z. B. Mindhuker

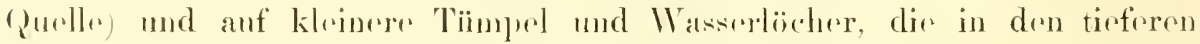

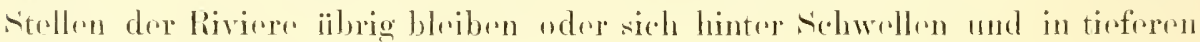
Kliiftern des Irgestoins lialtron.

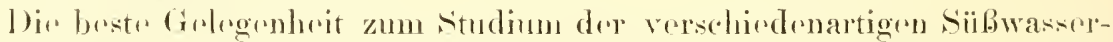

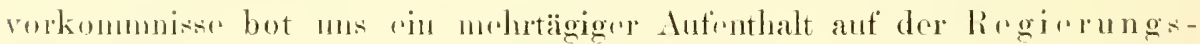

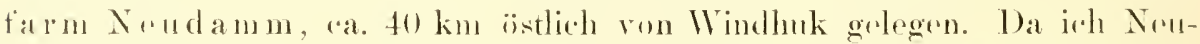
famm als Hauptquartier für das studium dor interessanten und bishere wonig

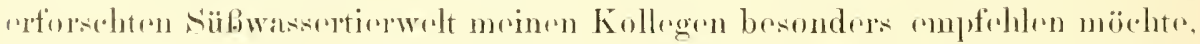

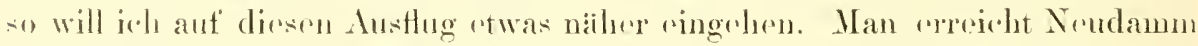
von IVindhuk aus pre Maultierkare berpurm in 5 stunden - nein, nicht

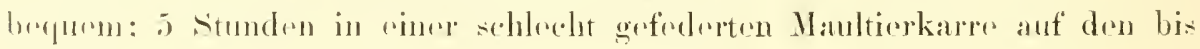




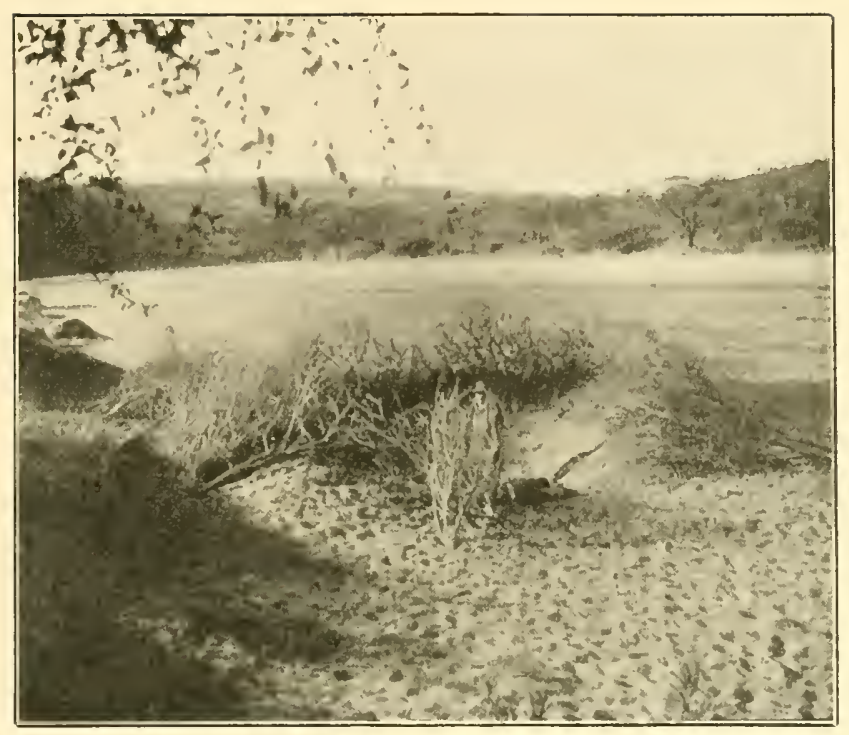

Fig. 9. Kïnstliches, durch Reisigbündel markiertes Wasserloch im sandigen Swakop-Rivier bei Osona.

jetzt noch solne prinitiven dontsch-südwestafrikanicchen straben kann nicht wohl als pine bequene sarke bozeichnet worden, zumal nicht, wenn man wio wir zu sechsen auber uns virr Europätorn mit der wissenschaftlichem Ansrïstung noch sin Hottrntott-Fahere und cin Herero-Pritedhemunamn) eng gedräingt auf der Karre hocken muf. I)a zur Keit dieses Austlugess in Windhuk gerade der Landerat seine erste sitzung hatte und zugleich dir. Farmervereinging tagte, so konnte uns wegen dre abnorm gesteigerten Insprüche an die verfügbaren Verkohrsmittel nur rine rinzige Manltierkare zur Verfügung gestellt werden. Trotzdem gohört die Fahrt ron Windhuk nach Noudamm durch das liebliche hügelige Crelände ästlich von Windhuk mit don priachtigun Ausblicken anf das näher und näher rïckonde Auas-Crobirge zu den landschaftlich schönsten, die wir in Dentsch-siudwestafrika unternohmen konnten. Die Regierungsarm Neudamm lixgt in riner breiten Mulde, depen hand sich nordwestlich zu der stril aufragenden Nindammer Kuppe und ihren Nebenbergen arlebt. Lie tiefste stelle der Inulde ist durch rinen Felsriegel unvollkommen abgeschlossen. Lin Durchbruch durch diesen Folsriegel gestatteste frïher dom aus weitem liobies in dieser tiefisten Stelle der Mulde zusammenfliobendon Wasser freien Mbflub nach dem Sers-Rivior, aus dom os dann in den Elefanten-FluB und mit diesem in den Tntrilauf des Nosob und in den Cranje-FluB gerangte. burch einen hohen und breiton gemanerton staudamm mit abschliobbarem $3 *$ 
IVaserdurchlab hat man mun dimen Durchbruch geschlossen und das oberhalb des Felsiegels zusammenfliebende Wasser zu einem Sere aufgestaut. der selbst in dieson abnorm trocknen Jalur noch ein recht stattliches

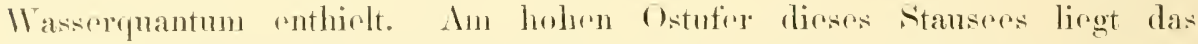
schumucke Haiuschon des Harmverwaltors mol jedersents in einigur Entformung davon rin Froundenhans, depen rines uns gute Tnterkunft bot. Der Karek

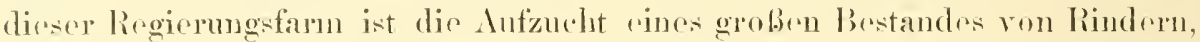
dir den Farmorn zur Bestockung ihrer Farm zu rinom foston, verhälnis-

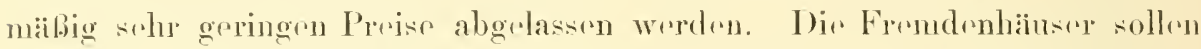
in sster Linie dron lindor kaufendon Farmern zur Wolnnung dirmen, nehmen aber gelegentlich auch andere Gaise anf, zwar nicht in dor Art cines ciasthofes. Fin in gut gemeinten, aber otwas holperigen lersen ab-

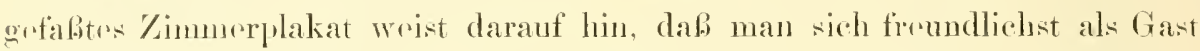
betracliten möge, dessen geringo pekuniäro Leistung lodiglich rine Deckung

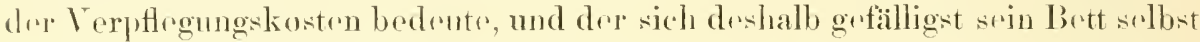
zurichten und sejne Stirfol rigenhändigst putzon möge. Ton diesem Haupt-

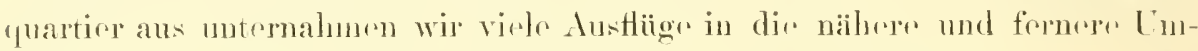

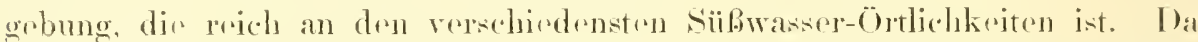

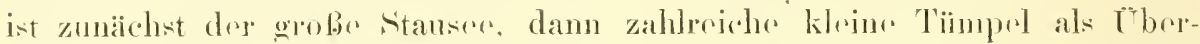

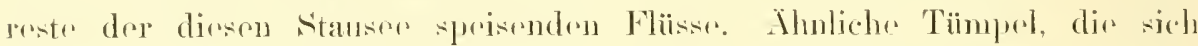

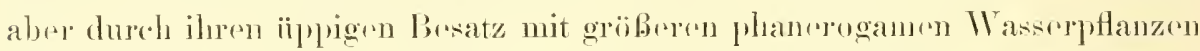

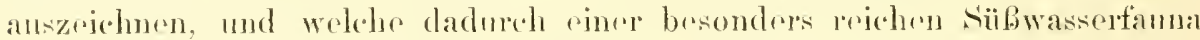
dir Fxistenzbedingungen gebren, liogen in rimem sich otwas nördlich von

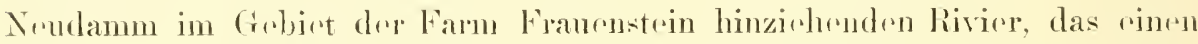

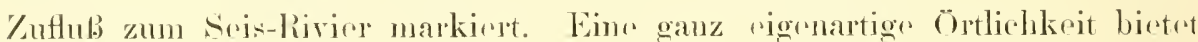

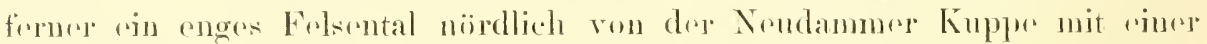

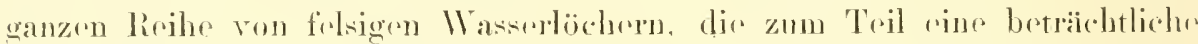

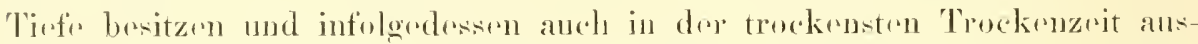

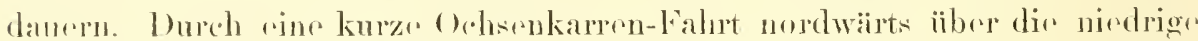

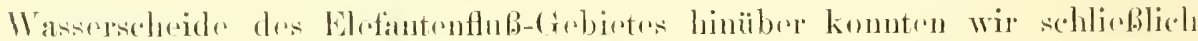

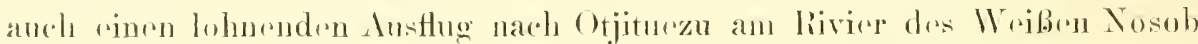

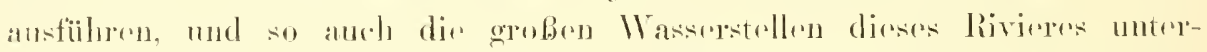

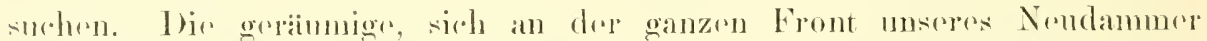

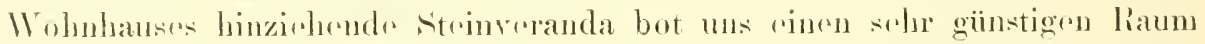

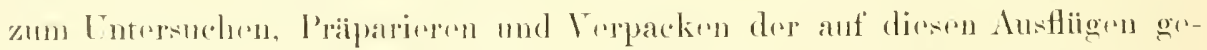

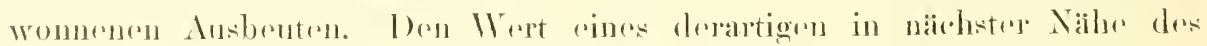

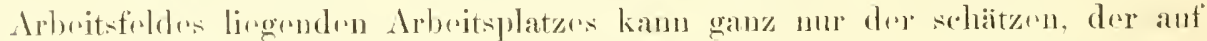

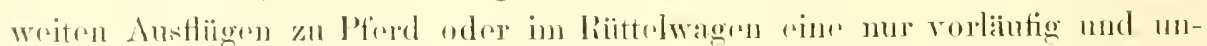

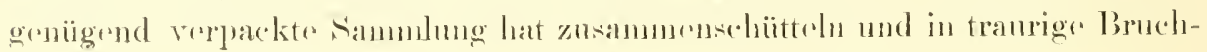




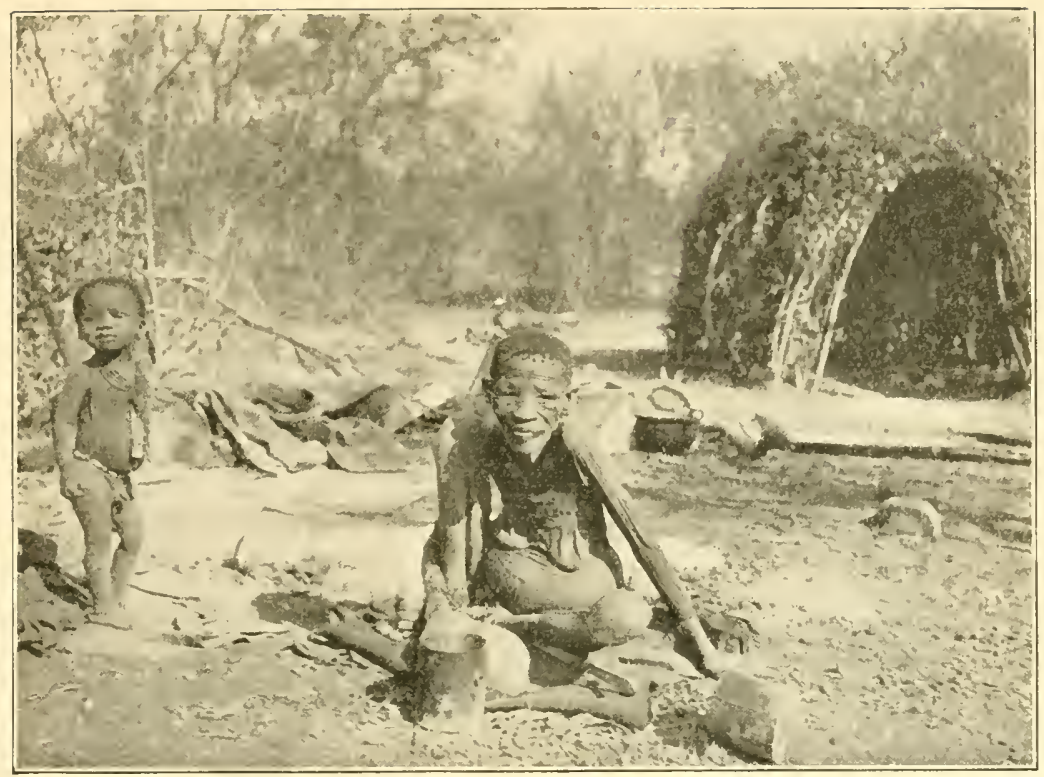

Fig. 10. Laubwald des Nordgebietes mit Buschmann-Siedelung bei Tsumeb.

stïcke zerfallen sehen. Nur drer vorsichtig wandelnde Fubganger kann rine im offenen Felde verstaute sammelausbeute umverselnt heinbringen.

Die nördliche Region 1)eutsch-siidwostafrikas untersehoidet sich landschaftlich ron der mittleren hauptsächlich dureh don charaktror ihror Vegetation. Fährt man mit der Otavi-Pahn iibre ()tjiwarongo, die Station des Waterberg-Jszirks, hinans nordwärts, so wandelt sich bald das Horistische Bild. Dis kloinlaubigen Dorn-sträucher und-büsche treten zurïck, und dornlose groBlanbige Bäsche und Bäume gewimnen allmählich die Vorhersoliaft. Kur Zeit unserer Anwesenherit, iu herbstlichen Juni, zeigten diese Laubbäume eine melur oder weniger writ vorgeschrittrn" Herbstfärbung: sic prangton in den versehiodensten Farbentönen vom Goldgolb bis zum Braunrot, und gewähron im V'rein mit dem verschiedenfarbenen Lntrergrund das Bild ainer farbenfrohen sonnigen Hrrbstlandschaft. Dir bunte Färbung des Untergrundes wurde in weiten Strocken stark durch oin im trocknen Zustandr hell-graurotes Strppengras breinflubt. Bei Grootfontein treten zu den dicotyledonen Laubliilzern sogar rehte, rinherimische (nicht durch den Menschen angeptlanzte) Palmen (vins Fächerpalmen-Art, Hyphaena) hinzu und führen uns deutlich zum Bewubtsein, dafs wir ums hier in tropiseher. Region betinden. Etwa $15 \mathrm{~km}$ südlich von Grootfontein bildet diese Fächerpalmo auch einen gröberen waldartigen Bestand. In der nächsten Umgrbung von Grootfontein tritt sir aber nur in kloinen ongen Gruppen 
anf, die hier und da ganz unvermittelt ans der diiren strelpe aufragen und

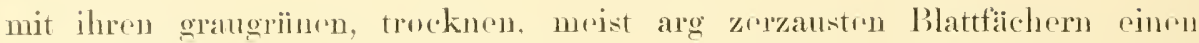
ziemlich kläglichen Anbliek darbieten. Sir enteprechen so gar nicht desn Bilde üpliger, in simmpen, an Flïssen und Seren aufichiorbender Tropen-

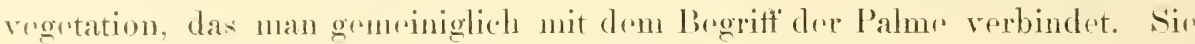

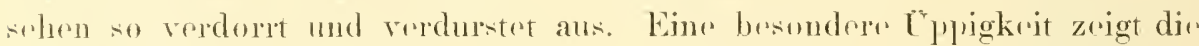
Vongration des Nordgobiotes aber an den kloinen konstant Hießenden

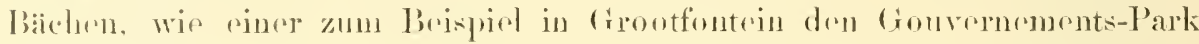

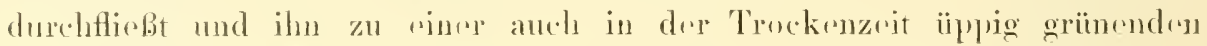
and blïhenden ()ase immitton dor trocknen Steppes umwandelt. In groben strecken des Nordgebietess bestedit der Boden aus Kalkstrin. In diesen Kalkstrin-Tistrikten, typischen Karstgobioten, findert man stellonwoise SüBwassur-Örtichkriton von ganz rigenem ('harakter, an-

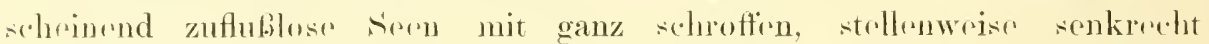
abfallonden oder gar iiberhïngendon strilufores. Wir konnton von T-umel), der bedoutendsten Kupfererz-Mins Ventech-siidwrstafrikas, in

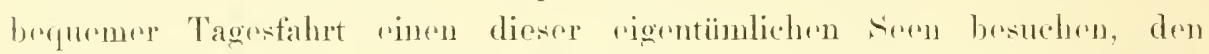

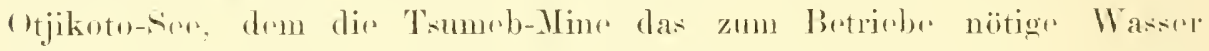

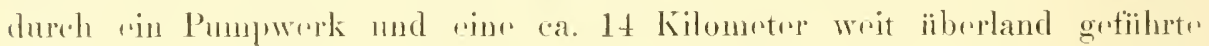

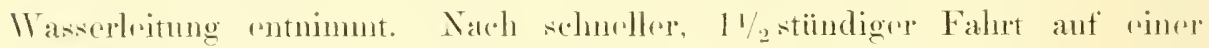

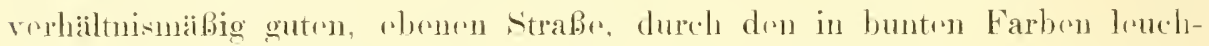

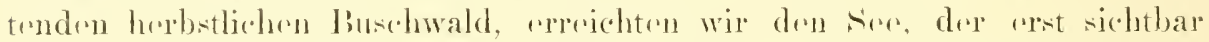

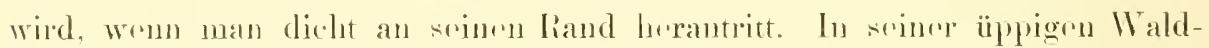

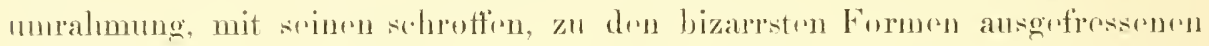
kalkstrin-Lfern und soimem tirfen, klaren Wassor mit moist spiegolglattrer.

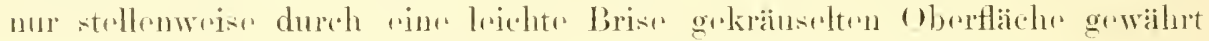

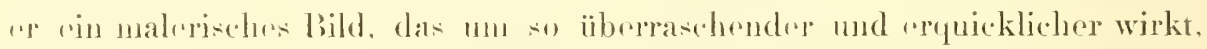

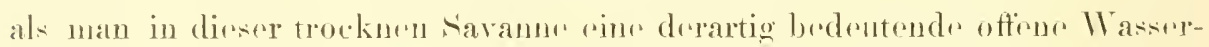
masser nicht vermutren, und das Wasser ist loch die ganze śchnsucht des

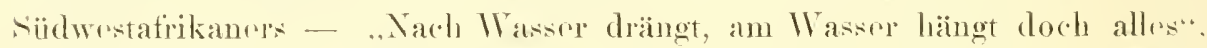

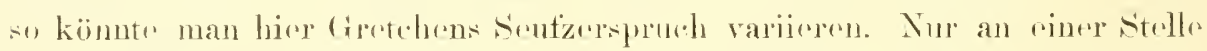

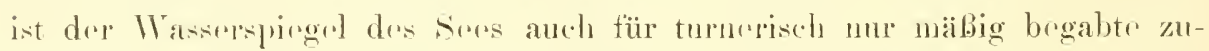

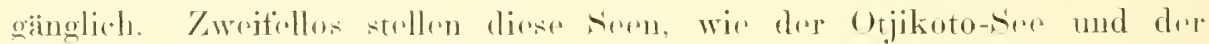

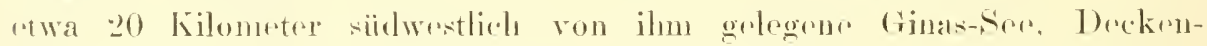

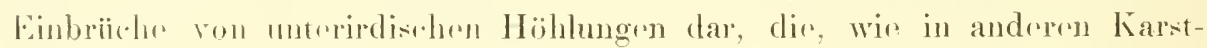

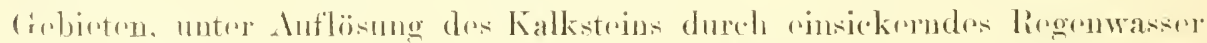

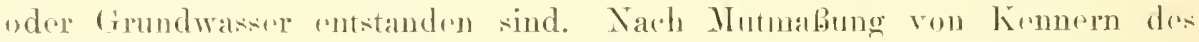

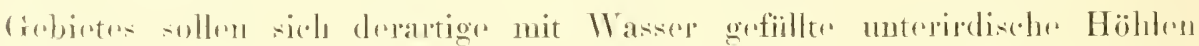

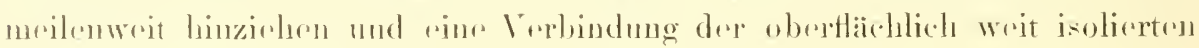




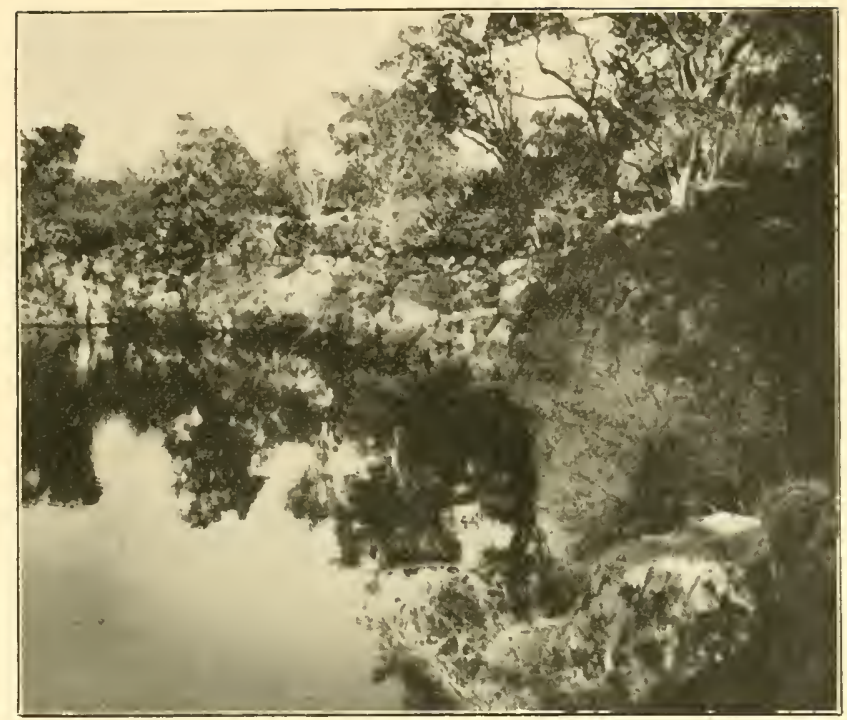

Fig. 11. Der Otjikoto-kee: rechts im Vordergrunde einige Biischu mit Kolonie-Gespinsten der spinne Curthophor,

Fion herstellon. Sie schließen dies daraus, daf Fischehen der gloichen Ant roine Cichlide dor Gattung Paratilapia) in den verschiedenen soren auttrotens. Ioh komnte mich dureh rigenens Fang davon überzengens. dab im

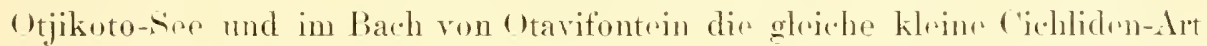
rorkommt. Nach zwei verselifedenen. ancrheinend reneinander mab-

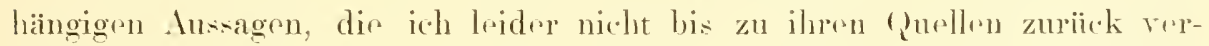
folgen kann, soll auch sin blinder Fisch, also wohl oin in unterirdischon

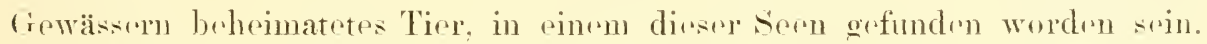
Jirse Aussagen erscheinen mir brsonders beachtenswert, als sis rom Männem stanmen, dis mit don biologisclen Besonderheiten unterirdischer (ruwäser niclit vertraut sind.

(iegen die südliche Region D)utsch-siidwestafikis ändert sich das Land-chaftsbild in ganz anderer Weiser, als wie wir es bei dor Manderung nach Norden brobarhteten. Wohl andert sich auch gengen süden der C'harakter dor Vogetation, aber nicht so grïndlich, nur graduell, nur insofern die Hochregetation an Tplegkeit abnimmt. Während nordwärs rine Groblaubvergetation die Dormeroetation verdrängt, bulailt diess letztere südwäats ilne Vorherrschaft auferelyt. Aber os tritt hier an stelle des

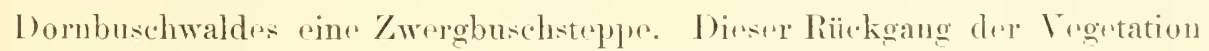
ist jedoch nicht so allgemein, dab hior in der siidregion unn gröberer Bäume ganz fehlten. An rinzelnen giinstigen Plätzon orreveluen anch hior 


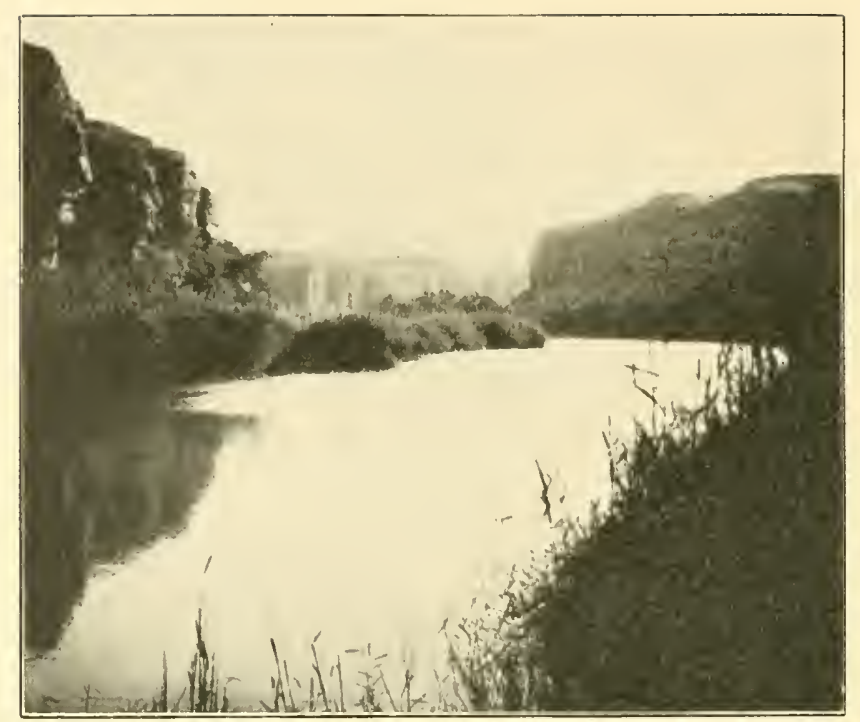

Fig. 12. Tafelherg-Landschaft bei seeheim am Groben Fisehflub.

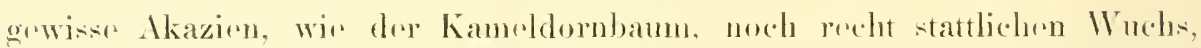
und auch rine grofe Alö̈, die rigentiumliche, viclfach gabelig vorästelte Aloë dichotoma mit ihrer groben, ans zahlmichen Blattrosettron bestrhenden Krone

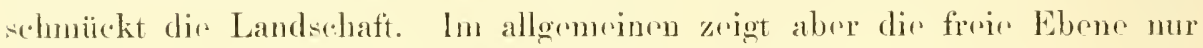

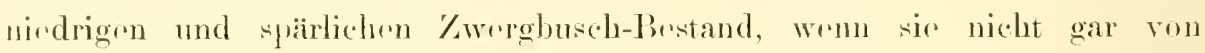
roiner Crassteple ringenommen wird. Sulne auffallend ist andererserits dore

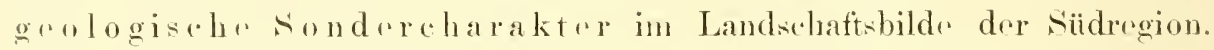
Hior im siidrn unseror Kolonie sind dem I regestrin diskordant jüngere. borizontal geschichtotr Grosteins aufgelagert, und diess verursachen ganz andere Erosionsformen wie das in der mittreron und in dene gröbten Teil der nördlichen Region zutage tretende l'rgestein. Die Verwitterung bildet aus disen horizontal geschichteten fiestrinslagen clatakteristisch geformte Tafelberge mit regohnäbig lorizontaler Kuplenfläele, stufenförmigen $\mathrm{Ab}$ -

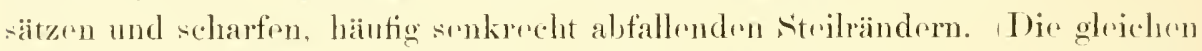
genlogisellen Vephältnisso findon sich übrigens anch in cinem groben Distrikt

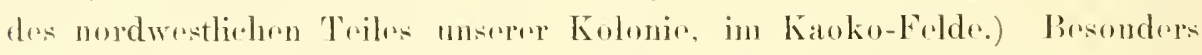
dentlich kommt dieser geologiselos Charakter dort zur Auschanung, wo dir Frosion in besonders scharfor Weise ringesetzt hat, dort, wo grïbero Fliisise sich ilu fast cañonartiges Bett in diese Gostrinsmassen ringograben haben. Giess cañonartigen Flubluetten mit vorwiogend folsiger solele, in denen das II assere nicht wegsickern kann, enthalten auch solor interessante Sïßwassoroptlichkeiten. In don tioforen Stellon des FluBbertens hält sicels das Wassere 


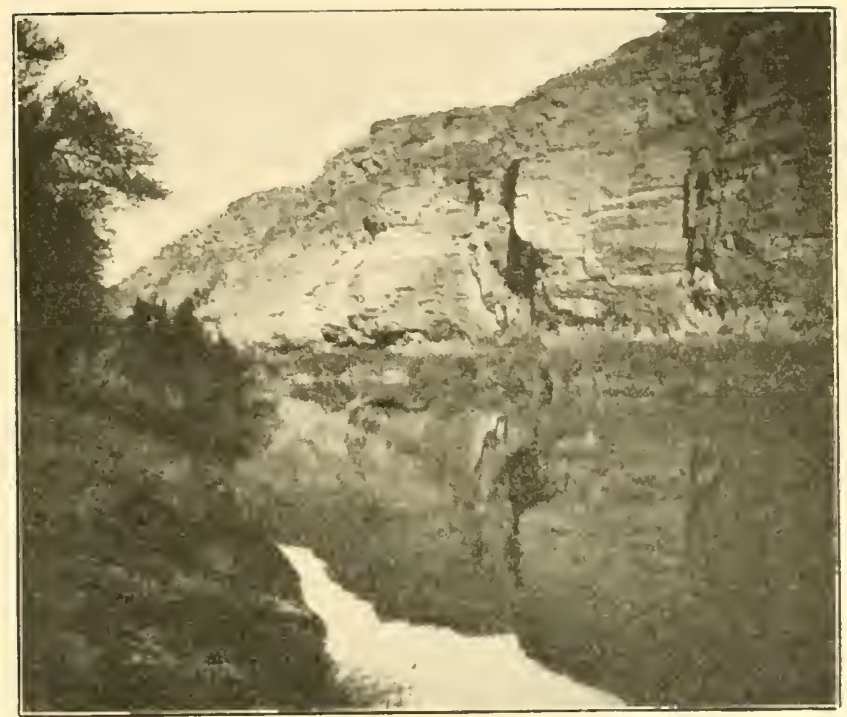

Fig. 13. Steilufer an einem S'ee-artigen Danergewïsser des Großen Fischtlusses bei Feehein.

auch während der Trockrnzeit und bilder hior zum Teil seler grober ausdauernde S̈ern.

Eine Falut von sorolerim aus südwäts das Rivier des Groben Fischflusses entlang, zu der uns unsere freundlichen Wirte, dor Eisenbahnkommissar Herr Ristelex und der Proviantamtemeister Hor Benrexus ringeladen liatten, gab uns din wertvollstrn Finblick in die landschaftlichen Verbälnisse dieser Region. Es war eine recht tolle Fahrt. Dir Ausfalurt bei Tageslicht auf dem sogenannten Wrag — cin derartiger Wre beruht lediglich darauf, daB in der betreftonden Linir schon sinmal eine Karre gefahren lat, deren liadspuren stellenweise noch crkombar, moist aber nicht mehr erkennbar sind - war sehr holperig, ging aber programmäio voustatten. Der Aufenthalt an Endziel, einom großen, ron üppigem Buschwerk und dichten Binsen umrahmten ser inmitten des von senkrecht abfallenden Felsen ringeschlosesnon Flubbettes, war ungemein lohnend. Die iippige Binsenvegutation bot einer interessanten Tierwelt Lnterschlupf, rinere Tierwelt, die sich im nackten FluBbett bei der scharfen strömung des abkommenden Flusses nicht wïrdr halten können, und von der in anderon. vegutationslosen Wasserstellen des Groben Fischflusses auch nichts zu tinden ist. Auch landschaftlich war dieser Aufonthalt sehr lohnend. Den Glanzpunkt bildete dir farbenprächtige szenerie des somnenunterganges, als sich die rom Abendrot hell purpurn getienten Felswände in klaren ITaster der 
griin umrahuten Sores wioderspirgelten. Wir momben aber das Abwarton

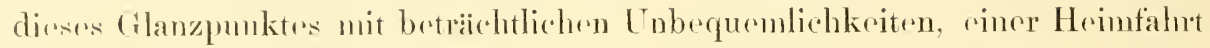

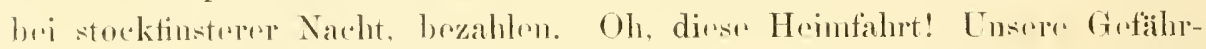

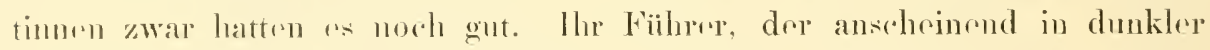

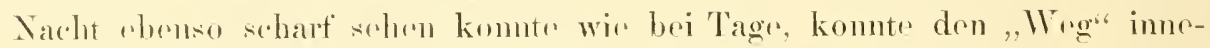
halten. und so hatten sir an Lubrounemlichkeiton höchstens ringe nicht writer buachtonswerte Klipponstufion von 1/2 bis $3 / 4$ Fub Höhr auszuhalten.

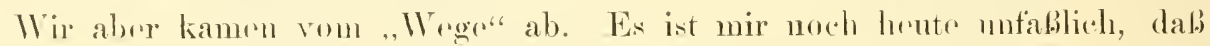

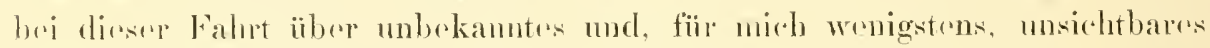

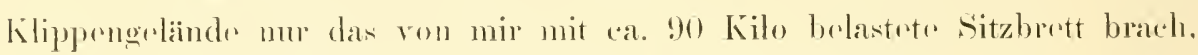

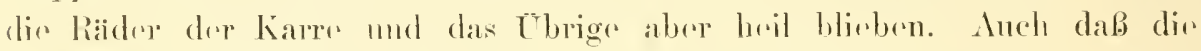

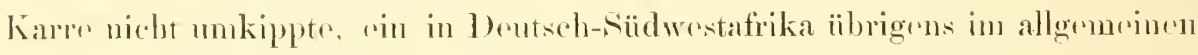
mur als bolangloser Kwischunfall eingeschätztex Vorkommnis, ist wohl als

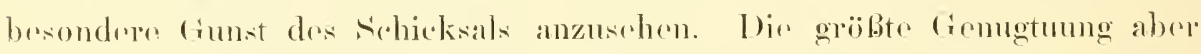

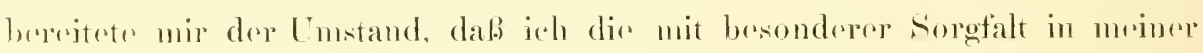

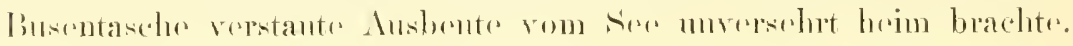

\section{IDie 'Tierwelt.}

Dis Eigenart der 'Tinwrelt rimes Landes wirel bedingt einerserits dureh

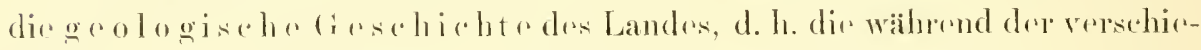

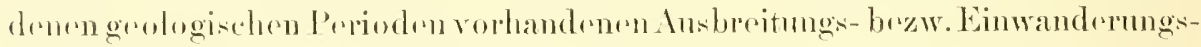

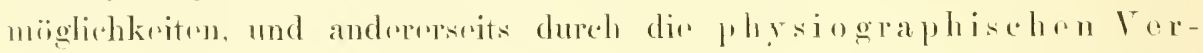
hältnisse, dir Lobensbudingungen, dir das in liage kommonder Land den versehiedenen Tioropuperen darbot. Während das historisehe Moment

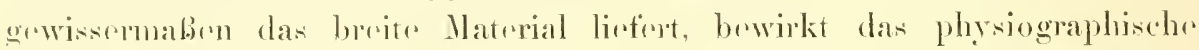

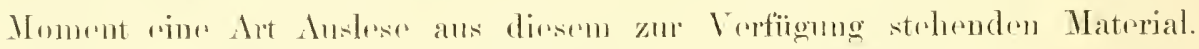

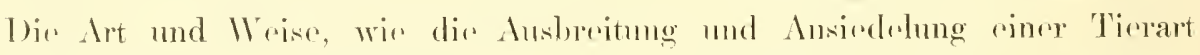

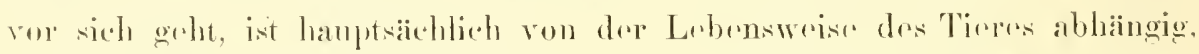
von dem Medium, in deme as lobt, und von dre Fähigkeit, gewisse mit der

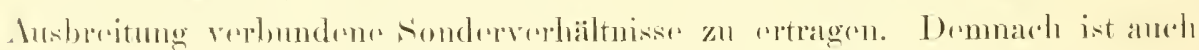

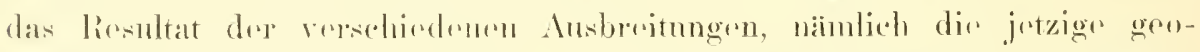

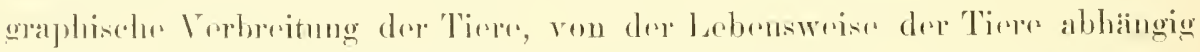

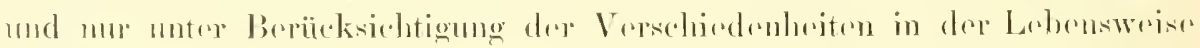
rerstiindlirh.

Landtiere. In rincm so trockencol Klina, wir bentedh-Niidwestafika

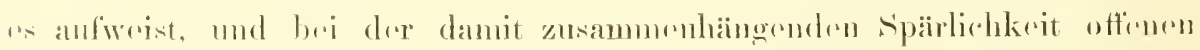

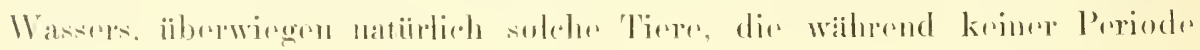


ihres Lebrns mmittelbar an offenes Wasser oder Fenchtigkeit gebunden sind, nämlich einesteils 'Tirere, denen wio schlangen, Eidechsen und violen Insekten dor Wassergohalt ihrer Nahrung vollständig genïgt, und anderen-

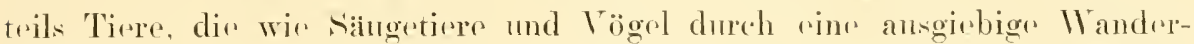
fähigkeit in den stand gesetzt sind, ihr täglieles Bedürfnis nach Wasiser

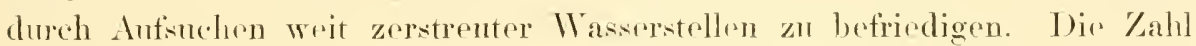

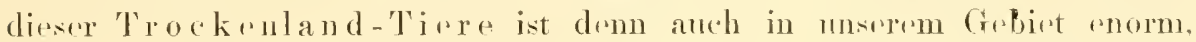
sowohl nach Individuen wie nach Arten gerechnet. Aber anch solche Tiere. die in aner gowissen Periode ihres Lebens, otwa in Eirer- und Larvonstadimm, an offenes Wasser gebunden sind, also amphibische Trirre, wir Frösche und gewisse Iipteren (Mücken), trifft man auf drm Lande nicht rben selten, manchmal wenigstens der Individuenzahl nach massenhaft au. sohs spärlich sind dagegen die Landtiere, die ich als Funchtland-Tier. bezeichne, die sterts einer gewissen Fenchtigkeit des Aufonthaltsortes bedïrfen und bei vollstindiger Fintrocknung zugrunde gellen. Land-Planarien frhlen in Drutsch-siidwestafrika (vielleicht mit Ausnahme des Caprivi-Ziptels. den ich hier nicht nit berücksichtige) anscheinend ganz. Regenwïrmer abgeschen von allen eingeschlopptron in Gästen und anderon kultiviorten Örtlichkeiten) sind nur in sehr spärlichen Vorkommunisen im Nordgebiet (Grootfontein und Watrorbrg-l)istrikt) sowir hart an der Siidgrenze (an

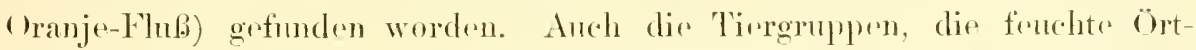
lichkerten berorzugen ohne gerade Fenchtland-Tiere zu sein, wie Landschnecken 'f und Landasseln, sind vorhältnismäbig spärlich vertreten.

lugrographischer Hinsicht, in ihrer Bedrutung füir die Abgrenzung und charaktorisierung tiereogeraphischer Gobiete, sind die Feuchtland-Tirer und die sich an diese biologische Grupper ansehlieBende Gruppe der feuchte Ortlichkeiten berorzugenden Tiere von hervorragendster Wichtig-

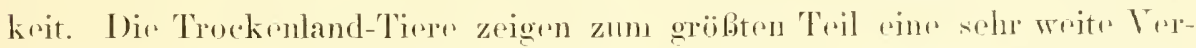
breitung nicht nur der Gattung, sondern auch der Art. Für ihre Ausbreitung gibt es im allgemeinen innerhall, des Kontinents keine soluanken. Wohl sind auch viele Arten der Trockenland-Tiere in ihrem Vorkommen selu beschränkt. In diesen Fällen breruht aber der Charaktro der Verbreitung zumeist auf gewisen speziellen Lebensbedingrugen. Ein Insekt, das an rine ganz bestimmte Futterptlanze gobunden ist, zeigt in seinem Vorkommen natiorlich die gleiche Beschränkung wio jenc Futterptlanze. Ein Tire, das

1) Manche Landschnecken, die die Fahigkeit besitzen, ihre schalenöfinnng währeud der Trockenzeit durch einen Deckel lnftdicht abzuschließen und ihren weichen Körper dadurch vor dem Austrocknen zu schïtzen, dïrfen geradezu zu den Trockenlandieren gerechnet werden. 
wie der Fandwat-(xreko Palmatogerko liangei), durelaus auf das Leben in lockeren s'ande angewiesen ist, kamn sich nicht über den boreich der. Diinen des llästrnstreifens der Namib hinats verbreiten. Es zeigt zugleich.

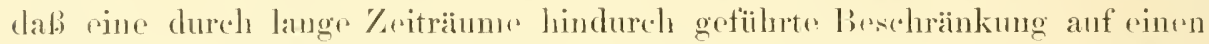
verhältuismäbig kloincn Lebensbremk anch bei Trockenland-Tieren zur . hs-

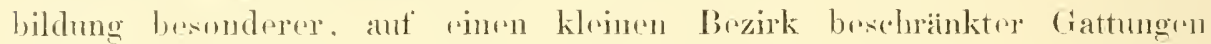

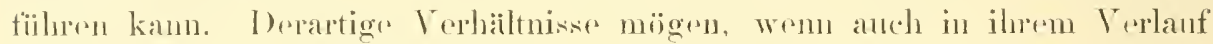
nicht immor so offinsichtlich, noch vieltach zul Bildung andemischer (rattungens anch bei rehten 'Tockenland-Tieren gofiilurt haben. Derartige Lebensbedingungen sind abor zu speziell und zu mannigfaltig, um zur all-

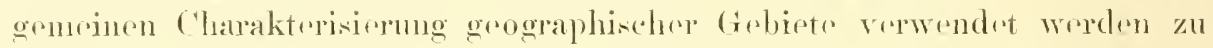
kënnou. In Hinsicht auf die Trockmuland-Tiere stellt sich demuach DeutschSïdwestafrika als un integriorendes. nicht in bedentsameu Zügen sich alssondernder 'Teil des ganzen siddliclı genäBigten bis subtropischen lfrikas dar.

Ganz anders stellt sich das bild geographischer Ciebietsteilung bei Betrachtung der Fenchtland-Tirere dar. Fïr diese, hauptuächlich dir LandPlanarion und lirgenwërurer, bildet das trockene und regenarme Land rom Kïstenrand der Namil, bis zum Cstrand der Kalahari, wenn nicht noch weiter ostwärts, riue absohutr linbreitungsseluranke, durch die das Kapland vom tropiscluen Atrika abgetrement wird. Tatsäbllich tinden wir diese Tiergruppen im Kaplandr durch ganz andere Gattungen und sogar Familien verterten wie in tropischen Afrika. Von Regenwürmern tinden wir in

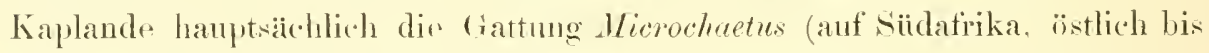
zum Zululande, beschränkt), dir sektion der Chilotecea mit iilmlicher Verbreitung in Afrika, auBerdem in (hile, siid-Patagonirn und Frurrland), mud

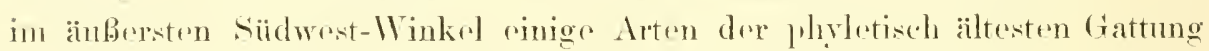
Acanthodrilus (iibrigens weltweit verberitet in zers])rengten Relikten-Gebicten). Im tropischen Afrika tinden wir dagegen die ganz anderen Unterfamilien angehöronden Eudrilinae, Trigastrinae und Ocnerodritinae. Thulich rerhält es sich mit den Land-Planarien. Hier stelte der rein kapländischen Gattung Artiocotyles dir roin tropisch-afrikanische (iattung Othelosoma gegeniiber, und die in tropischen Afrika anftrotenden, ïbrigens in indomalarischanstralisclen Gobiet weit verbreitexton (rattumgen Pelmutoplana und Dolichuplana selurinen in Kaplaude gauz zu fohlon. Nur in drum klimatiseh für

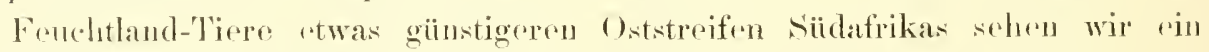
spärliches Tordrängen tropisele-afrikanischer Fenchtland-Tiere in das sïdafrikanisclur Gebiet hinein, so rinon Eudrilinen, Nemertodrilus Kellueri frinziger (iattungsgenosse in Mosambique in der Oranje-kolonio und hart an dro siidgrenze in Dnutsch-siidwestafrika, wohin ar zweifellos durch 
Verbroitung an stots Wasser führenden ()ranje-Flub abwärts golangt ist. Fiir die Charakterisierung der Fanna haben abor derartigr spärliche Eindringlings keine Bedeutme. In Hinsicht auf Fenchtland-Tiere ist demnach bentsch-sïdwestafrika der Hanptsacho nach ein Gobiot ohne endemische Formon. Der Nordrand. wenigstens der ('aprivi-Zipfel, wird dem tropisehafrikanischrn Gebiet zugerochnet werden mïsoen, denn es ist höchstwahrscheinlich. daß die sinige Kilometer ostwäts rom (1stende des Caprivizipfels (bri den Victoria-Fälen) am Sambesi gefundene Eudriline Platydrilus Agnes mod einige anscheinend endemische Oconsodrilinen anch im deutschen Gebiet am sambrsi rorkommen. Die im nördichen Teile unserer Kolonie bei Grootfontein und im Materberg-liezirk gefundenen Ocnerodrilinen, also der tropisch-afrikanischen Fauna angehörig, sind zientich writ verbreitete Arten, also al: Eindringlinge ans tropisch-lfrika anzusehen. Für dic Charakterisiorung der Fama haben sir nur rinc untergeordnete Bedentung.

Eine ähnliche, wenn anch deutlich abweichende geographische lirziohung zeigen gewiss. Tiere, die fenchte Ortlichkeiten bevorzugen, ohno geradezu Feuchtland-T̈ier zu sein, nämlich die Land-chnecken. (Über dir noch nicht bearbeiteten Landasseln kann ich eine geographische Feststollumg noch nieht geben.) Wie schon oben (Fubnote anf Srite 45 ) bemerkt, gehaben sich viele Landschnecken wir echte Truckenland-Tiers. Hhre Gattungen sind kosmopolitisch (wir Senlptrria ron den Ilelecidue, Lencodilus von dern Pupidae und Subulina von den Stenoyyridue), oder doch (wie Achetina) rom tropischen Afrika bis ins Kapland hinein repbreitet. Ander Gattungen dagegun zrigen rine sehr beschränkt. Verbreitung und sind charaktrristisch fiir Dentach-siidwestafrika und das angrenzende Gebiet der Kalahari, so die Gattung Dorcasia, eine der phyetetisch ältosten Helieiden dre auf Australion. Ceylon. Madagaskar und Sïdwestafrika rinschlieBlich dws Kaplandes beschränkten Lnterfamilie Acocinae, so die (rattungen Eburnea (Nerocerastu.;) und Leucochiloides (Pupoieles) der hauptsächlich paläarktivchen, abor in cin rm Kweige iiber Abessinien und (stafrika bis nach siudwestafrika reichenden Familir Buliminidae (Enidae). Für diese Landschneckrn, deren Ansbreitung durch ein trockenes Klima und durch wasserarme Landstrecken erschwert wird, ist Dontsch-sidwestafrika samt Kalahari also ein Gebiot dor Loliopung. die zur Bildung besonderer Gattungen fülırte, für Horeasia geradezu rin liibkzugsgebiet, in drm sich diese phyletisch alto Form halten komnte.

Fassen wir diese geographischen krgobnise zusammen, brachten wil vor allem die absolute Scheidnng, die das Trockenland Namib-Kalahari zwischen der sidafrikanischen und tropisch-afrikanischen Fauna der Fencht- 


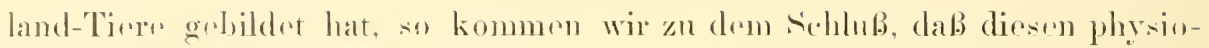

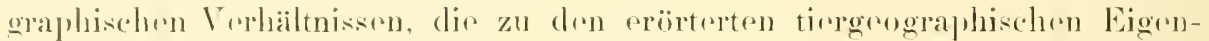
hriten geführt haben, ein pereht hohes geologisches Altre, rine große Konstanz

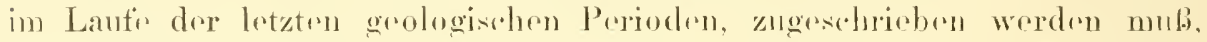
das gleiche Frgebnis, zu dem im speziellen dir Betrachtung des Charakters der Faluna und Flora der Namib fiihrte (vergl. oben seite 27 .

Wassertiere. In meinen Erörterungun über dir Fauna dus Baikal-šess,

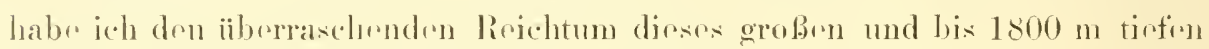
sions an ondemischen, zum Tril phrletisch soler alten Tierformen auf soin

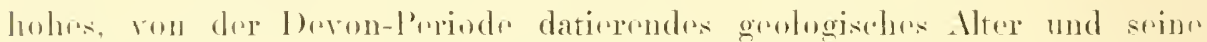

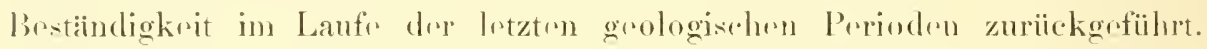

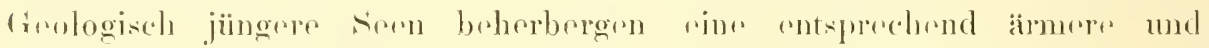

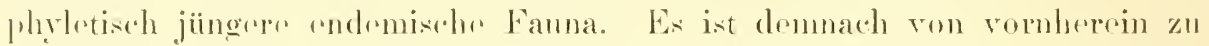

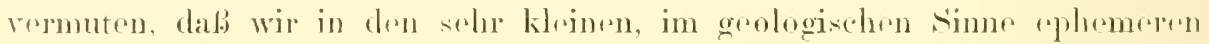

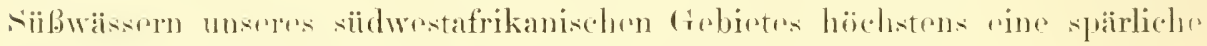

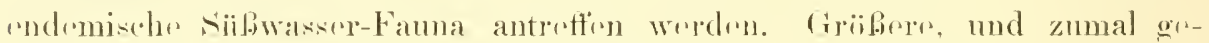

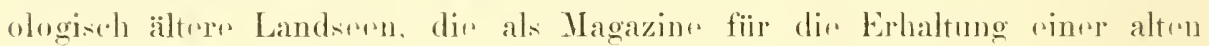

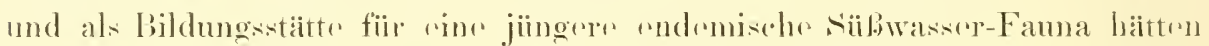

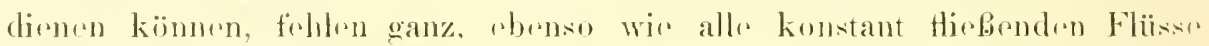

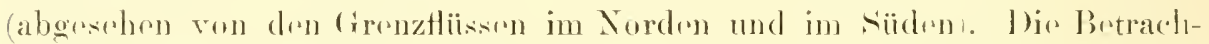

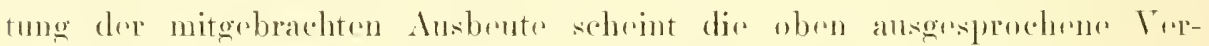
mutung zu bestätigen. Soweit ich es beurteilen kann, handelt we sich zu-

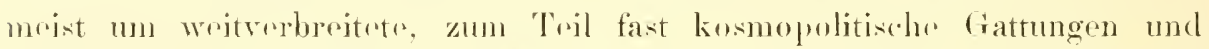
Artru, wio bei don Oligoeluätיn (Nais, Purenais und Aulophorus), den Planarien (Mesostoma), dron Hirudineren (Glossosiphonia, I'larobdella, Mirme), dron Mollusken (Snceriea, Ancylus. Planorbis und Sphaerium, dazu dic afrikanischr. wemu nicht afrikanisch-australische Isidore) und den liryozocen (Lophopulelle, Plumatella). Siibwassersehwämme sind bisher nicht benbachtet

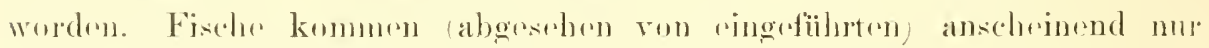
in dom mit dom ()ranje-Flud.) in Vorbindung stehendren Groben-FixchHufs und im (otari-bozirk vor, alse nahe dem daurend flirbenden nörd-

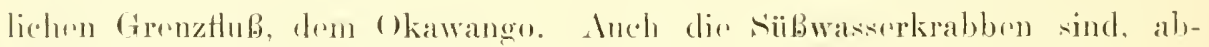

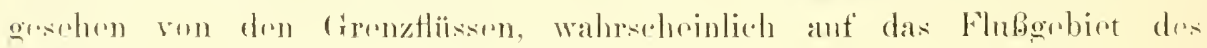

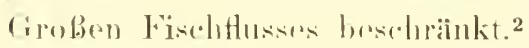

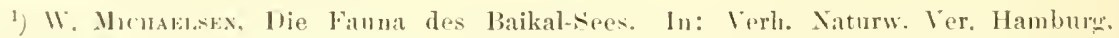
:3) IX, p. 43.

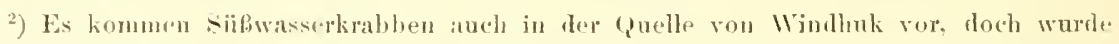

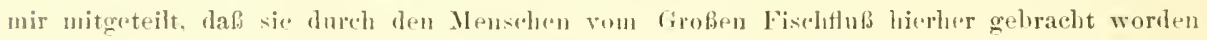
stin sollen. 
Lu allgemeinen macht aber die siißwasser-Fanna nicht gerade oinen spärlichen Findruck. Selbst kleinste, weit isolinetr Wassertiimpel iiber-

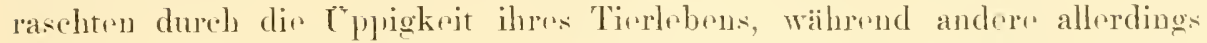
pecht arm zu sein selurinen. Vorwiegend sind in dieser siißwasser-Fauna

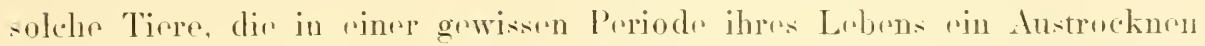
vertragen können, sei es, dab sir wie die Frösche und gevisse lusektron Mïcken pin amphibisches Lebren führen, also in dre Periode des Imago

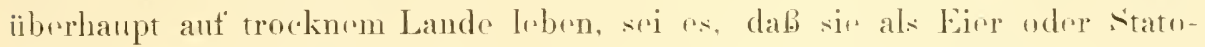
blasten rine Trockenzeit äberstehen könnon wie viele Krolstierehen und

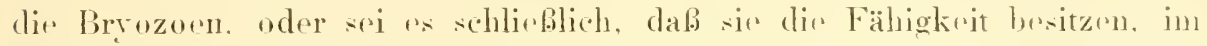
ausgewachsenen Zustande rine Austrocknumg zu äbreleben, wir viele kleine Fadenwïrmer, Bärtierchen und Lufusorien. Leh vrermutr. dab zu dere

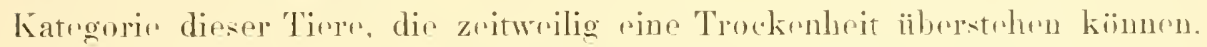
noch viel nelor dor sïdwestatrikanischen siibwasser-Tires gohören, als wir bisher anzumehmen berechtigt waren. Ich vernute, daß z. B. dir kleinon limicolen Oligochäten ihre weite, zum Teil kosmopolitische Trepreitung der

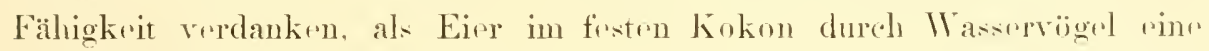
wenigstems kleine Strecke ïberland von rinem Tümpril zu einrm anderen verschleppt werden zu kïnnen. Die drerberen Blutegel mögen selbst als ausgewachsene Tirre, rtwa an anstliegenden Mrasserkitern haftrud, rine längere

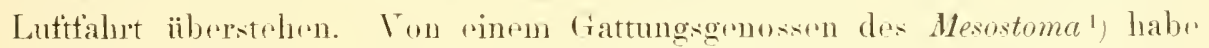

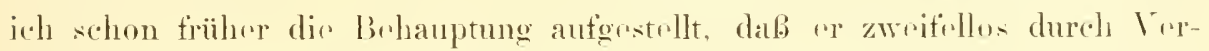
schleppung soinor Eirer dureh Väged oder Wasserkäfor in oine ephemere Wasserlache auf der Kupper oines Cranithiegls bei Bourabbin in siidwestAustralien gelangt sei. Auch eine Verschleplung durch den Menselenn mage viel zur gelegentlichen Vurbreitung der siißwasser-Tiere und zur bosiodelune woit isolierter Tïmper beitragen. In diesem wasserarmen Lande verläbt kein Herepe oder Hottentotte bri writeren Wauderungen eine Wasserstelle. "hno seine Kalabasso mit IVasser und dem darin lebenden Kleintior gefüllt zu haben, und beri der Xou-Füillung in der nach langer Manderung zunächlist rrreichten Trasserstelle werden mit dem Rest des mitgebrachten Massoles leicht wohl derartige mitgeschleppte 'Tiere. Eier oder Kokons in dio neur Wasserstelle geschüitter. Besonders gïnstig sind dir Lebensrorlältnisser in unserem Ciebiet natïlich fï̈ solche Massertiere. deren Eiro zur Entwick-

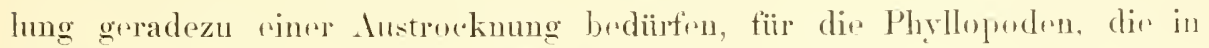
prächtigen Formen dir kleinen sïbwassertimupel beleben.

1) Mesostoma Michaelsemi Axis: WE1ss = ..Planaria?". W. MrChaklskx, Die Tierwelt siidwest-Australiens und ihre geographischen Beziehungen. In: Mitt. (ieogr. Ges. Hamhur.. XXII, P. 17. 
Anffillig ist rine Eiguhent in der Verteilung der sii lowasser-

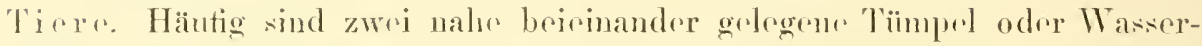

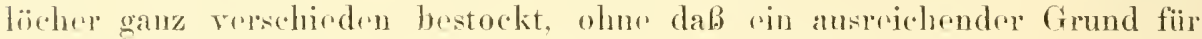
diese Verschiodenheit aus dom C'haraktor der Wassorstollen zu resolien wäip. handelte es sich doch um Wasserstellen, dir im gleichen und gleich-

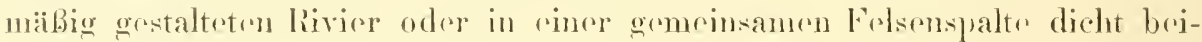
rinander lagen. I) fand $\mathrm{ich}$ in dom anen Tiimpel prichtige Branchipus

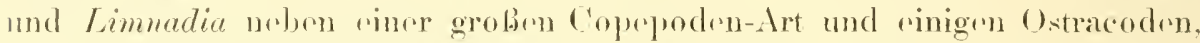

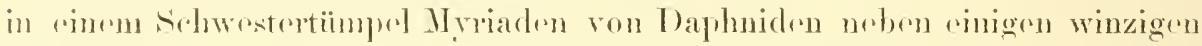

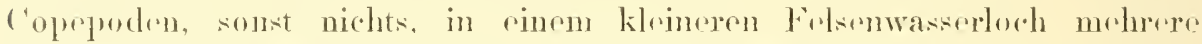
l'lutegel, ringe Masserwanzen und zahlreiche Nïckenlarven, in rinem be-

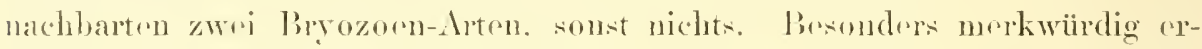
schion mir diesos Vorkommen dor beiden Bryozorn. Die cine, Plumatella

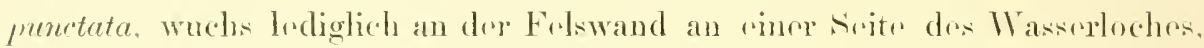
lie andere. Lophopodella capensis, sab in otwa 20 kleinen Kolonien an der.

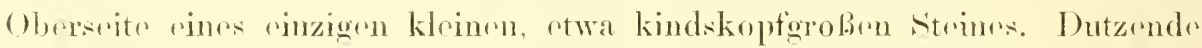

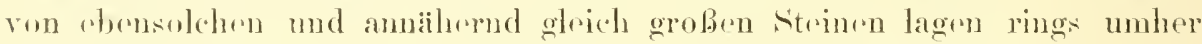
beri dissm Bryozoen-ktrin, ansehromend in durelans gleichwertiger Lage: auf krinem dersolben fand sich anch mur rine anzigo Bryozorn-Kolonir.

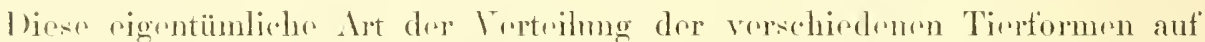
dio gloichartigen Wasserstellen vermehrt den Eindruck dos Yufälligen in der Bestockumg und dor rphemoren Natur dirsor Wasserstellen und spricht

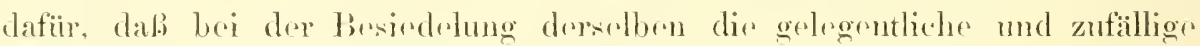

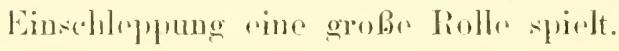

\section{Der Sambesi-Inistrikt von Khodesia: Heimfahrt.}

Wir luattren die mittlere Rergions, den Norden mod dens Siiden unseres

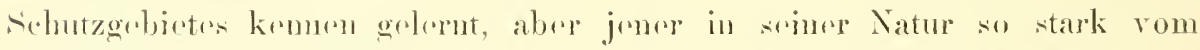

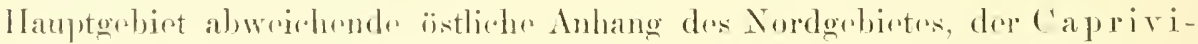
\%ipfrel, war uns mangänglich goblirben. Wir beschlossen drshalb, ms

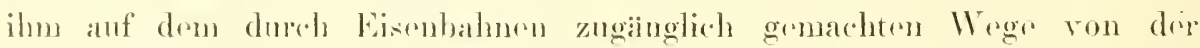

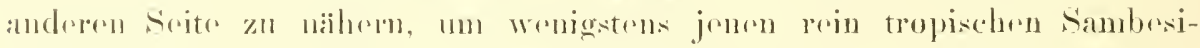
bistrikt kemmen zu kermen, der, kanm 70 Kilometer vom Ostende des Caprivi-

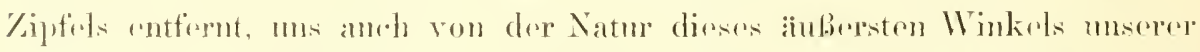

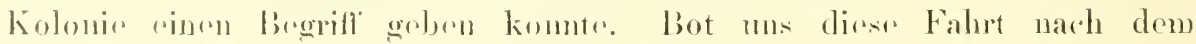


mittleren Sambesi doch zugleich Gelegenheit, das groBartigste Naturschanspiel Afrikas, die Victoria-Fälle, zu sehen.

Nach einem 14 tägigen Aufenthalt in der smaragdenen Kapstadt fuhren wir mit der Rhodesia-Eisenbahn bis ins Innerste Südafrikas - 5 Tage und 5 Nächte im Eisenbahnwagen bei nur zweimaliger wenigstündiger Fahrtunterbrechung in Kimberley und Bulawayo, ein Vorhaben, trostlos in der Voranssicht, aber durchans nicht schlimm, ja, ganz gemuitlich, in der Ausführung: man gewölnt sich schnell an den Zwang räumlicher Beschränkung bei weitem, wechselndem Ausblick. Durch romantische Felsentälor, über öde, steinige Karroo und unübersehbare flache Grassteppen, sowie durch trocknen lichten Buschwald führte uns der Zug. Erst am letzten Tagı der Fahrt, nördlich von Bulawayo, der Hauptstadt Süd-Rhodesias, nimmt die Vegetation einen üppigeren Charakter an. Die Bäume werden hïher und schließen sich zu einem dichten Hochwalde, dem Trockenwalde Mittelafrikas, zusammen. Unter den rerschiedenartigen, wit den bizarrsten Klapperschoten, Kürbis-artigen Kapseln und holzigen Birn-, Ei- und Leberwurst-förmigen Friichten behangenen Bäumen lagt vor allem der Affenbrotbaum oder Boabab hervor, ein Elefant unter den Genossen des Waldes. Auch hier herrscht noch winterliche Trockenheit. Die Bäume und Büsche prangen im buntfarbigen Herbstlaub. Einige, so der Affenbrotbaum, haben ihr Laub abgeworfen und strecken die kahlen Zweige gen Himmel. I)as Tierleben ist hier, im winterlichen Trockenwalde, selbst kaum einen Kilometer rom großen Wasser, dem Sambesi, entfirnt, seler spälich. Kaum melır als einige Fliegen sind bei obreflächlicher suche zu entdecken. Ein regeres Leben herrscht jetzt nur im unmittelbaren Bereich des Massers. und diesem streben wir zu, nicht nur im wissenschaftlichen Interesse.

Von der Bahnstation , Victoria falls" und dem in seiner Nähe lirgenden Hotel, die man in anerkennenswerter, weiser Einsicht kilometerweit ron den Fällen entfernt errichtet hat, führt rin wohlgeebneter IVog zu den offiziellen Ausichtspunkten. Wir aber verlassen diesen Weg und gehen auf einem kaum erkennbaren Negerpfad, den ein Gras schneidender Barotie uns verraten hat, gerade auf unser Ziel los, durch einen mit fast mannshohem trockenen Grase bestandenen steppenstreifen in den iippig griinenden, dämmerigen Galeriewald hinein. Ein feiner sprïhregen - oder ist es nur Nebel? - schlägt uns 'ntgegen, es tropft von den Blättern, und vorsichtig müssen wir im Waldesdunkel unseren schmalen Pfad rerfolgon, denn rechts und links droht tiefer Morast. Fin eigentïmliches Hiracsen, oder vielmehr ein tänendes summen in äuferst tiefer Tonlage, das uns bis ins Innerste vibrieren macht, erfiillt den Raum, eine stimmung und Klang- 


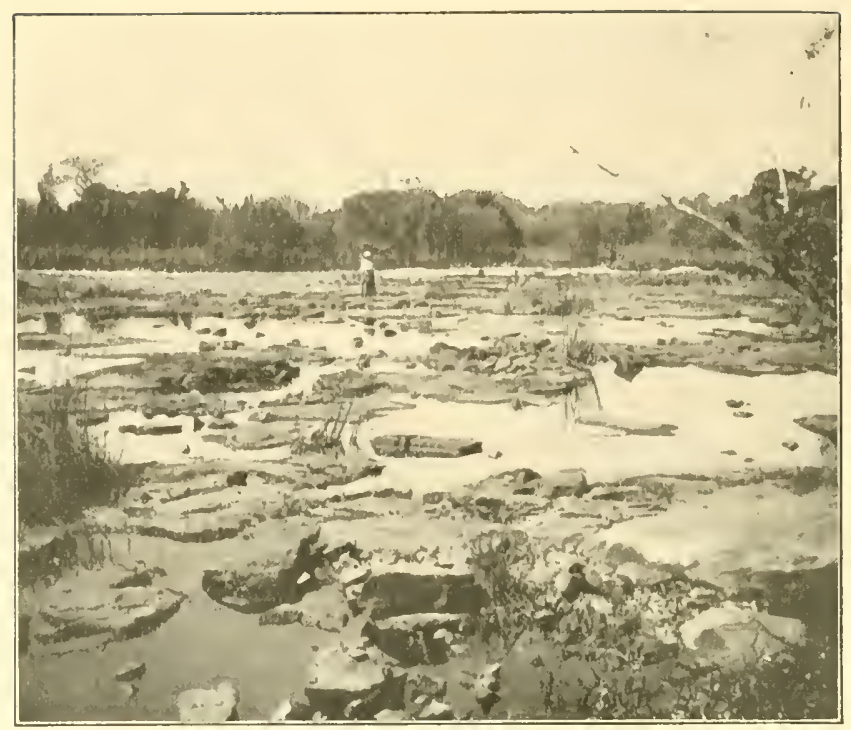

Fig. 14. Klippenreiches Flachwasser des Sambesi dicht oherhalb der VictoriaFälle, Fundort verschiedener siißwasserschwämme und -Hryozonen.

farbe, wie se an Anfange des Rheingold-Vorspielos herrscht. Dureh eine breite Lueke in diehten Laubwerk fluter jotzt das Tageslicht blendend, und jener vibrinendr 'Ton in verstäktem Brausen heroin. Wir troten hinaus und strhen plätzlich am senkereht abstïrzenden liandr oince tiefon, breiten

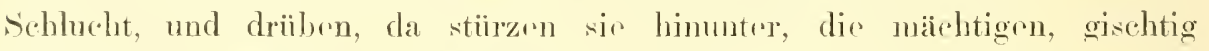
schäumenden Wasser des Sambesi, bransend und donnernd, als ob das Iner sich in oinen Erdrnsehlund hinabwälze, und versehlungen seheint alles zu soin: wir kïnnon an unserem standpunkt woder dio Tiofo des

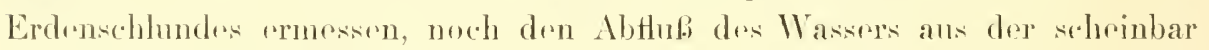
allsoitig geschlossonen schlucht arkennon; nur gewaltige, wir aus riner Gigantenbrust loransgefanehte und boch in (lio Lüfte goblasene Dampef-

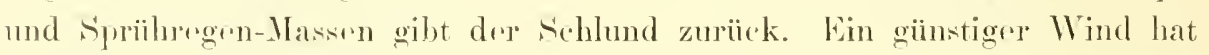
diesese sprïhnebel bisher seitwiats fortgetrichen und uns dadureh übrrhaupt

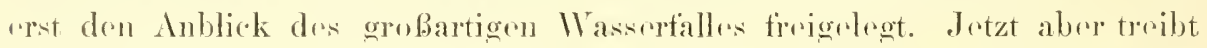

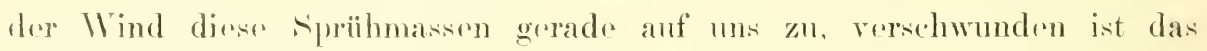
l'hänomen. Eingerhültt in rinen diehten Mantel von Nebes und Regen seben

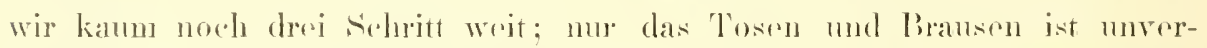
mindert und jotzt wiodere gehermnisvoll wir vorhere, da wir die gigantisehe lesache dieses Gigantentous siebst mehr vor Augen haben. Jotzt verstelsen

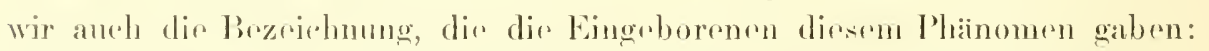

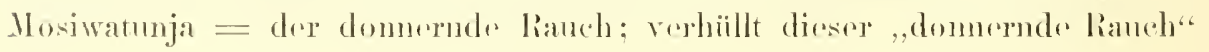




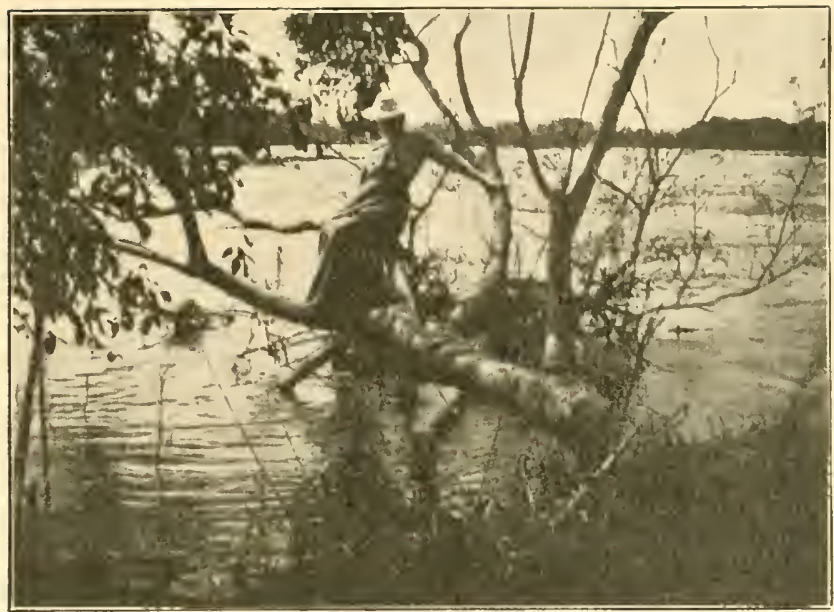

Fig. 15. Am Sambesi oberhalb der Victoria-Fälle, Fnndort des Platudrilus Ammes und der Ama sp.

den Wassorfall doch für Monate vollständig, nämlieh wäluend dor ganzen Jahreszeit, in der der sambesi die monehren Wassermassen der tropischen Sommerregen in soinem woiten Surllgebiet sammelt und abwïts führt. Es ist nicht ratsam, dir Fäle zur Zeit dieses Wasserrojeletums zu bestechen. Die aus der Tiefo des schlncht heransgeworfenen sprühnebel-Massen sind dann so rnorm, daf man dir Fälle ïberhaupt nicht zu (resicht bekommt, oder doch höchtens nur die Kanten der kleineren sieitenfäle, die dureh kleine waldige Inseln am Rande der Absturzkante ron dem Hauptfall gesondert sind. Ist d^r tresamtanblick der Faillo vom gegeniiberliegenden Regenwaldr aus, von wo sich der Haupttall in seiner ganzen lireite darstellt, gigantisch und ïborwältigend, so bieren doch rinzeln" Trile der Fälle, zumal, wenn sie sich bei gröberer Fntfernung in ilurer präehtigen tropischen Lmralmmung zor Sichau strllen, anch liebliche Bilder. I or allem lieblich aber sind die Cfur des sies-artig verbreiterten sambesi mit ihrem Palmenschmnck obrrhall, der Fälle. Ich woib da ein gar lauschiges Plätzchen, eine winzige von Binsen und Papyms umrahme, von dichtrm Baumund Buschwerk rerstecktr seichte Bucht: in vom Lfor niedergelsrochener, woit ziber das Wasser hiniberragender, aber nech im vollen Batter- und Blïtensehmuck prangender Baum diente uns als sitz nud Arbeitstisch, anf

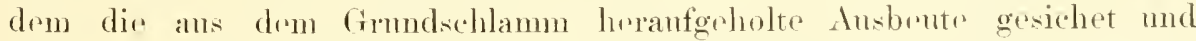
verstaut wurde. Hirr sah ich zum ersten Mals lebende Vertreter (Platydrilus ignes) der in ihrre wundrobaren und mannigtaltigen innorn (Yrganisation so interessanten Eudrilinen, riuer tropisch-afrikanischen RegenwumGruppe, die seit Jahren eines meiner hauptsächlichsten Forschungsgegen- 
stände bildete, die ich aber bis dahin nur an totem Material studieren konnte. Hier fand ich auch, als in ihrem südlichsten Vorkommen, die Gattung Alma wieder, deren nördlichster Vertecter (Alma nilotica) mich ror Jahron nach Agrpten zog (natürlich nur als mehr zufällige Veranlassung, nicht als alleiniger Zweck der Reise). Ich konnte durch diese und andere Funde foststellen, daß der Bezirk des mittleron Sambesi die siidliche Grenze des tropisch-afrikanischen Terricolengrbietes, dessen suidliche Ausdehnung bisher unbekannt war, bildet.') Es ist kaum 'zwrifelhaft, daß. auch die Nordkante Deutsch-Siidwostafrikas, wenigstens im Brreich dos Sambesi, noch zum tropisch-afrikanischen Gebiet gehöre; denn so wie wir die gleichen Arten noch melurere Kilometer weiter flußautwärts bei der Insel Kandahar fanden, so werden sie anch noch einige weiter fünfzig Kilometer flußaufwärts im deutsch-südwestafrikanischen Sambesi-Bezirk zu finden sein. Leider konnte ich diesen Bezirk nicht erreichen. Eine KanuFalnt nach der genannten Insel Kaudahar brachte uns demselben so nahe wie die zur Verfïgung stehende Zeit und Gelegenheit gestattete, ließ aber immex noch etwa füinfzig Kilometer zwischen uns und der östlichsten Ecke unseres Schutzgebietes.

Der achttagige Aufenthalt an den Victoria-Fällen bildete den Höhepunkt unserer Erobnisse. Mit dem Abschied ron diesem schoinen Erdenfleck, dem schönsten und interessantesten, den ich auf meinen rerschiedenen Reisen kemnen gelornt habe, bogann msero Hoimfalirt. Diese führte uns noch üper viole sehenswerte Punkte in Rhodesia, Transvaal und Natal und gab mir Gelrgenheit, die naturgeschichtlichen Mnsern in Bulawayo, Protoria, Pieter-Maritzburg und Durban zu besuchen und Brziehungen zu meinen Fachgenossen in diesen Stadten (wie vorher in Kapstadt) anzukuiipfen. Auch mancher interessante und ergiebige Sammelausflug wurde noch untrenommen, so besonders von Durban aus nach versehiedenen Orten dor natalensischen Kïste, so z. B. nach Isipingo mit soinen prächtigen tierroichon, Aquarimu-artigen Felsenbecken des Ebbestrandes, die mir einen lehreichen Einblick in dir ïppige und farbenpräehtige Litoralfauna des Indischen Ozeans gestatteren. Die Hoimfahrt über den , (Ostweg" bot ums

1) Was ohen, hei der Erörtermug der Tierwolt von Dentsch-Siidwestafrika erwähnte Vorkommen eines Eudrilinen, Vemertodrilus Kellneri, in der Oranje-kolonie und in siidDistrikt vou beutseh-sidhwestafrika suricht nicht gegen diese Feststellung, deun es handelt sich bei diesem um einen sogenannten „vorgeschohenen Posten“, einen „Weitwanderer", währond hei der Tougrenzung der eigentlichen Gehiete nur endemische Arten mit beschränkter und numeifelhaft selhständiger Verbreitung berïeksichtigt werden dïrten. 
ferner Gelegenheit, viele andere Küstenplätze Ostafrikas, vor allem Sansibar, Daressalam, Tanga und Mombassa zu sehen.

Über all diesen kurzen Besuchen lag aber die Unrast der Heimkehr, die keinen längeren Aufenthalt mehr zuließ. Die auf dem nächsten Wege, dem „Westwege", heimgesandte Sammelausbeute von Deutsch-Südwestafrika zog mein Sinnen nordwärts, der Heimat zı. Am 23. Oktober kamen wir wohlbehalten in Hamburg wieder an, und hier fand ich auch meine Ausbeute unversehrt vor. Nicht ein einziges der mehr als tausend Gläser und Gläschen war zerbrochen, ein Ergebnis sorgsamer Verpackungskunst, das selbst das meiner südwest-anstralischen Reise, bei der 2 kleine Gläser zerbrochen und ausgetrocknet ankamen, noch ïbertraf. $O b$ der wissenschaftliche Wert dieser Ausbeute die mancherlei Mühen und Kosten der Reise lohnen wird, werden die folgenden Blätter mit den wissenschaftlichen Bearbeitungen dirses Materials erweisen mïssen. 



\section{Bryozoa}

ron

\section{Karl Kraepelin}

(Hamburg).

Mit 1 Tafel. 

Unsere Kenntnis der afrikanischen Süßwasserbryozoën setzt bekanntlich erst mit dem Jahre 1890 ein, wo Stubuax bei seinem ersten Besuch des dunklen Kontinents nicht weniger als 4 verschiedene Arten erbeutete, nämlich Fredericella sultana bei Alexandrien, Plumatella repens und emarginata, sowie eine von mir irrtiimlicherweise als Pectinatella carteri HYatr bestimmte Art bei Bibisande zwischen Tabora und dem Victoria-See (Tgl. 1, 2, 3, 4 1). Für die beiden Plumatella-Arten wurde dann bald, teils durch weitere Funde Stuhlmaxis, teils durch Untersuchungen Merssderis $(3,4,5)$ von Statoblalsten an Inschel- und Schneckenschalen (Aetheriu, Paludina) eine ausgedehntere Verbreitung im Victoria-See, Albert-See, Albert Edward-See, im Gesamtlauf des Nil, im Niger- und Senegalgebiet nachgewiesen, während Kinкмax (6) 1901 das Vorkommen von Fredericella sultana auch im Equefa River in Natal feststellte. Nit einer nenen, fïnften Bryozoën-Art, der den Grmnolaemen zugehörigen Arachnoidia ray-lankasteri aus dem TanganykaSee, machte uns dann 1901 J. E. S. Moore bekannt (7). Besonders wertroil aber waren die Beiträge, die Cir. Rorsselet 1904 und 1907 zur Kenntnis der Moostierfauna lieferte $(\mathbf{8}, \mathbf{9})$, indem er nicht nur aus Rhodesia eine neue, der Gattung Lophopus nahe stehende Form (Lophopodella thomasi) beschrieb (8), sondern auch als Bewohner des Tanganyka-Sees außer Plumutella repens und Arachnoidia ray-lankasteri noch die nenen Arten Fredericella cunningtoni, Plumatella tanganyikae und Tictorella symbiotica feststellte 9). Damit war die Zahl der afrikanischen süßwasserbryozoën anf 9 gestiegen, denen dann J. Sollas 1908 als zehnte Art noch einen Lophopus capensis hinzufügte. Die jüngste Arbeit von G. Ulver (12) berichtet über die Bryozoënausbente der 1. Innerafrikanischen Expedition des Herzogs Adolf Friedrich zu Mecklenburg, olnne wesentlich Neues zu bringen: dagegen ist es, wie schon hier bemerkt werden mag, Prof. Мrchaessex gelungen, in Deutschsüdwestafrika noch eine 11. Art. nämlich die Plumatella penctata Haxc., aufzufinden und damit die Zahl der afrikanischen süßwasserbryozoën auf dieselbe Höhe zu bringen, wir dis der europäischen mit 2 Paludicella-,

1) Die Zahlen verweisen auf das Literatur-Yerzeichnis am Schluß. 
1 T'ictorella-, 1 Fredericella-, 4 Plumatella-, 1 Lophopus-, I Pectinatella-, 1 Cristalella-Art). Nur 4 daron diirften mit europäischen Formen identiseh sein, während 7 für die afrikanische Fauna speziticeh sind. Da auch dir Fauna Indions nur etwa 11 Arten aufweist, st wird man zahlereichere Neuentdeckungen in Afrika schwerlich mehr zu erwarten haben.

In llentsch-Südwestafritia, von wo bisher Sïßwasserbryozoën überhaupt noch nicht bekannt waren, hat MichaElsex 5 Arten nachgewiesen, deren Besprechung hier folgt.

\section{Frederilla sultana (Blbch.).}

1774 Tubularia sultana Blumensacn in: Gött. Mag. I. p. 117.

Fundangabe: Rhodesia, im mittleren sambesidichtoberhalb der Victoria-Fälle; W. Michaelsex, 18. Aug. 1911.

Dirse in Europa, Nordamerika, Sïdamerika (Brasilien, Patagonien) und Australien (Neu siidwales) verbreitete Art war bisher aus Afrika nur ron Alexandrien (dureh stumbuax) und aus dem Equefa-River in Natal (durel linkмax) brekannt. Michaelsex sammelte sie an steinen bei den V'ict o ria Fällen des Sambesi. Liegen diese auch noch etwa 60-70 Kilometer rom Caprivi-Zipfel intfornt, so wird man die Art nach diesem Befunde doch als zum Faunengebiet unserer Kolonie betrachten dürfon.

Die Exrmplare gleichen in jeder Hinsicht der typischen Form. Die Kolonien sind noch verhältnismäbig jung, doch finden sich schon vereinzelte. Statoblasten entwickelt, die allerdings fast um $1 / 3$ kleiner arscheinen, al solche von Exemplaren dor Elbfauna. - Die F. cunningtoni Rouss. des Tanganyka-sees hat der Cnterlage dicht anliegende, vielfach anastomosierend", im (querschnitt Hach ovale Zweige, die vïllig transparent, aber dick mit sand inkrustiert sind. Sie wurden aus 10 und 20 Faden Tirfe heraufgelselt und stellen dahor, wis Loppexs $(11$ p. 158) meint, wohl nur eine Varietät der Fr. sultana dar. Auch dirse tritt ja, wir Hrate schon 1869 von anerikanischen Formen berichtete, unter Cmständen mit völlig hyaliner Ektocyste auf; anch vermag sie in beträchtlichen Tinfen zu leben, wie Asper fïr die sehweizer seren nachwies. 


\section{Plumatella repens (L.) emend.}

175 S Tubipora repens LINÁ́ im Syst. nat. Ed. X p. 790.

1857 Plumatella polumorpha Krafeperix in: Abh. Natw. Ver. Hamburg X., Deutsche SüBwasserbryozoën p. 122.

Fundangabe: Neudam m: W. Michaelsex, 10. Mai 1911.

Die äuberst vielgestaltige, geradezu kosmopolitische Plumatella repens (L.), für die ich 1887 in irrtïmlicher Auftassung der Nomenklaturregeln den neuen, weil weit umfassenderen Namen $P$. polymorpha vorschlagen zu sollen glaubte, scheint namentlich im äquatorialen Afrika weit verbreitet zu sein (Bibisande, Victoria-šer, Albert-See, Albert Edward-see nach STumbiax, Tanganyka-see nach Roussezet, Fhugerbiet des Nil, des Niger und des Senegal nach MeIssxer).

Aus Deutsch siidwestafrika liegt mir nur ein einziger Schwimmringstatublast ror, den Michaelsex bei Neudamm sammelte. Das typische Verbältnis von Breite zur Länge (1:1,2) läßt abre kaum /weifol zu, daß es sich wirklich $1 \mathrm{~m}$ diese Art handelt.

\section{Plumatella emarginata Illm. emend.}

1843 Plumatella emarginata Altuax in Rep. Brit. Ass. 1843.

1857 Plumatella princeps Kraepelix in Deutsche siißwasserbyozoën I p. 119.

Fundangabe: Grober Fischflub etwas sïdlich ron seeheim, an Schilfstengeln: Ir. Michaelsex, 18. Sept. 1911.

Auch diese Art, deren 1887 von mir aufgestellter Namr P. princeps zu Gunsten desälteren, allerdings weniger umfassenden fallen muB, ist kosmopolitisch, ako bereits in sämtlichen Erateilen nachgewiesen. In Afirka scheint ihre Verbreitung im wesentlichen mit derjenigen von P. repens zusammonzufallen rgl. Jenssar 3, 5. Schubotz sammelte sir im Lohango-sere, westlich rom Victoria-see, nahe der Westgrenz' Dentsch-Ustafrikas (Cumer 12, p 287).

Aus Dentsch-südwestafrika ist die Art bis jetzt nur bei Seeheim am Gr. FischfluB im siuden der Kolonie beobachtet worden, wo si Michaelsex an Fichilfstengeln sammelte. Dir stöeke sind hirsclugeweihartig verzweigt, der Lntrrlage anliegend, ohne frei anforichtere Aste. Die Ektocyste ist verhälnismäßig zart, wenig inkrustiont und weib: Kiel und Furche treten nicht oder nur wenig herror var. stricta nach Allsax). Die ziomlich sparlich entwickolten schwimmringstatoblasten entsprechen in ihren relativen und sulbst in ihren absohuten Maßen durchaus denen der 
Elbfauna (Breite: Längo $=1: 1,7$ ) : dir sitzenden Ttatoblasten überwiegen an Zahl und zeigen keine Besonderheiten.

Oie älnliche, aber wohl als solbständige Art aufzufassende Pl. fruticosa Allana ist in Afrika noch nicht beobachtet. Die zur philippinensis-Gruppe gehörige, durch starke Chitinisierung der Ektocyste ausgezeichnete Pl. tangamyikae Rouss. kommt nach Axxaxuate (Freshwater Sponges, Hydroids and Polyzoa in: Fauna of Pritish India, 1911, p. 225) auch in der Nähe von B o mbay vor; sie wurde von letzterem Autor 1908 (Rec. Ind. Museum II, pag. 169, als $P l$. bombayensis Axx. beschrieben.

\section{Plumatella menctata Hancock.}

Tafel I, Fïg. 10.

1850 Plumatella punctata Haxcock in: Ann. Mag. Nat. Hist. (2) V. 1. 200.

Fundangabe: Neudamm, in felsigem Wasserloch hinter der Neudammer Kuppe, an der Felswand: W. Michaelsex, 14. Mai 1911.

F.s ist nicht zu leugnen, daß dieso bereits aus Europa, Indien, Nordund Sïdamerika bokannte Art einen von den ibrigen Plumatellen ziemlich abwrichenden Habitus besitzt, indem infolge der hyalinen Beschaffenleit der Ektoeyste die Ausbildung aufrechter \%weige völlig fellt und dadurch rin Zusammenlagern dor Polypide in der gemeinsamen, der Unterlage dicht anhaftenden und oberseits nur kurz buckelförmig sich vorwölbende Mündungskegel tragenden Cystidröhre bedingt wird (Vgl. Taf. I, Fig. 10). Da aber auch bei anderen Arten die Ektocyste oft recht zartwandig ist, auch dir Bildung aufrechter Sprosso ganz oder fast ganz unterdriickt sein kann z. B. bei Pl. javanica KrPLx.), so glaubte ichl bereits 1887 in meiner Monographie dor Auffassung Juluex's (Monographie des Bryozoaires d'eau douee in: Bull. Soc. \%ool. France X, 1885, nicht beipflichten zu sollen, der unsere Art zum Typus einer besonderen Gattung Hyalinella erhoben hatte. Besonders maBgrbend war für mich seinrr Zeit noch die 'Tatsache, daß der Gesanthabitus des Wachstums der Plumatelle punctuta doch im wesentlichen an den der iibrigen Plumatellen sich ansehließt, insofern es sich auch bei ihr um gestreckte, in ihrem Wachstum unbegrenzte und ihrer Veristolung keiner erkeunbaren Norm unterworfene Cystidröliren laandelt, die als Grosamtkolonie rine äuberst wechselnde Formgestaltung zeigen. R'chweriger wurde die Frage, als dann Ribley (Journ. Limn. Soc. v. 20 p. (61) 1887 eine neur Bryozoë aus Australien brschrieb, dir von ihm den Namen 
Lophopus lendenfeldi erhielt. Diese Art hatte ovale bis runde Statoblasten, ähnlich den Plumatellen, schloß sich aber in ihrem Wachstum mehr del Gattung Lophopus an, indem die Kolonien sich als kleine, in ihrem Wachstum begrenzte hyaline Platten darstelten, aus denen dis einzelnen Polypide in anscheinend regelmäßiger Anordnung wie aus einer gemeinsamen Gallertmasse hervortreten. Diese an Lophopus erimnernde Gestalt und Wachstumsform war es, die Riduey zur Einreihung seines Fundes in dir. Gattung Lophopus veranlaßte. Allein bereits Rousselet (8 p. 49) machte 1904 hiergegen mit Recht das Bedenken geltend, daß nunmehr der bisherige Gattungscharakter der Gattung Lophopus, der in der kahnförmigen Zuspitzung der Statoblasten liegt (vgl. Tafel I Figur 7), viillig verwischt sei, und Loppexs (11, p. 162) hat dann in Anerkennung dieses Einwandes die Riduer"sche Bryozoë aus der Gattung Lophopus entfernt und sie der wieder hervorgeholten alten JuLuiex'schen Gattung Hyalinella eingereiht, welche nach ihm nummehr die beiden Arten $H$. punctata und $H$. lenderfeldi imfaßt. ${ }^{1}$ ) Als befriedigend kann dieser Ausweg gewiß nicht gelten, da einerseits nach dem oben Gesagten die H. punctata durch kein scharfes generisches Merkmal von der Gattung Plumatella abzugrenzen ist, andererseits aber die beiden durch Loppexs in seiner Gattung Hyalinella vereinigten Arten zum mindestens in ihrem Wachstum eine ansgeprägte Verschiedenheit zeigen, die in Verbindung mit Unterschieden in den Statoblasten ganz wohl eine generische Trennung zu rechtfertigrn schrinen. Ich glaube mich daher der von Axnandale 1910 (Rec. Indian Jus. T, p. 40) und 1911 (Freshwater sponges, Hydroids and Potyzoa in: The Fauna of British India, p. 212) rartretenen Ansicht auschließen zu sollen, wach welcher Plumatella punctatu Haxcock nach wie vor der Gattung Plumatella verbleibt, der" "Lophopus" lendenfeldi Rides aber zum Typus einer besonderen Gattung Australella erhoben wird. Wir gelangen damit zu riner befriedigenden generischen Gliederung aller um die alte Gattung Lophopus sich gruppierenden Formen: die Gattungen Stolella und Stephanella sind beidr eharakterisiert durch ihre Stolonenbildung, Lophopodella dureh den Besatz mit Dornen an den beiden Polenden der Statoblasten, Lophopus durch die kahnförnige, beidendig zu-

$\left.{ }^{1}\right)$ Wenn Loppexs daneben den Lophopus jheringi, Meissaer (Zool. Anz. 1893, p. 260) wegen seiner sechseckigen Statoblasten bei der Gattung Lophopus beläbt, so geschieht dies ganz gewi\& zu Unrecht, da jene rermeintliche Sechseckigkeit ein Kunstprodukt war, wie ich bereits 18932 darlegte. Ist daher der $L$. jheringi vielleicht auch nicht dentisch nit $L$. lendenfeldi, so unterscheidet er sich doch jedenfalls nicht durch die Form der Statoblasten ron ihm. Erst eine Nachuntersuchung des L. lendenfeldi, dem Rubckx .,stolonenartige Luben“ zuschreibt, wird volle Klarheit über die beiden in Rede stehenden Arten bringen können. 
gespitzte Form der Statoblasten. Australella wäre dann diejenige Gattung, die sich durch das Fehlen der stolonen's wie dureh ovale unbedornte Statoblasten von den vorgenannten unterscheidet, dabei am meisten der fiattung Plumatella und insonderheit der P. punctata sich anschliebend. sie nuterschoidet sich aber scharf rou allon Plomatellen durch das begrenzte, zur ausgepragten Rosrttenform der Kolonie führonde Wachstum, welches dem ron Lophopodelle und Lophopres antepricht, wire auch durch Art und Crestaltung der Statoblasten. Nitzende Statoblasten, die nummehr bei allon Plumatella-Arten nacherewisen sind verol. waiter untem), treten bej ihr nicht auf: die oralen oder fast runden Schwimmringstatublasten aber besitzen rime cirobes. welehe die aller bekamten Plumatella-irten nahezu $11 m$ das doppelte iibortrittit (rgl. Tafol I Fig. 9, Statoblast von Austrolella jheringi Messsere mit Fig. 8. Statoblasten ven Plum. pmectata) nud selbst von denon dor Gattungen Lophopes und Lophopodella kaum errericht wird (rol. Tafiel I Fig. ? mit Fig. 1-7).

I'l. punctute, die aus Afrika bishor noch nicht bekannt war. wurde

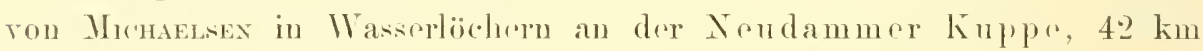
nordistlich von Windhork an stemen gesammelt. Lie mir vorliogenden Exrmplare rutsprechen in ihrem Wuchs und ihrem Habitus (Tafel I Fig. 10) recht gut der von mir 1887 (I)enteche siibwasserbryozoën I, p. 122 autgestrelltrn Form densa. Auch die prö̈chtigen, otwa 0,6 mu langen und $0,4 \mathrm{~mm}$ broiten statoblasten Taf. I Fig. 8) gleichen im wesentlichen nach Form und ciobe den groben Hrrbstatablasten jenor Form, wonn ihre seitrmiander violleicht auch otwas melur parallel apscheinen. Abweichend ron dem heimischen Vorkommen ist lediglich das Auftreten ron sitzenden statoblasten, die nemes Wissens bishere bej dirser Art in Emropa noch nicht boobachtet sind, die ich aber auch schon bei Exemplaren feststellon konnte, dir Mrohaklíes 1893 in Patagunion sammelte. Fie entsprechen durchaus den sitzendon Statoblasten der iibrigen Plumetelle-Arten und geben rinen weiteren boleg fïr die nahe Vorwandtechaft, in weleher Pl. punctata zul den ïbrigen Arten der Gattung stelit.

1) Diese Annahme steht zwar halbwegs im Widerspruch mit Rurky's Angabe (1. c. p. 62), scheint mir aher besser mit dessen Zeiclunungen in Einklang zu stehen: sie entspricht auch

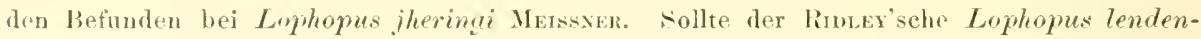
feldi dennoch wirklich, ,stolonen" haben, so wïre die Gattung Australella neben stolella und Stephanella wohl kaum aufrecht zu erhalten. Lophopus lendenfeldi und jheringi grıhörten danu verschiedenen Gattungen an. 


\title{
Lophopodella capensis (Sollas) var. michaelseni n. var.
}

\author{
Tafel I Fig. 4, 6 und 11 .
}

1908 Lophopus capensis Soldas, in: Ann. Mag. Nat. Hist. (S) II p. 264.

Fundangabe: Neudamm, in felsigem Wasserloch hinter der Noudammer Kuppe all einem stein: W. Mehaelsex, 14. Mai 1911.

Es war zweifellos ein sehr glïcklicher Gedank. Rocsselets (8), sowohl von den Formen mit ringsum gloichförmig berdornten Statoblasten (ristalelle Pertinatella), wie ron denen mit vïllig unbedornten, brzw. nur beidendig zugespitzten Statoblasten (Plumatella, Lophopms) alle diejenigen Arten girnerisch zu trennen, deren Statoblasten bei grstreckter Form nur an dru beiden Polenden mit mehr oder wenigor zahlreich entwickelten Dornen besetzt sind rgl. Taf. I Fig. 1-5\%. Dafo diese bornen bei ciner Art zuweilen krankhaft verkïmmern, wie Axxaxdate (Further Note on a Polyzoon from the Himalaya in: Rec. Ind. Mus I., 1907) beobachtete, kann don Wert dieses Gattungscharakters nicht wesentlich beeinträclutizen.

Die am längsten bekannte Art dieser von Rousselet 1904 (8) als Lophopodella in die Wissenschaft eingeführten, wahrscheinlich i allen iluren Arten der freien Urtsbrwogung fähigen Gattung ist "ine bereits im Jahre 1859 von Carter als Lophopus sp. abgebildete (Ann. Mag. Nat. Hist (5) III p. 341), dann von Hratr als Pectinatella carteri beschriebrne (Comm. Essex Inst. V Form von Bombay, die später in twas abweichender Form von $\mathrm{O}_{\mathrm{KA}}$ auch in Japan aufgefiundon und von ihm als Pectinutella davenporti uru benannt wurde (Ann. Zool. Jap. 1907 p. 117). Yit einer zweiten Art, der Lophopodella thomasi aus siidafrika, machte uns 1904 liocsselet (8) bekannt, mit riner drittrn, ebenfalls siidafirikanischen Art, dir L. capensis. Frl. J. Sollas (10) in Jahre 190s, und als vierte Art liabr ich die von strhumax bereits 1890 im äuatorialen Afrika enterekte Form hior aufzuführen, die ich seiner Zeit 1, p. 65) als Pertinatella carteri Hrate bestimmte, nummehr aber als rigene Art ansprechen zu sollen glaube.

Die Gattung Lophopodella orscheint somit heute geradozu als die eigentliche Charaktergattung dor afrikanischen Bryozeёnfauna, die an Artenzahl der Gattung Plmmatella glichkommt, im Gegensatz zu dieser kosmopolitischen Gattung aber fast ausschlieblich afrikanisch ist und nur mit einer Art in die orientalische Region hineinreicht.

Ob und inwioforn die einzoluen Arten in ihrem Tachstum und Habitus, ihrer Ektocyste. ihrer 'Tentakelkrone ote. stärker ausgeprägte Terschiedenheiten zeigen, ist bei der spärlichkeit des vorliegenden Lntersuchungsmaterials zurzeit noch nicht zu entscheiden: die statublasten aber biesten 
so charakteristische Unterschiede, daß ein Erkennen nicht schwierig ist, ja, daß man die 4 Fornen ganz wohl als gut voneinander abgegliederte Stufen einer geradlinigen Entwickrlungsreihe betrachten kann. Die folgende Tabelle mag dic Unterschiede der 4 Statoblastenarten in knapper Form zum Ansdruck bringen:

A. Statoblast an jedem Polende mit nur oinem einzigen, groBen, stachelartigen Dorn, der jederseits der ganzen Länge nach mit 14-16 gebogenen Häkehen besetzt ist (Taf. I, Fig. 4, 5). Kapland, DeutschSiidwestafrika.

L. capensis (Sollas).

B. Statoblast an jedem Polende mit einem Kranz ron $3-20$ verhältnismäßig kurzen Dornen (Taf. I, Fig. 1-3), doren Hakenbesatz selir versehieden ist.

I. Dic Polenden des Statoblasten jederseits stark kahnartig verjüngt, dann plötzlich konkav ausgerandet mit vorgezogenen Ecken (Fig. 3). Anf dor konkaven Polkante stehen jederseits $3-4$ (selten bis 6) gerade, dick" Dornen, die jederseits der ganzen Länge nach äuBerst dicht mit 20 und mehr Häkchen bersutzt sind (Fig. 3a). Kolonie bis $5 \mathrm{~cm}$ lang und $3 \mathrm{~cm}$ breit. Salisbury in Rhodesia. L. thomasi Rouss.

II. Die Polenden der Statoblasten sind jederseits nicht oder nur wenig verjünt, rntwoder konvex gerundet (Fig. 2) oder breit geradlinig abgestutzt (mit nur wenig vorgrzogenen Eeken; Fig. 1). Auf den Polkanten jederseits meist 7-20 Dornen, die jederseits nur mit $2-6$ Häkchen besetzt sind (Fig. 1 a und 2 a). Kolonien nur bis 2 em lang.

a) Polenden des Statoblaston breit geradlinig gestutzt, die l'olkanten mit dem Seitenrande des Statoblasten fast anen rechten Winkel bildend (Fig. 1). Zahl der Dornen an jedor Polkante otwa $6-8$, die Dornen winzig, mit nur 2-3, selten bis 4 Häkchen jederseits (Fig. 1 a). Deutsch-Ostafika.') L. stuhlmumi n. sp.

b) Polenden des statoblasten konvex gerundet oder doch nur schwach gestutzt und selur stumperwinklig in don Seitemand ïbrergehend (Fig. 2). \%ahl der lormen an jedom Pol 8-20, dor Einzeldorn mit moist 3 Hakehen jecterserits (Fig. 2a), bri einer jay andschen Variotait nut 6-8. Indien (liombay, Himalaya), Japan.

\section{L. curteri (HхаTT).}

1) Beschreihung und Erïrterung siche unten, seite 66. 
In Deutsch-Siidwestafrika ist von den vorstehend charakterisierten Arten bisher nur eine aufgefunden, und zwar von Michaelsex, der sie an einem Stein in demselben Wasserloche bei der Neudammer Kuppe nordöstlich von Windhoek sammelte, an dessen Felswand auch die Plumatella punctata erbeutet wurde. Auf den ersten Blick wird man geneigt sein, die Art mit I. capensis (Sollas) zu identitizieren; eine nähere Untersuchung ergibt aber doch gewisse anscheinend konstante Unterschiede, so daß ich es für geboten halte, die deutsch-süwestafrikanische Form von der typischen Kaplandform als Varietät, als $L$. capensis var. michaelseni, abzutrennen.

Uber Gestalt und Gröbe der Kotonien von L. capensis macht Frl. Soltas, der nur ein einziges Exemplar, und zwar ein lebendes, zur Vrrfügung stand, keine Angaben: ich ergänze nach dem Yrchaessex schen Jaterial dahin, daß die Einzelkolonien in kontrahiertem Zustande im allgemeinen flache, rundlich ovale Polster von etwa $1.5 \mathrm{~cm}$ Länge und 0,8 cm Breite darstellen, die der Tnterlage in der Mitte fest anfliegen und eine. gelatinöse Buschaffonheit zeigen. Aus rinem mittleren weiten Stammrohr strahlen gegen die Peripherie alksitig kurze, abermals verzweigte seitenäste aus, die dicht gedrängt nebeneinander die kegelförmigen Mündung'n der einzelnen Polypide tragen, wie es in Taf. I, Fig. 11 darzustellen versucht ist. Der Rand der Kolonio mit seinen gedrängten kegelförmigrn Vorwölbungen erinnert unwillkürlich an die dichte Verzweigung eines Bhmenkohlkopfes. Die Zahl der Tentakel soll nach Frl. SoLlas in einem Falle 57, in einem andern 70 betragen haben: ich habe an neinem konsirvierten Matrrial keine Nachprïfing vorgenommen.

Die Statoblasten der typischen $L$. capensis werden von Frl. Soldas eingehend geschildert und auch abgebildet (Fig. 5). Es geht darans hervor, dab der mächtige Dorn an jedem Polende weit über $1 / 3$ so lang ist wie der Längsdurchmesser des Statoblasten $(0,32: 0,80 \mathrm{~mm})$ und gerade $1 / 2 \leq 0$ lang wir der Querdurchmesser desselben $(0.32: 0,64 \mathrm{~mm})$. An jeder Seitr. trägt der Dorn nach Ausweis der verschiedenen Zeichnungen — im Text tindet sich keine Angabe darüber - 9 bis 11 bogig abwärts gekrümmte Häkchen, die sich auf einer vom Dorn auf die Seitenrandlinie des Statoblasten übergehenden zarten Kontur als Reihe kurzer selbständiger Häkeluen fortsetzen sollen (Taf. I, Fig. 5). Ist nun diese letztere Darstellung auch wohl mit Sicherheit auf einen Irrtum des Zeichners zuriekzufïhren, da solche Chitinthäkchen nach ihrer Entwickelungsgeschichte nur unterhalb der zarten peripherischen Restmembran ehemaliger, den Chitinapparat des Schwimmrings ausscheidender Randzellen entstehen können, so zeigen doch die andern, offenbar korrekt beobachteten Daten Abweichungen von dיn 5 Michael=en, Deutsch-Südwestafrika. 
Befunden bei den siidwestafrikanischen Exemplaren, die schwerlich als individuelle Variation aufzufassen sind. In erster Linie kommt lierbei die Långe des Poldorns in Betracht, der bei zahlreichen untersuchten Exemplaren ron Südwestafrika stets nur etwa 1/4 der Länge des Statoblasten (etwa 0,19:0,75) und nur $1 / 3$ seines Querdurclimessers betrug (Taf. I, Fig. 4). Sodann erscheint die Zahl der Haken (Taf. I, Fig. 4 a) jederseits des Dorns bei der var. michaelseni merklich größer als bei der typischen Form rom Kap $(14-16$ jederseits gegen 9-11); die Form der Chitinkapsel ist fast kreisrund, nicht gestreckt oval, wie bei der Hauptform, und die Seitenrandlinie des Schwimmrings erscheint nicht als einfache Ellipse, sondern ist jederseits nah" den Polenden morklich konkav eingebogen (Taf. I, Fig. 4). Aus allen diesen Abweichungen, die sich, wie gesagt, bei saimtlichen untersuchten Statoblasten in gleicher Weise zeigten, halte ich dis Aufstellung einer besonderen Varietät $u m$ so mehr berechtigt, als ja auch bei der Lophopodella carteri grrade im Hinblick auf die verschiedenartige Ausbildung der 1)ornen neben der Hauptform von Bombay noch ausgeprägte Varietäten - var. himalayana vom Himalaya und var. davenporti aus Japan - unterschieden werden miissen.

Bemerkt sei schließlich noch, daß die mir vorliegenden Statoblasten der L. capensis michaelseni, obwohl sie im übrigen ihre volle Reife erlangt zu haben schienen, doch noch ausnahmslos jene feine Chitinhaut als Uberzug über die Poldornen mit ihren Häkchen trugen, die als letzter Rest des zur Bildung des Hakenapparates verwandten Kellmaterials anzuselien ist. Selbstrepsändlich können die Häkchen der Dornen erst in Funktion treten, wenn diese zarte Haut sich abgelöst hat. Von Interesse sind anch gewisse Entwickelungsstadien des Statoblasten, in denen die Poldornen nur erst als schwache kegelförmige Zuspitzungen des. Schwimmrings an den beiden Polenden erscheinen (Taf. I, Fig. 6). Diese Stadien erinnern unwillkürlich an dio fertigen Statoblaston unseres lieimischen Lophopus eristalliuus (Taf. I, Fig. 7) und deuten auf engere phylogenetische Beziehungen hin, die zwischen beiden Gattungen bostehen dürften.

\section{Lophopodella stuhlmami n. sp.}

1893 Pertinatella carteri (non Hyatt) Kraepelin in D). Süßwasserbryozoën IIp. 62.

Im Anschluß an die Nïßwasserbryozoën I)eutsch-Südwestafrikas lasse ich hier rine kurze Erörterung über diese jetzt als neuc Art erkannte tropisch-afrikanische Form folgen. 
Lophopodella stuhlmanni n. sp. stellt offenbar eine Mittelform dar zwischen $L$. thomasi und $L$. carteri, zum mindesten in der äuBeren Form der Statoblasten: Die kahnförmige Verjüngung derselben an den beiden Polenden bei L. thomasi ist nur noch schwach angedeutet, die konkav geschweifte Polkante ist zu einer geradlinigen geworden, während die vorgezogenen Ecken oder doch der stark winklige Ubergang dieser Kante in den Seitenrand im Gegensatz zu der konvexen Rundung bei L. carteri noch erhalten geblieben ist. Auch in der Zahl der Poldornen stelit $L$. stuhtmanni ziemlich in der Mitte zwischen L. thomasi und carteri, wohingegen sie in Bezug auf die Zahl der Häkchen an den Einzeldornen meist hinter den beiden genannten Arten zurück bleibt.

Bis vor kurzem waren von dieser Art nur die wenigen Statoblasten bekannt, die Stuhlmann $1990 \mathrm{im}$ trockenon FluBbett bei Bibisande zwischen Tabora und dem Victoria Nyanza zusammen mit Plumatella repens und emarginata sammelte. Die ungenügende Beschreibung der L. carteri und das Fehlen verwandter Formen ließen mich 1893 (2) dirse Statoblasten als zu L. carteri gehörig ansprechen, was ich nach dem jetzigen Stande unseres Wissens iiber die Formen der Gatung Lophopodella nicht mehr aufrecht erhalten kann. Neuerdings dürften nun durch Sснивотz auch Kolonien der L. stuhlmanni erbeutet sein und zwar im Mohasi see westlich rom Victoria see noch im Gebiete von Deutsch-Ostafrika. Uuser (12) berichtet von zwei an dünnen Pflanzenstengeln wachsenden Kolonien von $1 \frac{1}{2}$ bis 2 cm Länge, mit gelblich hyaliner Ektocyste und - in kontrahiertem Zustande - als stumpfe Kegel aus dem Coenoecium schräg hervortretenden Zooecien. Leider waren beide Kolonien ohne Statoblasten, doch machen Habitus und Fundort es in hohem Grade wahrscheinlich, daß wir in ihnen die L. stuhlmanni vor uns haben.

\section{Literatur.}

Nur über afrikanische süßwasserbryozoën.)

1. 1893 Krafpeux. K.: Die deutschen Süßwasserbryozoën. II. Nachtrag

p. 65 in: Abh. Natw. Ter., Hamburg. Bd. 16.

2. 1893 Kraepeur, K.: Über afrikanische und sïdamerikanische Süßwasser-

bryozoën in: Verh. Natw. Ver., Hamburg 1893, p. 14.

3. 1893 Meissxer, M.: Beitrag zur Kenntnis der geographischen V'erbreitung der Bryozoën-Gattung Plumatella in Afrika in: Zool. Anz. 1893, Nr. 430. 
4. 1893 Merssner, M.: Die Moostiere Ostafrikas in: Die Tierwelt Ostafrikas. Bd. 1V. Berlin 1898.

5. 1897 Merssner. M.: Weiterer Beitrag zur Kenntnis der geogr. Verbreitung der Süßwasser-Bryozoën-Gattung Plumatella in: Zool. Anz. 1897, Nr. 531.

6. 1901 Kinкмax, Th.: The Rotifera of Natal in: Journ. R.Micr.Soc. 1901, p. 232.

7. 1903 Moore, J. E. S.: The Tanganyika Problem. London 1903.

8. 1904 Rorsselet, Сн.: On a new fresh-water Polyzoon from Rhodesia, Lophopodella thomasi n. g. n. sp. in: J. Quekett Mier. Club, p. 45-56. IIit 1 TH.

9. 1907 Rousselet, Сн.: Zoological Results of the third Tanganyika Expedition, conducted by Dr. W. A. Cunnington 1904-05 in: Proc. Zool. Fioc. 1907 , p. $250-7$. Mit 2 Tfl.

10. 1908 Soluas, B. J.: A new Freshwater Polyzoon from S. Africa in: Ann. Mag. Nat. Hist. (8) 2, p. 264-273.

11. 1908/09 Loppens, K.: Les Bryozoaires d'eau douce in: Ann. Biol. lacustre, III p. $141-183$.

12. 1913 Uluer, G.: Siißwasser-Bryozö̈n von Aequatorial-Afrika in: Wiss. Ergeb. D. Zentr. Afr. Exp. 1907-08 mter Führung Adolf Friedricus, Herzog zu Mechlenburg. Bd. IV, p. 285-290.

\section{'Tafelerklïrung.}

Tafel I.

Alle Statoblasten sind bei annähernd der gleichen Vergrößerung gezeichnet, um die gegenseitigen Gröbenverhältuisse klar hervortreten zu lassen. In den Figuren 6-9, bei denen nur die Größe und der Umriß zur Darstellung gebracht werden sollte, ist die Zollstruktur des Seliwimmrings nicht mitgezeichnet.

Fig. 1. Statoblast von Lophopodella stuhlmami n. sp.: ca. 55:1. - 1 a ein 1)orn stäker rergr.: $200: 1$.

Fig. 2. Statoblast von Lophopolella carteri (Нуатт); ca. 55: 1. - 2 a ein 1)orn stäirker vergr.: $200: 1$.

Fig. 3. Statoblast von Lophopodella thomasi liouss; ‘a. 55:1. - 3 a pin Dorn stårker vrrer.; $200: 1$.

Fig. 4. Statoblast von Lophopodella capensis michaelseni n. var.; ca. 55:1. - 4 a ein Dorn stäker vergr.: 200: 1.

Fig. 5. Statoblast von Lophopodella eqpensis typica (Soldas): ca. 55:1. 
Fig. 6. Unreifer Statoblast vou Lophopodella capensis michaelseni n. var.; ca. $55: 1$.

Fig. 7. Statoblast von Lophopus cristallinus PALL.; ca. 55:1.

Fig. 8. Statoblast von Plumatella punctata Have.; ca. $55: 1$.

Fig. 9. Statoblast von Australella jheringi (Meissner); ca. $55: 1$.

Fig. 10. Stück einer Kolonie von Plumatella punctata Haxc. von Neudamm; $4 \frac{1}{2}$ : 1 .

Fig. 11. Kolonie von Lophopodella capensis michaelseni n. var. von Neudamm, im kontrahierten Zustande; $4 \frac{1}{2}$ : 1 . 



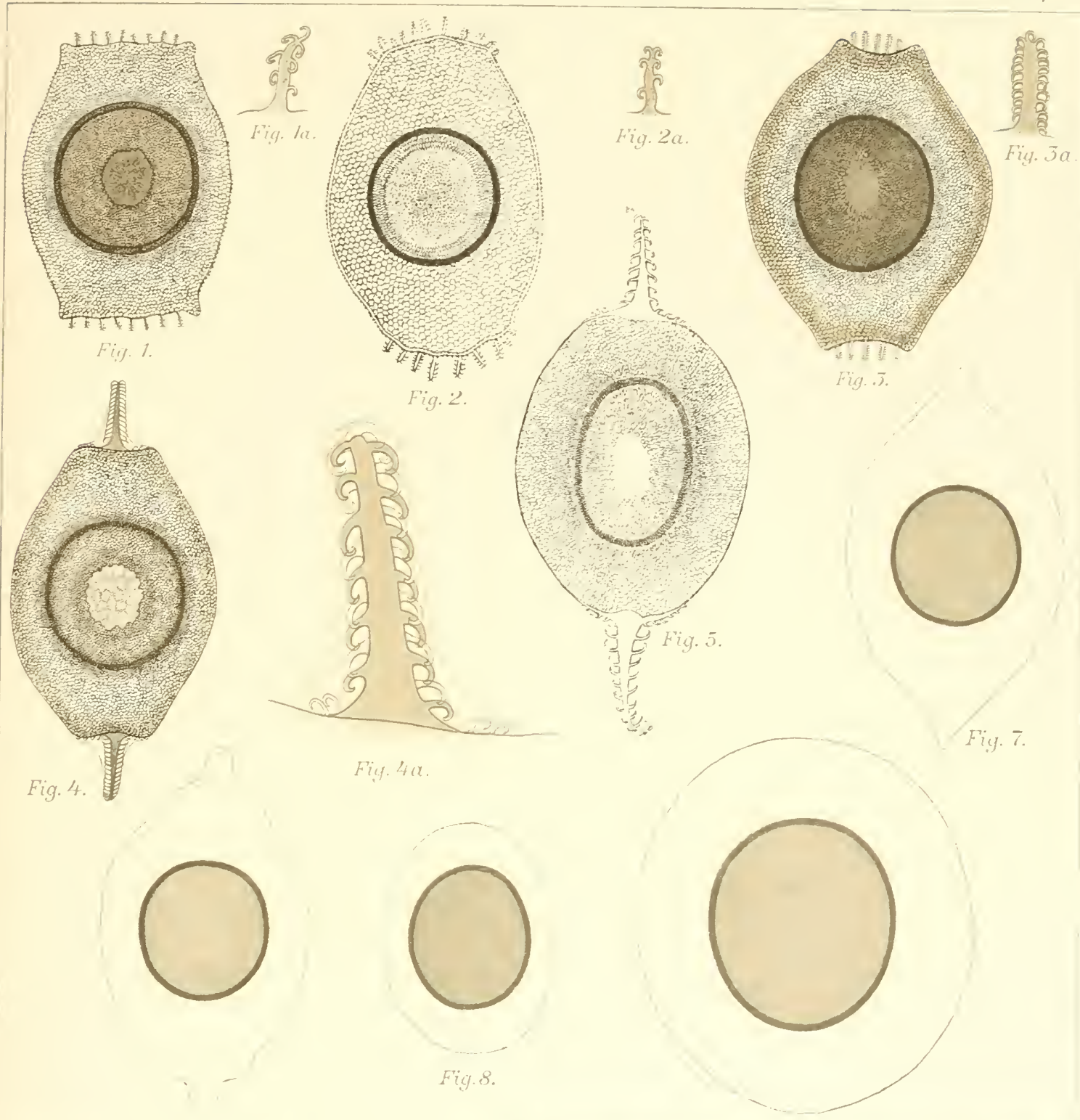

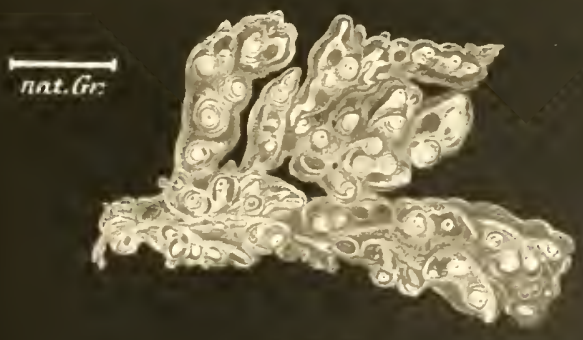

Fig. 10.

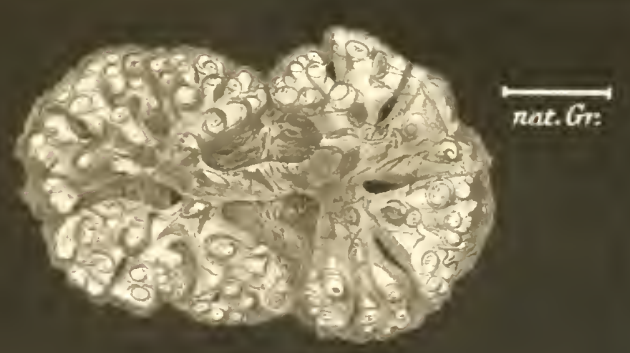

Fig. 11. 



\section{Isoptera}

von

\section{Yngve Sjöstedt}

(Stockholm).

Mit 1 Tafel und 2 Abbildungen im Text. 

Das mir von Herrm Prof. Mrchaelsex froundlichst zur Bearbeitung gesandte, während der Hamburger deutseh-siidwestafrikanischen Studienreise im Jahr 1911 gesammelte Termiten-Material umfaßt, soweit es bestimmt werden kounte, 18 Arten, darunter 6 nene. Außerdem fand sich in der sammlung das bisher unbekannte getlïgrelte Imago des ron Siidwestafrika beschriebenen Prammotermes allocems nebst einer dritten bei dieser Termite vorkommenden Soldatrnform.

Bei verschiedenen Gelegenheiten habe ich unter den zur Bearbeitung iibermittelten sammlungen bellicosus-ähnliche, aber sehr kleine Soldaten erhalten, olıne bestimmt entscheiden zu können, ob sie eine selbständige Art repräsentierten, oder ob sie nur zufällig kleine Individuen wären. Durch das reiche hingehörige Matrrial, nit wohl hunderten Soldaten, konnte festgestellt werden, daß sie eine selbständige, gut charakterisierte Art vertreten (T. Michaelseni).

Anch ein paar ron anderen Teilen Afrikas stammende, dem Stockholmer Museum gehörige Termiten sind hier in Zusammenhang mit den siidwestafrikanischen behandelt worden, in allem 20 (S n.) sp. Die neuen Arten sind:

Hodotermes macrothorax n. sp. Dentsch-Siidwestafrika.

Termes (Termes) Michaelseni n. sp. ", "

Termes hems n. sp. Abessinien.

Termes (Odontotermes) fockiamus n. sp. Deutsch-Südwestafrika.

Termes (Odontotermes) rehobothensis n. sp. "

Eutermes (Culitermes) pretoriensis n. sp. Transvaal.

Eutermes grootfonteinsis n. sp. Deutsch-sïdwestafrika.

Entermes hentschelianus n. sp.

Die ganze Sammlung ist in spiritus konserviert.

\section{Hodotermes macrothorax n. sp.}

(Tafel II, Fig. 9.)

Fundangabe: Okahandja, „im Hanse"; G. Fock, 1910 (meluere Soldaten und Arbeiter). 
Okalıandja, im parkartigen Garten; IT. Menaelsen, 27. April 1911 (1 Soldat und molorero Arbeiter).

Auch ron Goanikontes (Kleme, Juni 1911), Karibib (IV. Michaelsex, Juni 1!11), Windhuk (W. Mnchaessex, April - Mai 191i) und Neudamm (W. Mrchaelaes, 9. Mai 1911) liegen Arbeiter vor, die wahrscheinlich dirser Art angehören.

Typen ins Mus. Hamburg und Mus. Strekholm.

Soldat (Taf. II, Fig. 9).

Kopf gelbrot bis blaß rotgellb, grob, etwas hellgeflammt, besonders in der stirn; ron den Augen schräg uach innen jederseits ein mit einer punktförmigen hellen Grube versehener brauner Fleck; Kopf kurz abgerundet rektangulär mit breit bogenförmigem Hinterrand, breit abgerundeten Hinterecken und ziemlich geraden, nach rorn etwas konvergierenden Seiten; Ilandibeln schwarz, an der Bawis dunkelrot, wie bei H. mossambicus gebildet: Fïhler 29-gliedrig, gerade so lang wie der Kopf ohne Kiefer: Oborlippe zungenförmig, nach unten ziemlich stark rerengt, rorn schwach winkelig gebogen, Prothorax groß, wm 1/s schmäler als der Kopf, querrektangulär mit breiten abgerundeten soitenteilen mit einom zirmlich tief ringebuchtetem Hinterrand und hervortrotenden, rinen abgerundeten spitzen Winkel bildenden Vordereckrm; Vorderlappen vicl schmäler, vorn nicht, odor ganz wenig, ausgerandet, Seiten dïn, scheibunahnlich: Mesothorax 11 m 1/14 schmäler, schmal queroval, mit dïnnen, verbreiterten, ziemlich geraden, nach rorn atwas konvergierenden, mit breit abgerundeten Hinterecken versehenen Seriten; Hinterrand schwächer eingebuchtet als beim P'rothorax; Metathorax noch otwas schmäler, mit molu geraden soiten, die hinten rinen abgerundeten rechten Winkel bilden, dex Hinterteil an den seiten dureh eine stumpfwinkeligo Einburhtung abgesetzt, Hinterand breit, dentlich ringebuchtet; ahnolt ïbrigens II. mossumbirus.

Linge 14-17, Kop, mit Mandibeln $(6,5-) 7,5-8$, Kopfloreite (4.5-) $5,4 \mathrm{~mm}$.

Diese stattliebe Form strht $/ 1$. mossambiens selir nahe und ist viel-

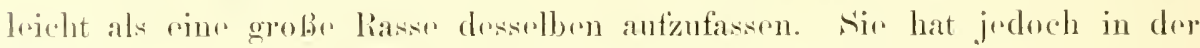

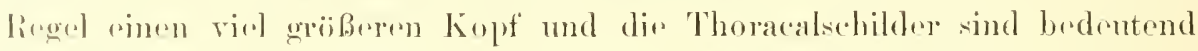

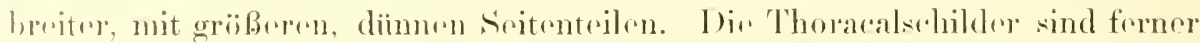

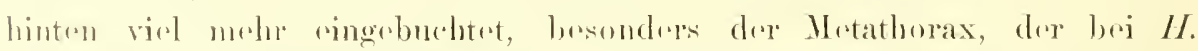

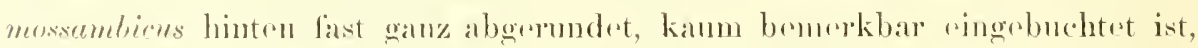

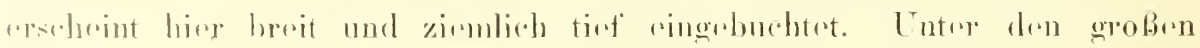

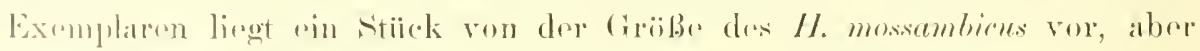
auch hior sind dir 'Thoracalschildrer vou angergabenor Form. 
Arbeiter.

Diese erschninen denen des H. mossambicus völlig zu ähneln. Di» größten liaben eine Kopfbreite von $4,2 \mathrm{~mm}$.

\section{Biologie.}

„Im Hause“ (Dr. Fock) und dem umliegenden waldartigen Gartenlande.

\section{Psammotermes allocerns Silv.}

Silvestri, Jenaische Denkschriften XIII p. 73, 1908. [Gr, and kl. Soldaten und Arbeiter.]

Imago alata (adhuc ignota): supra nigro-brunnea, abdomine supra panlo, subtus evidenter dilutiore; capite ovali, supra medium macula alba puntiformi instructo; epistomate Alavido, fronte dilutiore; oculis parvulis; diametro $2 / 3$ spationis inter oculos et marginem inferiorem capitis; ocellis parvulis, valde approximatis, 1/6 diametris modo ab oculis remotis; autennis 15-articulatis, articnlo basali duplo longiore quam secundus, articulo tertio minimo, articulo quarto et quinto longitudine eadem, ultimo ovali; protiorace ovali, antice paulo applanato, medio exciso; margine posteriore meso- et metatloracis postice curvato, medio non exciso; femoribns et tibiis fuscis, tibiis apice cum tarsis pallidis; segmentis ventralibus posticis exceptis medio linea alba; alis opacis, in spiritu hyalinis, venis parum distinctis; mediana ala antice de submediana oriente.

Exp. alar. 14, long. c. alis 9,5, long. alie 7,2 , lat. alce 1,7, cor

Fundangaben: Lii deritzbucht, in Nestern in festerem (zusammengebackenen?) Sande untor Steinen: W. Mrchatesex, 20. Juli 1911 (zahlreiche Imagines, mehrere Soldaten und Arbeiter).

Kuibis; W. Mrchaelsex, 15. Juli 1911 (2 soldaten und mehrere Arbeiter). Typen im Mus. Hamburg und Mus. Stockholm.

\section{Gefliigelte Imago.}

Kopf und Thoracalschilder glïnzend braunschwarz, Hinterleib oben etwas heller: Beine stark dunkel beraucht, die spitze der Schienen und die Tarsen blaß: Bauchplatten etwas hellır braun als dir Dorsalplatten drs Hinterleibes, mit Ausnalıme der letzten, einfarben, in der Mitte mit einu feinen hellen Linię, die an trockenen Exomplaren kaum zu sehen ist; Fïhler und Palpen bräunlich, mit hellen Gelenken; Epistom gelblich, deutlich heller als dor äbrige Kopf: Kopf oral, nach rorn nur wonig verengt, um 2/5 länger als breit: Scheitel mit hellem Zentralpunkt; Epistom oral, hinten gebogen, vorn breit abgeschnitten und otwas eingebogen, doppolt so brut wie lang, gelblich mit dunkler Mittellinie, A ugen mit großen Fazetten, sohr klein, wenig abstehend, nur zwei mal so broit wie die Ocellen, ihr Durehmesser um $2 / 3$ der Breite der Wangen: Ocellen oval, selır nahe an die Augen gestellt, ron ihnen nur so weit wie 1 m 1/6 ihres lorehmessers getrennt: Prothorax oval, vorn otwas abgeplattet mit kleinem 
bogenförmig abgesetztom, vorn in der Mifte etwas ausgeschnittenem Vorderlappen: Fïhler 15-gliedrig, das Basalglied doppelt so lang wie das 2., das 3. am kleinsten, das 4. und 5. gleichgrob, so lang wic das 2. aber mehr kugolig: die folgenden almählich etwas größer, dann allmählich kaum bemerkbar kleiner, dir zwei letzten schmäler, Endglied langgestreckt oval, so lang wio das Basalgliod: Moso- und Metathorax hinten bogenförmig, in der Mitte nicht ausgeschnitten: Kopf und Thoracalschilder glinzend, nur mit sinzolnen Haaren: Boine stark donkel beraucht, die spitze der Schirmen und die Tarsen Jlaß: Fliigel opak-glashell mit schwach hervortretender stwas gelblicher Aderung, schmal, fast gleichbreit: Yorderflïgel etwas schmäler: Modiana und submediana sind nur Einbnehtungen in der Jembrane: Mediana der Vorderflügel undeutlich, fast verschwunden, nur durch einigr unregelmäßig wellige Fragmentr vertreten; Mrdiana der Hintrerflïgel gerade, Submediana der Vorder- und Hinterflügel mit zahlreichen /wrigen bis an die spitze des Fligels.

Spannweite 15, Länge mit Flïgeln 9,5, Länge der Flïgel 7,2-7,5, Breite der Fliigel 1, 7 Körper mit Kopf $5 \mathrm{~mm}$.

Von P. fuscofemoralis sü̈sт. wird diese Imago folgendermaßen unterschieden:

+ Fiihler 16-gliedrig, Suhienen hell, Schenkel dunkel: Ocellen um $2 / 5$ ihres Durchmessirs ron den Augen getrennt.

1. fuscofemoralis.

++ Fïhler 15-gliedrig, schienen und Fohenkel dunkel; Ocellen nur um 1/6 ilues 1)urchmessers von den Augen getrennt.

P. allocerus.

\section{Soldaten.}

Unter den vorliegenden soldaten sind drei deutlich getrennte Formen vorhanden.

Sulvestu hat l. e. gribere und kleinere Soldaten und Arbeiter besthrieben. Von den grïßeren soldaten liegen mir 9 Cotypen vor, die indessen nichit mit don von Sillvestri angegebenen Maßen stimmen.

Gr. Soldat (nach Surestri) Kopt olne Mandiben 2, Kopfbreite 1,9, Mandibeh 1,7 $\mathrm{mm}$.

Gr. Soldat (nach den Cotypen) Kopf ohne Mandibeln 1,7, Kopefbreite 1,6, Mandibeln $1,35 \mathrm{nmm}$.

Gr. Soldat (nach dem vorliegenden Material) Kopf ohne Mandibeln 1, Kopflitere 1,6, Mandibeln 1,35 mm.

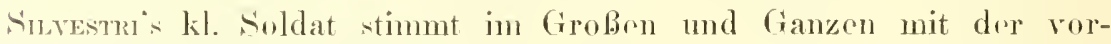
liogenden \%wischenform iberene 
Nach Silvestri: Kopf, ohne Mandibeln 1,45, Kopfbreite 1,22, Mandibeln 1,14 mm,

Vorliegende Zwischenform: Kopf, ohne Mandibeln 1,40, Kopfbreite 1,25. ILandibeln $1.15 \mathrm{~cm}$.

Diese Zwisehenform hat indessen oft nach aufen deutlich verjüngte Fühler, während Silvestra diese als ,apicem versus non attenuata" angibt. Bei einem Exemplar sind sie ziemlich glrichbreit. Dagegen hat die hior (wie bei Acanthotermes acanthothorar) vorkommende dritte, bisher unbeschriebene Soldatenform nach außen nicht verjüngte Fühler. Diese sind 13-ghedrig, das 2. Glied wenig länger als das 3., das so lang wie das 5. erscheint; das 4. etwas kleiner als dir anlirgenden: Endglied zirmlich kurz oval, wenig sehmäler als die vorhergehenden.

Länge 4,5, Kopt mit Mandibeln 2,1, Kopf ohno Mandibeln 1.1, Kopfbreite 1, Mandibelu $1 \mathrm{~mm}$.

\section{Termes (Termes) Hichaelseni n. sp.}

Tafel II, Fig. 1, 10.

Imago alata: supra castanea vel dilutior; ventre brunneo-flavido; tibiis fuseo-adumbratis; capite ovali, antice angustato, ${ }^{2} / 13$ longiore quam inter apices oculornm lato, nedio excavato, crista rotundata longitudinali; epistomate capitis colore, modice inflato, longitudine ocellorum; oculis magnis, fere rotundis; ocellis late ovalibus, modo $1 / 5$ diantetris ab oculis remotis; antennis 19-articulatis, articulo secundo minimo, tertio longo, longitudine articuli basalis; prothorace semicirculari, postice applanato et paulo incurvato, antice paululo angulatim incurvato, $1 / 20$ latiore quam caput enm oculis; alis opaco-hyalinis, panlo flavescente adumbratis, venis costalibus brunneo-flavidis; mediana et submediana alre anticae basi alae ipsius separatis.

Exp. alar. 77-75, long. c. alis 4., long. alce 3j-36, lat. alce 10, corp. c. cap. $19-20 \mathrm{~mm}$.

Fundangaben: Okahandja: G. Fock, 1910 (einige gefliigelte Imagines).

Okahandja: W. Michaelsen, 27. Nai 1911 (1 Königin, 1 gr. Soldat, 4 kl. Soldaten, 2 gr. Arbeiter).

Onjatu: O. Hextscueu, August 1909 (melurere hunderet Soldaten und Arbeiter).

Farm Okosongomingo am Kleinen Waterberg: H. Thomsex, August 1912 .

Dieser Art gchören wahrscheinlich anch 3 Königinnen ron der Farm Okapchuri bei Okasise (II. v. Rudo-Rumsiskr, 7. September 1911) an.

Typen im Mus. Hamburg und Mus. Stockholm. 


\section{Geflügelte Imago. (Tafel II, Fig. 1.)}

Kopf und Thorax rotbraun, Hinterleib oben etwas heller, unten viel heller, braungelb; Beine etwas mehr horngelb und besonders die Schienen dunkel schattiert: Kopt oval, nach vorn verengt, um $2 / 13$ länger als zwischen den Augenspitzen breit; Scheitel etwas konkar mit einem niedrigen, abgerundeten Längskiel; Augen ziemlich groß, kurz oral, fast kreisrund; Ocellen kurz oval, gerade halb so breit wie die Augen, nur um 1/5 ihres Durchmessers ron den Augen getremnt: Epistom von der rotbraunen Farbe des ïbrigen Kopfes, vorn gerade, hinten gebogen, von vorn nach hinten so lang wio der Jurchmesser dor Ocellen; Fühler 19-gliedrig, das 2. Glied an kleinsten, das 3. viel länger als die anliegenden, so lang wie das Basalglied: rom 4. an die Clieder zuerst ziemlich gleich groß, kurz oval, fast rund, dann allmählich etwas größer, nach unten verengt, länger, nach auben etwas schmäler, Endglied schmal oval, so lang wie das vorletzte Glied; Prothorax halbkreisförmig, mit etwas abgeplatteten Seiten, hinten breit, etwas eingebuchtet: von vorn gesehen der Vorderrand etwas winkolig eingebuchtet, um 1/2u breiter als der Kopf mit Augen; Meso-und I etathorax hinten breit, der erstere etwas melır, winkelig, eingebuchtet, der letztere schmäler, bogenförmig; Flügel hyalin-opak, schwach gelblich angehaucht, Costaladern bräunlich gelb, subcosta heller; vom hinteren Tril der Subcosta einige kleine Adern durch das Subcostalfeld; Mediana und submediana der Vordertligel gehen getrennt von der schuppe aus.

Spannweite 77-78, Länge mit Flügeln 42, Länge und Breite der Flïgel resp. $35-36$ und 10, Körper mit Kopf $19-20 \mathrm{~mm}$.

Diese grobe und schöne Art steht $T$. bellicosus und $T$. natalensis am nächsten, hat aher breitere Flügel und einen breiteren Prothorax, der breiter - bei den anderen sehmäler - als die Breite des Kopfes zwisehen den Augen ist. Von $T$. gratus, der einen breiten Prothorax hat, unterscheidet sich diese neue Art u. a. sofort durch die großen Ocellen, die von den Augen durch einen Abstand von nur um 1/5 ihres Durchmessers getrennt sind, bei $T$. gratus dagegen viel weiter abstehen. Wie die Sollaten zeigen, steht die Art dem $T$. bellicosus an nächsten.

\section{Königin.}

Diose ist am Kopf und Thorax otwas heller rotbraun als die anderen und dir schienen der Beine sind nur wenig dunkler. Sie ähnelt soust der des T. bellicosus. Prothorax in natülicher Lage gerade so breit wie der Kopf zwischen den Angenspitzon. Länge des Hinterleibes 67, Breite desselben $20 \mathrm{~mm}$.

Größerer Soldat. (Taf. II, Fï. 10.)

Von demselloen Ausselien wir der größere soldat des Termes bellirosus, aber bedentend kleiner. Der Protlorax ist verhältmismäbig breiter, 
nur um $1 / 12$ schmäler als der Kopf (bei $T$. bellicosus etwa $3 / 4$ von drr Breite des Kopfes). Ferner ist das 3. Füllerglied kürzer als bei T. bellicosus, deutlich länger aber nicht ganz doppelt so lang wie das 2. Dic einen spitzen Winkel bildenden Frontalrinnen tief, und das dazwischenliegende Dreieck ziemlich hoch. Totallänge 15, Kopf mit Mandibeln 7,5 , Kopfbreite 3,9, Mandibeln 2,2 mm.

\section{Kleinerer Soldat.}

Alnelt sehr dem des T. bellicosus, der Kopf ist aber etwas schmäler und verhält sich am Prothorax wie $40: 37$, bei $T$. bellicosus wie $45: 37$. Das 3. Fühlerglied ist nur selur wenig lïnger als das 2; bei $T$. bellicosns ist das 3. Glied dentlich länger als das 2. Läuge 9, Kopf mit Mandibeln 5, Kopfbreite $2,6 \mathrm{~mm}$.

\section{Größerer Arbeiter.}

Alınelt dem des T. bellicosus. Fühlor 18-gliedrig. Länge 7, Kopfbreite $2,5 \mathrm{~mm}$.

Biologie. In kegelförmigem festem Bau (Michaelsex).

\section{Termes (Termes) natalensis Har.}

SJöstedt, Monogr. p. 102, Nachtr. p. 50.

Fundangabe: Okahandja: W. Michaelsex, 28. April 1911 (1 kl. Soldat. mehrere gr. und kl. Arbeiter).

Als Anhang möge hier eine neue Termes-Art aus Abessinien beschrieben werden.

\section{Termes herus n. sp.}

Tafel II, Fig. 6.

Imago alata: corpore fere nigro, pedibus paulo dilutioribus; capite ovali, antrorsum angustato, $3 / 14$ longiore quam inter apices oculorum lato; oculis modicis, ocellis satis parvis. ovalibus, distantia ${ }^{1 / 3}$ minore diametro ab oculis remotis; antennis 19-articulatis, articulo tertio longitudine basalis, secundo paulo minore quam quarto; prothorace semicirculari, 1/11 angustiore quam eaput inter apices oculorum, antice incurvato, medio exciso, postice paulo applanato et incurvato; mesothorace postice rotundato et paulo incurvato; metathorace postice curvato, medio late applanato vel paululo incurvato; alis opaco-hyalinis venis costalibus brunneoflavidis; mediana et submediana alæ anticæ basi alæ ipsius separatis.

Exp. alar. 69--70, long. c. alis 38, long. alæ 32-32.5, lat. alæ 7,5-6,8, corp. c. cap. $18 \mathrm{mnt}$.

Fundangabe: Abessinien, Dire-Daua, 320 Kilometer von Djibouti entfernt. Typen im IIus. Stockholm. 


\section{Geflügelte Imago.}

Tatel II, Iïg. 6 .

Der ganze Körpor schwarzbraun bis schwarz, Beine zum Teil etwas heller, braungelblich angehaucht: Fühler und Palpen rotbraun mit hellen Gelenken. Bauchsegmente cinfarben schwarzbraun, die zwei oder drei oberen in der Mitte heller: Kopf fast vïllig glatt, oval, nach rorn verengt, um 3/1+ länger als zwischen den Augenspitzen breit; Scheitul deutlich konkar mit rinem kurzen abgerundeten Längskiel; Epistom ron derselben dunklen Farbe wi, der ïbrige Kopf, ziemlicls klein, nur wenig aufgeblasen, vorn abgeschnitten, hinten gebogen: Augen kurz oval, rorn kaum bemerkbar abgeplattet, ziemlich flach gewölbt: Ocellen kurz oral, ziemlich klein, um 1/5 weniger als die Länge ihres Durchmessers von den Augen getrennt: Wangen gerade so broit wie der Zwischenraum zwischen Augen und Ucollen: Fiihlor 19 glindrig, das Basalglied so lang wie das 3. Glied, das 2. Glied etwas mehr als halb so lang wie das 3., das 4. kaum länger als das 2.: die Glieder nach auBen zuerst ziemlich gleich grob, nach der spitzr zu rin wenig schmäler: Endglied oval, so lang wie das vorletzte Glied: Irothorax um 1/11 schmäler als der Kopf zwischen den Augenspitzen, halbmondförmig mit breit abgerundeten Vorderecken und eingebogenem, in der Mitte etwas winklig ausgeschnittenem Vorderrand; Hinterrand herabgebogen, in der Hitte abgeplattet und otwas eingebogen; II esothorax hinten abgerundet, in der Hitte deutlich ringebogen; Metathorax hinten bogenfiirmig, in der Jitte schwach ringebuchtet: Prothorax ringsum behaart, sonst fast glatt; Mrso- und Metathorax ganz glatt, Dorsalschildrr des Hinterleibs glatt, an den Hinterrändern frin, kurz und ziemlich dicht behaart: Iboine dicht brhaart, besonders Schienen und Tarsen; Flügel fast glashell-opak, kaum bemorkbar golblich angehaucht, mit rötlichgelben Costaladeru. vom hinteren, untren Teil der Subcosta bis an die Spitze der Flïgel ein paar kleinere Adern; Mediana und Submediana der TorderHiigel gehen getrennt von dor Schuppe aus.

Śpannwrite 69-70, Länge mit Flïgeln 38, Länge der Flïgel 32-32,5, Breitr der Flügel 7,5-7,8, Körper mit drm Kopf $18 \mathrm{~mm}$.

Dies. dunkle Art stcht Termes bellicosus am nächsten. unterscheidet sich aber von ihm leicht dureh die fast selwware Farbe des ganzen Körpers.

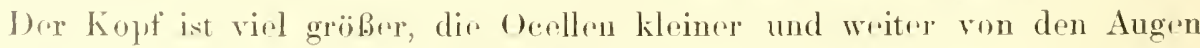
getrennt, dor Hinterrand des Motathorax ist bogenförmig, in der Mitte broit abgeplattet und schwach cingebuchtret, beri T. bellicosus dagegen deutlich winkelig alserschnittrn, nit abgerundeten stumptivinkeligen seiten. 


\section{Königin.}

Gelblich weiß, ohne dunkle Punkte, Länge 72, Hinterleib $60 \mathrm{~mm}$ lang und $16 \mathrm{~mm}$ breit.

\section{Termes (Odontotermes) fockianus n. sp.}

Tafel II, Fig. 11 und 12.

Fundangabe: Okah andja: G. Fock, 1909 ( $1 \mathrm{kl}$. und 4 gr. Soldaten, 1 gr. Arbeiter). Typen im Mus. Hamburg und Mus. Stockholm.

Größerer Soldat. (Taf. II, Fig. 11 und 12.)

Kopf dunkler oder etwas heller rotbraun mit dunkler Kehle, oval, etwas rektangulär zusammengedrückt, mit schwach gebogenen, nach vorn etwas konvergierenden Seiten, breit abgerundeten Hinterecken und flach gebogenem Hinterrand, flach gewölbt, glatt und glänzend: Stim flach, breit eingedriickt mit kurzem, niedrigem Kiel und ron dort schräg nach vorn ausstrahlenden kurzen feinen erhabenen Linien: am Walle dir Konkavität der Stirn jederseits ein deutlicher, punktförmiger Eindruck; Epistom flach, vorn schwach gebogen, fast gerade abgeschnitten: Oberlippe zungenförmig, in der Spitze mit einzelnen Haaren: Mandibeln glänzend schwarz, kräftig, von ihrem breiteren dunkel rötlichem Basalteil durch eine Rinne deutlich begrenzt, kurz, schwach scherenförmig gebogen, an der spitze etwas kräftiger gebogen: Innenrand jedersits mit einem deutlichen Zahn: von der seite gesehen sind die Mandibeln schwach nach oben gerichtet: Mentum sehr breit, bandförmig, in der Mitte kaum bemerkbar erweitert, vorn deutlich verengt, Vordurrand breit, gerade abgeschnitten: die Kehlpartie herabgesenkt, so daß sie mit Ausnahme des Vorderteils von der Seite deutlich sichtbar ist: Fühler 17 gliedrig, bis an die spitze gleichmäßig dick: das Basalglied am größten und wie das 2. zylinderisch, das 3. etwas kürzer als die anliegenden: die folgenden fast kugelig, in der Mitte der Fühler die Glieder etwas größer; Prothorax sattolförmig 13/20 so breit wie der Kopf. Torderlappen von der $9 / 13$ Breite der Hinterlappen, in der Mitte sehr deutlich breit herzförmig ausgeschnitten, Torderecken breit abgerundet, Hinterrand flach gebogen, in der Mitte breit und sehr deutlich eingebuchtet, gut doppelt (genauer ${ }^{3} / 3$ ) so breit wie lang: II esothorax 11/13 so breit wie Prothorax, oval, hinten flach eingebuchtet: Netathorax nicht völlig (genauer 12/13) so breit wie der Prothorax, kurz, hinten breit, sehr flach gebogen: Beine gelblich: Kärper und Beine ziemlich spärlich behaart.

Länge 12, Kopf mit Mandibeln 5.7, Kopfbreite $3.5 \mathrm{~mm}$.

steht zwischen $T$. fidens und $T$. monodon. 


\section{Kleinerer Soldat.}

Kopf mit Mandibeln $4 \mathrm{~mm}$, Kopfbreite $2,2 \mathrm{~mm}$, dunkel kastanienbram, wie der größere gebant, Fühler 17-gliedrig, Mandibeln verhältnismäig etwas feiner und länger, Stirn nicht so stark konkar, Hinterrand des Metathorax sehr flach gobogen, fast gorade.

\section{Größerer Arbeiter.}

Lopf einfarben ziemlich hell braun, nur die Stirn etwas blasser, kreispund, ron den seiten sehwach zusammengedrückt, in der Mitte konkav mit einer ringförnigen Cirube: Epistom kaum heller, schmal oval, wenig aufgeblasen, 2/5 so lang wie breit, längs der Mitte mit einer dunklen Linie, jederseits ron einem kleinen dunklen Fleck begrenzt: die zwei ersten Zähne der Mandiboln gloich grob: Fïhlor gelblich, nach außen etwas dunkler, 19-gliedrig, das 3. Glied am kleinsten, das 4. nur wenig größer, so lang wie das 5., das 2. so lang wir das 3. und 4. zusammen, das Basalglied ungefähr so lang wie die drei folgenden zusammen, in der Mitte der Fülller die Cilieder otwas größer, nach außen wieder etwas kleiner; Endglied doppelt so lang wie breit, oval: das 3. und 4. Glied nicht scharf getrenut, so daß man die Glieder für 1S-gliodrig ansohen könntr. Prothorax sattelförnig, Vorderlappen otwas triangular, zusammengedrückt, in der Mitte dentlich ausgeschnitten. Liinge 5, Koptbreite 1,95 $\mathrm{mm}$.

\section{Termes (Odontotermes) rehobothensis n. sp.}

Tafel II, Fig. 3 .

Imago alata: supra castanea, capite panlo obscuriore, ventre et predibus pallide brunnescente-flavidis, unicoloribus; capite ovali, antrorsum valde angustato, paulo longiore quam inter apices oculorum lato; medio puncto prominulo vix conspicuo et macula pallidiore; oculis magnis, ncellis late ovalibus, diametro dimidio ab ocnlis remotis; antennis 19-articnlatis, articulo hasali longitndine duorum serpentium, articulo tertio paulo minore secundo et quarto; prothorace semicirculari, latitudine vix capitis cum oculis, postice applanato et paulo incurvato; lobo antico parvulo, medio vix exciso; alis brunneo-adumbratis, costalibus obscurioribus; mediana et submediana ale autice basi junctis, petiolo venis $4-5$ instructo.

Exp. alar. 71, long. c. alis 39, long. alee ant. 33, lat. alee ant. 9, cor?. c. cap. $15 \mathrm{~mm}$.

Fundangaben: ()kahandja: W. Micnaeser, 28. April 1911 (1 Kïnigin). liahoboth: K. W Egelebex, 1912 (2 gotlüg. Imagines).

Typen in Mus. Hamburg und Mus. Stocklıolm.

\section{Geflügelte Imago.}

Tafiol II, Fig. 3.

Oben ziemlieh dunkel rotbraun, Kopf rin wenig donkler: Banchsegmente horngelb, von derselben Farbe wie die liaine; Kopt oval, nach 
vorn dentlich triangular verengt, ganz wenig länger ( $\mathrm{um} \mathrm{1/ \Omega}$ ) als zwischen den Augenspitzen breit (d. h. $3,2 \mathrm{~mm}$ ); Stirn mit einer winzig kleinen Erhabenheit und von dort nach vorn einem kurzen, kaum sichtbaren Kiel; Epistom klein, wenig gewölbt, wie die Oberlippe heller, braunrötlich, schmal oval, hinten flach gebogen, vorn ziemlich gerade mit dïnnem, weißlichem Torderrand, längs der Mitte mit einer dunklen Linie: A ugen ziemlich groß und abstehend, fast kreisrund; Ocellen kurz oval, um die halbe Länge ilhres Durchmessers von den Augen getrenut; Wangen so breit wie der Zwischenraum zwischen Augen und Ocellen; Augen doppelt so breit wie der längere Durchmesser der Ocellen: Fïhler 19-gliedrig, das Basalglied so lang wie die zwei folgenden Glieder zusammen, das 3. etwas kleiner als die anliegenden; das 2. cylindrisch, so lang wie das melnr abgerundete 4. Glied; nach außen die Glieder allmählich etwas größer, dann etwas schmäler, Endglied gut zweimal so lang wie breit, ziemlich schmal oval; Prothorax ungefähr 1 m 1/11 schmäler als der Kopf zwischen den Augenspitzen, halbkreisförnig mit sehr kurzen Vorderlappen, hinten abgeplattet und schwach eingebogen, Vorderrand etwas eingobogen, in der Mitte nicht oder kaum bemerkbar ausgesehnitten; Meso- und Metathorax hinten etwas winkelig ausgeschnitten mit aufgeworfonen Rïndern; Fliigol deutlich bräunlich angehaucht mit dunkleren Costaladern und pomeranzengefärbter unregelmäßiger Linie unter der äberen Häfte der Subcosta; Mediana und submediana der Vorderflïgel an der Basis vereinigt, der Sticl mit 4-5 Zwrigen; vom äuberen Teil der Subcosta krine deutliche Adern selıräg nach unten gegen dis spitze der Flïgel.

Spannweite 71, Läng( mit Flügeln 39, Länge der Vorderflïgel 33, Breite derselben 9, Körper mit Kopf $15 \mathrm{~mm}$.

Ich halte für sehr möglich, dab diese Art sich als die Imago des T. fockianus erweisen wird. Sie steht der Imago des T. badius sehr nahe, ist aber größer, wie anch der soldat des T. fockianus, obglrich bedeutend größer, dem des T. badius solır ähnolt. Beide stammen aus Deutsch-siadwestafrika. Von T. baclius unterscheidet sich die Imago nicht nur durch bedentendere Größe, sondern auch durch die Lage der Gcellen, welche von den Augen um dic halbe Länge, bei $T$. badius etwas weniger als um die ganze Länge ihres Durehmessers getrennt sind.

\section{Königin.}

Eine vorliegende anscheinend hingehörige Königin gehört jedentalls typisch der badius-Gruppe an. Sie ist an den Seiten dicht dunkel gefleckt nnd selır groß. Länge des Hinterleibes $105 \mathrm{~mm}$. Breite desselben $25 \mathrm{~mm}$. Sie stammt ans Okahandja wie die Soldaten und Arbeiter des T. fockianus. 


\section{Termes (Odontotermes) budius Ilav.}

Sзöstedt, Monogr. p. 110, Nachtr. p. 33, 56.

Fundangaben: Farm Pauliuenhof (siidl. vou den Auasbergen, ca. $36 \mathrm{~km}$ istlich ron Windhuk; W. Wichaelsex, 18. Mai 1911 (mehrere große und kleine soldaten und Arbeiter).

Otjituezu am WeiBen Nossob; Wr. Mrchaelsen, 13. Mai 1911 (Soldaten und Arbeiter).

Größerer Soldat: Kopf mit Mandibeln 5,85, Kopfbreite 2,80 mm.

Kleinerer Soldat: Kopt mit Mandibeln 4, Kopfbreite 2,1 mm.

\section{Termes (Odomtotermes) vulgaris Ilav.}

Sјöstert, Monogr. 1. 113, Nachtr. 1. 26, 35, 58.

Fundangabe: Okahandja: G. Fock, 1909 (1 Kïnigiu, Nymplien, Soldaten und Arberiter).

\section{Termes (Odontotermes) latericins Har.}

Ṡöstedt, Monogr. 1. 124, Nachtr. p. 35, 64.

Fundangaben: Tsume b: W. Mrchaelsen, 13.-19. Juni 1911 (1 Soldat, einige Arbeiter).

Windhuk; W. Mucnaelsen, 29. April bis 8. Mai 1911 (oinige Soldaten und Arbeiter).

\section{Eutermes (Cubitcrmes) pretoriensis 11. sp.}

Tafel II, Fig. 8 und 13.

Fundangabe: 'Transvaal, Pretoria.

Typen im Mus. Stockholm und Mus. Protoria.

Soldat. (Tafel II, Fig. 8, 13).

Kopf hell rotgelb, kurz rektangular, fast quadratiscl, nach hinten kaun bemerkbar verengt, mit geraden Seiten, gebogenem Hinterrand und breit abgerundeten Hinterecken: Stirn sulır hoch, von hinten gesehen einen alogerundeten rechton Wiukel bildond, Stirnmand scharf; Stirngipfel in der Mittr deutlich wulstig vorgezogen, so daß "r die Fontanelle iiberdeckt: Fontanclle nit foimem Sorstenkranz: Oborlippe kurz und broit, nach vorn frwejert, roru breit ringebuchtet, so dab nur zwei kurze Prozessen die (iabelspitzen bilden; Vorderrand mit Haaren besetzt; Fiililer 13-gliedrig: das basalglied erol, nach unten an der Innensoite repenot, otwas lïnger als dies zwoi folgenden Gireder zusammen: das 3. Glied länger als die 
anliegenden: das 2. und t. gleich lang: nachdem die Glieder allmählich viel länger und nach unten stark verengt, die letzten am längsten, ungeführ drei mal so lang wie breit; II entum fast gleichbreit, etwas vor der Mitte erweitert dann etwas verengt, vorn breit abgeschnitten; von der Seite gesehen etwas wulstig herabschiebend, ohne Prozesse: Mandibeln schwarz, fein und schmal, ziemlich schwach einwärts gebogen: Torderlappen des Prothorax viel kleiner als der Hinterlappen, ziemlich breit gebogen, in der Mitte nicht oder kaum bemerkbar ausgerandet; Körper und Beine weiß.

Länge 3, Kopf mit Mandibeln 2-2,20, Nandibeln 1, Kopfbreite $0,85 \mathrm{~mm}$.

Die kleinste bisher bekannte Cubitermes-Art. Kommt in der Übersicht Rev. zool. afric. II, fasc. 3, 1913 p. 376) bri: o Kopfbreite 1,10-1,50 $\mathrm{mm}$ (folgendermaßen: o० Kopflureite 0,85 pretoriensis S̈ösт).

\section{Arbeiter.}

Kopf weiß, fast völlig kreisrund: Ėpistom ungewöhnlich groß und wulstig aufgeblasen, oval, hinten breit gebogen, vorn abgeschinitten, die Seiten breit abgerundet; jederseits ist das Epistom von einem kleinen braunen Fleck brorenzt: Fïhler 14-gliedrig, das Basalglied gut so lang wie die zwei folgenden zusammen, das 2. etwas größer als das 3., das 4 . am kleinsten, das 5. so groß wie das 2: rom 5. an die Glieder nach außen allmählich viel größer, Endglied am längsten, langgestreckt oval, nach außen verjüngt: der erste Zahn der II andibeln viel größer als die anderen: Prothorax ungefälır um 1/t schmäler als der Kopf, sattelförmig, Vorder- und Hinterlappen gleich grof, Vorderlappen ohne Einschnitt in der Nitte: der ganze Körper weiß mit einzelnen Haaren, Fühler und Epistom schwach braungelblich angehaucht, Abdom mit schwarz durchleuchtenden Eingeweiden. Länge 4, Kopfbreite 0,80 mm.

\section{Eutermes (Hamitermes) rumconifer Silv.}

Hamitermes runconifer Silvestri, Jenaische Denkschrift Bd. XIII, pag. 77 (1908).

Fundangaben: Okahandja: W. Mrchaelsev, 27. April 1911 (1 Soldat. mehrere Arbeiter).

Nendamm: W. Mrchaelsen, 10.-15. Mai 1911 (Soldaten und Arbeiter).

Biologie: In Textfigur $1 a$ und $1 b$ anf Seite 89 ist ein Nest dargestellt, in welchem Hamitermes runconifer angetroffen wurde. ..Es will mir aber fraglich erscheinen," sagt Michaelsex, „ob das Nest tatsächlich ron Hamitermes runconifer angefertigt wurde. Das Nest war größtenteils leer (Winterzeit), nur in einem Winkel saßen Termiten. Nei Neudamm fand ich viele ganz leere Bauten, und in einem Hamitermes runconifer, in einem 
anderen ebenso aussolienden Eutermes trinercoides. Sollte der Bau nicht auch der Art Eutermes trinervoides angehören und nur nachträglich ron Humitermes meneonifer besetzt sein??

Yiolleicht ist Eutermes trinervoides dor aigentliche Baumeister. Mir liogt coin sohr ähnliches Nost aus Australien vor, das von eimer Art mit Nasuti-soldaten wie bei E. trinervoides) gebaut ist.

\section{Eutermes grootfonteinsis 11 . sp.}

Tafol II, Fig. 2, 5.

Fundangabe: Grootfontein: IT. Mrenaelsex, 7.-11. Juni 1911 (mehrere gr. und kl. Nasuti und Arbeit(r).

Typen im Mus. Hamburg und Mus. Stockholm.

\section{GröBerer Nasutus (Taf̊] [1, Fig. 2, 5.)}

Kopf rotgelb mit etwas dunklerer Nase, dir nicht ganz auf derselben Linie wir der scheitel lingt: von oben gesehen der Kopf ziemlich kreisrund, nach rorn verengt: Hinterrand der Fühlergruben vor des Mitte des Kopfes gelegen (6:5): Fühlre 13-gliedrig, das 3. Glied 1/3 länger als die anliegenden, das 2. und 4. Flied gleich lang. Basalglied 1/4 kürzer als die zwei folgendrn zusammen: die nittleren Glieder ungefälı doppelt so lang wio breit: nach anben die Glioder etwas kloiner: Fndglied oval, so lang wie das vorletzte Glied: Vorderlappen des Prothorax etwas alogeplattet und in der Mitte doutlich aber sricht abgerundet und mit feiner längsgohender Jittelrinne: Hinterlappen bogenförmig; Vorderlappen abstehend, joderseits an der Basis mit einem kleinen dunklen Flock, und etwas größer als der Hinterlappren. Länge 3,5-4, Kopf 1,95, Kopfbrrite 1,15, Kopfhöhe $0,66 \mathrm{~mm}$.

Diexe nene Art ist in die Cbersicht (Monogr. Nachtr. p. 39) folgendermaben einzufïhren:

$\triangle$ Torderrand des Prothorax in der Mitte etwas ausgeschnitten.

○ Größer. länge des Kopfes 1,95-2 nm.

† Das 2. Fïhlerglied kürzer als das 4.; Vorderlappen des Prothorax dunkler als der Hinterlappen: Nacken mit dunkler Längslinie. E. salebrithorax.

† Das 2. Fühlerglied so lang wie das 4. Vorder- und Hinterlappen rotgelb; Nacken olne duukle Längslinie.

E. grootfonteinsis.

oO Kleiner. Länge des Kopfes 1,50 mm. Das 2. Fühlerglied gleich lang oder etwas länger als das 4.; Vorderlappen des Prothorax von derselben rotgelben Farbe wie der llinterlappen.

E. usambarensis.

\section{Kleinerer Nasutus.}

Kilein und schmaiclitig: Kopf fast rotgelb mit selir dunkler, an der slitzr rötlicher Nase, ron oben gesehen oval, nach vorn rerengt; Nase 
und Scheitel nicht auf einer Linie: Hinterrand der Fühlergruben hinter der Hitte des Kopfes (20:24); Fühler 13-gliedrig, das Basalglied kaum so lang wie die zwei folgenden Glieder zusammen, das 2. ungefähr so lang wie das 4., das 3. viel länger als die anliegenden, etwas länger als das Basalglied; Vorderrand des Protlorax bogenförmig in der Nitte nicht ausgerandet, aber bisweilen mit einer kurzen kaum bemerkbaren Rinne versehen; Länge 3, Kopf 1,60, Kopfbreite 0,70, Kopflı̈he 0,50 mm.

Kommt in der Cbersicht (Monogr. Nachtr. p. 39) neben E. oeconomus, kl. Nasutus.

† Kopffarbe rotbraun, Kopfbreite $0,60 \mathrm{~mm}$. E. oeconomus.

++ Kopffarbe hellrotgelb, Kopfbreite $0,70 \mathrm{~mm}$. E. grootfonteinsis.

\section{Größerer Arbeiter.}

Kopf rotbraun mit drei in der Mitte zusammenlaufenden weißen feinen Linien, kurz rektangulär-oval, mit ziemliclı geraden Seiten, an den Kiefern am breitesten; Epistom viel heller, gelblich, doppelt so breit wie lang, hinten gebogen, vorn ziemlich gerade, ziemlich aufgeblasen, mit heller Längslinie in der Yitte: Fühler 14 gliedrig, weiß, schwach gelblich angehaucht, das 3. Glied deutlich länger als die anliegenden, das 2. und 4. gleich lang, das Basalglied 110 1/4 kürzer als die zwei folgenden zusammen; nach außen die Glieder allmälilich länger, etwas melur als doppelt so lang wie breit; Endglied langgestreckt oval, kürzel als das vorletzte; die zwei ersten Zähne der Mandibeln klein, gleich groß; Vorderlappen des Prothorax abstehend, nach unten rerengt, in der Mitte sehr deutlich ausgerandet. Länge 5, Breite des Lopfes 1,25 nm. Kommt in der Übersicht (Monogr. Nachtr. p. 45) E. salebrithorax am nächsten.

\section{Kleinerer Arbeiter.}

Viel kleiner als der größere. Länge 3, Kopfbreite 0,70 mm. Fiilıler weiß, mit dickeren Gliedern, das 2. Glied so lang wie die zwei folgenden, das 4. am kleinsten, ringförmig und unvollständig abgeschnürt: auch das 5.-7 breiter als lang, bisweilen auch mehrere: das vorletzte am größten, Endglied langgestreckt oval, viel schmäler als das vorletzte.

\section{Eutermes trinervoides Sjöst.}

SJöstedt. Ent. Tidskr. 1911, p. 187 vorläufig in die Ïbersicht eingefiihrt; Denkschr. Mat.-Nat.-Kl. Kaiserl. Akad. Wiss. Wien. Bd. LxxxvIII, p. 720 (1913). Aus dem Kapland.

Fundangabe: Neudamm; Wr. Michaelsex, 10.-15. Nai 1911 (zahlreiche grobe und kleine Nasuti und Arbeiter).

Okahandja: M. Michaelsex, 27. April 1911 (dasselber). 
Biologie: „Aus rinem liuppelfömigen Nest aus fester Erde".

Jieses soll nach Mhchaelsen dem in nebenstehender Textfigur abgebildeten Nest ron Okahandja rollkommen geglichen haben. In dem hier abgrbildeten Nest wurden aber nur Arbeiter von Hamitermes rumconifer SILT. gefunden, allerdings nur in rinem kleinen Winkel, während das Nest sonst leer war. Vielleicht ist Hamitermes runconifer nur als sekundärer Eimminter, dagegen Eutermes trinervoides, der in gleichen Nestern angetroffen wurde, als der Erbaner anzusehen (vergl. die Angabe unter Hanitermes runconifer, oben p. 85).

\section{Eutermes Aispar Sjöst.}

SJöstedt, Monogr. Nachtr. p. 40, 107.

Fundangabe: Okahandja; IV. Muchaelsex, 28. April 1911 (2 Nasuti, melırere Arbeiter).

Die Fühler sind meist 13 gliedrig, das 3. Glied schr lang, doppelt so lang wie das 2.; bisweilen sind die Fühler 14 gliedrig, indem dann das lange 3. Glied in der Mitte geteilt ist. Das 2., 3. und 4. Glied sind dann gleich lang. In diesem Fall ist diese Art in die Thersicht der mit 14 Fühlergliedern verschenen Arten (Sı̈̈sтет, Ent. Tidskr. 1911, p. 187) zwischen E. rhodesiensis und E. trinervoides cinzuführon. Die vorliegunden Exemplare messen: Kopf 2, Kopfbreite 1,10, Kopfhïhe 0,80. Hinterrand der Fühlergruben gerade an der Hitte des Kopfes gelegen.

\section{Eutermes hentschelinms n. sp.}

Tafol II, Fig. 4, 7.

Fundangabe: Otjosondyombo am Eiab: (). Hextscues, Juli 1909 (mehrere hundert Nasuti und Arbeiter).

Typen: im Mus. Hamburg und Mus. Stockholn.

Größerer Nasutus. (Taf. II, Fig. 4, 7.)

Kopf rotgelb mit schwarzer, langer, schmaler, in der spitze roter Nase, die nicht ganz auf dor Linie des Scheitels liegt; Kopfseiten stark abgerundet, so dafo der Kopf etwas breiter als lang rescheint: Hinterrand der Fühlergruben viel hinter der Mitte des Koptes gelegen (3:4); Nacken wit friner otwas eingedrückter Mittellinis: Fiihler 14 gliedrig, das 2. Glied an kleinsten, fast lualb so lang wie das 3., Basalglied so lang wie das 3 ., das dentlich lainger als das 4. crseheint; das 4. und 5. glejeh grob; nach auben die Glieder unbedentend griober und dann wieder etwas kleiner; 


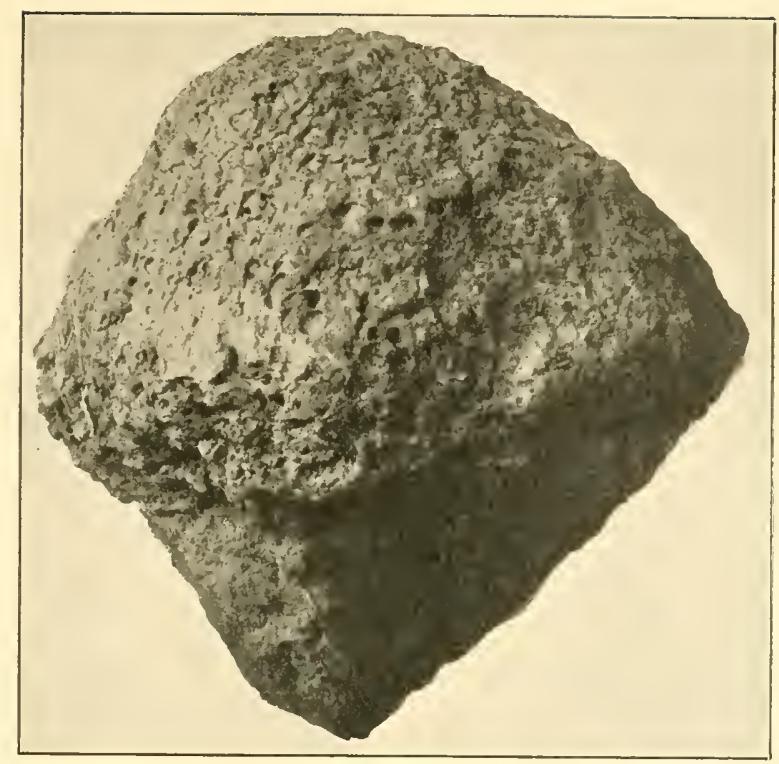

a.

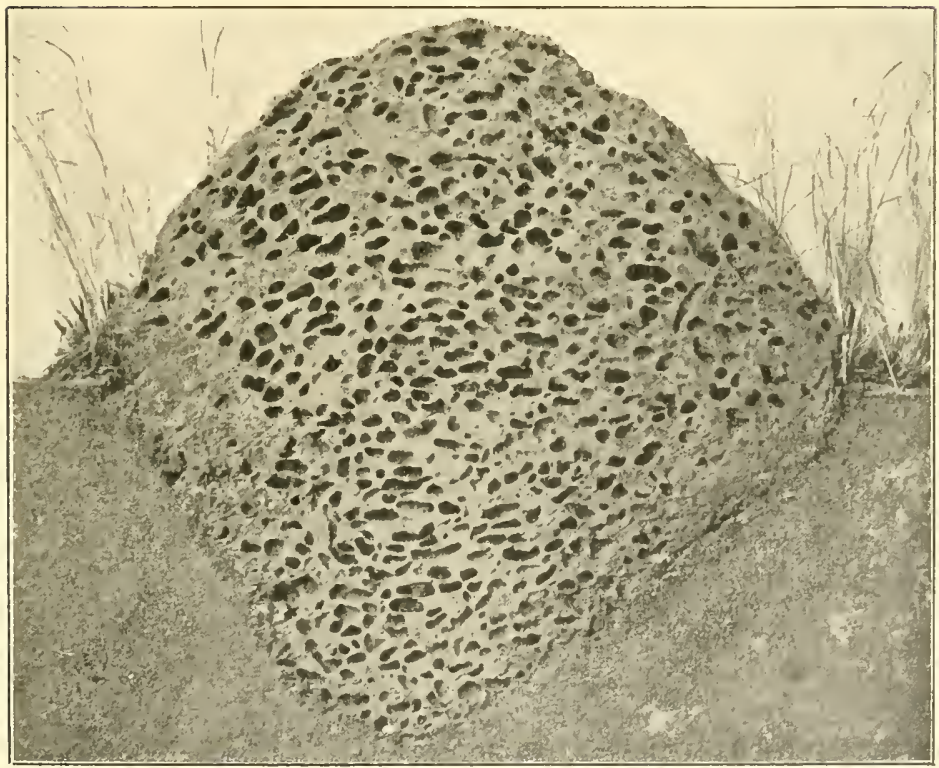

l.

Fig. 1. Termitennest aus fest mebackener Erde von Okillandja,

in einem Winkel bewohnt von IInmitermes runconifer;

a) $=$ Nest von der Seite, b) = Hauptlängsschnitt des Nestes mit kiinstlichem Erdboden. 
Endgliod ziemlich kurz oral, so lang wie das vorletzte. Protlorax sattelförmig. Irorderlappen ziemlich gleich lang wie der Hinterlappen, in der Titte schwach ringekrrbt. Länge 5-6, Kopf 2,45, Kopfhöhe 0,80, Kopfbreite $1.25 \mathrm{~mm}$.

\section{Kleinerer Nasutus.}

liopt rotgelb mit langer, feiner, schwarzer oder schwärzlicher, in der Spitze rötlicher Nase, die nicht ganz auf riner Linie mit dem Scheitel liegt, von obrn gesehen kurz oral, nach vorn etwas verengt; Fiihler 14 gliedrig, das 2. Glied am kleinsten, etwa halb so lang wie das 3.; das 3. und 4. Cilied gleich lang, das 5. ctwas länger; in der Mitte der Fühler die Glieder schmal, droimal so lang wie breit, nach außen kleiner, Endglied oval; Torderlappen des Prothorax in der Mitte schwach ausgerandet.

Länge 3-3,5, Kopf 1,85, Kopf'höhe 0,54, Kopfbreite 0,85.

Dir Nasuti dieser Art sind in die Ubersicht dor mit 14 gliedrigen Fïhlern verselenen Nasuti (Entom. Tidskr. 1911, p. 186) folgendermaßen einzufülıren :

O Kopfbreite unter $1 \mathrm{~mm}$.

$\triangle$ Die mittleren Fïhlerglieder dreimal so lang wie breit.

\# Länge und Breite des Kopfes 1,68-1,70 resp. 0,66 1 m.

E. geminatus kl. Nasutus.

$\neq \neq$ Länge und Breite des Kopfes 1,85 und $0,85 \mathrm{~mm}$.

E. hentschelianus kl. Nasutus.

oo Kopthreite ïber $1 \mathrm{~mm}$.

t. Das 3. Fühlerglied deutlich bis viel länger als das 4., etwa doppelt so lang wie das 2.

+ Nase kurz, vom Hinterrand der Fïhlergruben 1/4 kürzer als der übrige Kopf; Kopf rotbraun, Nacken ohne Längsrinne.

E. geminatus gr. Nasutus.

++ Nase sehr lang, vom Hinterrand der Fühlergruben 1/3 länger als der übrige Kopf; Kopf rotgelb. Nacken nit feiner Längsinne.

$E$. hentschelianus gr. Nasutus.

\section{Größerer Arbeiter.}

Kopf rotbraun mit drei weißen in dir Mitte zusammenlaufenden Linien, Epistom, Mundteile, Beine und Körper weiß, gelblich angehancht; von oben gesohen ist der Kopf rund, von den Seiten zusammengedrückt, an den Kiefern am breitestron, Nacken schwach gebogen; in der Hitte des Lopfes eine dentliche Grubu: Epistom grob, oval, hinten gebogen, voru abgeschnitten, doppelt so breit wie lang, jederseits ron einem braunen Fleck begrenzt; Fühler 15 gliedrig, das 3. Cilied lïnger als die anliegenden, das 2., 4. und 5. gleich lang; das Basalglied kürzer als die zwoi folgenden zusammen: die mittleren Glieder mehr als doppelt so lang wio breit $(5: 2)$, Fndgliod langgestreckt oval: die zwei erston Zaihne der II andibeln gleich groß, sohr klein; Protlourax sattelförmig, Vordorlappen länger als der 
Hinterlappen, in der Mitte ziemlich tirf ausgeschnitten. Länge 6, Kopfbreite $1,5 \mathrm{~mm}$.

\section{Kleinerer Arbeiter.}

Kleiner, besonders der Kopf: K opf mehr abgerundet als beim größeren Arbeiter, an den Kiefern am breitesten: Fiihler 15 gliedrig, das Basalglied so lang wie das 3. und 4. zusammen; das 2. kürzer als die zwei folgenden zusammen; das 3. und 4. gleich lang, das dritte nach innen verengt; bisweilen sind diese zu fast einem langen Glied vereinigt, so daß die Fühler 14 gliedrig erscheinen.

Länge 4, Länge und Breite des Kopfes resp. 1,35 und 1,15 mm.

\section{Eutermes mfonasalis Sjöst.}

Sјöstedt, Revue zool. africaine, vol. II, fasc. 3, p. 383 (1913).

Fundangaben: Windluuk; W. Mrchaelsex, April-Mai 1911 (zahlreiche gr. und kl. Nasuti und Arbeiter).

Farm Paulinenhof, südlich am Auas-Grobirge, ca. $36 \mathrm{~km}$ östlich vou Windhuk: W. Michaelsex, 18. Mai 1911.

Wie in der Originalbeschreibung schon angegeben worden eine mit E. agricola äuBerst nahe rerwandte Art. Einige der vorliegenden Nasuti haben eine ziemlich stark dunkle Nase und kommen dann $E$. agricola sehr nahe. Die Art ist rou Katanga beschrieben.

\section{Eutermes coarctatus Sjoist.}

Sjöstedt, Monogr. Nachtr., p. 41, 106.

Fundangabe: Kalkfeld, $48 \mathrm{~km}$ NNO. von Omaruru: IV. Michaelsex, 5. Juni 1911 (3 Nasuti!

Stockholm, Naturhistorisches Reichsmuseum, am 18. Nor. 1913.

\section{Tafelerklïrung. \\ Tafel II.}

Fig. 1. Termes (Termes) Michaelseni n. sp. Gefl. Imago 1/1.

Fig. 2. Eutermes grootfonteinsis n. sp. Nasutus, Kopf ron oben, rergr.

Fig. 3. Termes (Odontotermes) rehobothensis n. sp. Gefl. Imago 1/1.

Fig. 4. Eutermes hentschelianus n. sp. Nasutus, Kopf ron oben, vergr. 
Fig. 5. Eutermes grootfonteinensis n. sp. Nasutus, Kopf ron der Seite, vergr. Fig. 6. Termes herus n. sp. Geth. Imago $1 / 1$.

Fig. 7. Eutermes hentschelianns n. sp. Nasutus, Kopf von der Seite, vergr. Fig. 8. Eutermes (Cubitermes) pretoriensis n. sp. Soldat, Kopf von oben, vergr. Fig. 9. Hodotermes macrothorax $\mathrm{n}$. sp. Soldat $t / 1$.

Fig. 10. Termes (Termes) Michaelseni n. sp. Soldat 1/1.

Fig. 11. Termes (Odontotermes), fockianus n. sp. Soldat 1/1.

Fig. 12. Termes (Odontotermes) fockianus n. sp. Soldat, vergr.

Fig. 13. Eutermes (Culitermes) pretoriensis n. sp. Soldat, Kopf von der Seite, vergr. 

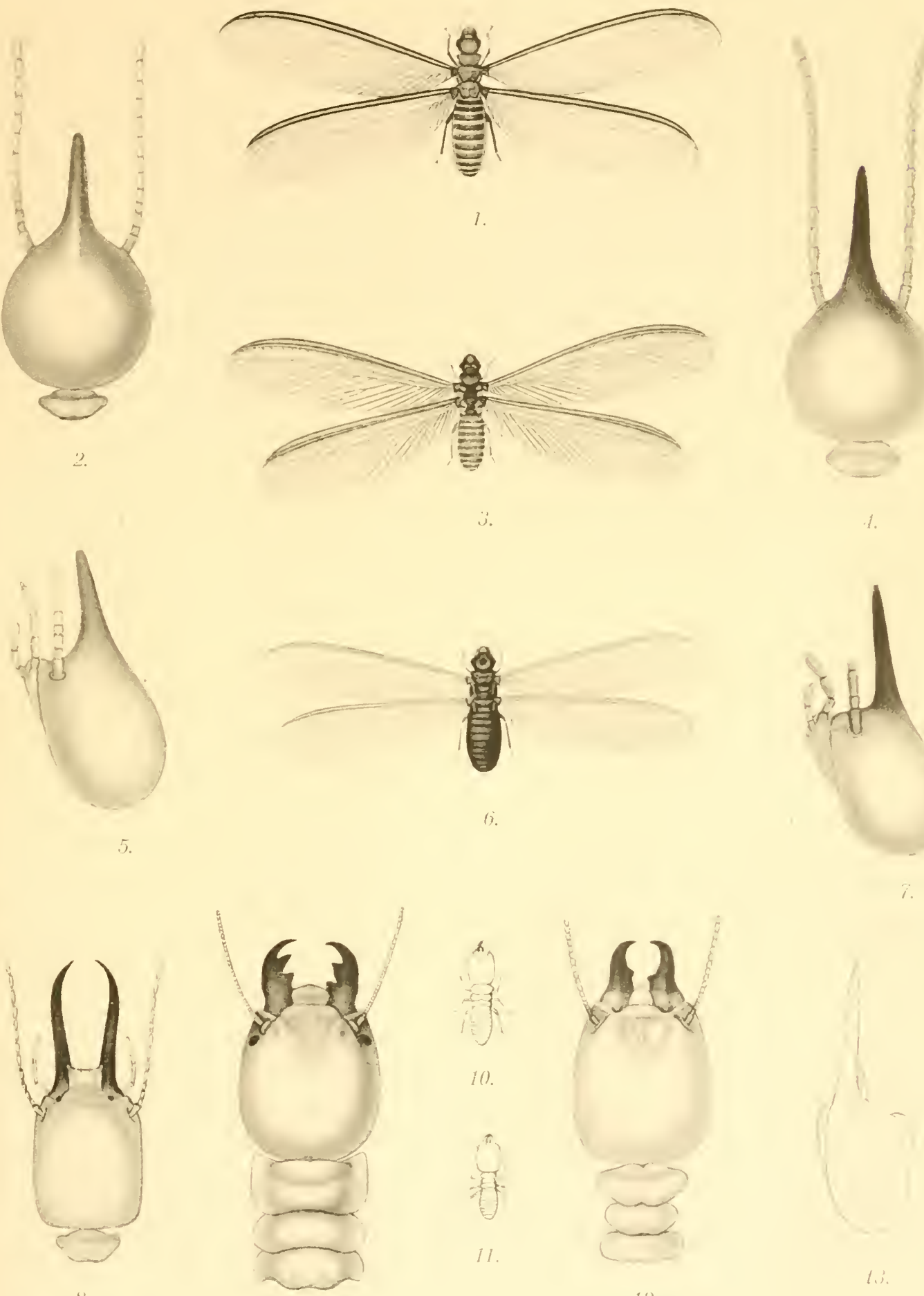

8.

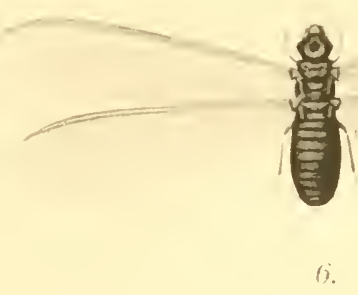

12

(). 

Erst den letzten Jahren war es vorbehalten, insbrsondere durch die Bearbeitung der Sammelausbeute von Oscar Neumans, Leosu. Schumtze, der deutschen Zentralafrika- und der englischen Tanganyika-Expedition und anderer etwas Licht in die Entomastrakenfanna des dunklen Erdteils zu bringen. Freilich stchen die bisherigen Ergebnisse in keinem Verhältnis zu dem imensen Gebiet, das hier in Frago kommt. Aus diesem Grunde muß auch das durch MuchaEssen von der Hamb. deutseh-südwestafrikanischen Studienreise 1911 mitgebrachte Copepodemmaterial, so gering es in quantitativer Hinsicht auch ist, - es bostand aus 8 Gläschen, deren Inhalt sehr gut in Alkohol konserviert war — als willkommene Ergainzung der bisherigen Resultate angesehen werden. Der zoogeographische Gesichtspunkt, soweit ein soleher bei dem geringen Lmfang des Materials in Betracht kommon kann, wird am schlusse dieser Arbeit gewürdigt werden.

Hinsichtlich der Arten und Fundstellen dre bisher aus dem Gebiet bekannt gewordinen Tiore diene nachstehende

\section{Zusa m me uste $11 u n g$}

der im Niidwestafrikanischen Schntzgobiet bisher gefundenen Copepoden.

\begin{tabular}{|c|c|c|c|c|c|c|c|c|c|}
\hline \multirow[b]{2}{*}{ Centropagidue } & \multirow[t]{2}{*}{$\begin{array}{l}\text { Groot- } \\
\text { fontain }\end{array}$} & \multirow[t]{2}{*}{$\begin{array}{c}\text { Otjitue- } \\
\text { zu am } \\
\text { Weißen } \\
\text { Nosob }\end{array}$} & \multicolumn{2}{|c|}{$\mid \begin{array}{c}\text { Farm Frauen- } \\
\text { stein } \\
\text { bei Neudamm }\end{array}$} & \multicolumn{2}{|c|}{ Neudamm } & \multirow[t]{2}{*}{$\begin{array}{l}\text { Groß- } \\
\text { Bruck- } \\
\text { Karoß- } \\
\text { berg }^{1} \text { ) }\end{array}$} & \multirow[t]{2}{*}{$\begin{array}{l}\text { See- } \\
\text { heim }\end{array}$} & \multirow[t]{2}{*}{ Kuibis } \\
\hline & & & & & & & & & \\
\hline $\begin{array}{l}\text { Paradiaptomus Schultzei } \\
\text { Dorw: }\end{array}$ & - & - & - & + & + & + & . & - & - \\
\hline $\begin{array}{l}\text { Paradiaptomus falcifer } \\
\text { (Lovíx) }\end{array}$ & - & + & + & + & • & - & - & - & • \\
\hline $\begin{array}{l}\text { Diaptomus colonialis } \\
\text { n. sp. }\end{array}$ & - & + & + & + & + & + & - & + & + \\
\hline $\begin{array}{l}\text { Diaptomus meridianus } \\
\left.\text { Docwe }{ }^{2}\right)\end{array}$ & - & • & - & - & • & • & + & • & - \\
\hline Cyclopiclae & & & & & & & & & \\
\hline $\begin{array}{l}\text { Cyclops diaphanus } \\
\text { FIsCHER }\end{array}$ & • & - & • & + & - & • & - & - & • \\
\hline Cyclops Leuckarti Claus & + & - & - & + & - & - & - & - & • \\
\hline
\end{tabular}

1) Auf den dem Herausgeber zugänglichen Karten als Gr. Brukaros-Berg oder Gr. Brukkaros-Berg bezeichnet.

$\left.{ }^{2}\right)$ Vax Dorwe „Copepoda“ in: Scutrtze, Zool, und antliropol. Ergebnisse einer Forsch. Reise im westl. u. zentralen Südafrika 1903-1905; V. Band 1912, 


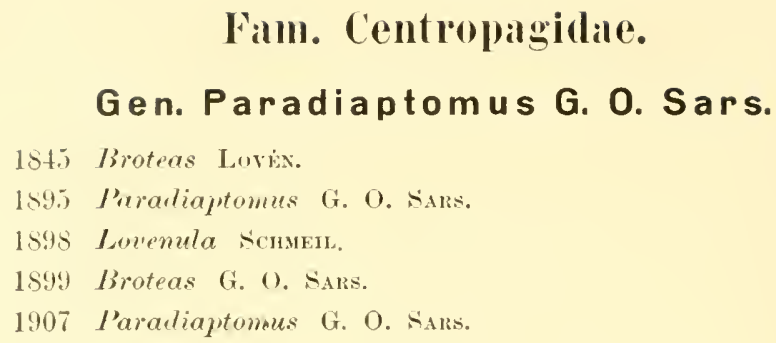

Fam. Centropagidale. Gen. Paradiaptomus G. O. Sars.

154.) Broteas Lorix.

189.5 Preradiaptomus G. O. SAss.

1598 Lovemula SinMeiL.

1599 Broteas G. (). Sins.

1907 I'aradiaptonnes G. O. SAks.

\section{Pardadiatomus schmltsei Douwe.}

1912 Dorwe „Copepoda“ in: Schrcze, zool. ఐ. anthropol. Ergebnisse etc. V. Band, p. 26. Tafel IV.

Fundangaben: Noud a m m, in 2 verschiodenen Wassorstellen: W. Michaelsex, 9. Mai 1911 Farm Frauenstein bri Neudamm, in einem Tïmpel: W. Michaelsen, 12. Mai 1911.

Die mehrach in geschlechtsroifen Exenplaren vorhandenen Tiere stimmen genan mit den von Scuuctze in der Kalahari gesammelten überejn.

\section{Praradiajtomess falcifer (Lovén).}

1845 Broteas falcifer luves in: Svensk. Vetensk. acad. Hand1. tabl. 6.

1898 Lonémula falcifera Scnment, Copepoda, I. Cymnoplea in: Tierreich.

1904 Lomínula mea Groxer in: Proc. zool. soc. London, vol. 2, tab. 18.

1912 Paradiaptomus falcifer Dorwe, "Ostafrikanische süßwassercopepoden" in Zool. Jalırbücher, system. Bd. 33.

Fundangaben: Otjiturzu an Quelltub des Mrabun $\mathrm{Nosob}$, in einem flachen 'lïmpel: W. Mrcmaessex, 13. Mai 1911.

Farm Fraurustrin bei $\mathrm{N}$ eudamm, in zwoi verschedenen Tümpeln:

IV. Michaelsin, 12. Mai 1911.

Dieser durcls soiurn Bau und scine Entdrekungsgeschichte interessante Copepode hat sich zum rrstrumal auch in muserem Gebiete an drei Stellen vorgefunden.

\section{Gen. Diaptomus Fischer.}

\section{Jiretommess roolmialis n. sp.}

Tafiel III, Fig. 1-11.

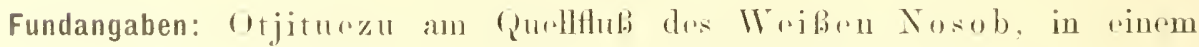

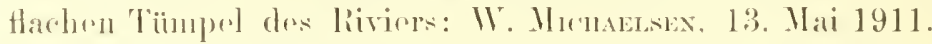

Nendamm und Farm Finuenstrin bes Neudamm, in rerschiedenen

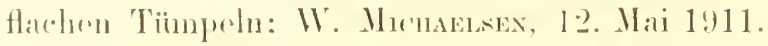


Kuibis, in einem künstlichen, eingemauerten Wasserloch; W. Michaelsex, 15. Juli 1911 .

Seeheim, in einem dauernd Wasser haltenden, von Binsen eingefaßten See im Rivier des Großen Fischflusses; W. Michaelsex, 19. Juli 1911.

Vorliegend in zahlreichen geschlechtsreifen Exemplaren, zum Teil vergesellschaftet mit Paradiaptomus falcifer (Lovéx).

Beschreibung: Der schlanke Cephalothorax (Tafel III, Fig. 1) erreicht seine größte Breite etwa in der Mitte des Körpers und gelit ohne besonders auffallende Verschmälerung in das vom vorletzten Segment nur undeutlich geschiedene 6. Segment iiber. Letzteres ist beiderseits ziemlich gleichartig und nur wenig nach hinten ausgezogen, die Sinnesdornen sind klein, der linke hakenförmig nach unten. der rechte horizontal abstehend.

Abdomen: Beim Weibchen (Tafel III, Fig. 1) dreigliedrig; lier ist das erste Segment linkseitig proximal herrorgewölbt, im distalen Teil des rechtsseitigen Randes sitzt die Genitalöffnung, die von einem halbkrrisförmigen Deckel, der eine eigentiumliche Randkerbung besitzt, ïberdacht wird (Tafel III, Fig. 4, 5). Beim II ännclinn (Tafel III, Fig. 3) bildet die linke Randpartie des 1. Segments einen charakteristischen Doppelwulst. ähnlich wie wir ihn rom Diaptomus Joriai Rich. kennen. Das 2. Segment ist das längste, das 5. (letzte) Segment kurz, etwa so lang wie das erste.

Die kurzen, beim Männchen gerade abgestutzten Furkalglieder sind am Innenrand fein behaart. Der rechtsseitige Furkalast des Weibchens (Tafel III, Fig. 2) ist etwas kïrzer als der linke.

Die Vorderantennen erreichen, an den Körper angelegt, kaum den Hinterrand des 1. Abdom. Segments. Am 10. Glied der genikulierenden Antennen (Tafel III, Fig. 6) ist ein kleiner, dem folgenden Segment angedrïckter, am 11. Segment ein ebenso großer senkreeht abstehender Dorn; nur das 13. Segment trägt den bekannten großen Dorn.

Das letzte Glied (Tafel III, Fig. 7 ) endigt in einen lyyalinen daumenförmigen Fortsatz. Hinterantennen und M I ndglieder zeigen keine bemerkenswerten Verhältnisse. Der II axilliped weist in den mittleren Gliedern eine feine Randbedornung auf (Tafel III, Fig. 8).

5. Fubpar des Weibehens (Tafel III. Fig. 9): Das erste Glied des Aubenastes schlank, etwa $2 \frac{1}{2}$ mal so lang als breit, stwas länger als das folgende, die Endklaue tragende Glied. Die Endklaue ist fast geradı, nur an der Spitze etwas gebogen und mit verschieden starken Zähnen besetzt. Am proximalen AuBenrand ein starker Dorn unter dem das 3. Außenastglied angefügt ist, das nebrn einem sehr kräftigen langen Dorn 7 Michaelsen, Deutsch-Südwestafrika. 
innenseits rin kleines 1) ̈̈rnchen trägt. Dor Innenast eingliedrig, länger als das 1. AuBenastsegment, an der Spitze rin Kranz feiner Haare und zwei lange, geschwungene Borstrn.

5. Fußpar des Männclens (Tafel III, Fig. 10, 11): Rechter Fub: Das zweite Basale ist stark bauchig aufgetrieben und an der Innenseite mit kurzın dichtstehenden 1)ormen bewehrt. Oas 1. AuBenastglied oblong, seine distale. Innenecke ist in cinen langen, geraden Chitinfortsatz ausgezogen. Das 2. schlaukr Glied trägt kurz ïber dem schwach gebogenen Greifhaken einen klimen AuBunranddorn. Der Innenast, weit über das erste AuBenastglied reichend, ist etwa trommulschlägelähnlich gebildet, und an der Spitze mit feine'n Haaren besertzt.

Linker FuB (Tafol III, Fig. 11): Innonast felult; der AuBenast bestuht aus einem in ein Polster ausgezogenen Gebilde, das mit feinen und an der Randpartie mit starken, kurzen llornen besetzt ist. An der Basis dieses Polsters entspringt ain zapfonförmiger Vorsprung, der eine kurze, gedrungene Klaue trägt. Auberdem sind noch ein paar dornartige Torsprïnge rorhanden, bezïglich deren Anordnung an besten auf dic Abbildungen rerwieson wird.

Der prall am Abdomon anliegende Eiballon trug eine große Zahl Eier. GröBe: Männchen ca. 1,0 mm, Weibchen ca. 1,4 mm.

Bemerkungen: Das Tier gohört zum Formenkreis derjenigen Diaptomiden Afrikas, die am männlichrn, f̈ü ften Fußpar einesteils durch die wulstige Auftreibung des 2. Basale und den rudimentären Außenranddorn des 2. Außenastgliedes, anderntrils durch den in rin Ninnespolster endigenden und mit Klanendornen bescotzten Innenast repraisentiert werden. (1). meridianus Dwe., D. aethiopicus IAms.)

\section{Fam. Cyclopidae.}

\section{Gen. Cyclopss o. F. Iiiller.}

\section{Cyclops diaphamms Fiseher.}

Fundangabe: Farm Fraucustein bei Noudamm, in einem flachen Tümpel; IV. Mehaldisex, 12. Mai 1911.

Diese bisher nur vereinzult anftrotende Form tritt uns in Afrika zum zweiten Male im gleichen (iobirt entgegen. 


\section{Cyclops Lenckarti Claus.}

Fundangaben: Grootfontein; W. Mrchaelsex, 11. Juni 1911.

Neudamm, in flachen Tümpoln; W. Mrchaelsex, 9. Mai 1911.

\section{Verbreitung der Copepoden-Arten (speziell Centropagidae) in Siidafrika.}

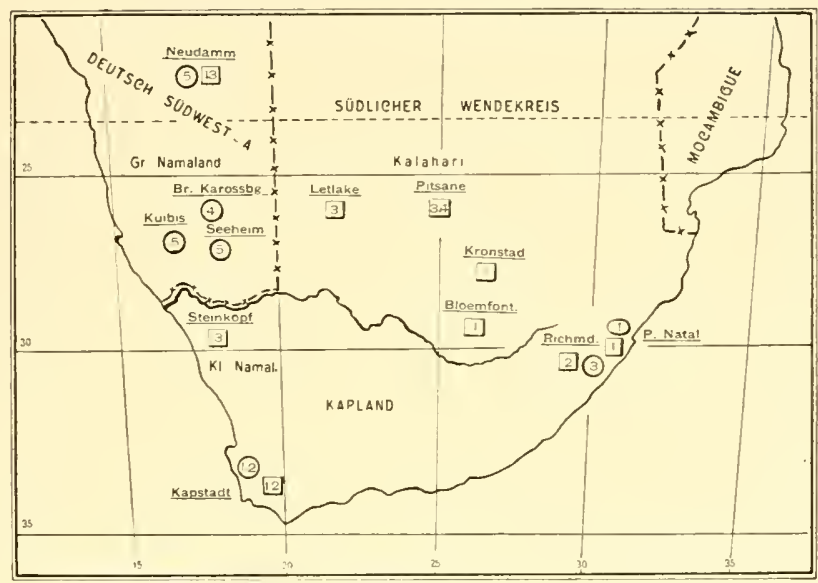

\section{Zeichenerklärung:}

- Diaptomus.

$\mathrm{O}_{1}$ D. capensis SARs: Kapstadt. $\bigcirc_{2}$ D. Purcelli SARs: Kapstadt. $\bigcirc_{3} D$. orientalis KradY: Richmond (Natal). $\bigcirc_{4}$ D. meridianus Docwe: Groß-Bruckkaroßberg $\bigcirc_{5}$ D. colonialis n. sp.: Neudamm, Kribis, Seeheim.

\section{- Adiaptomus.}

$\bigcirc_{1}$ A. natalensis Cooper: Verschiedene Fundstellen bei Port Natal.

\section{$\square$ Paradiaptomus.}

$\square_{1}$ P. falcifer (Lorḱx): Port Natal, Kapstadt, Kronstad, Bloomfontein und Nendamm. $\square_{2}$ P. lamellatus SARs: Kapstadt, Br. Richmond. $\square_{3}$ P. Schultzei DouwE: Letlake, Pitsane, Steinkopf und Neudamm. $\square_{4} P$. similis Docwe: Kalahari (Pitsane).

In der vorstehenden Kartenskizze wurde das Vorkommen der in geographischer Hinsicht bedeutungsvollen Centropagiden, soweit sie aus Afrika bis jetzt südlich rom Wendekreis des Steinbocks bekannt geworden sind, eingetragen. Was ihre hier vor allem interessierende Verbreitung in unserer südwestafrikanischen Kolonie anbetrifft, so sehen wir aus der Karte, daß durch das vorbesprochene Material, zu dem einzigen, bisher von da bekannt gewesenen Diaptomus meridianus Douwe neben einem 
weiteren, neuen Vertreter dieser Gruppe noch zwei Angehörige der für Siidwestafrika typischen Paradiuptomus(-Lovémla) Gruppe treten. Wrnn somit auch das Gesamtbild der siidafrikanischen Centropapidenfauna keine wesentliche Verschiebung durch die neuvorliegenden Befunde erfahren hat, so geben diese immerhin eine beachtenswerte Erweiterung unseres Wissens in Bezug auf das Vorkommen der letzterwahnten Gruppe. Wie in neuren Arbeiten nachgewiesen, gelit das in Kapland wurzelnde Genus Paradiaptoms an Ostrande des afrikanischen Kontinents ziemlich weit nach oben und erreicht seine nördlichste Verbreitungsgrenze zur \%eit in der Massaisteppe unserer ostafrikanischen Kolonie. Das hier erstmals nachgewiosene Auftreten ron zwei Arten disser Gattung im siidwostafrikanischen Schutzgrobet läßt vermuten, daß weitere Nachforschungen uns mit dem Übergreifen der Gattung in den äquatorialen Gürtel ibber Südwestafrika hinaus bekannt machen werden.

Jedenfalls lohren uns dir bisherigen Funde, daB wir im Grous Paradiaptomus keine rigentliche. Plankton-Form, sondern rine für die eigentïmlichen biologischen Verhältnisse der sïdafrikanischen "Wasserpfannen" typische Copepoden-Gattung sehen miissen.

Die Familie der Cyklopiden bietet uns auch anf Grund des vorliegenden Materials koine neuon geographischen Gesichtspunkte. Die eine ron den beiden vorgefundenen Arten: C. Lenckarti, ist eine kosmopolitische Copepodenart: die andere: $C$. diaphams, wurde sïdlich des Saharagïrtels bereits einmal festgestellt und zwar elonfalls in unserem schutzgebiet. Im allgemeinen gewinnt man den Eindruck - soweit man heute schon dariber urteilen darf - daß man es hinsichtlich der siidafrikanischen Cyclopiden zwar mit wenigen Arten aber innerhalb dieser mit weitgehenden Variationen zu tun hat, wofiir insbesondere die Befinde von Sars aus dem Tanganyika') ein bewrisendes Beispiel abgeben.

Dir dritte große Gruppe der freilebenden siißwasser-Copepoden Harpacticidae - ist im vorliegenden IIaterial nicht vertreten.

1) 1909 SArs, G. O., zoolog. Results of the third Tanganyika Exped. contucted by Cunington 1904-1905 in: Proc. zool. Soc. London. 


\section{Literatur iiber die Copepodenfauna Afrikas.}

1891 Barrols, Sur trois diaptomus nouveaux des environs du Caire; Rev. biol. nord France T. V.

1890 Blaxchard, R., et Richard, J. Sur les crustacées des Sebkahs et des chotts algér: Bull. Soc. zool. France T. XV.

1890 Blaxchard, R., et Richard, J., Faune des lacs salés d'Algérie; Mém. de la Soc. zool. France, T. IV.

1893 Bourne, G. C., Crustazeen ron Zanzibar: Zool. Anzeiger Nr. 411.

1904 Bradr, G. S., on Entomostraca collect. in Natal: Proc. zool. Soc. London vol. VI-VIII.

1907 Brady, G. Stewardsox, on Entomostr. coll. in Natal; Ann. Nat. Govern. Zool. Mus. London, vol I.

1908 Brens, r., Entomostraken aus Tripolis u. Barka: zool. Jahrb. Systematik., Band XXVI.

1909 Brend, v., Zur Kenntnis der Copepodenfauna von Deutsch-Kamerun. Zool. Anz. Band XXXIY.

1909 Bгенм, v., Ein neur Cyklops aus Deutsch-Kamerun; Arch. für Hýdrobiol- und Planktonkunde. Band $\mathrm{V}$.

1906 Cooper, IV. A., Notes on a new species of Grmnoplea from Richmond, Natal South Afr. Ann. Natal Zool. Mus. London. vol I.

1907 DADAY, E. vox, Planktontiere aus dem Viktoria Nyanza: Zool. Jahrb. Sirstematik. Band XXV.

1910 Dadar, E. vox, Die Nüßwasserfauna Deutsch-Ostafrikas; Zoologica, Heft 59 .

1910 Dadar. E. vox, Species aliquot novap Entomostr. Copepoda: Arch. Zoolog. rol I.

1912 Douwe, C. vax, Ostafrikan. SüBwassercopepoden: Zool. Jalrb. Srstematik. Band XXXIIL.

1912 Howwe. C. vax, Copepoden des ostafr. Seegebietes: Wissensch. Ergebmisse der Deutsch. Zentr. Afr. Exped. 1907-08. Band III.

1912 Douwe, C. vax, Noue SïBrassercopepoden ans siidafrika; Sculltze, Zool. und anthrop. Ergebnisse einer Forsch. Reise im westl. und zentr. Sïdafika. Band $V$.

1904 Ekstx, Srex, Chadoceren und freilebende Copepoden aus Agypten und dem sudan. Results swedish Zool. Exp.

1904 Gurser, R., on a small collection of freshwater Entomost. frum South Africa: Proc. Zool. Soc. London. vol VIII. 
1909 Gurner, R., on the freshwater Crustacea of Alger. et Tunesia; Roy. Microscop. Soc.

1888 Gursex, J., at Richard, J., Diagnoses de deux Diaptomus nouveaux d'Algerie. Bull. Soc. Zool. France T. XIII.

1890 Gurnes, J., et Ricinard, J. Diagnose d'un Diaptomus nouveau du Congo. ibid. T. $\mathrm{XV}$.

1894 Groner, J., et Richard, J., Diaptomus cherreuxi, Copépode nouveau d.Algerie: ibid. T. XIX.

1845 Lovéx, S., Fyra nya arter af Sötrattens Crustaceer fran Südra-Afrika; Kong. Vet. Acad. Handl.

1892 Maupas, M., Sur la Prolisarius viguieri, nouveau Copepode d'eau douce; Compt. rend. Ac. Sc. Paris.

1910 Méthuen, P., On a collection of freshwater Crustac from Transvaal. Zool. Soc. London.

1894 Мrazek, A., Uber eine neue Schmackeria (Schm. hessei) aus der Kongomündung; Sitz.-Ber. der K. böhm. Ges. d. Wiss. Math.-nat. Klasse.

1898 Mrazek, A., Die Copepoden Ostafrikas: Deutsch-Ostafrika, Band IV.

1895 Poppe, S. A. et Mrazek, A., Die von H. Stuhlmann auf Zanzibar und dem gegenüberliegenden Festlande gesammelten Süßwassercopepoden; Beiheft zum Jalırb. der Hamb. wiss. Anstalten.

1889 Richard, J., Description du Mesochra Blanchardi, Copep. nouveau des Sebkhas alger; Bull. Soc. zool. France. 'T. XIV.

1893 Rucnaro, J., Copépodes, recueillis en Egypte, en Syrie et en Palestine. Rev. biol. nord France.

1893 Sars, G. O., on some South-Afric. Entomostraca raised from dried mud. Vid. Selsk. Skrift I, math.-nat. Kl.

1907 Sars, G. O., on two new species of the Genus Diaptomus from Sonth Afr. Arch. math.-nat. Krl. Christiania. Band XXVIII.

1909 Sars, G. O., Kool. Results of the Third Tanganjika Expedition, conducted by W. A. Cumnington 1904-(15. Proc. zool. Soc. London. 


\section{'Tafelerklärung.}

\section{Tafel III.}

Fig. 1-11: Diaptomms colonialis n. sp.

Fig. 1. Weibchen von oben.

Fig. 2. Furka des Weibchens.

Fig. 3. Abdomen des Mäunchens.

Fig. 4. Abdominalsegment des Weibchens, dorsal.

Fig. 5. Genitalklappe des Weibchen..

Fig. 6. Mittelstiick der genikulierenden Antenne.

Fig. 7. Endsegment der gen. Antenne.

Fig. 8. Mittelstiick des Maxillipeds.

Fig. 9. 5. Fußpaar des Weibchens.

Fig. 10. 5. Fußpaar des Jfännchens.

Fig. 11. 5. linker Fuß des Männchens von der Hinter-(Rücken-)seite. 



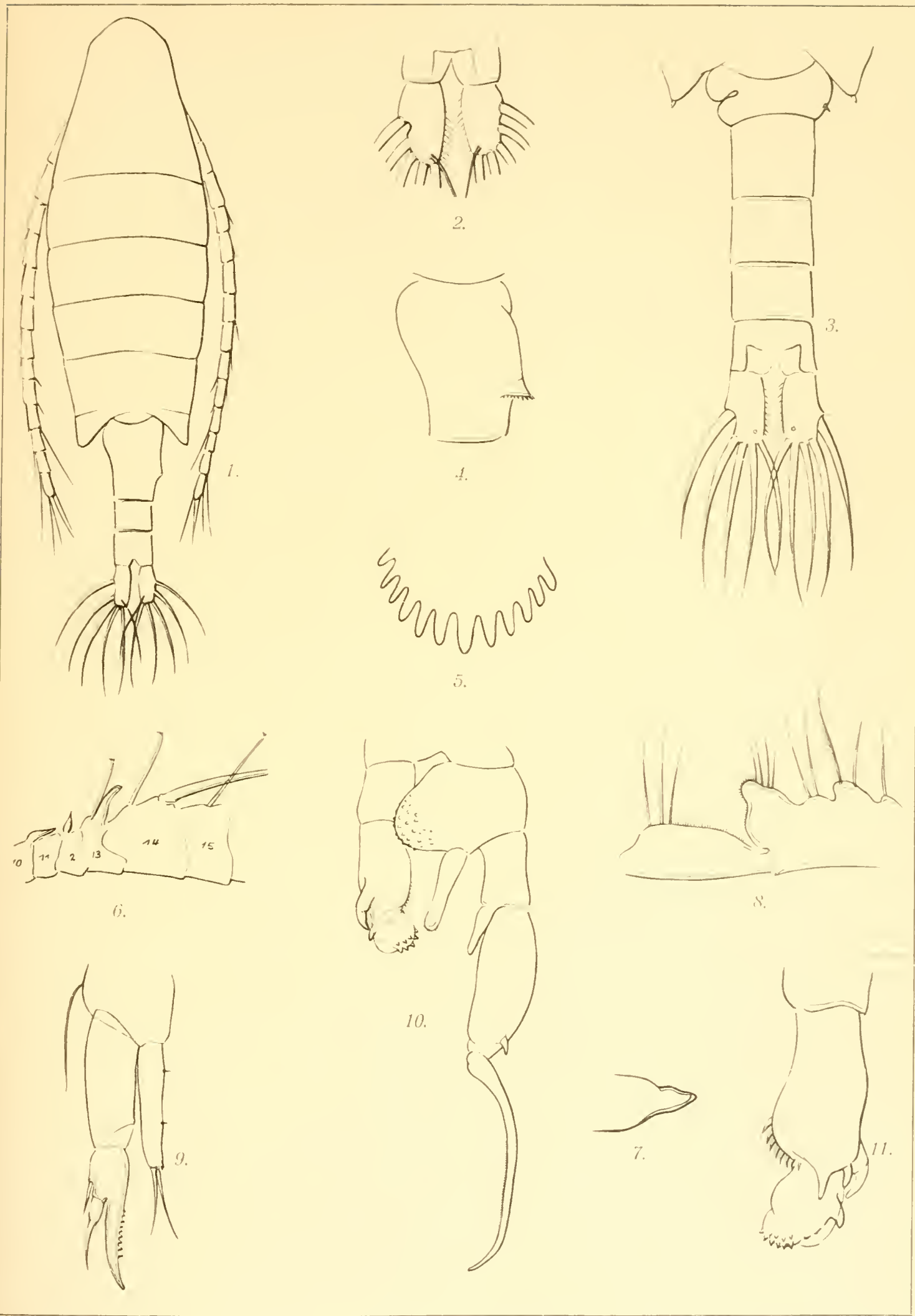





\title{
Skorpiones und Solifugae
}

bearbeitet von

\author{
K. Kraepelin \\ (Hamburg).
}

Mit 6 Abbildungen im Text. 



\section{Skorpiones.}

Die ersten Nachrichten über Skorpione Deutsch-Südwestafrikas verdanken wir Karsch, der im Jahre 1879 (2) ') zwei „Lepreus"-Arten (Uroplectes) aus dem mittleren Teil des Gebiets beschrieb, die im Zoologischen Mnseum in Berlin eingegangen waren. Unsere heutige Kenntnis der Skorpionenfauna der Kolonie stïtzt sich, abgesehen von mehr gelegentlichen Aufsammlungen, die ihren Weg in die europäischen Museen bezw. in das der Capstadt fanden, vornehmlich auf die Ausbeuten dreier Forschungs-Expeditionen, die im Laufe der letzten zwei Jahrzehnte ron den Herren H. Schixz, Leoxilard Schilltze und W. Michaelsex unternommen worden. Scrixz bereiste das ganze Gebiet von Angra Pequena bis zum Lande der Mossamedes im Norden und weit in die Kalahari im Osten im Auftrage des Herrn Lё̀enitz während der Jahre 1884-86. Seine SkorpionenAusbeute wurde 1887 von E. Smox (3) bearbeitet, der 7 nene Arten beschrieb, deren eine allerdings mit einer bereits ron Karsci benannten identisch ist. Auch Leoxharo Schultze, dessen Reise in die Zeit ron 1903 bis 190 j fällt. sammelte außer in einem großen Teile des deutschen Kolonialgebiets in den südlich und östlich sich anschließenden Ländern; das von ihm zusammengebrachte IIaterial an Cliederspinnen, das ich 1908 (15) bearbeitete, muß als außergewöhnlich reich bezeichnet worden und gibt mit seinen 13 Skorpionen-Spezies zum erstenmal pin verhältnismäßig klares Bild iiber den Formenreichtum disser Gruppe und über deren geographisehe Verteilung in den weiten Landschaften Deutsch-Südwestafrikas. Die letzte Forschungsreise, die von W. Mrchaelsex, fällt in das Jahr 1911: ihre Ausbeute, in weit kürzerer Zeit zusammengebracht als die der früheren Expeditionen, ist nicht ganz so reich, als die Schutrzesche, rhöht aber die Zahl der Arten auf 16. so daf wir heute, unter Hinzurechnung von 5 durch andere, gregentliche sammler im Grebiete beobachteten weiteren Arten, die Gesamtzahl der in der Kolonie sicher rertretenen Arten auf 222)

1) Die Zahlen verweisen auf die Literatur am scchluß.

$\left.{ }^{2}\right)$ Es ist vielleicht der Hinweis von Interesse, daß annähernd ebenso viele skorpionenarten auch in Deutsch-Ostafrika vorkommen. Während aber die deutsch-südwestatrikanischen 
bemessen köunen. Das in den bekannteren und kultivierteren Teilen des Landes diese Kahl bei weiterer Durchforschung noch erheblich steigen werde, ist kaum anzunehmen. Dagegen läßt sich erwarten, daß in den istlichen, an das Betschuanaland anstobenden Gebieten noch manche der Kalahari eigentümliche Formen sich finden werden, wie dies die Reise P'extmers (13) und der Vorsto B Leoniand Scurltze's in das Betschmanagebiet wahreheinlich machen. Ebenso dïrfte der bis fast zul den Victoriafällen nach Osten sich erstreckende Caprivizipfel noch einige der in Ostafrika verbreiteten Gattungen (Opisthacanthus, Cheloctonus) und Arten beherbergen.

Die skorpionenfauna Dentsch-Südwestafrikas schlioßt sich nng an diejenige des Kaplandes an, ist aber rrheblich artenärmer. Namentlich der Oranje-Flub scheint fiir viele Arten des Kaplandes die Nordgrenze zu bilden. Swhen wir ab von der Gattung Cheloctonus, die, wie ich vermute, irrtümlich fï̈ Deutsch-Sïdwestafrika angegeben wurde, so handelt es sich nur um die 5 Grenera Buthus, Parabuthes, Uroplectes, Upisthophthalmus und Hadogenes, wrehe — mit Ausnahme von Buthus — das Zentrum ihrer Verbreitung im Kaplande haben, wonngleich die meisten von ihnen namentlich im Osten des Kontinents mit einzelnen Formen noch weit nach Norden gehen. Wic solur vom süden her die Artenzahl in den verschiedenem Gattungen abnimmt, rrhellt am besten aus dem Beispiel der Gattung Oprsthophthalmus, die im Kaplande durch otwa 25-30 Arten, in Dentsch-Siidwestafika aber nur noch durch 8 Arten und am nördlichsten Punkt ihrer Verbreitung, in Deutsch-Ostafrika, gar nur noch durch 2 Arten vertreten ist. Ahnlich liegen die Verhältnisse bei der Gattung Uroplectes. - Dir unsere Kolonir bewohnenden Arten sind nur zum kleineren Teil mit denen rom Kaplande oder denen ästlicherer Gobiote identisch; die größrre Hälfte besteht aus Formen, die für D) utsch-südwestafrika spezitisch sind oder doch nur wenig nach Sïden, Norden oder Osten über dessen Grenzen hinatıorrifen.

Wie der Oranje-Fluß augrnscheinlich schon für eine ganze Reilse ron Formen des Kaplandes die Nordgrenze ihrer Verbreitung darstellt, so zeigt sich rine writere Abnahme der Artenzahl von Sïden nach Norden auch innorhalb unseres sïdwestafrikanischen Kolonialbesitzes selbst. Für das Grob-Namaland, als den sïdlichsten Tril der Kolonie, sind in ganzen bishrer 16 Arten von skorpionen nachgewiesen, fïr den mittleren Teil, also das 1) amaraland, 11 Arten (von diesen nur 5 Arten identisch mit den

Arten sich auf nur 5 Gattungen verteilen, lositzt Deutsch-Ostafrika deren 10. Beiden Gebieten gemeinsam sind die Gattungen Buthus, I'arabuthus, lroplectes und Opisthophthalmus; die Arten sind sämtlich verschieden. 
siddlichen Arten), während aus dem Orambo-Lande im Norden bisher nur 2 Arten als die letzten nördlichen Ausläufer der überreichen südafrikanischen Fauna vorliegen. Die - übrigens recht formenarme Charakterfauna des tropischen Westafrika mit ihren Babycurus- und Pandinus-Arten dürfte kaum erheblich über die Kongomündung nach Süden reichen und sendet jedenfalls keinen Vertreter bis in das Gebiet Drutschsüdwestafirikas.

In folgenden gebe ich eine Aufzählung der im Gebiete bisher nachgewiesenen Arten, unter Beifïgung der zurzeit bekannten Fundpunkte. Morphologische und systematische Bemerkungen haben dabei nur insoweit Aufuahme gefunden, als sie eine Frgänzung unserer Kenntnisse bringen.

\section{Fim. Buthidae.}

\section{Gen. Buthus Leach.}

\section{Buthus aremaceus Pure.}

Ton der in fast ganz Afrika verbreiteten, im Sïden aber äußerst seltenen Gattung Buthus ist nur die Kümmerform des zuerst aus dom Klein-Namalande von Purcels beschriebenen B. arenaceus in unserer Kolonie nachgewiesen und zwar bei Gibeon im Groß-Namalande.

\section{Gen. Parabuthus Poc.}

Die Zahl der in Deutsch-Südwestafrika bis jetzt beobachteten Parabuthus-Arten beträgt 7, von denen 4 ausschlieflich dem sudlichen Gebiet. also dem Gr. Namalande angehören.

\section{Parabuthus laevifrons (Sim.).}

Der Verbreitungsbezirk dieser zuerst ron Schusz (3) gesammelten Art scheint ziemlich beschränkt zu sein, da er bis jetzt nur das Grob-Namaland im Süden unserer Kolonie und die nördlichsten Teile des Kl. Namalandes etwa bis zum $29^{\circ}$ s. Br. umfaßt. Durch Schuctze sind als Fundorte im Gr. Namalande Kubub und Lüderitzbucht bekannt geworden. 


\section{Parabuthus gramulatus (I. E.).}

Diese Art gohört in erster Linie dem westlichen Kaplande an, wo sie etwa ron $33^{\circ}$ s. Br. auftritt und bis in das Kl. Namaland häufig ist. Aus dem dentschen Gobiet hat sie augenscheinlich in der Scminz schen Sammlung schon Simox vorgelegen, der sis als Buthus fulvipes neu beschrieb (3); doch hat dieser Autor es leider unterlassen, bei der Besprechung der einzelnen Arten die genaueren Fundorte beizufügen. Ein noch sicherer Bewris des Vorkommens dieser Art in dem suidlichsten Teile unserer Kolonic ist ein Exemplar (우 jur.) im Museum der Kapstadt (nach Purcell, 14, p. 172). Immerhin dürfte der Skorpion doch recht selten sein, da weder Schulize noch Mranaelsen ihn innerhalb der Landesgrenzen erbeuteten.

\section{Parabuthes renedus (Sim.).}

Über diese dritte Paraluthus-Art, welehe Smov aus der Ausbente von Schisz beschrieb (3) und ihr Verbreitungsgebiet herrschte lange Zeit Unklarheit, da, wie brmerkt, Sison es versäumte, speziellere Fundorte anzugeben, rine Nachprüfung der Art aber unmöglich war, weil das Originalrxemplar nach brieflichen Mitteilungen ron Sinos und Scmnz in Verlust geraten ist. Erst die Ausbente von Scmutze aus der Kalahari machte uns mit einer Form bekannt, die der Beschreibung des Simos'schen B. raudus im wesentlichen entspricht, so daß auch für das Scunnz'sehe Exemplar die Kalahari, also das im Osten unserer Kolonie gelegene Betseliuanaland, als wahrscheinlicher Fundort zu gelten haben wird. Daß dic Art aber von jenem mehr östlichen Zentrum ihrer Verbreitung auch nach Westen bis in Innere unserer Kolonie hinein vordringt, bewrist ein Exemplar des Hamburger Museums, welches bei Gibeon im Gr. Namalande gesammelt wurde.

\section{Parabuthus capensis (II. E.).}

Der echte I'. capensis (H. E.), der lange Zeit mit dem P.planicanda Poc. des siidlichen Kaplandes verwechselt und von Purcelu 1901 (14) als $P$. neglectus neu beschrieben wurde, ist, gleich dem P. granulatus, vorachmlich oin Bewohner des westlichen Kaplandes, wo er vom Worcoster- und Tulbagh-I)istrikt, also ctwa rom $33^{\circ} \mathrm{s}$. Br., bis in das Klein Namaland hinein ungemrin verbrritet ist. Im deutschen Gebiet, also nördlich des Oranje-Flusses, seheint er äuberst selten zu sein, da keiner der Erforscher unsorer Kolonie ihn erbentete. Nur im Inseum der Cap- 
stadt wird nach Purcell (14, p. 158) ein junges Weibchen aus dem Gr. Namalande aufbewahrt.

\section{Parabuthus krcepelini Werner.}

1902. Parabuthus kraepelini Werner, Die Skorpione, Pedipalpen und Solifugen in d. vergl. anat. Samml, d. Univers. Wien, in: Verh. zool.-bot. Ges. Wien, 1902, p. 599.

1908. Parabuthus flavidus Kraepelin, (non Poc.) 15, p. 254.

In meiner Bearbeitung der Skorpione in L. Schultze's Forschungsreise (15) habe ich diese Art mit dem P. flavidus Poc. (1899 in: Ann. Nat. Hist. (7) III p. 419) aus dem Betschuanalande identifiziert, dem sie jedenfalls sehr nahe steht. Nachdem aber Hewit (Records of the Albany Mus. II p. 300, 1912) daranf hingewiesen, daß der P. Havidus Poc. höchst wahrscheinlich dem I'. mosambicensis (PTRs) aus dיm Osten entspricht und ich dieser Ansicht beipflichten zu sollen glaube, wird es notwendig, fiir die im mittleren Teile unserer Kolonic verbreitete Form den Werner'schen Namen $P$. kraepelini wieder zur Geltung zu bringen. Ihre wesentlichsten Unterschiede von $P$. mosambicensis ( $=P$. flavidus Poc.) habe ich in der Arbeit über die Scuultze'sche Ausbeute (15, p. 249 und 256) unter P. Havilus mihi (non Pocock) gegeben.

Ob der $P$. kraepelini ïber die Gronzen Deutsch-Südwestafrikas nach Osten hinausiericht, läßt sich heute noch nicht feststellon. Innerhalb des Gebietes ist er bisher fast ausschließlich im mittleren Teile gefunden und zwar bei Gr. Windhuk, Neudamm, Okahandja, Swakopmund (Schultze, Michaelsex). Das Hamburger Museum besitzt auch ein Exemplar von Namutoni im südlichen Orambolande, so daß sich eine Gesamtverbreitung vom 23 . bis zum $190^{\circ} \mathrm{s}$. Breite erguben wïde.

\section{Parabuthus brevimamus (Thor.).}

Wenngleich Thorflu als Heimat dieser Art in seiner Beschreibung von 1877 (1, p. 113) "Caffraria“, also eine Landschaft im siidosten des Kontinents angibt, so kann es doch wohl keinem Zweifel unterliegen, dab sic ganz ausschlieflich der W'estkiiste Südafrikas angehört, wo sie, in der Nordwesteckeder Kapkolonie, dem Gr. Buschmannlande, beginnend, wahrseheinlich ganz Deutsch-Südwostafrika rom Siiden nach Norden durchzieht und schließlich erst als P. cristatus Poc. (1901 in: Ann. Nat. Hist. (7) VII p. 284) im Kongo-Gebiot die Nordgrenze ilurer Verbreitung tindet. Die für unsere Kolonie vorliegenden Beobachtungen entsprechen zur 
Zeit noch nicht ganz der hier ausgesprochenen Vermutung: Alle von Schultze und Micnaelsex gemachten Funde stammen ausschließlich aus dem mittleren Teile des Gebietes (Umgegend ron Windhuk, Brakwater, IV aldau.)

\section{Parabuthus villosus (Ptrs.).}

Diese ungemein stattliche und charakteristische Art schließt sich in ihrem Verbreitungsbozirk genau an die rorigo Art an, indem auch sie vom Gr. Buschmannlande im Süden über Deutsch-Südwestafrika und Penguela bis zum Kongo im Norden (teste Pocock) brobachtet wurde. In Deutsch-Südwestafrika ist sie bisher nur ans dem südlichen und mittleren, nicht aber auch aus dem nördlichen Teile bekannt geworden, wie die Fundorte Kubub, Kuibis, Walfisch-Bay, Windhuk, Usakos, Okahandja (Nonutze, Michaelsen) beweisen mögen.

Von bereits beschriebenen Arten, die möglicherweise in unserer Kolonie noch heimisch sein könnten, kommen einmal die beiden noch im Süden des Oranjeflusses im Kl. Namalande verbreiteten P. calvus Purc. und P. schlechteri Punc. in Betracht, sodann die dem Betschuanagebiet und dem weitren Osten angelörigen P. mosambicensis (PEт.) und P.transvaalicus Punc. (= P. pachysoba Pentner und P.obscurus Pexther).

\section{Gen. Uroplectes Ptrs.}

Die Formen der Gattung Uroplectes wird man zweckmäßig zunächst in zwei Gruppen teilen können, deren eine durch 11-12 Schrägreihen des bewoglichen Fingers und nur einkieligen Truncus, deren andere durch nur 8-9 Schrägreihen des bewoglichen Fingers und mehr oder weniger deutlich dreikielignn Truncus (neben dem Mrdianuskiel des Abdomens jederseits rin abgekürzter Seitenkiel) ansgezeichnet ist. Von der ersten, rocht artenreichen Gruppe, deren Hauptverbreitungsgebiet teils im süden, trils im Ostrn des Kontinents liegt, belrerbergt, unsere deutsch-südwestafrikanische Kolonie anscheinend nur 2 Arten, nämlich dio beiden leicht unterschridbaren $U$. vittatus und $\zeta$. otjimbinguensis; die zweite, wohl nur 3-4 gut unterchiedene Arten mufassende Gruppe ist allein vertroten durch den vermutlich zusammengehörigen Formenkreis des U.planimames - L . carinatus, wiihrend $U$. variegatres (mit Doru unter dem Stachel) und $U$. pilosus (untere Iredialkiel, im 1.-4. Cendalsegment vïllig fehlend) ausschlieBlich dem Kaplande angelhoipen. 


\section{Uroplectes rittatus (Thor.).}

Diese von Thorell (1, p. 121) 1877 zuerst aus dem .Kaffernlande“ beschriebene Art, scheint vor allem dem Südosten des afrikanischen Festlandes anzugehören, da sie auch von der Delagoabay und Transvaal bekannt geworken ist. Sie ist dann suäter aber anch für die westliche Kalahari nachgewiesen, und das Hamburger Musemm besitzt auch Exemplare aus dem mittleren und nördlichen Trile unserer Kolonie /Okahandja und Oramboland). Immerhin dürfte der Skorpion in Deutsch-südwestafrika zu den Seltenhriten gohören.

\section{Croplectes otjimbinguensis (Karsch).}

Im Gegensatz zu den bis an den indischen Ozean reichenden Verbreitungsbezirk der vorigen Art scheint der borrits 1879 ron Karsch (2, p. 125) beschriebene $\zeta$. otjimlinguensis ganz anf Deutsch-südwestafrika und zwar anf dessen mittleren Teil, das Damara- oder Hereroland beschränkt zu sein. Neuerdings wurde die Art wieder bei Usakos und Swakopmund ron Michaelsex erbeutet.

\section{Uroplectes plamimamus (Karseh).}

Dir bereits in der Bearbeitung der Schtzze schen Skorpionenausbeute $(16$, p. 259) ron mir gestreifte Frage, ob $U$. planimanus und carinatus vielleicht nur extreme Glieder eines großen, zusammongehörigen Formenkreises seien, wage ich auch heute noth nicht zu entscheiden, da hierzu ein wit reicheres Material aus allen Crebieten des Verbritungsbezirks gehört, als es mir zur Verfiigung steht. Hält man vorläutig daran fest, daß alle Formen mit lang sichelförmigem Kammgrundzahn des of als $U$. planimanus, alle diejenigen aber, bei denen dieser Kammgrundzalıu entweder ron gewöhnlicher Beschaffenheit oder nur stark rordickt, nicht aber verlängret ist, als $C$. carinatus aufzufassen sind, so mïssen folgerichtig die von Purcel (14, p. 175) neuerdings besehribbenen Formen I. alstoni, kurrooicus, schlechteri, denen ich 1908 15, p. 257) noch einon mediostriatns hinzufügte, sämtlich dem Formenkroise des $U$. carinatus zugerechnet werden. Nach dem mir vorliegenden Material ist os mir aber recht zweifelhaft, ob ein solche Zweiteilung das richtige trifft: ich relmute vielwehr, daß man später. rom typischen $U$. carinatus mit unvrändertrm Kammgrundzahn als Stammform ausgehend, alle Formen mit verindertem Kammgrundzahn — sowohl die mit verlängertem, wie die mit rerbreitertem — als von jener sich

8 Itichaelsen, Deutsch-Suidwestatrika. 
ableitend und einander nalse stehend betrachten wird. Dic hier gebranchten Artbezeichnungen können demnach nur als provisorische gelten.

Der typische $U$. planimanus Karsen mit lang sichelförmig gestaltetem Kiammgrundzahn des of, platten, verbreiterten Händen, geringer Körnelung der seiten des 4. und 5. Candalsegments etce otc., selreint ganz auf das Crebiet ron Dentsch-Südwestafrika beschrïnkt zu sein, das er rom Gr. Namalande im Süden bis in den Norden des Damaralandes bewolnt. Als Fundorte, von denen mir Belegexemplare Schultze's bezw. Michaelsex's vorliegen, nenne ich: Kertmanshoop, Kubub, Grootfontein, Windhuk, Noudamm, Kuibis, Okahandja, Rohobot, Omaruru, T'sumab, Owikokorro, ()sire.

Die Originalexemplare ron Karscu sind rinfarbig gelbrot; in der Regul aber zeigt der Truncus drei mehr oder weniger stark ausgeprägte Längsbinden, denen dann auch oft eine dunkle \%eichnung auf den Cephatothorax, an den Kanten der Beine ete untspricht. Die Kahl der Kammzähne schwankt beim or von $22-29$, beim 오 von $20-27$.

\section{Uroplectes carinatus Poc.}

Der typische $U$. carinatus mit auch in den crsten Candalsegmenten gek̈̈rnten unteren Medialkiulen und nicht umgeformtem Kammgrundzahn beim of gehört wohl ausschlieblich dem Kaplande an und dürte nieht in das Grbiot von Dontsch-südwestafrika hincinreichen. Dagegen hat Scuutze von Lüderitzbucht rine Form heimgebracht, die ich seiner Zeit (15, 1908) als $L$. carinatus karrooicus J'vrc. bezeichnete, sowie rine andere aus dem siidlichen Hererolande, die mir dem $U$. carinatus schlechter $i$ Perc. zu int-prechen scheint. Anch dir von Sicurtutze nur für die Kalahari nachgewirsene, von unir $U$. carinatus mediostriatus genannte (15, p. 257) Form ist inzwischen im mittleren Toil unseres Gobiets (Okasise, Ojosondyombo, Owikokorero, beobachtet worden. Nach dem untor U.planimanus Gesagton, möchte ich fast glauben, dab disse drei, durch kurzen, breiten

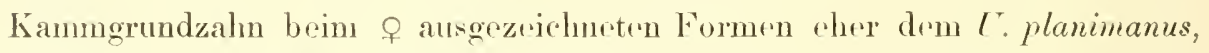
als dem $U$. carinatus anzureihen sind, falls sich iiberhaupt rine Trennung beider Arten aufrecht relialten läbt.

Die ron mir im "Tierreich" (12, p. 59) gentachte Angabe, daß auch der. U. triangulifer Thos. in Dontsch-südwestafrika hemisch sei, berulit aller Wahrscheinlichkeit nach auf einer irrtümlichen Fundortsangabe der mir vorliegenden Stïcke. Vermutlich ist die Art durchaus auf das siidöstliche Afrika (Port Elizabrth, Basutoland, Transraal) beschränkt. 


\section{Gen. Opisthophthalmus C. L. Koch.}

Obgleich die Gattung Opisthophthalmus nördlich des Kaplandes sehr schnell an Artenzahl abnimmt (rgl. S. 108), so ist sie mit ihron 8 zum Teil indigenen Arten doch dir artenreichste skorpionengattung unserer Kolome. 5 von diesen Arten scheinen ausschlieBlich dem süiden des Gebiets anzugehören.

\section{Opisthophalmus opinatus (Sim.).}

Schixtz erbentete zuerst diese Art und zwar im Lande der Mossamedes, jenseits der Nordgrenze unseres Gebiets. Erst durch Mrchaessex wurde sie für Deutsch-Südwestafrika aus der Umgegend von Windhuk und Rehobot festgestellt. Da mir auBerdem noch pin Exemplar von Gibeon im Gr. Namalande vorliegt, so ist das Vorkommen der Art durch das ganze Gebiet wahrscheinlich.

Beim o sind übrigens die Rückenplatten des Abdomens fein granuliert, nicht fein nadelstichig und glatt, wie ich im ,Tierreich" (12, p. 130) auf Grumd des mir vorliegenden 우 angab. Auch ist beim of die Handbreite nur etwa abenso groß wie die Länge der Hinterhand.

\section{Opisthophthalmus wahlbergi (Thor.).}

Wie beim Parabuthus brevimamus (Thor.) der von Thorel (1, p. 112) auf Wahlbergs Autorität hin angegoben, Fundort, ,Caffraria" wahrecheinlich auf einem Irrtum beruht oder nur ganz allgemein für ,Siidafrika" zu nehmen ist, so gilt dasselbe auch für den O. uhlbergi, dessen V'rrbreitung augenscheinlich ebenfalls auf den Westen suidafrikas beschüinkt ist. Percelu (10, p. 139) erwähnt sein Vorkommen südlich des Oranjeflusses im Gr. und Kl. Buschmannlande. In Deutsch-Siidwestafrika aber ist er von IV armbad im äußersten Süden (Schutrze) bis Rehobot und Osire im I amaraland beobachtet worden.

\section{Opisthophthalmus ravinatus (Ptrs.).}

Diese Art hat wohl den größten Verbreiterungsbezirk ron allen Opisthophthalmus-Arten, da sie rom Busclımannlande im Suiden etwa bis zum $15^{\circ}$ s. Br. nach Norden geht, und dabei keineswegs auf den Wraten des Kontinents beschränkt ist, sondern sicher nach Osten durch die Kalahari bis Rhodesia und weiter sich verbreitet. In Dentsch-südwestatrika gehört sie zu den häufigsten Formen, namentlich im mittleren T'ril des $8^{*}$ 
K. Kraepelix.

Gebiets. Ton sicheren Fundorten neunc ich: Gibcon, Grootfontein, Windhuk, Okahandja, Okasise, Omaruru, Neudamm und Tsumab.

\section{Opisthophthalmus schult:ei Krpl.}

Diese ron Scuultze entdeckte Art $(15, \mathrm{p} .262)$ ist bisher nur aus dem Sïden des Gebiets brkannt und zwar von Kubub.

\section{Opisthophthalmus modulatus Kipt.}

Die Art wurde mit der vorigen ron Sculduze (16, 1. 263) bei Kiubub im Gr. Namalande erbeutet.

\section{Opisthophthalmus intercedens lippl.}

Auch diese Art ist bisher nur vou $\mathrm{K}$ ubub durch Scoutcze (15, p. 265) bekannt geworden.

\section{Opisthophthalmus flacescens Pure.}

Das einzige Exrmplar, welches Puncell 1898 (9, p. 7 ) bei seiner Beschreibung vorlag, stammt von der Walfisch-Pay. Auch Scuutuze hat ein Exemplar von drmselben Fundorte heimgebracht. Daneben besitzt das Hamburger Inseum noch ein Exemplar von Ababis aus dem Hererolande. Die Art dürte also, gleich den 3 vorhergehenden, streng indigen sein.

\section{Opisthophthatmus gigas Pure.}

Dieser Skorpion brwolnt nach Purcell (9, p. 7; 10, p. 155) zunächst weite Gebiete suddich des Oranje-Flusses (Kenhardt Division, Kl. Nama land und Gr. Buschmannland), reicht aber anch in den Süden unserer Kolonic hinein, wie die Fundorte Warmbad (Prresus) und Kuibis Micmaelsen) bewrisun.

Von andern Formen siidlich des Oranje-Flusses, deren Verbreitung sich vielleicht noch bis in den süden unserer Kolonie erstreckt, kommen in Betracht: O. ater. granifrons, pallipes, schlechteri, granicande und peringuei, dir sämtlich bereits für das Kl. Namaland naehgewiesen sind. Von östlichen, durch Pextuar bereits im Britisch-Betschuanaland beobachteten Arten sind $O$. macer und $U$. glatrifrons zu nemurn, die möglicherwoise von der Kalahari her bis in das deutsch-siidafrikanische trebiet vordringru. 


\section{Gen. Hadogenes Krpln.}

Die Arten dieser Gattung erscheinen noch nicht genügend geklärt, um die bisherigen Fundortsangaben ohne Nachprüfung zur Festlegung ihrer geographischen Verbreitung verwerten zu können. So weit ich bis jetzt zu urteilen vermag, kommen in Deutsch-südwestafikika 2 Hadogenes-Arten vor, die ich als $H$. taeniurus (Thor.) und H. tityrus (SIn.) bezeichnen zu sollen glaube.

\section{Harlogenes themimms ('Thor.).}

Als Vaterland dieser Art gibt Thonel 1, p. 258) bei seiner Beschreibung nur ,Sïdafrika" an, doch stammt das Uriginal wohl, wie Purcelt (14, p. 206) andentet, von Damaraland. Die Art dürfte rorwiegend, wenn nicht ausschließlich, dem Westen des Kontiuents angehören, da sie von H. troglodytes (PTRs.) sicher spezifisch verschieden ist (glatte Blase, geringere Kammzahl). Das Hamburger Museum besitzt Exemplare, die rermutlich zu dieser Art gehören, rou Ababis im Hererolande, so daß ihr das Bürgerrecht in unserer Kolonie dadurch gesichert erscheint. Die ron Schutrze bei Kamaggas im Kl. Namalande erbeuteten Exemplare hingegen. welche ich rordem (15, p. 267) hierher rechnete, sind wahrscheinlich als Tertreter riner neuen Art aufzufassen. Die Formen der Gattung sind aber zurzeit so wenig geklärt, daß ich darauf rerzichten will, die schon jetzt vorhandene Unsicherheit durch Aufstellung neuer Arten zu vermehren.

\section{Harlogenes tityrus (Sim.).}

E. ist wohl anzmehmen, daß die Originalexemplare dieser von Scmxz zuerst heimgebrachten Art innerhalb des Gebietes unserer Kolonie gesammelt wurden, wenngleich Suov $(3$, p. 383) dies nicht ausdriicklich hervorhebt. Nachdem dann Scurctze zahlreiche Exemplare bei Kubub im Gr. Namalande erbentete, und auch ein vom Kaiser Wilhelm-Berg bei Windhuk stammendes Exemplar im Landrsmuseum zu Windhuk als H. tityme bestimmt werden muBte, ist das Vorkommen der Art in DeutsehSüdwestafrika außer Zweifel gestellt. Es ist sogar wahrscheinlich, dab wir in ihr eine rein indigene spozies unserer Kolonie zu erblicken haben.

Die Gruppe der Pedipalpi ist bisher in Deutsch-siidwestatrika noch nicht nachgewiesen. 


\section{Literatur.}

1. 1877 Thorell, Th.: Études scompiologiques in: Atti Soe. Ital. v. 19.

2. 1879 Karscu, F. : Skorpinologisehe Beiträge in: Mt. Münch. entom. Ver. v. 3.

3. 1887 Sinox, E.: Arachnides recueillis dans le sud de l'Afrique par le docteur Schinz in: Ann. Soc. ent. France (6) VII p. 369-384.

4. 1890 Pocock, R. J.: A Rerision of the genera of Seorpions of the family Buthidae in: Proc. Zool. Soc. 1890, 1. 114-141.

5. 1891 Kraepelis, K.: Revision der Skorpione I. in: Mt. Mus. Hamburg VIII.

6. 1894 Krafreun, K.: Revision der Skorpione II in: Mt. Mus. Hamburg XI.

7. Pocock, R. J.: (On the Species of the South African Scorpion Opisthophthalmus contained in the Collection of the British Museum in: Ann. Nat. Hist. (6) XVI p. $233-248$.

8. 1896 Pocock, R. J.: A further Revision of the Species of Scorpions belonging to the South African Gencra Uroplectes, Lepreus and Tityolepreus in: Ann. Nat. Hist. (6) XVI p. 377-393.

9. 1898 Percel, W. F.: Descriptions of new South Atrican Scorpions in the Collection of the South Afr. Museum in: Ann. South Afr. Mus. I p. $1-32$.

10. 1899 Purcelt, W. F.: On the Species of Opisthophthalmus in the collection of the South African Museum in: Ann. South Afr. Mus. I p. $131-180$.

11. 1899 Purcell, W. F.: Now South African Scorpions in the collection of the south African Museum in: Ann. South. Afr. Mus. I p. 433-438.

12. 1899 Krafperax, K. : Scoppiones ot Prdipalpi in: „Das Tiorreich". Lief: 8.

13. 1900 P'extmer, A.: Zur Konntnis der Arachnidenfauna Südafiikas (Scorpiones) in: Ann. K. K. Naturh. Hofmus. Wien XV p. 153-163.

14. 1901 Percell, W. F.: On some South African Arachuida belonging to the orders s'corpiones, Pedipalpi and Solifugae in: Ann. S. Afr. Мus. II P. $137-225$.

15. 1908 Kranelewa K. : Skorpione und Solifugen in: L. Scunltzes, Forschungsreise in westl. und zentralen Sïdafrika 1903-1905. Jena, G. Fischer, 1). $247-282$. 


\section{Solifugae.}

Unsere Kenntnis der Solifugen-Fauna Deutsch-Siidwestafrikas ist noch juingeren Datums als die der Skorpionenfauna: Im Jahre 1899 konnte ich (1) ${ }^{\mathrm{y}}$ ) auf Grund des mir ron versehiedenen Museen zur Bestimmung überwiesenen Matrials 7 für die Wissenschaft neue Arten aus dem in Rede stehenden Crebiet beschreiben und 2 Jahre später im .,Tierreich" (Lief. 12, Palpigraden und Solifugen) im Ganzen 13 Arten als zur dentsch-südwestafrikanischen Fauna gehörig aufführen. Etwa um dieselbe Zeit, 1899 bis 1903, erhielten wir durch Ptrcell in einer Reihe ron Arbeit'n (2, 3, 5) Aufklärung ïber die Solifugenfauna des Caplandes, wobei auch gelegentlich Fundorte aus unserer Kolonie Berïcksichtigung fanden. Noben manchen bereits früher beobachteten Arten lieferte daun die Ausbeute von Leoxhard Schultze (6) aus den Jahren 1903-1905 zwei fïr unser Gebiet neue Arten, und noch ergiebiger in dicser Hinsicht war dip Studienroise Mrchaflsen: im Jahre 1911, so daß wir heute, unter Hinzurechnung einiger weiterer, mehr gelegentlich den Sammhngen ron Berlin und Hamburg zugeflossener Eingänge, die Gesamtzahl der in Deutsch-Südwestafrika nachgewiesenen Solifugen auf nindestens 23 beziftern kömnen. Bei der Hurtigkeit und der näehtlichen Lebensweise vieler solifugen ist jedoch anzunehmen, daß diese Zahl bei weitrer Durchforschung des tiebiets noch erheblich wachsen wird.

Ahnlich der Skorpionentauna schlielst sich auch die Solifugenfauna Deutsch-Siidwestafrikas eng an dirjenige des Kaplandes an. deren Reichtum sie cbenfalls bei woitem nicht erreicht. Die Galcodiden fohlen ganz: aus der groben Familie der Solpugiden sind der Solpuginae, ganz wie im Kaplande, nur durch die Gattung Solpuga vertreten, während aus der Subfamilie der Dapsiinae und Karschiinae die Gattungen Duesia, Bloxsia, Gluviopsis, Lipophaga (=Pseudoblossia) und Ceroma namhaft zu machon sind. Die Gattung Hexisopus als Vertreter dor lamilie der Hexisopiden ergänzt den Bestand dex Gattungen, der sich somit im ganzen auf 7 boüuft grgen etwa 12 des Kaplandes. Alle 7 Gattungen von Deutsch-Siidwentafrika sind anch im Kaplande vertreten. Von den in letzterem ciebiet bisher beobachteten 66 Arten kommen 9 auch in unserer Kolonie ror, die damelben dann noch etwa 14 indigene Arten besitzt. Innerhalb der Kolonie tretru die solifugen namentlich im (irob. Namalande und in Damaralande auf,

1) Die Zahlen verweisen auf die Literatur am schlub der Arbeit. 
während sir nach Norden ganz außerordentlich an Artenzahl abnehmen. Nördlich ron Dentsch-Süidwestafrika, also in Angola, den Kongostaaten, Kamernn etc. entlang der ganzen Westküste des Kontinents bis Marokko, sind Solifugen fast umbekannt. Nur ein einziges o einer Solpuga-Art (S. Intleri) ist ron Pocock aus dem Kongogebiet beschrieben worden; doch kann es sich hierbei sehr wohl mu Verschleppung oder irrige Fundortsangabe handown, zumal die Art nit rincr in Ostatrika verbreiteten identisch zu sein seheint. Von den 6 in Deutsch-Ostafrika vertretenen solifugen-(iattungen sind + mit denen Deutsch-Ostafikas identisch, nämlich Solpuga. Maesia. Gluviopsis und Ceroma: die Arten aber sind sämtlich verschieden. Der Zusammenhang brider laumen wird zweifellos durch den Limweg iiber das Kapland vermittelt.

Bei der nachfolgenden Aufzählung der bisher im Gebiete beobachteten Arten wird es sich, soferu nicht nene Arten zu brschreiben sind, vornehmlich um eine Aufzählung der aus den Forschungs-Expeditionen, sowie aus dem Material der Museen zu Berlin und Hamburg sich ergebenden Fundorte handeln. Dem Museum zu Berlin bin ich fïr freundliche Darleihung des in Betracht kommenden Matrials zu lebhaftem Danke verptlichtet.

\section{Fam. Solpugidae.}

\section{Gen. Solpuga A. Licht.}

Gegenüber den otwa 30 Solpuga-Arten drs Kaplandes (einschließlich Transval) ist die Fauna Deutsch-Südwestafikas arm zu nemen. Immerhin dürfen wir schon heute etwa 12 Arten dieser Gattmg als Biirger unserer Kolonie in Anspruch nehmen, d. h. also ïber die Hälfte aller bisher im Gobiete beobachteten Solifugenformen.

\section{Solpuga lethalis C. Koch und s. remator Poc.}

Diese beiden häufigstrn Vertreter der gewaltigen, lrhmgelben Solifugen Sïdafrikas werden am besten gemeinsam besprochen, da sie morphologisch und geographiseh sehe enge Bezichmogen zueinander zeigen.

Was zunächst ilne Unterscheidungsmerkmale betriftt, so beschränken sir sich bei den 9 , wie ns scheint, ganz ausschließlich daranf, daß bei S. lethalis der dorsale Oberkiefertinger 2 \%wisehenzähne zu tragen pflegt, 
bei S. venator aber nur einen. Da nun gar nicht so ganz selten der eine Oberkiefer eines Individumms nur einen, der andere aber zwei Zwischenzähne zeigt, so ble bt es in diesem Falle dem Ermessen des beobachters ïberlassen, ob er von einer S. lethalis mit einseitig verkïmmertem ersten Zwischenzalın sprechen soll, oder aber von piner S. venator, bei welcher einseitig noch ein rudimentïrer erster Kwischenzahn zur Ausbildung gelangt ist. Etwas gliicklicher liegen die Terhältnisse bei dem o . In betreff der Zwischenzähne - ob jederseits 2 oder jedersoits 1 oder endlich einerseits 2 , andererseits 1 - herrseht allerdings bei ihnen dieselbe Variabilität wie bei den of: allein die im typischen Falle recht ansgeprägte Verschiedenheit dos Flagellum wird in der Regel rine sichere Bestimmung ermöglichen: Dasjonige von $S$. lethulis reicht mit sunem fragezrichenartig geschweiften Ende meist erheblich übor den Augenhïgel nach hinten und trägt kurz vor dem Ende einen spitzen Seitenzahn, während dasjenige von S. venator meist kaum bis zum Grunde des Oberkiofors nach hinten reicht und vor dem Ende kninen sirimzahn brsitzt. Wis sigillarien-artige Skulptur der Obertläche des Flagellum, die ich frïher anf S. lethalis brschränkt glaubte, findet sich in ähulicher Wrise auch ber s. venator. Leider variieren nun auch die im Obigen für beide Arten angegebenen Merkmale in verschiedener Richtung. So kann z. F. dio bogige Finsenkung des Flagellums ror dem Ende augenscherinlich bri briden Arten fast völlig fehlen, so daß dann der Verlauf des Flagollums auch in seinem Endtril fast völlig gerade ist: störender noch aber ist die augenseheinlich recht große Variabilitait in der Länge des Flagellum. Nehmen wir an, wie as ja wohl gerechtfertigt erscheint, dab der spitze seitenzahn vor dem Ende das eigentlich Charakteristische des lethalis-Flagellum sei, so miissen wir wohl oder iibel zugeben, daB os lethalis-Exrmplare gibt, deren Flagellum bei weitem nicht den Hinterrand der Mandibeln erreicht, andrerserits abor auch venator-Exemplare, deren Flagollum noch erhoblich äber den Augenhiigel zurickreicht. Es liche sich aber vielloicht auch die gegentrilige Auffassung vertreten, daß das Auftreten des siritunahines etwas moln Sekundäres soi, und daß man demnach eine Form mit auffallond langem Flagellum trotz des fehlenden soitenzahmes dennoch als S. lethalis, rime andere mit kurzem, aber ein Sejtenzähnchen tragendem Flagellum als S. venutor anzusprechen habe. Ich halte indes diese lotztere Auffassung nicht für richtig und bezeichm dementsprechend ein Exemplar der Hamburger sammlung wegen des beiderseits gut intwickelten seitenzahnos am Flagelhum als $S$. lethalis, obwohl dies Flagellum ungemein kurz und fast gerade ist, und obwohl in jedem der beiden dorsalen Oberkiefertinger nur 
ein einziger 'Zwischenzalın — bei einer allerdings auffallend großen Zwischenlücke - vorhanden ist.

Jedenfalls geht aus den vorstehenden Darlegungen hervor, daß die Unterscheidung beider Arten unter Umständen recht schwierig, ja beim bloßen Torlandensein von 오. gratezu mü̈glich soin kann. Ls werden daber auch Fundortsangaben iiber diese Arten immer mit einer gewissen Vorsicht aufzunthmen sein. Purcell sagt in seinen Schriften über die kapländischen solifugen (2, p. 409), daß man S. lethalis im allgemeinen als die westliche, S. venator dagegen als die östliche, in den Gebieten ohne Winterregen rorkommend" Art brzeichnen könne; nur im GroßBuschmannlande kämen beide miteinander vor. In Deutsch-südwestafrika liegen dic Verhältnisse sehon insofern anders, als hier Winterregen iiberhaupt nicht mehr auftreten. Soweit ich aus dem mir vorliegenden Material schlicßen kann, gehört S. lethalis hier mehr dem mittleren Gebiet, S. venator aber vornehmlich dom siiden an.

S. Iethalis liegt mir vor von den Fundorten: Ababis, Okasise, Okahandja, Windhuk, aber auch von Rehoboth und sogar von der spitzkoppe bei Keetmanshoop.

S. renator ist festgestellt bei Warmbad, C'hurutabis, Keetmanshoop, Kabus, Kuibis, Lïdritzbucht, Gibeon und Rehoboth.

\section{Solpuga monteiroi Poc.}

Diese auch ron der Delagoa-Bai und aus der Kalahari bekannte, in der Gröbe fast don beiden vorgenannten gleichkommende, aber schlankere Art ist in den mittloren Teilen mrserer Kolonie nicht selten. Als sïdlichster Punkt ihres Torkommens erseheint zurzeit Windhuk, dom sich nördlich die weitron Fundorte Okahandja, Okakena, Osire und Grobfontein auschlirßen. Die \& erkennt man, abgeschen von den 2 Zwischenzähnen im Oberkiefer, dem Fohlen der Zylinderborsten am Protarsus der Maxillarpalpen und der schmutzig gelbweiben Brhaarmg dos Abdomens, auch an dem meist gobriuntru Vorderrandr des Cophalothorax.

\section{solpuege schlerhteri Pure.}

Von dipser Art, wolchr 1899 von Pencele von Naroep in Grobbuschmanulande beschriolern wurde, ist bisher nur ein ơ bekannt geworden, das dureh dir Furm des Flagellums, dir stattliche Gioblos unel den

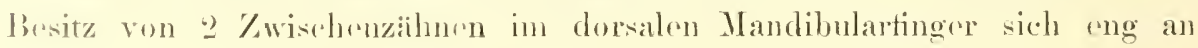


die S. serraticornis ron Rhodesia anschließt, aber der gestreckten bogigen Spitze des dorsalen Mandibularfingers entbehrt. Mir liegen num 2 o einer Solifugen-Art ror, und zwar eines ron Kuibis, ein zweites ans Lüderitzbucht, die durchaus der Beschreibung Perceuss entsprechen, mit der einzigen Abweichung jedoch, daß beide Exemplare nur einen Zwischenzahn im dorsalen Mandibularfinger besitzen. Bei der Variabilität, welche gerade diese Zwischenzähne auch bei anderen Arten zeigen (vgl. S. lethalis und venator), glaube ich dieser Abweichung von der typischen Form kein allzu großes Gewicht beilegen zu sollen und möchte daher beide Exemplare dem Formenkreise der S. schlechteri zuordnen. Erst ein reicheres Material wird die Entscheidung dariiber bringen können, ob diess Auffassung richtig ist.

\section{Solpuga leastata Krpln.}

Das einzige bisher bekannte or dieser Art stammt aus dem GrobNamalande olnne nähere Fundortsangabe.

\section{Solpuga chelicornis Licht.}

Fundangabe: Nord-Distrikt am Okawango zw. $10^{0}$ und $21 \frac{11}{2}{ }^{0}$ O. L.: v. Zastrow, 1912-1913.

Diese Art ist im Kaplande weit verbreitet und zwar von dessen südlichen Gebieten (z. B. Willowmore) bis in das Klein-Namaland. Aus Deutsch-Südwestafrika liegt mir nur ein einziges of vor, welches Herr v. Zastrow am Okawango im äußersten Nordosten unserer Kolonie im Eingange zum Caprivi-Zipfel erbeutete. Es ist dies zugleich der einzige Fundpunkt einer Solifuge im Norden von Deut-ch-südwestafrikat.

\section{Solpuga meripalisis Pure.?}

Obwohl die bisher nur im weiblichen (reschlecht brkannte Art ron Naroep im Grob-Buschmannlande durch dio Bezahnung des dorsalen Mandibularfingers recht gut charakterisiert erscheint, bin iell doch nicht ganz sicher, ob ein mir rorliegendes Solpuga-Weibchen ron Nuichas im GroB-Namalande mit ihr identisch oder nur nächst rerwandt ist. Ton den 3 winzigen Vorderzähnchen des dorsalen Mandibularfingers ist der 3. neben den 4., größeren gerïckt: linter letzterem folgen dann 3 winzige Zwischenzähne wie bei der Hauptform. Im ventralen Mandibularfinger ist ein Zwischenzahn micht erkennbar. 1)ie lange seidige Behaarung der Grundglieder des 4. Beinpaares erscheint zum größten Teil abgeschenert: 
die charakteristische zimmtbraune Berandung der Rückenplatten des Abdomens entspricht aber durehaus der Schilderung Purcelcs, ebenso die ungewöhnliche Küuze der Maxillarpalpen. Auch hier wird erst ein reicheres Material volle Klarheit bringen.

\section{Solpuga striatr I1. Sp.}

Fundangabe: Farm Voigtsland, ca. $38 \mathrm{~km}$ östlich von Windhuk; IV. Michablsen, 19. Mai 1911.

Nur mit Widerstreben entschließe ich mich, unter diesem Namen ein einzelnes Solpuga-lWeibchen zu beschreiben, welches Mucuaecsen auf Farm Voigtsland, $38 \mathrm{~km}$ ostlich von Windluk gesammelt hat. In Hinblick

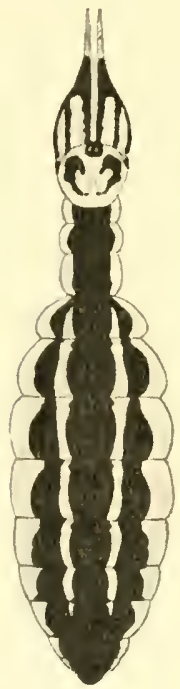

Fig. 1. auf die charakteristische Färbung des nur $11 \mathrm{~mm}$ (ohne Mandibcln) langen 'Tierchens kann es aber wohl keinem \%weifel unterliegen, daß wir es hier mit einer bisher noch unbeschriebenen Form zu tun haben. Die Mandibeln sind schmutzig gelbbraun mit je 3 dunkelbraunen Längsstreifen; dor Cephalothorax ist obenfalls gelbbraun, aber zu beiden seiten breit dunkellsaun beraucht, der Augenhiigel ist schwarz. Der Riicken des Abdomens zeigt auf schmutzig-lehmgelben Grunde 3 broite schwarze Längsstreiten, einen medianen und zwei laterale, die erst im vorletzten Segment zusammentließen (Fig. 1). Die Barchplatten sind schmutrig lo hmgelb, aber dic letzten 5 zeigen rine schware Berandung. Die Malleoli sind deutlich, aber ziemlich schmal braun berandet. Maxillarpalpen und Beine sind dorsal dunkelbraun, ventral in den Grundgliedern hell. Dor dorsale Mandibularfïnger ist nomal Solpugastriutan.s., \&, gebogen und bezalunt, mit nur winem Zwischenzahn. Tibia Körper von when; 6:1. und Protarsus des II axillarpalpus ohno Zylinderborsten, nur mit langen Fadenhaaren und Gabelhaaren besetzt. Geuitalplatten nicht nach hinten vorgezogen. - Cber die V'erwandtsehaft dieser Art mit andern Arten wird orst nach Auffindung des of ein sicheres Urteil zu gowinnen sein. Vielluicht schliebt sie sich an die Gruppe der S. laterulis an.

\section{Solmuga furcifera Kiplu.}

Jisse im männlichen (heschlecht durch ihr am Endr gabelspaltiges Flagellum aungezeichnete Art ist bisher nur innerhalb der Grenzen Dentsch- 
Sïdwestafikas brobachtet und zwar ausschließlich im Damaralande. Die 오 scheinen verhältnismäßig selten zu sein, wurden aber schon 1908 (6, p. 277) von mir beschrieben. Als Fundorte rermag ich anzugeben: Osire, Windhuk, Rohoboth, Walfisch-Bay, sowie, südliches Hereroland“.

\section{Solpuga sp. att: furciferce Кrplı.}

Fundangabe: Rehoboth: K. Wegeleben, Mai 1913. ? Okahandja: IV. Michaelsen, 27.-.28. April 1911.? Waldau, M. Michaelsex, 4. Juni 1911 .

Von Rehoboth liegt mir ein Solpuga-Wribchen vor, daß zwar in Größe und Färbung (Ritckenplatten des Abdomens schokoladenbrauu) mit S. furcifera übereinstimmt, aber doch vielleicht von ihr verschieden ist: der dorsale Oberkiefertinger zeigt nur einerseits 2 Zwischenzähne, wie S. furcifera, andererseits jedoch nur einen; auBerdem ist der Protarsus des Maxillarpus, im Gegensatz zu S. furcifera, mit zerstreuten Zylinderborsten besetzt. - Vielleicht gehört hierher auch je ein sehr jugendliches ㅇ von Okahandja und Waldau, die zwar der Zylinderborsten am Protarsus entbeluren, aber in jedem der beiden dorsalen Oberkieforfinger nur einen Zwischenzahm besitzen. Ob es sich bei diesen Abweichungen von S. furcifera nur um individuelle Variation handelt, oder aber um artliche Unterschiede, kann erst ein reicheres, auch Nännchen umfassendes Material lehren.

\section{Solpuga alcicomis 11 . sp.}

Fundangabe: Keetmannshoop: W. Krause, Aug. 1912.

Vou dieser im männlichen Geschlecht äußerst charakteristischen nenen Art liegt mir rin or und ein of ron Keetmannshoop vor, die Herr W. Krause gesammelt und dem Hamburger Muscum iiberwiesen hat. Die Färbung ist schmutzig hell rostbraun, die Mandibeln zeigen dorsal je z dunklere Streifen, auch die Maxillarpalpen und die Hinterbeine sind etwas dunkler braun. Der Truneus des o ist $17 \mathrm{~mm}$ laug, der des o $24 \mathrm{~mm}$. Der dorsale Oberkieferfinger des o ist vorn etwas bogig gekrümmt und trägt auf der Schneide 2 mäßig große Vorderzähne, nach größerer Zahnlücke einen winzigen Zwischenzahn und einen mäBig großen Hauptzahn, dem dann noch 3 kleine äuBere Wangenzähne folgen (Fig. 2 a). Ton den 3 inneren Wangenzähnen ist der erste sehr grob. Unterer Oberkieferfinger normal bezahnt, mit 2 Hauptzähnen und einem Zwischenzahn. 
Flagellum etwa über dem 2. Torderzahn inseriert und von hier aus schriig nach vorn gerichtet, dorso-ventral zusammengedrïckt, sich dann aufwirts wölbend und rerbreiternd, $u$ schlieBlich in 3 verschicden gestalteten Zipfeln zu enden, von denen zwei bogig nach hinten gerichtet sind (Fig. 2a Seitenansicht; Fig. 2) b Vorderansicht). Der rerbreiterte Teil

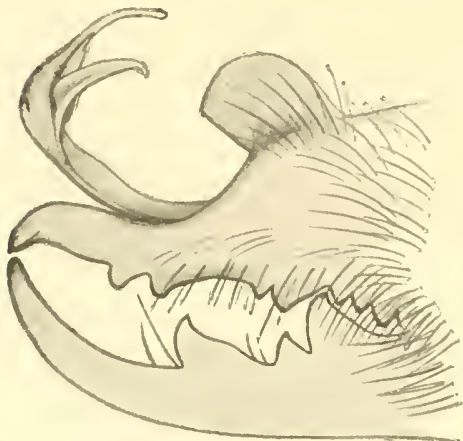

a)

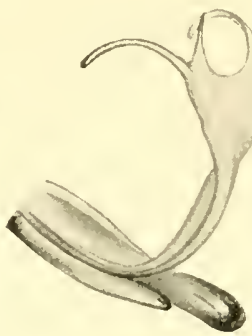

b)

Fig. 2. Solpuga alcicornis n. sp.

a) Mandibel des $\sigma$ mit dem Flagellnm von der Seite.

b) Flagellum von vorn.

borsten und längs der Mittellinie eine schmale Scopula. Dorsal stehen nur Borsten und Haare. - Dem of fehlen leider beide Maxillarpalpen, so daß über das Fehlen oder Vorhandensein ron Zylinderborsten nichts ausgesagt werden kann. In der Färbung gleicht es dem ơ; der dorsale Mandibulartinger besitzt nur 1 Kwischenzahn.

\section{Solpmer pieta Krpln.}

Die rigentïmlichen, kammförmig gestellten Keulenhaare am Metatarsus und Tarsus des 2. Beinpaares deuten darauf hin, dab wir in dieser Art einen von den übrigen Solpuga-Arten höchst abweichenden Typus vor Augen haben. Um so mehr ist es zu bedauern, dab das o noch immer nicht bekannt ist. Nur 2 우 mit dem Fundorte ,Damaraland" liegen bis jetzt vor, deren eines fast gleichzeitig mit der Veröffentlichung der S. picta von Purcell als S. nigrobraccata beschrieben wurde.

\section{Solpuga schult:ei Krpln.}

Auch von dieser, der S. picta durch den Busitz ron kammförmigen Keulenhalaren am 2. Beinpaar nächst verwandten Art ist bisher nur das 우 
in einem Exemplar bekannt geworden. Schutzze sammelte es bei Rooibank im Gebiet der Walfisch-Bay.

\section{Gen. Daesia Karsch.}

Von der bereits seit 1880 aus Nordafrika und den Kiistenländern des Roten Meeres bekannten Gattung Daesia stellte sich erst seit 1899 heraus, daß sie im äußersten Sïden Afrikas ein zweites Zentrum der Verbreitung unter Entwickehng einer ganzen Reihe eigenartiger Formen besitze. Von diesen sind zwei anch in Deutsch-Suidwestafrika sicher nachgewiesen, von denen eine indigen zu sein scheint, während die andere auch in der Kapkolonie auftritt.

\section{Daesia hottentotta Kipln.}

Dies ist bei weitem die häufigste Daesia-Art in unserer Kolonie; sie liegt mir namentlich aus dem Damaralande von zahlreichen Fundorten vor, verbreitet sich aber auch bis in das Groß Namaland. Zu nennen sind: Osire, Okahandja, Owikokorero, Waldan, Karibib, Usakos, spitzkopjes, Windhuk, Rehoboth, Hoachanes, Keetmanshoop.

\section{Daesia namaqua Kúpln.}

Diese Art wurde zunäclist aus dem Groß Namalande ron mir beschrieben. Später sammelte sie Scuutrze anch bei Steinkopf im Klein Namalande.

Ob Daesia kolbei Purc. von Bulawayo im Matabeleland wirklich in GroB Namalande rorkommt, wie ich im .Tierreich" (4, p. 97) angegeben, ist mir wieder zweifelhaft geworden.

Andrerseits ist es micht unwahrscheinlich, daß noch einige weitere südafrikanische Arten (D. pallida Ptrc, betschuanica KrPLx., schultiei KrPLx.) im Gebiet unserer südwestafrikanischen Kolonie anzutreffen sind.

\section{Gen. Blossia Sim.}

Von dieser Gattung gilt in erhöhtem Мaße, was über die geographische Verbreitung der Gattung Daesia gesagt wurde: Der einen, schon 
1880 ron Sisox beschriebenen nordafikanischen Art stehen heute fast ein Dutzend Arten aus dem siiden des Kontinents gegeniiber. Aus DeutsehSiidwestafrika kenne ich zur /eit nur 2 Arten, dir beide indigen sein dïrften.

\section{Blossia fulcifera Kiplu.}

Diese zuerst ron Áchulzz erbentete Art scheint in der Umgegend von Windhuk nicht selten zu sein. Auch ron Neudamm unweit Windhuk liegt sie mir ror und ebenso ron Tsinmab.

\section{Blossia fimbriata 11. sp.}

Fundangabe: Doutsch-siidwestafrika: r. Thotud (Mus. Berlin).

Ton dieser nemen Art liegt mir nur ein defektes o des Berliner Museums mit der Etikette "Dentsch-siidwestafrika, r. Trotua leg." vor. Obgleich die Maxilarpalpen folslen, glaube ich die Form wegen ilures

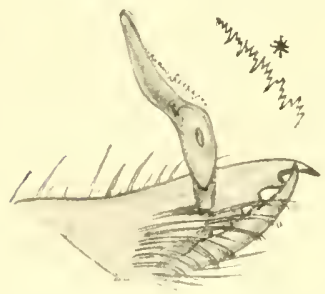

Fig. 3. Blossia fimbriata n. sp., Mandibel des $\sigma$ mit dem Flagellum von der Seite; bei * Randsaum des Flagellums stärker vergriißert. durchans cigenartigen Flagellums doch beschreiben zu sollen. Die Färbung der Mandibeln ist gelbrot, die dos Cephalothorax etwas dunkler, die des Abdominalriickrns golblich, aber braun ïberlanfen. Die Beine sind leellgalb, Frmur und Tibia des 4. Beinpares abre seitlich bloich schokoladenfarbig beraucht. Die Mandibeln sind dorsal mit Dornen besetzt, vorn mäBig gebogen und tragen auf der Fichuride 2 gleich grobe Vorduraihne, denen 1 kleiner Zwischonzalın, 1 gröberer Hauptzahn und 3 äuBerst winzigu Wangenzähme folgen. Die Zähne des ventralen Mandibulartingers sind niedrig. Das Flagellum ist gestreckt und rtwa iiber dem 4. Kahn inseriert, sehr beweglich und leicht aufrichtbar. Aus stilartigem crunde erweitert es sich zu rinem kurz flaschenförmigen, mit ovaler Oftnung rersehenen Hohlranm, der dann in rinen lang lanzottlichen, etwas geschweiften Endfortsatz auslänft (Fig. 3). An soincm rorderen liando int dieser Endfortsatz der ganzen Länge nach mit einem zarten, gofransten Saum besetzt (beim der liand:amm stärker reror.). D)e Cephalothorax trägt anf der Fäche kurze bornon, am Hinterrando rinrn Kranz von langen Dornen. Die Rürkruplatten des Abdomons sind am Hinterrande mit Querreilıen 
zarter Dornen besetzt. Am 2 und 3 Segment der Bauchplatten des Abdomens finden sich je 4 dicke, etwas gebogenen Fleischluorsten.

Ton südlich des Oranjefluß heimischen Arten, die vielleicht noch in unserer Kolonie zu finden wiren, sind B. clunigera Krws. und namaquensis Purc. zu nennen.

Die Gattungen Memiblossia und Melanoblossia des Kaplandes und der Kalahari sind bisher in Deutsch-Südwestafrika noch nicht beobachtet.

\section{Gen. Gluviopsis Krpln.}

Die von den Küstenländern des Roten Meeres bis nach Vorderindien verbreitete Gattung Gluviopsis wurde 1901 von Purcel. (3, p. 219) als auch zur Fauna siidafrikas gelïrig bezeichnet und zwar auf Grund oines einzelnen Individiums $\left(\sigma^{7}\right)$, das ihm ron Styrkraal sïdlich rom Orange-Fluf im Norden der Kenhart Division zugegangen war. Er hat dieses Exemplar als Gl. australis beschrieben.

Auch mir liegen 3 Exenplare ron verschiedenen Fundorten vor, die ich nur der Gattung Gluviopsis zurechnen kann, ohne indes, da es sich durchweg um Weibehen handelt, mit Bestimmtheit angebrn zu können, in welcher Beziehung sie zum $G$. australis Purc. stohen. Nur eines der 3 Exemplare dürte im Hinblick auf seine Färbung mit riniger Sicherheit als das of zu Prrcelus $G$. anstrulis or anzusprechen soin; iiber die stellung der beiden anderen glaube ich mich vorläutig eines absehließenden Urteils enthalten zu sollen.

\section{Gluviopsis anstralis Purc.?}

Fundangaben: Karibib; W. Mchaessex, 23.-26. April 1911.

Kalkfeld, nördlich ron Omaruru; W. Mrenaelsex, 5. Juni 1911 (rar.?, n. sp. ?)

Das mir vorliegende of ron Karibib mit $9 \mathrm{~mm}$ langem Truncus besitzt lehmgelbe Mandibeln' und Cephalothorax. Das Abdomen ist ebenfalls gelb, zeigt aber in den vorderen segmenten eine leichte Brïunung. Der Femur der Maxillarpalpen ist schwach berancht, die Tibia tiof dunkelbraun, während der Metatarsus, ganz, wie es PrRcell von seiner G. australis beschreibt, in den Grundzweidritteln luellgelb, im Enddrittel aber nebst dem Tarsus dunkelbraun ist. Die Beine sind lelmgelb, nur Tibia und 
Protarsus des 1. und des 4. Beinpaares blaß schokoladenfarbig beraueht. Dar normal gebogene dorsale Mandibularfinger trägt 2 starke Vorderzähno, einen mäßig großen Zwischenzahn und 1 großen Hauptzahn, dem dann noch 3 kleinere Wangenzähne folgen. Die inneren Wangenzähne sind groß. Im ventralen Mandibularfinger ist dor Zwisehenzahn kaum angedentet. Ier Angenhügel zeigt einen gelbrn Medianstrich und vorn neben 2 starken Cylinderborsten rinige kleinere Borsten. Die Tibia des Maxillarpalpus trägt an der Unterkante distal je 2-3 starke Dornen, zu denen wohl noch riner (beim rorliegenden Exemplar abgebrochen) in der proximalen Hälfte kommt. Der Mrotatarsus an jeder Kante rentral etwa mit 5 Dornen. Der eingliedrige Tarsus des 4. Beinpaares ist verhältnismäibig kurz.

Ein zweites o fon Kalkfold (nördlich von Omaruru) zeigt den Vorderrand des Cephalothorax etwas beraucht, dir freion Ringe des Cephalothorax und die Riickenplatten des Abdomens einfarbig bleichbraun, ziemlich seharf von der wrißgelben Bindehaut und der Unterseite abgesetzt; der Femur der Maxillarpalpon ist lehmgelb und nur am Ende gebräint, die Tibia ganz bramn, ebenso der Mretatarsus in der cirundhälfte, während die Endhälfte nebst den Tarsus wieder hollgelb sind. Die Färbung der Beine and dir Bezahnung der Mandibeln entspricht derjenigen des Exemplars ron Karibib; cobenso dir Bedornung der Tibia des Maxillarpalpus. Der

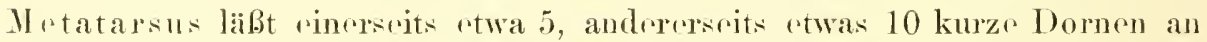
der Ventralseite erkennen. Ob es sich hier nur um eine Tarietit der arstbeschrioluenen Form handelt oder um cine solbständige Art, vermag ich bei der Unzulänglichkent des Materials nicht zu antschuiden.

\section{Gluviopsis sp.}

Fundangabe: Śwakopmund: Hekrx.

Sicher verschieden von diesen beiden Exemplaren ist aber ain drittes of von swakopmund mit sehokoladefarbenen Mandibehn und Cephalothorax, gellbrotem, an den Hinterräindern dunkelbraunem Abdomen und fast rinfarbig schekoladebraunen Vlaxillarpalpen (nur der Grund des Femur ist hell) und dunkel berauchten Beinen. Dio'Tibia des Daxillarpalpus trägt ventral nur 3 zarte Dornen nobst rinzehnen Cylinderborsten und langen Borstenlateren, der Mretatarsus ventral jederseits etwa 5 zarte Dornen. Der ringliedrige Tarsus des 4. Beinpares int rowa sechemal so lang wie breit, während or bei den besiden vorbesprochenen Exemplaren nur etwa riermal so lang wie breit ist. Der Kwischenzahn nach don beiden Vorderzähnen 
im dorsalen Mandibularfinger ist äußerst winzig und sitzt dem Hauptzahn dicht an, auf lutzteren folgt noch ein zweiter Hauptzalın. Der Zwischenzahn im ventralen Mandibulartinger ist ziemlich groß. - Bei der Unsicherheit der Stellung dirser Form glaube ith ron einer Namengebung absehen zu sollen, doch schien es mir immerhin angebracht, auf das Vorkommen solcher noch ungenïgend bekannter Arten hinzuweisen.

\section{Gen. Lipophaga Purc.}

Im Jahre 1903 beschriob Precelu (5, p. 10) dir Giattung Lipophaya mit der Art L. trispinosa rou der Malmesbury Division im Kaplande. In dieselbe Gattung gehört, wie ich mich jetzt iibresengt zu haben glaube, die ron mir 1908 (6, p. 280) beschriebene Psendoblossia sehultzei aus d'm Klein Namalande, die also dromgrmäb als Lipophaga schmltapi (KrpLx.) zul bezeichnen wäre. Beide bisher bekannte Formen besitzen in der Tat am Ende des 1. Beinpaares winzige klauen, dir allerdings nicht ïber den Haarbesatz herausragen. Das Flagellum des o fehlt; an dessen stelle finden sich nur einige stärkere Fiederborsten. Der Augenhügel trägt voru 2 starke Dornen. Der Metatarsus des 2. und 3. Beinpaares ist dorsal mit 4-5 Dornen besotzt; div einglirdrigen Tarson aller Beime haben unterseits nur Borsten, aber keine Dornen, dir Pulvillon am Grunde der Krallen sind winzig; die Mandibeln zeigen innenseits ausgeprägte stridulationsriefon. Metatarsus der Maxillarpalpen ventral mit Cylindroborsten. - Dic Gesamtheit dieser Merkmale läßt erkennen, daß dic Gattung in mancher Hinsicht zwisehen den Daesïnae und Karschionae die Mitte hält, so dab os sehwer zu cntacheiden ist, welcher von beiden sic zuzuordnen sri. 1)a ich nun auch noch bei anderen Gattungen der Daesiinae rudimentär" kirallen an Ende des. 1. Beinpaares beobachtet habe (z. B. beri Gluciopsis, so scheint es mir, daf die Frage nach der Existenzberechtigung dieser beiden von mir soiner Zeit (1, p. 206) aufgestellten Unterfamilien eincr arnenten Prïfung bedarf.

Wrenn die zwei bisher bekannten Arten der Gattung Lipophaga dem Kaplande angehören, so vermag ich jetzt noch iiber eine dritte Art zu berichten, welche Mrchasses in Dentsch-südwestafrika erbentete, und die ich ihm zu Ehren als L. michaelseni bezeichnen will. E- handelt sich 1 m rin o von Liuderitzbucht, dessen Beschreibung ich hier folgen lasse. Ob ein bei Okahandja gesammeltes of zu ihm gehör, wie ich rernute, muB ich vorläufig dahin gestellt sein lassen. 


\section{Lipopherge micherelsenti n. sp.}

Fundangaben: Liideritzbucht, W. Muchatesex, 5.-18. Juli 1911. (1 o'). ? Okahandja: W. Mrohasser, 27.-28. April 1911 (1 \&, fraglich, ob zu dem ơ ron Lïderitzbucht gehörig).

II ïnnchen.

Einfarbig gelbweib, nur die spitze der Mandibeln rot, und der Cephalothorax am Yorderrude dunkel beraucht: Abdomen, Naxillarpalpen und Brine weiggelb. Dorsaler II andibularfinger oberseits mit starken, z. 'T', abgestutzten (odra abgebrochenen?) Dornen, anf der ventralen Schneide mit sehr grobem, alle übrigen Zähne an Mäichtigkeit weit iibertreffenden Vorderzahn nahe der Spitze (Fig. 4), auf den dann 2 weitere kleine Vorderzähne, oin winziger Zwischenzahn und rin mäßBig grober Hanptzahn

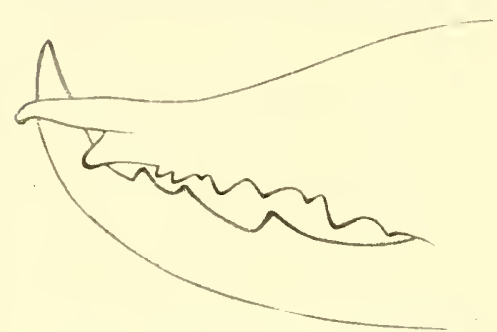

Fig. 4. Lipophaga michaelseni Mandibel des ơ". folgen. Der ventrale Mandibularfinger den dorsalen an Lünge iiberragend (wie bei L. trixpinose), mit 2 Hauptzïhnen und mäßBig grobem Zwischenzahn (Fig. 4). Cephalothorax auf derr Fläche mit kurzen Dornhöckern, an den Seiten mit längeren Dornen, am Vorderrande des 1. freien Thoraxsegments mit Reihe von etwa of langen Dornen. Rüickenplatten des Abdomens mit mur sparsamen Dornborsten besetzt, vornehmlich auf der Mitte der Segmente; die Rauchplatten dielit kurz weißborstig. Femur der If axillarpalpen rom mit rinigen längeren Dornborsten, die Tibia ventral mit 4-5 starken bornen (dir des proximalen Teiles bei dem rorliegenden Eximplar zum Teil abgubrocheny, der Mrotatsos ventral mit zahhreichen kurzen und langen Cylinderbursten zwischen langen geraden Haaren, dorsal mit kurzen und langen Borstenhaaren.

$$
\text { ? Wriluchen. }
$$

Bei dem viclleicht zu diesem or gehörigen of ron Okahandja ist der Cephalothorax anf der Fläche fein bram genetzt, und die vorderen liïckemplatten des Abdomens zeigen einen breiten brannen Mredianstreif, der in den hinteren Segmenten versehwindet: die Tibia des Maxillarpalpus crecheint am Grunde ctwas beraneht, ebenso an 4. Beinpar die Tibia am Grunde und der Fonur an linde. Im äbrigen zeigt das Exemplar das helle Letmegelb des or. Entsprechend dem wribliden Geschlechtscharakter sind Mandibeln und Gephalothorax nicht bedornt, sondern 
beborstet bezw. lang behaart; der dorsal. Mandibularfinger trägt auf seiner selmeide keinen durch Crröbe hervorragenden ersten Vorderzahn, sondern der 3. Vorderzahn ist der größte (Fig. 5); der ventrale Ilandibularfinger ist nicht länger als der dorsale. Die Tibia des Maxillarpalpus zeigt an der ventralon Gberkante 3 stiirkcre Borsten, dazu andere lange Borsten; der Metatarsus entspricht dem des $\sigma$.

Da nach dem Gesagten der von mir gewählte Name mit Sicherhoit nur für das or von Lüderitzbucht Geltung haben kann, so bin ich zurzeit auch nur in der Lage, die Männchen der drei nummelır beschricbenen Lipophaga-Arten in ihren Mrrkmalen scharf roneinander zu tremnen. Es mag hiorzu die folgende Ebersicht dienen. wobei zu bemerken, dab dir der L. schultzei sich natïrlich, gleich den ơ, ohne Nehwirrigkeit durch ilure gelbrote bis rostbrame Färbung rrkennen lassen.

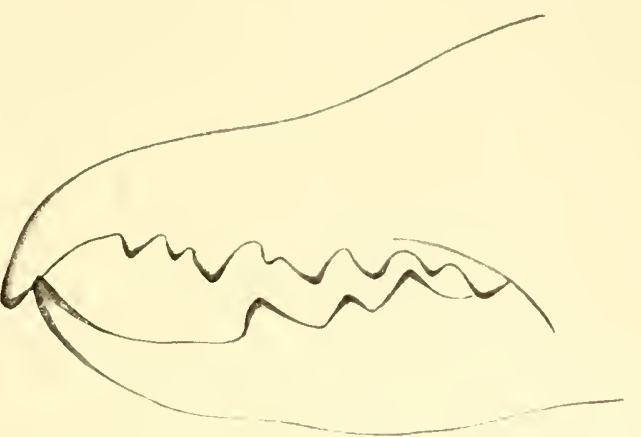

Fig. 5. Lipopharla sp. (michaelseni Krol.?) Mandibel des $q$.

A. Truncus und Gliedmaben gelbrot bis rostbraun. Dorsaler Mandibularfinger so lang wo der vontrale, in der distalen Hälfte völlig zahnlos, dir ersten dann auftretenden Kähne der sehnoide sehr winzig. Tibia des Maxillarpalpus rentral nur nit $2-3$ stäkeren Dornborsten. Kamaggas in Kl. Namaland. L. schultzei (Kripx.) o

B. Truncus und Glisdmaßen in der Grundfarbe bleichgelb, nur oberseits auf Cophalothorax. Abdomen und Naxillarpalpen manchmal otwas dunkel berauclit. Dorsaler Mandibulartinger deutlicl kürzor als der vontrale, fast bis zur spitze auf der schueide bezalint. Tibia des Maxillarpalpus ventral mit 3 oder 5 starken Dornem.

1. 1. Torderzahn des dorsalen Mandibulartingers seler grob und dick, weit grïßrr als dir proximal darauf folgenden Zähne (Fig. 4). Abdomen und Gliedmaben rein woibgolb, nur dor cephalothorax an Vorderrand. dunkel berauclit. 'Tibia des Maxillarpalpus in der Mitte ventral mit as starken Dormen, denen am Grunde noch z kleinere folgen; dazwischen in der Endhälfte zahlreicho lang Kylinderborsten.

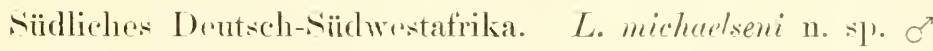

II. 1. Vorderzahn des dorsalen Mandibulartingers nicht gröbrer als der dritte. Cephalothorax, Rïekenplatten des Abdomens 
und Endglioder des Maxillarpalpus stark beraucht, auch Femmer und Tibia der Beine an den Seiten. Tibia des Maxillarpalpus im distalen Ende ventral mit 3 starkon Dornen, aber ohne lange \%ylinderborsten. Malmesbury Division in Kaplande. T. trispinosa Penc. o

\section{Gen. Ceroma Karsch.}

Die Gattung Ceroma gohört vorwiegend dem siidon des afrikanischen Kontinents an, goht jedoch im Osten bis etwa zum Aquator nach Norden. In Deutsch-südwestafrika ist mit Sichorheit bishrer nur eine Art beobachtet worden, der ich noch eine zweite, bisher unbeschricbene Art hinzufïgen kanu.

\section{Ceroma inerme Purc.}

Ton dieser Art sind bisher nur 2 o bekannt geworden und zwar von drer II alfisch-liay.

Coroma sclateri Pure., dessen or aus dem Südrn des Kaplandes beschrieben wurde, wird schwerlich in Dontsch-siidwestafrika heimisch scin. Das von mir im ,'Tierroch" (Lief. 12, p. 133) hirrher gerechnete o aus drm Damaralande dïrfte wohl riner andern Art angehören.

\section{Ceromar forliti n. sp.}

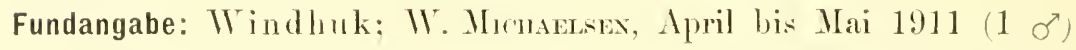

Von dieser Art lisegt mir zur Kait mur ein or ron Windhuk ror, das iols zon Ehren des um die Erforschung der dortigen Fauna hochrexdienten Herrn In. Foek in (1kahandja benenne. Dir Färbung der Man-

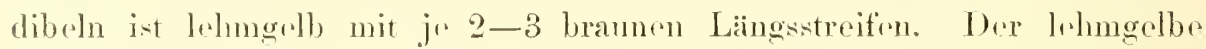
Cephalothorax ist vorn und an den seiten bran brraucht, dor Augenhiiget scluwarz. I)as Abdomen epsehrint dorsal grameglb, doch sind die hinteren Iriickemplatten an den seiten dunkler umsäunt, und auch dis Mittellinie

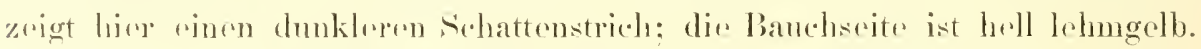
1) ar Fromur der Maxillarpalpen ist loll und nur an distalen Ende etwas brrancht, Tibia, Mrtatarsus und Tarsus sind rinfarbig dunkel. Die Schenkel der linine sind lonll, dir iibrigen Gilinder dorsal und auben schokoladen-

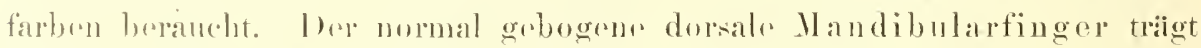

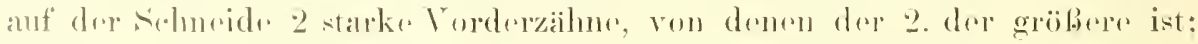

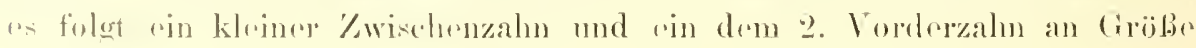


nahe kommender Hauptzalın, dem dann noch 3 kleinere Wangenzähne folgen (Fig. 6a). Das Flagellum, weleles etwa itber dem Zwischenzahn inseriert ist, erweitert sich aus kurz stilförmigem Grunde schnell zu einem breit keulen- oder kolbenförmigen Gebilde, das distal sich allmählich wieder rerjïngt und schließlich mit einor kurz hakenförmigen Abwärtsbiegung endigt (Fig. 6b.) Das ganze Gebilde lat, namentlich ron außen gesehen (Fig. 6a), wo seine Insertion nicht sichtbar ist, otwa die Form rime schinkenkenle: as wird in seiner Lage dureh mächtige Dornen festgelialten, ron denen 3 anf der dorsalen Firste des Mandibularfingers (Fig. 6a) das Ausweicluen des Flagellums nach auBen, rin noch erheblich stäkerer,

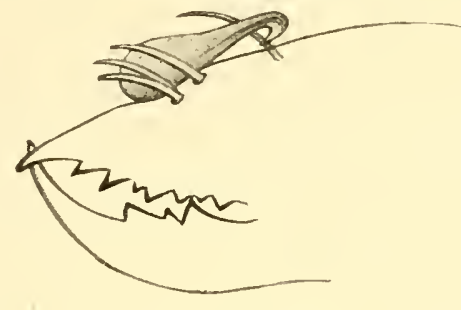

$a$.

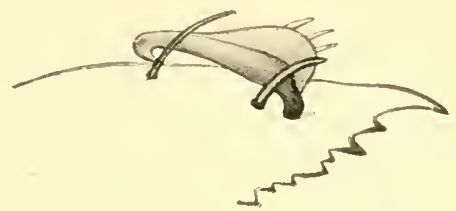

b.

Fig. 6. Ceroma focki n. sp.

a) Mandibel des $\sigma$, von außen gesehen.

b) dorsaler Mandihularfinger des $\sigma^{\top}$ mit dem Flagellum, von innen gesehen.

auf der Innenfläche der Mandibularfiache rntepringender, nebst einem entfrent davon stehenden schwieheren, das Ausweichen nach innen verhindern (Fig. 6b). Ton rinem ähnlichen Frstlegungs- oder Schutzapparat lerechtet Pocock schon bei C. pallidem ans dem Klein Namalande, doch ist er hior, wie auch das Flagellum. wesentlich anders gestaltet. Der rentrale Mandibulartinger trägt zwischen 2 Hauptzähnen oinem ziemlich grofen \%wischenzahn. Frmur. Tibia und Metatarsus der Maxillarpalpen sind mit kurzen Borstenhaaren und dazwischen mit langen Haarborston besotzt: Dornen und Cylinderborsten fiblen. Der Pulvillus dre Endtarsen ist fast bis zum Grunde gespalten. Längi des Truncus $10 \mathrm{~mm}$. 


\section{Fall. Hexisopidate.}

\section{Gen. Hexisopus Karsch.}

Von don sonderbaren und höchst seltrnen /lerisopus-Arten sind bisher 3 in merrer siidwestafrikanischen Kolonic beobachtet worden: d. h. nahezu die Hälte dor bishre aus der Familie (mit Einschlub der Gattung Chelipus) ïbrihanjt beschriebrnen Arten.

\section{Hexisopues mignolemates lippln.}

Bisher ist mur 1 o aus dim Damaralandr bekannt geworden.

\section{Hexisopus infuscatus lippln.}

Bisher mur 1 o von der Walfiscli-liay.

\section{Hexisopus lanatus (C. L. Koeh.)}

Diese aucle der Fauna des Kaplandes angehörige Art, bewolunt das Grof.) Namaland unserer Kolonie. Mir liegen Exemplare von Keetmansloopl und Kabus vor.

\section{Literatur.}

1. 1899 Kraepelux, K.: \%ur Systematik dop Solifugen in: Mt. Mus. Hanburg XVI, p. $197-258$.

2. 1899 Procele, W. F.: Now and little known Soutl African Solifugan in the Collection of the South African Musenum in: Ann. Sonth Afr. Hแ.. I, 3, 1). 381-432.

3. 1901 Pukcels, W. F.: On some South African Arachnida belonging to the Orders Scorpiones, Pedipalpi and Solifngae in: Ann. Soutle Afr. Mик. II, 6, p. $137-2 \cdot 24$.

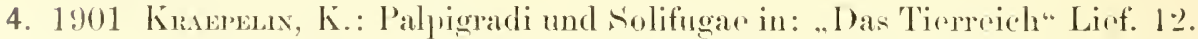

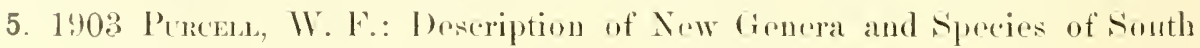
African Solpugidae in: Ann. Soutle Afr. Mus. III, 1, j’ 1-12.

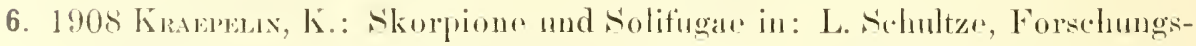
reise im wrstl. und zontr. Südafrika 1903-05. Jrna 1908, 1. 247-282. 


\section{Oligochaeta roll}

\section{W. Michaelsen}

(Hamburg).

Mit 1 Tafel, 6 Kartenskizzen und 1 Abbildung im Text. 

Es sind bisher keine Oligochäten von Deutsch-Sïdwestafrika bekannt geworden. Das in den folgenden Blättern erörterte, meist von mir selbst, zum Teil auch auf meine Anregung von Freunden meiner Bestrebungen gesammelte Material bildet mit 16 Arten den Grundstock einer OligochätenFauna Dentsch-sidwestafrikas. Wenngleich auch von vornherein anzunelimen ist, daB unsere Kolonie mit ihrer Armut an konstant Wasser enthaltenden Ortlichkeiten eine nur sehr spärliche Oligochäten-Berölkerung buherbergen kann, so dïrfen wir ihre Oligochäten-Fauna doch nicht als durch diese 16 Arten erschöpft ansehen. Zumal die Nordkante mag im Bereich ilurer konstant fließenden Grenzflisse, des Kumene, des Okawango und des Sambesi, noch manche weitere Art aufweison. Ton dem liezirk des Sambesi, der Nordkante des östlichen Caprivi-Zipfols, dürfen wir dies so gut wie sicher ammehmen. Ich habe eine sohr kurze Strecke vom Ostende des Caprivi-Zipfels entfernt, ca. 50-70 Kilometer flubabwïts, am Ufer des Sambesi, oberhalb der Victoria-Fälle bis zur Insel Kandahar zahlreiche Oligochäten (6 Arten) gefunder. Es ersehieno sonderbar, wonn diese Arten hier gerade ilne westlichste Vurbreitung fänden. Es ist nicht zweifelhaft, dab sie sich, wenigstens zum grobten Toil, auch noch die 50 Kiloweter weiter am Sambesi entlang verbreiton, also auch im dentechen sambesi-Bezirk vorkommen. Da wir demuacls diese Arton fast sicher auch als deutsch-südwestafrikanische ansolıen diurfen eino dersolben, Gordiodrilus Luylerleni, ist auch in Drutsch-Sïdwestafrika im Watroberg-Bezirk gefunden worden), so habe ich sie in der folgenden Zusammenstellung der Oligochäton Deutsch-südwestafrikas mit aufgofuilut. Fraglich ist es andererseits, ob wir auch ron einigen im nördlichsten Kaplande, also nahe der Nüdgrenze unseres Gebiotes gefundenen Arten vormuton dürfon, dab sir auch in unserer Kolonie gefunden werden möchten. Es handelt sich hirrbei nu zwei Vierochaetus-Arten, also typisch kapländische Formen, die bei Kamaggas in kilein-Namaland gefunden worden sind. Hirser Fundort ist, wenn auch nicht weit rom Oranje-Fhib, also der deutsch-südwestafrikanischen Grenze entfernt, doch durch vollstaindiges Trockenland von dieser Grenze getrennt. Hier liegen die l'rebreitungsverhältnisse also ganz anders als an Sambesi, wo dio Lfor des Flusses einen kontinuiorlichen Fonchtand- 
Streifen, also eine luicht gangbare Verbreitungslinir darstellen. Beror nicht der sichere Nachweis des Torkommons einer Microchuetus-Art in dentseh-südwestafrikanischen Gebiet erbracht ist, miissen wir Klein-Namaland als die nördliche Grenze dieser Gattung, und damit des siidafrikanischen Terrikolengebietes, answhen.

Wir durch Aufnahme der Rhodesia-Oligoehaiten die geographische Grenze, die diesem Wreke gesetzt ist, nicht ganz genau inne gehalten wurde. so wird durch Anfinahme dreier Meeresstrands-Arten die biologische Cirenzer etwas iiberschritten. Hiese ()liguchäten des Meeresstrandes hätten eigentlich in dem Schwesterwerkr, ,Beiträge zur Kenntnis der Meeresfauna Westafrikas," brhandelt werden müssen. Eine Sonderung dieser marinen oder, violleicht bosser gesagt, euryhalinen ()ligoehäen von den Land- und Siisswasserformen ist jedocel nicht ratsam, handelt es sich doch wahrscheinlich nur um junge Anpassungen urspriuglich kontinentaler, aber zugleich euryhaliner Tiere an eine nahrungseiche, aber durch den Wechsel des Aalzgelaaltes für die meisten kontinentalen Tiere unzulängliche und deshalb nur geringe Konkurrenz zulassende Ortlichkrit. Das geht sehon daraus hervor, dab die meisten der in Frage kommenden Arten Gattungsgenossen in kontinentalen Ortlichkeiten bexitzen, wenn sio nicht gar selbst, wio Enchytraeus albidus Hexise und Lumbricillus limeatus (MïLl.), anch in terrestrischen oder sübwassereörtlichkeiten vorkommen. Auch gehen diese Formen anseheinend nicht in betrichtliche Mrerestiefen, sondern halten sieh an die Nähe der Kiisten, wenn sir nicht geradezu an den Meeresstrand mit sinem Dotrituswall gobunden sind. $\left.{ }^{1}\right)$ Hinzu kommt, daß die Kahl der in Frage kommenden marinen oder euryhaliuen Arten so gering ist, daf. sich dio Behandlung in einer Sonderarbeit kaum lohnen wiirde.

Die Anfügung der marinen Oligorhäten an die kontinentalen und ihre Veräfientliehung in den .. Beiträgen zur Kenntnis der Land- und SibBwasserfauna Deutech-Südwestafikas" hat cine writrer Folge. Bei der Beschrankung dieses Trerkes auf dio Grenzen moseres südwestafrikanischen Selntzgobietes and bei strenger Innohaltung dieser Grenzen würde ein Kamerumer Moresstrands-Oligochä, Micheelsene Mengeri n. sp., gewissermaßen ., nnter den Tisch fallen". Lum dies zu vermeiden, füge ich die Beshohreibung dieser Art und die Eriorterung über Art und Gattme als Anlo ang an diese Arbeit an.

1) Fine Znordnung gewisser Meeresstraudstiere zu den Verwaulten rom Lande und rom sibwasser wird in diesen Werke anch bei anderen Tiergruppen. z. 13. bei den Oniscoiden orlar Landasseln, vorgenommen werilen.

Anmorkung des Herausgebers. 
Mit Einschluß jener am mittleren Sambesi nachgewiesenen Arten, die zweifollos wrnigstens zum größten Teil, wenn nicht simtlich, auch im doutschen Sambesi-Distrikt anzutreften sein werden, erhalten wir folgende Liste deutsch-südwestafikanischer Oligochäten:

\section{Niridirlae.}

Paranais multispinus 11.sp., aquatil, Windhnk-Bez., endemisch? Gattung weltweit rerbreitet. Nais pseudoobtusa (Pıgter) var.? aquatil, Windhuk-Bez, weit verbr., Gattung fast kosmopolitisch. Aulophorus africanus 11. sp., aquatil, Windhuk-Bez. u. Gr. FisclifluB, endemisch? Gattung weltweit verbreitet.

\section{Tubificidre.}

Limnodritoidles Winckelmamni n. sp., marin, S.- bis M.-Küstenbez., endenisch? Gattung weit rerbreitet (Mittelmeer).

Limnodrilus alpestris Eısex, aquatil, Grootfontein-Bez., weltweit verbr., Gattung fast kosmopolitisch.

\section{Enchytraeidae.}

Lumbricillus verucosus (CLAP.), marin., S.-Kïstenbez., weltweit verbreitet (N.- U. S.-Atlantik), Gattung fast kosmopolitisch.

Michaelsena georgiana (Mru.), marin, S.-Küstenbez., weit verbreitet (Süd-Georgien), Gattung weltweit verbreitet.

\section{Allmeirlinar.}

Alluroides tanqanuikae Bew口, amphibisch, Sambesi-Bez., weit verbreitet (Tanganyika), Gattung tropisch-ostatrikanisch.

$$
\text { Acanthodrilinae. }
$$

\section{Megascolecialar.}

Microscolex phosphorens (Axr. Dr.s.), terrestrisch, Windhuk-Bez.. peregrin, weltweit verschleppt. Trigastrinae.

Dichogaster Annae (Hows), terrestrisch, Waterberg- n. Okahandja-Bez., pergrin, tropisch W.-Afrika, Comoren, Jara. Ocnerodrilinae.

Gordiodritus Luykerleni (Мıсн.), amphibisch, Sambesi u. Waterberg-Bez., mäBig weit verbreitet, Gattung tropisch-, west- bis ost-afrikanisch.

Gordiodrilus Chuni Mur., amphibisch, sambesi-Bez., endemisch, Gattung tropisch-, westbis ostafrikanisch.

Oenerodritus occidentalis FisEx, amphibisch, Gr. Fischthß-Bez., peregrin.

Pymaeodritus rhodesiensis Mrch., amphibisch, Sambesi-Bez., endemisch, Gattung tropischbis gemäßigt-ostafrikanisch.

Pygmaeodrilus arausionensis Mici., amphibisch, Grootfontein-Bez., ziemlich weit verbreitet (Oranje-Kolonie), Gattung tropisch- bis gemäBigt-ostatrikaniseh. 
Eudritinae.

Matydrilus Altmes Mucm., terestrisch, Sambesi-Bez., endemisch, Gattung tropiseh-afrikanisch. Vemertodritus Kellueri Mucu, terrestrisch, Oranje-Fhß-Be\%, in geringem Jaße peregrin (Oranje-Kolonie), Gattung tropisch- bis sïdlich-suhtropisch-afrikanisch.

Criodrilinae.

\section{Glossoscolecirlae.}

Alme sp., aquatil, Sambesi-Bez., Gattung tropisch- bis nördlich subtropisch-afrikaniseh.

\section{Lumbricirlae.}

Ilelodilus caliginosus (S.w.) f. trapezoides (Axr. Dic.), terrestrisch, L'sakos, Kuibis, peregrin, fast kosmopolitisch.

Ielodvilus subulicundu: (Kisex), terrestriseh, swako],mund, peregrin, weltweit verschleppt. Ilelodrilus pareus (Essix), terrestrisch, Windhuk, peregrin, fast kosmopolitisch.

\section{Geographisches.}

Jir vorliegende Abhandlung ïber die Oligochäten Deutsch-Siidwestafrikas bildot den Abschlub rincre Reilse von Voröfoutlichungen, in denen ich das von mir in Sïdafirika gesammolte Material zusammen mit dem Ilaterial der von mir besuchten sïdafrikanischen Musen brarbeitet habr=1). Es rescheint mir angebracht, mit diesem AbschluB oine Kusammenfassung dor in dirsen Arbeiten gewonnomen Frgebnisses zu rerknüpfon: gewährt vine solehe Zusammenfassung doch zugleich oin klares Bild vom Charakter der Torrikolenfanna unseres siidwestafrikanischon Schutzgebietes.

Vou hervorragendster gongraphischer Bedentung ist, wio nurherfach herrorgehobon, die Vurbreitung der rein terrestrischen Formen, sowreit sic durch endemische Vorkommuisso markicrt ist. Narh Maßgabe dieser rndemischen torikolen Oligochäten ist der afrikanische Kontinent in droi scharf gesonderte Gobiote zu trilen. Nordafrika rinschlieblich dor Salsara und Tgyptrens ist ein Gobiot olene endemische Terrikolen. Das trupisch-afrikanisch" Trerikolongobiot ist bekantlich charak-

1) W. Micuablak, Oligochäten vom tropischen mu siinlich-subtropischen Afrika I. In: Zoologica, LXV11. - II. ebenda LxVIII.

Die Oligochäten des Kaplandes. In: Zool. Jahrb. Syst., XXXIV.

The Oligochaeta of Nittal and Zululand. In: Ann. Natal Mns. I.

lieport upon the Oligochaeta in the Sonth African Museum at Cape Town. In: Ann. South African Mns., XIII. 
terisiert durch die beiden Oligochätengruppen: 1. Gattung Dichogaster (Unterfam. Trigastrinae der Fam. Megascolecidae) und 2. Untrrfan. Eudrilinae (dr. Fam. Megascolecidae). Diese beiden (iruppen verbreiten sich aber nicht gleichmäBig über das ganze Gebiet. Die Gattung Dichogaster (Kartensk. 1), außerhalb Afrikas in Westindien und /entralamerika endemisch, setzt, den Atlantischen Ozean iiberspringend, in Westafrika, und zwar in Crambia, Portugiesisch-Guinea, Sierra Leone und Liberia, gleich in voller Macht ein. Hhr Gebiet durehsetzt jedoch nur in der nördlichsten Zone Mittelafrikas den ganzen Kontinent, und zwar von den genannten Distrikten bis zu den Galla-Ländern, Abessinien und Harar. Wreiter siddlich scheint sie nur bis an don ostafrikanischen Graben (Ruwenzori bis Ruanda und Nyassa-Land) ostwärts zu gehen. Die siidliche Erstreckung des DichogasterGebietes ist markiert dureh dir Fundr von Blantyre in Briti-ch-Nyassa-Land, "Oberlauf des Kongo"* and Fernand Vaz in Franzisisch-Kongo. Es wär ja möglich, dab endrmische Dichogaster noch südlich von dieser Linie gefiunden werden. Beachtenswert ist jedoch, daß rine reiche Ausbeute rom unteren Kongo (Chiloango, Mayili) wohl melnere ondemische Eudrilinen, jedoch nicht eine einzign endemische Dichogaster-Art autwies. Das Gobiet der Eudrilinae (Kartensk. 3) deckt sich nicht genau mit drm von Dirhogaster. Es erstreckt sich ostwiirts in ganzer Breite, von Frythraea iiber Harar, Britisch- und Doutsch-Ostafrika bis Mosambique (Mïndung des śambesi), bis an den Indischen Ozean, den es jedoch nicht äberspringt. Westwiarts dagegen reicht es nicht so woit wie das Vichogaster-(robiret. In Kamerun sind Eudrilinen noch vorherschend, in 'Togo aber sind sio schon spärlicher und in West-Liberia findet sich die westlichste Art als anschenend weit isolierter. Vorposten. Nïdwärts reicht das Gebiet der Eudrilinen viel weiter als das der Gattung Dichogaster. Sichere endemischo Eudrilinen-Vorkommnisso kennen wir rom Mïndungsgebiet des Sambesi, von mittloren Samberi (Victoria-Fälle) und von Lunda (näherer Fundort von Preussiella Inndaensis: Micu. umbekannt. 1)azu konmt noch der weite Vorstob des offenbar etwas peregrinen Nemertodrilus Kellneri Мıн. nach der Oranje-Kolonir (Bloemfontein) und dem ()ranje-FluB-Distrikt Deutsch-südwostafrikas. Für die Gebietsbegrenzung kann das Vorkommen dieser Art sicherlich nicht in Frage kommen, ebensowenig wie das des Eudriloides lurbanensis Benv. Es ist nicht einmal sicher, ob diese in den Kew gardens zu London an P'flanzen aus Natal entdeckte Art tatsächlich aus Natal stammt, noch unsicherer ist die endemische Natur dieses fraglichen Vorkonmens. Wir miissen demnach den samberi-Distrikt als dio Südgrenze des eigentlichen Eudrilinen-Gebiets ansehen. 
Ties id dafrikanische Terrikolentauna hat mit der geschilderten tropisch-afrikanischen nichts gemein. Das siddafrikanische Gebiet ist charaktrisiest hauptsichlichi') durch die beiden Gruppen: 1. Gattung Microchaetus (Unterfam. Microchaetinae der Fans. Glossosrolecidue), die ganz anf dieses sidafrikanische Gebiet beschrinkt ist, und 2. die Sectio Chilotacea (Unterfam. Arenthodrilinue der Fam. Megaseolecidae), die das siidlichste Afrika mit dem südlichrn südamerika, dem magalhaensiseh-chilenischen Gubiet, gemeinsan hat. (Ob eine Chilotacer von der Kaprerdesehen Insel San Antonio hier endomisch soi, und gewissermaben eine weit im Norden liegende Brieke zwiseben den berden jotzt auf die siidspitzen ron Südanorika und Afrika beschrainkten Sondergebieten der Chilotaceen darstelle, ist fraglich.) Dirse beiden Torrikolengruppen nehmen, soweit wir bis jetzt wissen, nahrzu die gleichen Distrikte ein, olne sich jedoch in der Art ihrer Virbreitung durch diese I)istriktr zu glejehren. Die zugheich im südlichsten Siidamerika rerbreiteten Chilotaceen (Kartensk. 5) herrschen an der Siidkante Kaplands und hier zumal in den westlehen Distrikten vor. Sie bilden in der Art ihrer goographischen Vorbreitung also eine Parallele zu der TrigastrinenGattung Jichogaster des tropischen Afrikas. Nach Osten hin werden die chilotaceen spärlicher und, was bedeutsam ist, durch Arten vertreten, die rine etwas writere V repbreitmug haben, also in geringem Maße peregrin sind. Im Gregensatz hierzu ist dir Gattung Microchetus (Kartensk. 6) im Osten Südafrikas rorhereschend, wenn sie anch in rinigen wenigen Arten bis an die Atlantischen Distrikte Kaplands vorgedrungen ist. Die Nordgrenze der Gebietr dieser typisch siddafrikanischen Terrikolengruppen wird im Westen durch ringe Funde in Klein-Namaland, eben sïdlich rom Oranje-FluB, markiort, in isstlehen Tril durch Funde am V'aal-FluB und im siddlichen Transvaal crine auch in Natal vorkommende, also in geringem Mabe peregrine (hilotaces), sowie durch zahlreiche Funde in Natal und Zululand mehrere rein endemischre Mieroehaetus-Arten und wrenige in geringem Maße peregrine Chilotaceen). Fraglieh ist es, ob und wie weit sich diese rein tririkolen ()ligochätongruppen Südafikas in diesen Ostgebiet nordwärts rpstrecken; denn das ganze Gebiet zwischen Zululand und dem Unterlanf des Sambesi ist in dieser Hinsicht so gut wie unbekannt. Für die Chilotacoen ist w unwahrsehrinlich, dab ilsr Gobiot sich hier noch beträchtlich nordwärts erstrecke; denu sie erscheinen in Natal, süd-Transvaal und Zululand schon spärliels und mur dureh in geringem Mabe peregrine Arten anselheinend vorgeschobeno l'osten - vertreten. I)ie rattung Microehaetus

1) Ich selse hier ab von der kleinen Relikten-Kolonie der in zerspengten Gebieten weltweit verbreiteten Gattung Acanthodrilus im siidwest-Winkel Kaplands. 
dagegen zeigt in Natal und Zululand noch eine ziemlich iippige Entfaltung prin endemischer Formen. Es ist demnach nicht ausgeschlossen, daß sie sich in diesem Ostgebiet noch beträchtlich nordwärts erstrecke, während sich andererseits vielleicht die äthopjseben Eudrilinen in dieser ,terra incognita" vom Gebiet des Sambesi noch weiter siidwärts verbreiten, den Microchäten entgegen. Ob diess beiden einander entgegen drängenden Oligochätenfaunen an einer Stelle dieses unbekannten Ostgebietes anfeinander stoben oder gar sich in einem mittleren Distrikte durchdringen ${ }^{1}$ ), ist fraglich. Es ist jedenfalls anzunehmen, dab die terrikolın Oligochätrn in dirsem fiaglichen Gebiet verhälnismäBig spärlich entwickelt sind; denn schon in Natal, Oranje-Kolonie und Siid-Transvaal ist die Fanna rndemischer terrikoler Oligochäten spärlicher als in Kaplande, ebenso wie diejenige des mittleren und unteren Sambesi spärlicher als die des mittlereo Afrikas ist.

Während nun im Ostgebiet des subtropischen Afrikas die Grenzbrziehungen der tropischen und der sïdlichrn Terrikolrnfaunen ganz unbokannt sind, sehen wir in Wosten einen breiten Trockenland-Distrikt sich als Grbiet ohne andemische terrikole oligoeläten zwischen jene beiden Gobiete rinschiobrn. Dieses Trockenland-Gobient bildet rine mübrrwindliche Verbreitungsschranke für terrikole Oligochäten und ist in erster Linie dafür verantwortlich zu machen, dab sich siidatrika in suiner () ligochätonfauna so anffallend solbständig orhalten konntr. Mässen wir doch siidafika, dessen hanptwichlichste und charakteristische cruppen terrikoler Oligochäten ganz anderen Familien oder Lntrufamilien angehören wie die typischen tropiscl-afrikanischen Terrikolengruppen, als selbständiges Trrrikolengebiet dem tropisch-atrikanischen Terrikolengobiot gegenüber-

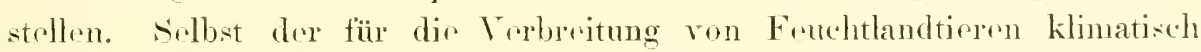
gïnstigere, weil weniger trockene Oststreifen dos subtropischen Afrikas vom Unterlanf des Sambesi bis /ubuland-Transraal hat dieso Selbständigksit des siidafikanischen Terrikolengebiets nicht zu stören vormocht. Der ganz vereinzelte Vorstob dor äthopischen Terrikolenfama bis in südatrika hinrin, wie dre offonbare Writwanderer Nemertodrilus Kelluevi ihn darstellt, bedentet keine wesentliche. Anderung dieses Faummbildos, da es sich eben

1) Der weite Vorstob der äthiopischen Eudrilinen sidwärts bis zur Oranje-Kolonie und zum Sïddistrikt Deutsch-südwestafrikas, wie er durch Nemertodritus Kollneri Much. ausgeführt worden ist, lïß vermuten, daß anch das eigentliche Gebiet der Endrilinen, für dessen Lmgrenzung Nemertodrilus Kollneri als etwas peregrine Art nicht in Betracht kommt, in diesem Gebietsstreifen weiter siidwärts reicht, als die bis jetzt gemachten Funde sicher erkennen lassen.

10 Michaelsen, Deutsch-Südwestafrika. 

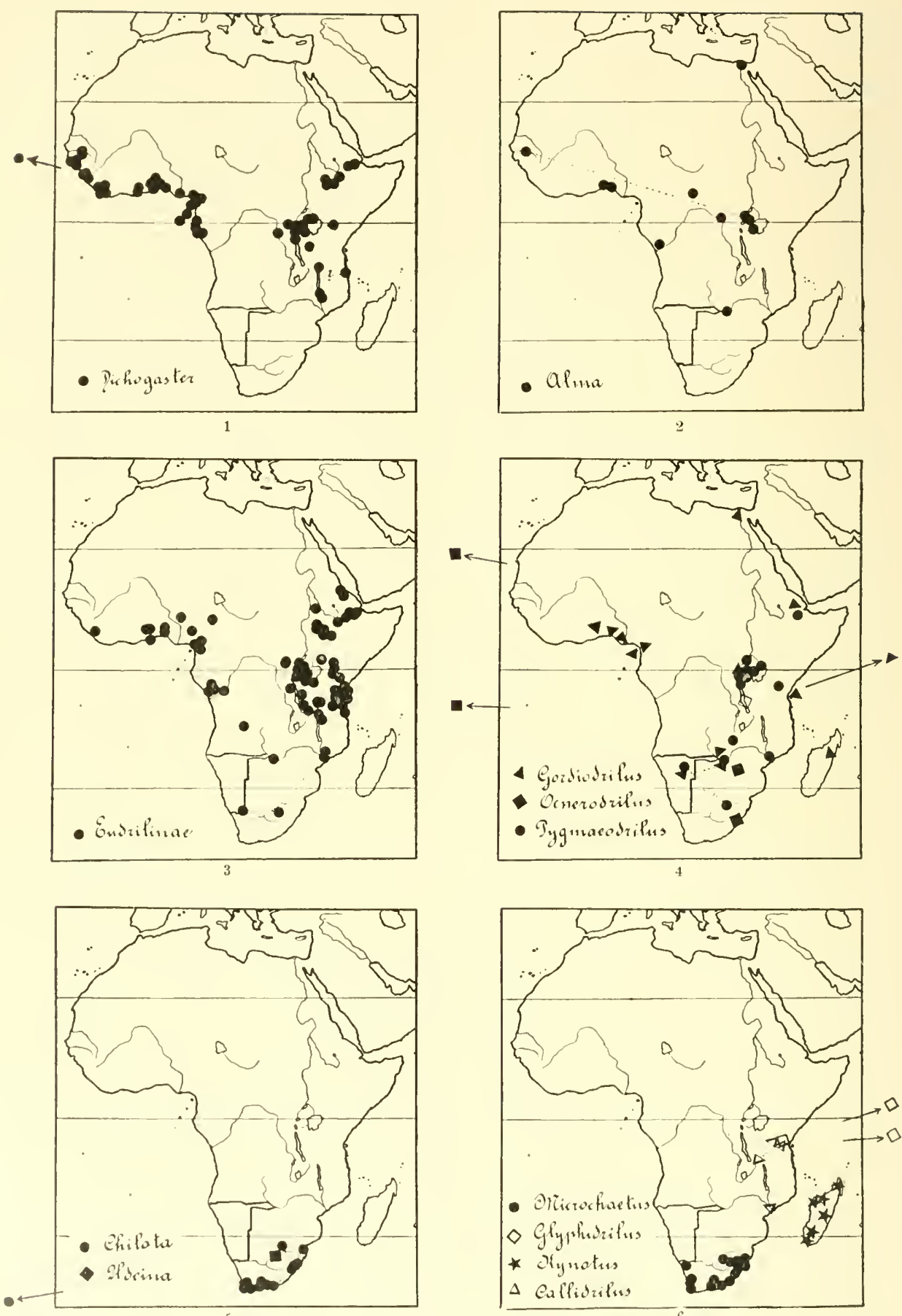

(Geographlische Verbreitung der hauptsächlichsten Gruppen terricoler und limicoler ()ligochäten in dfrika. 
um rinen Weitwanderer, nicht um eine rein endemische Form, und damit mutmaßlich um einen der jüngsten geologischen Epoche angehörenden Vorsto B handelt. Das südafrikanische Terrikolengebiet macht ganz den Eindrụck, wenn nicht gerade cines Reliktengebietes - dazu erscheinen die charakteristischen Gattungen hier in zu üppiger Entfaltung --, so doch rines Rückzugsgebietes. Die ganz auf südafrika beschränkte Gattung Microchaetus stammt wie ihre auf Madagaskar beschränkte Vetterngattung Kynotus von Formen ab, die jetzt noch als aquatile Formen im tropischen Ostafrika zu finden sind (Microchaetus von Glyphidrilus in Deutsch-Ostafrika und in Indo-Malayischen Gebiet, Kynotus von Callidrilus in Mosambique und in Deutsch-Ostafrika). Div Chilotacea zeigen in ihrem amerikanischen \%weig (in vielen Arten über Fuerland, süd- und Westpatagonien und Chile verbreitet. sonst nur noch in einer einzigen vielloicht peregrinen Art auf den Kaprerdeschen Insoln gofunden) die gleiche Beschränkung auf cin durch Wïste odor Trockenland abgeschlossenes Winkelgebiet. Verstärkt wird dieser Charakter des südafrikanischen Terrikolengebiets noch durch das Auftreten einer klinen Gruppe von Acanthodrilus-Arten, also einer typischen Reliktenkolonie, in seinem Südwestwinkel. (Die kloine durch 2 Arten repräscntiorte Microscoler-Kolonie im mittleren Teil der kapländischen Sïdkïste kommt hier nicht in Betracht, da Microscoler rine Gattung mit ruryhalinen Fähigkriten ist und deshalb in ihrer Verbreitung nicht mit rem turrikolen Formen zusammengestellt werden darf). Es läßt sich aus diesen Vurbreitungsverhältnissen der terrikolen Oligochäten im mittleren und sïdlichen Afrika der sichore schluß ziehen, daß die physiographischen Verhältnisse, die jenen Vrrbrritungsverhältuissen zu Grunde liegen, ein verhälnismäßig hohes grologisches Alter besitzen, dab also auch jonc Trockenland-Barriere, dio sïdafrika für Torrikolon fast hermetisch vom mittleren Afrika abschlob, grologisch alt ist.

Die westliche Hälfto diesor Trockenland-Barriere deckt sich fast genau mit dom politischen Brgriff Deutsch-siidwestafika, dessen Hauptmasse also ein Grbiet ohne endemisehetrerikolo oligochäten darstellt. Während aber msere Kolonie im Süden anscheinend nur an das siidafrikanischn 'Terrikolengebiet hranreicht, dringt os im Norden mit seinen Randdistrikten offenbar in das tropisch-afrikanische Torrikolengebiet hinoin; wenigstens von srinem Sambesi-Listrikt dürfen wir das als fast sicher anmomen. Hit der ganzen Trockenland-Barriere teilt natürlich Deutsch-südwestafrika das geologische Alter seinor physiographischen Verhältnisse.

Dir amphibischen Oligochäten, dio in Afrika durch die Megascolecidın Unterfam. Ornevodrilinae (Kartensk. 4) vertreten werden, weichen in ihren Ans$10^{*}$ 
breitungsverhältnissen, also auch in ihrer jetzigen geographiselıen Vorbreitung, in geringem Maße von den terrikolen Oligochäten ab. Nie nehmen in ihren Ausbreitungsähigkeiten eine Mittelstrllung zwischen den terrikolen und den aquatilen Oligochaiten rin. Wrenngloich sie bei weitem nicht die weite Vorbreitung der Gattungen und vielfach auch der Arten der aquatilen Oligorhäten zoigen, so sind sio moist doch nicht so beschrinkt wio die endemischen terrikolon Oligochätrn. Dementsprechend dringen auch die im wesentlichen tropisch-afrikanischen Ocnerodritinen-Gattungen in größerer \%ahl writer nach siiden vor als die terrikolen Oligochäton, die ja abgesehen ron dem Writwanderer Nemertodrilus Kellneri und dem seiner Heimatsbrechtigung nach sehr fraglichen Eudriloides durbanensis (angeblich ron Natal bis jotzt nicht siidlich rom Sambesi-Bezirk gefundon worden sind. Dir im tropisclen Afrika mit vielen Arten ïber dir ganze Breite des Kontinents verteilte Ocnerodrilinen-Gattmng Gordiodrilus roicht zwar südwïrts nicht viel writer als jene endemischen Terrikolen, nämlich mit 2 Arten (G. Chumi Mren. und G. Luykerleni Mscm.) bis in den Sambesi-Distrikt, und nur mit rincr dioser beiden Arten ( $A$. Luykerleni) noch otwas woitor, bis in Deutseh-Sidwestafrika (Watrberg-Distrikt) hinein. Die beidon Ocnerodrilinen-Gattungen Ocnerodrilus (Nubgen. 1lyogenia, die im iibrigen auch im tropischen und sïdlich-subtropischen Amerika in vielen Arten auftritt) und Pygmaeodritus (auf Afrika beschränkt) dringen aber beträchtlich weiter siidwärts ror, Cenerodrilus (Ilyogemu) vom Tanganyika-Sos bis Bulawayo in Suid-Rhodesia [O. (I.) Chubbi Mıн.] und Natal [O. (I.) africanus (Bedo.)], Pygmaeodrilus von den (ialla Ländern ïber den ostafrikanischen Giraben und das Seengubiet, und weitre ïbre Nord-Rhodrsia (P. Paulae Mnch.) rinerseits nach dem Hïndungsgabient des Samberi (P. quitimanensis Mırn.), andererseits nach drm mittleren Sambesi (P. rhodesiensis Micn.) und der Granje-Kolonie brzw. nach l)entech-Fïdwestafrika (P. arausionensis Mich. von Bothaville und Grootfontein . Ton diesen (Jenerodrilinen dringen also zwri Arten auch in Dentsch-siddwestafrika rin. allerdings zwei Arten, die cine weitere Vorbroitming aufweism, kommit doch die rine zugleich im Sambesi-Bezirk lihodesias vor, die andere sogar in dre Oranje-Kolonie. Es sind also Wreitwanderer, die fiir den rigentlichon C'harakter dor Fauna nur aine neben-

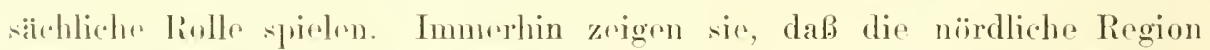
1) antsch-siodwestafrikas fïr weitwandernde tropisch-afrikanische Ocnorodrilinan zugänglich was. Der dritte Ocnerodriline unserer Kolonie, Oenero-

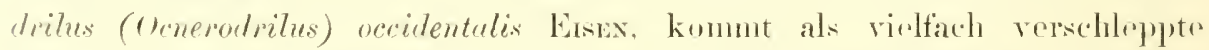

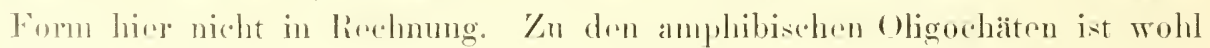

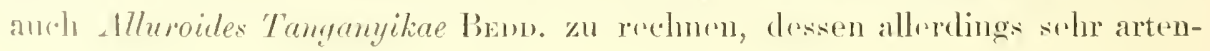


arme Gattung eine ähnliche Verbreitung zeigt wie die Gattung Pygmaeodrilus. Auch die Art Alluroides tanganyikae besitzt, wie schon sein Xame verrät, eine ziemlich weite Verbreitung.

Die aquatilen Oligochäten Deutsch-Siidwestafrikas gelı̈ren fast durchweg Gattungen an, die eine weltweite Verbreitung besitzen und demnach für die Feststellung besonderer geographischer Beziehungen dieser Fauna nicht in Betracht kommen. Zum Teil besitzen sogar die Arten eine welweite Verbreitung, wie Nais psendoobtusa (PIGLet) und Limnodrilus alpestris Essex. Zu diesen weltweit verbreiteten Gattungen, die den zweifellos phyletisch selır alten Familien der Naididae und Tubificidae angehören, kommt im Sambesi-Bezirk Rhodesias, also mutmaBlich auch im deutsehen SambesiBezirk, noch eine Art der phyletisch wahrscheinlich viel jüngeren Criodrilinen-Grattung Alma himzu. Die Gattung Alma (Kartensk. 2) ist beschränkt auf das tropisch-afrikanische Gebiet, das sie rom Atlantischen Ozean bis zum ostafrikanischen Graben und noch etwas weiter Distrikt des VictoriaNyanza) durchzieht. Nordwärts dringt sie, wie die Ocnerodrilinen-Gattung Gordiodrilus, nilabwärts weit in das subtropische Grobiet hinein bis ans Nittelmeer vor. Im Siiden scheint sie ihre Grenze im Sambesi-Distrikt Phodesias (und wohl auch Deutsch-siidwestafrikas) zu finden, unterstïtzt also die Terrikolengruppe der endemischen Eudrilinen in der südlichrn Begrenzung einer tropiscl-afrikanischen Region, der der Nordrand unserer Kolonie Deutsch-siidwestafrika noch zugeteilt wroden muß.

Auch die frattungen der marinen Oligochäten Drutsch-sïdwestafrikas, der Meerestrands- und Flachses-()ligochäten. haben eine weite, wenn nicht rine fast kosmopolitisehe Verbreitung. Die Gattung Limnodriloides ist auch aus dem Mittremerr bekannt, während Lumbricillws und Hichaelsena weltweit verbreitet sind. Auf derartige marine Oligochäten ist ïbrigens bis jetzt wenig goachtet worden. Es ist jedenfalls durchaus nicht ausgeschlosicn, dab auch Limnodriloides rine wroltwite Verbreitung habr.

Schlieblich sind auch noch die peregrinen Oligochäten, die zweifellos durch den Menschen in unsere Kolonie eingeschleppt worden sind, eince Erörterung zu unterziehen. Dirse nehmen mit 5 odre 6 Artrn einen breiten Raum in der Oligochätenfauna unserer Kolonie ein und umfassen hauptsächlich sämtliche terrestrischen Formen dor oben zusammengestellten Liste. Also alle „eigentlichen Regenwürmer." Dontsch-südwestafikas sind als eingeschleppt zu betrachten, und das entspricht ja anch den obigen geographischen Erörterungen über die terrestrischen Oligochätrn Siidafrikas, wonach Deutsch-siidwestafrika zu einem Gebiete ohne ondemische terrestrische Oligochäten gehört. Vielleicht ist außer den terrestrischon ()ligo- 
chäten auch der amphibische Ocnerodrilus occidentalis Essen als cingeschleppte Form zu betrachten. Diesp Art hat ilure weltweite Verbreitung überland und iibersee zweifollos nur mit Hilfe des Menschen erlangen können. Ob sie aber auch in den Bezirk des Großen Fischflusses durch den Menschen ringefuihrt worden ist, bleibt eine offene Frage. Als eine leichter verbreitbare amphibische Form mag sie sich auch unabhängig rom Menschen durch andere Hilfsmittel von Rhodesia (Bulawayo) aus nach Deutsch-Südwestafrika lin rerbreitet haben.

Erstamlich ist jedenfalls die verhältnismäßig große Zahl der eingorschleppten Oligochäten, wenn man in Rechnung zicht, daß dieses Gebiet doch erst wrnige Jahrzehnte unter gïrtnerischer und landwirtschaftlicher Kultur steht. Es ist dies wieder einmal ein Beweis dafür, wie schnell dir hauptsächlichsten Verschleppungsformen, zumal unsere europäischen AckerRegenwürmer Helodrilus. der europäischen Kultur auf dem Fuße folgen.

Der subtropischen Natur des Landes entepricht es, daß auch einige nichteruropäische Formen der auf wärmere Gebiete angewiesenen Gattungen Dichogaster, Nicroscolex und Ocnerodrilus in der Reihe der EinschleppungsArten rorkommen.

\section{Systematisches.}

\section{Fam. Naididae. \\ Paranais multispinus n. sp.}

Tafel V, Fig. 4.

Fundangabe: Farm Frauenstein bei Neudamm, in einem Wasserloch mit reichlichem Planzenwuchs. W. Michaelsex, 13. Мai 1911.

Torliegend ein einziges anscheinend vollständiges Exemplar, wahrscheintich nur das vorderste Glied einer Tierkette.

Äußeres: Dimensionen: Länge ca. 3 mm, Dicke (a. $0,35 \mathrm{~mm}$, S'egmentzahl 13.

Ko pf zygolobisch. Kopflappen breit und kurz, gleichmäßig gerundet, otwas überhängend. Augenflecke sind nicht rorhanden.

Haut-Epithel des Vorderkiirpers mit Arsnahme des Kopflappens und des 1. Segments dicht mit unregelmäßig gestalteten dunkleren Zellen (mit grob granuliertem Inhalt, Pigmentzellen?) durchisetzt. Etwa von der 
Mittelzone des 5. Segments an stehen diese dunkleren Zellen weitlaufiger, so daf die Haut in dieser hinteren Partie, sowie die des Kopfes, durchsichtiger erscheint als die des 2 . bis $1 / 25$. segments.

Borsten (Tafel V, Fig. 4) sämtlich annähernd gleichartig, nur in del Größe etwas verschieden. Borsten der Körper-Erden etwas keiner als die des Mittelkörpers. Fine dorsale Borste des 5. Segments erwies sich als $0,1 \mathrm{~mm}$ lang bei einer Dicke von ea. $4 \mu$. Die dorsalen Borsten beginnen wie die ventralen am 2. Segment. Borsten sämtlich schlanke, stark S-förmig gebogene Gabelborsten. Obere Gabelzinke deutlich kürzer und dünner als dis untere. Borsten zu (0) 2 bis $11 \mathrm{im}$ Bündel, in den briden ersten, dem 7 . und den letzton Borsten tragenden Segmenten in geringerer Zahl als in den iibrigen, wis dis folgendo Tabelle zeigt:

2. 3. 4. 5. 6. 7. 8. 9. 10. 11.12.13. Segnı.

Rinchtes dorsales Bündel $6 \begin{array}{ccccccccccc}6 & 9 & 10 & 9 & 5 & ? & ? & 4+? & 9 & 9 & 7\end{array}$

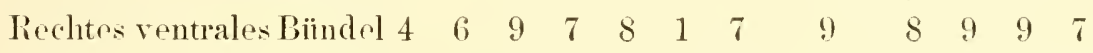

Linkes ventrales. Bündel $6 \begin{array}{lllllllllllll}6 & 9 & 6 & 8 & 4 & 4 & + & 5 & 9 & 9 & 8 & 5\end{array}$

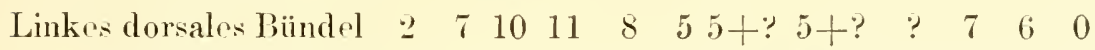

Auffallend arsheint mir die durchgehend. Verringerung der Borstenzahl in den Bündeln des 7 . Segments. /ugloich schienen mir diese Borsten des 7. Segments etwas kleiner zu sein als die iibrigen; doch konnte ich das nicht sicher foststellen, da ich sie nicht in gerader Seitenlage zur Anschauung bringen konnte. Sie scheinen auch darin von den iibrigen Borsten abzuweichen, das dis obre Gabelzinke zurückgebildet ist; doch kounte ich auch dies nicht mit vollkommener Sicherheit feststellen. Vielleicht hat man es hier mit einer Umwandlung in Geschlechtsborsten zil tun.

Innere Organisation: $\tilde{O}$ sophagus sich im 6. Segment zum Mitteldarm erweiternd. Eine Magen-artige Bildung konnte nicht nachgewiesen werden.

\section{Nris psendoobtusa (Piguet). var.?}

Nais obtuea (GERr.) var. preudoobtusa, PIGUET, Observation sur les Naïdidées et Revision systématique de quelques espéces de cette famille. In: Rev. Suisse Zool. XIV, 1906, p. 238, Pl. X Fig. 5-7, Pl. XI Fig. 4, 6, 7, Pl. XII Fig. 9.

Fundangaben: Farm Frauenste in bei Neudamm, in Wasserlöchern mit reichlichem Pflanzenwuchs; W. Michaelsex, 13. Mai 1911.

Seeheim, im GroBen FischfluB zwischen Bryozoen an den Stielen ron Binsen; IV. Michatlsex, 18. Juli 1911.

Weitere Verbreitung der Art: Mittel-Europa. 
Torliegend mehrere Exemplare einer Nais-Art, die am bosten mit I. pseudoobtusa (Pıgex) übereinstimmt, in gewisser Hinsicht aber zu $N$. obtusa (Gervass) hinzuneigen, scheint. Die Harborsten sind nämlich zart und bicgsam wie bei $N$. pseudooltusa, andererseits aber kamm so lang wie der Körperdurehmesser, also so kurz wie bei $\lambda$.obtusa. Zu erwähnen ist, daß die Haarborsten nur an einem Teil dor Segnente vorkommen, bei einzelnen Tieren nur an sehr wenigen, bei anderen an einer größeren Anzahl. Übrigens stcllte schon Plguet an seinem Untersuchungsmatcrial eino Variabilität in der Zalıl und Länge dex dorsalen Haarborsten fest; allerdings ging diese Variabilität nicht annähernd so weit, daf sie meine Befunde an der südwest-afrikanischen Form in sich einschlösse. Die dorsalen Nadelborsten sind, soweit ich sie erkennen konnte, sämtlich einfach-spitzig.

\section{Allophomes afiricanus n. sp.}

Tafil V, Fig. 1-3.

Fundangaben: Farm Frauenstoin bei Nendanm, in Wasserlöchern mit reichlichen Pflanzenwuchs; Wr. Micnaensex, 18. Mai 1911.

Soehoim, im Großen Fischfluß zwischen Bryozoen an Binsen: W. Wichaelaiex, 18. Juli 1911.

Vorliegend einige wenige Stiicke.

Äußeres: Dimensionon des gröBten Ntiickus: Länge ca. 6 mm, Dicke im Maximum $0,23 \mathrm{~mm}$, Segmentzahl ca. 45.

F ärbung bleveh, weißlich.

Kopflappen gerundet-kegelförmig.

Borston: In don ventralon Bündoln (Tafel V, Fig. 2) bis 4 (oder

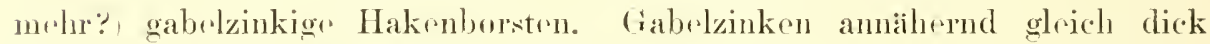
und höchstens sohr wonig rorschieden an Liinge; obere Gabelzinkr am Vorderkörper sohr wenig länger, an Hinterkörper soln wenig kiirzer als die untere Gabelzinkr. Dicke der ventralen Borsten am Hals (an der Basis des ans dre Haut hreauragenden Teils, ca. $2 \mu$. Dir spannweite der schlankm, ziemlich stark gebogenen (iabelzinken ist dentlich gröber (etwa um dir Hälfte gröber) als die Borstendicke. Dorsale Bïndel (Tafel V, Fig. 1) am 5. Segment beginnond, mit riner Haarborste und ciner gabelzinkigen Nadelborste. Obere Gabulzinke der Nadolborsten dentlich dïmner, abrer nur sehr wenig kiirzer als die nntere Gabelzinke. Die Spannweite der Gabclzinken ist vorhälnismäBig grob. Das beruht nicht auf riner besonders starken krümmung der unteren Gabelzinke, sondern auf der 
Stellung der oberen Gabelzinke, die ganz gerade in der Richtung der Borste verläuft oder gar noch etwas zuriickgebogen ist. Dicke der Nadelborsten am Hals ca. $1 \frac{1}{2} \mu$.

Kiemennapf (Tafel V, Fig. 3) am ventralen Hinterrande mit zwei basal etwas verdickten, distalwärts dïnner werdenden schlanken Palpen, deren Basen aneinander stoben, und die nur wenig divergieren. Dorsaler Vorderrand median eingesehnitten. In der Höhlung des Kiemennapfes stehen drei Paar dick-wulstige bis plattenförmigr Kiemen. Die Kiemen des vordersten resp. des dorsalen Paares stehen so dicht am Rande des Kimemenapfes, daß sie sich in mancher Körperlage lediglich als wuktige Verdickungen des Kiemennapfrandes darstellen. Sie kïnnen deshalb leicht fïr sekundäre Kiemen gehalten werden. Ich glaube, ihre primäre Natur deutlich erkannt zu haben.)

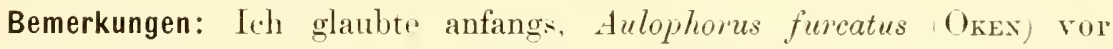
mir zu haben, mußte aber nach genauerer Cntersuchung annehmen. daß die obersten beiden Kirmen nicht am Rande des Kiemennapfes, sondern oben noch innerhalb desselben stehen, also priniar Kiemen sind. Ton Au. furcatus unterscheidet sich Au. africanus übrigens auch durch die strellung der Palpen, die bri Au. furcatus im stumpfen Winkel divergieren, bei Au. africanus dagegen dicht nebeneinander stehen und nur selu wenig, in spitzem Winkel, divergieren.

Jedenfalls gehört Au. africanus mit Au. furcatus zusammen zu der jüngst ron mir erörterten') (iruppe von Aulophorus, deren Cephalisation sich auf 4 oder 3 Segmente beschrinkt, und deren dorsale Nadelborsten rinfach gabelspitzig (nicht fä̀cherspitzig) sind.

In die Klarheit dieser Gruppenteilung der Giattung Aulophorus drolit rine neuere Notiz Fruexd ${ }^{2}$ ) Konfusion zu bringen - wo hätte Friexu nicht Verwirrung geschaffen, wenn er eine Oligothätengruppe in Erörterung nahm! - Friesd beschreibt 1. e. als Dero olearia n. sp. nach einem einzigen Exemplar, „breaking up almost as soon as it is placed on the microseopic sip, even if not subjected to pressure" (!) eine Naidide, deren dorsale Borsten gabelspitzig sind und am 6. segment beginnen, und die ,closely resembles D. stuhlmanni, stieren, reported from the Victoria Nyanza:" also, so müßte man danach annehmen, ein Aulophoms (1)ero Stuhlmanni ist zweifellos ein typischer Aulophorus), dessen Organisation sich der von

1) W. Mrchatesex, Über einige zentralamerikanische Oligochäten. In: Arch. Naturg., LxxviII, 1912, A., p. 115.

$\left.{ }^{2}\right)$ H. Friexd, Some Annelids of the Thames Valley. In: Journ. Linu. Soc., Zool,, Xxxil. p. 98. 
mir herausgefundrenen Gruppenteilung nicht anpaßt. Betrachtet man die Fruexdeche Beschreibung genauer, so crkennt man, daß tieser Vergleich mit Aulophoms Stuhlmami ganz haltlos ist, dab iibrrlıaupt die AulophorusNatur der Dero olearia durehaus fraglich orscheint. Fuexo hat anscheinend von der jetzt üblichen Teilung der alten Gattung Dero (s. l.) in Dero (s. s.) und Aulophorus keine Alınung. Er stelit ganz auf dem veralteten Standpunkt moines "Tierreichs" von 1900. Stellt man nun die Angaben Friexos ïber Dero olearia mit drnen der von Frneso zitierten Diagnose über Aulophorus [Dero] Stuhlmanni zusammen, so ergibt sich, daß diese Formen kaum in einem einzigen der auf beiden Seiten angegebenen Organisationsverhälnisse ïbrreinstimmen. Das cinzige, was annähernd stimmt, ist unwesentlich, nämlich dir Zahl der Borsten in den ventralen Bündeln - 5 bei Aulophorus Stuhlmanni, 4-5 bei Dero olearia - Aber dagegen stehen: Aulophorus Stuhlmanni

Längo:

Segmentzahl

Dorsale Hakcuborsten

Kiemennapf

\section{$2 \mathrm{~mm}$}

18

nicht gegabelt

Aulophorus-artig
Dero olearia

$$
8-10 \mathrm{~mm}
$$

gegabelt

I believo it has the gills which distinguish

Dero from Nais.

Dic Bolıauptung Friexds, daß diese beiden Formon sich sehr ähnlich (.,It closely resembles...") sehen sollen, bleibt unverstindlich. Nimmt man hinzu, daß Friexu nicht eimmal sicher aussagın kann, ob sein Tier ïberhaupt cin Kiemen-tragonder Oligochät ist ( „I believe it has the gills . ."), so muB man sich fragen, ob Friexu als Oligochätenforscher überhaupt ernst zu nehmen ist. Eine derartige wesenlose Art-Diagnose ist in ihrer Haltlosigkeit wohl nur anderen problematischen Feststellungen Fruexds selbst an dir Seite zu stellen, otwa soinem famosen System dor 'Tubificiden, ${ }^{1}$ ) in dem diese Fanilie in rrster Linie danach geteilt wird, ob Haarborsten rorkommon oder nicht, und in der all die alten haltlosen, längst zu den Synonymen gestellten Gattungen Keterochaeta, Iemitubifex, Psammoryctes und Spirosperma wieder auftauchen, und selbst dir uralte Grobesche Gattung Saenuris wiodor zum Leben erweckt wird, ein wissonsehaftlicher Standpunkt, der ungofïhr dem von der Mitte drs vorigen Jahrhunderts rntsprechen mag. Doch genug davon. Hier gilt es luauptsäehlich festzustellen, dab die Specios inquirenda Dero olearia kein Aulophorus ist, und daß die von mir unterschicdenen Gruppen in dirser Gattung nach wie vor rein gesondert rescheinen.

1) H. Friexw, British 'Tuhificidac. In: Journ. R. micr. Soc. 1912, p. 26i5-293. 
Ich habe schlieBlich noch ein Versehen in jener Erörterung iiber dic Gruppen von Aulophorus richtig zu stellen. Ich habe dort (l. e. p. 116) gesagt, daß es dahin gestellt bleiben muisse, zu welcher dioser Gruppen Au. Stuhlmanni gehïre: es sei nicht bekannt, wieviele Segmente dio Cophalisation bei dieser Art umfasse. Aus der Originalbeschreibung ${ }^{\text {I }}$ STLHzxaxss geht aber deutlich hervor, daß die Cephalisation bei dieser Art 5 segmente umfaßt. Stunluax gibt an, daß die ersten 4 segmente (wir wiirden jetzt sagen: das 2.-5. Segment; STumuaxx zählt den sehr kurzen, borstenlosen Kopfring nicht als sugment) je 5 gegabolte Hakenborsten, die ïbrigen - also rom 5. borstentragenden Segment, das wil als das 6. Segment brzeichen, an - auberdem noch mit Dorsalbündeln ausgestattet seien. Es entbehren also die crsten 5 Siegmente der Dorsalbïndel. Aulophoms Stuhlmanni schließt sich also an dir Gruppe der Arten mit Fäclerborsten [Au. tonkinensis (VEJD.), Au. discocephalus Scum., Au. vagns Lewr und $A u$. Schmardai Mr'n.)] an. Brei der Winzigkeit der Tiepe und der Schwierigkeit der Borstenuntersuchung will es mir fraglich recheinen, ob diese Art aus dem Vietoria Nyanza wirklich einfach-spitzige Nadelborsten in den dorsalen Bündeln habe. Vielleicht sind die etwaigen äußerst kleinen

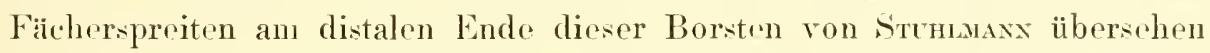
wordon. Da diese Fitherspreiten ihro Flichr meist dre benachbarten Haarborste zuwenden, so kommen sic in einem Quetschpräparat meist in der Kantenlage zur Ansicht, sind also leicht zu ïbersehen, falls nicht geradezu danach gesucht wird, und dazu fehle strulusxx bei drom damaligen stande der oligochätologischen Wissenschaft dir Anregung.

\section{Fam. 'Tubificidae.}

\section{Limmodriloides Winckelmammi 11 . sp.}

Tafel 1 , Fig. 6 und 7 .

Fundangaben: Sw w k o p m und, am Ebbestrande untrr Stuincen: W. Michaelsex, 1. Juli 1911 .

Liideritzbucht, am Meorsstrande untru strinen und angeschwemmtem feuchten Scetang: W. Michaelsex, 22. Juli 1911.

Vorliegend mehrere Exemplare, darunter einige wenige geschlechtsreife.

1) F. Stchumax, Beiträge zur Fauna zentralafrikanischer seen I. In: Zool. Jahrb., sist., Y, p. 925 . 
Äußeres. Lä ng̊ ca. 12-18 mm, Jicke im Maximmm, in der Gü̈telrogion, 0,6 mm, am Hinterende $0,2-0,25 \mathrm{~mm}$.

Fä r bung der lebenden Tiere blabrïtlich.

Koptlappen gremelet kegelfiirmig, ungefalur so lang wie an der Basis breit, manchmal etwas geschweift, mit etwas vorgezogener rundlicluce spitze.

Kinigr Sogmante des Vorderkäpers vom 2. bis rotwa zum 6. zweiringlig, mit kïrzerem Vorderringel, der ctwa $1 / 4-1 / 3$ so lang wir der borstentragende Hinterringel ist.

Borsten ("Taf.' V, Fig. 6) fast immer zu 2 in Bündel, selbst an Segmenten dos Hinterköppers. soweit diese überluaupt mit Borsten ausgestatet waren. An den letzten S'egmenten fohlen nämlich die Borsten. Nur ganz ansmahmsweise, nur bei einem dor näher untersuchten stioke, fand ich 3 Borsten in ringen der ventralen Borstenbiindel des Vorderkïrpers. Violleicht handelt es sich hior nur un eine Anomalie vorzeitige Entwicklung (riner Ersatzborste?) Die Borsten sind simtlich schlank S-förmig gebogene gabelspitzige Hakenborsten ohne dertlicluen Nodulus, in den ventralen und lateralen Bïndoln ganz gleich gestalter. Die obrere Gabelzinke der Borste ist dentlich diinner and merist, besonders deutlich an den Borsten der vordersten Singmente, anch otwas kürzer als die obere; an den Borstrn des Mittrlkärper's ist der Unterschied in der Lainge der beriden Gabelzinken jodoch sehr gering, meist kaum rrkembar. Hir spannweite der Gabulzinken ist kaum gröber als die Dicke der Borste nnterhalb der Ciabelung. Dio borsten der resten Fingmente sowie die des Hinterkörpers sind retwas kleiner als die des Mittrkörpers. Y)iese sind ca. $0,09 \mathrm{~mm}$ lang und im Iaximum ea. 5 p dick. l)ir Länge der unteren Gabrlzinke beträgt ungeffilır 5 je.

Giirtol ringförmig, an der linteren Hälfte des 10. Sergments und am ganzin 11. Singmant.

If ännliclse l’orrn parig, ventral am 11. Fengment, anscbeinend an stello der hior fohlendon ventralen Borstren.

Weibliche Por'n nicht erkanut.

siamentaschen-I'oreu, 1 Paar, ventral aus 10. Segment in den Linion der ventralen Borsten, der Borstrnzone wtwas nälor als der Inters.ementalfurehe $9 / 10$.

Innere Organisation. Harm: Schlund mit kleineme, ziemlich niedrigem

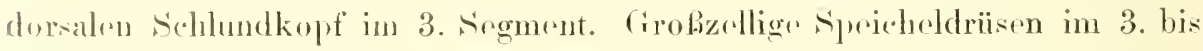
5. Sergment, in 3. Serement den dorsalen Siclulundkopt in dicker Lage bedeckend, in 4. und 5. Srement jederseits als viol- mod kloinlappige Gobilde 
cinen grofen Teil der Leibeshöhle einnehmend. Chloragogenzellen im 4. und 5. Segment sehr spärlich, wenn iiberhaupt vorhanden, vom 6. Segment an als dichter, geschlossener Besatz des Darmes ausgebildet. Der Osophagus erweitert sich nach hinten allmählich. Im 9. segment trägt der Osophagus ein Paar dick-schlanchförmige Blindsäcke, dit hinten seitlich entspringen und ron hier seitlich am Darm nach rorn ragen. Die Wandung dor Blindsäeke ist ungefahr so dick wir dir des Gsophagus, etwas gefältelt. Das Lumen ist je nach dem Konservierungsustand weit oder eng; es kommuniziert in vollem Unfange mit dem des Osophagus. Der vordere blinde Pol der Osophagealtasehen scheint. wie bei L. appendiculatus Pieraxtoxi, durch einen dïnnen Strang mit dem Dissepiment $8 / 9$ verbunden zu sein; doch konnte ich diese Vorbindung und ihre Natur bei L. Winckelmanni nicht ganz klar erkennen. Wir haben in diesen Orophagealtaschen echte Chylustaschen ror uns. sie sind mit rinem Blutgefäßplexus durchwebt, und dic Zellen ihrer Epithelschicht zeigen dir charakteristischen, vorzugsweise in der Längsrichtung parallel der ZyclinderAchse der Zylinderepithel-Zellen! verlaufenden feinen Durchbolurungen, wir wir sie als Chylusgefäbe, romolumliel bei violen Enchyträiden, kennen gelernt haben. Die Zellkanälchen sind bei L. Winckelmanni seler frin: sie lassen den Querschnitt der Zelle fast siebartig erscheinen.

Blutgefäfsystem: 1 Paar Herzen, mäBig stark angeschwollone Transversalgefaße, umspannen den Osophagus hinten im 9. Segment.

Nervensystem: Gohim hinten median tief und schmal ausgeschnitten.

II ännliche Geschlochtsorgane (Taf. Y. Fig. 7): 1 P'aar grobe, binförmige, engstielige Hoden ragen rom ventralen Rande des Dissplimrnt: $9 / 10$ in das 10. Segment hinein, auberdem findon sich im 10. segment freir Samenmassen. Ein unpaariger, brejter und selur kurzer Samensack ragt von Dissepiment 9/10 nach rorn in das 9. Segment lincin, cin zweiter unpaariger, selır langer Śamensack ragt von Dissepiment 10/11 (?. der Zısammonhang mit diesem Dissepiment konnte nicht sicher nachgewiesen werdea), durch einige sogmente nach hinten. Ein Paar mäßig oxofo samentrichter (Tafel I. Fig. 10) liegen vor Dissepiment 10,11 im 10. sorgment. sie gehen nach hinten in je einen dümen, nicht selur langen, etwas verbogenen und unregelmäbig geschlängelten Samenleiter iiber. Die Samenleiter nelmun distalwärts rtwas an Dicke zu, 10 dam plätzlich in din breitun proximalen Pol der Atrim cinzutreten. Die proximale Hälfte der Atrien ist ungefulh halb so dick wir lang, proximal broit abgermendet, distal ohne deutlichen Absatz in die diinn-schlauchförmige distale Hälfte iibergehrend. Das Lumen dos dicken Atrimmtriles ist durch eine rinsoitige 
stark Verdickung der Wandung stark ringeengt. An dem dicken Atrium sitzt, den größton 'Teil drsselben bedeckend und nur rinen Teil seiner ()berfläche frei lassend, ungestiolt rinc breite, ziemlich niedrige, aus grobrn Zellen bestehendr, kleinlappige Prostatadrïse. Dir Ausfülırgänge der Grïsenzellen münden durch die verdickte Wandung der cinen Atrium-Seite hindurch in das Lumen des Atriums ain. Diese Prostata scheint ihrer Form nach oin Mittelding zwischen den kompakten, ong gestielten Prostaten von Tubifen', Limnodrilus stc. und dem das ganze Atrium proximal umlü̈llenden niedrigen Prostatadrüsen-Besatz von Rhyacodrilus ete. zu sein. Die Ansmiindungen der Driisenzellen sind auf rin beschränktes Areal der Atrium-()berfläche zusammengedrängt und dic bei Rlygacodrilus noch einzolligen I rüsen haben sich zu kleinen Läppehen mehrzelliger Drüsen zusammon geselslossen. Das ganz" Atrium (vordickter proximaler 'Teil plus dünnschlauchförmigem Ausmïndungstril) ist etwa um $1 / 3$ kürzer (nach ziemlich unsicherer schäzung an einer Schnitserie) als der Samonleiter. Die Ausmiindung scheint einfach zu sein. Ein eigentlicher, durch Duplikatur der Schlauchwandung unel weitere Komplikation gebildeter Penis scheint nicht gebildet zu worden; anch aine chitinöse Prnisseheide frhlt infolgedessen. Eine. Komplikation der Ausmündung wird aber dureh eine anseheinend ron auben hinzutretende Bildumg hervorgerufen, durch rine die offinung des männlichen Ports von der Seitr luer überdeckend. Papille. Lrider genïgte das Material nicht, un diese Bildungen mit vollkommener Sicherheit festzustellen.

Weiblicho Geschlochtsorgano: Ein Paar großo Orarien ragen rom ventralen Rande des Dissepinents 10/11 in das 11. Segmeut hincin. Die Eizollen rrlangen schon eine brträchtliche Größe und Ausstattung mit grob-körneligen 1)ottermassen während sie noch im Orarim sitzen. Eiersäke kounten nicht nachgewiesen werden. Losgeloste, anselieinend reife Eizellen ron ca. 0,3 mm Inuchmosser fanden sich (froi?) in der Leibeshöhle des 12. bis ea. 15. Aregments. Eileiter waren nicht nachweisbar.

Samentaschon: Ampulle sehlank, nmgekehrt birnförmig, mit dickom distalen P'ol und schlank ausgezogenom proximalen Troil. Ausführgang ziemlich scharf von der Ampulle alggesotzt, spindelfiirmig, in der Mitte verdickt, viel dünner als das dicke Enele der Ampulle und etwa doppelt so lang wie in der Mitte dick. Dir Samentaschen-Ampullen enthalten nach der BeEattung anßer unregelmälig kömoligen Massen oine spermatophore oder

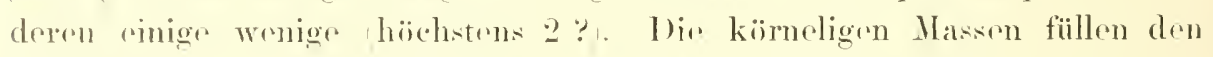
"sweiterten proximalen Teil der Ampull, an; die spermatophoren, von lang- und dümn-zylindriseluer fiestalt, liogen in schlanken, diimnen proximalen reil dor Ampullo. 
Bemerkungen: Die neue Art L. Winckelmanni steht dem $L$. appendiculatus Pieraxtosi nahe. Sie hat mit diesem den Charakter des Besitzes ron einem Paar Chylustaschen am Osophagus gemein. Während jedoch die Chylustaschen bei $L$. appendiculatus im 8 . Segment liegen, finden sie sich bei L. Winckelmami im 9. Segment. Im übrigen unterscheidet sich die neus Art von L. appendiculatus durch die geringe Zahl der Borsten in den Bündeln des Vorderkörpers und durch die Gestalt der șamentaschen, bei denen ein deutlich abgesetzter Ausführgang erkinnbar ist.

Einer Erörterung bedarf noch die Gattung unserer neuen Art, die Gattung Limmodriloides. Sie soll sich nach ihrem Autor, Pieraxtoxi, ${ }^{1}$, ron der nahe rerwandten Gattung Limnodrilus CLAP. durch das Fehlen einer deutlichen chitinisson Penisscheide und durch die relative Kürze der samenleiter unterscheiden. Der letztere C'harakter läßt sich diagnostisch nur so lange verwerten, als or von seinem fregenstïck durch rine breite Lïck' deutlich zn scheiden ist. Das ist aber meiner Ansicht nach schou jetzt nicht mehr möglich: denn wir kennen in der Reihe LimnodritoidesLimnodritus C'bergäinge zwischen den Zuständen kurzer und langer samenleiter. Als Limnodriloides mit rolativ ziemlich langem samenleiter muls vielleicht die kïrzlich von Porsxen ${ }^{2}$ ) als Isochaeta virulenta beschriebene Art angwsehen werdיn, als Limnodriloides mit relativ sehr langen samenleiter vielleicht meine ätere Art Limmodrilus baralensis. ${ }^{3}$ Limnodriloides verhält sich in dieser Hinsicht zu Limnodrilus, wie die früher als gesonderte Gattung gefiihrte Ciruppe Ilyodrilus zu Tulifex. Die Gattung Ilyodrilus mußte zur Gattung Tubifex gezogen werden (als Lntergattung), da wogon der sehr verschiedenen Länge der samenloiter innerhalb dieser cruppe rine generische Trennung ron Tubifex sich nicht mehr rechtfertigen ließ. Bei Limnodriloides kommt num als Unterschied ron Limodrilus das Fehlen viner deutlichon chitinäsun Penisscheide hinzu. Es ist aber fragheh, ob nicht auch hierin lbergänge autreten könnten. Eine zarte chitinöso Bekleidung des Penis-Apparates findet sich auch bei den Limnodritoides-Arten und bei Isochaeta virulenta 1. c. Pontwer Taf. 28, f. 7 ct.). Eine partiolle Verstärkung dieser chitinösen Brkleidung würde den ersten schritt zur Bildung der charakteristischen Chitinröhren typischer Limnodrilus darstellen.

1) Pieraxtoxi, Altri nuovi Oligocheti del Golfo di Napoli (Limnodriloides n. gen. . In: Boll. Soc. Nat. Naproli XVII, 1903, p. 191.

2) Ponten, Beiträge zur Kenntuis der Oligochaetenfauna der Gewässer von Graz. In: Zeitschr. wiss. Zool. XCVIII, 1911, p. 280, t. 28, f. 6-16, t. 24, f. 17-30.

3) Michaelsex, Oligochaeten der Zoologischen Museen zu st. Petersburg und Kiew. In: Bull. ete. Imp. Sc. St. Petersb. XY, 1901, p. 140, t. 2, f, 11-12. 
Eine solche Bildung findet sich bei Limnodrilus nevaensis Mren. ${ }^{1}$ ) Im C̈brigen gleicht dor Prnis-Apparat dieser Art so sehr dem ron Isochceta vimlenta, dab an oine generische Sonderung auf Grund dieser partiellen Cuticula-Verdickung wohl nicht zu denken ist. Will man nach dor Gestaltung des Penis-Apparates pine Sondermo rersehiedener Gattungen vornehmen, so mïBte Limnodrilus newaensis zwoifollos ebonso wie I. baicalensis zul 7sochaeta gestellt werden. Fraglich aber bleibt dann noch das Verbältnis der Limnodriloides-Formon zn Isochaeta. Inin Material von Limnodriloides Winckelmanni genügt leider nicht zur Feststellung dieser Organisationsverhältnisse, und aus den Pleraxtoxi'schen Angaben lïßt sich anch nichts sicheres entnehmen. Teh habe bei T. Winckelmami einen eigentlichen Ponis nicht erkennen kïmnen, nur cinen Pseudopenis, durch eine äubere: neben der männlichen freschlechtsioftinung stehende Papille gebildet. Nach Preaxtoxi soll bei seinen Limnodriloides-Arten die äufere Offinung des männlichen Ausfïhrapparates läutig aincn Penis tragen (.porta spesise 111 peno." 1. c. p. 186): doch ist seinen Detail-Angaben nicht zu entnehmon, ob es sich hier nu cinen oigentlichen Penis, wie bei Isochaeta, oder nur um pine akzessorische Hautbildung handelt. Eine Nachprïfung dirser Verhältnisser an roicherem und bosonders für diese /wrecke konscrviertem Material wär" erwïnscht. Mir scheint, daB Limmodriloides die unterste stufo riner Stufentolge bildet, doren höchste Stufe dureh die typischen Limmodrilus-Arten reprisentiert wird: Limoulriloides Winckelmanni (u. a.? - Isorhaeta virulentu - Limnodrilus newaensis - Limnodrilus udekemirnus CLAP. 11. a.

\section{Limmorlrilus alpestris Eisen.}

Tafel Y, Fig. 5 .

1879. Limnodrilus alpestris Ersex. In: Bihang Svenska Ak., V, Nr. 16, 1. 19.

1886. Limmodrilus alpestris Eswex, Oligochaetical Researches. In: Rep. U. S. Fish Comm., Xl, p. 896, Pl. 12, Fig. $11 \mathrm{a}-\mathrm{h}$, Pl. 17, Fig. $11 \mathrm{i}-\mathrm{k}$.

Fundangabe: lirootfontrin, im sande zwischrn Planzenwurzeln am Grunde oiner konstant fliefonden (pulle: W. Muchavlsex, 8. Juni 1911.

Weitere Verbreitung: K alifornion, Nirra Norada (nach Eisex).

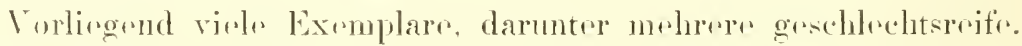

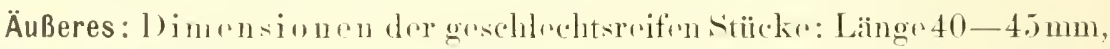
Jicke in der Jitte des anterelitellialen Kïrpertrils (*a. 0,5 1mm, an Mittol-

1) Murnass, Nelie Oligochaten und nene Fundorte alt-bekanter. In: Mt. Mus. Hamburg XIX, 1902, ]. 3, t. f. 2 chr. 
körper ca. $0.4 \mathrm{~mm}$, an Hinterkörper ca. $0,3 \mathrm{~mm}$. Crürtelegion bis zu einer Dicke ron etwa $0,6 \mathrm{~mm}$ angeschwollen, Segmentzahl ca. 180 .

Färbung der lebenden Tiere fleckig rot, stellenweise ziemlich dunkel lot, Hinterende blaß.

Kopf zygolobisch. Kopflappen von oben gesehen gerundet dreiseitig, breiter als lang.

Segmente des Vorderkïrpers rom 2. an bis etwa zum 6. zweiringlig. Vorderer Ringel viel kürzer als der die Borsten tragende hintere Ringel, etwa nur $1 / 5$ bis $1 / 4$ so lang.

Borsten am Vorderende bis zu 8 in den rentralen Bïndels, zu 6 oder 5 in den lateralen. Grogen das Hinterende veringern sich die Borstenzahlenn auf 2 und 1. An den unvollkommen gesonderten Segmenten des Hinterendes fellen die Borsten ganz. Am Vorderende rentrale Borsten mit stark gebogenem distalen Gabol-Ende. Gabelzinkon otwa im rechten Winkel abgebogen. Obrre Gabelzink ungefähr doppelt so lang wis die untere. Beide Gabelzinken an der Basis ungefähr gleich dick. Dorsale Borsten mit etwas weniger stark (etwa um 450) abgrbogenen Gabelzinken, dic ebenfalls basal ungefähr gleich dick sind, während die obere ca. doppelt so lang wie dio untero ist. Bej ventralen und lateralen Borsten rin drutlich ausgreprägter Nodulus ungeführ am Endo des distalen Drittels. Längo piner dorsalen Borste des 4. sogments ungefälır 0,1 mm. Dicke oberhalb des Todulus ca. $6 \mu$. Die Borsten des Hinterkörpers werden allmählich klriner.

Gïrtel ringförmig, am 11. und 12. Segment.

Iänuliche Poren an stelle der zurüekgrbildeten ventralen Borsten des 11. Siegments.

Weibliche l'oren dieht hinter Intersegmentalfurehe 11/1: in den Linien dex ventralen Borstenbündel.

Samentaschen poren dicht ror den rentralen Borstenbiundeln des 10. Segments, die normal ausegebildet sind.

Innere Organisation: Dissepimente sämtlich zart. Dissepiment $3: 4$ vollkommin ausgebildet.

Darm: Fchlund bis an Dissepinent $3 / 4$ nach hinten reichend, dorsal ausgesackt, mit undeutlich ausgeprägtem dorsalen sehlundkopf, rentral mit lohem, faltenbildenden Epithel. Osophagus im 4. und 5. segment, an Anfange des 6. Segments sich zum Mitteldarm erweiternd. ChloragogenzellenBusatz rom 6. Feoment an rorlanden.

Blutgefä system nicht ganz klarzustellen. Es scheint nur ein cinziges Paar stärker angeschwollener Transrersalgefässe im 8. Sregment vorzu11 Michaelsen, Deutsch-sidwestafrika. 
kommen. Im 9. Negment finden sich nur dünne Transversalgefäße. Ein integumentales Blutgefäßssstom war nicht nachzuweisen.

Grhirn hinten ziemlich stark ausgeschnitten (?: nur an einer Sagittalschnittserie untrersucht).

Nephridien anscheinend sämtlich ohne Blasenzellen-Besatz.

Männlichs Geschlechtsorgane: Ein Paar großu Hoden ragen rom ventralın Rande drs Dissepiments 9/10 in das 10. Segment hinein. Jo ein unpaarigor Samensack ragt von Dissepiment $10 / 11$ nach vorn in das 9 . Segment hinein und ron Dissepiment 10/11 nach hinten in das 11. Segment und die folgendru (?). Der vordere samensack im 9. Sogment ist kloin und fast kugelig. Der hintere Sameusack ist schlauchförmig und ragt wahrschcinlich (nicht genau erkannt!) in die vordero Partio des Eicrsacks hinein. Ein Paar mäBig große, ziemlich flache, gefältelte blumenkelchförmige Samentrichter sitzen vorn ventral am Dissepiment 10/11 im 10. Segment. Die Samonleiter sind eng und ziemlich lang, nnregehmäBig gewunden. Distal gehen dio ca. $7 \mu$ dicken samentriter in ziembich deutlichem Absatz in die Atrion über. Die Atrion sind stark gebogen, spindelförmig, $0,2 \mathrm{~mm}$ lang und im Maximmm, "twas proximal von dep Mitte, ca. $40 \mu$ dick. Distal verengen sie sich alluählich bis zu niner Dicke von etwa $16 \mu$. Die Atrien tragen jo rine ziemlich kleine, tief eingeschnittene, gelappte Prostatadrïse. Ilas distale Ende des Atriums geht in seharfem Absatz in den grate gestreckten, ca. $0,35 \mathrm{~mm}$ langen und an den Enden $60 \mu$, in der Nitte $40 \mu$ diekın P'enisapparat ïbrer. Dor Pronis besitzt cine chitinöse Penissehride ron charakteristischer (rostalt (Tafol V, Fig. 5). Sie ist gerade gestreckt, ca. 0,135 mm lang und an drer engsten stolle, rtwa am Ende des distalon 1)rittols, ca. 20 e diek. Sire erweitert sich gegen die Enden, langsam und gleichmäbig gegon das ca. $33 \mu$ dick" proximale Ende. schurllor, trichterfömig, gegen das otwa 48 p worte distale Ende. Dor land dos proximalon Endes ist ganz glatt, kreisförmig, der des distalen Fndes ist unrogelnäbig, strllowweise mit gerundeten Vorsprïngen, im allgemoinen sehr foin, stollonwoise, zumal an den Vorsprïngen, etwas verdickt.

Wejbliche Greschlechtsorganr: Fine Paar große (Garien hängen rom ventralen liand des l)issepiments $11 / 12$ in das 12 . Segment hinein. Ein unparigor, sich nach linton bis in das 16. Srgment (oder woiter?) restreckender Eiersack enthält mehrere grobe, bis ea. $0,25 \mathrm{~mm}$ dicke Eier. 1) ir Eiloiter schoinen auf rine trichterförmign Einsonkung des Dissepiments i 1/12 bexchüäkt zu soin.

samontaschon: Ampullo schlank sackförmig, umregrelmäBig verbogen

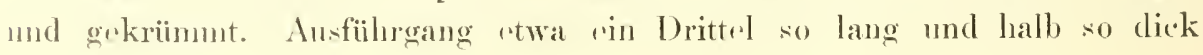


wie die Ampulle, ron der er ziemlich scharf abgesetzt ist. Der Ausfühırgang ist bei dem näher untersuchten Stück in der Mitte undeutlich erweitert (normaler Zustand oder zufälliger Kontraktiouszustand?). Die Samentaschrn rnthalten Spermatophoren. Diese Spermatophoren sind zu einem kleinen Bïndel zusammen gedreht, und bilden daher im Einzelnon eine schlanke, ziemlich unregelmäßige Spirale. Die spermatophoren sind sehlank, ca. $0,2 \mathrm{~mm}$ lang und im Maximum $20 \mu$ dick, an einem Ende ziemlich plump, am anderen Ende zu einem dïmeren, meist stärker gekrïmmten Faden ausgezogen.

Bemerkungen: Nur unter einem gewissen Vorbehalt ordne ich die vorliegende Form dem kalifornischen Limnodritus alpestris Ersex zu. Die Original-Beschreibung dieser Art ist sehr liickenhaft: zumal fehlt ihr jegliche Angabe iiber die Borstenverhältnisse: so daß eine Identifizierung nach der Original-Beschreibung nur unsicher sein kann. Leider konnte ich auch an dem südwestafrikanischen Material nicht alle fiir die Srstematik wesentlichen Organisationsverhältnisse klar stellen. $\operatorname{Lm}$ eine etwaige spätere Richtigstelhung zu ermöglichen, gab ich rine genauere Besthreibung des vorliegenden Materials.

\section{Fam. Enchytraeidae.}

\section{Lumbricillus verucosus (Clap.).}

Tafel V, Fig. 8.

1S61. P'achydritus vervcosts, Chapanéde, Recherches anatomiques sur les Annélides, Turbellariés, Opalines et Grégarines observés dans les Hébrides, In: Mém. Soc. Genéve XVI ${ }^{1}$, 1. 8ะ, t. 1 f. 1--6.

1896. Pachudrilus maculatus, Bretscuer, Die Oligochaeten von Zïrich. In: Rev. Suisse Zool., III, 1. 513, t. f. 2, 3 .

1896. Pachydrilus remrucosus, UDE, Enchytraeiden. In: Erg. Hamburg. Magallaens, Sammelreise, p. 3 , t. f. 6 a $a$. $b$.

1900. Lumbricillus verrucosus, Mrchatusex, Oligochaeta. In: Tierreich, X, p. s0.

Fundangabe: Liideritzbucht, am Meeresstrande unter angeschwemmtem feuchten Tang: W. Michaelsex, 22. Juli 1911.

Weitere Verbreitung. Sü d-Feuprland (Uschuaia), Hebriden (Insel sky); Grobbritannien (Schottland, Irland, England), NordwestFrankreich (Loire Inférieure), șchweiz (Hitnau).

Vorhegend zahlreiche unreife und mohrere geschlechtsreife Exemplare. 
Bemerkungen. Die vorliegende Form ist zweifellos mit der von UDE beschriebenen Form von siid-Fenerland identisch und höchst wahrseheinlich auch mit der C'Laparìneschen Hebriden-Form. Es liegt nach dem Fund von Tiren, die meist im Maximum 4 borsten in einem Bündel besitzen, kein Grund mehr vor, Bretschers Pachydrilus maculatus von der Chararèueschen Art gesundert zu halten. Es erscheint mir ganz belanglos, daß Buetscher. we ja anch C'Laparèue, den Drüsenkranz an der Basis der s'amentaschen unerwähnt lïßt und ihn anch in der Abbildung von der heranspraparierten Samontasche, die ja oberhalb des Drüsenkranzes abgerissen sein mag, nicht andeuter. 1)ie Abbildung der samentasche (1. (. p. 514 tf. 3) ist übrigens nachweislich ungenau; dem der proximale Pol der Samentasche erscheint hire geschlossen und intakt, während er doch mit dem Darm zusammengehangen hat, also cntwreder das Kommunikations-Loch oder an seiner stelle aine Zerreifumg zeigen müßtr.

Zur Organisation der vorliegenden stïcke ist noch folgendes zu bermerken:

l)ie Borsten stehon in den ventralen Bündeln dos Vorderkörpers meist zu 4 im Bïndel, soln selten zu 5 , in don lateralen Bündels dos Torderkiirpers, soweit beobachtet. stets zul 3. Am Hinterkörper ist dir Kahl drep Borston um 1 grringer, also 3 bezw. 2 im Bündel. (Nach Une 3, 4 oder 5 im IB̈̈ndıl. - "Häutig enthaltrn die dorsalen Bïndel oine Borste weniger als dio ventralen." Nach Claparède ,par faiscratx 3 aे 5.0

Das G ehirn (Taf. V, Fig. 8) ist nicht ganz doppolt so lang wie im Maximum breit, hinton in zwoi gerundet rechtwinklige Liippchen ausgezogen, zwischen denen ein dentlichere, aber nicht grober, gerundet rechewinkliger bis fast halbkroisfömiger Ausinchnitt lingt. Dor Vorderrand orseleint in dor Ansicht ron oben nicht ansgeschnitten, sondern schwach konvex, da dere vordere "Teil des Gohirns abwirts gobogen und die Aste der Schlundkommissur infolgedessinn nicht ganz rorn entspungen. Ein nach rorn stark geneigter Horizontalabschnitt zeigt jedoch eine schwache Konkavitat zwischen

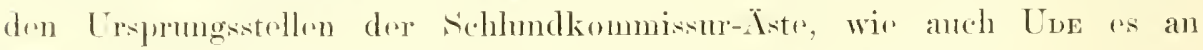

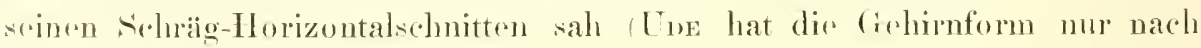
solvhen Schnitten fostgestrilt).

Jie śanontaschen wind an der baxis ron einem ziemlich großen, kompakton Drisenkranz mngoben, wie bri den feurländischen stücken.

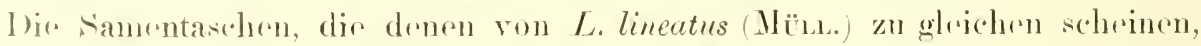
mïnden proximal in den Oxophagus oin. 


\section{Mirhaelsena georgiana (Mich.).}

18SS. Enchytraeus monochaetus, Mrchaelsex, Die Oligochaeten von Süd-Georgien nach der Ausbeute der Dentschen Station von 1882-83. In: Mt. Mus. Hamburg, V, p. 66, Taf. II, Fig. $6 a-c$.

1900. Enchytraeus monochaetus, Michancsex. Oligochaeta. In: Tierreich, X, p. 91.

1903. Michaelscna monochaeta, Michaecsex, Die geographische Verbreitung der Oligochäten, Berlin, p. 56.

Fundangabe: Lüideritzbucht, in einer an den Strand geschwemmten, anscheinend noch ganz frischen Spongie: IV. Mhchaelsex, 21. Juli 1911.

Weitere Verbreitung: Siid-Georgien (nach Michaelsex).

Torliegend 2 geschlechtseife Exemplare, die in ihrer Organisation ganz den Originalstiicken ron Siid-Georgien entsprachen.

Bemerkungen zu der Morphologie der Gattung Michaelsena sielse unten im Anlange, in den Bemorkungen zu M. Mangeri 11. sp. von Kamerun.

\section{Fallm. Alluroididae.}

\section{Allmoides tamyamyliare Bedd.}

'Tafel $\mathrm{r}$, Fï. 13.

1906. Alluoiles tamuanyikae, BEmaru, Zoological liesults of the Third Tanganyika Expedition ete. Report on the Ohigochaeta. In: Proc. Zool. Soc. London, 1906 I, p. 215. 1912. Alluroides tun!umikae. Micnatssx, Oligochäten vom tropischen und siidhich-subtropischen Afrika I. In: Zoologica Heft 67, p. 145, Taf. XIX, Fig. 9.

Fundangabe: Rhodesia, am mittleron Sambesi in dop Nïhe der Victoria-Fälle, in morastiger Erde zwischen fraswurzehn mo in Uformorast: IV. Micmaelsex, 15. August 1911.

Weitere Verbreitung: Tanganyika-sos (nach Redodis).

Bemerkungen: Da der Originalbeschreibung nur ain rinziges Exemplar zu Crrunde lag und sir deshalb mur unvolstandig sein konnte, so mögen hier cinige rrgänzendr Bemerkungen ïbor die immere Organisatiou von Alluroides tunganyikae gemacht worden.

Leibeswand: Die Lïngsmuskulatur des Hautmuskelschlanches wird ron selır frinen, schmalen und dïmen Bandmuskeln gobildet, die am Vorderkörper in unregehnäbiger mehrfacher Lage vine verhailtnismäBig dicke sichicht, am Yittel- und Hinterkïrper cine schicht von geringerer 
Dickr bilden, in der sio jedoch auch nicht in rinfacher Lage, wronn auch nirht in so vielfacher Lage wir am Vorderkörper, angrordnet sind.

Norrosystom: 1)as (iohirn ist ziemlich kompakt, fast doppelt so broit wir lang, hinten jederseits etwas gewulstet und modian ausgeschnitten.

Iännlicho Grsehlochtsorgane: Dir Organisation der männlichen (reschlechtsorgane ist mir nicht ganz klar geworden. Fin Paar Hoden hängen von l)issepiment $9 / 10$ in das 10 . Segment hinein, eingebrttet in anscheinend frew samenmassen, die fast die ganze Loibushöhle des 10. Segments ausfüllon. Auch im 11. Segment tinden sich grobe Massen sich ontwickolnder männlicher Geschlechtsprodukte, und zwar anschoinend ron rincm feinon Häutchen wmhïllt. Es macht dicso ()rganisation demnach den Eindruck, als rage rin äuberst feinwandiger, rom weit offener Samensack vou Dissepiment 10/11 in das 11. Segment hinein. Fin Paar ziemlich kloine, unregulnäbig fältelige Samentrichter ragen rom rentralen Tril des Dissepiments $10 / 11$ in das 10. Sogment hinein. Diess Samontrichter sind eng an dir samenmassen des 10. Segments angeschmiegt. An manchen sehnitton kam as mir so vor, als scoion auch dieser Samemmassen des 10. Segments sant den Hoden und den Samentrichtern von rinem feincen Häutchen umhüllt, also in aine Testikulblase eingeschlossen: doch konnte ich dies nioht sicher nachweisen. Es wollte mir nicht gelingen, an einer Schnittserie dio mutmablich sohr dünnon samenteiter nachzuwoisen. Die dicken, langen, rine dureh mehrere segmente nach hinten ragende Schleife bildenden Atrion enderen proximal dicht hintre Dissepiment 12/13 in rogermäbiger', anscheinend intaktor Rundung.

sam cntaschen-l'orus: J)ir Samentasche mïndet, wio ich schon

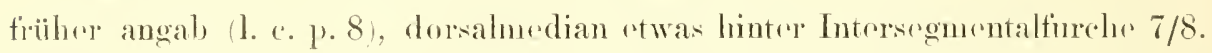

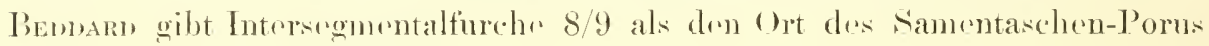
an I. (. 1).216), und zwar nicht nur fiur . 1. tangunyikae, sondern für dio

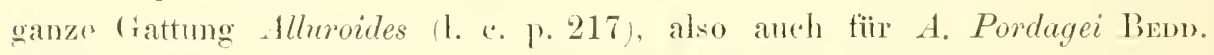
Jiese letztere Angaber stimmt jedoch wedere mit meinem Bufunde an 1. tanganyike noch mit Bewdums Abbildung von A. Pordagei'). Hier liegen dir bri A. I'omdayed parrigen Samentasehen-Pomen aut dem 8. Sog-

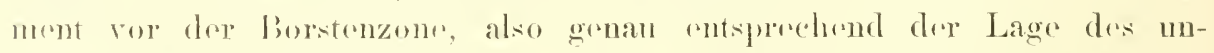

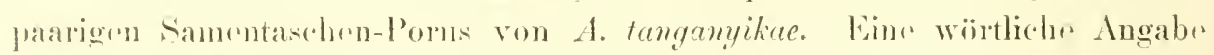

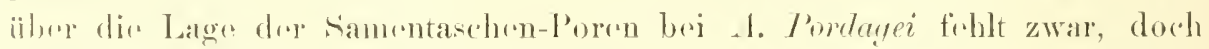

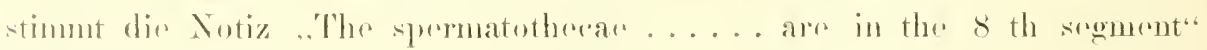

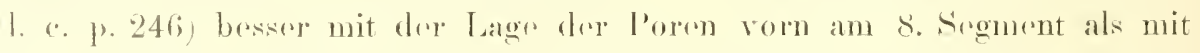

1) F. H. liemskn, A ('ontribution to our Kuowlenge of the Oligochaeta of Tropical

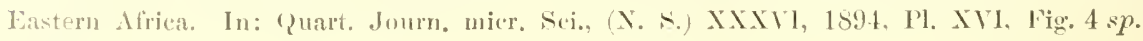


der anf Intersegmentalfurche 8/9, wie sie der allgemeinen Angabe Beduaros ïber die Gattung Alluroides entsprechen wïrde. Ich darf wohl annehmen, daß diese Angabe Bendaros auf einem Versehen beruht.

Die s'amentasche (Taf. V, Fig. 13), von BevoAm, als, ,an oval sac" bezrichnet, ist nicht so rinfach, wie nan ats jener Angabr schließren kïnnte. Sie zeigt ane dentliche Sondermo in Ampulle und Ausfïhrgang. I)ie Ampulle ist unregchmäBig sackförmig. plattgedrückt und rorschrumpft, zurïckgeschlagen, ungefahle so lang wir breit. Die Wandung der Ampulle ist verhältnismäßig dick, aber doch viel dünner als die des Ausführganges; ihre Muskelschicht ist sehr zart. Dor Ausfühlegang ist ziemlich seharf rom der Ampulle abgesetzt, lainger als die Ampulle und viel dïmner. I) proxinale Teil des Ausfülrganges ist im Querschnitt oral, jedoch nur wenig breiter als dick. Das Elithel des Ausfihrganges zeigt hier hohe, weit in das Lumen hineinragende und das Lumen rerengende Längsfalten, wälerend die AuBenflache des Ausführganges glatt ist. In der distalen Hälfte, in dor sich diese Längsalten verliren, ist der Ausführgang von vorn nach hinten abgeplattet und stark rerbreitert, gegen das äuberste distale Ende, also an der Ausmïndung, wiedere otwas versehmailert, ohne jedoch die Schmalhrit der proximalen Partie zu rreichen. I)er Ansführgang ist riol dickwandiger als die Ampulle. Diose Dickwandigkeit beruht liauptsächlich atuf dor starken Ausbildung der Iluskulatur. Im distalon Toil des Ausführoanges kommt auch noch rin mäBig dicker äuburer I)rïsubsatz hinzu. Der Ausfïhrgang geht rom samentaschen-Porus aus hauptsächlich gerade nach hinten. Erst soin proximaler Teil woicht zur soite, um soitlich in dir zuriekgesehlagene Ampulle ïberzugehen.

\section{Fam. Megascolecidae.}

\section{Unterfam. Acanthodrilinae.}

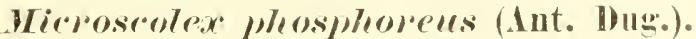

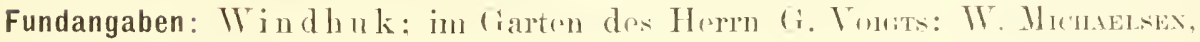
7. IIai 1911.

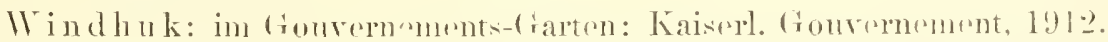

Weitere Verbreitung: Jurch Vrechleppung und vinlloicht als murylualino

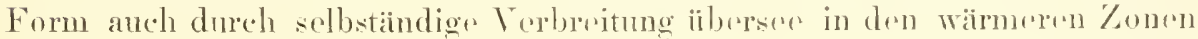


circummundan, doch im tropischen Afrika nicht gofunden; nächstliegender Fundort: Kloin-Namaland im Kaplande.

Bemerkungen. Diese Art ist zwroifollos durch den Mrensehon in DeutsellSiidwestafrika dingeschlepet wordin. Den mir rom Kaiserl. Crourernement iibersandten Tieren war die Notiz beigefïgt, dab sie im Dunkeln leuchteten. Diese Eigenhrit ist bekanntlich schon molurfach an dieser Art beobachtet worden, wie der Artname andeutet, auch sehon ron ihrem Autor.

\section{Unterfam. Trigastrinae.}

\section{Dirhoyaster Amuce Horst.}

1894. Benhamia imnae, IIoRst, Earthworms from the Malay Archipelago. In: \%ool. Erg. Reise Niederländ. Ost-1ndien, 1II, 1. 32, P'l. II, Fig. 1- \%

1895. Benhumia insularis, Micuatesex, Zur kenntnis der Oligochäten. In: Abh. Ver. Hamburg, XIII, 1. 31, Tat. Fig. 13.

1900. Dichouaster Amnar und I. insuluris, Mscnsenswix, Oligochaeta. In: Tierreich, X, p. 347,347 .

Fundangaben: Watrobre, im Garten; Frïulein MarTu NAss, 1911.

Okahandja, im Forstgarten: (i. Fock, 1910.

Weitere Verbreitung: Sierra Lrono Schorbo-Insol), Kamerun, Comoren (Johanna), Jara.

Bemerkungen: Diclogaster lnnae steht zweifellos der D. atjinis Mron. seler nahe. Dir Unterschiedo zwischom beiden sollen anf der Grostalt des

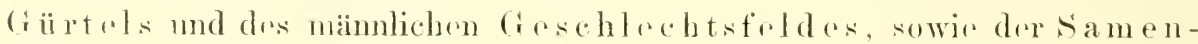

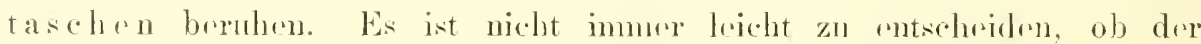
Giirtro rinos Stiickes ringfïrmig oder sattelförmig ist. Auch der ringfömign Giirtel ist meist ventral schwächer ausgolildet. Tritt num in der

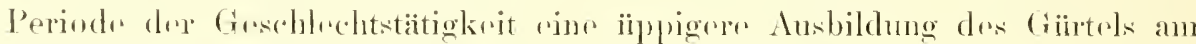
Kiieken and an den seiten rin, während die an und fiir sich schon

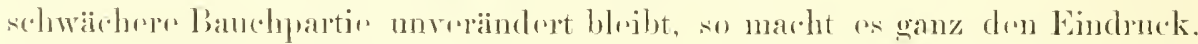

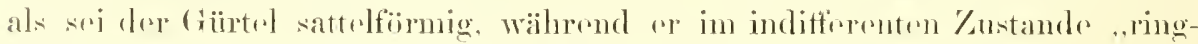

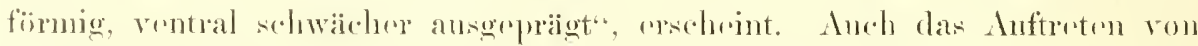

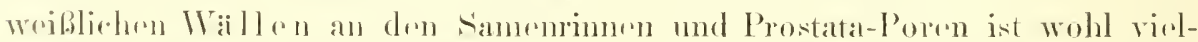

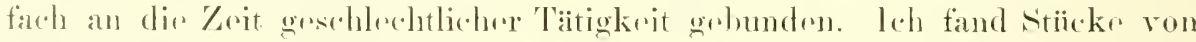

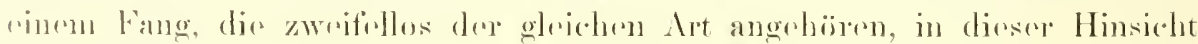

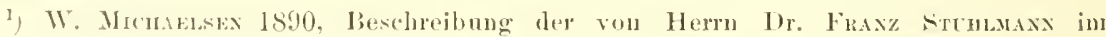

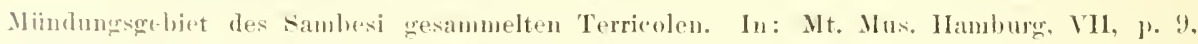
Taf. 11, Fig. 20. … 1900, Oligochateti. In: Tierreich, X, 1. 345. 
verschieden ausgebildet. Die Gestaltung dor siamontaschen ist bei D. affinis und D. Anwae fast die gleiche; anschrinend gröBere Untersehiede in den Beschreibungen berulien auf unrichtiger Darstellung. In den Diagnosen, gegeben 1900 im 'Tierreich X. p. 345 und 347, bestimme ich füir D. affinis: ,Wamentaschen mit sehr dickem, längeren Ausführgang, der dicht distal ron seiner Mitte rin kleins keulenförmigns Dirertikel trägt", und für D. Annae: "Ausführgang der Samentaschen schlank, wenig längur als dir birnförmige Ampulle; oin schlankes, schlauchförmiges, schwach angeschwollenes, herabhängendes Dirertikel mïndet an der Girenze von Ausführoang und Ampulle." Dir letztere Darstellung (iiber D. Innae) beruht auf einer irrtümlichen Auffassung von Fig. 5 anf 'Tab. II des Horstischen Werkes 1. (. 1894). Ich habe den Beginn des Austïhrganges irrtïmlich mit dem Beginn der engstrn Partie hier mïndet das Divertikel ein), identitiziert, während der Verlant des muskulosen Bulages dentlich zeigt, dab der Ausführgang proximalwärts noch ein brträchtliches stïck weitrer geht. Tatsächlich miindet also bei D. Annae das Divertikel in den proximal angeschwollenen Ausführgang, etwas proximal ron dessen Mittr. Auch beri D. affinis mïudet das Divertikel proximal, nicht distal ron der Mitte, wio irrtiimlich angegeben, in den Austührgang. Die irrtimliche Angabe beruht daraut, dab ich beri dor Präparation des winzigen originalstiickes nur rin Bruchstïck der samentasche zu sehen bekam, und dieses für rine vollständigo Samentasche hiolt. Mrine Angabe (1. (. 1890, 1). 11), dafo die Samentaschen genau dieselbe Gestalt wie die der D. Stuhlmanni haben sollten, und dere Hinwois auf dir Abbildung dirser letztren (l. c. Tat. I, Fig. 8) ist demnach unrichtig. Dio Entersuchung an anderem. zweifollos zu J. affinis gohörendem Material ergab, dab der Autührgang bei dor beobachteren Samontasche des (riginalstückes etwa zur Hälfte abgerissen gewesen srin mußte, daß auch beri $D$. aftinis der Ausührgang länger als dir Ampulle, distal rerengt, ist, und dab das Divertikel proxinal von der Mitte des Ausführganges mïndet.

Als wesentlicher Enterschind zwischen 1). Annae und D). atrinis ist wohl das Fehlen bezw. Torkommen ron ventralmedianen intersegmentalen Papillen anzushen. Bei 1). Annae, dis iibrigens nine etwas robustere Form zu sein scheint, sind nir derartige Papillen brobachtet worden: bri D. af̈̈nis scheinen sir nu1 soltun ganz zu fohlen. so dab man dirse Art stets rekennen kann. wenn man pine Anzahl von Exemplaren von rinem Fundort zur Vorfïgung hat.

Iras H. insuleris anbetrifte. so bloibt nach Hinwegfall der siamen-

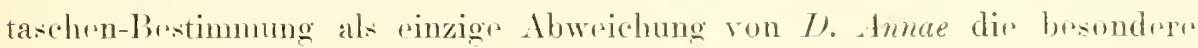


Borsten-Anordnung. Bei I). insularis soll dic rentrahmediane Borstendistanz etwats kleiner als dir mittleren lateralen Distanzen sein ( $a a<b c)$. sollte dieser geringfügige Lntroschied nicht etwa auf ainer besonderen Lonserviermg des cinzigen zur Beobarhtmng golangten stückes zurückzufïhren sein? Ich glaube nicht, daß man diese Art anf diesen geringtïgigen und unsieheren ('barakter hin anfereht erhalten dart, und rereine sie deshall, mit I). Innae (Hokst).

Zur inneren Organisation der südwestafrikanischen Stücke von D). Annae ist noch zu bemerken, dab hier die Mikron nohridirn des postclitellialen Körpers nicht immer zu + jederserts in einems seoment liegen, wio es der Griginal-Jiagnose cutspricht. Es fanden sich violfach deren 5, und zwar

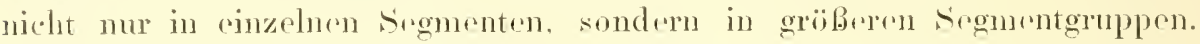
bir Vierzahl schroint jedoch in allgemeinen vorherrsehend zu sein. Ich labe schon frïher, bej D. Bolaui (Mren.) und der von mir daranfhin eingezogenen Form Benhamia octonephra liosa, auf die Variabilitat dieses C'halakters bej der Gattmog Vichogaster hingrwiesen.

Jichoguster Amnae gehïrt zu den kleinen, woit varbreiteten. zwaifellos

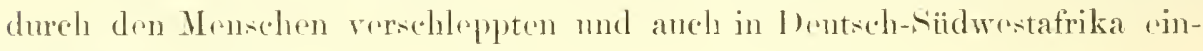

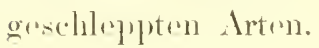

\section{Unterfam. Ocnerodrilinae.}

\section{Golvliorlrilus Luglierleni Hich.}

Tat. I., Fig. 14.

1913, Fordiodritus Lumkerleni, Mundessex, ()ligochäten rom troprischen und siidlich subtropischen Afrika. Il. In: \%oologica, Heft 65, p. 9. 'Fat'. H. Fig. 21, Textig. 4.

Fundangaben: Rhodesia, am mittleren sambesi bej don Victoria-Fällen: II. Michaelsen, 1s. August 1911.

Farm ()kosongomingo am Kloinun II atrrberg: H. 'Tuousex, \u@ist 191:.

Otjurutjondjou am Oborlauf des(1)uramba. im Siande des Flnsose; Fräblein Mancula Nass, Januar 1912.

Bemerkungen: Torliegend melurere Fxemplare, von drmen kiness roll-

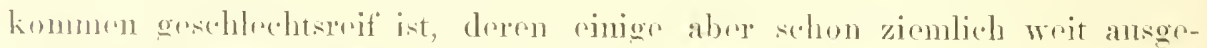

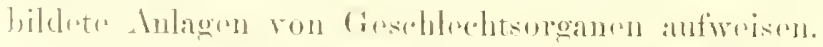

1)iese dentsch-sïdwestatrikanischen stiicks stimmen in allen wesent-

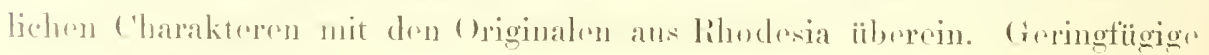


Abweichungen mögen auf abweichender Konservierung beruhen. wenn nicht darauf, daß es sich um halbreife Stïcke handelt, während ich zur Feststellung der Charaktere bei dem Original-Laterial vollreife Stiicke benutzto.

Dimensionen: Die Dicke, bei größreren Stïcken rtwa 1,7 mm, ist etwas beträchtlicher als bei dem Original-Material (1.4 mm).

Der Gröben-Unterschied zwischen den Prostata-Papillen des vorderen und hinteren Paares ist fast noch auffallender als bei dem () riginalMaterial und zweifellos ein wesentlicher Charakter der Art. Zu bemerken ist, daß auch bei dem weitest rorgeschrittenen Stiick ron Otjurutjondjou die rentralen Borsten des 19. Segments sämtlich noch erhalten geblieben sind, während bei vollreifen Stiicken von lihodesia die Borsten b des 19. Segments (wie in allen Fällen die Borsten $b$ dos 18. Segments) geschwunden sind. MutmaBlich wïrden auch bei dem neuen Material die Borsten $b$ des 19. Segments bei Weiter-Entwicklung dre Prostata-Papillen noch ausgefallen sein.

Das Dissepiment $8 / 9$ ist bei dem neuen Material anscheinend ebenso stark verdickt wir das Dissepiment $7 / 8$, während es bei den RhodesiaSticken sehwächer erschien — jodenfalls ein wenig belangreicher Lnterschied.

Darm: Die Chylustaschen (Taf. $Y$, Fig. 14) zeigen im wesentlichen die gleiche ungemein charakteristivehe Gestaltung wie bei dem OriginalMaterial: doch sind die bei letzterem „mäßig eng kanalförmigen“ Lumina bei dem neuen Material writer, so daß sie kaum noch kanalförmig genannt werden können - eine belanglose Abweichung, wahrscheinlich nur beruhend auf einer Aufblähung der Lumina bei der besonderen Konservierung des nenen Materials. Die Zahl der Sonder-Lumina scheint bei dem nenen Material konstant 4 zu sein (bei dem Original-Material „bis 5*).

II ännliche Geschlcehtsorgane: Zwei Paar grobe Hoden ragen frei ins 10. und 11. Segment hinein (bei den ()riginalsticken nicht deutlich erkannt, wahrscheinlich infolge von Ausreifung schon in Aufläsung begritten Im 9. Segment fand ich niemals freis Samenmassen odre Samensäcke, ebensowenig wie bei dem ()riginalmaterial.

\section{Govrliorlvilus Chumi Michaelsen.}

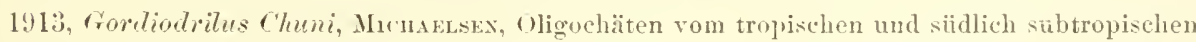
Afrika. II. In: Zoologica, Heft 68, p. 7, Taf. II, Fig. 17, Texttig. 3.

Fundangabe: Rhodesia, Kandalar-Insol im mittloren Sambesi einige Kilometer oborhall der Victoria-Fällo, in humöser Erde am Fluf-Lfer; W. Michaelsen, 17. August 1911. 


\section{(omerortrilus (Ocmenortuilus) oreirlentalis Eisen.}

Fundangabe: s'reheim, in teuchter Erde am Utor rines konstanten Grewissers im liett des Groben Fiscliflusses in der Nähe eines (iartens): IV. Michaessex, 18. Juli 1!11.

Weitere Verbreitung: lihodesia (Bulawayo). Kap Vordesche Inseln. Comoren, Californien, Arizona, Mexico, St. Thomas, Ceylon. Vorderindicn (Travancore).

Bemerkungen: Diese Art hat ihre fast circummundane Verbreitung zwoifellos melufacher Vrrschleppung durch den Menschen zu verdanken. IV enngleich dis Gattung (merodrilus sichere rudemische Vorkommnisse in Siidafrika anfweist, so gibt uns dieser sïdwostafrikanische Fund von O. oceidentalis doch keinen AufschluB ïber den C'haraktrer der Oligochätronfauna des Grobots, da soine endemische Natur zum mindesten sehr zweifelhaft ist.

\section{Iygmacorbilus arausionensis Mich.}

Textfigur 1 und 'Taful V, Fig. 15.

1910, Py!m. arausionensis, Micmatsex, Oliguchäten von verschiedenen Gebieten. In: Mt. Mus. Hamburg, XXVII, I. 114, Taf. Fig. 17.

Fundangabe: Grootfoutein, am Rande rines Teiches und am Grunde eines kleinen baches zwischen den Wurzoln von Pflanzen: W. Michaelsen, 7.-11. Jumi 1911.

Weitere Verbreitung: () ra n e-Kolonie (Bothavillı, nach Michaecsex).

Vorliegend zahlreiche Exemplare, darunter melurere halbreife und 3 vollkonmen geschlechtsroife, mit einem Gürtel ansogstatete Tirre, die mich in den stand sotzen, dio nach sehr spärliehem, nur halbreifem Material aufgestrltte Diagnose zu vervollständigen und in einigen J'unkten zu berichtigen.

Äußeres. Dimonsionmn: Halbreifo 'Tiors bis $65 \mathrm{~mm}$ lang und im Maximum bis 2 mm dick; Segmentzahl his 1요. Dio volkommen ge-

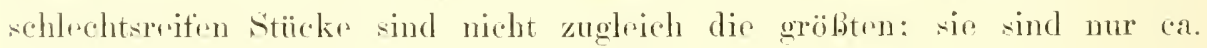
$5.5 \mathrm{~mm}$ lang bei siner maximalen Dicke von $14 / 5 \mathrm{~mm}$, und die segment-

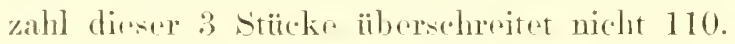

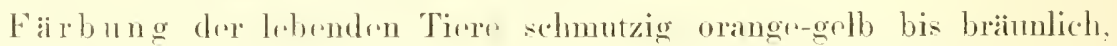
der konservierten Stückr vinfarbig gran oder gellubraum; pigmentlos.

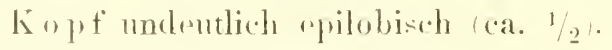

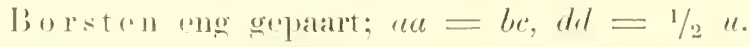

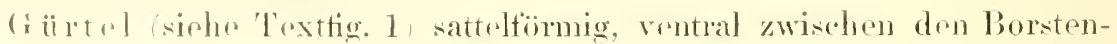
linien e unterbrochese, am 13.-19. segment $i=7$, aber am 13 . und 
19. Segment weniger scharf ausgeprägt, an 13. Sogment bri rinem Stilck nur dorsalmedian erkennbar. Die Intersegmentalfurchen 13/14 und 18,19 sind weniger vollständig ausgeglätet als die übrigen Intersegmentalfurehen der Giirtelregion.

II änuliche Poren (siche Textfig. 1) am 17. Segment an Stelle der fehlenden Borsten ab, auf stark vorragenden, mehr oder weniger deutlich abgeschnürten riförmigen Zäpfehen, die auf der Kuppe je rines quer-ovalen, fast habbugeligen Tuberkels strhen. Die Tuberkel nehmen fast die ganze Länge des 17. Segments ein und sind ventralmedian nur durch einen kleinen Zwischenraum vonernander getrennt.

Weibliche Poren siehe Textig. 1) vor din Borsten $b$ des 14. Segments oder ein sehr geringes median von dieser stelle, aber immer noch lateral rou den Borstenlinien $a$, rou diesen weiter entfernt als ron den Borstenlinien b. Die weiblichen Poren stehen auf winzigen Papillen, dir ron einem mehr oder weniger dentlichen, unscharf begrenzten Driisenhof umgeben sind.

samentaschen-Poren siehe T'extfig. 1।, I Paar auf Intersegmentalfurcho $8 / 9$ in den Borstenlinien $b$ (nicht ab, wie in der () riginalbeschreibung irrtiumlich angegeben , klein L Lïher, dis von unscharf begrenzten.

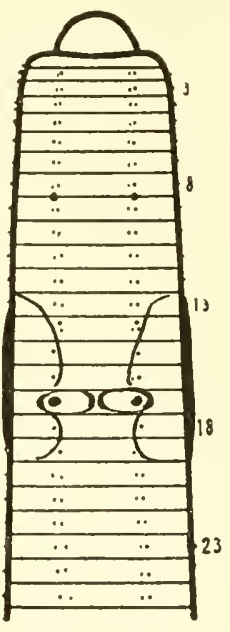

Fig. 1. P'y!marodilutus arausionensis: Mich. Vorderköruer von der Ventralseite (schemat.). Hachen oder schwach erhabenen Drüsenhöfen umgeben sind.

Innere Organisation: Dissppimpnt 6/7 und 78 mäBig stark rerdickt, 56 und $8 / 9$ swhe wenig verdickt, fast als zart zu bezeichmen, 9/10 kaum merklich verdickt, alle übrigen sehr zart. Dissepiment 4 is deutlich ausgebildet. Yeine abweichenden Angaben in der Originabeschreibung, nur auf der Untersuchung eines freihändig präparierten Stiicks beruhend, sind irrtïmlich, wir die Cntersuchung an einer nachträglich angefertigten rehnittscrie durch ein unreifes Tier ergab.

Darm: Die septaldrïsen sind bei dem neuredings untersuchten Material am stärksten im 5. Segment ausgebildet, im 6. Segment viel kleiner: in das 7 . Segment scheinen nur winzige Teilstiicke der lappigen Septaldrüsen hinein zu ragen. In der Ausbildung der Septaldrüsen scheint ein geringer Unterschied zwischen don südwest-afrikanischen stücken und denen von der Oranje-Kolonie zu liegen: doch ist dieser Tntreschied jedenfalls nieht so groß, wie nach den Beschreibungen angenommen wreden müßte. Bei dem neuerdings untersuchten Stïck von Bothaville waren, wie bei den stücken ron Grootfontein, dis Septaldrüsen im 5. Segment am 
größten und die des 7 . Segments am kleinsten, aber diese letzten doch noch von ansehmlieher firöbr, nicht so klein wie bei den südwest-afrikanischen Stiicken. Die Größe der verschiedenen Septaldrüsen mag variabel sein.

Von einem Inskelmagen ist keine Spur exkennbar. Die paarigen ('hylustasehen in 9. Segment varieren etwas. Die Zahl der Längsscheidewände ist nicht konstant, und sie stoßen nicht immor sämtlich in der Achse der Tasehe zusammen. In einer Chylustasche fand ich 9) vollständige, in der Achse zusammenstoßende Längsscheidewände und 5 mvollständige, die saumförmig an der Wandung der Chylustasche entlang laufen und dir primären Kammern unvollkommen teilen. An einer anderen Chylustasehe fand ich nur 6 vollständige und 7 unvollstindige, von denen 5 zusammen in der einen der primären Kammern lagen. Der Osophagus erweitert sich im 12. Segment plïtzlich zum umfangreichen Mitteldarm.

Nophridien ungefähr rom 13. Segment an von fottkörperartigem Aussehen.

Letzte Herzen im 11. Segment.

Vordere mainnliche Geschlechtsorgane: 2 Paar Hoden und samentrichter frei im 10. und 11. Segment, zusammen mit freien Samenmassen. 2 l'aar vielteilige, gedrïingt traubige Samensiicke ragen von Dissepiment 9/10 in das 9., von Dissepiment 11/12 in das 12. Segment lhinein. l)ie vorderen des 9. Segments sind bei dem ()riginalstück nicht geschen worden, wahrscheinlich weil sie bei dem noch unreifen Stürck noch nicht, oder erst sehr schwach, ausgubildet waren.

Hintere mänliche Geschlechtsorgane: Prostaten lang und dümn schlauchlf̈̈rmig, vielfach verschlıngen, fast geknäult; Ausführgang enger, nicht scharf abgesotzt. Das verdickte proximal. Ende der Samenleiter ist otwas xhlanker als bei den Originalstïck und nicht gerade, sondern sichelförmig gobogen. Diese Versehiedenheit berult wohl auf verschiedenen Kontraktionszustainden.

Weibliche Geschlechitsorgane in normaler Lagerung.

Samentaschun (Taf. V, Fig. 15): Ampulle dick birnförmig, durch rinen etwas dünneren und retwas kïrzeren, schwach abgesetzten Ausführgang atsmündend. In den Ausfülıgang mündet, etwas proximal ron seiner Nitte, ein einziges Divertikel ein, das fast so grob, wenn nicht ebenso grob, wir dir Ampulle ist und aus einem einfachen, dick birnförmigen Sannenram und einem viel engeren, etwas kürzeren stiel besteht. Die Ampulle onthält rinen zart granulierten, mit kleinen ovalen kernen dicht durehsetzten, fast kugeligen Ballen, der Samenraum des Divertikels einen 
einzigen Samenballen. Die Ampulle ragt stets in das 9. Segment, das Divertikel in das 8 . Segment hinein. In der (Originalbeschreibung ist die Ampulle mit dem Divertikel verwechselt worden, da ich die granulierte Ballenmasse der Ampulle für Spermien hielt. Die untersuchte Samentasche des unreifen Originalstückes enthielt ïberhaupt noch keine Samenmassen, so daß das leere Divertikel irrtümlicherweise als Ampulle angesprochen werden konnte.

Bemerkungen: Pygmaeodrilus arausionensis Мron. steht wegen des einzigen siamentaschen-1)ivertikels einzig in seiner Gattung da: alle übrigen Pygmaeodrilus-Arten besitzen mehr als ein Divertikel. Auffallend ist die weite Verbreitung dieser Art.

\section{Pygmaeodrilus rhodesiensis Vich.}

1913, Pygmaeodrilus rhodesiensis, Мснағыsex, Oligochäten vom tropischen und südlich subtropischen Afrika. II. In: Zoologica. Heft 68. p. 17, Taf. II, Fig. 24, 2., Texttig. 7.

Fundangabe: Rhodesia, am mittleren Sambesi bei den VietoriaFällen, in humusreicher Erde an Flußufer; W. Michaelsex, 18. August 1911.

\section{Unterfam. Eudrilinae.}

\section{Nemertodrilus Kellneri Mich.}

1910, Nemertodritus Kellneri, Mrchaelsex, Die Oligochäten des inneren Ostafrikas und ihre geographischen Beziehungen. In: Wiss. Erg. Deutsch-Zentral-Afrika-Exp. 1907-1908, III, p. 57, Taf. II, Fig. 21, Textfig. X.

Fundangabe: Kummeruais am Oranje-Flub, untre der Rinde eines halb im Wasser liegenden Baunstammes: H. 'Thomsex, Anfang IIai 1913.

Weitere Verbreitung: Oranje-Kolonie Bloemfontein, nach МichaELSEN).

Bemerkungen: Ich kounte 3 noch nicht ganz geschlechtsreife deutschsiidwestafrikanische Stücke dieser interessanten Art untersuchen. Dieselben stimmen anscheinend in allen wesentlichen Punkten mit den Originalstückrn überein. Zu bemerken ist noch, daß die weiblichen Poren nicht ror den Borsten $d$ des 14. Segments liegen, sondern vor den Borsten c. Die Nachprifung einer Schnittserie von einem Originalstiicke ergab, daß auch das Originalmaterial diese Lage der weiblichen Poren anfweist. Meine ander: lautende Angabe (l. c. p. 58) ist unzutreffend. 
Diese zur äthopischen Unterfan. Eudrilinae gehörige Art ist anscheinend in grriugem Ma Be pregrin. Sie hat ofterbar den Weg am Oranje-Flub stromabwärts genommen, $u$ von ihrer ursprünglichen üstlicheren Heimat nach Dentsch-Siidwestafrika zu gelangen. An eine Verschleppung dureh den Menschen braucht bei der Verbreitung dieser Art nicht gedacht zu werden. Fs handelt sich hier zweifellos um eine selbstäudige Wanderung als Weitwanderer.

\section{Platydrilus Agmes Mich.}

1913, Platydrilus Agnes, Mranelsex, Oligochäten vom tropischen und siddich subtropischen Atrika. II. In: Zoologiea, Heft 68, p. 19, Taf. I, Fig. ذ, Texttig. 8.

Fundangabe: Rhodesia, am mittleren Sambesi bei den VictoriaFallen, in humuseicher feuchter Erde; W. Michaedsex, 18. August 1911 .

\section{Fim. Glossoscolecidae.}

\section{Unterfam. Criodrilinae.}

\section{Almere sp.}

1913, Alma sp. Michaessex, Oligochäten vom tropisehen und sïdlich subtropisehen Afrika. II. In: Zoologica, Heft 65, 1. 57.

Fundangabe: Rhodrsia, im mittleren Sambosi etwas oberhalb der Victoria-Fille, in Grundschlamm und zwischen Wurzelu von Wraserpflanzen nahe dem Ufre: W. Michaelsex, 18. August 1911.

\section{Fam. Lumbricidite.}

\section{Holodrilus (Allolobophore) caligimosus (Sar.) f. trapesoides (Ant. Dug.).}

Fundangaben: Usakos, im Garten; W. Michaelsex, 22. April 1911.

Farm Lichtenstrin, $25 \mathrm{~km}$ Ssio. von Windhuk; Landesmus. ITindhuk.

Kuibis, im (rarten: W. Mucuabtsex, 17. Juli 1911. 
Weitere Verbreitung: Infolge von Verschleppung nahezu kosmopolitisch, doch im tropischen Afrika noch nicht gefunden, in Südafika (in Transvaal, der Oranje-Kolonie und im Kaplande) wohl die gemeinste Art geworden.

Bemerkungen: Diese Art ift zweifellos durch den Menschen in DeutschSüdwestafrika eingeschleppt worden.

\section{Helodrilus (Dendrobaena) submbicundus (Eisen).}

Fundangabe: Swak opmund, im Garten; Herurs 1910.

Weitere Verbreitung: Infolge Verschleppung durch den Irenschen in den nördlichen und südlichen gemäßigten und subtropischen Zonen nahezu circummundan, doch in Afrika früher noch nicht nachgewiesen. Nächstliegende Fundorte: Madagaskar, Falkland-Inseln und Azoren.

Bemerkungen: Zweifollos durch den Menschen in Deutsch-Südwestafrika eingeschleppt.

\section{Helodrilus (Bimastus) pareus (Eisen).}

Fundangabe: Windhuk, im Garten; W. Michaelsen, 7. Mai 1911.

Weitere Verbreitung: Durch Verschleppung nahezu kosmopolitisch, doch im tropischen Afrika nicht gefunden; nächstliegende Fundorte: Kapland und Oranje-Kolonie.

Bemerkungen: Zwrifellos durch den Menschen in Deutsch-suidwestafrika cingeschleppt.

\section{Anhang.}

\section{Fam. Enchytraeidae.}

\section{Hichaelsena Hangeri n. sp.} Taf. $T$, Fig. $9-12$.

Fundangabe: K a merun, Vict oria, Meeresstrand, in dichten, moosartigen Algenpolstern an der Landungsbriicke, C. Maxger, Dez. 1913. Vorliegend zahlleiche, zum Teil geschlechtsreife Exemplare.

Äußeres. Dimensionen winzig: Länge 2,2-3,2 mm, Dicke ca. 0,12 mm, Segmentzahl etwa 29-30. Bei mehreren genan untersuchten Tieren, darunter 12 Michaelsen. Deutsch-Südwestatrika. 
größte Exmplare und kleinere, noch unreife, fand sich ausnahmslos die Srgmentzahl 29 oder 30 , die also als mindestens annähernd konstant angesehen werden darf.

Färbung der konservierten Tiere gelblich-weiß.

K opflappen gerundet, kuppelförmig, nicht ganz so lang wie breit. Borsten stiftförmig, fast gerade, nur am proximalon Ende etwas gebogen, cinfach zugespitzt, ohne deutlichen Nodulus. Die Borsten des Vorderkörpers sind dentlich kleiner als die Borsten des Hinterkörpers. Eine Borste rom 3. Segment erwies sich als $0,028 \mathrm{~mm}$ lang, eine rom 28. Segment als $0,04 \mathrm{~mm}$, bei einer größten Dicke rou etwa $5 \mu$. Die Borsten sind an allen Segmenten rom 2. bis zum vorletzten regehmäßig in 4 Bündeln ansgebildet. Eine Abortierung ron Borstenbündeln hat, abgesehen von den ventralen Bündehn des 12. Segments bei gesehlechtsreifon Stiicken, in keinem Falle stattgefinden. Die Bündel bestehen, offenbar konstant - bei einer gräßeren Zahl von genauer untersuchten Stiicken -, aus jo 2 Borsten. Die Borsten sind also regelmäßig paarig angeordnet: anch cine Reduktion der Pare auf Einzelborsten, wis sie sich bei den meisten anderen Michaelsena-Arten vollstaindig durchgeführt oder bei einem bestimmten Teil der Bündel ausgeführt findet, scheint bei M. Mlangeri in keinem Falle vorzukommen.

Einen Kopfporus konnte ich nielit erkennen.

Rückonporen scheinen nicht vorhanden zu sein.

ler Giurtel scheint das ganze 12. und 13. Segment einzmehmen. Er ist nur ventral zwischen den männlichen Poren nuterbrochen oder schwächer entwickelt, im übrigen ringförmig. Die großen Drüsenzellen der Gürtelhypodermis (Taf. V, Fig. 12) lassen nur einen geringen Strukturuntersehied arkrnnen; sie sind nicht so deutlich wir bei anderen Enchyträiden in hellere durchichtige and dunklere mit grob granuliertem Inhalt nuterschieden. Die groben Drüsenzellen sind ziemlich regehniaßig in Zonen von ca. $15 \mu$ Breite angesodnet. Es wird jedoch die lireite dieser Zonen nicht immer ron einer einzigen Zelle eingenommen. Vielfach schieben sich kleinere Zollen am Rande der Zone keilförmig ein, und manchmal liegen zwei kleinere Zellen nebeneinander, zusammen die Zonenbreite ausmachend.

Die männlichen Poren liegen meist anf mäßig stark rorragenden warzenförmigen Penissen.

Innere Organisation. Luibeswand: [Die Längsmuskulatur besteht ans verhältnismäbig groben, bresten und ziemlich dicken, mehr oder weniger genan senkereht zm kibene der Leibeswand gestelten Bandmuskeh. 
Leibeshöhle: Lymphkörperchen habe ich nicht mit roll sicherheit nachweisen können; doch glaube ich spärliche, anscheinend scheibenförmige, mit kleinem Kern ausgestattete, zart granulierte Zellen in der Leibesflïssigkeit als solche ansprechen zu sollen. Große Lrmphkörperchen, wie sie für manche Enchyträiden, z. B. Enchytraeus argenteus Micu., charakteristisch sind, sind jedenfalls nicht vorhanden.

Darm: Der dorsale Schlundkopf ist ziemlich dick, oval. Die Septaldriisen des 4., sowie die des 5. Segments sind zu einem durehaus unparen, dick bohnenförmigen Körper verschmolzen, der oberhalb des Darmes an der Vorderseite von Dissepiment $4 / 5$ bezw. $5 / 6$ liaftet. AuBerdem ragt ein Paar dick kolbenförmiger Septaldrïsen ventral vom Darm durch das ganze 6. Segment hindurch. Sekundäre Septaldrisen, d. h. Drüsenwuchrrungen an den Septaldrüsen-Strängen, sind nicht ausgebildet. Peptonephridien scheinen nicht vorhanden zu sein. Der Osophagus ist eng und besitzt keine Anhangsorgane, wie Drüsen oder Taschen. Er geht allmählich in den Mitteldarm über.

Blutgefäßsystem: Die Ursprungsstelle des Riuckengefußes konnte ich nicht feststellen.

Nervensystem: Das Gehirn (Taf. T, Fig. 9) ist nicht ganz doppelt so lang wie im Maximum breit, hinten deutlich verbreitert, vorn verhältnismäßig selımal. Der Hinterrand ist in der Mitte schwach konkav ansgebuchtet, fast gerade.

Exkretionssystem: Die Nephridien (Taf. V, Fig. 11) besitzen ein plattes, hinten verbreitertes Postseptale. das nicht ganz doppelt so lang wie im Maximum breit ist. Das Anteseptale ist oval, nicht ganz halb so lang wie das Postseptale, etwa $2 / 3$ so breit wie lang. Der Ausführgang entspringt linten an der ventralen Kante des Postseptale und geht vou hier aus nach vorn. Er ist ungefuhr so lang wie das Postseptale.

Iännliche Geschlechtsorgane: Ein Paar längliche Hoden von Dissepiment 10/11 in das 11. Segment hineinragend und anseleinend direkt in je rinen länglichen, auf das 11. Segment beschränkten samensack iibergehend, in der Art, wie es für die Gattung Lumbrieillus (bei dieser jedoch Hoden und damit auch samensäcke nicht einfach, sondern mehrfach) charakteristisch ist. Samentrichter micht ganz dreimal so lang wie dick, proximal mit Kragensaum. Samenleiter ca. $6 \mu$ dick, mindestens doppelt so lang (wahrscheinlich noch länger) wie der Sanentrichter, unregelmäßig geschlängelt, eine unregelmäBige, nach hinten ragende schleife bildend, aber anscheinend auf das 12. Srgment beschränkt. Der kleine änber Penis sitzt an einem dicken, etwa zur Hälfte in die Leibeshöhle hinein- 
ragenden, der Hauptsache nach aus großen Drüsenzellen bestehenden Bulbus, der durch ein feines peritoneales Häutchen glatt gegen die Lribeshöhle abgeschlossen ist. Es scheinen an und neben diesem Bulbus keine in die Leibeshöhle hineinragenden Drüsen zu sitzen.

Weibliche Geschlechtsorgane: Die meisten geschlechtsreifen Tiere enthalten, anscheinend im 13. Segment, ein einziges großes reifes Ei von etwa $0,22 \mathrm{~mm}$ Länge und $0,06 \mathrm{~mm}$ Breite. Wine Mehrzahl reifer Eier ist bei keinem Exemplar angetroffen worden.

Samentaschen (Taf. V, Fig. 10): Ampulle dünnwandig sackförmig, im Querschnitt kreisrund, mit dem etwas schräg abgebogenen proximalen Ende in den Osophagus eimmündend. Ausführgang ziemlich scharf von der Ampulle abgesetzt, ungefähr so lang wie diese, dünn schlanchförmig, in der distalen Partie bis ctwas über die Mitte hinaus mit einer mäßig dicken, äberlich nicht ganz ebenen, aber auch nicht zottigen, sondern ziemlich glatten Drïsenschicht bekleidet.

Biologisches: Der Darm-Inhalt besteht der Hauptsache nach aus Diatomeen jener Arten, die den Algenfiden der Algenpolster, in denen die Würmer leben, anhaften.

Bemerkungen: Wichaelsena Mangeri repräsentiert in einem für seine Gattung sehr bedeutsamen Organisationsverhältnis, in der Borstenanord$11 u n g$, ein Extrem der Ausbildung, und zwar anscheinend das phyletisch älere Extrem, das direkt zu der mutmaBlichen Ahnengattung Enchytraeus hiniberführt und zugleich der mutmaBiiche Ausgangspunkt für die sich meiner Ansicht nach von Michaelsena abzweigende grobe und charakteristische Gattung Fridericia war. Bei der Schilderung der Oligochäten Siidwest-Australiens ${ }^{1}$ ) habr ich die morphologischen und wahrscheinlich zugleich verwandtschaftlichen Verhältnisse zwischen diesen Gattungen einguhend rroirtert und dabei besondors den Gegensatz zwischen der „,unbestimmten" Borstenzahl (etwa 3-5 oder 1-4 Borsten in einem Bündel) und der ,bestimmten gringen“ Borstrnzahl (1 oder 2 Borsten im Büindel, d. h. Borsten einzeln oder paarig) klargestellt. Ton des Gattung Enchytraeus mit unbestimmter, manchmal allerdings auch selır geringer Borstenzahl (z. B. Enchytraeus argenteus Hıcu. nit 2 bis 3 Borsten im Bündel) unterscheidet sich die Gattung Michaelsena fast lediglich durch die bestimmte geringe Borstenzahl. Einzolne Michaelsena-Arten besitzen lediglich paarige (.1. subtilis UDF), andere lediglich einzelne Borsten (H. monochaeta [MicH.] und $M$. macrochaeta P'ineantona): bei anderrn Artrn schlieblich (M. Normani Mucus.) werden gewisse Bündel durch parige, andere durch einzelne Borsten

2) II. Michafiska, Oligochaeta. In: Die Fauna Südwest-Australiens, I, p. 127 u. f. 
repräsentiert. Alle bisher bekannten Michaelsena-Arten zuigen zugleich eine Abortierung der Borstenbïndel gewisser Segmente, zumal des Vorderkörpers, und meist erscheinen dio dorsalen in gröBerer Strecke abortiert als die rentralen. M. Mangeri ist die erste Art dieser Gattung, bei der eine solche Abortierung nicht vor sich gegangen ist, die an allen Segmenten rom 2. an, und hüchstens mit Ausnahme des letzten, je 4 Borstenbündel besitzt. Jedes dieser Borstenbündel besteht nach Untersuchung einer großen Zahl ron Tieren ausnahmslos ans einem Paar Borsten. Diesr Art ist also von der Ahnengattung Enchytrceus (mit manchmal auch nur wenigen, 2 bis 3 Borsten im Bündel) nur durch die kunstante Zweizahl, die Paarigkeit der Borsten unterschieden. Sie vermittelt also einen engen AnschluB der Gattung Michaelsenc an die Gattung Enchytraeus und mag zugleich auch als Vermittler zwischen Michaelsena und Fridericia aufgefaBt werden. Anch bei Fridericia, bei der die Borsten parig oder durch vorzeitiges W Wachstum der Ersatzborsten bei gleichzeitiger Erhaltung der älteren Borsten mehrfach paarig sind, ist eine Abortierung von Borstenbündeln nicht bebeachtet worden: wenn man nicht das Fehlen der latralen Borstenbïndel bei Distichopus silvestris Lenr, die sonst ganz Fridericia-Charakter hat, als Beispiel für eine Abortierung ron Borstenbindeln bei einer Fridericia-Form gelten lassen will.

Es bleibt noch die Synonymie der Gattung Michaelsena zu vervollständigen. Kïrzlich beschrieb Soctherx') als ,gen. et sp. nor." einen Enchytrïiden, Grantia maricola, von der Südwest-Küste Irlands. 1)iese Art ist eine typische Michaelsena, nahe verwandt, wenn nicht identisch mit 11. macrochaeta Pierantosi²) aus dem Golf von Neapel.

Die Gattung Grantia ist, wie wahrseheinlich anch die Art G. maricola, hinfällig, als Synonym zu Michaelsena zu stellen. Sotmers hat die nahe Verwandtschaft seiner Art mit Endytraens monochaetus Мıсн. ${ }^{3}$ ) wohl erkannt, aber ïbersehen, daß diese Art ron süd-Georgion seit langem in die Gattung Michaelsena $\mathrm{UDE}^{*}$ ) eingereiht ist, und daß seitdem noch weitere Glieder dieser marinen Strand- oder Flachwasser-Gattung entdeckt worden sind. Eine ungeniigende Beriicksichtigung der modernen Literatur geht auch aus

1) R. Socthers, Oligochaeta. In: Clare Island survey, Part. 18. Dublin 1913, p. 8, Pl. VIIl, Fig. 1-10.

2) U. Pieraxtoxi, studii anatomici su Michaelsena macrochaeta Pienaxt. In: Mitt. Zool. Station Neapel, XVI, 1903, p. 409. Tafel XV, Fig. 1-16, Taf. XVI, Fig. 17-28.

3) W. Mrchatesex, Die Oligochaeten von Sïd-Georgien ete. In: Mt. Mus. Hamburg, v, 1885, p. 66, Taf. Fig. 6 a-c.

$\left.{ }^{4}\right)$ H. Ude, Enchytraeiden. In: Ergebn. Hamburg. Magalhaens. Sammelr., III, 1596, p. 23. 
dem sonthers:shen Ausspruch hervor: ,Apparently no species belonging to the order Oligochacta las yot been recorded from below low-water mark" (1. (. p. 3). Hat uns doch l'iesantovi, abgeschen von der schon genannten Lichaelsena macrochaeta, in verschiedenen Schriften mit mehreren marinen Oligochäten des Golfes von Neapel, in ca. 3 bis 6 m 'Tiefe grdredget, bekannt gemacht, nämlich mit: Phallodrilus parthenopaeus, Heterodrilus arenicola, 3 Arten der Gattung Limnolviloides und Paramais elongata.

\section{Figurenerklärung.}

Tafel V.

Fig. 1. Aulophorus africanus n. sp. Freic distale Enden der Borsten eines dorsalen Buindels; $2500: 1$.

Fig. 2. Freies distales Ende einer ventralen liorste: $2500: 1$.

Fig. 3. - - - - Hinterende mit Kiemennapf, von der lorsalseite: $10: 1$.

Fig. 4. Puramais multisetosus n. sp. Freies distales Finde einer Borste: $1600: 1$.

Fig. 5. Limmodritus alpestris Eisex. Chitinöse Penisschride: 300:1.

Fig. 6. Limnodriloides Winckelmannin.sp. Distales Ende ciner Borste: 1200:1. Fig. 7 .

- Mämnlicher Ausführapparat: 150:1.

Fig. 8. Lumbricillus vermeosus (CLar.). T'mrifs des Gohirns, von oben gesehen; $350: 1$.

Fig. 9. Michaelsena Mangeri n. sp. Lmpib dos Gehirns, von oben ges!ren: $300: 1$.

Fig. 10. - - - C Samentasche; $450: 1$.

Fig. $11 . \quad$ - $\quad$ - S Segmentalorgan: $300: 1$.

Fig. 12. - - - G Gürtolhypodormis in dor Flächonansicht; $700: 1$.

Fig. 13. Alluroides tanganyikue Beñ. Samentasche: 30:1.

Fig. 14. Gordiodritus Luykerleni Mren. Querselnnitt durch rine Clyylustasche: $120: 1$.

Fig. 15. I'ygmaeodrilus aransionensis Hucn. Samentaschunarh Aufluellung; 50:1 


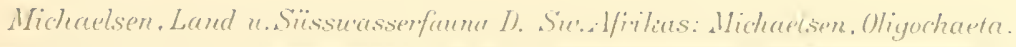

Tal:II:
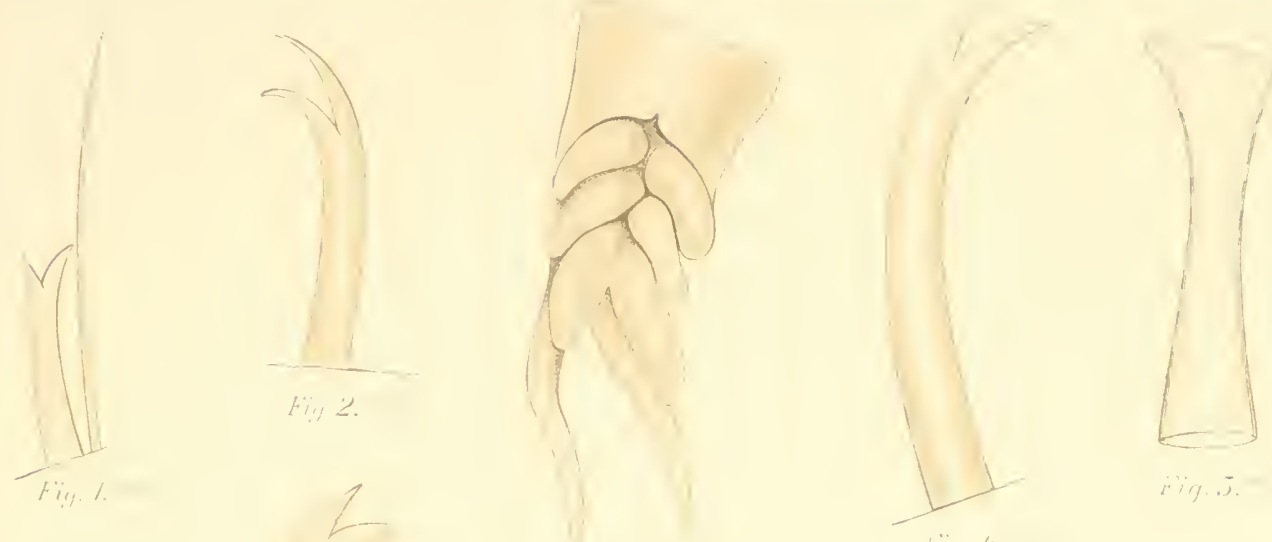

Fiy. 1.
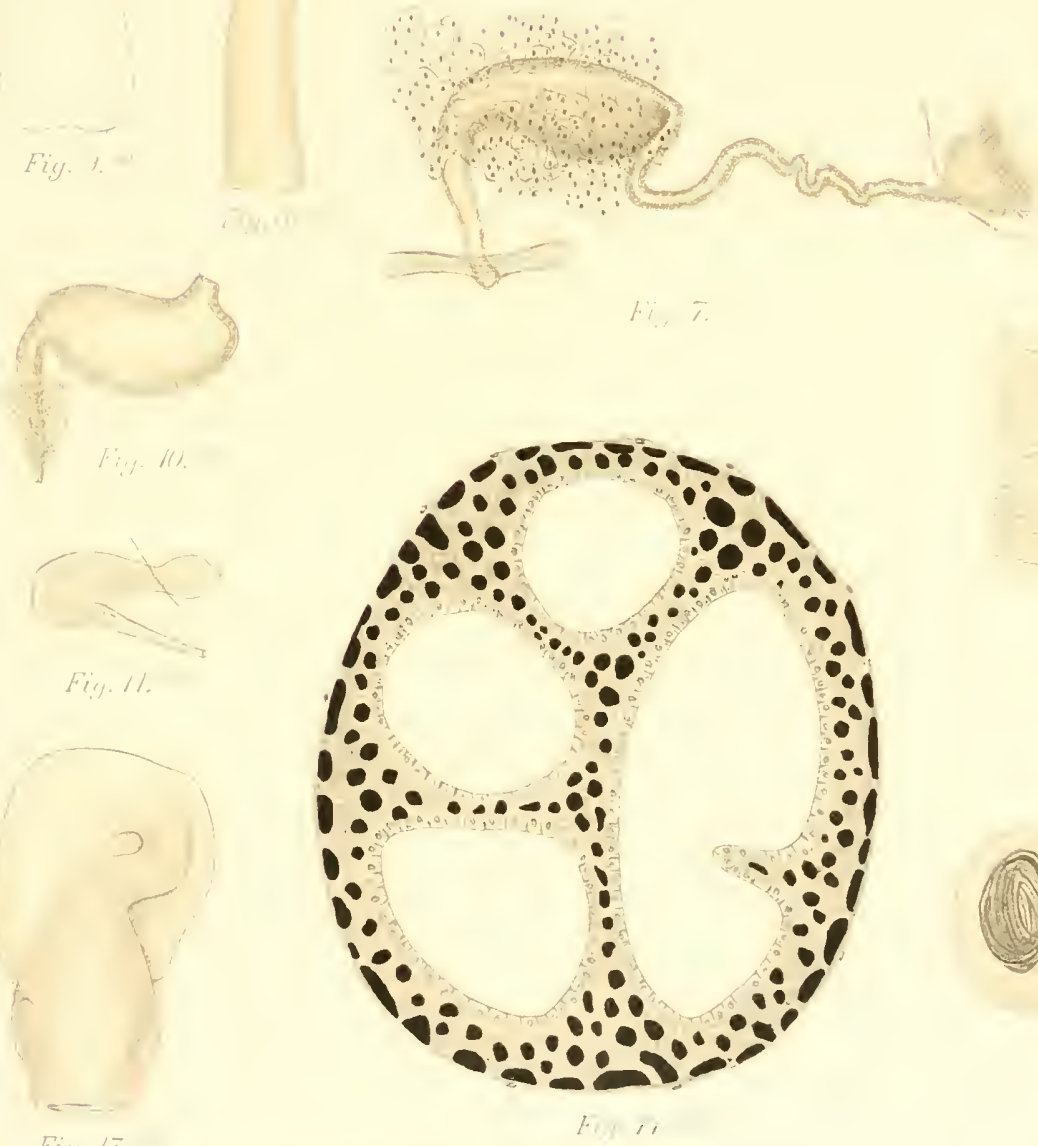

Fig. I.j.

L. F: Fine in i. Hanburg 





\title{
Hymenoptera I: \\ Braconidae
}

Voll

\author{
Gy. Szépligeti
}

(Budapest). 

Die klimatischen Eigentïmlichkeiten von Deutsch-Südwestafrika und die damit zusammenhängende Einförmigkeit und Armut der dortigen Pflanzenwelt lassen bei einer Familie, wie die Braconiden, dis in herrorragendem Maße auf phytophage Insekten angewiesen sind, keinen groben Artreichtum vermuten. Dio Ausbeute an Braconiden aus Dentsch-Südwestafrika ist darum nicht groß: sie umfaßt nur 26 Arten, von denen 6 bisher nicht beschrieben waren. Fs ist dies die erste größere Ausbeute aus diesem Ciebiete, und es ist daher ein gewagtes Unternehmen, ans dieser rinmaligen Ausbeute schon allgemeine Schlüsse zu ziehen. Ton charakteristischen Zügen der sïdwestafrikanischen Braconidenfauna kann kaum schon gesprochen worden; immerhin ist es suhr interessant und hängt vielleicht zusammen mit der verborgenen Lebenwweise zahlreicher Insekten jener Gegenden, dab die Formen mit langem Bohrer entachieden überwiegen. Im übrigen spielen dieselben Unterfamilien, dis anderswo unter den afrikanischen Praconiden worherrochen, auth hior die Hauptrolle. Allen voran stehen die Braconince, zu denen von den 26 Arten 18 gehören. Die iibrigen \& Arten rerteilen sich auf die Doryctinae (2), Cheloninae (3), Aguthinae (1), Iacrocentrinae (1) und Meteorinae (1). Von den beiden zuletzt genannten [nterfamilien waren bisher noch keine Tiere ans Afrika brkannt. Auch die hier vorkommenden Gattungen treten fast sämtlich ebenfalls in anderen Teilen ron Süd- und Zentralafrika auf: nur zwei ron Camenox aufgestellte Gattungen, Holcolracon und Bacuma, sind bisher mu aus Siidwestafrika bekannt. Anders steht es natïrlich mit den Arten. Ein Teil ron ihmen ist nur ans diesem Gebiet bekannt; andere dagegen sind in Afrika weit verbritot, vor allem Arten aus der auch anderswo in Afrika häufig auftretenden Gattnng 1phiaulax. I. flagrator GFrst. kommt nördlich bis Zentralafrika vor, I. coccineus Br. bis zum senegal und I. varius Bu. bis Nubien. Ebenso findet sich Gastrotheca fureata GcÉr. bis Abessinien. Eine genauere Durchforschung ron Deutsch-siidwestafrika wird hoffentlich in späterer Zeit ein schäufor umrissenes Bild der Braconidenfauna dirses Landes ergeben; immerhin werden die liraconiden wahrscheinlich stet; $13^{*}$ 
schwader vertreten bleiben als andere Familien, die dem Klinua in Bau und Lebensgewohnheiten besser angepaßt sind, wie z. 13. die Crabroniden, Apiden und ror allem die Formiciden, die daher auch in der rorliegenden Ausboute weit stärker vertreten sind.

\section{Gen. Vipio Latreille. \\ Vipio Michuelseni n. sp. - - -}

Fundangabe: Neudam (ca. $42 \mathrm{~km}$ ONO. von Windhuk): M. Michaelsex, 10.-15. Mai 1911.

f - Lopf quer, glatt, hinter deu Augen gerändert, Gesicht punktiert, Wangen lang, mit Furche, Augen klein. Fühler kïrzer als der körper, borstenförmig; Scluaft eiförmig, 3. Cilied doppelt so lang wie dick und stwas länger als das 4. Thorax glatt, gedrungen, Parapsiden tief, Intamotum in der Mitte runzlig. 'Zweite Cubitalquerader gerade und schief gestellt. Hintrerhïfen länger als dick. Hinterleib gestreckt, Segmente $1-3$ und Basis des 4. frin gerieft: 1. Segment breit, länger als breit, gewïlbt, mit schmalem seitenrand; 2. Segment quex, so lang wie vorne breit, Mittelfeld klein und glatt, mit langem kielartigen Fortsatz: 2. Sutur breit und runzlig: Ecken des 3. Segmentes qure, sie rreichen nicht die Mitte des Segmentes.

Lot; Rostrum, Fühler, Brust, Sehienen und Tarsen der Mittel und Hinterbeine schwarz, Rand und Flïgel schwarz, Nitte mit hellem Fleck.

Länge 11, Bohrer $12 \mathrm{~mm}$.

\section{Gen. Glyptomorpha Holmgren.}

\section{Glyptomorplace punctidorsis Brullé.}

G. punctidorsis Bruldé, Hist. nat. Hymén. Insect. 4, 1st6, p. 44 .

Fundangaben: 'T'sum eb; IT. Michaelsex, 13.-19. Juli 1911.

Kleiner Waterborg, Farm Okosongomingo; H. Tiomsex, Juli-August 1912.

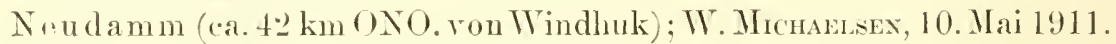

\section{Gen. Merinotus Szépligeti.}

\section{Merinotus rosu cameron.}

H. rosa (Aamur, Archiv f. Mathem. og Naturg. (Kristiania) 30. 1909, p. 11.

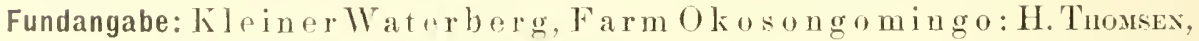
Juli-August 1912. 


\section{Werinotus 12 fasciatus Cameron.}

1. 12 fasciatus Camerox, Albany Mus. Rec. 1. 1904, p. 154.

Fundangaben: Kle in er W a ter be g, Farm Okosongo m in o: H. Thousex, Juli-August 1912.

Windhuk (Dixter, nach Cayerox).

\section{Gen. Megagonia Szépligeti.}

Megagonia niger Szépligeti.

1. niger SzÉpligeti, Ann. Mus. Nat. Hung. XI, 1913, p. 594.

Fundangabe: IT ind huk.

\section{Gen. Holcobracon Cameron.}

Holcobracone motheraspis Cameron.

H. erythaspis Casenox, Arehiv for Math. og Naturw, 30. 1904, p. 20.

Fundangabe: Windhuk (nach Canerox).

\section{Gen. Bacuma Cameron.}

\section{Bacuma rufa Cameron.}

B. mufa Camerox, 1. c. p. 26.

Fundangabe: Deutsch-siidwestafrika (nach CAMerox).

\section{Gen. Goniobracon Szépligeti.}

Gomiobracon areolatus Szépliggeti (in litt.).

Fundangabe: Kleiner $\mathbb{K}$ a t e rberg, Farm Okosongom in go: H. Thousex. Juli-August 191:2.

\section{Gen. Rhytimorpha Szépligeti.}

\section{Rhytimorpha atriceps Széplizeti.}

Rh. atricepse Szépligeti, Ann. Mus. Nat. Hung 4. 1906, p. 551.

Fundangabe: Karibib: Wr. Michaesex, 23.-26. April 1911. 


\section{Gen. Iphiaulax Förster. Iphiaulax Bohemani Holmgren.}

1. Bohemani Houmgrex, Eug. Resa Insekt. 1868, p. 423. undangabe: K a libib: W. Michaelsev, 26. April 1911 ( $\left.\sigma^{\prime}\right)$

\section{Inthianlax flugrator Gersticker.}

I. Hayrator Gerstäcker, Mon. Acad. Wiss., lerlin. 1858, p. 264.

Fundangabe: K a ribib: Wr. Mrchascsex, 23.-26. April 1911.

Omaruru: W. Mrchaelsex, 21.-2.2. Juli 1911 .

\section{Inhianlax Wahtbergi Holmeren.}

I. Wahlberai Holmgrex, Eug. Resa Insekt. 1S6s, p. 425.

Fundangabe: Kleiner IV a terberg, Farm Okosongo mingo; H. Thomsex, Juli-August 1912 .

\section{Iphianlax coccineus Brullé.}

I. coccineus Brclé, Hist. nat. Hymén. Insect. 1846, p. 428.

Fundangabe: K leiner W a ter b erg, Fa rm U kos o ngom ingo; H. Thonsex, Juli-August 1912.

IV ind huk (nach (Anenos, Archiv for Mathem. og Naturw. 30. 1909, p. 19).

\section{Iphiamelcex callosus n. sp. - - -}

Fundangabe: Deutsch-Sïdwestafrika: Lïввегт, 1901.

I) I. elegans m. ähnlich: Gesicht fast glatt, die Sritrn des Randmals fast gleich lang. Segmente $1-4$ runzlig, das 5. fast glatt: 2 . segment quer, kürzer als vorn breit; das 1. Segment länger als breit; Ecken des 3. Segmentes ganz klein, undrutlich begrenzt und glatt; Hintrrrand der Segmento schmal: 4. und 5. Siegment stark gewölbt.

Schwarz, s'remento vom 4. an rot. Fliigel scliwarz, Nlitte, 1. Cubitalzolle hell goffeckt, 2. Cubitalquerader hell gerandet. Randmal rot.

Liinge 12, Bohrer $4 \mathrm{~mm}$.

\section{Ipleinulax motalensis Szépligeti.}

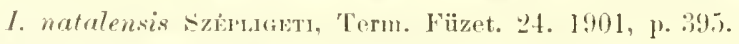

Nur die Nitte des 1. Segmentes schwarz.

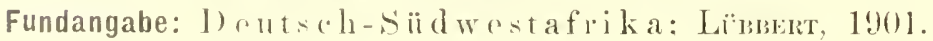




\section{Iphiaulax varius Brulle.}

I. varius Brullé, Hist. nat. Hỳmén. 4. 1846, p. 428.

Fundangabe: Okah andja: L. Schultze, 1903-1905.

\section{Iphiaulax difficilis Szépligeti (in litt.).}

Fundangabe: $\mathrm{D}$ e utsch-S ü d westaf rika; LёвBErt.

\section{Iphianlax pictus Brullé.}

I. pictus Brollé, Hist. nat. Hymén. 4. 1846, p. 426.

Fundangabe: Windlı k (nach Caverox, Archiv for Matlı. og Naturg. 30. 1909, p. 19).

\section{Gen. Bracon Fabricius.}

\section{Bracon suaris n. sp. - $\rightarrow$ -}

Fundangabe: Wind huk: Krause.

Kopf halbkugelförmig, fein runzlig und matt. Mesonotum matt, Parapsiden undeutlich, Metanotum glatt. Innere Seite des Randmals kürzer, Radialzelle rreicht nicht die Flügelspitze, 2. Cubitalzelle kurz, Cubitalader an der Basis gerade. Hinterhüften kurz, Hinterleib fein runzlig und matt, lanzettlich, etwas gerundet; erstes segment dreiseitig, so lang wie am Ende breit: 2. Seginent quer, etwas kïrzer als vorn breit und etwas länger als das 3., an dor Basalmitte mit Kiel und neben dem Seitenrande beiderseits mit Gribchen: 2. Sutur bisinuiert.

Gelb, Hinterleib und Beine gelbrot: Fiiller, Ftemmaticum, Hinterkopf, 3 Makeln am Mesonotum, Brust, Metanotum, Spitze der Hinterschienen, Hintertarsen fast ganz, Mitte des 1. Aegmentes, Basalmitte des 2., ein groBer geteilter Kleck an den Segmenten 3-5 schwarz. Fliigel hyalin, Randmal gelb, Endhälfte braun.

Länge 1,5 mm, Bohrer etwas länger als der halbe Hinterleib.

\section{Gen. Zombrus Marshall.}

\section{zombme Thomseni II. sp. - Q -}

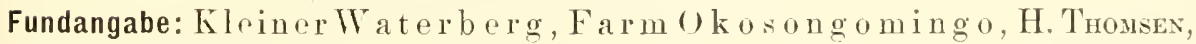
Juli-August 1912. 
Absteliend behaart. Propleuren und die Furche der Mesopleuren gerieft, Metanotum grob runzlig. Segmente $1-5$ gerieft, das 2. an der Seite mit groben liveren.

Schwarz, Mittelbrust und Hinterleib rot, Segmente an der Seite mit schwarzem Makel. Flügel und Randmal schwarz, Flügelmitte hell gefleckt.

Länge 12, Bohrer $7 \mathrm{~mm}$.

\section{Zombrus minor H. sp. - $\sigma-$.}

Fundangabe: Windhuk: H. Thossex, Jan.-Febr. 1913.

Abstrhend behaart. Pronotum grob runzlig, Furche der Mesopleuren glatt, Metathorax zellenartig r'unzlig. Segmente $1-3$ gerieft.

liot: Kopf, Fühler, Prothorax, Mesonotum oben, Vorder- und Mittelbeine, schirnen und Tarsen der Hinterbeine schwarz. Flïgel schwarz, mit hellem Fleck in der Mitte des Vorderrandes; Randmal an der Basis gelb.

Länge $7,5 \mathrm{~mm}$.

\section{Gen. Gastrotheca Guérin.}

Grastrotheca furrata Guériu.

6. furcata Gínix, Lefebure, Voy Ahyss. 6. 1848, p. 349, t. 7, f. 4.

Fundangabe: Kloiner Watcrberg, Farm Okosongomingo; H. Thouses, Juli-August 1912 .

\section{Gen. Phanerotoma Wesmael.}

Phanerotoma pygmaea Szépligeti.

Fundangabe: $1 \mathrm{~T}$ ind huk: 'Tecuow.

Phanerotoma lencobasis Kriechbaumer var. 2. Szépligeti.

Ph. leucobasis Krouecubacmer, Berl. ent. Zeitsch. 39. 1894, 1, 62.

Fundangabe: Windhuk; TeCrow.

\section{Gen. Disophrys Förster. Disoplerys lutece Brullé.}

D. Tutea Britudé, Hist. nat. Hy̆mén. Insect. W. 1846, p. 506.

Fundangabe: Okahandja: W. Mchaersex, Mai-Juni 1911. 


\section{Gen. Macrocentrus Curtis. \\ Hacrocentmus mgulosus szépligeti (in litt.).}

Fundangabe: Deutseh-sii dwestafrika; LüBrert.

\section{Gen. Meteorus Haliday.}

Meteorus Kleini n. sp. - - -

Fundangabe: Swak opmund: K. KLess, 1911.

Kopf quer; glatt, hinter den Augen schmal und gerundet: (iesicht runzlig, zicmlich breit, nach unten zu verschmälert. Fühler 25 gliedrig, Endglieder gerundet. Mesonotum fast glatt, in der Mitte vertieft und runzlig, Parapsiden deutlich; Mesopleuren glatt, die Mitte eingedrückt und punktiert: Metapleuren punktiert, \etanotum runzlig. Randmal groß, die innere Seite länger, Radiusende gerade, Areola vierseitig, vorn nicht zusammen gezogen, Nervulus postfurkal. Beine schlank, Hinterhüften kurz und glatt. Hinterleib glatt: 1. Segment mit gut sichtbaren Luftlöchern, Postpetiolus nadelrisig-runzlig; 2. S'egment quer, etwas länger als das dritte; 2. Sutur fein.

Schwarz: Tastor, Clypeus, Fühlerbasis, Prothorax, Tagula, Beine und Hinterleib rom 2. Segment an gelb oder braungelb; Hintersehenkel oben und Ende der Hintersehienen gebräunt. Flügel hyalin, Basalnerven gelblich; Randmal braun, die Mitte dunkel.

Länge 3,5, Bohrer 2,5 mm. 



\title{
Hymenoptera II: Archihymenidae
}

\author{
ron \\ Günther Enderlein \\ (Stettin).
}

Mit 1 Tafel und 1 Abbildung im Text. 

Die Ausbeute von Herm Professor D. IV. Mhchaelsen aus Südwestafrika enthielt eine außerordentlich interessante Hymenopterengattung, die durch eine ganze Reihe auffülliger altertïmlicher Charaktere unter den iibrigen Hymenopteren isoliert ist und diesen gegenübersteht. Ich neme sie Archihymen. Tor allem finden sich 2 nach dem Außrnrande zu laufende Radialiaste, der eine völlig entwickelt $\left(\mathbf{r}_{3}\right)$, der andere nur angedentet $\left(\mathbf{r}_{4}\right)$. von denen sonst $r_{1}$ als Querader nach $m_{1}$ entwickelt ist, ebenso anch meist $r_{3}$ als Querader erscheint oder wenigstens sonst immer gegabelt ist und cinen Ast als Querader, den anderen als Längsader nach dem Rande zu entsendet (z. B. bei vielen Mutilliden). Die Querader zwisehen $m_{1}$ und $\mathrm{eu}_{1}$ fohlt, ein C'harakter, der z. B. für die Braeoniden eharakteristisch ist, aber anch zuweilen bei den Mutilliden vorkommt. Zweifellos hat Architumen viele Beziehungen zu den Mutilliden, in zwoi Hauptmomenten weicht diese Gattung aber von ilmen ab, und zwar ist 1) das 1. Abdominalsegment keine Spur rom 2. abgeschniirt und 2) weist der Vorderschenkel ein basales Schnïrstiick (sogen. 2. Trochanter) auf: während die Mutilliden hinten ein etwas abgeschniirtes 1. Abdominalsegment und an keinem der schenkel ein basales schnïrstiick ( 2 . Troclranter) besitzen. La nun ferner das Geäder auch viele Brzichungen zu den Braconiden erkennen läßt, besonders zu dem der Subfamilie lcheutinae, und allo Braconiden an all'n Schenkeln basale Schnürstiicke (2. Trochanter) anfweisen, so dürften auch zu den Braconiden verwandtschaftliche Bezichungen vorhanden sein. Aber auch selbst zu den Formiciden seheinen gewisse Annäherungen erkennbar zu sein, besonders im Geaider. Auf jeden Fall handelt os sich aber bei Archilymen um den Vertreter einer besonderen Familie, dis viele sehr altertïmliche Charaktere aufweist: ich nenne sie: Archihymenidae.

In diese Familie ist nun noch eine erst vor wenigen Jahren ron Axuré beschriebene Gattung einzuordnen und zwar: Konowiella Axuré 19091, (mit K. hirticomis, 1909, aus Mendoza in Argentinien). Sie steht Archihymen

1) Axuré, Sur un nonveau genre d'Hyménoptère de famille incertaine. Bull. Soc. Ent. de France. 1909 pag. 106-10s. 
naho. Auffällig ist bei dieser die selır lange feine Behaarmg an den Fühlern, die ebenfalls senkrecht absteht und den Fïhlorn ein struppiges Aussehen verleiht.

Die Terbreitung dieser beiden altertïmlichen Gattungen (Siid AfrikaArchiplata-Gobiet), ist wieder rin hervorragendes Beispiel der biogeographischen Beziehmengen innerhalb des notocraten Biocosmos's, und zeigt auch wioder, wir sich gerade hier die altertïmlichsten Formen aus allen () rgauismengruppen häufin.

\section{Gen. Archihymen n. gen.}

Typus: A. miscus n. sp. Deutseh-Siidwestafrika.

Fühler (Taf. T, Fig. 5) 13-gliedrig, so lang wie dir Torderfligel: die Geibelglioder langgestrockt (oft noch länger als in Figur 5 ) und mit kurzer verstrout stehonder, senkrodit abstehender feiner Behaarmo. Ocellen groß, zu "inem grofen rechtwinkligm Jroirck angeordnet. Mandibel (Taf. $\mathrm{V}$, Fig. 4) mit 3 großen, ziemlich stumper'm Zähnon; nicht knicartig gobogen, niclut anfwirts gerichtet und iibereinand re greifend. Maxille (Taf. V, Fig 2) mit nur einer deutlich ausgebildroten Lade, die au Ende mit feinen Härehen beserzt ist. Cardo (c) zart und gestreckt. Maxillarpalpus 6-gliedrig, lang. Labium ('Taf. T. Fig. 3) langgestreckt, von den versclimolzenen Cardines ist noch rin schwaches und schmales Skelettstick vorhanden. Labialpalpus 3-gliodrig. Mesonotum poliort glatt und olue Parapsidenfurchorn, stark gowölbt, vorn steil abfallend: Scutellum von oben goselen fast so lang wie das Mesonotum, glatt, fast quadraticch, hinten stark gerundet, rhaben: vor dom Vorderrand ein tiofer, ziomlich breiter und foin längsgoriefter Quoreindenck. Hintrer dem ficutellum rin obenfalls quadratisches Postsentellum, das weniger orhaben nud $2 / 3$ so lang wit das Sentelhum ist. Mrodiansegmont ziemlich glatt und ohne Leisten. Abdomen dorsoventral zusammengedritckt, von obon groshen stark spindolfömig, an beiden Enden zugespitzt, in der Vitte am broitesten und so breit oder wenig broitor als der Thorax; an Ende des Mrediansegments zwiselen den Coxen inseriert; brim of ans 7 sogmenten zusammongesstzt. Torderbrine (Taf. V, Fig. 8) mit rinem drutlichon basalen frunoralen schnïrstück sogenannter 2. Trochantere, das aber hinten nicht guschlossen ist und bei den Mittel- und

1) Exblizbix, Die biologische bedentung der Antarktis und ihrer Fannengebiete nit hesonderer lieriteksichtigung der Insektenwelt. Mit 1 Tafel und 2 Ahb. im Text. Dentsche sidpolar-Expedition. Bd. X (Zoolog. II). 1908, pag. 323-360. 
Hinterbeinen (Taf. V, Fig.6) välig fehlt. Vorderschienen etwas kürz‘r als die Torderschenkel. Tarsen lang, diinn und schlank. Klaurn ungezähnt.

Flïgel (Taf. V, Fig. T) zirmlich breit, mit gegabeltem Radialramus: der vordere Ast $\left(r_{2}\right)$ ondet dicht distal rom l'terostigma und $r_{3}$ etwas proximal der Flügelspitze. Ferner ist auch noch $r_{4}$ dureh einen bräunlichen Pigmentstrich angedentet und $r_{\overrightarrow{3}}$ grenzt die kleine dreieckige Zelle $\mathrm{R}_{5}$ ab die 2. Cubitalzelle der Autoren). Nervulus (morphologisch cur. postfurcal. Im Hinterflïgel (Taf. V, Fig. T) ist anffällig die Anwesenheit von $m$, ferner die Isolierung des Radialramus, dor durch eine Falte angedentete Verlauf des Basalteiles der Media sowie die Anwesenheit rines durch tiefe schmale Einbuchtung abgetrennten Anallappens.

Das of ist vielleicht flügellos.

\section{drehillymen miscus nor. spec.}

Taf. $\mathrm{T}$, Fig. $1-8$, Textfigur 1.

Fundangaben: Usakos; W. Michaelsex, 22. April u. 22. Juni 1911 ( 3 kleine ${ }^{\prime}$ ). Windhuk; W. Michaelsex, 29. April bis 8. Mai 1911 (3 kleine und 2 grobe $\left.\sigma^{\top}\right)$.

Farm Voigtsland, ca. $38 \mathrm{~km}$ (). von Windhuk: W. Michaelsex, 16.-19. Lai 1911 (6 große o).

Sepheim am Gr. FischfluB: W. Mr'hatesex, 16.-19. Juli 1911 (2)kleine und 2 große ơ).

б. Kopf poliert sehwarz. Oberkiefer und Trorderrandsaum des Clypeus ocker- bis rostgelblich. Fühler schwarzbraun bis gelbbraun, die beiden ersten Gilieder zuweilen bräunlichgelb: Pubescenz grauweißlich. Angen oral, stark abgesetzt. Palpen dunkelbram. Hinterhaupt deutlich aber eng kantig gerandet. Ocellen grob, gelblich, Abstand der hinteren rom Augenrand ca. $1^{3}$ t Ocellendurchmesser. Scheitel jederseits mit einer an die hinteren Ocellen hinten anschließenden etwas ringedrïckten Stelle.

Thorax poliert schwarz bis schwarzbram. Beine gelbbraun, schenkel mit Ausnahme der Endspitzen und Coxen braunsehwarz. Abdomen glatt schwarz: Spitzenhälfte des ziemlich zugespitzten 7 . Segmentes rostrot bis rostfarben. 1. Tergit in der Basalhälfte in der Mitte ziemlich stark eingedriickt. Copulationsorgane (Textfig. 1) rostgelb. Diese bestehen aus: 1) dem Penis (p), der ans ״- langen Chitingebilden zusammengestellt ist, zwischen denen sich ein feines Häutchen ausspannt, -2) zwei Seitenklappen. die Valvulae $(\mathrm{r})$, denen sich imnen jederseits eine Haltezange anschliubt: diess besteht aus 3) einem oberen Haken (oh), der auf einer gröBeren Chitin- 
llaut inseriert und 4) einem unteren Haken (uh), der basalwärts stilottförmig ausläuft; der Rand des unteren Hakens ist auBen ganz undentlich wellig.

Die Subgenitalplatte (sg) ist das Sternit des 7. der vorhandenen Segmente (das Mittelsegment nicht mitgrezählt).

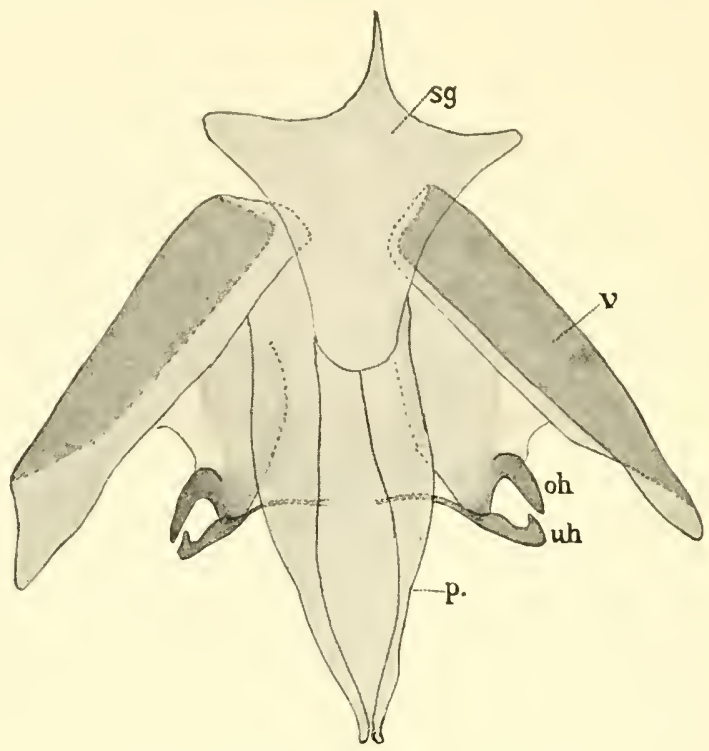

Fig. 1. Arehilummen priscus n. sp., o'.

Kopulationsapparat von unten; $86: 1$.

Es finden sich merkwärdiger Weise 2 Formen von Männchen, die ich anfangs für die briden Greschlechter liclt, ein größeres und kräftigeres und oin kleineres und zarter gebautes. Eine genaue Untersuchung der Kopulationsorgane zeigte jedoch, daß es sich bei dem vorliegenden Material nur um o handelt. Möglichepwoise ist nur die Körpergröße so stark varierend, da sich aber zwischen den beiden Gruppen ein wenn auch unbedentender Gröbrnabstand bei den vorlirgenden Stücken zeigt, führe ich hire die Gröben getrennt an:

Körperlängr der kleineren of $3-3,5 \mathrm{~mm}$, dor größeren of $4-5$ 1\% mm. Vordortlügrllänge der kleineren o $2,5-3,6 \mathrm{~mm}$, der eröberen $\sigma 3,7-5 \mathrm{~mm}$.

Im Habitus arinnert dise Spezies sohr an Ameisen-Mainnchen. Ein mansgefairbtes o hat rine braungelbe Farbe.

Typen in Muserum Hamburg und Stettin.

Konowiella hirticornis Axmlé, 1909, ans Argentinien (Mendoza), von donen ich schon frihrer Stïcke im Berliner Muscum sah, tritt ebrnfalls in 2 Grögen im männlichen Geschlecht auf; diese Form hat mehr den Habitus (iner Blattwespe. 


\section{Figurenerklärung.}

Tafel V.

Fig. 1-8. Archihymen priscus n. sp., o'.

Fig. 1. Ganzes Tier von oben; 10:1.

Fig. 2. Maxille; $105: 1$.

Fig. 3. Labium; 105: 1.

Fig. 4. Linker Oberkiefer; $70: 1$.

Fig. 5. Fühler; $25: 1$.

Fig. 6. Hinterbein; $57: 1$.

Fig. 7. Flïgel; $25: 1$.

Fig. 8. Vorderbein; $70: 1$.

$a b f=$ femorales Schürstïck (sogen. zweiter Trochanter.) 



\section{Hymenoptera III: \\ Serphidae (Proctotropidae)}

roll

\section{J. J. Kieffer}

(Bitsch). 

Serphiden (Proctotrypiden) sind bisher aus Ieutsch-Südwestafrika nicht bekannt. Die zur Untersuchung vorliegende Ausbeute der Hamburger doutsch-südwestafrikanischen Studienreise muf deshalb trotz ilures geringen Umfanges - sie entlält die Vertreter von nur 6 Arten - als willkommen bezeichnet werden. Über die geographischen Verhältnise der Serphidenfauna unserer Kolonie läßst sich nach dieser kleinen Sammlung natürlich nicht viel sagen. Dic Arten sind sämtlich neu, also nach unserer jetzigen Kenntnis auf das südwestafrikanische Gebiet beschränkt. Die Gattungen sind dagegen meist altbekannt und weltweit verbreitet, Epyris übor Europa, Asien, Nord-, Zentral- und Südamerika, Anstralien und Afrika (Nordafrika, Kap Verde, Portugiesisch Guinea, Erythräa, Ostafrika und Madagaskar), Holepyris uiber Europa, Asien, Nord-, Zentral- und Südamerika, Anstralien und Afrika (Nordafrika und Erythräa), Purasierolu über Europa, Asien, Nord-, Zentral- und siidamerika, Australien und Afrika (Nordatrika und Madagaskar), Trichopria iiber Europa, Asien, Nord-, Zentral- und Südamerika, Afrika (Algerien, Ostafrika und Madagaskar). Nur die Gattung Usakosia ist neu und mag als Charakterform unseres Gebietes gelten.

\section{Gen. Usakosia n. gen.}

Kopf quadratisch, etwas quer, vorn steil abfallend, ohne deutlichen Clypeus. Mandibel groß, distal stark rerbreitert, seliräg abgestutzt, 4 zälnnig, unterer Zahn lang und spitz. Augen kahl, kreisrund, kiirzer als ihr Abstand rom Hinterrand des Kopfes, Wange fehlend. Naxillarpalpus 5 gliedrig, lang. Antennen 13 gliedrig, vonoinander weit entfernt, an der abschüssigen Stelle der Stirne entspringend, dïnn und feinharig. Thorax $21 / 2$ mal so lang wie hoch. Pronotum vorn abgerundet, hinten allmählich breiter, schmaler als der Kopf, kaum so lang wie das Mesonotum, dureh 2 Quernähte in 3 fast gleichlange Abschnitte geteilt. Mesonotum mit 2 parallelen, vor dem Vorderrande erlosehenen Parapsidenfurchen und je einer kurzen Längsfurche auferhalb der Parapsidenfurchen. Scutellum ziemlich dreieckig, vorn mit einer Querfurehe. Mediansegment nicht gerandet, hinten 
und sritlich abgerundet, Flïgel nicht brwimpert: Stigma breit, lang elliptisch, liadialis glashell, nur als erloschene Ader sichtbar, den Vorderrand nicht erroichend: ähnliche erloschene Adern bilden aine distale Medianzelle; Subcostalis dem Vorderrande genähert, Basalis wenig schräg, das Distalende der subeostalis rreichend, länger als die fast senkrechte Transversalis. Femora in der Mitte nur wonig verdickt, mittlere Tibia auben schwach bedornt, alle Tibien und Tarsen zottig beharrt, Tarsenglieder länger als dick, Kralle fast gerade, mit einem kaum sichtbaren Zahn über der Mitte, die 2 Sporen der Vordertibia gekammt, so lang wie die 1)icke der Tibia. Abdomen flach godrïckt, wie bei Pristocera.

\section{Isakosia relbipenmis n. sp.}

Fundangaben: Usakos: IV. Muchaelsex, 22. April u. 22. Juni 1911. Karibib: W. Mronaelsex, 23.-26. April 1911.

o'. Kopf schwarzbram, glatt, glänzend, mit einigen zerstreuten Punkten. Mandibel gelbrot. Intenne scliwarz, 1. Glied rot, stark bogig, ctwas länger als das 2. und 3. zusammen, 2) kamm länger als dick, 3. etwas länger als das 4., dieses doppelt so lang wir dick, dir fulgenden wonigstens so lang wie das 4., 13. länger als das vorhergehende. Thorax schwarz, Pronotum rot, ausgenommen der Hinterrand, glatt und glänzend, wie das Mlesonotum und das scutellum. Mediansegment germelt, mit einer den Hinterrand nicht erreichenden Mittellingsleiste, hintere abschïssige Fläche dicht quergestreift, Metapleure längs gestreift. Flïgol weif, Adern dor Basalzollen gelb, Stigma schwarzbraun. Brine rot, Coxae schwarz. Abdomen schwarzbraun, hintre Iülfte der Tergite und oftmals noch ihr Vorderrand rïtlich. L. $4,5 \mathrm{~mm}$.

\section{Gen. Parasierola.}

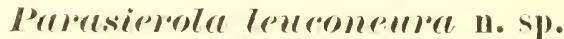

Fundangabe: Windhuk: W. Mrenaemsex, 29. April bis \$. Mai 1911.

Q. Schwarz, gläuzend. Mandibel mattschwarz. Kopf' linglich, schwach und wong dicht punktiert, Seitenrinder parallol. Clypeus kaum wahrnehmbar. Stirnloisto zwischen don Antennen bis gogon das proximale 1)rittel dor Augon reichend. Auge kahl, um serine ganzo Länge rom Hinterrande

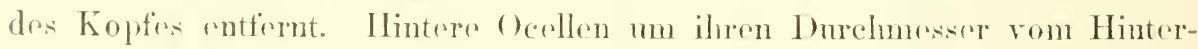
rande des loptes entfornt, so weit voneinander als von der vorderen abstrhend. Antrume hlaboglb, nicht linger als der Kopt, 3.-12. Glied rtwas 
quer, 13. länglich. Thorax etwas schmäler als der Kopf, glatt, auch Mediansegment glatt. Flïgel weiß, Prostigma und Stigma schwarzbraun, die Adern weiß. mur die Radialis gelblich weiß. Beine rot, Femora schwarzbraun. Abdomen schwarzbraun. L. $2.5 \mathrm{~mm}$.

\section{Genus Epyris Westw.}

1. Kopf etwas länger als breit, Radialis $3-4$ mal so lang wie dis Basalis . . . . . . . . 1. E. Michaelseni n. sp. - Kopf etwas quer, Radialis 2 mal so lang wie die Basalis: 2. E.uindhukiensisn..pp.

\section{Epyris Michaelseni n. sp.}

Fundangabe: Windhuk; W. Michaelsex, 29. April bis 8. Mai 1911.

f. Schwarz, glänzend. Mandibel rot, ziemlich lang, schmal, distal zugespitzt, ungezähnt. Lopf fast quadratisch, etwas länger als breit, ziemlich glatt. Auge kahl, um die halbe Länge rom Hinterrande des Kopfes entfernt. Ocellen wenig deutlich. Palpen nicht bis zur Mitte des Kopfes reichend, mit 4, bezw. - vorstehenden Gliedern. Antemne braun, ventral heller. Scapu, dick, kahl, doppelt so dick wie das Flagellum, um die Hälfte länger als dick, 2. Glied so lang wie dick, dir folgenden quer, dicht gedräugt, das 13. länglich. Pronotum 11/2 mal so lang wie das Mesonotum, nach hinten allmählich breiter, schwach und zerstrent punktiert. Mesonotum glatt, Parapsidenfurchen fuin, durchlaufend, nach hinten kouvergierend. laterale Abschnitte mit je einer nicht durchlaufenden Lïngsfurche. Seutellum glatt. die 2 Gruben punktförmig und voneinander seher entfernt. Mediansegment fast quadratisch, lederartig, matt, mit einer bis zum Petiolus reichenden Längsleiste, soitlich und hinten gerandot. l'lenren lederartig, Flügel schwach getrübt, Stigma und Adern braun, Subcostalis der Costalis fast anliegend, Basalis weniger schräg als die Transversalis, in das Distalrnde der Subcostalis mündend, Radialis 3-4 mal so lang wir die Basalis. Postmarginalis punktförmig, Stigma klein. Beine rot, C'oxae und Femora dunkler, mittlere Tibia lateral sehr kurz bedornt. Abdomen gewölbt, glatt, fast kahl. L. $3 \mathrm{~mm}$.

\section{Elymis mindhuliensis n. sp.}

Fundangabe: Windhuk: W. Mrchaelses, 29. April bis \&. Mai 1911. 
o Schwarz, glanzend. Kopf etwas quer, glatt. Auge kahl, um 1/3 seiner Länge vom Hinterrande des Kopfes entfernt. Tordere Ocelle dem Hinterrande der Augen gegeniber liegend, die hinteren so weit voneinander entfernt wie rom Hinterrande des Kopfes. Maxillarpalpus mit 4 vorstehenden Gliedern. Antenne lang, kahl, Scapus nicht dickor als das Flagellum, so lang wio das 3. Glied, 2. Glied quer, rom 3. nicht dentlich getrennt und daher leicht zu überselsen, das 3. $11 \mathrm{~m}$ die Hailfte langer als dick, 4.-13. wenigstens doppelt so lang wie dick. Pronotum fast quadratisch, wenig länger als das Mesonotum, beide glatt. Parapsidenfurchen sehr frein, fast parallel, voneinander woit entfernt. Sentellum glatt, die 2 Gruben selır klein, punktförmig, vonrinander sehr weit abstehend. Mediansegment quer, lederartig, mit einer durchlanfenden Mittellängsloiste, seitlich und hinten gerandet. Flügel schwach gebräunt, Subcostalis der Costalis fast anliegend, Postmarginalis punktförmig, Radialis 2 mal so lang wie die Basalis, diese schräger als die Transversalis, Stigma kumz und stumpf. Tarsen rot, alle Glicder länger als dick, mittlere Tibia lateral ziemlich dicht bedornt, die 2 sporen der 4 linteren Tibien gekïmmt, Kralle schwach gebogen, mit einem kaum wahrnehmbaren Kahn distal von der Mitte. Abdomen ziemlich stark von oben zusammengedrückt. L. $3 \mathrm{~mm}$.

\section{Gen. Holepyris. \\ Holepymis Wregmeri II. sp.}

Fundangabe: Ir ibis; W. Micuaelsex, 15. Juli 1911.

б. Schwarz, glinzend. Mandibeln dunkelbraun. Kopf länglich, foin loderartig und feinhaarig. Clypeus gekielt. Ange elliptisch, feinharig, S mal so lang wie die Wange, fast $11 \mathrm{~m}$ seine ganze Länge rom Hinterrands des Kopfes entfrent. Hintere Ocollen den Hinterrand des Kopfes fast beriblend. Antenne schwarzbramn, dir 3 proximalen Glieder gelbrot, Sicapus dopjult so lang wie dick, 2. Glied länglieh, 3. - 13. wenigstens so lang wie dick, kaum fiunhaarig. Pronotum schmaler als der Kopf, doppelt so lang wir das Mesonotum, hinten alluablich breiter, glatt wie das ungetrilte Mrsonotum. Sentellum glatt, vorn mit einer schwach bogigen Querfurche. Mediansegment $1131 / 3$ länger als broit, seitlich und hinten gerandet, ziemlich grob quergerunzelt, hinteres I rittel quergestreift, Mittellängsleisto his zum Petiolus durchlaufend, auBerdom noch jo 2 dor Mittellängslejste genährete, nicht durehlaufrnde Längsmuzeln; hintere absehiissige Fläche lonlerartig. Flügel scluwaleh getrübt, Subrostalis dor Costalis fast anliogend, liadialis doppolt so lang wie dio liasalis, diose mohr schriig als die 'Trans- 
versalis, in das Distalende der Subcostalis mïndend, Postmarginalis fehlend, Stigma klein und stumpf. Beine gelbrot, Coxae und Femora schwarzbraun, alle 'Tarsengheder länger als dick. L. $2 \mathrm{~mm}$.

\section{Gen. Trichopria.}

\section{Trichopria rhopalica u. sp.}

Fundangabe: Seeheim am Gr. Fischfluf; W. Mlchaelsen, 16. bis 19. Juli 191 I.

Q. Schwarz, glatt und glänzend. Schläfe und Prothorax mit grauem Haarfilz. Kopf kuglig. Antenue dunkel rotbraun, die 3 gliedrige Keule schwarz, Scapus stark keulenfïrmig, distale Hälfte doppelt so dick wie die proximale, 2. Glied dicker als das 3., 3.-9. gleichdïn, alnü̈hlich verkïrzt, das 3. wenigstens $1 \frac{1}{2}$ mal so lang wie dick, das 9. fast kuglig, 10.-12. mehr als doppelt so dick wie das 9., 10. und 11. so lang wie dick, 12. eirund. Scutellum gewölbt, vorn mit ciner Grube. Mediansegment mit einer wenig vorstehenden Lamelle. Flïgel mit dem gewöhnlichen Gr. äder. Protiolus foinharig, so lang wie dick, Abdomen kürzer als der iibrige Kïrper, von oben zusammongodriickt, gestreckt eiförmig, hinten schwach zugespitzt. L. $1.3 \mathrm{~mm}$. 



\section{Hymenoptera IV: Ichneumonidae}

\section{G. Enderlein}

(Stettin).

Mit 6 Abbildungen im Text. 

Aus der Ausbeute der „Hamburger deutschsüdwestafrikanischen Studienreise 1911" stellte mir Horr Professor Dr. W. Michaelsex die Ichneumoniden zur Bearbeitung zur Verfïgung. Durch Herrn Professor Dr. Hexmoss erhielt ich noch das Material dieser Gruppe aus dem Berliner Zoologischen Museum. Diesen beiden Herren sage ich auch an dieser Stelle für das bereitwillige Entgegenkommen besten Dank. In der Beschreibung der Gattung Pleurodontoplax habe ich außer einer Art aus Deutsch-Siidwestafrika noch je eine Art aus Transvaal und rom Kongo bei dieser Gelegenleit mit eingefïgt.

Die vorliegende Abhandlung schließt sich als: „Beiträge zur Kenntnis auBereuropäischer Ichneumoniden III" an zwei früher von mir veröffentlichte Arbeiten ${ }^{1}$ ) an.

\section{Subfam. Ichneumoninae. Tribus Joppini. Gen. Joppites Berth. 1894.}

Joppoides, Berthocmiex, Gen. Ins. Ichneumoninae. 1904. pag. 23.

Typus: J. apicalis (BR. 1S46), Süd Europa, Nordafrika.

Berthocmed, veranlaßt durch die irrtïmliche Angabe ron Tosquixet (Mém. Soc. Ent. Belg. 1896, pag. 35 an Schuß), daß die Klauen einfach seien, hat die Gattung Joppoides auf die folgende Spezics aufgestellt. Sie fällt mit Joppites zusammen, da die vorliegenden Stücke, die völlig auf J. xanthomelas Br. passen, deutlich gekämmte Klauen besitzen.

1) 1. Paniscinae. Stettiner Ent. Z. 1912, pag. 105-144.

II. Ophioninae. Die Gattung Thyreadon und ihre Verwandten. Zoolog. Anz. 39, 1912, pag. 624-632. 8 Figuren. 


\section{.Joppides xanthomelas (Brullé 1846).}

Fundangabe: Deutseh-Sïdwestafrika, Farm Okosongomingo am kleinen Waterberg; Haxs Tuomsex, Juli-Aug. 1912 (1 \%, 3 우).

Die Hintereoxen des $\sigma$ sind ganz grauschwarz, die der 오 nur an der Basis.

\section{'Tribus Ichneumonini. Gen. Neotypus Först. 1862. \\ Neotypus Mirhaelsemi nov. spec.}

Fundangabe: Deutseh-Siidwestafrika, $\mathrm{N} e \mathrm{udamm}$, (a. 42 Kilometer ostnordästlich vou Windhuk; W. Mughaelsfer, 10.-15. Mai 1911 (1 \&)).

‥ Kopf rostrot, nit sehr wenig deutlicher und sehr feiner weißlicher Pubescenz. Palpen braun. Mandibeln gelb mit braunen Spitzen. Fühler schwarz, Unterseite braun, 1. Glied unten rostgelb, 8.-11. Glied unten und innen, 7. Glied nur unten weiBlich. Kopf nur mit sehr feiner Punktierung.

Thorax rostrot, P'unktierung fein. Parapsidenfurehen fehlen. Mesopleure nahe am Vorderrand mit ein r senkrecht stehenden oben verkürzten scharfen Kante und in der hinteren oberen Ecke mit einer poliert glatten Stelle. Mittelsegment geuetzt, Area basalis und eentralis quer, Area petiolaris lang und konkav. Al,domen schwarz, 4.-7. Tergit mit Ausnahme des Vorderrandes weiblich, ebenso die Hinterrandsäume aller Sternite. 2. und 3. Tergit mit diehter Punktierung. Coxen sehwarz. Beine schwarz, Vorder- und Mittelschienen aufen gelblich weiß, ebenso die Endhälfte der Vorderseite des Vorderschenkels. Allo Schienenendsporen weißlich. Flïgel hyalin, Aderu und Pterostigma dunkelbraun, Nervulus interstitial. Areola 5-eekig. Disconbitalader mit unscharfer Ecke.

Körperlainge $8 \mathrm{~mm}$,

Vorderflügelläinge $5,6 \mathrm{~mm}$,

Fïhlerlïnge $4 \mathrm{~mm}$,

Länge des Hinterleibstieles $1,6 \mathrm{~mm}$.

Type im Hamburger Zoologisehen Museum.

Gewidmet wurde diese Spezies dem Sammler. 


\section{Subfam. Cryptinae. 'Tribus Cryptini. \\ Gen. Osprynchotus Spin. 1841. Osprifuchotus flavipes Brullé 1846.}

Fundangabe: Deutseh-Sii dwestafrika: LëBrert (1 q).

Gesicht und Clypeus rostbraun, Vordertarsus dunkel rostbraun. Vorderschenkel und -schiene rostfarben.

\section{Ospmymchotus capensis Spin. $15+1$.}

Fundangabe: Deutsch-Sïdwestafrika, Bezirk Waterberg, zwischen Okandjache und Okanjante: H. Thomsex, August 1913 ( $\sigma$ ). Gesicht und Clypeus hellgelb, Tordertarsus olmo das letzte Glied hellgelb.

\section{Subfam. Cryptinae. Tribus Cryptini. \\ Gen. Gambrus Först. 1868.}

\section{Gambius antefurcalis nor. spec.}

Fundangabe: Deutsch-siidwestafrika, Farmokosongomingo am Kleinen Wat erberg, H. Thonsen, Juli-Aug. 1912 (1 f ).

‥ Kopf matt schwarz. Untergesicht fein punktiert. Stim an den Seiten poliert glatt, vorn etwas eingedriickt, und rorn in der Mitte mit einer kurzen medianen Längsleiste. Umgebung des Stemmaticum mit feinen Runzeln. Clypeus scharf abgrsetzt, gewölbt. Fïhler dunkelbraun, 1. Glied schwarz, 6. am Ende und 7.-12. Glied oben weiB, 3. Glied dicht an der Basis rostrot.

Thorax rötlich rostfarben, schwarz ist: der Prothorax, die Unterscite. die untere Hälfte der Mesopleure, dic Metaplenre mit Ausnalume des oberen Endes, die Seiten des Mittelsegmentes: fein punktiert. Parapsidenfurchen scharf. Mittelsegment hinter dem Vorderrand mit Querkiel, dahinter mit dichten Längsrunzeh, hinten und an den seiten unregelmäßig gerunzelt: Luftlöcher kurz und eiförmig: an der Srite hintel der Mitte jederseits mit 1 ziemlich scharfen Zahn. Pleuren dicht längsgerunzelt. 
Mesopleure hinten oben mit einem poliert glatten Wulst. Abdomen schwarz, i und 8. Tergit weiß; microskopisch frin und dicht punktiert, 1. Tergit poliert glatt; Sternit am Hinterrand fein hell gesäumt. Legerohr dunkel rostrot. Coxen sehwarz. Vorderbeine gelbbraun. Mittelbeine braun. Hinterbeine sehwarz. Klauen ungezähnt.

Flïgel hyalin, Spitzendrittel des T.fl. mit sehr blassem bräunlichen Hauch. Adern schwarzbraun. Areola groß, fünfseitig, Seiten parallel, hinterer Winkel sehr stumpf. Nerrulus ziemlich weit antefurcal. Diseocubitalader distal der Mitte flach gebogen, ohne Ramellus. Nervellus unten (am Eude des ersten Viertels) gebrochen.

Körperlänge $8 \% \mathrm{~mm}$,

Vorderflügellänge $7 \mathrm{~mm}$,

Fühlerlänge $71 / 2 \mathrm{~mm}$,

Liinge des 1. Abdominalsegmentes 1,6 mm,

Liinge des Legerohres $5 \mathrm{~mm}$.

Type im Zoologischen Museum in Hamburg.

\section{Gen. Cryptus F. 1804.}

\section{Cryptus Thomseni nov. spec.}

Fundangabe: Deutsch Südwest-Afrika, Farm Okosongomingo am Kleinen Waterburg: Haxs Thonsex, Juli bis August 1912 $\left(\begin{array}{ll}1 & \text { - }\end{array}\right)$.

ㅇ․ Kolf rostrot, Untergesieht und Stim mit feinen Querrunzeln. Fülıler rostbraun; 1. Glied ziemlich dick, rostgelb; 6.-9. Glied innen blab gelblich.

Thorax rostrot, dicht und fein punktiert. Parapsidenfurchen ziemlich scharf, mit durehgrhenden Querrunzeln. An dor oberen Hinterecke sind die Mesopleuren nur sohr wenig glatt. Mittelsegment sehr feimmaschig genetzt, hinter der Mitte ein scharfer, nach linten offener stark gebogener Querkiel, der joderseits in einrn ziemlich scharfen Zahn ausläuft. Abdomen rostbraun, matt. 7. Tergit oben in der Mitte schmutzig gelblieh, Sternit des 3. Srgmentes hinten in der Jitte schmutzig gelbliclı gesiumt. Legescheide rostbraun. Penis mit den Coxen rostfarben. Hinterbeine rostrot. Flïgel lyalin, Adrrn und Pterostigma braun. Ramellus deutlich. Nervulus interstitial.

K̈̈̈perlänge $9^{3 / 4} \mathrm{~mm}$

Torderflïgellänge $7 \mathrm{~mm}$ 
Länge des Abdominalstieles 2,1 mm

Länge des Legerohres $4 \frac{1}{2} \mathrm{~mm}$.

Gewidmet wurde diese Spezies dem Sammler.

Type im Hamburger Zoologischen Museum.

\section{'Iribus Mesostenini.}

\section{Gen. Scenopathus, nov. gen.}

Typus: s. ferrugineus nov. spec. Deutsch-Südwestafrika.

Unterscheidet sich von Cratocryptoides Schmedens. 1908 [C. maculiceps (Cas. 1905) aus Borneo] durch den ziemlich weit antefurcalen Nervulus.

Grube vor dem Scutellum mit 4 kleineren Längsleistchen. Areola winzig klein, quadratisch, dessen AuBennerv etwas verblaßt.

\section{Scenopathus fermuineus nov. spec.}

Fundangabe: Deutsch-Südwestafrika, Farm Okosongomingo am Kleinen Waterberg: Haxs Thousex, Juli-Aug. 1912 (1 ㅇ.).

of Kopf rostrot, matt. Oberkiefer rostrot mit schwarzen Spitzen. Fühler schwarz, die beiden ersten Glieder rostrot: das 8. an der Spitze, das 9., 10. und 11. auf der Oberseite weiblich.

Thorax rostrot, fein gerunzelt, Riickenschild fein quergerunzelt. Parapsidenfurchen scharf. Am Hinterrand der Hesopleure oben eine poliert glatte Beule. Scutellum nur ganz vorn mit Seitenleisten: die Fortsätze dieser Leisten seitlich der anteclypealen Grube schwefelgelb. Mittelsegment mit dichter, kräftiger und feinmaschiger Netzrunzelung: hinten fast eben: an den Seiten hinter der Mitte mit je einem undeutlichen zahuartigen Höcker. Abdomen rostrot: 7. Tergit mit Ausnahme der Seiten weiBlich; 1. Segment oben mit jederseits einer feinen Längsfurche, außerhalb derselben kräftige und ziemlich dichte Punktierung, zwischen ihnen nur hinten mit einzelnen hinten rissig ausgezogenen Punkten. 2. und 3. Tergit dicht punktiert. Seiten des Vorderrandes des 4. Tergits mpunktiert und glatt. 5. und die ibrigen Tergite matt. Seiten des 7 . und 8. Tergites schwarz. Unter dem 7. Tergit schiebt sich wach hinten sine blasse poliert glattr fast halbkreisförmige Platte hervor. Beine mit den Coxen rostrot. Schienen gelblichweiß, oben und unten mit rotbrannem Längsstreif, Hinterschienen schwarz, Basalsechstel gelblichweiß. Schienenendsporne rostgelb. Legerohr schwarz, Klauen ungezähnt.

15 Michaelsen, Deutsch-Südwestafrika. 
Flïgel hyalin, Adern des Torderflïgels und Pterostigma schwarz, mittleres an der proximalen Basis mit gelblichem Punkt. Norrulus antefurcal. Discocubitalader in der Mitte flach gebogen. Areola sehr klein, quadratisch oder wenig breiter als hoch.

Körperlänge $11 \% \mathrm{~mm}$,

Vorderflïgellänge $8 \mathrm{~mm}$,

Fühlerlänge ea. $7^{1 / 4} \mathrm{~mm}$ (Spitze abgebrochen!)

Länge des 1. Abdominalgliedes $2,2 \mathrm{~mm}$,

Länge dos Legerohres $5 \frac{1}{1} / 2 \mathrm{~mm}$.

Type im Zoologischen Museum in Hamburg.

\section{Subfam. Mesochorinae. Tribus Mesochorini. Gen. Mesochorus Grav. 1829. Mesochorme herero nor. spec.}

Fundangabe: Deutsch-Sï dwestafrika, Okahandja; W. Michaecsex, 2.). Mai - 3. Juli 1911 ( 1 o $)$.

o Kopf hell rostgillb, Augen auf allen Seiten ausgenommen an den Schläfen mit schwefelgelbem Saum. Oberkieferspitzen rostbraun. Fühler und Palpen hellrostgelb. Untergesieht mit sohr friner Punktiorung, in der Mitte fast etwas kantig, oben unter den Fïhlern eine spur eckig.

Thorax rostfarloen mit wenig dichter sehr feiner Punktierung und rtwas golber Pubescenz: Parapsidenfurchen uur etwas angedeutet. Tegulae und rin Fleck darunter schwefelgelb. Metonotum vollständig gefeldert, Area petiolaris breit, Area centralis schmal und schlank, Area basalis kurz und nicht von der Area centralis getrennt. Abdomen dunkelbraun, poliert, unpunktiert, Mittelstreifen des 3. Trergites rostgelblich, Unterseite größtentrils gelb. Brine mit den C'oxen hellrostgelb. Die griffelfoirmigen Fortsätze an der Abdominalspitze ( $\sigma$ ) rostgelb und 0,6 mm lang. Längerer Hintertibiensporn fast lualb so lang wie der Metatarsus.

Flügel hyalin, Adrern braungolb, Pterostigma blaß ockergelb. Dic grofor rhombinche Areola ist voru kurz gestielt. Norvulus interstitial. Basalnerr gebogen. Dircocubitalader glviclumäßig gebogen.

Kïrperlainge $5 \mathrm{~mm}$,

Vorderflïgelläinge jo mm,

Fühlerlïngr ca. 6 mm.

Type in Hamburger Zoulogischen Jusrum. 


\section{Subfam. Ophioninae.}

Tribus: Ophionini.

\section{Divisio: Gravenhorstiaria.}

Exderleix, Zool. Anz. 39. 1912, fig. 624.

\section{Gen. Hypselogastrina, nov. gen.}

Typus: II. saliina nov. spec,, Deutsch-Sïdwestafrika.

Diese Gattung steht nahe der Gravenhorstiarienen-Gattung Hybopleurax ExinerL. 1912 und besitzt auch den für diese charakteristischen Metapleuralhöcker, der hier kräftig zahnartig ziemlich spitz und an der Spitze abgerundet ist. Von dieser Gattung unterscheidet sie sich dureh Folgendes:

Scutellum nur mit äußerst feiner dichter Punktierung, Clypeus vorn gerade abgestutzt, der Hinterleib ist sehr hoch (in der Nitte $8 \mathrm{~mm}$ hoch), und das 2. Segment ist hinten fast $1 \frac{1 / 2}{2}$ mal so hoch wie lang. Das 1. Sternit endet unter den Luftlöchern des 2. Tergites, das 2. Sternit am Ende des 2. Tergites. Bei Hyboplenrar ist das Scutellum mit groben tiefen Punkten besetzt, der Clypeus in der Mitte in eine spitze Ecke ausgezogen und das 2. Segment ist doppelt so lang wie am Ende breit.

In der Erscheinung ist diese Form einer großen afrikanischen Salius sehr ähnlich. Auch Thyreodon Brclé $18 t 6$ und die andereu verwandten Gattungen haben viel Ahnlichkeit in der Erscheinung mit großen Pompiliden. Sollten sie vielleicht bei diesen Pompiliden schmarotzen?

\section{IIypelogastrina saliina nor. spee.}

Fundangabe: Deutseh-südwestafrika, Namutoni am Ostende der Etoscha-Pfanne: Seewaln, 20. März 1909 (1 \&).

ㅇ Kopf dunkel rostbraun. Stirn und Stemmaticum schwarz, Ocellen schwarz; Punktierung dicht und fein, auf dem Clypeus und besonders den Handibeln kräftiger und gröber. Palpen schwarz. Antennen nicht ganz so lang wie die Vorderflügel, schwarz, unten etwas gebräunt, allmählich zugespitzt.

Thorax schwarz mit rotbraunem Anflug auf den Pleuren, dem Rïckenschild und Scutellum. Riückenschild mit 3 etwas erhabenen Längslinien, und hier und da mit kleinen Büscheln kurzer schwarzer Pubescenz. Sontellum mit dichter schwarzer kurzer Pubescenz, Skulptur ist nicht dureh dieselbe erkennbar. Mesopleure fein punktiert, in der Mitte mit einer großen poliert glatten unpunktierten Stelle, Hinterrand mit dichten kurzen Querleistchen. $15^{*}$ 
Metapleuraldorn loch und ziemlich spitz. Abdomen poliert glatt schwarz mit blanem bis blangrïnem auf dor Unterseite bis violettem Glanz. Beine schwarz, Schenkel und Schienen mit braunrötlichem ìon. Klauen dichtgekämmt.

Fliigel dunkelbraun mit rötlich violettem starken Glanz. Adern schwarz. Nervulus interstitial. Nervulus in der Mitte gebrochen. Discocubitalader etwa an Ende des 2. Drittels umgebogen, die 2 ersten Drittel gerade.

Körperlänge $30 \mathrm{~mm}$,

Vorderflügellänge $27^{3} / \mathrm{t} \mathrm{mm}$,

Fïhlerläinge $22 \mathrm{~mm}$,

Abdominallïnge $17 \mathrm{~mm}$,

Größte Abdominalhöhe $8 \mathrm{~mm}$,

Länge des ersten Tergites ea. $6^{3} / 4 \quad 11 m$,

Länge der Hinterschiene $11 \mathrm{~mm}$.

Type im Berliner Zoologischen Museum.

\section{Divisio: Ophionaria.}

\section{Gen. Henicospilus Steph. 1835.}

Typus: H. merdarius (Grar. 1829), Europa.

Torgl. unter Amesospilus!

In dem haarlosen Feld der Tiscocubitalzelle ist der mittlere, im Innern des unbelaarten Foldes liegend. Hornfleck (zontraler Hornfleck immer vorhanden. Der basalwärts am Rand des haarlosen Feldes liegende Hornfleck (proximalor Hornfleck) ist meist grob und immer vorhanden, wenn anch zuwrilen nur winzig punktförmig entwickelt, und hat häufig eine sichelmondfömige Gestalt; der spitzenwirts am Rande des haarlosen Feldes liegende Hornfleck (distaler Hornfleck) ist meist nur streifenförmig entwickelt und häutig nur undentlich.

\section{Henicospills simicarimatus nov. spec.}

Trextfig. 1 und '2.

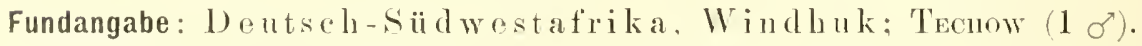

ơ. Kopf mit Stemmaticum rostgelb, Fïlllor mïBig dick, rostfarben, an der spitze stark zugespitzt. Schläton am Augenrand rotwas anfgehellt. Thorax hell rostgelb, Inesonotum in der Mrdianlinir in der vorderen Hailfte mit einem dunkel rostfarbenem Lingsstreif. Scutrllum otwas lueller gelblich. Mesoplrure dicht punktiert, unten etwas mah, oben ziemlich glatt. 
Mittelsegment (Fig. 1) mit kräftigem Querkiel am Ende des vorderen Viertels, das mittlere Drittel bildet aber eine kräftige Ecke nach vorn, die in eine winzig quadratische und abgerundete von scharfem Kiel umgebene Area basalis ausläuft; vor diesem Kiel sehr fein punktiert, dahinter vorn in mittleren Drittel mit feinen Längsleistehen, die in der hinteren Hälfte in schräg nach außen laufende Leistchen übergehen: mehr als die vordere Hälfte der Seiten poliert glatt. Abdomen hellrostgelb, Beine hellrostgelb. Ventralseite des 3. bis letzten Segmentes etwas gebräunt.

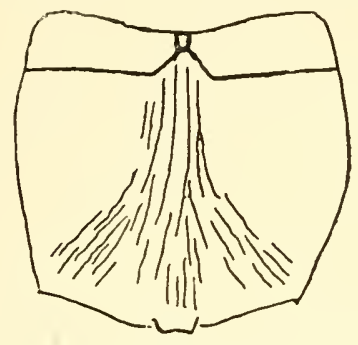

Fig. 1. Henicospitus sinicavinatus ExDERL. $\sigma$.

Sculptur d. Mittelsegmentes.

Vergr. $16: 1$.

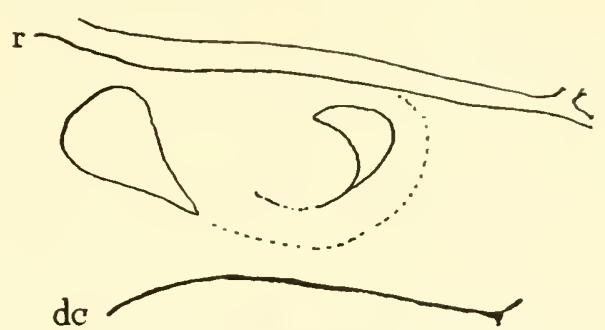

Fig. 2. Henicospilus sinicarinatus ExderL. $\sigma$. Hornflecken der Discocubitalzelle. Vergr. 25:1. $\mathbf{r}=$ Basalabschnitt des Radius, $\mathrm{dc}=$ Discocubitalader.

Flügel hyalin, Adern braun. Costa und Pterostigma hell ockergelb. Nervulus etwas antefureal. Basalabschnitt des Radius ein wenig gewellt, dick, am Ende etwas rerjuingt. In der Discocubitalzelle (Fig. 2) sind - Hornflecken vorhanden, der proximale tropfenförmig und der zentrale breit sichelmondförmị.

Körperlänge ca. $16 \mathrm{~mm}$,

Vorderflïgellänge $11 \frac{1}{2} \mathrm{~mm}$,

Länge des Hinterleibsticles $2,7 \mathrm{~mm}$,

Fühlerlänge ca. $16 \mathrm{~mm}$.

Type im Berliner Zoologisehen Museum.

\section{ILnicospilus Techowi nor. spee.}

Textfig. 3.

Fundangabe: Deutsch-Sïd westafrika, Windluk: Tecuow ( $\left.1 \sigma^{\prime}\right)$.

$\sigma$. Kopf und Stemmaticum hell knochenfarben, Fühler rostfarben, ziemlich duinn, fadenförmig. Schläfen nicht heller. Thorax hell matt knoehenfarben: Rückenschild mit 3 glatten etwas mehr rostgelben Längsstreifen, die seitlichen vorn, die mittlere hinten rerkürzt. Hesopleure ziem- 
lich glatt, unten mit sehr feiner und sehr dichter Querritzung. Mittelsegment mit geradem, nur in der Mitte undrutlich welligem, kräftigen Qnerkiel, Feld davor matt, ziemlich dicht pubesciert, Fold dahinter in der Mitte

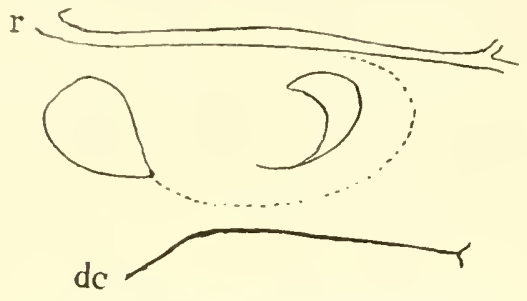

Fig. 3. Henicospitus Techowi Exieru. $\sigma^{\prime}$. Hornflecke der Discocubitalzelle. Vergr. 25:1.

$r=$ Basalabschnitt des Radius. $\mathrm{de}=$ Discocubitalader, der vorderen Hälfte mit 3 kräftigen Längsleisten, in der hinteren Hälfte mit riner Anzahl krïftiger Leisten, die strahlenförmig nach hinten und nach den Feiton ron den Fnden der Längskicle ausgehen: dic vordersten also quer.

Flïgel hyalin. Adern gelbbraun, Costa und Pterostigma hellrostgelb. Nervulus etwas antefurcal. Basalabschnitt des Radius fast gerade, an der Spitze wenig diinner. In der Discocubitalzelle ist der proximal. Hornfleck groß, rundlich, auben wenig ansgozogon; der zentrale Hornfleck sichelmondförmig: der distale Hornfleck fehlt völlig.

Körperlänge ca. $16 \mathrm{~mm}$,

Vorderflügellänge $11 \frac{1}{2} \mathrm{~mm}$,

Länge des Hinterleibstieles $3.2 \mathrm{~mm}$,

Fühlorlänge ca. 16 mmı.

Type in Berliner Zoologischen Museum.

\section{Henicospilns Dinteri nov. spec.}

Texttig. 4 .

Fundangabe: I) eutsch-siidwestafrika: Dixter (1 f).

․ Kolf nit Stemmaticum schwefolgelb, glatt, Fühler lobhaft rostgell, fast zirgelrot, dicker. Thorax gelb, Mittelsegment etwas mehr rostgelb. Mesopleure unten äuferst frin quergeritzt. Mittelsegment vorn mit scharfen querkid, der vorn in der Mitte nur ein wenig eingedrüekt ist. Fold davor ctwas glatt; Feld dahinter mit ziomlich dichten frinen umeregelmäbigon (purrunzeln, in der Mitte vorn mit einer Anzahl älnlicher Längsrunzeln. Abdomrn solur hell rostgolblich, Hintrerand des 4. Tergites etwas gebribunt. Beine luellorstagell).

Fliigel lyvalin, Adern gelbbran. Ptorostigna, Costa und Subcosta hellockeroulb. Nerrulus antefiureal. Basalal sechnitt des hadius schwach 
gewellt. Discocubitalzelle mit 2 Hornflecken (Fig. 4), der proximale dreieckig und nach außen spitz ausgezogen, der zentrale (im Innern des unbehaarten Feldes) mondsichelf ̈̈rmig und unten nach innen zu spitz ausgezogen; der distale fehlt.

Körperlänge $191 / \mathrm{t}$ mm,

Vorderflügellänge $14 \mathrm{~mm}$,

Länge des Hinterleibstieles $4,6 \mathrm{~mm}$.

Type im Berliner Zoologischen

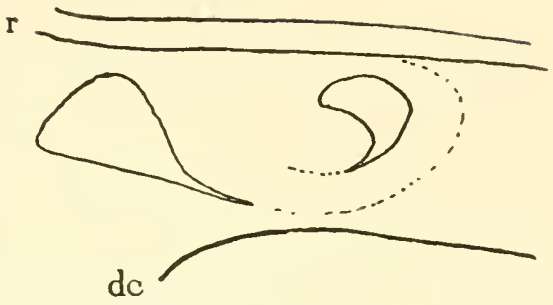

Fig. 4. Henicospilus Dinteri Exterl. $\sigma$. Hornflecken in der Discocubitalzelle. Verg. 25:1.

$r=$ Basalabschnitt des Radius, $\mathrm{dc}=$ Discocubitalader. Iuseum.

\section{Henicospilus Liibberti nor. spee.}

Textfig. 5.

Fundangabe: Deutsch südwestafrika; Lёввеrт, '1901 (1 우).

ㅇ Kopf rostfarben. Stemmaticum schwarz. Schläfen an Augenrand schmal, gelb gesäumt. Fühler lang, dünn, fadenförmig, dunkelrostfarben, Spitzenhälfte rostbraun. Thorax hell rostfarben. Iesopleure fein punktiert, oben etwas geglättet. Mittelsegment etwas vor dem Ende des ersten Drittels mit einem scharfen, völlig geraden Querkiel; der Raum davor glatt, der dahinter sehr dicht unregelmä̊ig und sehr kleinmaschig netzgerunzelt, vorn in der Mitte mit kräftigeren Längsrunzelu, an den Seiten schwächer ats hinten gerunzelt. Abdomen hell rostfarben, dis Unterseite des 3. bis letzten Segmentes schwächlich. Beine hell rostfarben

Fliigel hralin. Adern braun. Pterostigma rostgelb. Terrulus ein wenig antefureal. Basalabschnitt des Radius

r

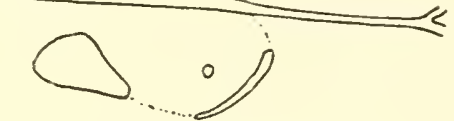

$\mathrm{dc}$

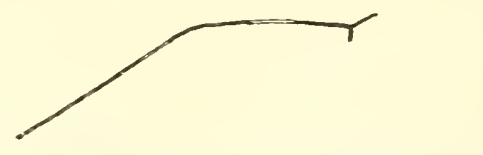

Fig. 5. Henicospilus Lübberti Exiert. 오. Hornflecke der Discocubitalzelle. Vergr. 25: : I. $\mathrm{r}=$ Basalabschnitt des Radius. $\mathrm{dc}=$ Discocubitalader. gerade, Basalhälfte etwas verdickt. I)iscocubitalzelle mit 3 Hornflecken. der proximale dreieckig tropfenförmig, der distale linienförmig und der zentrale in Form eines winzigen Punktes.

Körperlänge $14^{1 / t} \mathrm{~mm}$,

Vorderflïgellänge $11 \mathrm{~mm}$,

Länge des Hinterleibstioles $: 21{ }_{2} \mathrm{~mm}$.

Type im Berliner Zoologischen Museum. 


\section{Gen. Amesospilus, nov. gen.}

Typus: A. unicallosus (Vollexн, 1878), Europa (Frankreich).

Diejenigen /lenicospilus-Arten, die im Zentrum des haarlosen Feldes in der Discocubitalzelle keine Spur eines Hornfleckes besitzen, trenne ich als Amesospilus ab. Hier ist ein Gegensatz immer deutlich erkennbar; wïhrend bei dem Vorhandensein oder Fehlen des außeren (distalen) Fleckes am Rand des umbehaarten Feldes alle Übergänge vorhanden sind. So ist es bei $H$. merdarius (Grav.) nicht mit Sicherheit zu sagen, ob er vorhanden ist oder fehlt.

Kriechbaumer läßt die Formen mit nur 1 Hornfleck für die Gattung Henicospilus S'тенн. 1835: dies ist aber nicht richtig, weil der 'Typus der Gattung /1. merdarius (Grar. 18:29) [Europa] ist. Dieser hat aber den zentralen Hornfleck neben dem proximalen. Dispilus Kunecus. 1901 jich lege als Typus II. merlarius (Grav.) fest] fïllt also völlig mit Henicospilus zusammen.

Trispilus KRIECHB. 1901 ist, wie schon erwähnt, nicht scharf von Henicospilus getrennt, und wäre nur als Gruppe verwondbar, ist aber besser ganz fallen zu lassen.

Zu Amesospilus gehören die folgenden bisher zu Menicospilus gestellten Arten: A. monostigma (Vollent. 1879) Zentral-Europa, A. variegatus (Szép.. 1905) aus Turkestan, A. Akngeri (Kokuj 1907) aus Transkaspien, A. Semenovi (Kok. 1907) aus Transkaspien, A. repentimus (Holmgk. 1858) aus Nord- und Mittel-Europa.

\section{Amesospilus herero nov. spec.}

Textfig. 6 .

Fundangabe: I)eutsch-Sïdwestafrika, Oka handja; Dr. ( Dontsch-siidwestafrika, Windhuk: Tecnow (1 q gröBeres Ex.).

Q. Kopf rostfarben, Scheitel und Stemmaticum, Seitensäume der Stim, Sritendrittel dos Untrrgesichtes und breite Augensäume anf den Schliafen schwefelgelb. Fühler dunkel rostfarben, dünn. Thorax dunkel rostfarbon. Scutellum eine Spur heller. Mesoplenre mit gleichmabiger feiner Punktirrung, die sich in der Mittr linten rtwas zu feinen Querreilien anordnet. Mittelsegment am Eude des ersten Viertels mit scharfenı ganz geradem Querkiel, davor mit sehr feiner Punktierung, dahinter dicht verworren gerunzelt. Abdomen dunkel rostfarben, ventrale Soiten des 4.-7. Seguentes schwarz odur braun. Beine duskel rostfarben. 
Flügel getrubt hyalin. Alle Adern dunkel rostfarben. Pterostigma rostgelb. Nervulus eine Spur antefureal. $2 / 3$ des fast geraden Basalabschnittes vom Radius verdickt, Enddrittel dünn. Discocubitalzelle mit 2 Hornflecken (Fig. 6), der innere drei- $r$ eckig, der äußere am Außenrand des unbehaarten Feldes, sclilank, dünn und grade.

Körperlänge ca. $15-19 \mathrm{~mm}$, Vordertlügellänge $11 \frac{1}{2}-121 / 2 \mathrm{~mm}$, Länge des Hinterleibes $3-3^{1 / 4} \mathrm{~mm}$.

Typen in den Zoologisclien Museen von Hamburg und Berlin.

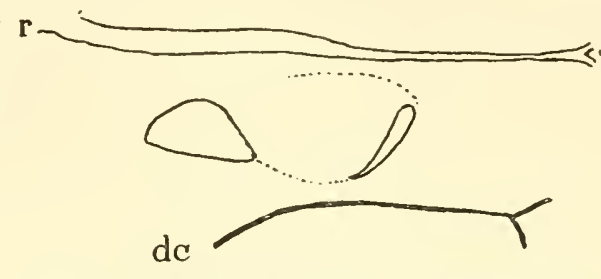

Fig. 6. Amesospilus herero, ExverL. $Q$. Horntlecken der Discocubitalzelle. Vergr. 25 : 1. $\mathrm{r}=$ Basalabschnitt des Radius. $\mathrm{de}=$ Discocubitalader.

\section{'Tribus: Campoplegini.}

\section{Gen. Zachresta Först. 1868.}

\section{zachresta orhreiventris nor. spec.}

Fundangaben: Deutsch-sid id estafrika, Windhuk; Techow $\left(1 \sigma^{7}\right)$.

Deutsch-Siidwestafrika, Swakopmund: K. KLew, Mai-Juli 1911 (1 ㅇ).

б오. Kopf schwarz, matt, feinkörnig punktiert. Oberkiefer, Palpen und 1. Fühlerglied gelblichweiß, beim $\&$ ist nur die Unterseite des 1. und 2. Fühlergliedes gelblichweib, Fühler schwarz, unten etwas rötlich, besonders gegen die Spitze zu, beim $\sigma$ ganz rötlich. Untergesieht etwas convex. Untergesicht, Schläfen und Seiten der Stirn mit kurzer silberweißer Pubescenz.

Thorax schwarz, punktiert. Parapsidenfurchen fehlen. Mesopleuren oben quergeritzt, in der Mitte poliert glatt. Mittelsegment gefeldert; Area basalis sehr klein, rechteckig, beim o lang, beim of quer: Area petiolaris groß, dicht mit feinen Querleisten angefüllt und rou der 6eckigen Area centralis nicht deutlich abgetrennt. Abdomen matt, ockergelb, 1. Segment, 2. Tergit und der Torderrand des 3. Tergites schwarz, Mitte des 5. und 6. Tergites etwas gebräunt. Coxen ockergelb, Mittelcoxen beim o hinten an der Basis schwarz, Hintereoxen schwarz mit gelblichem Endrand. Beine ockergelblich, Hinterbeine des 울 gebräunt. Legerolır dunkelbraun mit feiner Pubescenz.

Flügel hyalin, Adern dunkelbraun, die des Hinterfligels braungelb. Areola wenig gestielt oder fast ungestielt $(f)$, verschoben rhombiseh. 
Nerrulus interstitial. Nervus parallolus in der Mitte der Brachialzelle. Nervellus ungebrochen.

Köperlainge of $7^{3 / 4} \mathrm{~mm}$, ㅇ $7 \frac{1}{2} \mathrm{~mm}$,

Tordertlügcellänge or $4,4 \mathrm{~mm}$, \& $4,7 \mathrm{~mm}$,

Länge des Hinterleibstieles o $\sigma^{7,7} \mathrm{~mm}$, 우 $1 \frac{3}{\mathrm{f}} \mathrm{mm}$,

Länge des Legerohres $4 \frac{1}{2} \mathrm{~mm}$,

Lïnge des Fïhlers $5 \mathrm{~mm}$.

Typen im Berliner ( $\sigma^{7}$ ) und Hamburger (오 Koologischen Nuseum.

\section{Zachresta afiricall nov. spec.}

Fundangabe: Deutsch Sïdwest-Afrika, Farm Okosongomingo am K l e in en Wa terberg; Haxs Thonsen, Juli-August 1912 (1 q ).

우 Körper ganz matt sehwarz. 1 Fülllerglied rostbraun. Palpen und Uberkirfor ockergolblicl. Fühler und Legerohr schwarz. Coxen schwarz. Torderbeine rostgrlb. Mittelbeine rostbraun, Hinterbeine matt, schwarzbraun mit rostgelben Gelenken. Area basalis sehr kurz, Area centralis auch, mit Querleistchen angefüllt. Flïgel schwach gebräunt mit dunkelbraunen Adern.

Sonst wis Z. ochereiventris.

Körperlinge $71 / 2 \mathrm{~mm}$,

Vorderflïgellänge $5 \mathrm{~mm}$,

Fülılerläinge $5 \% \mathrm{~mm}$,

Lïinge des Legerohres 4,3 mm,

Länge des Abdominalsticles 1,7 mm.

Type im Hamburger \%oologischen Musemm.

\section{Zarbresta pedunculata nov. spec.}

Fundangabe: Deutsch-Siidwestafrika, Farm Okosongomingo am Kileinen Waterberg; Haxs Thomsn, Juli-August 1912 (1 ㅇ).

P. Thuelt der Z. orheiventris und unterseheidet sich durch folgendes: Fïlılor ganz schwarz. Area prtiolaris von der kleinen Area contralis getrennt; Area basalis vorn breiter als linten. Abdomen oben sclnwarz, Hintrrrand und Seiten des 2. und 3. Tergites, sowie die Seiten der folgenden Tergite rostgralb, Unterseite hollgelb. Legerolır kurz, rostgalb. Coxen schwarz, Poine rostgelb, von den Hinterbeinen ist der 1. Trochanter, die Basis und Spitze der Schenkel, das Basalviertel und die Enchäftr der Schiene und die Tarsen schwarzbram. Alle Schienensporno 
hell gelblich. Flïgel hyalin. Areola deutlich gesticlt. Adern braungelb, Costa und Pterostigma rostgelb, Nervulus postfureal.

$$
\begin{aligned}
& \text { Körperlänge } 5 \mathrm{~mm} \text {, } \\
& \text { Vorderflügellänge } 4 \mathrm{~mm} \text {, } \\
& \text { Länge des Legerohres } 1 \mathrm{~mm} \text {. }
\end{aligned}
$$

Type im Hamburger Zoologischen Museum.

\section{'Tribus Cremastini. \\ Gen. Cremastus Grav. 1829. \\ Cremastus sammio nor. spec.}

Fundangabe: Deutsch-Südwestafika, Windhuk: Tecuow (1 o $)$.

๙. Kopf und Mandibeln knochenfarbig. Mandibelspitzen braun. Stemmaticum und die beiden Gruben hinter der Fühlerbasis schwarz. Hinterhaupt nahe am Halse schwarz. Fühler dunkelbraun, jedes Glied am Ende gelblich gesäumt. Ein Mittolstreif des Untergesichts rhaben. Clypeus scharf geschieden.

Thorax gelb knochenfarbig. Schwarz ist ein Mrodianstreifen auf dem Rückenschild seitlich bis fast an die seharfen Parapsidenfurchen; die seitenlinie des Rückenschildes: das Jesonotum seitlich rom Seutellum bis zur Flïgelwurzul, mit Ausnahme rines feinen Hinterrandsaumes; das Metanutum mit Ausnahme rines feinen Hinterrandsanmes, ein schmales Band auf der Mesopleurr von der Basis der Hintercoxe bis zur Fligelwurzel; ein Saum um die untere Hälfte der Metapleure; der Vorderrand des Mesostrinum: ein Medianstreifen des Mittelsegmentes und dessen Torderrandsaum ohne die Seiten feinpunktiert, der schwarze Meso-Pleuralstreif glatt und eingedrïckt. Mittelsegment mit langær Area petiolaris, die mit Querleisten angofüllt ist. Abdominalstiel schwaz. Tergite schwarzbraun, Hinterrand des 2., Hinterhälften des 3.-5. und Hinterdrittel des 6. Tergits hell golblich knochenfarben, ebenso die Unterseite dos 2. bis letzten Segments sowie der Copulationsapparat. 1. und 2. Tergit mit Spuren solu feiner Liingsritzung. Beine hell galblich knochenfarben; längs der oberen Hälfte der Innenseite der Hintershenkel und Hinterschirnen ein brauner Längsstreif: Endviertel der Hinterschiene braun. Hintertarsen braun, Basalhälfte des 1. Gliedes und die äußerste Basis der übrigen Glieder hell gelblich. Klanen klein, mngezähnt.

Flügel hyalin, Adern und I'terostigma gelbbraum. Nervulus interstitial. Rücklaufende etwas distal von der Cubitalquerader. 
Körperlänge $81 / 2 \mathrm{~mm}$,

Vorderfligellängo 4,4 $111 \mathrm{~m}$,

Fïhlerlänge $4 \frac{3}{4}$ 1mm,

Abdominallänge $5 \frac{1}{2} \mathrm{~mm}$,

Läinge des 1 Abdominalsegmentes 1,6 $\mathrm{mm}$.

Type im Berliner Zoologischen Museum.

\section{Cremastus flavithorax nov. spec.}

Fundangabe: Deutsch-Siidwestafrika, Windhuk: Techow (I $\left.\sigma^{\top}\right)$.

๙. Kopf hell rostgelb. Stemmaticum dunkolbraun. Fïhler braun, dio beidon Basalglieder rostfarben. Oberkieferspitzen rostbraun. Mittelstreif des Untergesichtes rerhaben.

Thorax hell rostgelb. Die winzige schmal dreieckige Area basalis und die Area centralis des Mittelsegmentes braun. Scutellum etwas heller. Abdomen hell rostgelb, 1. Segment und 2. Tergit schwarzbraun, 6. und 7. 'Tergit in der Mitte gebräunt. Mesopleure in der Mitte selur fein quergeritzt. 1. und 2. Tergit dicht und sehr fein langgerieft. Beine hell rostgelb, Hintertarsen braun.

Fliigel hyalin, Adern und Stigma gelbbraun. Nervulus interstitial oder fast interstitial. Rücklaufende Ader selur wenig distal von der Cubitalqueradec.

Körperlänge $73 / 4 \mathrm{~mm}$,

Vorderfliigelläuge $4^{3 / 4} \mathrm{~mm}$,

Fiihlerlänge $6 \mathrm{~mm}$,

Abdominalläinge $4,8 \mathrm{~mm}$,

Läuge des 1. Abdominalsegments $1,4 \mathrm{~mm}$.

Type im Berliner Zoologischen Museum.

\section{Subfam. Pimplinae.} 'Tribus Xoridini.

\section{Gen. Gonioprymnus Cam. 1906.}

Typus: 1: meculiceps Cax. 1906, Kapland.

I)ir Torder- und Hinterschienen haben rine Längspilse sehr kurzer, dicker, zahuartiger Dornen, die das Basaldrittel freilaibt, bei den ersteren in riner Anzalul von 4 stïck auf dre AuBenserite, bei den letzteren in riner 
Anzahl von 6 Strick auf der Oberseite. CAmerox erwähnt hiervon nichts bei den Diagnosen der Gattung und Art, und, falls sie dem G. maculiceps fehlen sollten, ist auf vorliegende Art eine neue Gattung zu begründen.

Die 3 Ietzten Fühlerglieder sind ebenfalls fast rechtwinklig abgebogen, das 4.-letzte Glied trägt unten nur 1 kurzes borstenartiges senkrechtabstehendes, gleichdickes Chitinstäbchen, das 5.-letzte Glied jedoch 2, davon das distale viel länger, und das 6.-letzte Glied wieder 1 kurzes.

\section{Gonioprymmas serratibia nor. spec.}

Fundangabe: Deutsch-Sii dwostafrika, Farm Okosongomingo am Kleinen Waterberg; Hass Thomsen, Juli-Aug. 1912 (1 \&).

ㅇ. Kopf rostrot, Oberkiefer mit schwarzer Spitze und stark von oben nach unten zusammengedruickt. Fühler rostbram, das S.-letzte bis 11.-letzte Glied weiBlich, ebenso die Basalhälfte des 7.-letzten Gliedes. Das 5.-letzte und 6.-letzte Glied etwas dicker als die iibrigen. Untergesicht mit etwas blaßgelblicher Pubescenz. Punktierung spärlich, auf dem Lntergesicht dichter.

Thorax lang, rostrot; die Tergulae glatt schwarz, ein Längstreif auf der Brust schwarz. Parapsidenfurchen sehr undeutlich. Punktierung dicht. Oberes Hinterviertel dor Mesopleuren poliert glatt. Felderung des Mittelsegmentes sehr undeutlich. Abdomen schwarzbraun. Hinterrandsaum des 1. Tergites mit Ausnahme der. Seiten hellgelb, abenso ein schmaler Hinterrandsaum in der Mitte des 2. und 3. Tergites. 4. und 5. Tergit mit schmalem, hellgelbem Hinterrandsaum mit Ausnalime der Seiten, 6. und 7. Tergit mit breitem Hinterrandsaum mit Ausnalme der Seiten: Unterseite blaß, die Mitte der Sternite dunkelbraun. Die vorderen Seiteneeken des 2. und 3. 'Tergites durch zimmlich scharfe Linien-Eindrïck' abgetrennt, am Ende des zweiten Jrittels des 1. Trergites und in der Mitte des 2. Tergites ein gebogener nach vorn konkaver Quereindruck mit länsriefiger Skulptur: 1.-3. Tergit mit dichter ziemlich grober Punktierung. Legescheiden dunkelrostbram, ein $0,8 \mathrm{~mm}$ breiter, lull rostgelber Ring vor der spitze. Beine rostfarben, Coxen und Schenkel dunkel rostrot. Vorder- und Hinterschienen mit einer Lïngsreihe von kurzen, dicken zalmartigen Dornen, die das Basaldrittel froiläßt, auf der Tordersehiene 4 anf der AnBenseite, auf der Hinterschiene 6 ant der Oberseite.

Flïgel hralin, Vorderflïgel mit eiuer bramnen schmalen Querbinde längs des Basalnerven und des Nervulus, eincr zweiten schräggestellten, die auf der äußeren Hälfte des Pterostigmas fußt, und auf der Innenseite der C'ubitalquerader und der rücklanfenden Ader entlang läift. Außerdem 
ist der Rand der Flügelspitze zwischen Radius und Parallelnerv hellbraun gesäumt. Nerrulus antefurcal. Riucklaufender Nerv distal rom C'ubitalquernerv. Adern braun. Pterostigma braun, an der Basis blaß gelblich.

Körperlinge $8 \% \mathrm{~mm}$,

Vorderflïgellainge $6 \frac{3}{4} \mathrm{~mm}$,

Fühlerlänge ca. $4 \frac{1}{2} \mathrm{~mm}$,

Thorakallainge $3 \% \mathrm{~mm}$,

Thorakalbreite $1,4 \mathrm{~mm}$,

Länge des Legerohres 6,3 mm.

Type im Hamburger Zoologischen Museum.

\section{'Tribus Pimplini. \\ Gen. Pleurodontoplax, nov. gen.}

Tribus: $P$. congoensis nov. spec., Kongo-

Kopf glatt, Clypeus vom Untergesicht durch eine stark gebogene sutur geschieden, vorn lalbkreisförmig eingedrückt, aber der Vorderrand nicht ansgeschitten (wie es auf den ersten Blick erscheint), sondern gerade. Letztes Fühlerglied so lang wie die 2 vorhergohenden zusammen. Wangen solnr kurz. Thorax poliert glatt, mpunktiort, Parapsidenfurchen bis zur Mitte des Rückenschildes oder wenig darüber hinaus. Mittelsegment ohne Felder, nur jederseits linten eine kurze scharfe Längsleiste; poliert glatt und nur auf den Seitenteilen punktiert; Luftlöcher klein und kreisrund. Die hasis jeder Ocelle einzeln stark erboben; Ocellen groß und ziemlich dicht.

Abdomen oben dicht und grob punktiert; 2.-6. Tergit vor dem Hinterrand je mit einem kräftigen tiefen Quereindruck und vorn mit jederseits rinem schräigen Linieneindruck, die die Vorderecken abschneiden und in der Hitte bogig zusammenstoßen. 2.-5. Tergit an den Seiten hinten in einem meler oder weniger scharf abgesetzten nach hinten gerichteten Zahn ankgezogen. Luftlöchur des 1. Segmentes etwas vor der Mitte, sehr kloin und rund, dicht untrr dem Rand dor scharfen Scitenkante und voncinander etwa so weit enfernt wir vom Hinterrand. Legerohr otwas kürzer als dir halbe Hinterleibslänge bis fast so lang wie der Hinterleib. Klanen mugekimmt, an der Basis ain kräftiger Zahn. Flïgel gelb mit schwarzer Zhichnung. Arrola 4 eckig, vorn kurz gestielt. Nervulus interstitial. Nervollus unten gebrochen. Discocubitalader etwas proximal dor Nitte geknickt und mit deutlichem Aderstummel oder (bei P. nigricentris n. sp.) nicht gekniekt und mit weniger deutliehem Aderstummel. 
Die Gattung ist ans der Verwandtschaft von Holcopimpla Cas. und Hemipimpla Sauss.

\section{Plemrodontoplax congoensis nor. spec.}

Fundangaben: Französisch Kongo, Fort Crampel; H. Scuubotz (InnerAfrika Fxpediton des Herzogs Adolf Friedrich zu Mecklenburg). 6. Januar 1911 (3 $\sigma^{7}, 1$ 우).

Französisch Kongo, Fort Possel bis Fort Crampel; H. Schubotz, Nov. 1910 (1 ㅇ․).

$\checkmark$ ㅇ. Kopf ockergelb. Fühler sehwarz, beim $\sigma$ bis zum Ende des 2. Drittels unten gelblich, und ror der Spitze ein wenig rerbreitert, beim 우 nur das letzte Glied ziegelfarben, die $1-2$ vorletzten Glieder rostbraun, und die 2 ersten Glieder auf der Unterseite gelblich.

Thorax hell rostgelb. Abdomen dicht und grob punktiert, rostfarben, unten heller. Legerohr schwarz, Scheiden an den Seiten schwarz pubssciert. Beine mit den Coxen hell rostgelb, Hinterschiene dunkelbraun, 1-3. Hintertarsenglied braun, selten sehwarz $\left(\begin{array}{l}1 \\ 0\end{array}\right)$. Klauen gelblich, Endhälfte schwarzbraun, ungezähnt. 4. Tarsenglied breiter als lang.

Flügel lebhaft ockergelb: dunkelbraun ist im Vorderflïgel eine Querbinde durch die Flügelmitte, die im Hinterrande der Brachialzelle endet; eine Querbinde durch das Ende des 3. Viertels und cin ebensobreiter Spitzenrandsanm, der rorn schmal, hinten breit mit der 2. Binde verbunden ist; im Hinterflïgel ist dunkelbraun die spitzenhälfte mit Ausnahme eines großen halbkreisfömigen Fleckes an Rande vor der Mittw der Spitzenhälfte und beim of bis zur Flïgelmitte, beim $\sigma$ bindenförmig fast bis zum Hinterrande nach hinten reiehend. Discocubitalader geknickt und mit deutlichem Aderstummel.

Körperlïnge o $10-12 \frac{1}{2} \mathrm{~mm}$, f $11 \% \mathrm{~mm}$,

Vorderfliigelliange or $9-11^{1 / 2} \mathrm{~mm}$, f $11-11^{1} \div \mathrm{mm}$,

Fühlerlänge or $81 / 4-11 \mathrm{~mm}$, 우 $9 \mathrm{~mm}$,

Lïnge des 1. Abdominalsegmentes o $1,2-2 \mathrm{~mm}$, ㅇ $2 \mathrm{~mm}$,

Länge des Legerohres $7-7$ 1/2 $\mathrm{mm}$.

Typen im Zoologischen Irseum ron Hamburg und Stettin.

\section{Plemodontoplax pulchra nov. spec.}

Fundangabe: Deutsch-Sïdwostafrika, Farm Okosongomingo am Kleinen Waterborg, Haxs Thomsex, Juli bis August 1912 $(2 \sigma)$. 
6. Diese Art unterscheidet sich ron $P$. congoensis durch Folgendes:

Fühler schwarz, 1. und 2. Glied auf der Unterseite ockergelb; Hinterschiene mit Ausnahme des Basalviertels schwarz; 1. und 2. Hintertarsenglied braun. Das eine Exemplar zeigt auf den Seiten des Hinterrandsaumes des 2.-5. Tergites je ein kurzes schwarzbrames Sammstrichel.

In Vorderflïgel ist die Mittelbindo nur am Vorderrand durch einen rundlichen dunkelbrannen Fleck angedeutet, der bis zur Mitte der Discocubitalzelle nach hinten roicht. Die Binde an Ende des 3. Viertols ist iun 2. Viertel ron vorn aus unterbrochen, so dab rorn nur ein rundlicher Randfleck sich bis zur Mitte dor Radialzalle nach hinten erstreckt und die Binde erst wieder an der Discocubitalader beginnt. Der Randsaum ist hinten mit dieser Binde verbunden, vorn jedoch nicht und hier ist nur die Costa schwarzbram. Hinterflïgel wie beim or von P. congoensis.

Kïperlänge $11-11 \frac{1}{2} \mathrm{~mm}$,

Vorderflügellänge $10 \frac{1}{4}-10 \% / 2 \mathrm{~mm}$,

Fühlerlänge ? $^{3 / 4} \mathrm{~mm}$,

Länge des 1 Abdominalsegmentes 11/4 mm.

Typen in den Zorologischen Museen in Hamburg und Stettin.

\section{Plentorlontoplax migniventris nov. spec.}

Fundangabe: Transvaal, Zoutpansberg (2) Q ).

․ Kopf dunkelrotbraun, Clypeus und Oberkiefer gelbbraum. Oberkieferspitzen s.hwarz. Palpen rostgelb. Fiihler schwarz, ziemlich dick.

Thorax tiefichwarz. Scutrllum punktiert, ebenso die seiten des gowälbten Mittelsegmentes. Abdomen und Legerohr schwarz. Buine mit den Goxen schwarz, Vordorbeine rostfarben, Vordercoxen rostbram, Schienen und Tarsen drr Jittelbrin. rostfarben. Alle Schienenendsporne rostgelb.

Flïgel ockrrgelb, Adern und Pterostigma liell rostgelb. Spitzen-

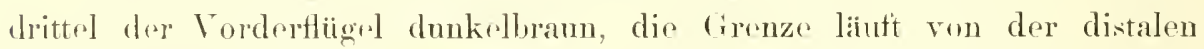
spitze des Pterostigmas atuselend geradlinig. Nicht ganz das spitzendrittel dor Hintertlïgol braum.

Kïrperlänge $13 \%-14 \mathrm{~mm}$,

Vorderflïgellänge $12 \mathrm{~mm}$,

Föhlprlainge $10 \% \mathrm{~mm}$,

Läinge des 1. Abdominalsegmentes 1,7 num,

Linger dos Legrombers 3,4 mm.

Typen in Yonlogischen Musemm in Stettin. 


\section{Subfam. Tryphoninae.}

\section{Tribus Paniscini. \\ Gen. Scammatonotum nov. gen.}

Typus: S. heroro nov. spec.

Unterscheidet sich von der Gattung Paniscus Schr. 1802 durch den Besitz einer scharf eingedrücktrn Längslinie in der Medianlinie des Riickenschildes zwischen den Parapsidenfurchen.

\section{Srammatonotum herevo nov. spec.}

Fundangabe: Deutsch-Si dwestafrika, Spitzkoppe; Puescher, 22. Sept. 1911 ( 1 f).

ㅇ Schläfen breit, Hinterhauptskiel scharf, Gesicht so lang wie breit, Seiten nach rorn deutlich konvergierend; etwas gewölbt; am obersten Ende vor den Fühlern ein erhabenes Körnchen. Clypeus deutlich rom Gesicht geschicden, Vorderrand gerade. Hintere Ocellen die Augen nahezu berührend. Fühler dünn, nach der Spitze zu verjüngt. 1. Geißelglied 1 1/3 des zweiten.

Thorax matt, Parapsidenfurchen und Mittelfurche scharf. Scutellumrand ziemlich kräftig, gerade, hinten mäßig stark genähert. Pleurenpunktierung selir fein, Propleure sehr fein schräg von vorn oben nach hinten unten nadelrissig, in dieser. Richtung auch eingedrückt. Leiste zwischen Metapleure und Mittelsegment schwach. Mittelsegment mit der dichten Querriefung, die vorn am dichtesten wird, nur das hintere Fünftel, das an den Seiten etwas kantig abfällt, ist glatt; man schäitzt in der Mittellinie etwa 24 Querriefen. 1. Alsdominalsegment 11/2 vom zweiten; Luftloch etwas hinter dem Ende des 1. Viertels. Legerolır 1,4 mm lang. Hintertarsus wenig länger als die Schiene; Metatarsus $2 \%$ mal so lang wie der längere Hintersehienensporn. Klauen dicht schwarz gekämmt.

Stigma mäßig breit, 1,9 $\mathrm{mm}$ lang. Areola schmal und hoch, vorn kurz gestielt, auben nur mit abgerundeter Ecke und ohne Aderstummel. Discocubitalader an dem kleinen Aderstummel mit Hacher Ecke. Nerrus recurrens gerade, nur vorn nach der Basis zu gebogen; die beiden Fenster sehr lang. Cubitus am AuBenrande der Brachialzelle nur schwach winklig gebogen. Nervulus weit postfurcal, Abstand fast so lang wie seine Länge; linten gerade und senkrecht, rorn nach der Basis zu eingebogen, dann aber wieder gerade.

16 Michaelsen, Deutsch-Südwestafrika. 
Rostfarben, Augeninnenrand etwas heller gesäumt, an den Schläfren mit breitem blaßgelblichrm Saum. Stemmaticum nicht verdunkelt. Tegula hell rostgelblich, ebenso rin Fleckehen unter der Vorderflügelwurzel. Hinter- und Torderrandleiste der Mesopleure blaß. Legerohr dunkelbraun. Fligel lyalin. Adern bram. Subcosta schwarz, Costa blaß ockergelb. Pterostigma hellrostgelb. Diseocubitalader rostgelb.

Kïrperäinge $13^{3} / 4 \mathrm{~mm}$.

Vorderfliigellänge $121 / 4 \mathrm{~mm}$,

Läinge des 1. Abdominalsegmentes $3 \mathrm{~mm}$,

Länge des Hintertarsus 5/4 mm.

Type im Berliner Zoologischen Musem.

\section{Gen. Paniscus Schr. 1802.}

\section{Paniscus parvus nor. spec.}

Fundangabe: Deutsch-Sii dwestafrika; Lëввект, 1901 (1 우).

ㅇ. Schläfen breit, Kiol scharf. Gesicht etwas breiter als lang, Seiten parallel, in der Mittr hiigelartig orhoben. Clypens nur durch unscharfe seichite Einsenkung vom Gresicht getrennt, Vorderrand in der Mitte otwas cingedrïckt. Fuihlar dünn, fadenfïrmig, erstes Geibelglied $1 \frac{1}{2}$ des zweiten.

Thorax matt, Rïckenschild ziemlieh glatt: l'arapsidenfurchen fein aber ziemlich seharf. S'crtellumrand gerade, scharf, hinten ziemlich weit getrennt. Pleuralpunkticrung selor fein und dicht, Mesopleure nach oben glätter werdend und die Punktierung fast verschwindend. Leiste zwischen Metapleure und Mittelsegment fein und gerade. Mittrolsegment mit selır dichter Qnerriefung, an den Seiten mit sehr dichter, feiner, körniger Punktierung, der ganze Vorderrand mikroskopisch fein punktiert. 1. Abdomimalsegment $12 / 3$ des zweiten; Luftloch am Ende des ersten Drittels. Legerohr 1,8 mm lang. Hintertarsus wenig länger als die Schiene: Metatarsus doppelt so lang wie der längere Hintorschienensporn. Klanen mit dichter und langer schwarzer K:immung.

Pterostigma ziemlich breit und 1,4 $\mathrm{mm}$ lang. Aroola mäßig breit, vorn nielat gestielt, die beiden schenkel in rinem l'unkte sich treffend; anBen mit flacher alogerunderor Ecke und olune Adrestummel. Discocubitalader (1. rïlkkaufende Ader) ghrichmäBig stark gewälbt, Enddrittel gerade, Aderstummel am Ende des ersten I)ritels fast fohlend, nur als spur angedentrot. Norvus rexurrens (2. rücklaufende Ader) schwach gebogen. (ubitus am Aubenende der Brachialzolle stark ungebogen aber abgerundet. 
Nervulus mäßig weit postfureal, Abstand seine halbe Länge, senkrecht und schwach gebogen.

Hell rostgelb, Fühler rostfarben, Oberkieferspitzen schwarz. Stemmaticum hell und Legerohr rostfarben.

Flïgel hyalin. Adern hellrostbramn. Pterostigma hellbraungelb. Costa hellgelblich, Subeosta schwarz.

Körperlänge $81 \% \mathrm{~mm}$,

Vorderflügellänge $\lceil 1 / 2 \mathrm{~mm}$,

Länge des 1. Abdominalsegmentes $1,6 \mathrm{~mm}$,

Länge des Hintertarsms $3 \frac{1}{2} \mathrm{~mm}$.

Type im Berliner Zoologischen Museum. 



\section{Spongillidae \\ by}

N. Annandale

(Calcutta).

With 1 plate. 

We do not know of any freshwater sponges from Cierman South-WestAfrica. The collection described in this paper was made in August, 1911, in the Zambesi, at a point near the Victoria Falls and actually in Rhodesian territory though only a few miles from the frontier. It is at any rate most probable that the sprecies also occur some miles further up in the Zambesi in the German Zambesi territory. Although small, the collection is of considerable systematic and geographical interest. Four species are represented, of which three are new to science, while the fourth, although known to be widely distributed in Tropical Africa, has not been found previously in the Zambesi system. All this is noteworthy in view of the fact that sponges have been collected at the same place on two former occasions $^{1}$ ), and that no single species is represented in any two collections - an excellent illustration of the wealth of the inland sponge-fauna of Tropical Africa.

I have to thank Dr. W. Michaelsex for sending his collection to Calcutta for me to examine. The identification of the species has been greatly facilitated by the presence in the Indian Museum of schizotypes of most of the African Spongillidae preserved in the collections of the British Museum and the Natural History Museums of Berlin, Hamburg and Amsterdam. These we owe to the kind offices of Mr. Kirkpatrick, Dr. Weltaer, Dr. Kraepelis, Dr. Max W Weber and Dr. Michaetsen himscelf.

The exact locality of the 4 species of the collection is: Rhodesia River $Z$ ambesi near the Victoria Falls, on the under-side of stones in shallow water off the right shore some $150 \mathrm{~m}$ above the brim of "Cataract Fall" "2): W. Michaelsex, 18 th August, 1911.

1) See Kinkpatrick, Proc. Zool. Soc. London, 1906 ; (i), 1. 218.

2) See the landscape of Fig. 14 in the "Reisebericht" of this volume, p. 50. 


\section{Part 1. A Systematic Account of the Collection.}

\section{Gen. Spongilla, Lamark.}

\section{Subgen. Eunapius, Gray.}

The subgenus Eunapius, which is separated from Euspongilla by the well-defined polygonal air-spaces in the investment of its gemmules, is represented in Tropical Africa by several species. Dr. Muchaelsex's collection includes specimens of yet another new ont.

The following key tho the African species may be useful:

\section{Key the to African spezies of Eumaluius:}

I. Ciemmule-spicules smooth.

A. Gemmules single and free in substanee of sponge S. carteri. ${ }^{1}$ )

B. Grimmules forming a pavement-layer at base of

sponge . . . . . . . . . S. aetheriae.

II. Gemmule-spicules spiny.

A. Gemmules single and free in substance of sponge.

1. Skeleton-spienles stout, amphistrongylous

S. nitens.

2. Skeloton-spicules slender, sharply pointed

S. michaelseni.

B. Gemmules forming a parement-layer at base of sponge.

1. Cremmule-spicules amphioxous . . . . S. ambigua.

2. Gemmule-spicules amplistrongylons . S. permixta.

\section{spongilla nitens, Carter, var.}

Carter, Ann. Mag. Nat. Ilist. (5) VII, p. 89, pl. V, fig. 3, a--k, \& pl. VI. fig. 18 (1881); WeltNer, "Die Coelenteraten und Schwämme des Sïßen Wassers Ost-Afrikas" in Mömus, ()st-Afrika IV, p. 3, tigs. (1898), and „Süßwasserschwämme (Spongillidae) der Deutschen Zentralafrika-Expedition 1907-1908 in Wiss. Ergeb. d. Deutsch. Zentral-Afrika-Exp. IV (Zool. ii), Lief. 12, 1. 475.

This sponge is reprosented in 1)r. Micuablsisys collection by four cushion-shaped masses detached from stones; the largest of the four is about $35 \times 28 \mathrm{~mm}$ in diameter. The external surface of both is ormamented with numerous sharp sfonder projections of irregular outline, as appears to be usual in the specios. Although hard, the sponge is very brittle. The skeleton-spicules measure on an average $0,363 \mathrm{~mm}$ by $0,026 \mathrm{~mm}$, being thus cunsiderably more slencler than in the type. The gemmules are abundant and fully developed. 
Spongillu nitens has hitherto been found in the White Nile and in the neighbourhood of Lake Tanganyika.

\section{Spongilla michaelseni, sp. nor.}

Pl. II, fig. $3 \mathrm{~A}-\mathrm{C}$.

Sponge encrusting, forming thin flat fitms of limited area and of a grevish colour: moderately hard, friable, brittle. Oscula and pores minute, inconspicuous. subdermal space relatively small.

Skeleton formed of slender, well-defined but not very colerent radial spicule-fibres joined together by an irregular notwork of spicules that exhibit little evidence of fascitulation: little spongin present.

spicules (Pl. VI, Fig. 3): skeleton-spicules perfectly smooth, sharply and gradually pointed at both ends. feebly curved, on an average about 23 times as long as thick. Free microscleres skenter, straight or nearly so, sharply and gradually pointed at both ends, bearing numerous sharp spines that stand out straight at right angles to the surface and are muth larger in the middle of the spicule (while they are often as long as the shaft is wide) than at the ends. Gemmule-spicules rery rariable in size, spiny, amphistrongylous, moderately stout: their spines as a rule longer and more numerous at the ends of the spicule than in the middle where they are sometimes almost absent), often distinctly recurved at and near the former, very variable in length: a single terminal spine often present at one or both extremities.

Gemmules somewhat depressed, small, provided with a thick coat of well-dereloped polygonal air-spaces and with a straight and rather stout foraminal tubule, which stands upright in a cratrelike depression of the pnemmatic coat: spicules arranged both tangentially and horizontally in this coat, forming a somewhat ill-defined horizontal laver on its external surface.

Diameter of gemmule (ค. $0.42 \times 0.36 \mathrm{~mm}$

Length of skcleton-spicule. $0.308-0.356$..

Thickness of skeleton-spicule. $0.012-0.017$,

Length of fiee mivrosclere 0.068

Thickness of free microsclere shaft) . . 0.004

Length of gemmule-spicule . . . . 0 0.078-0.156 ..

Thickness of gemmule-spicule shaft . 0 0.005-0.016,

This species is related to spongillu carteri, the commonest of the Indian Spongillidae, but distinguished by possessing free microscleres and 
spined gemmule-spicules: from S. nitens, another allied form, it is distinguished by its very much sharper and more slender skeleton-spicules.

Locality: R. Kambeni near the Victoria Falls; W. Michaelsex, 18. August 1911.

Type in the Hamburg Natural History Museum. A co-trpe in the Indian Museum.

\section{Subgen. Stratospongilla, Annandale.}

This subgenus is also well represented in the African fauna, to which four species were hitherto known to belong. I have here to add a fifth from Dr. Mranascsex's collection. The tive species may be distinguished one from another by the following ker, which may be used in comection with those of the Indian species given on p. 385 of Vol. VII of the Records of the Indian Musenu (1912) and on p. 68 of my volume in the „Fauna of British India".

\section{Key to the African species of Stratospomgilla.}

I. Skeleton-spicules amplioxous.

A. Skeleton-spicules rough or irregular in outline

1. Gemmulo-spicules sausage-shaped . .

S. sumatrana.

2. Ciemmule-spicules shonder, amphioxous or nearly so

S. bombayensis.

B. Skeleton-spicules quite smooth.

1. Gemmulo-spicules smooth . . . . . S. schubotzii.

2. Gemmule-spicules bearing blunt spines. S. rousseletii.

II. Skoleton-spicules amplistrongylous (spiny).

Gemmule-spicules spiny, sansage-shaped,

eylindrical: gemmules enclosed in a dense cage of spicules

S. africana.

\section{spomegilla africama, sp. not.}

Pl. II tigs. $1 \mathrm{~A}-\mathrm{C}$, and 2 .

sponge. This sponge is represented by two circular films about 10) nm in diamotrer and not as much as $2 \mathrm{~mm}$ thick. They are attached to a piore of stom in a dry condition. The colome is nearly white. The sponge is hard but friable. Its rxternal structure can not be dearly seen, hut the pores and osema were revdently minute and the subdermal cavity sorms to have been (o)mparatively small. 
Skeleton: The skeleton consists of a close reticulation of single spieules with very little trace of fasciculation; they are fastened together by delicate reils of spongin where they meet.

Spicules (PI. TI fig. 1): The skeleton-spieules are slender, blunt. nearly straight, covered somewhat sparsely and almostly uniformly with sharp spines much less than half as long as the diameter of the shaft, to which they stand out at right angles. Free microseleres exist in the form of slender, nearly straight amphioxi bearing sharp or blunt spines that stand out straight at right angles: they are much longer in the middle region of the spicule than elsewhere but are never quite as long as its transverse diameter. The gemmule-spieules as a rule resemble the macroseleres in general form, but are rather more densely spined; they are extremely variable in size and proprortions and occasionally a little inflated at the extremities.

Gemmules (Pl. VI, Fig. 2): The gemmules adhere at the base of the sponge in groups. Each is enclosed in a dense eage about $0.04 \mathrm{~mm}$ thick and composed of microscleres lying horizontally several spicules abreast in a chitinous membrane: between this cago and the real gemmule (inner capsule) there is a considerable gap; in the specimens examined the roof of the cage is deficient. The actual capsule has a relatively thick chitinous eoat $(0.01 \mathrm{~mm}$ thick $)$ of a bright yellow colour and is of a somewhat irregular shape; there is possibly a single very minute foramen at one side in a very short foraminal tubule, but the appearance may be deceptive and I have not cut sections. On the surface of the eapsule lie a few microseleres as a rule of somewhat distorted form and smaller than those that eompose the outer cage.

Diameter of outer cage of gemmule $0.67 \mathrm{~mm}$

Diameter of inner capsule of gemmule . . . 0.27

Length of skeleton-spicule. . . . . . . 0.16

Thickness of skeloton-spicule. . . . . . . 0.014

Lenght of free microsclere . . . . . . 0.064-0.08 ..

Thickness of free microsclere (shaft) . . . . 0.004

Length of gemmule-spicule . . . . . . 0.104(orless) ..

Thickness of gemmule-spicule

Locality: R. Zambesi near the Victoria Falls: IV. Michancase. 18. August 1911.

Type in the Hamburg Natural History Museum.

Spongilla africuna resembles $S$. indica Axxandale in the structure of its skeleton-spicules and its skeleton, but differs considerably therefrom in 
that of its gemmule, if I am right in believing that the gemmules here assigned to the species actually belong to it. They were not found inside the sponge, which was evidently young and immature, but closely adjacent to it on the same stone, together with gemmules of Corrospongilla victoriae. Some of their spicules, however, approach those of the skeleton of S. africana very closely.

\section{Gen. Corvospongilla, Annandale.}

Including the new sponge described below, six species of this genus are now known from Tropical Africa, of the fauna of which, as also of that of Peninsular India, it is particularly characteristic. The species fall naturally into two groups - those with smooth and those with spiny skeleton-spicules. The latter group, to which the new species belongs, is only known from Tropical Africa.

\section{Key to the African Species of Corevospongilla.}

1. Skeleton-spicules smooth.

A. Skeleton-spicules on an average $7 \frac{1}{2}$ times as $\operatorname{long}$ as thick.

C. zambesiana.

B. Skeleton-spicules 11 to 13 times as long as thick.

C. loricata.

II. Skeleton-spicules spiny or granular.

A. Gemmule-spicules sparsely spined (about 50 spines to a spicule) . . . . . C. böhmii.

B. Gemmule-spicules much more densely spined.

1. Inmer capsule of gemmule flaskshaped

C. victoriae.

2. Inner capsule of gemmule spherical or subspherical

a. Cremmule-spicules (amplistrongryi) 2 to 5 times as long as thick

C. micrumphidiscoides.

b. ciemmule-spicules (amphistrongyli, 3 to 12 times as long as thick.

C. scubrispiculis. 


\section{Comespongilla victoriae, sp. nov.}

Pl. VI., figs. 4 and $5 \mathrm{~A}-\mathrm{C}$.

Sponge: The sponge forms small lichenoid patches, often somewhat densely congregated, on stones. Their outlines are irregular, their diameter not more than about $25 \mathrm{~mm}$ in the specimens examined, and their thickness inconsiderable. It is possible that at a later stage the different patches may grow together to form a uniform layer. The texture of the sponge is hard but moderately friable; its colour in dry specimens yellowish, but darker and browner in spirit. The pores and oscula are small and inconspicuous.

Skeleton: The skeleton forms a dense reticulation composed mainly of single spicules, the spicule-fibres are not well differentiated (although the vertical fibres can be detected as somewhat irregular fascicles) and the greatly thickened pillars of spicules characteristic of some species of the genus are absent.

Spicules (Pl. VI, Fig. 5): The skeleton-spieules are relatirely slender amphistrongyli as a rule almost uniformly but by no means densely corered with minute spines; occasionally these spines are almost absent. Not infrequently the extremities of the spicule are somewhat inflated. Rather shorter and distinetly more slender amphioxous macroseleres also occur, but sparingly and not incorporated in the skeleton. The free microscleres are of two types, mieramphidiscs and amphioxi. The former are of the usual form and are not, in the specimens examined, abundant. As a rule their discs are formed of six long spines, which project outwards further than in some species and are not recurred at the tips: the slaft is nevor strongly curred. The amphioxi, which are scarcer than the micramphidiscs, are slender and nearly straight: they bear stout spines, which stand out straight at right angles and are short at and near the extremities but often of considerable length near the middle of the spicule. The gemmule-spicules are stout and relatively short amphioxi, but exhibit great variation in length and outline. which is sometimes distorted and irregular: they are uniformly and fairly densely spined.

Gemmule (Pl. VI, Fig. 4): The gemmules are circular in outline and dome-shaped externally, without an aperture of any kind. They adhere firmly at the base of the sponge. The outer coat consists of a single layer of gemmule-spicules arranged horizontally and mosaic-wise in a stout chitinous membrane more or less continuous with the basal membrane of the sponge. Within this coat the inner capsule lies free. It has the form of a narrow flask with a well-defined neck (the foraminal tubule) and lies on 
one side horizontally. Its walls are comparatively thin and have only a few micruscleres adhoring to them. These spicules are parallel to the external surface of the capsule.

Length of skeleton-spicule (amphistrongyli) . . . 0.152-0.172 mm

Thickness of skeleton-spicule (amphistrongyli) . . 0.012

Length of free microsclere (amphioxi) . . . 0.036-0.06 "

Thickness of free microselere (amplioxi). . . . ca. 0.004

Length of micramphidisc . . . . . . . . . ca. 0.024

Length of gemmule-spicule . . . . . . . 0.024-0.04 "

Thickness of gemmule-spicule . . . . . . 0.008-0.012 "

Diameter of complete gemmule . . . . . . . 0.425-0.52 ,

Length of inner capsule of gemmule (including tubule) ca. 0.323 "

Lesor diameter of inmer capsule of gemmule . . ca. 0.255 ,

Locality: R. Zambesi, near the Victoria Falls; W. Michaelsen, 18. August 1911.

Type in the Hamburg Natural History Museum; co-type in the Indian Museum, Caleutta.

This species differs from the others in the C. boghmii group in the structure of the genmule and in particular in the peculiar form of its inmer capsule.

The other members of the gronp (namely, C. höhmii, C. micramphidiscoides, and $C$. scalnixpiculis) have always been found associated with other animals; - C. micramphidiscoides and C. scubrispiculis as also C. loricate in the group with smooth skeleton-spienles) on shells of the molluse Ltheria, and C. böhmii on the external surface of Spongilla nitens. It is therefore, interesting to note that the types of C. rictorice were found on stones. As a rule they were not associated in any way with other organisms, but in one instance gemmules of the Corcospongilla lay side by side with those of the type sprecinen of Spongilla atricana.

\section{Part II. The Distribution of the African Spongillidae.}

In a pecent paper $W_{\text {Entxen }}{ }^{1}$ ) has given a list of the African Spongillicke, with precise details of the locality or localities from which each specius has been recorded. His list ineludes the names of 23 species; in the sanne paper two new Spongillidue are described by him, and, ineluding the

1) Wist. Ergebn, ג. Deutschen Zentral-Afrika-Expedivion, 1907-1908, Band IV, Zoologie ii, Lief. 12 (siibwasserschwämme), pl. $475,476$. 
three described above, I have mrsolf lately added five additional representatives of the family to the African fauna. The precise provenance of one of the sponges on Weltxer's list (Corrospongilla loricata, Weltaer) is doubtful: it probably came from the Nile; whils one other (Spongilla carteri, Carter) has been recolded from Africa (Tictoria Nyanza) on evidence that does not seem to me by any means conclusive. ${ }^{1}$ ) Omitting these two doubtful species, we have thus 28 known to occur on the Continent of Africa.

Their distribution on that Continent may be stated concisely as follows: -

\section{Sponges of the Nile System.}

Spongilla (Euspongilla) alba var. cerebellata, Bowereaxk.

Spongilla (Euspongilla) biseriata, Weltxer.

Spongilla (Eunapius) aetheriae, Axxaxdale.

Spongilla (Eunapius) nitens, Carter.

Spongilla (Stratospongilla) sumatrana, Weber, var. A, Weltyer.

Dosilia brounii (KinкPatrick).

Corrospongilla scabrispiculis, Axwaxdale.

\section{Sponges of Tropical East Africa (coastal region).}

Spongilla (Stratospongilla) sumatrana, Weber, var. B, Wextrer.

Pectispongilla sansibarica (Weltxer).

Corrospongilla böhmii (Hragexdorf).

\section{Sponges of the Zambesi System.}

Spongilla (Euspongilla) biseriata, Weltxer.

Spongilla (Eunapius) nitens, Carter.

Spongilla (Emapius) michaelseni, sp. nor.

Spongilla (Stratospongilla) rousseletii. Kıнкатвıcк.

Spongilla (Stratospongilla) africuna, sp. nov.

Corrospongilla victoriae, sp. nov.

Comospongilla zambesiana (Кнкратвіск).

\section{Sponges of the Congo System.}

Spongilla (Stratospongilla) schubotzii, I ELtaker.

Tubella pottsii, Wertrer.

1) See Kirkpatrick, Proc. Zool. Soc. London, 1906 (i), p. 219 and Axwandale. Faun. Brit. Ind., Freshw. Sponges. p. 87 (1911). 
Conospongilla micramphidiscoides, Weuter.

Potamolepis chartaria, Malshall.

Potamolepis leubnitziae, Marsman.

Potamolepis pechuëlii, Marshall.

\section{Sponges of the Tanganyika System.}

Spongilla (Eunapins) nitens, Carter.

spongilla (Ennapius) pernirita, Weltarer.

Corrospongilla böhmii (HiLgendonf),

Nudospongilla runningtoni (KinкPatrick).

Nudospongilla moorei (Evans).

Nudospongilla tanganyiliae (Evass).

Potamolepis weltneri, Moore.

\section{Sponges of Africa South of the Limpopo River.}

Spongilla (Eunapius) ambigua, Annandate.

Spongilla (Stratospongilla) bombayensis, CakTER.

Ephydatia fluviatilis sulsp. capensis, Kinspatrick.

Our knowledge of the African Spongillidae is still deficient, and there are seviral important river-systems from which no sponges have as yet been reported. It is, therefore, impossible to divide the Ethiopian Region with any pretence to finality into definite subregions or districts in which different sponge-famas actually have becn discovered or might be expected to exist. The foregoing attempt to deal with the known forms geographically is therefore no more than an attempt; but it may have some interest if we pay attention to genera and subgenera rather than species.

At present representatives of six well-established genera of Spongillidae have been found in Africa, including the Palaearctic and southern districts of the Continent. They are:

$$
\begin{aligned}
& \text { Spongilla, } \\
& \text { Pectispongilla, } \\
& \text { Epleydutia, } \\
& \text { Dosilia, } \\
& \text { Tubella, } \\
& \text { Comosponyilla. }
\end{aligned}
$$

To these must be added two provisional grnera of somewhat doubtful status, viz. Nudospongilla and Potumolepis.

Spongilla, moreover, is divided into three subgenera, all of which have been recorded from Africa - Euspongilla, Eunapius and Stratospongilla. 
We have, therefore, to deal with 10 genera and subgenera in considering the Spongillid fauma of the Continent.

Of these, two subgenera (Euspongilla and Eunapius) may be regarded as cosmopolitan.

Enspongille is at once the most primitive in the family and perhaps the most generally distributed. In Africa it is represented by only two species, so far as we know at present, and both of these occur in Lower Egypt. One (Spongilla alba) is a widely distributed and abundant Indian form, doubtfully distinct as a species from the cosmopolitan s. lacustris; while the other (S. biseriata), which is closely related to the N. American and Indian species S. crateriformis (Роттs), has been found both in the delta of the Nite and in the Zambesi river-system. It would thus seem that the subgenus is very poorly represented in Africa; but it must be noted that many of the species are usually found in ponds and other small masses of water and that such situations have been very little examined in Africa so far as sponges are concerned. and, indeed, are scaren in most parts of the Continent.

Euncpius is represented in many countries only by what are practieally races and rarieties of a single cosmopolitan species, Spongilla fraqilis, Leiny. In Africa, howewer no less than four distinct species have already been found, one of which (S. nitens) is evidently of wide distribution in the easteru tropical part of the continent, the remainder being only known for the most part from single records. In India also four species are kuown.

The genus Ephylatia is very widely distributed, but chiefly in temperate climates, reaching its acme in Japan. In Africa the only form as yout discovered is a local race of the cosmopolitan E. Huciatilis and has only been found south of the Limpopo.

Dosilia, on the other hand, is essentially tropical and subtropical in its range, consisting of three closely allied species which are regarded by some authors as varieties. One (T). plumosa) is found in the Indian Peninsular Area, one (D. pulmeri) in Hexice and the neighbouring states, and one (I). brounii) in the White Nile.

Tubella appears to have its headquarters in North and South America, but is represented by scattered species in Europe. tropical Asia and Australia, as well as by one (T. pottsii) in the (bongo system.

None of the foregoing genera and subgenura an be said, in the present state of our knowledge, to east much light either on the distribution of the African fauna within the Continent or on its relations to the 17 Michaelsen, Deutsch-Südwestafrika, 
fanna of other regions. The remaining four African genera and the third subgemus of Spongilla that is to sar, Stratospongilla) are more intoresting from both points of view.

Although both Nudospongilla and Potamolepis aro possibly mere assemblies of convergent species, it is at least notrworthy that the latter serms to have its headquarters in the Congo, while the former is particularly woll represented in Lake Tanganyika. Potemolepis is not known outside Africa, whereas Juedospongilla is found in l'alestine, C'lina and possibly Celobes. The former genus seems to have boen moditiod in accordanee with a life in rapid-running water, the latter with one in the still waters of large lakes. ${ }^{1}$ ) Strietly speaking, the Tanganyika system is of conser part of the Congo system.

Corespongilla in several important charactors resembles Potamolepis, which may have been driried from it, at least in part, by the loss of free microseleres of the type called micramphidises by Weltxer. The genus is only known from Tropical Africa, Poninsular India and Burma: ${ }^{2}$ ) it has been found in all the river-systems of Tropical Africa as yet investigated, but not in either the northern or the southern districts of the Continent. It is well reperesented in Peniusular India, more partienlarly in the Malabar Zone.

Stretosponyille ${ }^{2}$ ) has a distribution resembling that of Corespongilla but more extrusive. Singhe species occur on the one hand in South Africa and on the other in the Malay Arehipelago. In both cases these species have a very wide range; oue (S. bombayensis) is found both in Peninsular India and the Himalayas and in Natal, while the other (S. sumatrensis) occurs both in Sumatra and in the Nile system and the coastal districts of Tropical Last Africa. Finglo species ar"also known from Fiji (S. gilsoni, Tupsext and S. Amurica (S. navicella, CArter).

Pertispomillas, las hitherto bern thonght to be contined to the Malabar 'zone of the Indian l'eninsular Area, but an examination of a cotype of Spongille samsiberire, Westake, from the Island of Zanzibar convinees me that it must be assigned to the same genus as Pectispongille anea fiom 'Travancore and cochin, the type species of its gems.

considering these facts, wre may say that, althomgh there is not sufficient revelence as yet beefore us to pareel out the inland spongr-famna of Africa into definite famnistir areas, the Spongilledere of the Continent as a

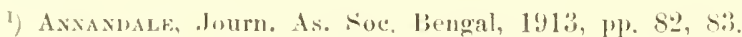

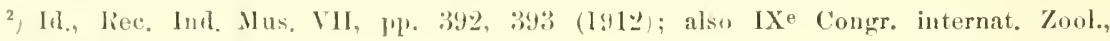
1. 579 et(c. 110 ma(e): 1911).

3) Axixbalk, Fanna of British lutia, Freshwater sponges, ete, p. 106 (1911). 
whole exhibit dose aftinity with those of the Indian Peninsula - and posibly with those of Tropical Asia generally, for outside the Indian Empire the Spongillidue of Tropical Asia have been even less studied than those of Africa. Thuse collected by Professor Max Meber in the Malay Arehipelago, and a few from Western China. Bornew and the Malay Peninsula are all that are known, and most of these have cosmopolitan attinities.

\section{EXPLA NATION OF FIGLRES.}

\section{Plate VI.}

Fig. 1. Spicules of Spongille africana, sp., nov., $\times 255$.
1. Skeleton-spicules.
B. Grmmulespicules.
C. Froe microscleres.

Fig. 2. Gemmule of spongilla africana, sp. nor., as sern from above $\times 75$. Fig. 3. Spiculos of Spongilla michaelseni, sp. nov., $\times 255$.
A. Skeloton-spicules.
B. Cirmmule-spicules.
C. Frop microscleres.

Fig. 4. Grommule of Corrospongilla victoriae, sp. nov.. $\times 75$. The onter cage has boen laid open to show the inner capsule.

Fig. 5. Apicules of Corrosponaillu virtoriae, sp. nov.
A. skeleton-spicules. $\times 2.55$.
B. (iemmuli-spicules, $\times$ 2.5.5.
C. Fres microsclress $\times 255$ cexeept the figure marked with a $X$, which is multiplind by 500 ).





\section{Coleoptera I:}

Chrysomelidae und Coccinellidae

bearbeitet von

J. Weise

(IVarmbrunn). 

Die folgenden Arten sandte mir Herr H. Geriex aus dem Naturhistorischen Nuseum in Hamburg zur Durchsicht ein. Sis wurden zum Teil ron Herm Prof. 1)r. W. Mrchaelsex während der Hamburger dentschsïdwestafrikanischen Studienreise 1911 gefangen, teils von anderen Sammlern, besonders von den Herren Dr. G. Fock und Haxs Thossex, dem Museum überwiesen. Es ist dir größte Kollektion ans den Familien der Chrysomeliden und der Coccinclliden, die ich bisher aus siidwest-Afrika gesehen habe, und sie bestäigt aufs nene die schon ans der Bodenbeschaffenheit und der ziemlich einförmigen Vegetation gefolgerte Vermutung, daß dieser Landstrich zu den an Insoktenarten ärmsten des afrikanischen Kontinentes gohört. Zwar erhöht sich jetzt die Zahl der nachgewiesenen Chrysomeliden ron 21 , die ich 1908 in der Forschungsereise im westlichen und zentralen Siidafrika von L. Scnutrze, Denkschr. der medicin. naturw. Zeitschrift in Jena, anführte, auf 46, und die der Coccinelliden von 2 auf 12, aber nach Abzug der zahlreichen gemeinen Arten, die sich ïber Mittel- und siidafrika verbreiten, bleibt nur eine kleine Anzahl indigener Arten übrig, die sich mit der von den Nachbargebieten Angola, Kapland, Natal nicht entfernt messen kann. Bezüglich der Färbung der behandeltnn Tiern sind vielleicht zwoi Punkte erwähnenswert. 1, Von dem hübschen, oberseits zweifarbigen ostafrikanischen Corynodes Ilejecni BerT. tritt im Gebiete massenhaft eine einfarbig grïne Form auf, von der nur wenige Stiicke auf den Flïgeldecken eine bräunliche Beimischung bekommen, oder, ron der Seite betrachtet, sehwach violett schimmern. 2 Neben den afrikanischen Hauptfarben rot oder gelb der meisten Arten, haben auch melnere, namentlich die in den Sandfeldern lebenden Monolepten, eine golblich weibe Farbe, ähnlich dem hellen sande, die sicher als schutzfärbung aufunfassen ist. 


\section{Chrysomelidae.}

\section{Sagrea bicolor Lac.}

Ifon. Phyt. I, 18t5, p. 55.

Fundangabe: Okali a $11 \mathrm{dj}$ a: Jr. G. Fock, 1909.

Hauptsaichlich von Niederliind.-Ostafrika bekannt.

\section{Lema chalcoptera Lac.}

Mon. Phyt. I, 1845, p. 352, ab. sanguinicollis LAc, l. c. p. 379.

Ws. Arch. f. Naturgesch. 1901, p. 155.

Fundangabe: Gross-Okatjeru im südlirhen Sandfeld, ea. $50 \mathrm{~km}$ siidlich rom Waterberg; Haxs Thomsex, Dez. 1912.

Bei dem rinzigen Exemplare sind Kopf und Thorax rot, metallisch grün überflogen, der innere Teil der beiden Quergruben des Thorax bildet eine kurze, tiefe Längsfurche, die Flïgoldreken sind metallisch dunkelgriin mit Messingschimmer, der größte 'Tuil der Untersaite und Beine rotgelb. Die Art ist iiber Ost- und Südafika verbreitet.

\section{Sphoudylia afina Klug.}

Ent. Mon. 1824, p. 67, t. 6, f. 7.8 .

Fundangabe: Deutsch-s ï dwestafrika; Landrsmuseum zu Windhuk.

Zwei Exemplare, die aus dem Landesmuseum in Windhuk stammen, halte ich für eine helle Form, ab. maculatu. Anf dem Halsschilde befinden sich zwei schwarze, querovale Makeln vor dor Mitte und zwei kleinere gerundete an der Basis, meist durch cinen schwarzen Quersanm verbunden. Wird letzterer breiter, so ist er vor dem Sichildchen zahnförnig vorgezogen und bezeichnet so den Anfang zu der herzförmigen golben Makel der Normalform. Später verbinden sich die Vordermakeln stricluförmig mit den Hintermakeln. Jede Flïgeldecke hat drei schwarze Makeln, die erste auf der Schulterbenle, länger als breit, die zweite gröBer, quer, an der Nahtkante hinter 1/3 Linge, und die dritte hinter der Mitte, chenfills an der Nahtkante, die grijgtr von allen, nach auBen verbreitert und mehr oder weniger weit rom Seitenrande endigend. Der 'Thorax ist in der Hitte der Scheibe sparsamer als auben punktiert, Fiihler und Beino kiomm rinfarbig rotgelb oder scliwarz soin. 


\section{Cryptocephalus callias Suffr.}

Mon. XI. 1857, p. 122. - Ws. in Voeltzkow Reise Ostafr. II, 1910, 448.

Fundangabe: Kleiner Waterberg: Haxs Thomsex, März 1913.

Nur ein Exemplar hat die ron Strmerax beschriebene Normalfärbung: Flïgeldecken gelb, rine gemeinschaftliche Querbinde an der Basis und eine zweite, außen abgekürzte hinter der Mitte schwärzlich blau, beide durch einen Nahtsaum verbunden. Bei einem andern Stïcke sind diese Binden auf je eine mäßig große Längsmakel beschränkt, eine auf der schulterbeule, die andere in grader Richtung dahinter: vier weitere Exemplare gehören zur ab. chalybeipennis SFrr. 1. c. 12t. Sie haben schwarzblaue odel sehr dunkel metallisch grïne Flïgeldecken, eine Quermakel in der Spitze, oder noch eine zweite unter der S̈chulter rötlichgelb. Die Beine aller Stücke sind wie in callias gefärbt: rotgelb, die Hinterschenkel mehr oder weniger weit schwarz.

\section{Pausiris desertorum n. sp.}

Nigro-aenea, nitida, ore, antennis, margine antico prothoracis pedibusque plus minusve testaceis vel ferrugineis, fronte prothoraceque crebre punctulatis, elytris subtiliter subseriatim punctatis, seriebus alternis subtiliter flavo-albido-pilosis, femoribus posticis dente minuto armatis. - Long 3 mm.

Fundangaben: Farm Neitsas im Bez. Grootfontein: Dr. Gr. Fock. Okali andja: Dr. G. Fock.

In der Körperform und Größe ungefähr mit $P$. fuscitarsis JAC., Proc. zool. Soc. Lond. 1900 p. 240, übereinstimmend, aber der Thorax nur mit äußerst kurzen, gelblich grauen und wenig in die Augen fallenden Härchen besetzt, und die Hinterschenkel mit einem kleinen, deutlichen Zahne bewehrt: P. femoralis JAc., l. c. 1904 p. 255. hat an allen schenkeln einen kleinen Zalın.

Metallisch grïlich schwarz, glänzend, Iandibeln pechschwarz, die iibrigen Mundteile nebst Fïhlern und Beinen, sowie einem rerloschenen Saume am Vorderrande des Thoras heller oder dunkler rotbraun. Füller ziemlich schlank, die 5 Endglieder beim $\sigma$ dicker als beim $f$. Thorax etwa so lang wie breit, an den Seiten gerundet, hinten mehx als vorn verengt, dicht und sehr fein punktiost, hinter dem Vorderrande mit einer Quervertiefung, welche jederseits, ïber den Vorderecken, von einer kurzen. glatten Querleiste begrenzt wird; die Seiten sind fein gerandet. Flïgeldecken an der Basis gradlinig leraustretend und in den Schultern be- 
deutend breiter als das Halsschild, dahinter fast parallel, im letzten Drittel gerundet-rerengt, auf dem Rïcken fein gereiht-punktiort und reihenweise mit aufgerichtoten kurzon, gelblichen Borstenhäachen besetzt. Die beborsteten Reihen haben otwas gröBere Punkte als die oingeschlossene kahle lieihe. Die Schenkel sind normal grbaut, keulenförmig, mit langer und diinner Basis und etwas dickerer Spitze: die Hinterschenkel haben ein spitzos Zälunchen.

\section{Colasposoma senegalensis Lap.')}

sirbera. Rev. I, 1833 , p. 22.

Fundangabe: Kileiner Wa triberg; Haxs Thousen, März 1913.

Fin Exemplar mit metallisch violett-kupferigen Flïgeldecken, dunkel griinlich-bronzefarbenem Kopf und Halsschild und grünem S'childehen.

\section{Colasposoma I'rremalorffi n. sp.}

Breviter ovalis, convexa, subtus viridi-aenea, antennis apicem rersus infuseatis) pedibusque obscure ferrugineis, supra anneo-cuprea, nitidula, fronte prothoraceque obsolete alutaceis et crebre subtiliter, elytris paullo fortius punctatis, margine laterali arneo-riridibus. - Long. 4,5-5 mm.

Fundangabe: Wind huk.

Mas.: elytris haud impressis, punctis pone humeros vix rugulosis. Fomina: elytris latera versus transversim rugulosis, pone humeros impressis et pone medium carinula sublaterali instructis.

Diese kleine Art ist mit pusilla Jac., Proc. zool. Foc. Lond. 1904 p. 250, aus Natal, und pareula Ler., Trans. S. Afr. Phil. Soc. 1890 p. 42, aus Transval, am nächsten verwandt, ron erstrer durch die gleichmäßige

1) Obgleich Kuatz, Berl. Zeit. 1872 p. 187 Anm., darauf hingewiesen, daB für Lalorte nichit Castelcau zu branchen ist, zitiert lakferre, Abeille 1876 p. 3 (Synopsis des Eumolp.), unter P'seurloeolespis den Autor wieder falsch als Castelxad de Laporte, Sicherin. Rev. I, 153:3, 1. 23. Ilier findet man jedoch nur den Autor M. F. L. ne Laporte, der nicht mit Cantes. sondern mit LAl. bezeichnet werden darf. Anch die Insicht, jedes anf, soma" rndigende Genus miisse als Ventrun behandelt werden, ist meiner IJeinung nach hinfiillig; denn dil z. B. Cifmas und Bulusag das Recht hatten, die einwandfreien Maseulini Eusomus und strophosmmes zu bilden, die nehen I'horticosomus, Trachysomus, Rhadinosomus, Trichosomms, sphodrosomms und vielen anderen Giltigkeit hahen, muB mir anch freistehen, rine Zusanmenset\%ung mit, sonu“ als Femininum zn betrachten. Tatsichlich hat LAmute,

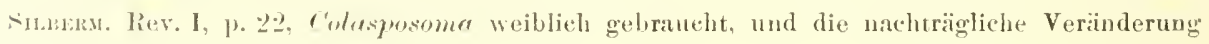
in ein Neutrum berulit deshall aut Willkiir. 
Punktierung des 'Thorax und die verworrenen P'unkte der Fliigeldecken, sowie das längere dritte Fühlerglied versehieden, anch ist die Größe des Thorax und die Bildung der Schienen in beiden Geschlechtern dieselbe: von parvula, die nach einem of beschrieben zu scin scheint, dürfte sie sich durch dichter punktierte Stirn und die abweichend gebildete Fläche der Flïgeldecken unterscheiden lassen.

Die Unterseite ist dunkel metallisch griin, dis Oberseite wenig leblaft bräunlich kupferfarbig, mit gränlicher Beimischung, mäßig glänzend, der Seitenrand des Thorax zuweilen, die Rïndor der Fliigeldecken und das Sehildchen stärker metallisch grün, Beine und die 3 ersten Fülılerglieder dunkel rostrot, die folgenden Glieder angedunkelt, die Schenkel in der Mitte bisweilen metallisch grün angelaufen. Kopf und Thorax dicht und ziembich fein punktiert, mit zart gewirkten Zwisehemäumen. Koptselild ron der Stirn kaum getrennt. Thorax mehr als doppelt so breit wis lang, an den Seiten gerundet und vor dor Mitte verengt, mit fast rechtwinkeligen Vorder- und stumpfwinkeligen Hinterecken, in jeder Ecke eine kleine Pore, in der eine mäßig lange Tastborste befestigt ist. Flïgeldecken etwas breiter als das Halsschild und etwas stärker als dieses punktiert, beim ơ ziemlich gleichmäBig gewölbt, beim \& mit ciner grubenförmigen Quervertiefung hinter der Schulterbeule und einer schmalen und niedrigen Längsleiste dahinter. Die Punkte sind in der äußeren Hälfte der Seheibe kaum ( $\sigma^{\prime}$ ) oder deutlich stärker als auf der inneren (q) und die Zwischenräume bei diesem zu Querrunzeln rereint.

Es liegt mir nur sin Pärchen ror, welches ich von Herrn Landgerichtsrat r. VAREndorf in Hirschberg erhielt.

\section{Euryolpe terminalis Baly.}

Journ. Ent. I, 1860 , p. 34 .

Fundangaben: Noudamm, $42 \mathrm{~km}$ ONO ron Windhuk; Dr. W. Mrohatesex 10.-15. Mai 1911 .

Windluk: Haxs Thossex, Jan. u. Febr. 1913.

7 Exemplare, teilweise mit der normalen schwarzen Zeichnung der Oberseite, oder die Makeln der Cuere nach verbunden. 3 andere stiicke von Okahandja (MronaEssex und Foek) sowis aus dem Landesmusemm in Windhuk gohören zur ab. semipartita JAC., Trans. Lond. 1895 p. 178 , mit schwarzen Flügudeckm, anf denen eine Qurloinde in der Mitte, ein Sritensaum und an Nahtsaum hinter der Mitte norh die urspringliehe gelbrote Grundfarbe behalten haben. Von der ab. discirollis Jac. l. c. 17!), 
Thorax und Fligeldecken schwarz, beide an den Sriten rotgelb gesäumt, lingen keine. Stïcke ror.

Als eine Hungerform dieser Art dürfte sich später E. pictipennis $\mathbf{J}_{\text {Ac. }}$ 1. e. p. 17s herausstellen.

\section{Psemdoroluspis sp. divers.}

Fundangaben: Kloinor Waterberg: Haxs Thossex, März 1913 (1. und 2. sp.).

Deutsch-sïdwrstafrika: Landesmuseum zu Windhuk (2.sp.).

Ton Psezdorolaspis wurden 2 Arten gefangen, welche in der Kïrperform, Farbe und der doppelten Behaarung der Oberseite ganz mit Jacrocoma eriopleora Cuap. ïbereinstimmen; aber die Scitenstiicke der Vorderbrust haben am Vorderrande hintre den Augen je einon dornförmigen Zahn. Dic erste Art (1 Exemplar vom Kleinen Waterbero) zeichnet sich dureh das Kopfsehild, dessen Vorderraud durch zwei winkelige Ausschnitte dreizähnig ist, und rin verhältnismäßig großes Halsschild aus, welches um die Hailfte breiter als lang und nach rorn kamm molır als nach linten verengt ist.

Beri der zweiten Art, metalliseh grïn wie die vorige, teilweise kupferig angelaufon (abenfalls 1 Stück rom Kleinen Waterberg) oder gesittigt dunkolblau (1 Ex. aus dem Landesmusem in Windhuk), bildet der Vorderrand des Kopfschildes rinen nur mäfig tiofon konkaren Rogen, und der 'Thorax ist klriner, an der Basis wenig breiter als über die Mittellinio lang, nach rom im Bogen bedentend verengt.

Diese beiden, scheinhar weit verbreiteten Tirre lassen sich erst mit IIilfe rines auseichenden Matriales beschreiben: sie wurden von JAcons nicht richtig als Marocoma eriophore angesprochen. Die Typen der letztroen erhielt ich dureh dir Freundlichkejt von Herrm SEvers aus dem lirïsseler Juseum zum Vergleirhe. Nir bestrhen aus 5 in Natal gesamnolton Exemplaren: zwoi davon, das Zettelstïck mit der eigenhändigen Etikette ron Chapus, sowio das zwoite, als cotype bezeichnote, ans der Foll. Jourues, habon einen lojeht konkaren Vordoprand der Seitenstieke der Vorderbrust idaher ist meine Auffassung der Gattmo Macrocome, mit der Eubrarkis Jisu idontisch ist, Dentsehe Ent. \%eit. 1903, p. 356, richtig,

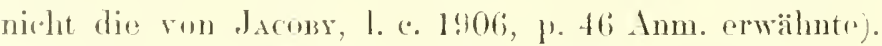

l)as drite stiick, ('otype, Restit. 1885 , ist cine Psendorolaspis, mit

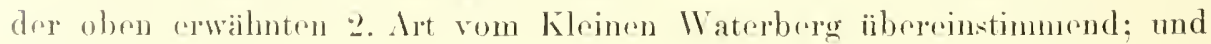


die 2 letzten Stïcke, beide als Type, Loll. Charus bezeichnet, gehören wahrseheinlich zu Wacetes und sind sehwarz, oberseits mit leichtem motalliseh grüulichen schimuer und einfacher, anliegender Behaarung.

\section{Corymodes Dejeani Bertol.:' var. Imsio Marshall.}

Journ. Linn. Soc. Lond. 186.5, p. 33.

Kuxtzex, Arch. Naturg. 1913, p. 97.

Fundangaben: Deutsclo-siidwestafrika; Landrsmuseum zu Windhuk (2) Ex.).

Kleiner Waterberg: Haxs Thumsex, März 1913 (Ex.). Okahandja; Dr. G. Fock, 1910, und I)r. W. Mronamesex, Nov. 1911 (zus. 14 Ex.).

Ich gobe die Bestimmung nach der verdienstrollen Arbeit von Kuxtzes, welche es uns erst möglich macht, die vorhandenen Formon untrezubringen, möchte aber bemerken, dab sich das in Dentsch-südwestafrika häutige, oberseits meist einfarbig grüne Tier, kaum auf pusio Mansnalu deuten lassen dïrfte, da dieser oinen Thorax "at the base mor" than twice as broad as in front; the sides subparallel from the base to rather more than one-half their length, then obliguely rounded to the frout" und einen rorgestreckten Kopf besitzen soll, auch in der Färbung kupferig-purlurn, Stirn, Scheitel und Thoraxseheibe nobst dem Schildchen griin) abweicht.

\section{sygrgmes opreus Jac.}

Proc. zool. Soc. Lond. 1900, p. 231.

Fundangabe: Farm Okosongomingo am Kleinou Waterberge: Haxis Thomsex, August 1912.

Das einzige, $5 \mathrm{~mm}$ lange stiick läßt sich nur fraglich auf diese Art beziehen, denn die Flïgeldecken desselben haben einen dentlichen Fettglanz, der Kopt ist nicht rotgelb, sondern auf dem scheitel pechschwarz (wie die idbrigen Teilo der (Oberseite), darunter rotbraun gefäbt und dur Thorax nicht stark punktiert. Bessor pabt die Beschroibung von s. muireps Ler. Trans. S. Afr. IV, $189 \%$, 1) 43, nur dir GröBe $(6,5 \mathrm{~mm})$ nichth.

\section{Syagmeles mashomamus Jae.}

Proc. zool. S. Lond. 1897, 1. 541.

Fundangabe: Okahandja ; Dr. Fock, 1909. 


\section{Euryalemus t-marulatus Jac.}

1. c. 1904, p. 250 .

Fundangaben: Nïrdliches Šandfold zwischen Löwen-Omuramba und Owangowa-V eld; Bezirksamtmann v. Zastrow, $1912-1913$.

Tsume b: 1)r. W. Michaescex, 13.-19. Juni 1911.

l)ie schwarze Zejchumg der Fligeldecken bestelst ans je 2 verscherden groben Makeln, ron denen sich die erste in 4. und 5. Zwischenstreifen in oder hinter dem Quereindrucke, die zweite dicht dahinter im 5. oder im 3. bis 6. \%wischenstreifen befindet. Der 'Thorax ist bedentend breiter als lang, in der Mitte ziemlich stark und dicht, nach dem Seitenrande hin finor punktiert, oder auf rinem soitenstreifen tast glatt.

\section{Phactonia circellmeincta Sahlb.}

Thos, Arch. II, 1829, p. 30.

Fundangabe: Nördliches sandfold zwischon L̈̈wen-Omuramba und Owanguwa-Veld: Bezirksamtmann v. Zas'row, 1912-1913 (1 kleines Stïck von 4,8 mm Länge).

\section{Chersomela n. gen.}

Corpus ellipticum, sat convexum, alatmm. Aertabula antica aperta. J'rostrornum bicarinatum, processu postico instructum, epistrernis sulco profundo impressis. Prothorax in angulis sine seta ot fovea, basi utrinque loviter sinuatus, muticus, Etytra striatopunetata, epiplenris vix abbreviatis, medio acute inflexis, glabris. Unguiculi fere simplici.

Diese mit Melesome verwandte Gattung erinnert habituell an australinche Puropsis-Arten aus der Gattung Pyrgo, z. B. suturalis Genu. oder Hera STas. Lor Körper hat einen ziomlich regolmäbig elliptischen Lmrib, ist maBig gewiilbt und oberseits gläinzend gelb gefairbt mit metallisch blauer oder grïnliches Zeichnung. Ton den ïbrigen Clurssomelinen ist das 'Tier dureh die Bildung der Vorderbrust verschieden, anf weleher, otwas unterhalb der sellr feinen Soitenrandleistr des Thorax, rine feine. tiofe linne rom lorderrando bis noben dio Ilinterecken läuft, nicht breit grnug, un dir mäbig shlauken Fiillew aufzumelmen. Diese rejelen etwas iiber die Mittelhüften himans, sind 11 gliedrrig und haben 7 verdickte Endgliedor, ron denen Glied 5 das kleinste, 6 nicht ganz so brest ist wie die folerendon annälurend dreieckigen Glioder (an dor spitze broiter als lang),

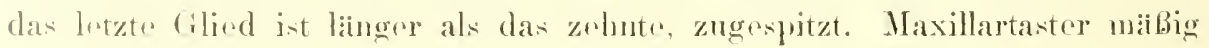


stark, das Endglied wenig länger als das vorhergohende, lang eiförmig, an der ziemlich schmalen spitze abgestutzt. Kopfschild und stirn stark quer: Thorax fast dreimal so breit wie lang. vorn stärker als hinten queriiber gewölbt, die Seiten Jeicht gerundet, vor der Mitte konvergierend, mit stumpfwinkeligen, abgerundeten Torderecken, die Basis jederseits in Irichtem Bogen ausgerandet. Flügeldecken an der Basis so breit wie der Thorax. dahinter allmählich sanft erweitert und in oder hinter der Mitte am breitesten, hiorauf schneller verengt und in der ziemlich schmalen Spitze abgerundet; auf der Scheibe mit 10\% Punktreihen, von denen die 6. (ganze) Reihe an der Innenseite der Schultrebenle rntlang läuft, die $テ$. erst hinter dem Höcker beginnt und die 8. und 9. aus gumeinsamer Iiasis an der Außenseito des Hïckers entspringen. Die Epipleuren sind glatt, vorn wäbig breit und fast rben, dann allmählich vrrongt, in der yitte ziemlich steil abfallend, in letzten Drittel wieder oben und endigen an der Nahtecke. Prosterum lang, muldenförmig. auben von einer Leiste begreuzt, hinter don Hüften alhmählich verbreitert, am Ende abgestutzt. Vordere Gelenkhöhlen ottin. Beine normal gebaut, scluenkel schwach rerdickt, bis an den Rand der Flïgoldecken reichend, Schienen nach der Spitze verbreitert, auf den Riicken eine suur gewïlbt, glatt, ror der spitze mit riner Vertiefung zur Einlagerung des ersten Tarsengliodes. Dieses ist so lang wie die beiden folgenden zusammen. das zweite wenig kleiner als das an der spitze ausgerandetr dritte Glied: das vierte sehr sehlank mit einfachen Klauen, an denen das Basaldrittel etwas verdickt ist.

\section{Chersomela hottentotia n. sp.}

Aeneo-nigra, nitida, antemnis nigris, basi, labro antice, tibiis, tarsis, macula verticis, prothorace macula basali bifida excepta) elytrisque dilute testace-flavis, his nigro-coeruleo-maculatis. - Long. 5.5-6 mm.

Fundangabe: Kanus, Bezirk Keotmanshoop; Haxs 'Thoysex.

Fühler schwarz oder pechbraun, dir ersten + Glieder gelb, oberseits zuweilen angedunkelt, Kopf und Thorax dicht, fin punktiert, auf letzterem werden die Punkte im äuberen Viertel plötzlich stark. In den Reihen der Flügeldecken sind die Punkte bisweilon nicht ganz genau lintereinander gestellt, die inneren Roihon fein, die äuberen kräftiger, die breiten Zwischenstreifon sind foin punktuliert. Thorax und Flïgeldreken sind hellgelb, mit bräunlicher Beimischung (das Halsschild auch rötlich gelb), dunkel violett bis schwäralich blan gefleckt. die Flocks öfter metallisch grï übertlogen. Auf dem Thorax liegt ein Fleck ror dem Schildchen, 
der ans 2 lang droieckigen, nach vorn divergiorenden Spitzen besteht. Iuf den Flïgeldecken sind ein Nahtsaum, drei Makeln anf jeder und cine gemeinschattliche mondfürmige Querbinde dunkel gefärbt. Letztere nimmt das letzte Drittel ein mit Ausuahme eines schmalen Seitensaumes, der in ${ }^{3}+$ der Länge und mben der spitze erweitert ist. Die erste Makel, nahe der Naht hinter dem sehildehen, int quer und nit dem Nahtsaume öfter zu cincr graden oder aus zwei leichten, nach vorn offenen Bogen bestehenden Qurebinde vereint; die zweite Makel bildet einen nach auBen gröfheren Bogen in der Schultrereke und schrint aus 2 Makeln zusammengesertzt: die erste lang, rechteckig, von der 5. und dem Anfanger der ?. Punktreihe begrenzt, vorn die Basis berïhrend und hinten mit der zweiten Makel, cinem Querflocke, verbanden, der bis an den Seitenrand reicht. Makel 3, unmittelbar vor der Mitte, ist obenfalls quer, am Vordersande winkelig erweitert, atter nit riner Erweitrung des Nahtsaumes zu einer gemeinschattlichen Querbinde vereint, welche zuletzt auben die vordere ( prepbinde und die spitze des hinteren Mondfleckes beriihrt.

\section{Felecenthre ennifera Fairat.}

Ann. Belg. 1852, p. 56.

Fundangabe: Kloinfr Waterborg; Haxs Thomsex, Mär 1914.

Ion dieser in Ostafika writ rerbreiteten Art wurden 2 o von normaler Färlonng und 1 f, dessen Flidgeldecken mit Ausnahme der unbestimmt rötlichen Basis schwarz sind, gofinden.

\section{Laetrema solumbiaci Ws.}

Denkschr. medizin. natnrw. Gesellsch. Jena, XIII, 1908, p. 148.

Fundangaben: ()kahand ja; 1)r. (i. Fock, 1909 (14 Kx.).

Kloiner IVaterborg; ILass Thomsix, März 1911 (1 Ex.).

Von diesen stïcken weichen 3 dadurch von der typischen Form ab, dab dor gemernsane selwwarze Flock am schildehen mach hinten rerläingert und mit der sehwarzen Farbe der hintroren Scheibe der Flïgelderekrn verbunden ist (Var. a). Nach der Farbenverteilung könnte

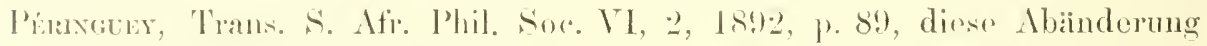

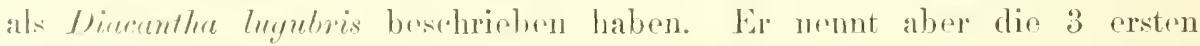

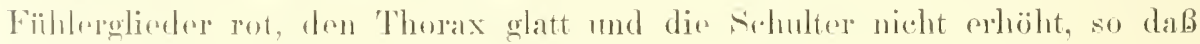

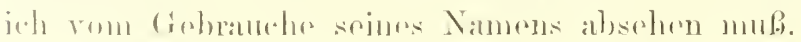




\section{Exosoma pectoralis 11. sp.}

Dilute rufo-flava, nitida, elytris pallide flavis, subtilissime punctatis, pectore fusco. - Long. 5-6 $\mathrm{mm}$.

Fundangabe: Nördliches Sandfeld zwischen Löwrn-Omuramba und Owangowa-Veld: Bezirksamtmann v. Zastrow, $1912-13$.

Den fast einfarbig gelben afrikanischen Arten transvaalensis, pallida und Dalmani JAc. ähnlich, aber durch die schwärzliche Hinterbrust sofort zu unterscheiden. Der Körper ist sehr hell rötlich gelb, glänzend, die Flügeldecken blaßgelb, spitze der Mandibeln und die Hinterbrust schwärzlich, letztere bei frischen Stiicken nur leicht angedunkelt. Stirn mit grader Querfurche ïber den dreieckigen, nach außen zugespitzten Höckerchen, Fïhler ziemlich schlank, sonst normal gebaut. Thorax mäbig gewölbt, quer, vorn mehr als nach hinten verengt, glatt, mit einigen verändrichen Griibchen. Flïgeldecken sehr fein und seicht punktiert, in den Zwischenräumen noch feiner punktiert, eben oder mit einigen ganz verloschenen Längseindrücken.

\section{Yomolepta rpicalis Sahlb.}

Tnox, Ent. Arch. II, 18:9, p. 27.

Fundangaben: Okahandja, Seehrim, Windhuk; Dr. W. Michaelsex, April-Juni 1911.

Bei einigen Stitcken verkleinert sich der rote spitzenfleck der Flïgeldecken immer mehr, bis er völlig sehwindet und die Flïgeldecken einfarbig schwarz sind: ab. Salllhergi; oder derselbe erweitert sich, bis er mehr als die hintere Hälfte der Flügeldecken einnimmt, die jedoch meist fein schwarz gesaiumt ist: ab. praeclara.

\section{Womolepta tristis $11 . \mathrm{sp}$.}

Sat elongata, parum convexa, nigra, nitida, antennis pedibusque flavis, prothorace medio transversim impresso, elytris crebre obsoleteque punctulatis. - Long. $3,5 \mathrm{~mm}$.

Fundangabe: Farm Frauenstein, $50 \mathrm{~km} 0 \mathrm{NO}$ ron Windhuk: Dr. W. Michaelsex, 13. Mai 1911 (1 Ex.).

Fine kleine, ziemlich schlanke und wenig gewölbte Art von schwarzer Farbe, Fühler und Beine gelb, die äuberste spitze der Fühlerglieder rom 18 Michaelsen, Deutsch-Südwestafrikn. 
vierten ab angrdunkelt. Stirn breit, fast glatt, die Höckerchen schräg zueinander gestellt und mit dem Nasenkiele verbunden. Fühler viel länger als dor halbe Körper, Glied 2 und 3 gleich, klein, 4 länger als beide zusammen. Thorax so breit wie der Kopf an den Augen, an den Seiten schwach gerundet und in den Vorderecken etwas breiter als an der Basis, dicht und äuberst fein, fast erloschen punktiert, mit einem breiten und ziemlich tiefen Quereindrucke nahe der Mitte, von ainem liande zum andern. Flïgeldeeken wonig stäker punktiort und nicht ganz so gläuzend wir der Thorax, mit Spuren sehr feiner, kurzer Rumzeln, an den Seiten fast parallel, hinten schwach einzeln abgerundet.

\section{Homolepta misella n. sp.}

Sat elongata, parum convexa, pallide flava, subopaca, vertice maculisque quinque obsoletissimis prothoracis $(2,3)$ fulvis, antennis apicen versus liviter infuseatis, elytris subtiliter nigro-cinctis, seutello, metasterno abdomineque nigris. - Long. $4 \mathrm{~mm}$.

Fundangabe: Farm Otjituru, $66 \mathrm{~km}$ NO vou Windhuk: Dr. W. Michaeliex, 13. Mai 1911 (1 Ex.).

Schlank gebaut und wen:g gewölbt, weiblich gelb, der obore Teil der Stirn rötlich gelb, etwas blasser sind 5 wenig dentliche, rigentlich nur durchschimmernde Fleckchen dos Thorax (3 in einer Querreihe nahe der liasis und 2 davor in der Mitte); das Schildehen, ein friner saum um jede Flïgeldecke, die Hinterbrust und der Bauch schwarz, die Mitte und der vordere Trail von den Seitenstïcken der Mittelbrust schwärlich, die j lotzton Fühlerglieder otwas dunkler als die Basalglieder, blab rïtlich gelbbraun, mit angedunkeltor Spitze jedes Giliedes. Fïbler schlank, etwa bis zur Mitte dor Flïgeldecke roichond, Gliod 3 kam lainger als 2,4 länger als beide zusammen und ungefülur so lang wie das erste colied, 5 und 6 , 10 und 11 unter sich von fast gleieher Linge, jedes wenig kiurzer als 4 , 7-9 jedes so lang wie 4, aber ctwas stirker. Thorax kurz, doppelt so broit wir lang, an don Soitren wenig gerundet und nach der Basis hin selır schwach verengt, mäBig dicht und nur unter starker Vergröborung sichtbar punktuliert, in der Mitte jederseits mit einsur kuzen Quereindrueke. Fliigeldecken in den schultorn wonig broitre als das Malsschild, dann unbedentend erwoitert, hieranf fast parallobseitig, hinten selunell verengt

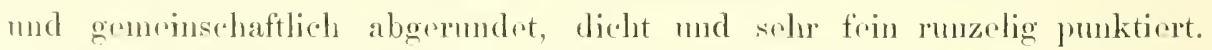
Hor foine schwarze Sieitensamm goht dureh einon bräunlichen Streifen allmählich in die lulle Farbe der scheriber iibrer. 


\section{Homolepta desertorum ir. sp.}

Sat elongata, comrexiuscula, pallide testaceo-flava, nitidula, antennis apicem versus plus minusve scutelloque infuscatis, elytris albidis, sat crebre punctulatis, metasterno abdomineque niguis. - Long. $3-3,5 \mathrm{~mm}$. Fundangaben: Okahandja und Farm Frauenstein, $50 \mathrm{~km}$ ONO von Windhuk; Dr. Wr. Micuaelsex, April und Mai 1913.

Kleiner als die vorige, etwas glänzender, abweichend gefärbt und namentlich durch die Fühler verschieden, an denen Glied 3 deutlich länger als 2 und nur uubedeutend kïrzer als 4 ist. Schlank und fast von gleicher Breite, mäßig gewölbt, blaß rïtlich gelb, Flïgoldreken weißlich, die Fühler nach der Spitze hin mehr oder weniger weit und das Schildehen angedunkelt, Hinterbrust und Bauch schwarz. Stirn und 'Thorax gewölbt, glatt, letzterer doppelt so breit wie lang, ohne Quereindrücke. Flügeldecken mäßig dicht, fein und sehr flach punktuliert.

\section{Monolepta Mirhaelsemi n. sp.}

Oblonga, convexa, flava, prothorace, scutello elytrisque albidis, nitidis, subtilissime punctulatis. - Long. $5 \mathrm{~mm}$.

Fundangaben: Okahandja und Grootfontein; Dr. W. Mucuaecsex, April und Juni 1911.

Größer, etwas breiter gebaut und mehr gewölbt als die rorhergehenden Arten, von der älnlich gebauten tabida Ws. durch viel feinere Punktierung und stäkeren Glanz der Oberseite sofort zu unterscheiden. Thorax, Schildehen und Flïgeldecken sind weißlich gofärbt, die ïbrigen kïrperteile blaß bräunlichgelb, Mandibelspitze rotbraun oder uebst der äubersten spitze der letzten Fühlerglieder angedunkelt. l) Fïhler sind schlank und reichen bis hinter die Mitte der Fliigeldecken. cilied 3 ist unbedeutend schlanker und kaum länger als 2, beide zusammen kïrzer als Crlied 4. Stim glatt. Thorax um mehr als die Hälfte hreiter als lang, mit annäherud parallelen Sriten, oben schwach querüber gewölbt (rorn melur als hinten, und dicht, verloselien, unter starker Vergröbrung erst deutlich punktuliert. Fliigraldecken in den schultorn morklich breiter als das Halsschild, an den seiton sehr wenig gerundet, hintru mäbig breit gorundet abgestutzt; auf der scheibe wenig dichter und deutlicher als der Thorax punktuliert.

\section{Somolepta comtaminata n. sp.}

Oblongo-ovata, convexa, Havo-albida, nitida, antennis apicem versus, vertice, scutello lateribusque pectoris infuscatis, elytris crobre subruguloso$18^{*}$ 
punctulatis, singulo maculis quatuor vel quinque ferrugineis, 1,1 (vix distineta), 1,2 collocatis. - Long. $3-3,5 \mathrm{~mm}$.

Fundangaben: Ka ribib; Dr. W. Mrchaelsen, April 1911.

Ok a handja; Dr. G. Fock. 1909.

Es steht dahin, ob dies 'Tier nur eine verkïmmerte Abänderung der mir unbekannten M. 10-maculata JAc., Ann. Mus. Genova 1886, p. 127, von Massaua ist, die auf jeder Flïgeldecke 5 ähnlich angeordnete schwarze IIakeln besitzt; aber die Fühler sind nicht einfarbig goll, sondern vom 6. oder 7. Gliede ab angedunkelt (das Endglied zuweilen gelb, mit schwärzlicher Spitze) und die Makel 3 jeder Flïgeldecke liegt nicht nahe dom Seitenrande, sondern diesem nur etwas mehr genähert als der Nalıt, die zweite ist kaum angedeutet, und die übrigen rier haben eine rerschossene rostrote oder rotbriunliche Farbe. Der Körper ist länglich eiförmig, gewölbt, gelblich weiß, ziemlich glänzend, Glied 2 und 3 der Fïhlor sind annähernd gleich, der Thorax ist otwa doppelt so breit wie lang, vor der Mitte etwas zusammongedriekt-verengt, dicht, äuberst fein punktuliert, mit einem Quereindrucke jederseits nahe der Mitte. Fliigeldecken in den Schultern breiter als der Thorax, an den Seiten leicht gerundet, etwas deutlicher als der Thorax runzelig-punktuliert, jede mit 5 Makeln. Die erste ist lainglieh und reicht vom Basalrande bis auf die höchste Stelle der Schulterbenle; die zweite ist gewöhnlich nur durch ein Piinktchen neben der Naht hinter dem Schildehen angedentet; die dritte, quer, vor der Mitte, dem Außenrande etwas näher als der Naht, ist die größte von allen. Makel 4 und 5 liegen in einer schrägen Querreihe hinter der Mitte, 4 nalıe der Naht, 5 viel weiter nach hinten gerückt, nebrn dem seitenrande.

\section{Wonolepta arenaria n. sp.}

()blongo-ovalis, convexa, flavo-testacea, antennis (basi exeepta) fuscis, prothorate olytrisque subtilissimu punctulatis, dilute luridis, nitidulis, lis fascia ochracea obsoleta vix pone medium signatis. - Long. $4,5-5 \mathrm{~mm}$.

Fundangaben: Klein ()katjeru, im südlichen Sandfeld, ea. $50 \mathrm{~km}$ siidlich rom Waterberg, und zwischen Okandjacloe und Okandjaute im Bezirk Waterberg; Maxs Thonsen, 1912.

Okabandja; Dr. W. Michaelsex, Mai und Juni 1911. 
Kleiner und etwas schlanker gebaut als Haveola Gerst., hell rötlich gelbbraun, die Fühler vom vierten Gliede ab schwärzlich, Thorax und Flïgeldecken blaß schmutzig gelb, letztere mit einor verloschenen und wenig in die Augen fallenden rötlichen Querbinde, welche innen nicht die Naht prreicht, nahe den seiten schräg nach rorn biegt und hier wenigstens immer sichtbar bleibt. Fïhler länger als der halbe Körper, Glied こ und 3 klein, annähernd gleich, beide zusammen kürzer als 4. Thorax, um die Hälfte breiter als lang, an den Seiten schwach gerundet und nach vorn etwas mehr als nach hinten, im ganzen wenig verengt, oben sehr dicht und äußerst fein punktuliert. Flügeldecken hinten gerundet-abgestutzt, sehr dicht und fein runzelig punktiert.

AuBerdem liegt noch ein Stück einer Monolepta? aus dem Landesmuseum in Windhuk vor, rötlich gelb, Nittel- und Hinterbrust nebst dem Bauche schwarz, welches unbestimmbar ist, da Fühler, schienen und Tarsen fehlen.

\section{Übersicht der Monolepten aus Deutsch-Suidwest-Afrika.}

1 Das dritte Fühlerglied dem zweiten ungefälı gleich, beide zusammen kürzer als das viorte Glied. Monolepta i. sp. . . . . . . . .

1' Drittes Fühlerglied erhoblich länger als das zwoite (Candezea).

2 Kïrper rot. Fühler gelblichweib. Flïgeldeckin schvarz, die spitze gewöhnlich mohr oder weniger weit rot. - L. $4-5 \mathrm{~mm}$

?' Körper schwarz, nur Fühler und Prine gelb. L. $3.5 \mathrm{~mm}$

2" Körper ganz oder gröbtenteils solur holl golblich gefärbt

3 Kïrper fast rinfarbig glänzend weiblich gell). L. $5 \mathrm{~mm}$

3' Oberseite mit dunklerer Zeichnung

+ Hinterbrust, Bauch, schildchen und ein feinor Naht- und Seitensaum der Flügoldecken schwarz.

- L. $4 \mathrm{~mm}$.

4' Flïgoldecken mit einer verloschenen rötlichen Querbinde dicht hinter der Mitte. - L. 4,5-5 mm 4" Jede Flïgeldecke mit + bis joräunlichen Flecken.

- L. $3-3,5 \mathrm{~mm}$ apicalis SAHLB.

2
5
apicalis SAHLB.

\author{
tristis n. sp. \\ 3 \\ Michaeliseni n. sp.
}

4

misella n. sp.

arenaria n, sp.

contaminata n. sp. 
5) Oberseite weiBlich gelb, dicht gormuzelt und fast matt. - L. 4,2 mmı. Kalahari . . . . . tabida W's.

5) Hintrebrust und Banch schwarz, Oberseite ziemlich glïnzend. Stirn und Thorax glatt, blal. rïtlich gelb, Fliigeldecken foin und sohr Hach punkticrt, gelb. - L. $3-3,5 \mathrm{~mm}$. . . . . . . . desertorum 11. sp.

\section{Podregrica reserticola 11. sp.}

Oblungo-ovalis, ronvexiuscula, pallide rufo-flava, nitida, antennis apice infuscatis, postpectore abdomineque nigris, prothorace subtilissime punctulato, striolis basalibus parvis, nytris stramineis, corbre punctulatis et parum fortiter striato-punctatis. - Long. 3-4 $11 \mathrm{~m}$.

Fundangaben: Windluk und Neudamm, ca. $42 \mathrm{~km} \mathrm{ONO} \mathrm{von}$ Windhuk; Mr. W. Michaelsex, Mai 1911.

D)urch dis feine und resloschene Punktierung der Oberseite und die kurzen und feinen, zuweilen kamm angedenteten Pasalstriche des Thorax ron den ähnlich gefäbten Arten, namentlich der P. nigriventris Jac., Ann. Fr. 1907 p. 518 ats Britisch-Ostafrika, verschieden.

Länglich rifürmig, mälbig gewölbt, hell rötlich golb, dic Flïgeldeckrn blasser, strohgelb, Glied 7 und 8 der Fuihler an der Fpitze, die folgenden gainzlich angedunkelt, Hintorbrust und Banch schwarz. Stim fast glatt oder soicht punktuliort, die Hïckorchon quer, immen schmal, anfen verbreitert und nahe der Nitte dureh ainen Eindruck zionlich unterbrochen. Fiiller bis hintre die schulter probrend, Glied 2 das kleinste, 4 wronig, 3 bedentend lïngere, 5 gleich 3, li gleich t, aber dicker und an der spitze fast so breit wie die folgenden cilieder. Thorax ungefälur doppelt so breit wir lang, an don seiton gerundet, schwah kissenartig gowiolbt, dicht und froin, oder sehr frin punktuliort. Fliiguldecken ähnlich wio das Halsschild, nur stiolker punktuliert, nit wenig kriftigeren, itellenweise verdoppelten Punktreihen, dir nur gut zu benceken sind, wrom siu dunkol durchseheinen.

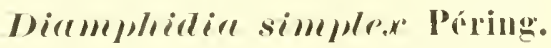

Trans. A. Afr. Phil. Foc., VI, 2, 18!)-2, p. 85 (C'ladoreve)

minl

\section{alb. Cormeste Fairm.}

Ann. Fr. Isis: Bull. :347.

Finger Exemplane olun naileren Fundangaben. 


\section{Phygasia basalis Ws.}

Deutsche Zeitschr. 1902, p. 302.

Fundangabe: Okahandja; Dr. G. Fock, 1909.

Das ninzige Stiick ron $5 \mathrm{~mm}$ Länge rermag ich nicht spezifisch ron den bei Dar-es-Salaam gefangenen zu unterscheiden, obwohl bei ihm die Hinterbrust schwärzlich gefärbt ist und die Fühler eine Spur kräftiger gebaut sind. AuBer den 3 gelben Basalgliodern ist das vierte rotbraun, 5 und 6 pechbraun; die Glieder sind vom dritten ab allmählich eine Spur verschmälert, das dritte bis achte Glied sind innen, nach der Spitze hin, verbreitert, so daß dirse winkelig vortritt.

\section{Haltica indigacen III.}

Nag. VI, 1807, P. 114.

W's. Memor. Soc. Espan. I. 1907, p. 393.

Fundangabe: Farm Paulinenhof, $30 \mathrm{~km}$ () ron Windhuk; Dr. II. Michaelsex, Mai 1911.

\section{Iphthona damaromem n. sp.}

Alata, oblongo-elliptica, dilute rufo-flava, sublaevis, nitidisima, ore, antennarum articulis 7 ultimis pedibusque nigris, gemubus femoribusque posticis interne rufescentibus. - Long. $3 \mathrm{~mm}$.

Fundangabe: Farm Okosongomingo am Kloinen Waterberg; Haxi Thomsen, Aug. 1912.

Durch dunkle Beive ron den ähnlichen, hell gefärbten Arten abweichend. Lang elliptisch, gewölbt, blaß rötlichgelb, stark glänzend, Mandibeln pechbraun, Oberlippe, Taster, die 7 Endglieder der Fiihler nebst den Beinen schwarz, an letzteren die Kinie, die Lnterseite der Hinterschenkel und zuweilen auch der Rïcken der Vorderschienen dunkelrötlich. Fiihler bis hinter die Mitte der Flügeldecken reichrnd, Glied 2 und 3 kurz, $t$ eine spur länger als 3 , die folgenden deutlich länger, unter sich von annähernd gleichor Größe. Nasenkirl schmal, stumpf, Stiruhöckerchen kloin, gorundet, ziemlich scharf umgrenzt. Thorax gewölbt, etwas breiter als lang, hinter der Mitte am breitesten, nach hinten unbedeutend, nach vorn etwas mehr verengt, glatt. Schildchen klein. Fliqgeldecken in den Schultern wenig breiter als der Thorax, bis zur Hitte sanft erweitert, dann ähnlich rerengt und hintrn mäßig breit gemeinschaftlich abgerundet, auf der Scheibe fast glatt: orst unter starker VergrïBerung werden mäßig dicht stehende Pünktchen sichtbar. 


\section{Aphthoma relucens 11. sp.}

Oblongo-oralis, rufo-testacea, nitida, ore antennarumque apice infuscatis, fronte lineis binis decussatis, clypeo lato, prothorace lacri, elytris sublaevibus. - Long. ? $111 \mathrm{~m}$.

Fundangabe: Windhuk; Mr. W. Mchaelses, April und Mai 1911.

Dir einzige Art, die :ihnlich zu sem scheint, ist A. convera Alu., Ann. Fr. 1890 (1891) 557 ron Assinie in Guinsa, die aber gar nicht zur Gattung gehören dïrte, da die Fïhler des o rom 4. Gliede ab erweitert sein sollen, und vou der vorliegenden schon durch die Punktierung der Flïgeldecken abweicht, die an der Basis ziemlich stark und etwas gereiht soin soll.

Auch das vorliegende. Tier, von dem nur 1 of gefangen wurde, entfernt sich von den ïbrigen Gattungsgenossen durch die weit getronnten Fühlrewurzeln, zwischen denen sich das Ende des Kopfschildes als rine schwach gewölbte Fliche ausdolnt, welche otwas breiter als das riste Fühlorgliod lang ist.

Der Kïrper ist lang eiförmig, lebhaft rötlich golbbraun, stark glänzond, der Mund und die 3-4 letzten Fïhlerglieder etwas angedunkelt. Dio Stirn ist glatt, ihro feinen, aber sehr dentlichen Linien durchsehneiden sich x-förmig, ohne in dem jederserits abgesetzton Droiecke dentliche Höckerchen abzusetzen. Die Fiihler roichen etwa bis zur Mitte der Fliigeldecken, Gilied 1 ist lang und dick, 2) ebenso breit, aber bedentend kiirzer, 3 bis 6 diinn, unter sich ron ziemlich gleicher Größe (3 und 6 wonig länger, 4 und 5 so lang als 2), die Endgliodor otwas dicker. Thorax schwach quer, an den Sriten leicht gerundet nud nach vorn wenig rorengt, anf der Scheibe glatt. Flügeldecken in den Schultern wenig broiter als das Halssehild, bis zur Mittr unbedeutend erweitert, damn zunächst ähnlich-, später stärker gerunder-verengt und an der spitze schmal gemeinschaftlich abgerundet, auf dor Schoibe äubrest zart punktuliert, mit kleiner Schulterbeule.

\section{Dibolia bimerenlata Jac.}

P'roc. zonl. Sioc. Lond. 1900, 1. 25:3; Trans. Ent. Soc. Lond. 1903, 1. 4.

Ws. Kilimandj., 1. 235.

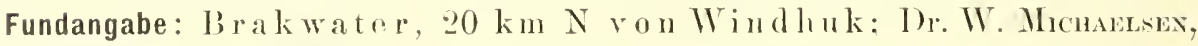
Mai 1911 .

Dir Art ist writ verloreitert: sie wurde von Natal beschrieben und auch in der Mrru-Niedormug aufgefunden. 


\section{Dorcathispa extrema Péring.}

(sub Podispa) Ann. S. Afr. Mus., I, 1898, p. 117.

Fundangaben: Tsumeb: Dr. Wr. Michaelsex, Juni 1911.

Farm Okosongomingo am Kleinen Waterberg:

Haxs Thousex, Juli und August 1912.

Okahandja und Windhuk; Dr. W. Michaecsex, April 1911.

\section{Dactylispa desertomm n. sp.}

Nigra, elytris parum nitidulis, antennis sat brevibus, articulo primo crasso, extus oblique producto, sexto transverso, articulis quinque ultimis praecedentibus crassioribus, prothorace subtilissime ruguloso-punctato brevissimeque albido-piloso, lateribus spinis tribus arquilongis $(2,1)$ armato, elytris striato-punctatis, sat longe multi-spinosis. - Long. $3 \mathrm{~mm}$.

Fundangabe: Windhuk; Dr. W. Mremaelsex, April und Mai 1911.

Mit D. sulcute Chap. (? zuluensis PÉr.), clavata IVs. und perpusilla GEst. nahe verwandt, aber durch längere Fïhler und die zahlreichen und bedeutend längeren Diskoidal-Dornen der Flïgeldecknn abwejchend. Schwarz. die Flügeldeckon mit geringem Glanze. Fühlır bis zur Basis der Flïgeldecken reichend, Glied 1 sehr stark, kaum länger als breit, und wie bei den rerwandten Arten an der spitze schräg abgeschnitten, 2 gerundet, so lang wie breit, die folgenden vier etwas schmaler, 3 ziemlich so lang wie 1, fast doppelt so lang wie breit, 4 und 5 unter sich gleich, jedes länger als breit, das sechste kiurzer, quer, die folgenden fast doppelt so breit wie 6,8 bis 10 stark quer und bedeutend kürzer als Glied 7 oder 11 . Thorax kurz, leicht der Quere nach gewölbt und vor dem leistenförmigen Antebasalrande weit quer eingedrückt; gleichmäßig dicht und selor fein längsunzelig punktiert, sowie sparsam und äuberst kurz weiblich belaart. Die Dormen sind unter sich ron sleicher Länge; ron den Vorderranddornen strobt der ein fast wagerecht nach vorn. der andere etwas schräg nach hinten. Die beiden ersten seitenranddornen vereinigen sich dicht an der Basis. Die Flügeldecken sind gereiht-punktirrt, habon in jodem Punkte ein äuBerst kurzes, weißliches Härchen und sind mit 4 lieihen ron l)ornen besetzt, die etwas kürzer und dïnner als die Thoraxdornen sind. In der ersten Reihe befinden sich 9, in der zweiten und dritten je 5, in der viren 8 Dornen, von denen 4 auf der Schulter stehen. Lie drei ersten Iornen der beiden inneren Reihon sind kürzer.als die dahinter stehenden und wenig länger als die 4 bis 5 Tornen an Basalrande. Am Sieitenrande sind 16 bis 17 Dornen; sie ähneln den längeren scheibendornen und rerkürzen sich hinton nur wenig. 


\section{Coccinellidae.}

\section{Solanophila aremaria n. sp.}

Subhemispluaerica, subtus picea, supra nigra, dense brevissimeque cineren-pubescens, fer pruinosa, frmoribus intrdum obscure rufescentibus, elytris crebre punctulatis et minus dense punctatis, singulo maculis septem $(2,2,2,1)$ epipleurisqur maxima parte fulvis. - Long. $7 \mathrm{~mm}$.

Fundangabe: Windhuk; Ḧixs 'Thonsex, Jannar und Februar 1913.

Mit S. vicuria Ws. Kilimandj. I, 1909, p. 249, verwandt, stäker gerundot, die Bauchlinien gribBer, rogelmäBig gebogen und die Makehn der Flügeldecken zwar ähnlich angeordnet, aber abwoichend geformt.

Ftwas länger als breit, gewölbt, mit dor hächsten Stelle vor der Hitte der Flïgeldecken, von hier aus nach vorn fast gradlinig bis zum Vorderrande des 'Thorax, nach hinten dagegen im Bogon abfallend, unten pechbraun odor noch otwas rötlichere, oben schwarz, dicht und äuBerst kurz grau behaart, beinahe bereift rscheinend. Die Epipleuren der Fligeldeckon im immeren 'Teile nebst 7 verhältnismäbig kleinen Makeln jeder 1)rekr rotgelb. Von diesen befinden sich 2 an der Basis, die innere, noben dem Schildehon, ist gurmolet, ctwas breiter als lang, die zweite, unterhalb der hïchsten Stelle rom Schulterhöcker, ist länger als breit, nach vorn verengt. Die folgenden beidon Flecke liegen in einer graden Querreilu, unmittelbar vor der Mitte und sind quer, 3 doppelt so breit, 4 IIm die Hältte breiter als lang; Makel 5 nud 6, hinter der Mitte, ebenfalls quer, 5 narh innen zugespitzt und schrig nach rorn auf Makel 4 zu gerichtet, 6 schmal, doppelt so breit wie lang. Makel 7 ist otwas dicker als 6, schrig nach hinten und außen geriehtet.

\section{Bulrea Bocamatei Huls.}

spece. $1850,1 \% 71$

Fundangaben: Farm Okosangomingo am Kloinen Waterberge und Gr. Okatjern im sidlichen sandfold ca. $50 \mathrm{~km}$ südlich rom Waterberg; Hans Thomsen, 1912.

Dio Art ist uibur Mittel- und Nïdafrika verheretet.

\section{thea cerripgata F.}

spee. Ins. 1, 17\$1, 1. 99. Mикs. 1. c. 206.

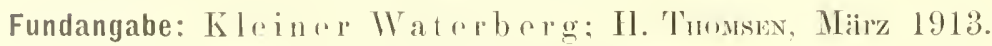

Tैbor Mittel- und Sïdafrika ausgebreitet. 


\section{Chilomenes vicina Muls.}

Spec. 1850, p. 440.

Fundangabe: Farm Okosongomingo am Kloinen Wraterberg; H. 'Thomsen, Juli-August 1912.

Diese Art kommt von Agypten bis siidafrika ror.

\section{Cydomia Lenceter.}

Syst. Ent. 1775 , p. $\$ 6$.

Fundangaben: Kleiner Waterbergund Farm Okosongomingo am Kloinen Watreberg: Haxs Thomsen, März 1913 und Juli bis August 1912.

Oka handja; Dr. G. Fork, 1910 und Dr. W. Michaelsex, Juni 1911.

Neudamm, ca. $42 \mathrm{~km} 0 \mathrm{x} O$ von Windhuk; Ir. W. Mighanesen, 10.-15. Mai 1911.

Ton dieser lübschen, aber in Afrika gemeinen Art, wurde nur die typische Form gesammelt.

\section{Alesia striata F.}

Ent. Syst. I, 1, 1792, p. 269.

Fundangaben: GroB Okatjeru imsüdlichon Sandfold, ca. $50 \mathrm{~km}$. rom Waterberge, und KJeiner Waterberg; Haxis 'THomsex.

Die Exemplar gehören gröbtenteils zu der Form mit 7 freien schwarzen Makeln auf dem Thorax.

\section{Exorhomus flaripes Thumb.}

Ins. spec. nov. $17 \$ 1$, p. $2 \$ 1$.

Fundangaben: Tsumeb; Dr. IT. Munaelsex, Juni 1911.

Farm (1)osongomingo am Kleinen Waterberg: Haxs Tuonsex, Juli-Aug. 1912.

Windhuk: Dr. W. Mrehalesex, Mai 1911.

Seelejm am Gr. Firchfluf.: Dr. Wr. Michafusex, Juli 1911.

Cber das südliche Europa und den ganzen afrikanischen Kontinent ausobreitet. 


\section{Platymaspis capicola Croteh.}

Rev. 1874, p. 197.

Fundangabe: Farm Okosongomingo am Kleinen Waterberg; Haxs Thousex, Juli-Aug. 191..

Siidlich bis zum Kap und durch Ostafrika nördlich bis Britisch Ostafrika verbreitet.

\section{H!yereaspis hottentotta Muls.}

Spec. 1850, p. 686 .

Fundangabe: Farm Okosongomingo am Kleinen Waterberg; Haxs Thomsex, Juli-Aug. 1912.

Ias einzige Fxomplar, ein $\sigma$, läbt sich nur fraglich auf diese suidafrikanische Art boziehen: denn die Beine sind viel dunkler gefärbt als bei dem von Musaxt beschriebenen : nu die Vorderbeine und die anberste spitze der Mittrlschenkel sind gelblichrot, die ïbrigen Teile schwarz, der Kopt und ein schmaler Vorderrandsaum des 'Thorax gelb, ein breiter Seitensanm des Halsschildes, mit konvexem Innenrand, sowie rine ovali Quermakul an der hinteren AuBenecke der Flïgeldecken rot.

\section{Pullus Casstroemi Muls.}

Spec. 1850, p. 978 .

Fundangabe: Okahandja: I)r. Wr. Michaelsex, April 1911.

Ein Stïck, welches auber den beiden rotgelben Schrïgmakeln jeder Flïgeldecke noch einen ähulich gofärbten schmalen spitzensaum besitzt.

\section{Aulis Micharemeni n. sp.}

Gralis, convexa, nigra, nitidula, autennis, palpis (maxillaribus articulo ultimo "xcepto) tarsisque fulvis, prothorace, maculis octo (1, 2, 1) limboqur latrali (ante modimm) dytrorum rutis, dense cincuro-pubrsentibus. Long. $f$ mm.

Fundangabe: (irootfontrin: Ir. Wr. Mrenaelsex, Juni 1911.

1)er Aul. mitis Ws., in F́sosstedt, Kilimandj. I, 1909, p. 263, scho ahmlich, der Thorax aber hell gefübt und nobst dor roten /erohmung der

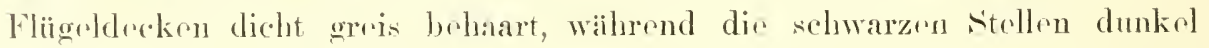
behart sind. Dir Bamehlinien sind grob, gerundet V-förmig, reichen bis

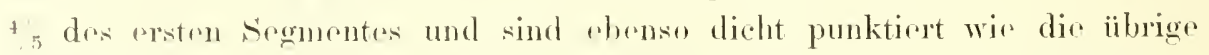
segnenttäiche, die klauen liaben einen kleinen, schlecht sichtbaren Basalzahn. 
Oval, gewölbt, schwarz, dunkel behaart, mäßig glänzend, Fühler, Taster (ausgenommen das sehr große beilförmige Endglied der Maxillartaster) und Tarsen rötlichgelb, der Thorax, ein Seitensaum der Flügeldecken, von der Basis bis etwas hinter die Mitte reichend, nebst 4 Makeln auf jeder rot. Thorax stark quer, dicht und äußerst fein punktiert, ein schmaler, ziemlich unbestimmter und beiderseits abgekürzter Saum an der Basis schwärzlich. Schildchen schwarz; Flïgeldecken in den gradlinig heraustretenden Schultern wenig breiter als das Halsschild, bis zur Mitie etwas verbreitert, dann gerundet-verengt und hinten schmal gemeinschaftlich abgerundet, dicht und etwa doppelt so stark punktiert wie das Halsschild. Von den roten Jlakeln liegt die erste nahe der Naht, hinter der Basis, und ist quadratisch, mit abgerundeten Ecken; die zweite unmittelbar vor der. Mitte, dicht vor dem Ende des Seitensaumes und mit letzterem verbunden, ist quer rechteckig. Die dritte, neben der Naht unmittelbar hinter dor Nitte, ist rund und etwas kleiner als die erste: die vierte endlich, vor der spitze, mondförmig, vorn convex, innen etwas breiter als außen und von der Naht wenig weiter entfernt als 1 und 3 ; außen berührt sie fast den Seitenrand. 



\title{
Coleoptera II:
}

Histeridae

\author{
bearbeitet ron
}

\section{H. Bickhardt}

(Kassel). 

Das aufgefundene Material an Histeriden ist nicht sohr groß. Es wurden 10 Arten in 23 Exemplaren erbeutet. Ton den auberordentlich interessanten Trormiten-Gästen der Gattung Monoplius ist leidor kein Stück gefunden worden. Im Vergleich zu Deutseh-Ostatrika Kolbe, DentschOstafrika IV, Col. 1897, Lewis in Ssöstedt, Kilimandjaro-Meru-Exped. 1908, nud Pickhando, Verzeichnis der ron Dr. F. Eicuelbacm in Deutsch(Wtafrika gesammelten Histeriden 1911 [Arrh. f. Naturg. 1, 1. Suppl.]) scheint Deutsch-sïdwestafrika noch wenig erforscht zu sein. so bietet demn das Rersultat dor Hamburger Studienreise 1911 eigentlich die erste Gelegenheit, eine kloine suite Histeriden für Dontech-südwestafrika im Zusammenhang nachzuweisen. [ch gebe hicrunter eine Liste der anfgefundenen und der sonst bekannt gewordenen wenigen Arten. Es fand sich nur eine neue Art unter der Ausbente Professor Munuelsexis.

\section{Serprinls splenders Payk.}

Monogr. Histerid. 1811 , p. 53 , t. 4. f. 7. - Mars. Monogr. 155.5, p. 350, t. 16, f. 22.. Fundangaben: Farm Noitsas im Baz. Grootfoutoin; Dr. G. Fock, 1907 (1 Ex.).

Nördliches sandfeld zwischen Löwen-Omuramba und Owangowa-Veld: liezirksamtmann v. Zisтrow, 1912 (1 Ex.).

Diese über fast ganz Afrika rerbreitete Art wurde auch in Deutschsiidwrstafrika schon einigemal aufoefunden.

\section{saploinus rhydipterus Mars.}

Monogr. 1862, p. 469 , t. 16, f. 21 .

Fundangabe: swak opmund: HerLyx, 1910.

Anch diese Art scheint in Afrika weit rerbreitet zu sein. I lie Trpe Marsede; stammt aus Abesinien.

19 Michaelsen, Deutsch-Südwestafrika. 


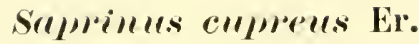

In Kuxg, Jahrb. Ins. 1. 1834, p. 182. - Mars. Monogr. 1855, p. 448, t. 18, f. 73. matalensis FAmrs. in Bom. Ins. Cattr. I, 1851, p. 543. - Mars. Monogr. 1862, p. 472, t. 16, f. 31 .

Fundangabe: (Okalıandja: 1)r. (:. Fock (5 Ex.).

Auch dirse Samime-Art ist über den größten Teil ron Afrika rerbreiter, selbst anf den Cap-Verdeschen Insoln wurde sie gefunden.

\section{Pech!glomes dispar Er.}

In Kuet, Jahrl, Ins. 1, 1834 , p. 197, t. 2, f. 4. - Mans. Mon. 1856, p. 100, t. 3, f. 1. Fundangabe: strakoplutud: Hextyx, 1910.

Eine seltenere und auf den Sïden Afrikas beschränkte Art. Das vorliegende Stiick lat rote, nur in der Giegend des Schildchens dunklere Flïgoldecken, es ist wahrseheinlich noch nicht ganz ausgefärbt.

\section{Prech!glopuss gTruens n. sp.}

Ovalis, convexus, atroviridis, nitidns; antemis pedibusque rufis. Fronte sublaevi, sulcis duobus angulatis, carina transversa prominula. Pronoto ciliato, sat dense fortitre punctato. lateribus partim rugulosis, disco postice lacri. Elytris in quarto interstitio post medium sat dense punetatis, striis dorsalibus 1.-4. postice nltra medium abbreviatis, 4. cum suturali antice arcuatius conjuncta, subhumerali interna obliqua brevi disjuncta, rxtrua nulla. Pyoidio punctato. Prosterno carinato, striis convergentibus anticre conjunctis. Mesosterno marginato, laevi. 'Tibiis anticis valide 4-dentatis. Long. 3 $\mathrm{mm}$.

Fundangabe: (Okaliandja; I)r. W. Michaelsen, 28. April 1911 (1 Ex.).

l)ie Art ist dem $P$. grossipes Mass. ans Sïdenpopa nahe verwandt, so dab es gentigt, die Cnterschirde anzufiiluren. Dir Farbe ist dunkelgriin-motallisch. J)ie Stirn ist anber den beiden winkelig gobogruen Querrmuzeln glatt. Jas Halsscluild ist an den Seitrn kürzer und spälicher bewimpert als bei grossipes. Anf der Soheibe ist dor unpunktirete Raum "twas broitru und gröBor; rer ist vällig glatt. Die Stroifon der Flïgeldecken sind ofwas lïnger. I)ie Junktienung anf dent vierten /wischenraum reicht hördstens bis zur Mitte der Fligeddecken nach voru. Das Mosostremum ist röllig glatt. 


\section{Tribalus amnicola Lew.}

Ann, Mag. Yat. Hist. (7) V, 1900, p. 252.

Fundangaben: (Omaruru: Dr. W. Mrchaecsex, 22. Juni 1911 (6 Ex.). Okahandja: Dr. W. Michaelsex, 28. April 1911 (I Ex.).

\section{Hister herero Bickh.}

Ent. Blätt. VI, 1910, p. 183.

Fundangabe: Okahandja: Dr. G. Fock, 1910 (1 Ex.).

Diese Art ist bisher nur in Deutsch-siidwestafrika und dem anstoBenden Teil der Kapkolonie gefunden. Die 'Type stammt aus Gobabis.

\section{IIister rilis Fălus.}

Вон. Ins. Caffr. I, 1851, 1. 536.

Mars. Mon. 1861, p. 522. t. 6, f. 13.

Fundangabe: Usakos: Dr. IV. Mrchaetsex, 22. April-22. Juni 1911 (1 Ex.).

\section{Hister ropmophilus Reiche.}

Galti. Voy. Abyss. 1851, p. 302, t. 15, t. S. - Man.. Mon. 1854. p. 226, t. 7. f. 42. tumidus FiHrs. in Bolr. Ins. Caftr. I, 1551, p. 587.

Fundangabe: $0 \mathrm{kah}$ andja: Dr. W. Michaessex, 28. April 1911 (4 Ex.).

Ton dieser iiber ganz Afrika (außer der Nordküste und Agypten) verbreiteten Art liegen 4 ïbereinstimmende Exemplare aus Okalandja vor.

\section{Ilister furciger Mars.}

Berl. Ent. Zeitschr. XIII, 1\$69. p. 290.

Scrumt, Deutsche Ent. Zeitichr. 1859, p. 153.

Fundangabe: Deutsclu-südwestafrika; Landrimusem zu Windhuk $(\because \mathrm{Ex}$.$) .$

\section{Wonoplies infletus Mars.}

Mars. Mon. 1855. p. 124, t. S, f. 1. - Lew. Ann. Mag. Nat. Hist. (S) II, 1898, p. 173. Fundangabe: Ninclair bei Kubub: Koll. Bronard ( $\mathrm{Ex}$.).

Dirse im Kapland weit rerbreitete, bej Termiten (insbesondere Hodotermes-Arten lebende Art kommt auch in l)eutsch-rïdwestafrika ror. Das einzige stiick dieser Herkunft (in coll. m.) gohört der wegen der goldgelben Behaarung der Unterseite und der Beine von H. Brauxs anfgestellten Varietät afinis an Ent. Blätt. VIII, 1912, 1.275). 


\section{Pachyerememes pumeticollis Lew.}

Am. Mag. Nat. Hist. (6) XIY. 1894, p. 180.

Fundangabe: 'T'sume b; Wr. W. Michaelsen, 13.-19. Jumi 1911.

Eine wie as scheint seltenere Art, die bishor mur in Kentralafrika getunden wurde.

\section{Parllycrorms spec.}

Fundangabe: Karibjb: Dr. W. Michaelsex, 23.-26. Maj 1911 (1 Ex.).

Das einzige Exomplar ist leider so stark beschädigt, daß sich die Zugehörigkrit zu einer bokannten Art oder das Vorliegrn einor newen Art nicht rekemmen läßt. 


\section{Coleoptera III:}

Malacodermata et Bruchidae

par

Maurice Pic

(I)igoin). 

Les espèces décrites ici proviennent du Sud-Ouest Africain Allemand et appartiennent au Musée de Hambourg; sauf Bruchus Michaelseni n. sp. qui est unique, elles figurent aussi dans ma collection. La variété est représentée par deux exemplaires.

\section{Malacodermata.}

\section{Lyeus trabeatus Guér.}

Habitat: Klein-Wind huk; H. Thomsen, III. 1913.

Sans indication de localité; Landesmuseum Windhuk.

\section{Lycus subtrabeatus Bons.}

Habitat: Osiresur l`O muramba-O matako; O. Hextsculet, I.-II. 1910. Région septentrional du ,Sandfeld“, entre Omuramba du Lion "Löwen-Omuramba") et Owangowa-Teld; Bezirksamtmaun r. ZAstrow, 1912.

\section{Attalus (Mixis) Michaelseni 11. sp.}

Oblongus, postice dilatatus, mediocre pubescens, nitidus, testaceus, pro parte albidus, elytris signaturis nigris ornatis, seutello et infra corpore pro parte nigris.

Habitat: O maruru; Dr. W. Mhohaelsex, 22. VT. 1911.

Oblong, un peu rétréci en arrière, modérément pubescent, brillant, testacé avec le pourtour postérieur du prothorax et une partic du milieu des élytres blanchâtres, tête un peu moins large que le prothorax, yeux noirs; prothorax court, un peu élargi vers lo milieu, rebordé, parfois vaguement maculé de brun sur le disque; antennes pas très longues 
et moremues: dytros un peu plus larges que le prothorax, dargis apres le milien ot rétrécis au sommet, subearénés sur les cotés an milieu, (chez lo o munis au sommot diune épine recombée), ornes d'un dessin noir médian formé d’une bande arguée vers la suture et d'un petit prolongoment externe, noirs parfois arec me petite macule de elsaque côté de l’écusson), ponctuation assuz fine, irrógulire; pattes assez grêles, testacées; dessums du corps noir avee l'abdomen plus on moins testacr à l'éxtrémité; pygidium testacé. Long. 3 mill.

Voisin de .1. expuisitus Ab. élytres plus brillants, à dessins noirs differents, autrement terminés an sommet chez ơ.

\section{Apalochrus festime Er.}

Habitat: K loin-Wind huk: H. Thomsex, III. 1913 ( ${ }^{\prime}$, q ).

\section{Cantharis fomosu Schnz.?}

Habitat: Ferme Otjituezu, $66 \mathrm{~km}$ NO de Windhuk: Dr. W. Muchaelsex, I. 1911 .

\section{Falsomel!mis Sthml:i n. sp.}

Modice elongatus, fere opacus, luteo pubeseens, niger, elytris pedibusque plus minusre testaceis.

Habitat: Wind $\mathrm{l} u \mathrm{k}$.

Nodérément allongé, presque mat, orné d'ume pubeseence jamne un pell dorée, tris distincte et assoz demse sur lavant-corps, espacée sur les Élytros, noir arec les élytres ot les pattes plus on moins testaces, dordinaire pattes testaceses arec les genoux foncés, tète pas tris longue, un peu moins large que le prothorax, yeux moyens; antrmmes noires a base parfois un pell roussatre, a articles 4 ut suivants tris denteles; prothorax assez court, retréci en avant, marque d'une trace de carime pres des bords ot antélemenent, sillonne sur le disque; écusson transersal: élytres bien plus laress que to prothorax, subparalleles, courtement rétrécis an sommet, rebordés, omés chacmu de trois cotes, on outro de la suture, rolévées, intrrvalles avee trois ou quatre rangees de gros points subarrondis; pattes moyonnes, variablement marfures de noir sur colaration gínérate testacée.

Long. (i-s mill. Conte esperee, facile à recennaitre par sa coloration, perut prendre place pris de rufieolor Cuos. 


\section{Welyris viridis ral. subreuminctus 11 . Val.}

Satis elongatus, nitidus, apice subacuminatus, viridis, pro parte subcoeruleus.

Habitat: Lü deritzbuclit: Dr. W. Michaelsen, 5.-13. VII. 1911.

Assez allongé. très rétréci et subacuminé au sommet des élytres. vert avec des reflets bleutés par places, membros foncés. Long. 12 mill.

Principalement distincte par la forme plus allongée du corps et laspect plus brillant.

\section{Bruchidae.}

\section{Bruchus Hichaelseni n. sp.}

Cblongus, antice posticerue attenuatus, subopacus, sat dense albo aut luteo pubeseens, testacens, elytris pro parte subdenudatis, pro parte signaturis albidis ornatis.

Habitat: Okahandja: Mr. IV. Michaelsex, 28. IV. 1911.

Oblong, rétréci aux deux axtrèmités, presque opaque, testacé, revêtu dune pubescenee grise ou jaune dense entremelér sur lavant corps, lo pygidium et le dessous, étytres en partie subdénudes, "n partie ornés de macules allongées blanches. Tête assez longue, earénée entee les reux, cenx-ci moyeus, noirs, antennes courtes, épaissios à l'extrêmité prothorax obeonique, très rétréci et un peu étranglé en arant, impressiumué sur les côtés on arrière, à lobe médian faiblement échancré au sommet ot subsillonné 'n dessus: écusson intaillé au sommet: élytres un peu plus larges fue lo prothorax, faiblement élargis au milien, un pesl retrecis et séparement arrondis an sommet, déprimés vers la suture, striés; pygidium grand: cuisses posterieures allonges, inermes, faiblement creusies en dessous. Long. 4 mill.

Voisin de B. mimus Grum. = senegalensis PIC, mais tres distinet par sa coloration générale testacée et son dessin élytral sans maenles noires.

\section{Bruchus celeithorer. I1. Sp.}

Hodice elongatus, subopacus. pro parte griseo aut fulvo pubescens, niger, variabiliter rufo notatis, antennis ad basin pedibuscue plus minusve testaceis. 
Habitat: Windluk: dans des cosses de gousses de l'acacia sauvage.

Modérément allongé, courtement rétréci aux deux extrêmités, subopaque, en partie revêtue dun pubescence grise ou jaunâtre, noir arec le dessous du corps en partie ot variablement marqué de roux, de même quelquefois lo disque, ou les côtés des elytres, base des antennes et pattes phus ou moins testacées. Têtr longue, yeux noirs; antennes courtes, épaissies à l'oxtrêmité, testacées au moins à le bass; prothorax court ot transversal, subarqué en avant, marqué d'une forte impression sur le disque, fortement ponctuée, al lobe postérieure large et tronqué, écusson carré; Clytres peu plus larges que lo prothorax, subarqués sur les cotés, séparément arrondis au sommet, un peu déprimés sur la suture et tubreulés à la base, finement stries, dordinaire aveu de petites macules blanches détachées de la pubescence foncière en partio fauve; pygidium grand, plus ou moins rougcâtre, mais noir sur le miliru; pattes plus ou moins testacées, les postérieures parfois foncéos, cuisses postérieures épaissies mais inermes. Long. 5-5,3 mill.

Cette espece, facile à reconnaitre par la structure de son prothorax qui oftre une forte impression discale, jointe it sa coloration, peut prendre place près do B. submeculatus Fions.

\section{Bruchus mimus (fyll. (= semegatensis Pic).}

Habitat: 'Tsumab; T)r. W. Mundelsex, 13.-19. VII. 1911. (1 Ex.).

\section{Curyoborus intrustinctus Finhe}

Habitat: K a ribib: Dr. W. Murlaelsen, 23.--26. IV. 1911.

\section{spermoplengus reppresis Motsch.}

Habitat: Furme Okosougomingo aux pied du . Kleiner Waterborg": H. THoxkex, VII.-VIII. 1912.

\section{sjermophayus natalensis Fihrs.}

Sans indication de loealité: Landesmuseum Windhuk. 


\section{Coleoptera IV:}

Lyctidae

par

P. Lesne

(Asnière). 

La faune des Lretides du sud-Ouest Africain Allenand est encore totalement ignorér. J'ai en loccasion dexaminer un de ces Coléoptères, recueilli par M. Ie Dr. (i. Fock à (1kahandja I)amaraland) et envogé par lui au .Natuhistorisches Jusenun" do Hambourg. ("est une forme tres voisine du Lyctus cornifrons Lesse ${ }^{1}$ ), espéce qui habite les régions périsahariennes et qui est caractérisér notamment par larmature de la tête, composée de trois paires de lobes lateraux dentiformes et doue forte épine médiane frontale comprimér, par la forme du menton qui est angulé en avant ot par le pronotum courert d'un réseau de carinules saillantes tris particulier.

Ces caractères ainsi que tous les autres traits de conformation importants du L. comifrons sobservent chez l̈individu d Okahandja, qui diftere

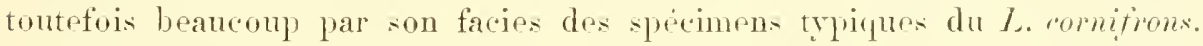
La taille est plus grande que chez ceux-ei, la seulpture du pronotum et des élytres est notablement phus accusée. le pronotum ast plus converes et parait etre plus largement arrondi anx angles antériurs, enfin la coloration est beancoup plus foncese. Au lisu d'utre diun roux uniforme, le dessus du corps est en partie noir, en partie d'un brun foncé: senls, la tête, les bords autérienr et postérieur du pronotum, le sommet du calus humeral et le bord apieal des elytres sont roux on d'un brun roux. De plus, los elvtres sont brillants an lien d'être mats.

Cos caractiers ne semblent pas etre specifiqurs. et il ast probable quion sp troure en présence d'unt race australs dus. comifirons tont à fait analogue a la race capenis de l'Enneadesmus forficula Fans.. Bostrychide dont la forme tỵe est répandure dans lidfinue tropicale perisahariemne et dans une partie do l'Afrique mientale. Il est interesant d" noter que chez la forme australe do l'Eneadesmus forficulu. comme whez colle du Lyetus comifirons. lat coloration est plus foncese ot la taille plus grande que chez lus exemplaires du pourtour sahariun.

La forme de Lyrtus dont il sat iei fuestion prendra le now de L. comifrons australis nov. subsly. Je crois utile d'enumerer ci-dessous fuelquesuns des earactios que présente lindividu que jai sous les reux.

1) Bulletin du Muséum d'Histoire Taturelle, 1s98, n. 3, p. 139. 


\section{Lyctus cormifroms Lesne, subsp. n. australis.}

Habitat: Okalıan d ja; Dr. G. Fock, 1910.

Long. 3,4 millim. Tête, bords antéricur et postérieur du pronotum, calus huméral et bord apieal des élytes roux; disque du pronotum noir; èvtres, presque en entior d'un brun foncé dessous du corps roussâtre; antemnes ot pattes rousses. Tête mate, marquée en dessus diune très fine sculpture réticulée. Articles 3-5 des antemnes allongés, assez grêles, 6-9 plus épais, mais uon transverses: $1^{\text {er }}$ article de la massue suballongé, à bords presque paralliales, trouqué à l'extrémité; 2er article de la massue jus court que le $1^{\mathrm{er}}$, subcirculaire, légèrement allongé, pas plus étroit que le précédent. Labre petit, profondément impressionné au miliou du bord antérieur. Ienton triangulaire et pointu on arant. Prothorax légiement allongé. Pronotum fortement convexe sanf le long du bord antérienr oì il est déprimé, largement arondi aux angles antérieurs, sillonné longitudinalement an milieu, mais convert sur toute sa surface d'un résean de carinules trés fines, mais bien plus apparentes que chez la forme type. Lobes du bord antérieur du prouotum pointus, dentiformes. Poils du pronotum extrêmement courts, épais, clavifommes, surtout apparents dans la région des angles antérieurs. Prosternum convexe, phus long que les hanches antérieures rn avant de celles-ci; son lobe intereoxal tris etroit, presque laminitorme. Élytres brillants, relativement convexes, déclives à l'apex, marqués, chacun sur In disque do 5 ou 6 sérjes striales régulieres, formés chacme d'unc rangée linéaire de fius points enfoncés. C'es stries convergent légèrewent rn arricre rers la suture et sont eftacées arant lapex: dos des élytres mullement strié an voisinage de la suture, et marque seulement d'une ponetuation "xtrêmenent fine ot non sirjée. Pilosité élytrals uniquenent forméc de poils épais, encore phus courts que ceux du prothorax, inclinés en arriare et visibles soulement à un assez fort grossissement. Hanchos antérieures subarrondies. Cuisses modérément dilatées, faiblement comprimess. 
Coleoptera V:

Buprestidae

\author{
par \\ Ch. Kerremans
}

(Bruxelles). 

La Collection de Buprestides provenant du Sud-Ouest Africain Allemand et appartenant au Musée de Hambourg contient des représentants de 33 espèces dont une seule est nouvelle pour la science.

\section{'Trib. Julodini Lacordaire.}

\section{Gen. Sternocera Eschscholtz.}

Ce grand et beau genre ost largement représenté en Afrique. Il est confiné dans la région intertropicale de l'ancien continent. On ne lo troure pas à Madagasear, ni en Amérique, ni dan. l’Insulinde, ni en Australasie.

\section{Stemocera Wahbergi Boheman.}

Oefr. Vet. Ak. Förh. (1860), p. 14, Kernex. Ann. Soc. Ent. Belg. XXxil, 1sss, t. $1, \mathrm{f}, 3$.

Habitat: Ferme Okosongomingo au pied du "Kleiner Waterberg”: Haxs Thomsex, VII.-VIII. 11.

Ababis; O. E. Müller.

Ferme Paulinenhof, ca. $30 \mathrm{~km} \mathrm{E}$ de Windhuk; Dr. Wr. Michaeliex, 18. I. 1911.

Forme Neudamm, ca. $42 \mathrm{~km}$ ENE de Windhuk; Ir. W. Michaelsex, 10.-15. T. 1911.

Jen ai vu des exemplaires des environs du lac Ngami, de la Zambésie. du Damara et d'orambo.

\section{Sternocera funebris Boh.}

Oefv. Vet. Ak. Förh. (1860), p. 14.

Habitat: District septentrional du ,sandfeld" entre l'Onuramba du Lion ("Löwen-Omuramba") et Owangowa-Teld; Bezirksamtmann r. ZAstrow, 1912-13.

20 Michselsen, Deutsch-Südwestafrike, 


\section{sternocera orissa Buq.}

Bull. Soc. Ent. Fr. (1S37), p. 76.

Habitat: District septentrional du ,Sandfeld" entre lommamba du Lion ( „Lïwn-Onuramba") et Owangowa-Teld; Bezirksamtunann у. Zastlow, 1912-13.

Osiresur l’Omuramba-Omatako; (). Hextscher, I.-II. 1910. Grootfontrin; Dr. W. Mchalcsen, 7.-11. VI. 1911. „KIeiner Waterberg"; H. Thunser, VH.-VIII. 1912. Okahandja; Dr. G. Fock, 1900.

Ababis; O. E. Mïller.

Windhuk: Dr. W. Michaelsex, IV.-Y. 1911.

Neudamm: Dr. W. Michangsex, 10.-15. I. 1911.

Fermo Itsawisis pris de Keetmanshoop; H. W. Burmester. Narubis près de Keetmanshoop; H. THomsex, III.-IV. 1913. Lespece est répandue parmi toute l:Afrique australı, au sud du Zambise, et est excessivement variable. L'expedition d. Hambourg an a recueilli 21 exemplaires appartenant it deux variétés: liturata Wurte et funeraria Kernem., avee des passages entre elles.

\section{Gen. Julodis Eschscholtz.}

L'habitat des Julodis est, dans son ansemble, le même que celui des Sternocera, mais il est phus étrudu vers lo bassin de la Méditerranée; bien que cet habitat soit le même, il semble que les premiers abondent là où les seconds sont plus rares, et réciproquement, en sorte que l'on est admis à supposer que les Sternocera ont empéché l'extension des fulodis sur certains points diuse are géographique tres étendur qui eomprend tonte l'Afrique (à l'exception de Madagascar), lo sud de l'Europe, I'Arabie, la région Caspienne, lo 'Turkestan, la Perse, le Bélontehistan, l'Afghanistan et la partie occidintale de l'Hindoustan. (In pent constater en effet que tout le territoire africain habité par dr nombreux Sternocera, écst à dire l'Afrique épuatorialo, est exeessivement paure en Julodis, tandis que cenxci sont tres nombjoux dans la sous-région mediterranécune ot dans celle du sud de l'Afrique. Fin Asie, le mime fait se reproduit dans l'Inde proprement dite.

\section{Subgen. Julodis (s. s.)}

\section{.Julodis IIrel Kerrem.}

Bull. Soc. Ent. Fr. (1902), p. 38; Wrtsa. Gen. Ins., fasc. 12, Buprestides (1903), 1). 1, f. 2. 
Habitat: Ababis: O. E. MüLLER.

Rehoboth: K. Werelerex.

Lexemplaire recucilli par M. (). E. MïLler est un pen différent du type, mais pas assez toutefois pour l'en separer.

\section{val. arueovirpns Kerrem.}

Habitat: ?, Sans indication de localité; Landesmuseum Windluk.

\section{Fulortis Echo Gory.}

II onogr. supp., t. IV (18t1), p. 14, pl. 3, f. 1․

Habitat: Ferme Paulinenhof, $30 \mathrm{~km} \mathrm{E} \mathrm{de} \mathrm{Windhuk;} \mathrm{Mr.} \mathrm{W.} \mathrm{Mrchs-}$ ELSEX, 1S. V. 1911.

Ababis: (). E. Mïhler.

Narubis pris de Koetmanshoop; H. Thomsex, III.-II. 1913. sans indication de localite: Landesmusemm Windhuk.

Il rxiste, entre 10.J. Cuf̈ra ('Ast. ot lo.J. Echo, que j’ai réunis dans ma Monographie t. 1. p. 277 ), des differences constantes et suffisantes pour séparos ess doux formes.

Chez le .J. Cufira, le sillon médian du pronotum ast il peine indiqué et les mavules dytrales sont plus grandes ot ì pulverulenes jaunatro. Chez le. J. Echo, l, sillon dn pronotmm est not, profond, bion marqui sur toute son itendue, les macules élytrales sunt beancoup plus petites, at à pulvérulence blanche, et, en gineral, l’insecte est moins robustr, plus étroit at moins élargi en arriere. Les deux exemplaires qur jai soms les yeux appartiennent à la forme Echo.

\section{fllodis mamolere $110 \mathrm{v}$. sp.}

A .J hirsuta differt rlytris non fascienlatis sed multo marmoratis plagis lateralibus rubris, non fasciculatis.

Habitat: Narubis pri.s de Keetmanshoop; H. Thomsex, III.-IV. 1913.

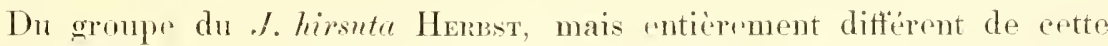
espece ot de ses rariétés par l'absence de fascieules sur les bytres, dont les taches blanches sont fentrés pulverulentes, et tris nombreuses, formant un dessin marbré. Thetr ornér de deux courts fascienles jaune oraugé; pronotum impressionné à la base. comvert de poils dressés, conrts, plus jaumes on avant qu'en arriere, beaucoup moins allongés, plus denses $20 *$ 
et plus pulvérulants que dhez less rspeces de son groupe. De même, la rangée latérale de taches rouges n'est pas composée de fascicules, mais de taches, comme dhez le J. omatipemis Gorr, au nombre de onze ou douze de chaque coté. Le pronotum est bleu foncé et le dessous est noir et le fond des elytres noir-broncé avee les côtés bleus. La ponctuation du dessous est plus grossière et plus inégale que ehez l\%irsuta; la pubescence qui le recourre moins longue et moins dressece au miliru; les fascieules latéraux des segments abdominaux sont plus accentues et blanes, ceux des hanches ot des épipleures jauurs, onfin les pattes sont luisantes et grossieremont ponctuées.

Jai vu toutes les espices connues, du gouro .Julodis habitant la région sud-africaine et jai sous les yeux la plupart dentre elles. Je ne saurais rattacher colle-ci a ancuns dielles et je crois bien me trourer en frésence diue forme nourelle.

\section{Inlodis momerealis Gory.}

Monogr. Buprest. Suppl. IV, 1811, 1. 10.

Habitat: Narubis pres de Kretmanshoop; H. Thomsex, III--IV. 1913 (3 exempl.).

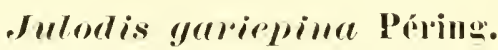

Trans. A. Afr. Plitil. Soc. (1885), p. 32, pl. 1, f. 8.

Habitat: Narubis pres do Keetmanshoop; H. 'Tunusen, III-CIV. 1913.

\section{Julodis damarima lierrem.}

Mo o ogr. Bupr., t. I (1905), p. 286, pl. 5, fig. 1 .

Habitat: Moitié méridionale du Fud-Uuest Africain allemand: M. Beutemaxis.

Le type de cette especer proviont do Namaqua.

\section{Subgen. Neojulodis Kerrem.}

Co sous-gente essentiellement afrieain. savanee davantage daus les regions dquatoriales, ò les fulodis vrais sont plus rares. Il comprend une serie despices de taille méchoire ou mome protite pour le genre, dont le . hivia L. est le type. 


\title{
Neojulod is Vylderi lierrem.
}

Monogr. Bupr., t. III (1909), p. 585.

Habitat: Ababis: O. E. M̈̈llle (un Exempl.).

Le trpe dre cette espece provient du Damara.

\section{Neojulodis subrittata Sannders.}

Trans, Ent. Soc. Lond. (1872), p. 239.

enyassica Haroli, Mon. Berl. Ak. Wiss. (1879), p. 215.

nyassica Falrs., Ann. Soc. Ent. Fr., 6e Sér., t. VII (1887), p. 279.

Habitat: Ferme Paulinenlof, $30 \mathrm{~km} \mathrm{E} \mathrm{he} \mathrm{Windluk:} \mathrm{Wr.} \mathrm{W.} \mathrm{Mreua-}$ ELAEx, 18. V. 1911 (un Exempl.).

Le type provient de la Zambesie. On trouve aussi lespece dans la région du lac Nyassa.

\section{Teojulodis mfolimbata Fairm.}

Ann. Soc, Ent. Fr., Ge Sér., t. VIII (1858), 1) 179.

Habitat: Ferme Okosongomingo an pied du "Kleiner Waterberg";

H. 'Тникех, VII.-VIII. 1912.

\section{'Trib. Polycestini Latc.}

Groupe: Acmaeoderites Kerrem.

\section{Gen. Acmaeodera Eschscholtz.}

\section{Acmaendera vividiaenea Desect.}

\author{
II ém. Ins., t. VII $(17 \% s /$, p. 631 , pl. tí, f. $s(q)$.

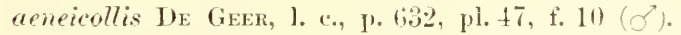 \\ elateroides Herbst, A rch., t. VII (1784), 1. 174, 11. 46. f. 3 (Q). \\ mficollis Thexв., Nov. Sp. Ins. Diss, t. $5(1799)$, p. 92 (Q). \\ giblosa Fabr.. Ent. Syst., t. 1. pl. 21794, 1. 201 (f). \\ fulvieollis Hermst, Col., t. $1 \mathrm{X}(1801$ \% p. 156, f. S (ઉ). \\ violacea Gonr, II on ogr. supl., t. IV (1840), p. 48, pl. 9, f. 48 ( f).
}

Habitat: Ukah and ja: Dr. W. Micmelsex, 10.-15. V. 1911 (un seul exemplaire of).

L'enpece parait continie dans lo sud de l'Afrique et ne dépasse pas le Zambèse au Nord. 


\section{Acmeceoderen freternal Boheman.}

Oefvers. K. Vetensk. Akad. Förh. (1860), p. 19.

sulatueolata Thomsex, 'Typ. Bupr. (18is). p. 61.

chrysoloma Tuoss., 1. c.. ibid.

Habitat: Noudamm, 42 km ENE de Windhuk: Or. M. Mucmaelsen, 10.-15. I. 1911 ( 1 q).

Sans indication dr localité: Landesmuseum Windhuk (1 O’).

L'habitat de cette mpice sétend darantage vers le nord: on la trouve dans lifrique Orientale Allemande, bien quelle soit commune dans la région du cap de Bomme Espérance.

\section{Acmacoderel lugmbrima Boh.}

Gefv. Vet. Ak. Förh. 1860, p. 20.

Habitat: ?, Sans indication de localite: Landesmusem Windluk.

\section{Armacodera reficandis de tieer.}

VIém. Ins. VII, 1778, p. 63:-, 11. 47, f. 11.

Habitat:?, Sans indication do localite: Landesmusom Windhuk.

\section{demereoderel posticalis Cast at Gory.}

Monogr. I. 1836 , p. 28, pl. 8 , f. 47.

Habitat: ?, Sans indication do localite : Landesmusemm Windhuk $\left.1 \sigma^{\top}\right)$.

\section{streaspis hyluenerta 'Thoms.}

liev. Mag. Zool. (1879), p. 295 .

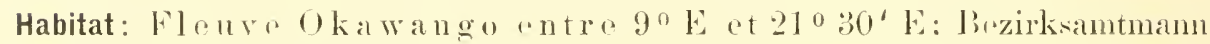
ง. KAsTRow, 1912 .

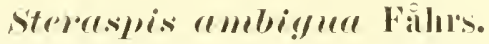

Ins. (atfonr I, 185) 1, 312.

Habitat: ?, Sans indiration dr. lucalite: Landromusem Windhuk. (1 exempl.).

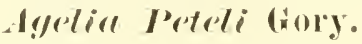

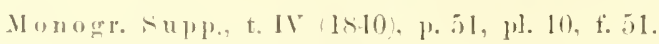

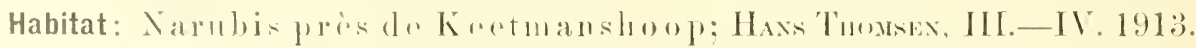
sans indication dre localite: Landermmermun Windunk. 


\section{Trib. Chalcophorini Lac.}

Groupe: Psilopterites Lac.

\section{Gen. Psiloptera Solier.}

\section{Subgen. Damarsila Thoms.}

\section{Damarsila confluens Harold.}

II on. Berl. Ak. Wiss. (1878), p. 215.

Habitat: Karibib.

Narubis près de Keetmanshoop: H. Thousex, III.-IV. 1913. Cetto espèce paraît confinée dans sud-Onest Africain Allemand.

\section{Damarsila foreicollis Gory.}

Nonogr. Supp, t. IY (1St0), p. 95, pl. 17, f. 13.

calemitose Finr., Ins. Caffr., t. 1 (1551), p. 315.

sublaevicollis Bonem., Oefv. Vet. Ak. Fïrh. (1S60), 1\% 16.

Habitat: Tsumeb: Dr. W. Michaelsex, 13.-19. VI. 1911.

Ferme Oknsongomingo au pied du ,Kleiner Waterbol'g”; H. Thomsex, VII.-VHI. 1912.

Ferm" Paulinenhof, $30 \mathrm{~km} \mathrm{E}$ de Windluk; Dr. W. Michatane. 1S. Y. 1911.

Narubispris de Kontmanshool': H. Tronsex, ILI.-TY. 1913.

sans indication de localité: Landesmuseum Windhuk.

Liespece sitrond dn sud de l'Afriqur au lac Nomi. La taille varie extrêmement.

\section{Hamarsila Meyerei Kerrem.}

Ionogr. Bupr., t. Y (1911), p. 293 , pl. 30 , f. 5.

Habitat: Ferme Neitsas pris de Grootfoutein; 1). G. Fock, 1909 (un seul exemplaire).

Le type provient du Hant-Zambese.

\section{Damarsila quadriatreolata Fink.}

Ins. Cafr.. t. 1 (18j1), p. 318.

Habitat: Ferma Okosongomingo au pied du . Kleinnr Waterberg: Hans Thumsex, III.-V'III. 1912. 
District septentrional du . Saudfeld" entre l'Ounramba du Lion ( "Löwon-Omuramba“) et Owangowa-lrold: Bezirksamtmann v. ZAsтrow, 1912-13.

\section{I'siloptera stormsi lierr.}

Ann. Soc. Ent. Belg. Xxxy , 1892, p. 56.

Habitat: ? Sans indication de localité; Landesmusenun Windhuk.

\section{Oredisterma subrengosa Boh.}

Oefv. Tet.-Ak. Firh., 1860, p. 14.

Habitat: ", Sans indication de localite: Landesmuseum Windlunk.

\section{sylmemoptera rectipemis lierrem.}

Ann. soc. Belg., t. XLII (1s98), p. 295, Monogr., t. VI 1913), pl. 35, f. 7.

Habitat: Ferme Okosongomingo a u pied du, Kleiner Waterberg": Haxs Thomsex, VII.-VIII. 1912.

Sans indication de localite: Landesnusemm Windhuk.

\section{splesepteva cupida Kerrem.}

II onog., t. VI, (1919), p. 546 .

Habitat: Distriet septentrional du .sandfeld" entre l"Omuramba du Lion ( Löwen-Umuramba") rt Owangowa-Vild: Bezirksamtmann v. ZAsтrow, 1912-13.

\section{sibemoptera obrial Thoms.}

Tур. Вирг. $(1878)$, p. 67.

Habitat: Fermo Okosongomingo an piod du , Kleincr Waterbore" Haxs Thomsex, VII-VTII. 1912.

.. Kloinnl Waterbarga: H. Thomsex, III. 1913.

\section{Sillewopterel subobess lierr.}

Ann. Foce. Ent. Belg., t. Xlili (1599), p. 26:3; Monoggr, t. VI (1913), pl. 38, f. 6. Habitat: "Kleiner Watroborg": Haxs "Thmsex, III. 1913.

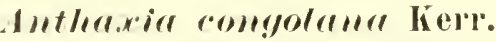

Habitat: ?. Sans indication do localite: Landesmuseum Windhuk. 


\section{Anthaxia pilifrons herrem.}

Ann. Soc. Ent. Belg., t. XLII (1898), p. 299.

Habitat: Ferme Okosongomingo au piod du, kleiner Waterberg": Haxs Thumsex, VII.-TITI. 1912.

Agrilus sexguttatus Thunb.

Nov. Sp. Ins. Diss. (1789), pl. 5, f. 11.

Habitat: Wind huk: Haxs Thousex, I.-II. 1913. 



\section{Coleoptera VI: \\ Cetonidae}

bearbritet von

\section{J. Moser}

(Berlin). 

Die deutseh-siidwestafrikanischen Cetoniden des Naturhistorisehen Museums zu Hamburg enthalten keine neuen Arten und keine solehr, die einer Erörterung bedïrften. Ich kann mich deshalb auf' die Zusammenstellung einer Liste der betreffenden Arten mit Angabe der Literatur und der Fundorte beschüinken.

Eudicella Smithi Mach. subspec. heveroensis Ǩr. Deutsehe Ent. Zeitschr. 1900, p. 416.

Fundangaben: Farm (1kosongomingo am Kleinen Waterberg; H. Thomisex, V'II.-VIII. 1912.

Ababis; O. E. Mïller, 18. X. 1910.

Ohne nähere Angabe; Landesmusemu zu Windhuk.

Dicranorrhina derbyana Westw. Arcana Ent. I, p. 173, t. $42 \%$ 오.

Fundangaben: Windhuk: H. Thomsex, I.-II. 1913.

Ababis; O. E. Müller, 18. X. 1910.

Cheirolrsia Burlei Westw. var. histrio Bates, Ent. Monthly Mag. XVIII, p. 157.

Fundangabe fehlt; Landesmuseum zu Windhuk.

Amandodes Passemini Westw. Areana Ent. II, p. 71, t. 67, f. 1 б. Fundangabe: Farm Neitsas, Bez. Grootfontein: 1)r. G. Fock, 1907.

II!psologenia comrara forr und Perch. Mon. p. 121, t. 17, f. 1 \%'. Fundangaben: Ababis: O. E. MïLlek, 18. X. 1910.

Farm Paulinonhof, $30 \mathrm{~km}$ O von Windhuk; Dr. W. Michaelsen, 18. V. 1911.

Pachmoda calcecete Has. Monatsber. Acad. Berl. 1878, p. 29.

Fundangaben: Farm Okosongomingo am Kloinen Waterberg: H. Thomsex, VII.-VIII. 1912.

Olıne nähere Angabe: Landesmuserm Windhuk. 
I'arhluorla rufu Gebl. Mem. Ins. III, p. 640, t. 48, f. 1. Fundangabe: Farm Paulinenhof, $30 \mathrm{~km} \mathrm{O} \mathrm{von} \mathrm{Windhuk;} \mathrm{Dr.} \mathrm{WV.}$ Michallater, 18. I. 1911.

Pachumala bella Ka. Deutsehe Ent. Keitschr. 1898, p. 14. Syn. .J. pirta scoroci.

Fundangabe fehlt: Landesmuscrm zu Windhuk.

Dischista rincta GeEr. Mem. Ins. V[1, p. 641, t. 38, f. 3. - Buru. Handb. Ent. III, p. 512.

Fundangaben: Narubis bei Kretmanshoop: II. Thussax, III.--IV. 1913. Okahandja: 1)r. G. Fock, 1909.

Osire am Omuramba-Omatako; O. Hextsonel, I.- [I. 1910. Ohne nähere Angabe: Landesmusem zu Windhuk.

Moleabdotis semifmectata F. Ent. Syst. I. 2, 1. 140. - Bum. Handh. 111, 1.529.

Fundangaben: Narubis bei Keetmanshoop; II. Tunswex, III.-IV. 1913. Farm Itsawisis bei Keetmanshoop: II. IV. Bunester. siidl. Hälfte ron loentsch-südwrstafrika; M. Beutemax. Kuibis: Dr. Raxies und Dr. W. Mondelsex, 1., VII. 1911.

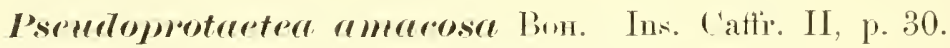

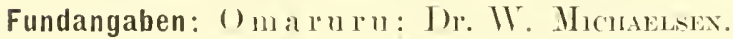

Ohne nähere Angabo: Landesmuserm zu Windhuk.

Gametis balterta Giver. Mem. Ins. VII, p. 642, t. 48, f. 4. Bunu. Handb. Ent. III, P. 367.

Fundangabe fohlt: Landremusrum zII Windhuk.

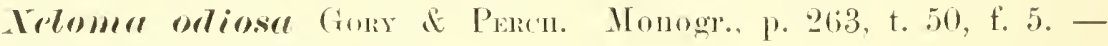
liun. Famdls. Ent. III, J. 508.

Fundangaben: Wind huk: H. THomsex, L.-II. 1913.

()he nährer Angabe: Landesmusem zu Windhuk.

Hamseleopsis mmabilis Sim. Ann. Suc. Ent. Fr. 1844, 1. 408. Fundangabe fohlt: Landesmusoum zu Windhuk.

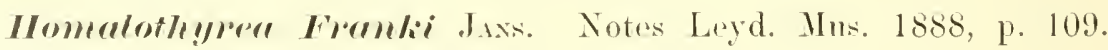

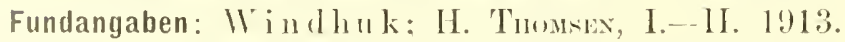
(Ohne nähree Angabe; Landromuserm zu Windhuk. 
Lencocelis ametleystima MacL. Ill. \%ool. Afr. III, p. 48.

Fundangaben: Farm Paulinenhof, $30 \mathrm{~km}$ () von Windhuk: Dr. Wr. Michaelsex; 18. V. 1911.

Olnne nähere Angabe: Landrsmuseum zu Windhuk.

Hoplostomus fullgimeus OL. Entom. I. 6, p. 20, t. 3, f. 12. Burm. Handb. Entom. III. p. 637.

Fundangaben: Reho both: K. Wegelebex.

Okahandja: Dr. G. Fork.

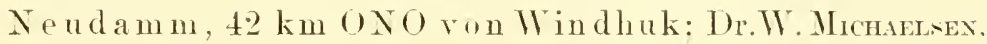
10.-15. T. 1911 . 

Michaelsen. Land-u. Süssu'usserfauna I). Su Afrikas: Enderlein. Archihymenidae.

Taf: I:

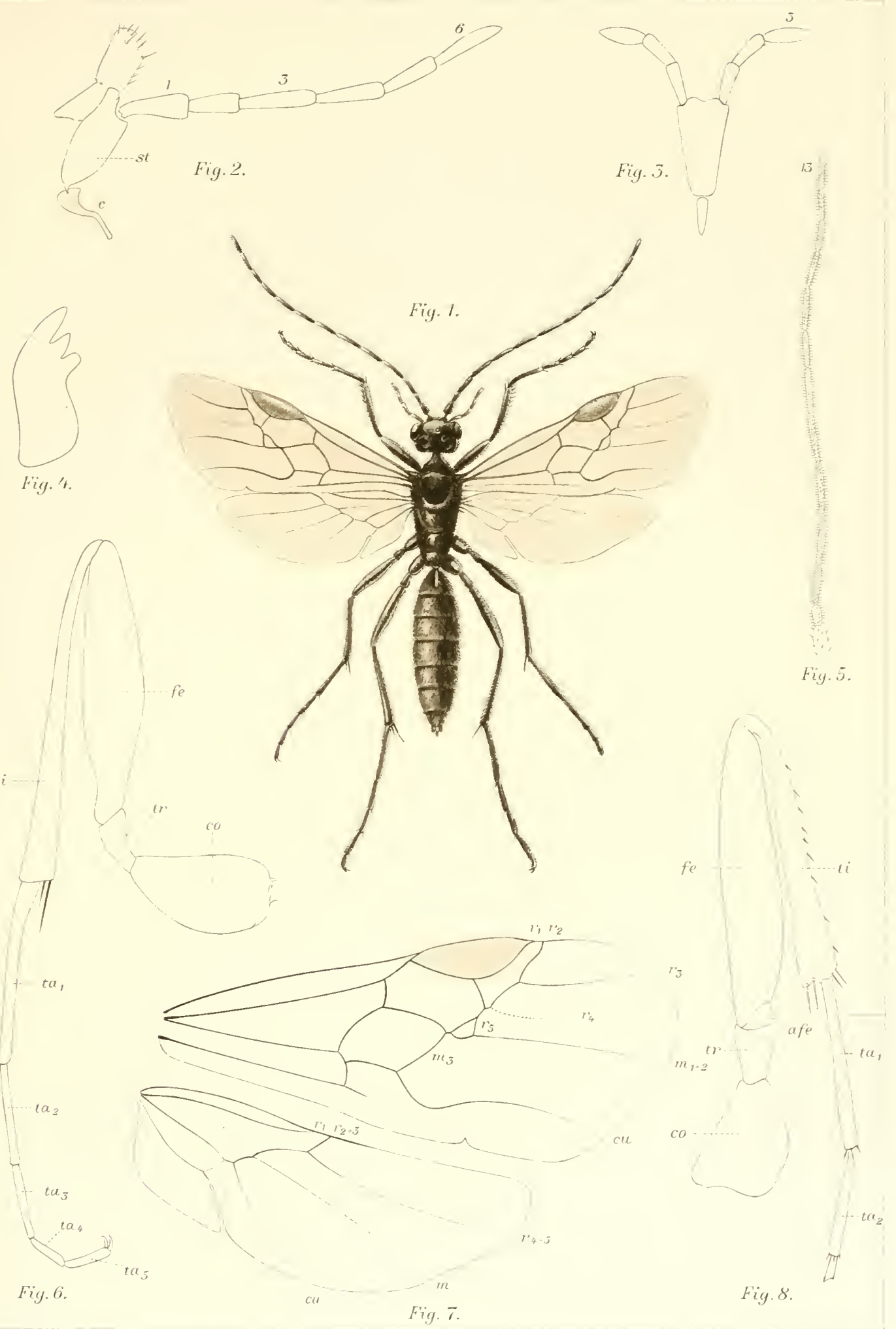



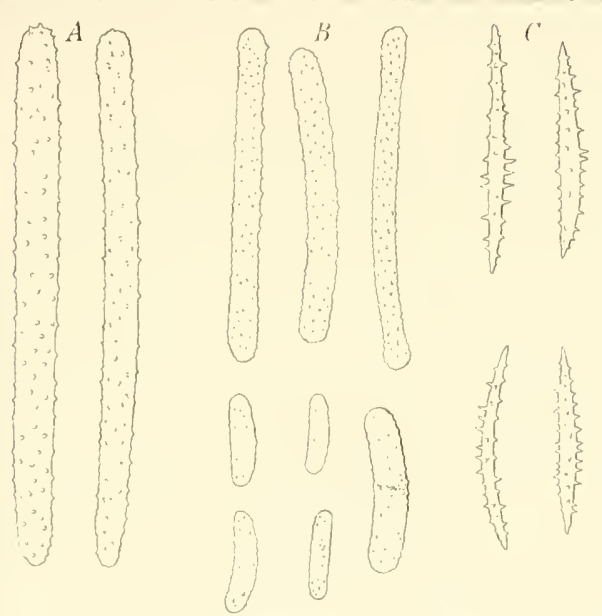

Fig. I.
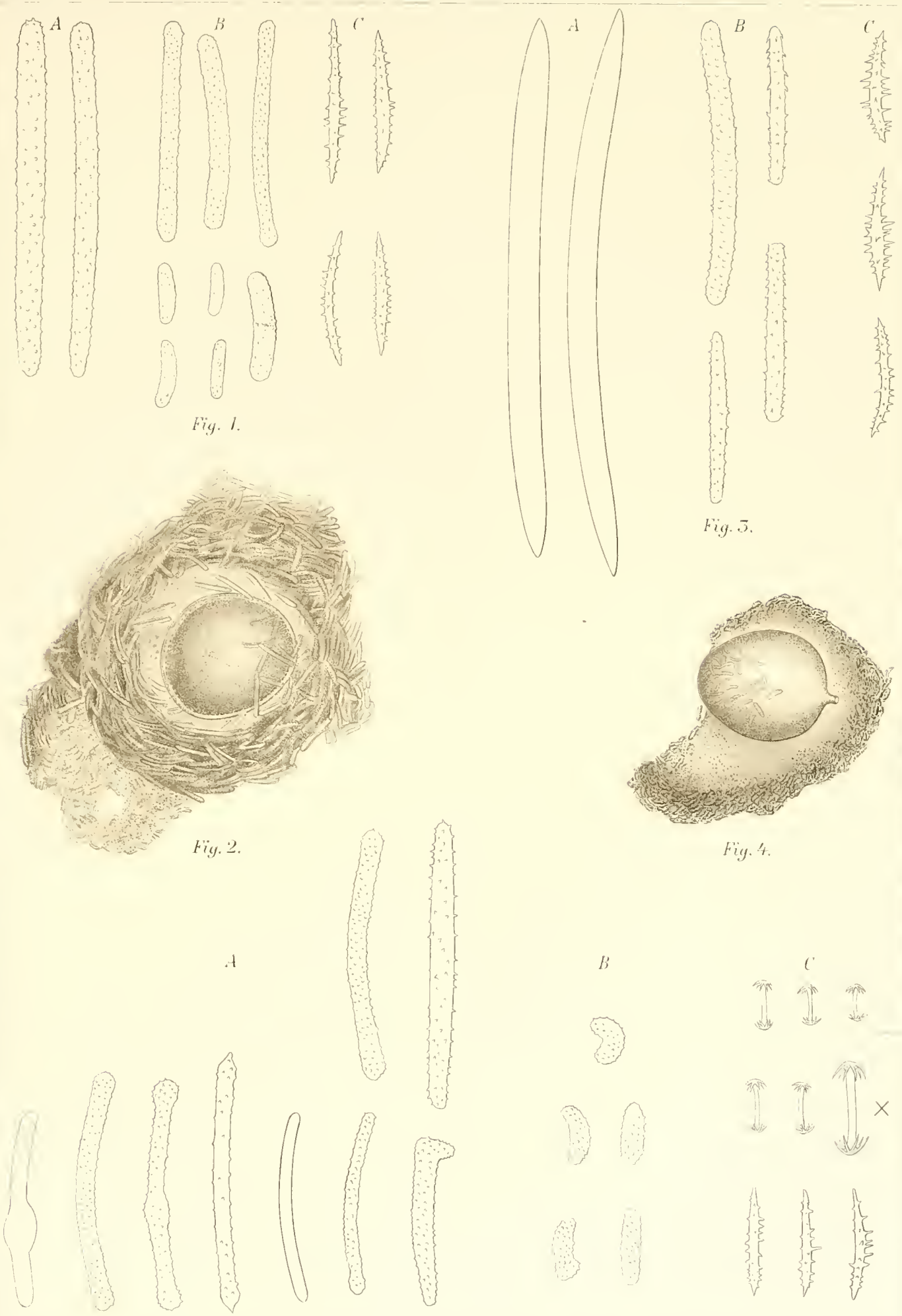

Fig. 't.
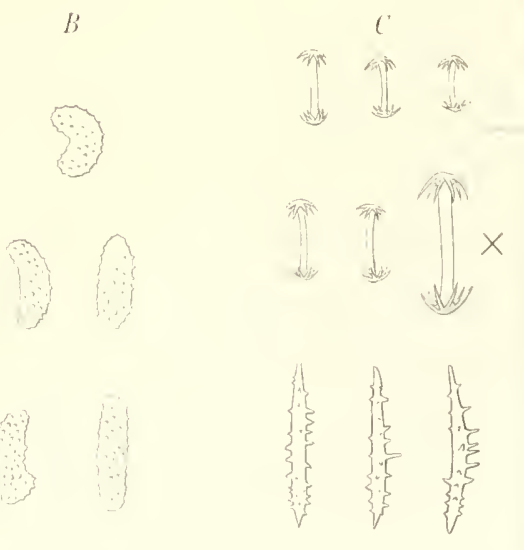

Fig. 5. 



\title{
Coleoptera VII: Staphylinidae
}

\author{
bearbeitet ron \\ Dr. Max Bernhauer, k. k. Notar \\ (Horn in Niederösterreich).
}



Tom Naturhistorischen Museum zu Hamburg wurde mir die Bearbeitung der ron Herrn Professor Dr. W. Mrcnaelsex auf der Hamburger deutsch-südwestafrikanischen studieureise 1911 gesammelten staphyliniden iibertragen. Ich gebe in nachstehenden eine Aufzählung der mitgebrachten Arten.

Diese Gelrgenheit wurde von mir benutzt, um auch einige andere in meiner sammlung befindlichen Arten aus dem südlichen Afrika in die Bearbeitung einzubeziehen.

\section{Tribus Oxytelini.}

\section{Bledius suboprens Bernh.}

Denkschr. med. naturw. Ges, Jena XIII, 1908, p. 104.

Fundangabe: Wio es scheint, eine ziemlich häufige Art, dis über Deutseh-siidwestafrika. Transvaal und Französisch-Kongo verbreitet ist.

\section{Bledius (Hesperophitus) Hichaetseni n. sp.}

Fundangabe: Deutseh-sï dwestafrika, Pinguin-Insel bei L ï deritzbucht; W. Michaelsex, 10. Juli 1911.

Dem Bledius tristis Avré sohr nahe verwandt, von demselben jodoch durch die Färbung und folgendo weitere Merkmale sicher versehieden:

Der Kopt besitzt zwischen den Fühlemwrzeln eine feins, aber scharf eingegrabene Querfurche, welche den ('lypeus vom Kopfe trennt, die Pubescenz ist deutlicher.

Der Halsschild ist viel größer, breiter und länger, so breit wie die Flügeldecken und nur mäßig breiter als lang, wenigor dicht und dadurch deutlicher punktiert, weniger matt, aber ziemlich dicht goldgolb behaart.

Die Flügeldecken sind viel kürzer, kaum länger als der Halsschild, weniger dicht punkticrt, weniger matt.

Der Hinterleib ist ebenfalls weniger dicht punktiert, glänzender.

Länge: $3 \mathrm{~mm}$. 
Der Kiifer wurde in zwei Stïcken aufgrofunden, von denen sich eines in der Sammlung des Natmhistorischen Museums zu Hamburg, das zweite in meiner eigenen Sammlung betindet.

\section{'Tribus Pinophilini. Oedichirus melammons Epp.}

Deutsche Ent. Zeitschr. 185\%, 1. 138.

Fundangabe: Deutsch-südwostafrika, Grob-okatjeru ins südlichon siandfeld, ca. $50 \mathrm{~km}$ s. von Waterberg: H. Thousex, 1912.

Sonst von Westafrika, den Kap-Verdeschen Inselu und Abessinien bekannt.

\section{dedichims densus ओ. sp.}

Fundangabe: Natal; von Herrn Baxa-HAAs rhalten.

Von allen ïbrigen mir bekannten Arten durch die gleichmäBige, dichte lomktiorung des ganzen Kïrpers leicht zu untorscheiden, auch durch verhälnismäbig kleine liestalt attsgezeichnet.

Hell rostrot, die Fühler und Taster rötlichgelb, die Beine blaßgelb.

Kopf viel schmäiler als dor Halssehild, wenig breiter als lang, mäßig wrob und ziemlich dicht punktiert, am Scheitel an einor stelle weitläntiger punktiert, linter den Augen fast parallel mit kurz verrundeten Hinterecken. Achläien so lang wie der Läingsdurchmesser der Augen. Fiihler viel kïrzer als bei puederims.

Halsschild im ersten Viertel am breitesten, daselbst fast so breit wie dis Flügeldecken, nach rïckwairts weniger stark verengt als bei poederimu, auf der hinteren Hälfte mit glänzendem Mittelkiel, sonst kräiftig und ziemlich dicht, ähnlich wie der Koyt punktiert.

Flïgeldecken selor kurz, fast nur rin I)rittel so lang wie der Halsschild, znsammen stark furer, ähnlich wie der Halsschild, jedoch dichter punktiert.

Der Hinterleib ist kraiftig und gleichmaißig dicht, am 7. und 8. Torgit feiner und weitlainfiger punktiert.

Läinge: $71 / 2 \mathrm{~mm}$.

Lin rinziges Stück in meiner Sammlung.

\section{Tribus Paederini. P'acderus opdeus Berinh.}

Denkschr. med. naturw. Ges. Jena XIII, 1908, 1. 10\%.

Fundangaben: Doutsch-sid westafrika, Nooloim, am Grobon 
Fischflu B, 16.-19. Juli 1911: Farm Paulinenhof, ca.-30 km O. von Windhuk, 18. Mai 1911; Us akos, April bis Juni 1911; TV. Mrchaelsex.

\section{Prederus luctuosus Klus.}

Monatsber. Berl. Ac. 1855 , p. 644 .

Fundangabe: Deutsch-siidwestafrika, Seoheim am GroBen Fischflub: W. Michaelsex, 16-_-19. Juli 1911.

Sonst von Kapland und II zambique bekannt.

\section{Pecderus fuscipes Curtis.}

Ent. Brit. $1828-1540$, p. $10 \mathrm{~s}$.

Fundangaben: Deutsch-Siidwrstafrika, Grootfontein; Wr. Micuselsex, 7.-11. Juni 1911; GruB-()katjexu im sïdlichen Sandfeld, (a. $50 \mathrm{~km}$ S. von Waterbore; H. 'Thomsex, 1912.

Kosmopolitisch.

\section{Paederus sabacus Er.}

Gen. Spec. Stap. 1839-1840. 1. 655.

Fundangabe: Deutsch-siidwestafika, Grootfontein: W. Mrсн.ELSEX, †.—11. Juni 1911.

Uber den größten Teil von Afrika verbreitet.

\section{I'cederus incogmitus 11. sp.}

Fundangabe: Ka pland, Algoa Bay: Dr. H. Brauxs.

Mehr als doppelt so groß wie eupensis Er., in dessen Nähe er zu stellen ist.

Auberdem ist die neue Art noch ron diesem in folgenden Punkten verschicden.

Der Kopt ist güber, breitre, hinten weniger vorengt, die Hinterecken in kürzerem Bogen vorundet, oben dichtel punktiert.

Der Halsschild ist rorn stark erweitert, nach rückwärts mehr verengt, dunkler rot, viel weitläniger punktiert, in den Dorsalreihen mit $5-6$ foinen Punkten.

Diø Flügeldeckrn sind nicht breiter als der Halsschild, viol weniger dicht als bei cupensis Er. punktiert.

Länge: $10 \frac{1}{2}-11 \frac{1}{2} \mathrm{~mm}$.

Ein Exemplar in meiner Sammlung. 


\section{Papderus biralusi 11. sp.}

Fundangabe: Ka pland, 11 go a liay: Dr. H. Bhauxs.

In die brevipennis-Gruppe gehïrig.

Etwas größer als brexipemis Lac, ganz von derselben Farbe, nur dir siehienen sind dunkel.

Der Kopf ist viel langer als bei der genamnten Art, fast krrisrund, so lang wie breit. Die Fühler sind riel länger und dïnner, alle Glieder wenigstens doppelt so lang wie brrit.

I) Halsschild ist viel länger, verkohrt eifürmig, um ein Virrtel länger als breit, feinor und weitliutiger punktiert.

Flïgeldecken sehr schmal, kiirzer als der Halsschild, aber viel längr' als bei hrevipunis Lac., viel dichter punktiert, ziemlich matt.

Länge : $71 / 2 \mathrm{~mm}$.

Kwoi Stücke in moiner Sammlung.

\section{Stiliens capirolu Sachse.}

Stett. Ent. Zeit. XIII, 1852, p. 145.

Fundangabe: De uts ch-siidwestafrika, Toufels bach, ca. 2.5 km SNO. Von Okahandja: W. Muchaesesen, 1. Juni 1911.

li a pland.

\section{Acanthoglosise intemmixta Epp.}

1)entsche Ent. Zeitschr. 1885 , p. 134.

Fundangabe: Deutsch-Sï dwestafrika, Omaruru, 21..2-2. Juni 1911: Okahandja, 27.-28. April 1911; W. Mhraelsex.

(ioldkiiste.

\section{Acarthoghlossa Dereeti n. sp.}

Fundangabe: Oranjo-Kolonie, Botharilln: H. Brauxs (rin einziges stiirk).

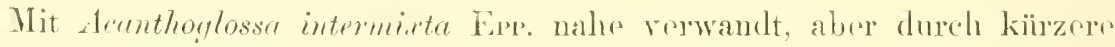
und breitere Gestalt des Koptes, des Halsweliddes und der Flïgeldeckon verschieden.

liostrot mit gelben Fiihlem und Beinen.

Kopf so breit wie der Halsschild, hintrer drun Angen tast parallelseitie, um rin Viortel broiter als lang, kriiftig und dicht punktiert.

Halsschild viel schmäler als dir Flïgoldecken, um ein 1)rittel breiter als lang, manh riarkwäits gradlinig verengt, wruiger stark, abor viel dichter als der kopef punktiert, vor dom Hintrerande mit oiner gurereihe von 4 l'unkteriibchron. 
Flïgeldecken um die Hälfte länger als der Halsschild, fein und dicht punktiert und mit einer größeren Zahl von kräftigen, ungleichmäßig verteilten, hier und da in Reihen angeordneten Punkten besetzt.

Hinterleib sehr fein und iuberst dicht punktiert.

Länge: fast $3 \mathrm{~mm}$.

\section{Lathrobium cafium Boh.}

Ins. Cafr. I. 1848, p. 285.

Fundangabe: Deutsch-siidwestafrika, Grob-okatjeru im südlichen SSandfeld, ca. $50 \mathrm{~km}$ S. von Waterberg: H. Thomsex, 1912.

Cber das tropische Afrika und einen groben Teil des Indomalayischen Gebiets weit verbreitet.

\section{Gen. Perierpon n. gen.}

Eine in ihrer Stellung etwas zweifelhafte Gattung. In der Bildung der Zunge hat dieselbe unverkennbare Ahnlichkeit mit Medon, in der Bildung der Oberlippe und auch in der allgemeinen Körpergestalt nit Lathrobium, durch die Bildung der Hintertarsen mit Scimbulium. Ich glaube die Gattung am besten zwischen Medon und Lathrobium einreihen zu sollen.

Körper gestreckt. Kopf schmäler als der Halsschild, hinten sehr stark eingeschnürt, der Hals fast nur ein Viertel so breit wie der Kopf. Kehlnähte auf der Unterseite nicht vorhanden.

Oberlippe quer, vorn ausgerandet, ungezähnt.

Ki efer krättig, sichelfärmig, der eine mit vier Zähnen in der Mitte des Innenrandes, von denen die beiden mittleren kleiner sind, der andere mit drei ziemlich gleichgebildoten Zähnen. AuBrnlade der Maxillen ähnlich wis bei Lithocharis, kurz, fast breiter als lang, an der spitze dicht bewimpert. Die Innenlade ist viel größer, breiter und länger, der ganzen Länge nach dicht mit langen Haaren besetzt.

Kiefertaster viergliedrig, das 1 . Hlicd sehr klein, das 2. lang gestreckt, etwas gekrïnmt, das 3. wonig länger als das 2., gegen die Spitzo mäßig verdickt, lang gestreckt, das Endglied äußerst klein, pfriemenförmig, ungefähr ein Achtel so lang wie das rorletzte.

Zunge wie bei Medon in zwei häutige, voneinander weit getrennte häutige Lappen geteilt, zwischen denselben dicht bewimpert. Die Paraglossen ïberragen die Zungenlappen beträchtlich und sind innen dicht behaart.

Lippentaster dreigliedrig, das 2. Glied doppelt so lang wie das an der spitze erweiterte 1. Glied, keulig rerdickt, das Eudglied sehr selmal, pfriemenfïrmig, ein Drittel so lang wie das vorhergehende. 
Halsschild länglich, die obere Seitenrandlinie ist in der Mitte stark auf die Unterseite herabgrbogen, sodaß die Torderecken weit ibrer diese Randlinie vorgezogen sind; die untere Seitenrandlinie ist rudimentär, Epimeren der Vorderbrust stark entwickelt und mit den Epipleuren ohne Unterbrochnng rerbunden.

Vorderbrust ror den Vorderhïften endigend, in der Mittellinie scharf gekielt.

Mittelbrust kurz, der spitzwinkelige Fortsatz zwischen den Mittelhiiften nur bis zu einem Viertel derselben eintrotend, die Hüften ganz aneinander geriickt.

Hintreloils an der Wurzel gekielt.

B e in e mäbig lang, die Vordertarsen in beiden Geschlechtern einfach, an den Hintertarsen das erste Glied viel länger ak das zweito, das Endglied so lang wie dir beiden vorhergehrnden zusammengenommon.

Div Gattung ist bisher nur durch die folgende Art in Afrika vertreten.

Iber die Lebenswrise ist nichts Genanes bekannt. Fines der ostafrikanisclen Stücke (Kaguru) wurde an rinem Bachufer gofangen.

\section{Perievon Hewitti u. sp.}

Fundangaben: Siid afrika (der nähere Fundort konnte leider nicht entziffert werden): Hewrt.

Deutsch-Ostafika, Utzungwe-Bergo, 1500-1600 m, November 1912; K ondoa-Irangi, Iai 1909; Kaguru, Mai 1909; Geh. lingierungsrat MrTuxer.

Abrssinien, Lmgebung ron Harrar; Kristexsex.

Pechschwarz, der Hintrrand der Flïgoldecken zienlich breit, die

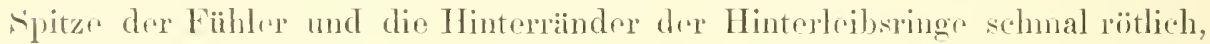
die beine rïtlichgells.

Kopf um ein gutes Stïrk shomäiler als der Halsschild, oblong: nit

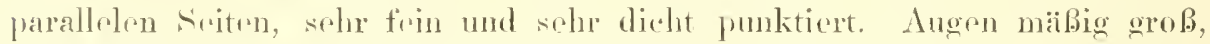
dir schläfen hintre drenselben fast dreimal so lang wie der von oben sichtloare Augenlängsdurelumesser. Fïhler schnurtörung, gogen dir spitze kaum verdickt, die vorletzten Ciliuder fast lainger als breit.

Malsschild wenig schmälor als dir Fliigeldreken, um rin Viertel länger als broit, nach vorn schwach verengt, mit gradlinigen seiten, äBorst fein

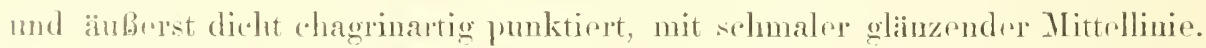

Fliggoldecken wonig länger als dor Halssehild, mäbig foin und äuberst dicht runzelig junktiert, zu anmen viol längre als breit, mit parallelen seiten. 
Hinterleib äußerst foin und äuferst dicht chagrinartig punktiert und dicht grau seidenschimmernd pubescent.

Länge : $5^{1}, 2-61^{1 / 2} \mathrm{~mm}$.

Beim $\sigma$ ist das 5. Sternit breit. mäbig tiof. im Grunde gerundet ausgeschnitten, das t. ist anf dem gröBten Teil des Hinterrandes mit äuberst kurzen, starren, glänzenden, tiefschwarzen Borsten äuberst dicht besetzt.

\section{Tribus Staphylinini. Philonthes samgnimens Faur.}

Rer. d'Eutom. NXYI, 1907, p. 46.

Fundangabe: 1) e uts (ch-sii d westafrika, () kahandja; Dr. G. Fock, 11. Sorember 1909.

sonst ron D,utsch-und Britisch-0stafrika bekannt.

\section{I'leilomthus turbidus Er.}

Gen. Spec. Staph. 1839-1840, p. $4 \$ 4$.

Fundangabe: Deutscl -sii d westafrika, Gro b-okatjeru imsii dlichen siandfeld, ca. $50 \mathrm{~km}$ S. ron Waterberg: H. Thomsex, 1912.

Cber den gröbten Teil ron Afrika, Srrien, Siid-Rubland und die Hawai-Insoln verbreitet.

\section{Plilonthus quisquiliarius (iyll.}

Ins, suec. II. 1S10, p. 335.

Fundangabe: 1) rutsch-sï dwestafrika, (trob-okatjeruims iud lichen sandfeld, ca. $50 \mathrm{~km}$ s. ron Waturberg: H. Thumsex, 1912.

Hosmopolitisch.

\section{Philonthus cafjer. Boh.}

Ins. Caffr. I, 1848, p. 280.

Fundangabe: Dentsch-sïdwestafrika, Grob-Okatjeru imsïdlichen S̈andfeld, aa. $50 \mathrm{~km}$ s. ron Taterberg: H. Thowsex, 1912: Farm Paulinenhof, ea. $30 \mathrm{~km} \mathrm{O.} \mathrm{ron} \mathrm{Windhuk,} \mathrm{18.} \mathrm{Mai} \mathrm{1911:} \mathrm{Ls} \mathrm{a-}$ kos, 22. April bis 22. Juli 1911: Okahandja, 227.-2.8. April 1911: II. Michaelsex.

Bekannt ron sïdafika und Britiscli-Ostafika.

\section{Imilonthus mifescens in. sp.}

Fundangabe: Kapland, Umgebung ton K a pstadt: Dr. H. Bracxs. 
Von langgestreckter, gleichbreiter Gestalt, in die Grmpe des quisyuiliurius Grus. gehörig, dmreh die Gestalt des Kopfos, vierpunktige Dorsalreihen des Halsschildes, lange Flügeldecken und sehr dicht punktierten und sche dicht graugelb behaarten Hinterleib leicht zu erkennen.

In der Ciestalt ist die Art gewisenn Molicaon-Arten (indirus Kr.) nieht mnähulich.

Einfarbig bramurot.

Kop, schmäler als der Halsschild, so lang wie breit, nach rïckwärts rrweitert, nit stmmpf verrumdeten Hinterecken, zwischen den Augen mit riner Pnerreile von 4, einander paarweise genäherten Punkten, hinter den Augen bis zur Halseinschnuirung mit einer grögeren Anzahl ungleicher Punkte. Augen klein, ilır Liingsdurclmmesser ein Drittel so lang wie die Solläten hinter denselben. Fühler kurz, die mittleren bis vorletzten Glieder stark quer.

Halsschild so breit wie die Flïgeldecken, etwas länger als breit, mit parallelen Seiten, in den Dorsalpeihen wit vior voneinander ziemlich gleichwrit rutferntru Punkten. Ton den fïnf Sritenpunkten stehen die inneren zwri in riner zur Dorsalreihe sehr stark nach hinten divergierenden Linie.

Flïgeldecken vicl linger wie der Halsschild, schmal, 1 m ein Viertel länger als zusammen breit, ziemlich kräftig und ziemlich diclit punktiert, am Hinterrand mit einem dichten wribgelben Haarsaum.

Hinterleib gleichbreit, matt, fein und selur dicht punktiert.

Das orste Gliod der kurzen, dicken Hintertareen wrong länger als das Endglied.

Läıge: $12 \mathrm{~mm}$.

lin vinziges of in meiner Sammlung.

\section{'Tribus Myrmedoniini. Zylus cicutuicosus Bernh. var.}

Ann. Mus. Hung. 1915.

Fundangabe: Deutsch-küdwestafrika, ()kahaudja: 1)r. (i. Fork, 190 \%.

Fomst von Abrsinion bekannt.

\section{Z!!rus Kristruseni Bernh.}

1. c.

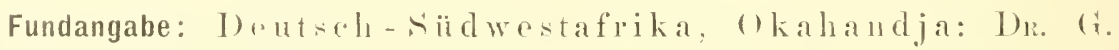
Fin, 1 !)(1).

sonst ron $A$ bessinien und Erytleaca bekannt. 


\section{Zyura lucemus Bernl.}

1. c.

Fundangabe: Deutsch - Siidwestafrika, Okahandja: Dr. G. Fock, 1909.

Sonst ron Deutseh-Ustafrika bekannt.

\section{Zymas pharmomenalis Beruh.}

l. c.

Fundangabe: Deutsch-siidwestafrika, Okahandja: 1)k. (i. Fock, 1909.

Sonst von Deutsch-()stafrika bekannt.

\section{Porus Tougicollis Faur.}

Rev. d'Entom. 1899, p. 37.

Fundangabe: Deutscli-siadwestaf rika, Ka ribib: W. Henaedsex, 23.-26. April 1911 .

Ton Si dafrika bekannt.

\section{Tribus Aleochamini. Aleochara renticulata Motseh.}

Bull. Nosc. 1855, III, p. 22:8.

Fundangabe: Drutsel-sii westafrika, Tsumeb; M. Mrchaelsex, 13.-19. Juni 1911.

Fonst ron Ostiudien, Sumatra, Deutsch-Ostafrika. Abessinien. Senegal, Kongu und Angola bekannt. 



\section{Reptilia und Amphibia ron}

Fr. Werner (Mien).

Mit 1 Tafel und 1 Abbildung im Text. 

Das schöne Material, welches dieser Arbeit zugrunde liegt, ist der Hauptsache nach ein Teil der Ausbeute der „Hamburger deutsch-sii dwestafrikanischen Situdienreise 1911 ”, gesammelt von Herrn Prof. IV. Michaedsex und, auf dessen Anregung, von Frounden seiner wissenschaftlichen Bestrebungen. Dazu kommen noch einige kleinere Ausbeuten, die dem Naturhistorischen Juseum zu Hamburg direkt überwiesen sind. Eine vollständige Liste der verschiedenen Sammler folgt untrn.

Das ganze, mir von Herrn Prof. Muraelsex freundlichst zur Bearbeitung ïbergebene Material umfaßt 4 Arten von Schildkrïten. 35 Eidechsen, 2 Chamaeleons, 26 sehlangen und 9 Batrachier. Von diesen sind Pachyductylus Weberi und Brunnthaleri, Eremias lineo-ocellata und inomata, sepsina angolensis, sowie der schöne Python anchietae neu für Dentsch-Südwestafirika, außerdem konnte eine neue Gattung und Art von Schlangen beschrieben werden. Von den 9 Batrachiern sind drei neu für das frebiet, davon zwei der Gattung Pyricephalus angehörig ( $P$. natalensis und Rudili). Von diesen vorstrhenden Arten sind die meisten bisher nur aus siudafrika, Sepsina angolensis und Python anchietae nur aus Angola (Bengurlla bekannt gowesen. Auber diesen Arten waren in der reichen Kollektion von Leoshanu śchutuz nicht vertreten: Testudo Smithii, Typhlops muruso, Glauconia labialis, Prosymna Bergeri, Tarboplis semianmulatus, Trimesorhims tritaeniatus, Psammophis trigrammus, Leightoni und brevirostris, Thelotornis Kirtlandi. Pachydactylus Brunnthaleri war damals noch nicht von mir unterschieden, sondern als $P$. ocellatus aufgeführt, diese letztere Art dürtte in Deutsch-siidwestafrika iiberhaupt fehlen.

Seit dem Erscheinen meiner Arbeit ist durch Nienex und STExxem eine Reihe von Arten neu für Deutsch-siidwestafrika nachgewiesen worden, so von Nieuex Xenocalamus Mechowii Ptrs, Monopeltis colobura, Ciasina sentgalensis und der neue, auch in vorliegender sammlung vertretene Arthrolepti: Sehebeni, von STERxpedo Typhlops mucruso (gleichfalls hier rertreten), implorhinus nototaenia, Psammophis Bocagii, trigrammus, hrevirostris, Thelotornis Kirtlandi (die drei letztgenannten ebenfalls in dor Koll. Michaelsex), Aparallactus Jïbberti n. sp., Elaperhis Decosteri und Tendraspic angusticeps. 
Eine sehr gute Zusammonstellung der Sehlangen von Südwestafika

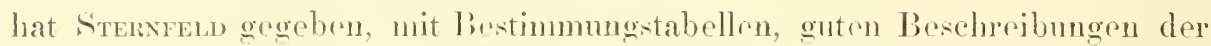
Gatmngen und Artru, genanen Fundortsangaben und liologicchen Bemerkungen, sowie grobentrils gnton, teilweise sogar ausgezeichneten Abbildumgrn. Dab "r in rinem Wreke, das nicht nur den gegenwärtigen Zustand

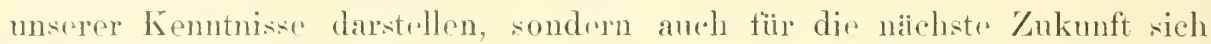
at. nützlich erweisen soll. anch Arten aus den Nachbargebieten anfgenommen hat, ist gewif borechtigt: in der srstematischen [borsicht iiber die schlangen Dontseh-sïdwestafrikas (p. t.2-43) sollten aber num dir bisher wirklich aufoefundenen Arten vorkommen. und daher sind jetzt $1 \mathrm{~m}$ mindesten 20 Arten zu viel in diesem Torzeichnis von 73 Arten! Jaß man bei der Aufuahner von Arten, dir in angrenzenden Gebieten vorkommen, in ein Fannenverzoichni, oft ganz im lunklen tappen kam, simt man gleich dalans, dab Python anchietue darin fohlt: nan mïBte konsequonterweise alle Schlangen von Angola, der südafikanischen Union und Portugiesisch-süd-

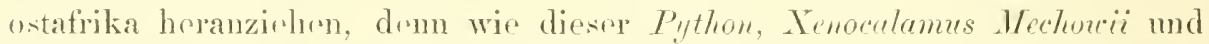
Elapeches J pecosteri kïnnten natürlich theoretisch noch alle wöglichen Arten dirser Liander in linbiete gefunden werden. Duch bezweitle ich

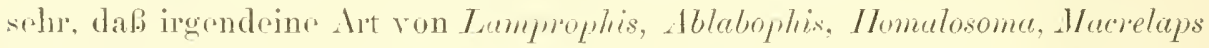
oder Cuesus noch in l)entoch-sïdwestafika angotroften werden wird: eben-

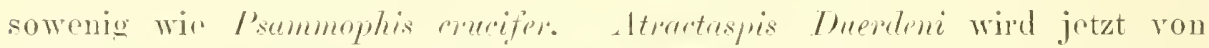
Hewrte zu A. Bibromi gezogen, ist also als brsondere Art auszuscheiden.

\section{Verzeichnis der Sammler des nachstehend bearbeiteten Materials:}

BatmgarT, 1)r. med. (Lïderitzbucht!

Benrexus, Proviantantsmeistre (Sephrim).

Buscn, Bankberamter (Windhuk).

Fock, Dr. med. G. (Ckahandja, Farm Neitsas bei (irootfontein).

Guver, Kanfmann (lkahandja).

Gregrtr, Farmer Frarm Nondammi).

Hentyx, Lehror (Swakopmund; Nwakoprivior).

Hulemaxx, Fil., Hauslorerin (Farm Paulinenhof).

Jacoвs, Dr. med. (Nwakopmund, Sandfeld).

KLEIN, Kaufmann (Nwakopmund).

Kraner, Walter (Bahnstreke bei Keetmanshoop).

Lixкехвеix (Grootfontein; sandfeld).

Maxger, C.. Gehithingenieur (Lüderitzbncht, Swakopmund). 
Matoscir, Apotheker (Omaruru).

Michaelsex, Pruf. IV. (Nord-; Mittel- und Süd-Gebiete).

Müller, O. E. (Ababis, Swakopmund).

Raxge, Dr. P., Dircktor der Bohrkolonne (Kuibis).

Rudxo-Rudzixiki, Max r., Farmer (Farm Okapehuri bei Okasise).

Thomsex, Haxs, Referendar (Gerab-Revier).

WEgelebex, K., Gerichtssekretïr (Rohoboth).

W utтke, Gerichtssekretär (Windhuk).

v. Zastrow, Bezirkisamtmann (1)kawango; Nördl. Sandfold).

\section{Alphabethisches Verzeichnis der Fundorte:}

Ababis (O. MüLLER).

Asis, zwischen Otavi und Grootfontoin (W. Mrchaelsex).

Brackwater, $20 \mathrm{~km}$ N. von Windhuk (W. Mrchaelsex).

Farm Neitsas, Bez. Grootfontein (G. Fork).

" Noudamm, $42 \mathrm{~km}$ (NO), ron Windhuk (W. Michaelsex, (irRGOR.

. Okapehuri bei Okavise (Max v. himpu-Ruzixasi).

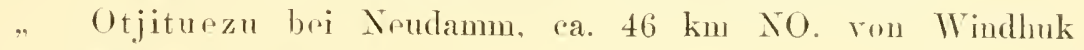
(IT. MICHAELAE).

. Pantinentof an den Ausbergen, $36 \mathrm{~km}$ (1) von Windhuk (Frt. Hillemaxy, W. Michaelsex).

"Voigtsland an den Bismarck-Bergen, $38 \mathrm{~km}$ (). ron Windhuk (II. Michaelsex).

Geiab-Rivier bei Stolzenfels, s. und O. der Harras-Berge (HAXS THOM:EN).

Grootfontein (Luxkexbein, W. Humalisex).

Karibib (W. MHALAELEN.

Kretmanshoop, Bahnstrecke bei (Walter Kramer).

Kuibis (P. Raxge).

Lü deritzbucht (W. Michaelsex, C. Maxger, Padmgart).

Neitsas, Farm (soben).

Xoudamm, Farm (s. oben).

Okah andja, G. Fock, W. Mremansex, Gaubr).

()kapohuri. Earm (s. oben).

(Okawango, zwischen $199^{\circ}$ und 210 30' ïstl. Lg. (v. Zastrow).

Omaruru (W. Michanesex, Matusch .

Osona bei (Kahandja (W. Mrehaelasex). 
Otjituezu, Farm s. oberu).

Paulinenhof, Farm (s. oben).

Pinguin-Insel bei Liideritzbucht W. Minhalsex).

Rilloboth (K. Wegelerex).

Siandfeld, $60 \mathrm{~km}$ SO. von Grootfontein (Haxs T'Hoxisex). nördl., zwischen Löwen-()muramba und (Owangowa-Veldt (v. Kastrow).

Scelleim (W. Michaelsex, Behrenis).

siraknpmund (JACos).

Swakop-Rivierzw. Nonidas und Cioanikontas (Herlys).

Trufelsbach, $25 \mathrm{~km} S \mathrm{~s}($ ). von (Kahandja (W. Michaelsex).

T's u m e b (W. MichaElsex).

Usakos (W. Michaelsex).

Voigtsland, Farm ( $\therefore$ oben).

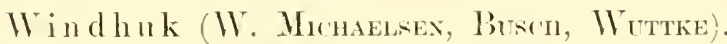

\section{Literatur.}

Bis 1909 ist die Literatur ïber Deutsch-siidwestafrika in meiner Bearbeitung :

Werver, Fr., Reptilia und Amphibia: in: Scuultze, L., Koologische und anthropologische Ergebnisse riner Forschungseise in westlichen und zentralen Südafrika, ausgeführt in den Jahren 1903-1905, 4. Band, 1910; in: Denkschr. Jena, X $V^{+} I$, p. 279-370, Taf. VI-XI und 15 Fig. im Text angrgeben. (Diese Arbeit ist als WERxer, SF. citiort.) seither ist noch arschienen :

Boulenger, G. A., A Revised List of the Fouth African Reptilos and Batrachians with Synoptic Tables, Special References to the Speciurens in tho south African Museum, and Descriptions of Now Species, I; in: Ann. South African Mus., Vol. V, Part IX, Nr. 16, 1910, p. 455-538.

Hеwiтt, J., Description of a New Snake, Prosymna transvaalensis, from tho Transval: in: Ann. Transval Mus., Vol. II, 1910, p. 73.

- A key to the South African Spereies of Geckonidar. Scincidae, Gerrhosauridae, and Lacertidar, together with some Notes on the specitic characters and a Brief Summary of the Known Facts of their Distribution; in: Anu. Transval Mlus., Vol. I1, 1910, p. 77-115.

- Lifeords of South African Lacertilia and Amphibia. Addenda and Corrigenda; in: Ann. Transval Mus., Tol. III, 1911. 1. 42-55. 
Hewrt, J., Notes on the Specific characters and distribution of some South African Ophidia and Batrachia: in: Rec. Albany Mus., Vol. 2, Nr. 4, 1912, p. $264-281$.

- A Key to the species of the south African Batrachia together with some notes on the specific characters and a Synopsis of the Known facts of their distribution: in: Rec. Albany Mus., Tol. 2, Pt.3, p. $189-228$.

Hewrt, John \& Pace A. Methuex, Descriptions of some New Patrachia and Lacertilia from south Africa: in: Trans. R. Soc.s. Africa. Vol. III, Pt. I, 1913, p. 107-111, Taf. III.

Hewitt, Johx \& J. H. Power, A List of South African Lacertilia Ophidia and Batrachia in the Mc. Gregor Museum, Kimberley, with Field Notes on Various Species; in: Trans. R. Soc. S. Africa, Vol. III, Part I, 1913, p. $147-176$.

Hewitr, J., Description of Heleophryne natalensis, a new Batrachian from Natal and Notes an Several South African Patrachians and Reptiles; in: Ann. Natal Mus., Vol. II, ץ. 475-486, Taf. XXXTX.

Methuex, Parl \& Jonx Hewrt, Records and Doseriptions of the Reptilia and Batrachia. In: The Perey Sladin Memorial Expedition to Great Namaqualand 1912-1913; in: Ann. Transval MIns. Vol.IV, 1914, p. 118-145, Taf. XN, Textfig. $14-16$.

Cuube, E. C., The Batrachians and Reptiles of Matabrleland; in: Proc. Zool. Soc. London, 1910 , p. 590-597.

Nienex, Fritz, Herpetologisch-Neues aus Dentsch-südwestafrika; in: SB. Ges. naturf. Fr. Berlin, 1913, p. 449-452.

Laype, Ev.. Erster Nachtrag zum Katalog der Reptilien- und AmphibienSammlung des Naturhistorischen Museums der Stadt Wiesbaden; in: Jahrb. Nassau. Ver. f. Naturk. Wiesbaden, 64.Jahrg., 1911, p. $137-236$.

Peracca, Rettili racolti nel Alto Zambese (Barotseland) del sig. Luigi Jalla: in: Poll. Mus. Zuol. Torino, Vol. XXV, 1910, Nr. 624, p. 1-6.

Siebexrock, Fr., Schildkröten aus sid- und südwestafrika, gesammelt ron Dr. R. Päch und J. Brunnthaler: in: sB. Ak. Wiss. Wien. Bd. CXIX, 1910 , p. 693-720, Taf. I-IV, 2 Textfig.

Sterxéto, R., Die Schlangen Deutsch-Südwestafrikas; in: Dis Fauna der deutschen Kolonien, Reihe IV, Heft 1, Berlin, 1910, p. I- IV, 1-45, 1 Karte, 50 Textfigg.

- Zur Schlangenfauna Deutsch-südwestafrikas: in: Mitt. \%ool. Mus. Berlin, T. Band, 1910, p. 53-60, 6 Texttig. 


\section{REPTILIA. \\ 'Testudinati (Chelonia). \\ Testudinidae. \\ Testudo L. \\ Tresturlo pardalis Bell.}

Siemenrock, Zool. Jahrb., Suppl. 10, 1909, 1.522. - Werker, SF., p.800. - Lampe, p. 146.

Fundangaben: Farm Neudamm, ca. $42 \mathrm{~km}$ ONO. ron Windluk: Gregok. (1 o Panzer, Länge 155, Breite 130 mmi).

Omarurn; IV. Mnchessex, 21.-22. VI. 1911. (1 ㅇ in Alkohol, Panzerlänge 195, Breite 150 mms).

Wird von LAsne fiir Rietmond, Windhuk und Gibeon erwähnt.

Bemerkungen: \&: Rïckenpanzer dicht, Bauchpanzer schr wenig gefleckt. Vorderrand des Plastrons solur stumpfwinklig ausgeschnitten.

o: Flecken der Lnterseite mehr strichelfömig, Vorder-Lappen des Plastrons mehr nach aufwäts gebogen, mit stark nach abwïts gewulstetem Vorderrand der Gularia. Fehale im allgemeinen schlanker.

\section{Testudo Iemoxii Smith.}

Siebexrock, 10.525. - Werner, SF., p. 302. - LaMpe, P. 146.

Fundangaber: Kll ibis; P'. Raxge.

Nach Lanpe boi Aus gefundin.

Bemerkungen: Winkw zwischen Costalen und Marginalen sehr deutlich. supracaudale sehr dick, ohms Längsfurche. Aubenecke des Anale berïhrt nicht das Marginale vor dem Supracandale. Seitliche Marginalia olone Laingsfurchr. Vertebralia ziemlich deutlich häkkrig rorepringend. Gularia ungleich grob (linkos griiber). - Vererïberte Tuberkeln an Vordereande des Lntrer-

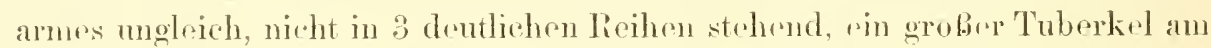
Hinterande des Obrechenkels. - Radien 7-s breite, anlbe, (einfarbig), schwarze Radien michen otwas in die Areolen himein.

\section{Testude Sillithii Blngr.}

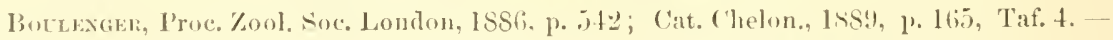

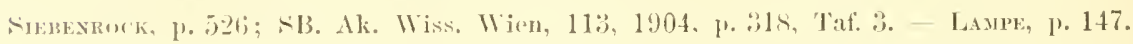

Fundangabe: Kuibis: P'. Raxge (f l'anzor, l'lastronlingo los mm, ('arajax $1: 30$ laug, y+ breit.) 
Diese Art war in der Coll. Srmultze nicht vertreten, wird aber von Laupe von Aus erwähnt.

Bemerkungen: Vorderrand sehr schwach, Hinterrand wenig deutlicher gesägt. S'eitliche Marginalia bilden mit den angrenzenden Costalen keinen Winkel: 1. Costale nicht wesentlich grüBer als das 4.: links 2, rechts 3 Axillaria.

Carapax braun, Areolen gelbrot, am Rande schwarz gefleckt. Radien gelb oder gelbrot, dazwischen schwarze Flecken; im allgemeinen ist die Zeichmung sehr undeutlich.

Verschieden von Boettgeri durch: Färbung: Vertelsralgegend nicht flach von Ferrorii: Seitliche Maroinalia bilden mit den Costalen keinen Winkel.

Fïr die freundliche Hilfeleistung bei der Bestimmung dieser und der vorhergehenden Art bin ich unserem ausgezeichneten Schildkrötenkenner Hern Kustos F. Sieberrock sehr zu Dauk verptlichtet.

\section{Testudo angulata Schweigg.}

Siebexrock, p. 543. - Wrexer, SF., p. 305.

Fundangabe: K uibis: P. Raxge, 1 \& Panzor, $101 \mathrm{~mm}$ lang: Vorderlappen des Plastrons fehlt, da die Schale wohl als Buchu-Täschchen gedient hat).

Bemerkungen: Unterseite des 3. (links auf das 4.) Marginale mit schwarzen dreieckigen Flecken: ebenso auch 9.-11. Marginale. Briicke und seitenränder des Plastrons gelb, dieses sonst schwarzbraun.

\section{Lacertilia. Geckonidae. Palmatoger.ko Anderss. Palmatogerlio Iiangei Inderss.}

Axderssox, in: Jahrb. Naturk. Wiesbaden, Bd. LXI, p. 299.

syndactylosaura schultzer, WerNer, sF., p. 306, Taf. VI, Fig. 3, 3a-c.

Fundangabe: Deutsch-sitdwestafrika: Hrgienisches Institut zu Hamburg.

Liideritzbucht, ca. $12 \mathrm{~km}$ N. von der stadt. im Saude der Dïnen: A. K. Lmunax (nach brioflicher Mitteilung, begleitet von einer farbigen skizze [Texttig.] nach dem lebenden Tier).

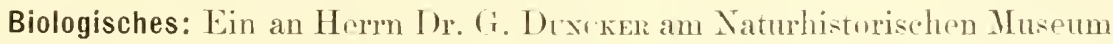
zu Hamburg gerichtetes schreiben des Herm A. R. Lummsx in Lideritzbucht enthält sehr wertyolle, von einer Farbenskizze begleitete Mittrihungen iiber das Aussohen des lobenden Tieres und über seine Lebensweise.

Ich lasse den auf Palmatogecko Rangei beziiglichen Twil jenes Schreibens 
hier im Wortlaut folgen und füge auch eine verkleinerte autotypische Nachbildung jener Farbenskizze (siehe Textfigur!) ein. Das schreiben lautet: "Am Norgen cines Sonntags Anfang 1910 fiel mir die Scharrstelle eines Jakals in einer Sanddüne ea. $12 \mathrm{~km}$ nördlich von Lüderitzbucht am Dünenrande auf. Als rifriger Naturfreund und Sammler grub ich vorsichtig in dem weichen Flug- und Dünensande nach und legte eine kleine Höhlo frei, in der zusammengrollt eine Art Eidechse lag. Bei meiner Beriihrung sprang diese schnell auf und nahm die auf dem Pilde wiedergegebene Kampfstellung ein, wobei sio wiegend den lï̈rper vor und zurück bewegte, dabei schnappende und zischende Laute vou sich gebend. Irh verhielt mich einige Keit ruhig. Das Tier beruhigte sich nun und fing daun an, sich mit don VorderfüBon schnell in den Fand cinzugraben, während die Hintrertiße den Sand weiter zuriekselsoben.

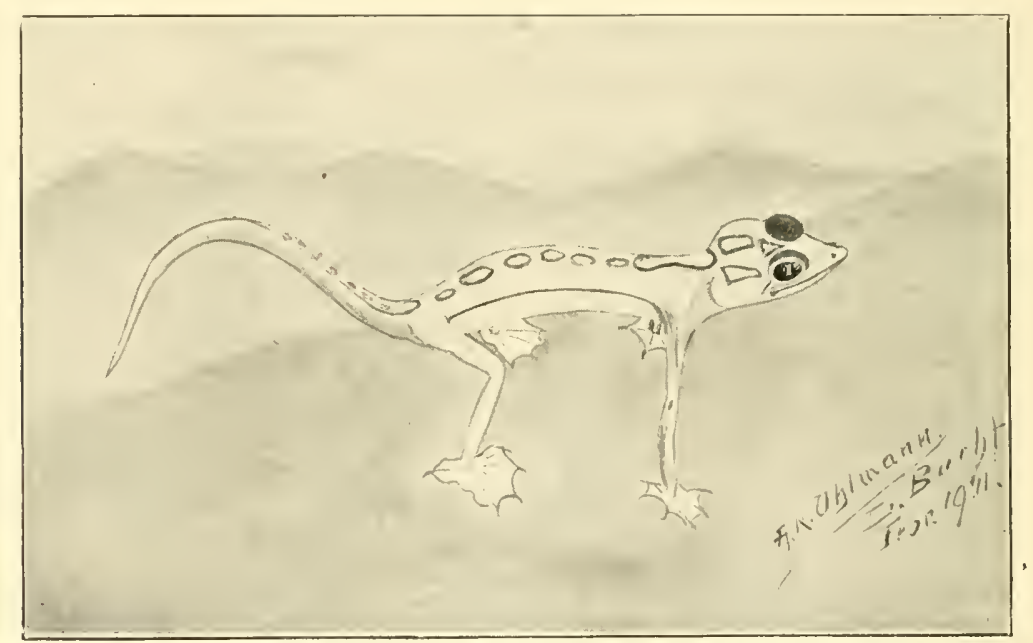

T'ulmatogecho Rangei Axiness., nach dem leben gez. ron A. R. Umbmax.

Die \%ehen der Fibe sind mit lirallen versohen, und zwischen den Zehen befindet sich eine Art Fichwimmbant, die zum Schutze gegen das Einsinken in den wrehen Dïnensand dient.

Jas Aussehen dos lobenden Tieres ist wir folgt: Am Banch gelblich weib, an dem ïbrigen Körper stumpf hell violett, \%eichnmgen auf liicken, Kopt und schwanz bräunlich; der ganze Körper durchscheinend: Augen schwarz, Pupille länglicle, in dor Mitte weib, oben und unten rot, in der Mittellinie an schwarz'r Schlitz, Angenlider (Ummandung) woilb, die Hüllen iiber den Angen bläulich schimmornd. Nase spitz, rote Naslïeher. 
Das Tier komnt nur nachts zum Torschein und wird dann sehr lebhaft; ich kounte es daher beim Fange von Fliegen, kleinen schmetterlingen und Würmern beobachten. Die eigenartige Kampifstelhung, das schankeln des Körpers und der hochgohaltene, gekrümmte Fchwanz, das schnolle Zuschnappen und Zischen kann ängstliche Zuschauer sehr erschrecken; nur der Naturfreund findet eigenartigen Reiz bei Beobachtung des Tieres". . .

gez. A. R. UHLmaxi.

Bemerkungen: War schon nach Körperform und Beschuppung diesem merkwürdigen Gecko suine systematische Stellung in der Nähe der paläarktischen Wüstenformen Stenolactylus und Crossobanon anzuweisen, so ist es nach den Beobachtungen und der Skizze des Herm Unums nummehr ganz zweifellos, daß diese Einordnung richtig sein muß. Wenn wir von den ,Sandschwimmhäuten" des Palmutogecko absehen, so ist dieses 'Tier in der Haltung der Beine und des Fichwanzes ein echter Stenodactylus und besonders dem St. Petrii Axuers. tauschend ähnlich. Wenngleich natürlich die Anpassung an gleiche Lebensverhälnisse auch gleichartige Wirkungen auf den Organismus herrorl'uft, so kann doch rine so verblüffende ethologische Tbereinstimmung, wie sie aus Schilderung und Abbildung hervorgeht, nur der Ausdruck einer nahen Blutsverwandtrehaft soin. (Tergl. Brens's Tierleben, Bd. T, 1913, p. 11, Taf.)

\section{Pachydactylus Wiegm.}

\section{Pachegdactylus Bibromii Smith.}

Boclexger, Cat. Liz. I, p. 201. - Werner, FS., p. 308. - Nieden, SB. Ges. nat. Fr. Berlin, 1913, 1. 450. - Hewit, Ann. Transvaal Mus., 1911, p. 43. - Lampe, p. 157. HeWTTt \& PoWer, p. 150.

Fundangaben: Karibib, W. Mlehaelsex, 23.-26. IV. 1911 (5 Ex.).

Wind hu k, W. Mrnaelsex, 29. IV.-8. V., 20.-22. V. 1911 (7 Ex.).

T'sumeb, W. Munaelsex, 13.-19. V1. 1911 (1 Ex.).

Pinguin-Insel bei Lüderitzbucht; W. Michaelsex, 10. VH. 1911 (1 Ex.).

Śephoim, W. Michaelsex, 16.-19. NII. (1 Ex.).

Okahandja, (r. Fock, 1910 (6 Ex.).

Bahnstrecknbei Keetmanshoop, Water Kraner 1910/11 2 Ex.)

swakopmund, Hercix (2) Ex.).

Deutsoh-sidwestafrika (1 Ex.).

Rehoboth, K. Werelebex (1 Ex.).

Nach Nievex auch bei Kuibis, nach Lanes bei Rietmond und Kuibis.

Bemerkungen: Die rorliegenden 27 Exemplare reprisentieren die rerschiedensten Alterstadien und Beschuppungsformen. Das gröbte Exemplar 
mißt $90 \mathrm{~mm}$. Kopfrumptlänge (Swakopmund), die nächst größten vollständigen Ex. sind $84+76$ (1kahandja), $80+80$ (Kostmanshoop), $75+80$ (Karibib), $67+65$ (Windhuk) lang. 'Tuberkelreihen: Okahandja 19-22; Keetmanshoop 23: Seeheim 19; Pinguin-Inswl 17; Windhuk 14-25; Swakopmund 17-18; Karibib $17-2.2$.

Der var. laevigute Fisen. entsprechen Exemplare von Okahandja, Windhuk und Keetmanshoop, der var. stellata WEsx. (mit auch sternförmig gerjeften Hintorhaupttuberkohn) das Ex. von Seeheim. Der Schwanz ist oft an der Basis sehr breit, $(12 \mathrm{~mm}$ bui einem Wx. ron Windhuk, $65+$ 65 mmi, noch mehr bei einem Regenerat $16 \mathrm{~mm}$, bei Ex. von Windhuk, $85+59 \mathrm{~mm}): 4-5$ grobe Tuberkelschupere jederseits vor der Kloakenspalte bei erwachsenen Exemplaren. Mediane Tuberkelreihe oft fellend, aber wemn rorhanden, immer klein: Seitenschuppen oft mohrzackig, an serpocken (Balunus) erinnernd. Bauchschuppen ofters durch zwsammenhängende Reihe vergriberter Tuberkelichuppen von den Rumpfreihen abgegrenzt.

\section{Perlyglactylus IIeberi Roux.}

Rocx, Zool. Jahrb. Syst., XXV, 1907, p. 408, Tat. XIV, fig. 4 und 5. - Hewrt, Ann. Trausval Mus., III, 1911, p. 44.

Fundangaben: Ka ribib, W. Muchaelsex, 23.-26. IV. 1911.

Bahnstrecke bej Koetmanshoop, Waster Krauer, 1910/11.

Bemerkungen: Diese Exemplarw sehen ganz so als wie meine Abbildung von $P$. fasciatus (Scnumze Forschmosroise Fig. 8, 1. 312), doch sind die wesentlichsten Merkmale Nasentoch an 1. Nupralabiale, Länge des symplysialr) dirjenigen des P. Heberi. Die 8 Querbinden des Schwanzes rom und hinten dnnkel gesaimut; hri erwachsenen Exemplaren, wir sir die Abbildung bei loox darstellt, bleibren von drn breiten, dunkel gesiumben Rückenquerbinden des jungen Tieres nur die dunklen säumo iibrig; ganz dasselbe ist auch bei Bibroni zu beobaclsten. - Hewrer verglejeht Weberi ebenfills mit freciatus und betrachtet beide nobst formosus als Formon von rapensis. Wr hat aber auch Ahmlivhkrit mit Bibroni, von dem sich die jungen Exemplare aber

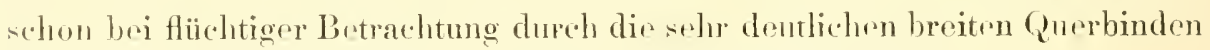
and don schmährem Kopef seler leicht unterseheiden lassen.

\section{P'arlyglactylus Ismmuthaleri Wern.}

Wrixen, Denkschr. Ak. Wiss. Wien, IBd. LXXXVII, 1913. p. 718; sF. p. 313 (ocellatus).

Fundangaben: (i roottontrin, W. Mumaksex, 7.-11. 1911.

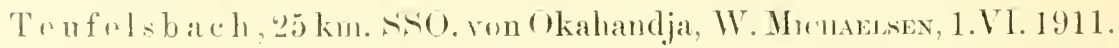


Osuna bei Okahandja, Wr. Mirndelsex, 2. YI. 1911.

Karibib, W. Mirhaterex, 23.-26. IV. 1911.

Windhuk, W. Michaelsex, 29. IV.-8. V. 1911 (ad. u. 2 pull).

Bemerkungen: Die Exemplare von $P$. ocellatus aus Deutsch-südwestafrika, die ich bisher gesehen habe, sind ausnahmlos zu dieser Art zu rechnen, die dem $P$. ocellatus ja zwoifellos selur nahe steht, sich aber durch die stets über den Rostrale aneinanderstoßenden supranasalia und dio deutlichen schindel(nicht Kïner-) schuppen der Oberseite von Rumpf und Schwanz, die an Homopholis Wahlhergi erinnern, sofort unterscheiden lassen.

Ex. yon Grootfontein: Länge $34+38 \mathrm{~mm}$. Schnanze $1 \frac{1}{2}$ mal so lang wie der Augendurchmesser, so lang wie del Abstand rom Augenhinterrand zur Ohröffinung. 11 Subdigitallamellen unter der t. Kehe, 3 unter dem rweiterten Teil. Jentale nach hinten etwas weniger verschmälert, als bei dem Typ-Exemplar: Rückenschuppen ebenso grob wie die des Bauches, schwanzschupen noch größer, am größten auf der Lnterseite. Gestalt plumper, Schwanz viel dicker. Oberseite hellgrabraun, dunkelbraun gefleckt und marmoriert, nit weißen Punkten und Flecken. Lippenschilder au Nundrand mit dunklen Flecken (auch liostrale und Jintale). I'nterseite sonst weil.

Fx. vom Teufelsbach: $26+34 \mathrm{~mm}$. Schwanzwael anfgetrieben. aber Achwanz dünn, wie beim 'Trp-Fxemplar: an jeder seite der Anschwellung drei abstehende Höckersehuppen. Eine breite dunkle Prä- und Postocularbinde, eine schmal" nach hinten concave dunkls Stirnbinde zwischen den Augenvorderrändern, líicken mit unregrlmäBiger. Leller Zickzackbindo, durch einen dunklen saum ron der graubraunen Grundfarbe Fortsetzung des Postocularbandes) abgegrenzt. Achwanzwurzel mit schmalen liellen (Qurbinden. Seiten mit hellen, dunkel geränderten Flecken.

Ex. von 0 sona: $21+30 \mathrm{~mm}$. Im wesentlichen wie roriges Exemplar, aber schwanzwurzel nicht aufgetrieben: () berseite hellbraun mit rerwaschenen dunklen Flecken.

Ex. von K aribib: $33+36 \mathrm{~mm}$. Oberseite hellbraun. Kopf oben dunkel getiipfelt. Rückrnzeichnung aus helleren, dunkel gesiumten Flecken. schwanz dunkel gofleckt.

Ex. von Windhuk: $37+27 \mathrm{~mm}$ - Achwanz regeneriert). Inentale schmal, ähnlich wie bei dor Type. Hellgelbbraun mit selı undeutlicheu groben grauen Flecken, die auf den Rïcken win undeutlichos helle- Zickzackband freilassen. Junge $20+42 \mathrm{~mm}$, anscheinend eben aus dem Fi geschlïpft, hellgraubraun mit späplichen feinen dunklen Punkten, ailnlich dem Typ-Exemplar. 
\%eichnume dor Labialia und Prä-Postrenlarbinde bei allen Exemplaren gleich, ebenso wie die Beschuppung: suprababia 6-8. Lie Rïckenzeichnume dor meisten kxemplane eliunert solur an Gedura Lesuemi.

\section{Rhoptropus Ptrs.}

\section{Irhoptropues afer Ptrs.}

Iollexere. Cat. Liz. I, p. 2017. - Weraer, SF., p. 215.

Fundangabe: Lü deritzbucht, ('. Maxrele, 1911 (3 Fx.).

Bemerkungen: (1berseite graubraun, mit weiblichen und dunkelbramen Flecken. Schwanz gollsbraun, dumkolbram gebindort: Gliednaßen gallobraun, dunkelbraun marmoriert.

Nupralabialia !)-11. Sublabialia 9.

\section{Lygodactylus Gray.}

\section{Lygeoluct!lues coppensis Smith.}

Bollexger, Cat. Liz. I, I. 160. - Werier, SF., 1. 307.

Fundangabe: (1kawango, zwischen 19" und $21^{\circ} 30^{\prime}$ östl. Lg.: v. ZAsтrow, $1912 / 13$.

Bemerkungen: Das Exemplar ist dureh eine Reihe ron weiben, schwarzgesiumten Augenflecken jederseits (iiber dem dunklen, rom Auge nach hinten zichenden und ïbere der Romptunite verschwindenden Läugsbande. aber nach hinten bis zur s.luwanzipitze fortgesetzt) ausgezeichnet, aber sonst ganz typisch. Supranasalia dureh ein seliildchen getrennt.

\section{Agamidae.}

\section{Agama Daud.}

\section{Igremere ation Inaud.}

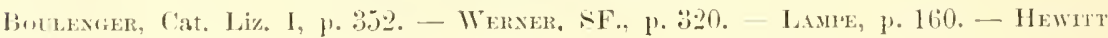
\& POWEL, P. 15\%.

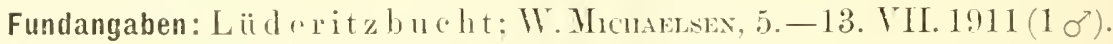

Nach Lane in der Wüstr bei Garub.

Bemerkungen: Lainge $95+105 \mathrm{~nm}$. Achuppen der Rumpfoberseite rollkommen gleichartig, ()ecipitale nicht unterscheidbar, sodab ein Bestimmmos-

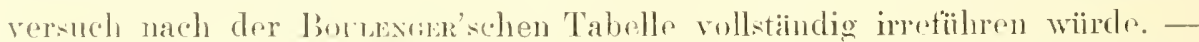

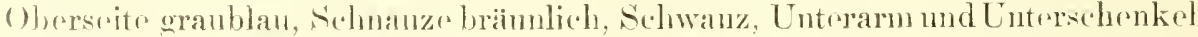
gelbbraun, aine woiße Riikkenmittellinie, nit kleinen (schujpengrofen) schwar-

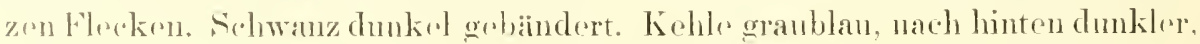


mit dunklen sclunörkellinien. Brust einfarbig grau, gegen den Bauch zu heller, Gliedmaßen und der Schwanz unterseits gelblichweif.

\section{Agama aculeata Merr.}

Botlesfer, Cat. Liz. I, P. 351. - Wekser, SF., p. 31\$. - Hewtt \& Power, p. 151.

Fundangaben: Farm Neud a m $m, 42 \mathrm{~km} O \mathrm{NO}$. von Windhuk: W. MicnAELAEX, 10.-15. V. $1911\left(1 \sigma^{\top}\right)$.

Windluk: W. Mrouatsex, 29. IV.-S. V. 1911 (2 Junge).

Karibib: W. Michatesex, 23.-26. IV. 1911 (3 Junge).

Bemerkungen: Kehlo des o bläulich mit dunkelblauen Zickzacklängslinien, ein grober tintenblauer Fleck ror dem liande der Kehlfalte. Oberseite braun, Kopf mit srumetrischer schwarzer Keichnung, Rücken und Schwanz mit dunkel branen querbinden. Lïngs $80+115 \mathrm{~mm}$.

Die Jungen sind hellgelbgrau (bei armata meh" gelbbraun, mit dunklen Querbinden auf Rüeken und Schwanz. Ein breites, tiefdunkles Band begrenzt hinten die Kehlfalte an der suite und rerschmälert sich gegen die Mitte, das der anderm Seite fast erreichend (bei armata viel schmäler und schwächer). Kehle mit dunklen Längshinien. Vergrößerte Rüickenschuppen scharf mucronat, ganz unregelmäßig, Iauchschupen gokielt.

\section{Agamer comate Ptrs.}

Botlearier, Cat. Liz. I, p. $352 .-$ Laspe, p. $15 \%$

Fundangaben: Relyoboth: K. Wetelebex 1913.

Okahandja; W. Michaesex 27. 28. IT.: (\%. Fork, 1910.

Farm Otjituezu bei Neudamm, a. $46 \mathrm{~km} \mathrm{NO.} \mathrm{ron} \mathrm{Windhuk:}$ IV. Michaelsex, 13. V. 1911 .

Windhuk: W. Mwhalsex, 29. M.-8. W.

Brackwater, $20 \mathrm{~km}$ N. ron Windhuk: W. Micmabsex, 23. Y.

Farm Neudamm, ca. 42 $\mathrm{km}$ ONO. ron Windhuk: W. MunaELSEX, $10 .-15$. $\mathrm{V}^{2}$.

Farm Paulinenhof an den Anasbergen, (‘a. $36 \mathrm{~km}$ (). ron Windhuk: W. Michatesex, 18. T. 1911.

sพwakupmund: Henmx, 1911.

Ts $\mathrm{smeb}$ : W. Michalsex, 13.-19. TI.

() kaw a n $g 0$, zwischen $19^{\circ}$ und $21^{\circ} 30^{\prime}$ öst. Lg.: v. ZAstuow, 1912/13.

Bemerkungen: Durch die in regelmäBigen zusammenhängenden Laingsreihen angeordneten vrgrößerten Rückenschupen (jederseits wenigstens eine 
Lipilse und die in Flecken, nicht in Querbinden angeordnete dunkle Rïckenzoichnung läbt sich diese Art von der vorigen, sow it Exemplare von DentschSiidwestafika vorliegen, stets recht gut unterseheiden. Dagegen ist die Länge der 5. \%ehe nicht groignet, mit Nicherheit zur Untrrschridung von hispida beizutragen, da garnicht selten wenigstens auf einer seite die 5 . Zehe kürzer ist als die 1.; ebenso ist die 3. und 4. luautig ganz gleich lang. Bri jungen Tiren ist das ()ecipitale moist sehr grob, von einem Kranz von 7 -8 vergeobrerten Schildchen (moist symmetrisch angeordnet) mmgebrn. Bovlexgen zioht (Rer. List. ... Afr. Liept., p. 465) armata zu aruleata Mers. Dazu kann ich mich jetzt doch nicht entsehliofen. Wenn wir von der Berïcksichtigung der Zehenlänge und anderer von ButLexger in erster Linie rrwähnter Merkmale abselsen, wird man die siidwestafrikanischen Aganens schon untorscheiden könnon. Wenn jels vielleicht in meiner Bearbeitung der L. Srulutze-Ausberute manches Exemplar in der unrichtigen Art untergebracht habe, so ist das deswegen gescheluen, weil ich mich von dem ungliekseligen \%ohen-Jogna noch nicht fromachen konnte. Jetzt bin ich auber Kwrifel, was armate und aculeate ist.

Länge $70+90\left(\sigma^{7}\right), 60+80$ (ㅇ) $10 \mathrm{~m}$. (Windhuk).

\section{Agame planiceps Ptrs.}

Botlexker, Cat. Liz. I, p. 35s; Ann. A. Atr. Mus., V/9, Nr. 16, p. 466. - Wehxer, SF.. p. 324 .

Fundangaben: lieholooth; K. Wegelebex, 1913.

Okahandja: F. Fink, 1910.

Ka ribib; $\mathbb{1}$. Michaensex, 1911.

Bemerkungen: Das ( kahandja-Kxemplar ist halbwïchsig: die helle Kopfzoichnung ist golb: runde, bliuliohgrane, dunkrl eirgofaßte Flocken an den limmpfseiten: brame (purrbinden und Flecken auf Glirdmafen und Schwanzwruzel. Das Karibib-Exomplar, ein junges Tier $(35+60 \mathrm{~mm})$ mit der charakteristischen Zeichnung und einer unterborolenen hellen (gelben) Rïckenmittellinie, Grundfarbmog des Kopfes hallbram, des Rumpfes sehwarzbuaun, ähnlich das ebensogrober stück von Reholosth.

\section{Zonuridae. \\ Zonurus Merr.}

\section{Zonur) jol!yor)mes Smith.}

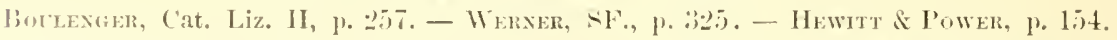

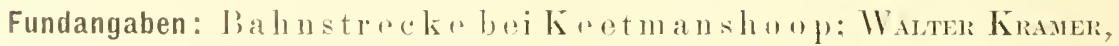
$1 ! 1011$. 
Us akos; W. Michaelsex, 22. IV.-22. TI. 1911.

Bemerkungen: 1.36 Schuppenquerreihen, 32 Längseihen, Schuppen an vorderen Ohrrand und in der Halsgegend stark rorspringend.

2. 33 Längs- und 30 Q Querreihen von Dor-al-Schuplen, 5-6 Femoralporen. In der Rïckmmitte sind stellenweise in die nach rorn rorspringenden Winkel der Querreihen kurze querreihen eingeschaltet. Fichmale dunkle Querbinden dunkle Hinterränder der (Querreihen teils halbe, teilvollständige, auf dem Rïcken.

\section{Varanidae. \\ Varanus Merr.}

Taramus albiguluris Dand.

Boclexgar, Cat. Liz. II, p. 307. - Werver, sF., p. 327. - Lampe, p. 16j. - Hewtt \& Power, p. 155 .

Fundangaben: Oka handja: G. Fock, 1910 (3 junge Ex.

Wird von LAupe aus der $\mathrm{K}$ al a hari angeführt.

Bemerkungen: 1.) Ton Nacken bis Hinterbeinansatz 100, zur Schwanzwurzel 105, rund um die Körperseite 128 sahppen.

12 schwarze linge auf dem schwanz: Kehle schwarzbraun, dunkle Sichläfenbinde vorhanden.

2. Vershieden durch 19 shwarze schwanzquerbinden, die ersten sind Doppolringe.

3.) 11 schwarze Querbinden des Schwanzes, die ersten jo nur unten, die nächsten 4 auch oben quer getrilt.

\section{Amphisbaenidae.}

\section{Amphisbaena L.}

\section{Amphishnemer ruadrifioms Ptrs.}

Botlextiek, Cat. Liz. II, 1. 447. - Nifiex, SB. Ges. Naturf. Fr. Berlin, 1903, p. 450. Werser, SF., p. 327. - Lampe, p. $16 \pi$.

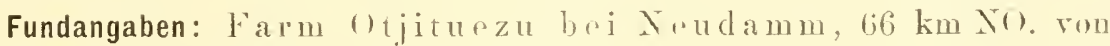
Windhuk: W. Mr'HALsex, 13. V. 191!

Okahandja: G. Fork, 1910.

Grootfontain: Luxhexisis. 7.-11. VI. 1911 (ron Niedex bereit von dorther erwähnt).

Windhuk: Btscre 1911 (3 Ex. (von Laspe bereits ron dorther genannt.)

Farm Neudamm, $42 \mathrm{~km}$ (NO. von Windhuk; W. Michaelsex, 10.-15. V. 1911 (4 Ex.). 
Bemerkungen: 1)ir vorlirgenden Exmplare unterseheiden sich außer in der Farbung, die von golblichbram zu bramviolett variert (die alteren 'Tiere sind am dunkelsten), kaum roneinander. Das kxemplar von Otjituezu ist das gribte $(192+35 \mathrm{~mm})$.

\section{Monopeltis Smith.}

\section{Mompeltis capensis Smith.}

Butlextier, Cat. Liz. II, p. 45.), Taf. 14, tig. 1. - Nibuex, 1. c., 1. 450. - Werner, SF, p. 32s.

Fundangabe: Grootfontein; Lunkenbex, 1911 ( $1 \mathrm{Ex}$.).

Von Nienex für die Gegend Aub-Klein-N a u as rrwähnt.

\section{Monopeltis quadriscutata Werner.}

Wrexel: in: Schutz: Forschungsreise, 1910 p. 329 und Mitt. Naturhistor. Mus. Hamburg, XXVII, 1910 p. 33.

Fundangaben: Okaw ango, zwischen $19^{\circ}$ und $21^{\circ} \quad 30^{\prime}$ ïstl. Lg.; v. /Asтrow, $1912 / 13$.

Bisher erst aus Grootfontein bekannt, anscheinend auf den Norden der Kolonie beschränkt.

Bemerkungen: Ein schönes Exrmplar von $270 \mathrm{~mm}$ Gesamtlänge. $192\left(\begin{array}{l}22 \\ 16\end{array}\right)$ Rumpf- und \& Schwanzringel, 2 große Praeanalschilder, 2 Praeanalporen.

Kopf obru hellgelbbraun, Oberseite sonst hellgrau, spärlich und unregohnäßig weib gefleckt, Unterseite weiB.

\section{Aomopeltis :eoloburel Blngr. (M. lomgicanda n. sp. ?)}

Burlexfier, Ann. S. Afr. Mus., V/9, Nr. 16, 1910, p. 495. - Niedfa, SB. Ges. nat. Fr. Berlin, 1913, P. 450.

Fundangabe: (1) kawang go, zwischen $19^{\circ}$ und $21^{\circ} 30^{\prime}$ ästl. Lg.; v. Zastrow, $1912 / 13$.

Bemerkungen: Dios Monopeltis vom Ckawango, der leider dic obere Hälfte des Kopfos fehlt, lißt sich am besten der oben genannten, ursprünglich von Siesheke, Barotseland beschriebenen und dam auch von Niemes ans Dontsch-Südwostafrika erwähnten Art rergloichen, doch ist der Schwauz ganz auffallend lang. Es sind 330 Rumpf- und 37 Schwanzringel vorhanden, 1 s. segmente in rinem lingel. Länge $255+44 \mathrm{~mm}$. Anber dem bedentend langerem schwanz bei der Type ${ }^{2} 20=\frac{1}{2}$, bei den vorliegenden Exemplare aber $\frac{1}{6}$ der fresamtlinge), der zwar plïtzlich abgestutzt, aber gegen das knde nicht verdiekt ist, fält anch noch ein anderer Untresehied ron der ()riginalbeschroibung der Art anf; das mediane Paar von Pectoralschildern ist nicht das lïngste (das anstoßende ist ebonso lang) und auch nicht das 
breiteste, da alle droi Paare ziemlich gleich breit sind. Vielleicht erweist sich das Tier, das guradezu unglaubliche Thnlichkeit mit einem großen liegenwurm hat, als Vertreter oiner nenen Art, für die ich don Artnamen longicauda vorschlagen wiirde.

\section{Lacertidae.}

\section{Eremias Wiegm.}

\section{Evemias lugubris Smith.}

Boclexaer, Cat, Liz. III, p. St. - Werxer, SF, p. 330.

Fundangaben: $0 \mathrm{k}$ a hand a a, Gaver 1911.

() k a wa 11 go, zwischen $19^{\circ}$ und $21^{\circ} 30^{\prime}$ astl. Lg.: v. Kastrow, 191213.

Bemerkungen: Ex. von ()kahandja: Ein junges Excmplar in der charakteristischen schwarzweißen Tracht.

Ex, von (Hawango: Erwachsen, Eemoralporen 14-13, 7 Halsbandsschildchen, $6 \times 27$ Ventralia. Praefrontalia stark gekielt, Frontale rorn 2kielig (Fortsetzung der Präfrontalkiele). Tor der Scapular- und hinter der Sacralgegend hellbraun, mit der gewöhnlichen Zeichmng, dazwischen tiefschwarz. Helle weibe Medianlinie durchlanfend, die weibe Längslinie anf jeder Seito endigt aber ïber dem Ellbogen.

\section{Evemias umata Smith.}

Bollexfer, Cat. Liz. III p. 9:.. - Werxer, SF., p. 331.

Fundangaben: Wind huk: W. Mifhaelsex, 29. IV.-8. V. 1911.

Karibib; W. Michaelsen, 23.-26. IV. 1911 (2 Junge).

Bemerkungen: Das erwachsene Exemplar von Windhuk ist $118 \mathrm{~mm}$ lang (Kopfrumpflänge $37 \mathrm{~mm}$ ). 5 Supralabialia vor dem Subocular», 12 Halsbandschildehen, 12 Femoralporen. Oberseite mit is schwarzen Liangsstreifen (ein wrniger dentlicher auch am Bauchrand), der mediane am Nacken gegabelt, schmäler als die übrigen, nicht über die Schwanzwurzel hinausreichend. Grund färbung gelblichweiß. Hinterbeine weif gefleckt. Spitze der 4. Zehe reicht äber Ohröffnung hinaus, Vorderbeine cinfarbig, graubraun.

Die 2 Jungen, $62(21+41) \mathrm{mm}$ lang; Grundfarbe der Uberseite fast weiß, der schwarze Medianstreifen vorn gegabelt, linten nicht über die Sacralgegend hinaus zu verfolgen. Dorsal- und Lateralstreifen (ersterer wenigstens hinten) aus zusammenhängenden schwarzen runden Flecken gebildet. Schwanz einfarbig rötlich (wie bei der jungen E. lugubris). 


\section{Eremias inomata Roux.}

Roux, Zool. Jahrb. Syst. XXV, 1907, p. 427, Taf. 15, Fig. 1, 2, 3. - Hewit, Ann.

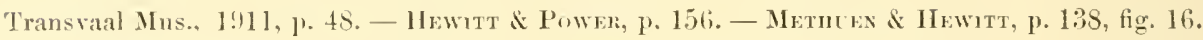

Fundangaben: Usakos; II. Mrchaesisex, 22. IV.+22. VI. 1911. (4 Exemplare).

Rehoboth: K. Wegelebex, 1913 (2 Ex.).

Bemerkungen: Diese Art ist bisher aus Deutsch-siidwestafrika nicht bekannt gewesen. Ilue Artsellstandigkeit steht für mich außer Zweifel, und auch Hewrt hält sie fïr rersehieden ron undutre. Sie int in allen wesentliehen Merkinalen seher heständig.

Exemplare ron Tsakos:

\begin{tabular}{|c|c|c|c|c|}
\hline & I & II & III & II \\
\hline $\begin{array}{l}\text { Supralabialia vor } \\
\text { dem suboeulare }\end{array}$ & $5-5$ & $t-j$ & $5-j$ & $\dot{j}-6$ \\
\hline $\begin{array}{l}\text { Halshandsclild- } \\
\text { chen }\end{array}$ & 10 & $1: ;$ & $1 \ddot{2}$ & 12 \\
\hline $\begin{array}{l}\text { Analschildchen } \\
\text { umgeben von klei- }\end{array}$ & 4 & 2 & 4 & $\ddot{3}$ \\
\hline neren schildchen & $\frac{8}{30 y}$ & $\frac{6}{10 \times 9}$ & $s$ & $10 \times 30$ \\
\hline Tentralia & $10 \times 25$ & $\begin{array}{l}10 \times 25 \\
12-11\end{array}$ & $10 \times 30$ & $10 \times 510$ \\
\hline Femoralporen & $\begin{array}{r}10-11 \\
145(50)\end{array}$ & $169(45$ & $15-10$ & $15-12$ \\
\hline $\begin{array}{c}\text { spitze der } 4 \text {. \%ehe } \\
\text { reichit lis }\end{array}$ & nicht gatuz zum olır & $\begin{array}{l}\text { zwischen Auge } \\
\text { and ohir }\end{array}$ & $\begin{array}{c}\text { zwischen Ange und } \\
\text { ()hr }\end{array}$ & $\begin{array}{l}\text { zum Angen- } \\
\text { hinterrand. }\end{array}$ \\
\hline $\begin{array}{l}\text { Färlung n. Zeich- } \\
\text { nung del (b)er- } \\
\text { seite }\end{array}$ & 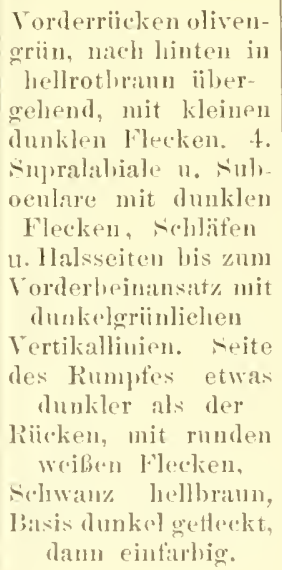 & 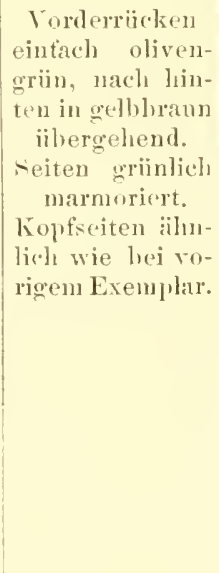 & $\begin{array}{c}\text { Alulich wie voriges } \\
\text { Exemplar; feiten mit } \\
\text { grianlichen, unregel- } \\
\text { mäbigen Vertikal- } \\
\text { linien auf weiblichen } \\
\text { Grunde. Auel sujra- } \\
\text { labialia linter dem } \\
\text { suloeulare nit } \\
\text { dunklen Fleeken, } \\
\text { vordere grau. }\end{array}$ & $\begin{array}{l}\text { Wie voriges } \\
\text { Exemplar, } \\
\text { aber supra- } \\
\text { labialia alle } \\
\text { einfurbig hell }\end{array}$ \\
\hline
\end{tabular}

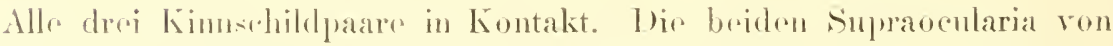
Frontale und Intrepariobale nicht dureh Granula abgeglenzt. - Auffallend 
lang ist der Schwanz bei Exemplar III (fast $23 / 4$ mal so lang wie der übrige Körper). Die Art scheint sehr lokal verbreitet zu sein, da sie bisher noch niemals aus Deutsch-Siidwestafrika erwähnt wurde, obwohl sie von ihren Verwandten sehr leicht durch ihre unscheinbare Färbung, die Rotx sehr gut durch den Artnamen kennzeichnet, untersehieden werden kann.

Nachtrag: Die beiden Exemplare aus Rehoboth, die ich nach AbschluB dieser Arbeit erhiclt, machen mich doch in meiner Ansicht ron der sprzifischen Selbständigkeit dieser Art (inomata Roux) schwankend. Während das kleinere Exemplar noch eine typische undatı int, dürfte es schwer fallen, das größere rom inomatu zu unterscheiden. Es scheint mir auch, daß, wenn man das untere Augenlid am undata genïgend in dis Höhe zicht, unter den beiden großen Glasfenstern noch zwei zum Vorschein kommen. was den Unterschied beider Arten erleblich verringert.

Nachstehend die Beschreibung:

1.) $\sigma$ ron $152 \mathrm{~mm}$ Gesamtlänge mit 12 Halsbandschildchen, $10 \times 31$ Ventralen und 13-12 Femoralporen. 5 Supralabialia vor dem Suboculare: Frontonasale und Frontale mit medianer Längsfurche. Interparietale dureh ein kleines Schildchen rom Occipitale getrennt. 4. Zehe reicht bis zwisehen Tympanum und Augenhinterrand. - Hellgraubraun, mit 5 schwarzen Streifen, der mediane im Nacken gegabelt: der äußerste Streifon jederseits wenig deutlich, die drei mittleren hinter der sacralgegend in Flecken aufoelïst. Zwischen den streifen ist auf dem Rücken die Grundfarbe zu gelbbraun aufgehellt.

2.) O ron $135 \mathrm{~mm}$ Gesamtlänge, mit 11 Halsbandschildchen, $10 \times 29$ Ventralen und 14 Femoralporen. 5 Supralabialia ror dem Suboculare; Frontonasale und Frontale mit tiefer Medianfurche, Präfrontalia stumpf, aber deutlich längsgekielt. Parictalia nahe dem Aufenrande mit starkem Längskiel, oder eher nach aufen steil abfallend. 4. Wehe reicht bis zum Trmpanum.

Oberseite vorn trüb olivengrïn, nach hinten hellbraun. Riiickenzeichnung ähnlich wie bei vorigem Exemplar, aber undeutlich, Seiten dunkel genetzt. Unterseite rötlich.

Jedenfalls stehen die drei Arten lurubris, undata und inormata einander sehr nale.

\section{Eremias pulchella bray.}

Bollexger, Cat. Lic. III, p.93. - Werker, SF., p. 331.

Fundangabe: Liideritzbucht: IV. Мrehaessex, 5.-15. VII. 1911. (2 $\mathrm{Ex}$. 우)

23 Michaelsen, Deutsch-Südwestaririka. 
1.) nit 2 dunklen Längslinien. Suboculare zwischen 5. und 6. Supralabiale. Praifrontalia dureh ein schildchrn getronnt. Halsbandschildehen sehr klein, nur dio 5 mittleren von don Kehlschuppen unterschoidbar. 3 Kimschilderpare median in Kontakt. Femoralporen 10-12.

2.) ()brrseite ganz einfarbig gran. 4 vergriißerte Halsbandschildchen. 3. Paar ron Kinnschildern nur rorn in Kontakt. Femoralporen 12-12. suboculare wir oben.

Bei beiden Exemplaren gelit rom Interpariotale vine Sutur jederseits in das Parictale hinein, wie bei den niederiasterreichischen Exemplaren ron Lacerta muralis.

Diese Form der E. prulchella ist von E. lineo-ocellata durch schlankeren, zarteren Körperban, Färbung und Zeichmung so gut unterscheidbar, dab man sir für Dentsch-siidwestafrika auch daun als besundere Form aufrechterhalten darf, wemn man sio sonst, dem Torgange Butluxger is in Iotzter Zeit (Ann. S. Ifr. Ins., V/9, No. 16, p. 477) mit dor suidafrikanischen Art vereinigen wïrde.

\section{Evemias limeo-ocellata DB.}

Bullexier, Cat. Liz, III, p. 94. - Werser, Fs., 1. 334. - Hewitt, Ann. Transvaal Mis., III, 1911, 1. 48. - Hewitt \& Power, p. 156.

Fundangaben: Farm Voigtsland a. d. Bismarck-Bergen, $38 \mathrm{~km}$ (). von Windhuk; W. Micmatesen, 16-19. V. 1911 (Wx., No. 1.)

Windhuk; Buscu, 1911 und W. Monnelsen, 29. IV. - S. V. 1911 3 Ex., Nr. 2-4.).

Bemerkungen: Obwohl dir rorliegenden Exemplare nach der Kielung der schuppen in dre scapulargegend alle Cberginge von der als formosu Sumur zu bezeichnenden Form der pulehella zur rigentlichen lineo-ocellata erkenmon lassen, wïrde ich es doch als cine unnatioliche Gruppierung betrachten, die sonst sehr ibbereinstimmenden Tiope deswegon anf zwoi Arten zu verteilen, sondern belasse sie alle bei obiger Art.

1.) $\sigma^{7}$ : suboculare zwischen 5. und 6. Nupralabialı; 1 upares schild(chen zwischen den Präfrontalen; 1: Halsbandsehildehen, 12 X33 Ventralia, 12 - 13) Fomoralporon. länge $50+100 \mathrm{~mm}$.

()borseite hellbran mit zwoi sehwarzen Längshinen und ciner medianon

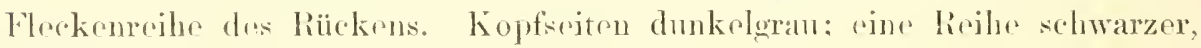
blangekernter ()eollen an joder Kimmptisite.

2.) F : Suboculare zwis.hen 5. 11. 6., 6. и. 7. Supralabiale; 9 Halsbandschildchen, $12 \times 32$ Ventralia, 11-10 Fomoraljoren. Läuge $50+123$ mm.

Riickenzon" olivenfarbig, joderseits ron riner dunklen Linie eingo-

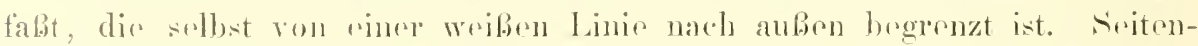


zone mit dichtgedrängten wrißen, dunkel uingufabten Angrnflecken. Schwanz hellbraun.

3.) 오 : Supravenlaria (2), rundherum von Franulaschuppen umgeben. Suboculare zwischen dem 5. und 6. Supralabiale. 7 Halsbandschildchen, $12 \times 33$ Tentralia, 12-12 Eemoralporen.

()berseite rotbraun mit 4 gratuen, dunkel eingefabten Längsinien, das innere Paar, an der Grenze zwischen lïicken- und Lateralzone ron del. Mitte zwischen Torder- und Hinterbeinansatz an in schwarz beronenzte Flecken aufolïst. Koptseiten dunkelgran.

4.) of: Praefrontalia durch ein unpaares schildchen getremnt; Suboculare wie bei rorigem Exemplar zwischen 5. und 6. supralabiale: 9 Halsbandschildchen, $12 \times 30 \mathrm{~V}^{\top}$ entralia: $11-11$ Femoralporen. Länge 50+87 mm.

Färbung wie beim vorigen Exemplar, aber oberes (inneres, streifenpar schon frïher in einzelne Flocken aufgelöst und zwischen dirsen und dem unteren (dem Bauchrande genäherten) Streifen eiuzelne ebensolche IngenHecken. Hinterbeine mit zahlreichen weibrn Flecken.

\section{Scatpteina Wiesm.

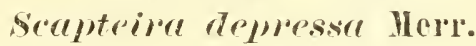

Botlexger, Cat. Liz. 111, p. 110: Ann. A.Afr. Mus., T/9, Mr. 16, 1\% 46. - Werxer, SF., p. 336.

\begin{tabular}{|c|c|c|c|c|c|c|}
\hline Fundangaben: & $\begin{array}{l}\text { Supralabiala } \\
\text { unter dem } \\
\text { suboculare }\end{array}$ & $\begin{array}{l}\text { Halsband- } \\
\text { sclibldelen }\end{array}$ & $\begin{array}{l}\text { Kinnschil- } \\
\text { derpaare } \\
\text { in liontalit }\end{array}$ & Ventralia & $\begin{array}{l}\text { Femoral- } \\
\text { poren }\end{array}$ & Färbung d. Oberseite \\
\hline $\begin{array}{c}\text { Lüderitzbucht. } \\
\text { C. MAxrer, } \\
1911 .\end{array}$ & $\begin{array}{l}5 .-7 . \\
6 .-5 .\end{array}$ & 11 & 1. & $12 \times 32$ & $20-15$ & $\begin{array}{l}\text { Gran, rorn mit zien- } \\
\text { liclı groben, scliwar- } \\
\text { zen. unregelmäßigen } \\
\text { Flecken. }\end{array}$ \\
\hline $\begin{array}{l}\text { Liideritzbuclit. } \\
\text { WV. M1cHAELAL, } \\
\because 0 .-24 \text {. THI. } 1911 \text {. }\end{array}$ & $5 .-7$. & 6 & 1. 11. 2. & $12 \times 2: 3$ & $17-16$ & $\begin{array}{l}\text { Hellgran m. schwarz- } \\
\text { liranner Nacken- } \\
\text { lïngslinie, zwei } \\
\text { Reihen dunkler, run- } \\
\text { der Ribkenflecken, } \\
\text { Kopf dunkel gefleckt. }\end{array}$ \\
\hline $\begin{array}{c}\text { Swakopmand. } \\
\text { C. Maxier, } \\
\text { Feloruar 1912. }\end{array}$ & ). & 6 & 1. 11. 2 & $12 \times 30$ & $18-18$ & $\begin{array}{c}\text { Hellhlaugran mit } \\
\text { schwarzen Flecken } \\
\text { und Schnörkeln, } \\
\text { schwarze Nicken- } \\
\text { längslinie. }\end{array}$ \\
\hline $\begin{array}{l}\text { I iidelitzbucht. } \\
\text { IV. Mr'HAELEA, } \\
5-13 . \text { VII. } 1911 \text {. }\end{array}$ & $\begin{array}{l}\text { t. }-6 . \\
5 .-7\end{array}$ & 9 & $\begin{array}{l}\text { 1. }-3 . \\
\text { (3. nur vorn) }\end{array}$ & $14 \times 3=$ & $15-15$ & $\begin{array}{l}\text { Hellgrau, nuregel- } \\
\text { mäßig schwarz ge- } \\
\text { Heckt, nach hinten } \\
\text { die Flecken kleiner } \\
\text { werdend. }\end{array}$ \\
\hline, & $5 .-7$. & 6 & 1. แ. 2. & $14 \times 31$ & $19-19$ & $\begin{array}{c}\text { Hellgrau mit dunkler } \\
\text { Nackeni] } \\
\text { sonst fein schwie, } \\
\text { getleckt. }\end{array}$ \\
\hline
\end{tabular}


Daß Eremias suborlitalis PTRs. mit dieser Art identisch ist, scheint mir selır wahrscheinlich zu sein: merkwürdig ist es, daß dies Bortexger, der bei Abfassung seines Katalogs auch die Type von Perens untersuchen konnte, noch nicht auforofallen ist, obwohl schon ans seiner Beschreibung dic große Thnlichkeit hervorgeht. Eime von Roux als $E$. suborbitalis brstimmte Eidechse der Wremschen Ausbente in meiner Sammlung ist eine sichere Scapteira depressa, welche Art in seinem Verzojchnis nicht angefïhrt ist.

\section{Scapteira retirulata Boc.}

Boulexger, Cat. Liz. II, 1'. 112; Ann. S.Afr. Mns., Y 9 , Nr. 16, p. 479 (serripes). WERNER, SF., p. 338.

\begin{tabular}{|c|c|c|c|c|c|c|c|c|c|c|}
\hline Fundangaben: & $\begin{array}{l}\text { Supra- } \\
\text { labialia } \\
\text { unter dem } \\
\text { snboculare }\end{array}$ & $\begin{array}{l}\text { Auri- } \\
\text { cnlar- } \\
\text { schiilp- } \\
\text { clien }\end{array}$ & $\begin{array}{l}\text { Ilals- } \\
\text { baud- } \\
\text { scluild- } \\
\text { chen }\end{array}$ & $\begin{array}{l}\text { 1. Supra- } \\
\text { oculare } \\
\text { aufgelöst } \\
\text { in }\end{array}$ & $\begin{array}{l}\text { Kinn- } \\
\text { schilder- } \\
\text { paare in } \\
\text { Kontakt }\end{array}$ & $\begin{array}{l}\text { Ven- } \\
\text { tralia }\end{array}$ & 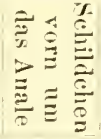 & $\begin{array}{l}\text { Femo- } \\
\text { ral- } \\
\text { poren }\end{array}$ & $\begin{array}{l}\text { 4. Zehe } \\
\text { reicht } \\
\text { bis }\end{array}$ & Lïnge \\
\hline $\begin{array}{c}\text { Swakolomund. } \\
\text { C. MANGER, } \\
1912 .\end{array}$ & $6 .-5$ & $2-3$ & 11 & $1 \mathrm{gr} .2 \mathrm{kl}$. & 1. -3 & $14 \times 30$ & ; & $20-20$ & $\begin{array}{l}\text { Vorder- } \\
\text { rand } \\
\text { des } \\
\text { Auges }\end{array}$ & $50+100 \mathrm{~mm}$ \\
\hline $\begin{array}{l}\text { Swakopmund. } \\
\text { Jacoss, } 1911 . \\
\text { (3 Junge, in allen } \\
\text { wesentlichen } \\
\text { Stiicken gleich.) }\end{array}$ & 6. - -8 . & & $S$ & $\begin{array}{l}1 \mathrm{gr} .1 \mathrm{kl} \text {; } \\
\mathrm{l} \mathrm{kl} .1 \mathrm{gr} . \\
1 \mathrm{kl} .\end{array}$ & $1 .-3$ & $14 \times 32$ & ;) & $22-20$ & & \\
\hline $\begin{array}{l}\text { Swak opmund. } \\
\text { KLAI , } 1911 \\
\text { (jung). }\end{array}$ & $6 .-5$ & 2 & $y$ & & $1 .-3$ & & 6 & $20-19$ & & \\
\hline
\end{tabular}

Bemerkungen: Da den untersuchten Exemplaren ans Dentsch-südwestafrika das Suboculare ansnahmslos vom Oberlipprenrand getrennt ist, so dürfte es sich bei S. serripes PTRs. doch zum mindesten un rine wohl ansgesprochene und leicht erkembare Lokillasso handeln. Wrum Bovlexcer für serripes Klein-Namaqualand, Dontsch-siidwestafrika und Bonguella als Heimat angibt, also reticuluta zu serripes zinht, anstatt momerohrt (retiruluta Bocags: 1867 hat die Prionitit vor serripes PrTens 1869), so ist dios unzulissig; man kann die beiden Formen als Arten trennen: tut man dios abor nicht, so num die Art reticulata hoißen.

\section{Nucras Gray.}

\section{Jurvess tessellater Smith.}

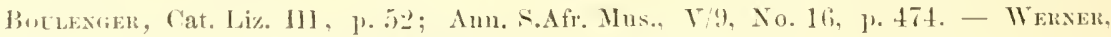
SF., 1. 329. - Hewst, Ann. 'Transwal. Mns., 1911, 1. 4s.

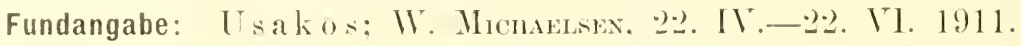


Bemerkungen: Eiu schïnes Exemplar, anscheinend der typischen Form angehörig, obwohl der Fub deutlich kürzer ist als der Kopf bis zum rorderen Ohrrande, von $240 \mathrm{~mm}$ Länge (Kopfrumpelänge $75 \mathrm{~mm}$ ), mit 8 Halsbandschildchen, $8 \times 37$ V entralen, 14 Femoralporen, 40 Schuppen quer iber den Rumpf: 4 große Analschildchen, von 9 schmalen schildchen umgeben.

Färbung im allgemeinen hollrotbraun: Nackengegend schwarz und weiB reticuliert. Schläfen und Halsseiten mit schwarzen Vertikalstreifen anf weißem Grunde; diese werden nach hinten immer kürzer, schlieflich breiter als hoch: diese. Stroifen bezw. Flecken werden in der Halsgegend nach oben durch eine lelle Längsfleckenreihe begrenzt, die nach hinten zu einer Linie verschmilzt, von einer dorsalen dunklen Linie abgegrenzt. Nach hinten verschwinden alle Streifen und Flecken allmählich in der hellrotbraunen Grundfärbung. Schwanz einfarbig hellbraun.

\section{Aporosaura Blngr. Ajorosamra anchietae Boc.}

Boclexger, Cat. Liz. III, p. 117. - W Erxer, SF., p. 310.

Fundangabe: Swak o pmund: Hercyx, 1911.

Bemerkungen: Ein Exemplar von $54+54$ mu Länge ( $\sigma^{7}$ ?). Oberseite hell lehmgelb. Hinterbein spärlich dunkel genetzt. Eine dunkle Längslinie auf der sehr breiten schwanzwurzel. Schwanzzeichmung nach dem Schema nv. (Werner, SF., p. 340).

\section{Gerrhosauridae. Gerrhosaurus Wiegm. Gerrhosalmus flavigularis Wiegm.}

Boclexger, Cat. Liz. III, p. 122 (nigrolineatus Halt.). - Werser, SF, p. 341 . Hewitt, Ann. Transvaal Mus,, 1911, p. 49.

Fundangabe: Farm Ukapehuri bei Okasise: Max v. Rimpxo-Rudzixski, VIII.-IX. 1911.

Bemerkungen: Ein Exemplar von $135+260$ mu Länge: $24+8$ Schuppenlängsreihen, 17-16 Femoralporen.

Tielleicht ist $\rightarrow$. nigrolineutus doch als eino westafrikanische Lokalrasse des flavigularis aufzufassen, da mir diese Form aus Westafrika zum mindesten als vorherrschend bekannt ist.

\section{Cordylosaurus Gray.}

\section{Cordylosaume trivittetus PтRs.}

Bollexier. Cat. Liz. III, p. 126. - Weraer, SF., p. 341. - Lasue, p. 173.

Fundangabe: 'Tsume b: Wr. Jichaelsex, 13.-19. IV. 1911.

Ein Exemplar, anscheinend erwachsen, ganz typisch. Wird von Lampe aus Rietmont erwähnt. 


\section{Scincidae. \\ Mabuia Fitz. \\ Mabuice trivittata C'ur.}

Bottexger, Cat. Liz. IH, p. 195. - Werner, Fs., p. 341, Taf. VII, fig. 6. - Hewitt, Anu. Transvaal Mus., II, 1910, p. 93; Hewite \& Powel, p. 157. - Laspe, p. 174.

Fundangaben: Okahandja; G. Fock 1910.

Wr ind huk; W. Mrmaessex, 2?. IV.-8. T. 1911 (auch von Lumpe ron dortler erwälnt).

Noudamm, t2 km ON(). von Windhuk: W. Micursersex, 10.-15. T. 1911.

Bemerkungen: Das (1kahandja-Exemplar ist mit $255 \mathrm{~mm}$ Gramtlänge (105 mu Lónfrumpflänge) das gröBte, das von Windluk miBt?215 (88). das von Neudamm $85 \mathrm{~mm}$ Kopfrumpflänge (Schwanz regeneriert). Schuppen bei allen in 34 Ririlurn: 4 Supralabialia ror dem suboculare.

Diese dickköpfige Art rerhält sich zn der . W. sulcata etwa so wie Lacerta agilis zu L. muralis.

\section{Mabria ramia Ptrs. tmpica.}

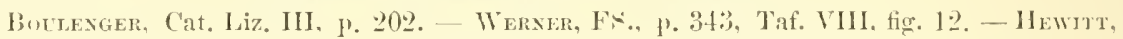
Ann. Transwaal Mus. 1910, f. 95. - Nifiex, SB. Ges. nat. Fr. Berlin. 1918, p. 451.

Fundangaben: Swak p pund; Klus, 1911 (Ex. Nr. 1 ).

Lüdartzbucht: ( MAxger, 1911 (Ex. Nr. 2).

Ka ribib; W. Micuaflsw, 23.-26. IV. 1911 (Wx. Nr.3).

'Ts ume b; W. Michaelsex, 13.-19. VI. 1911 (Ex. Nr. 4).

0kawango, zwischen $19{ }^{\prime \prime}$ und $21^{\circ} 30^{\prime}$ istl. Lg.: v. KAstrow, 191213 (Ex. Nr. 5 ).

Bemerkungen: schuppen in 32-34 Reihen: Auricularschiipphen 2-3, das unterste manchmal sehr klein und schmal; Supralabialia zwrimal 4 ('T'sumeb, ()kawango), zweimal 5-6 (Swakopmund, Karibib), zwoimal 5 (Swakopmund, Lüderitzbncht). (iröbtes Exemplar $115 \mathrm{~mm}$ lang.

Firbung und Zeichnung:

la.) (iung) (Obersoite lrellbraun, wit 3 sehr schwach angedeuteten hellen. Längsliniens.

1b.) jung) Oberseite hellbram, Oborlippe briunlichgelb: ein weiber Flecken vor und hinter der (Mhriftinung, dahinter weibe Punkte. Seitenrïuder der Riickenschuppen schwäzlich, daher spurweise fein lïngsegestreift.

2.) (Oberseite selur hellbraus, mit 3 gelblichen, undentlichen Längslinien und vereinzelten schwarzen Punkten. (Oberlippenlinie weiblich, nach hinten verlägert, aber nicht iibor die erste limmpflälfte hinans bemerkbar.

3. ()herlipprenstreifen bis zum Ilals fortgessotzt; eine weibe Jorsolateral-

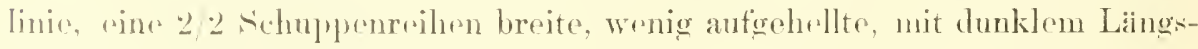
t]roken ringerfalote Mredianlinie. 
4. (jung) Rücken bram, Seiten schwarz nut zwei gelblichen, scharf begrenzten Läıgslinien.

5.) (jung); ähnlich, obere Linie gelblich, untere rein weib: Rïckenzone mit kleinen dunklen Flecken.

So rerschieden die Zeichnung der typischen Form dieser Art ist. so ïbereinstimmend verhalten sich in dieser Beziehung die Exemplare derjenigen Varietä, die ich frihher als M. Hildebrandti P'Eters botrachtet habe, worin mir auch Boclexger gefolgt ist. Ich stimme aber, nachdem ich writeres Material gesehen habe, Hewro bei, der diese Form nur als Varietät betrachtet und als $\boldsymbol{M}$. varia var. longiloba bezeichnet.

\section{Mabnia raria Ptrs. var. Comgiloba Methuen a Ilewitt.}

Mabuia Hildebranelti Werser nec Pferers, Fs. p. 34i. Taf. VII, fig. 5. - Hewitt, Ann. Transral Mus., 1911, p. 50. - Мethex \& Hewtт, p. 142.

Fundangaben: Lüderitzbucht: C. Maxrer, 1911, 1912 Ex. Nr. 1). Pinguin-Insel bei Lïderitzbucht: W. Mnchaelsex, 10. VII. 1911 (7 Ex. Nr. - ) ).

Wind huk: W. Michaelsex, 20.-2.). T. 1911 Ex. Nr. 3.

Usakus: W. Michatsise, 2.2. IV.-2.2. V1. 1911 (Ex. Nr. 4).

Niedex fuilurt diese dit aus liehoboth an.

Bemerkungen: 1a.) Sq. 32; 5. Supralabialia vor dem - nuboculare; $2-3$ spitze Auricularschüppchen: b. (in zwei stïcke zerschlagen); Nupralabialia $4-3$.

2.) Sq. $32-3 t$ nur 1 mal 34$)$ : 5 mal 5-5, 2 mal 5-t Supralabialia vor dem subuculare: 5mal $2-2$. 1 mal $3-2$ Auricularläppehen; 4. Lehr erreicht den ( berarm (1 mal), die Achselhöhle: (3 mal), die schulter (1 mal), drn Ellbogen (2nal). Länge $50+70.48+68, .2+63,55+70,50+53$, $42+80,36+63 \mathrm{~mm}$. D)as gröbtr Exemplar ist also $125 \mathrm{~mm}$ lang.

3.) S.q. 34. Auricularschüppehen vicht unterscheidbar.

4.) Sq. 32; 5 Supralabialia vor dem Suboculare: 2 Auricularschiupehen, das untere klein, spitzig. Durch den mehr walzigen, nicht abgeplatteten Rimplf, etwas bodentendere (rröbe und die in der oben zitierten Abbildung dargestellte Zeichnung namentlich den ungefleckten, aber nicht aufgehellten Mredianstreifen) ist diese V'arietait leicht erkennbar. Den durch die Benennung Hewrts als besonders charakteristisch hervorgehobenen Ohrschüplohen möchte ich aber keinerlei Bedentung als Varictätsmerkmal beilegen.

Obwohl beide Formen bei Lïderitzbucht gefunden wurden, so sind doch die Mehrzahl der Fundorte verschieden. Es wäre zu untersuchen, ob bis Läderitzbucht Stammform und Varietät nebeneinander und unter gloichen Lebensbedingungen gefunden werden ivergl. Mabuia sulcata). 


\section{Mabuia striata Ptrs.}

Boulexger, Cat. Liz. 1II, p. 204. - Werxer, JS., p. 343, Taf. VII, fig. 7. - Hewrtt, Ann. Transvaal Mus., II. 1910, p. 94. - Niedex, l. e., p. 451. - Hewit \& Power, p. 158.

Fundangaben: 1. Okahandja; G. Fock 1910; W. Michaelsex, 27., 28. IV. 1911 (3 Ex.).

2. Farm Otjituezu bei Neudamm, (a. $46 \mathrm{~km}$ No. von Windhuk; II. Michielsen, 13. V. 1911.

3. Asis, zwischen Otavi u. Grootfontein; I. Minaelsex, 6. VI. 1911.

4. Farm Paulinenlof an den Auasbergen, ca. $36 \mathrm{~km}$ (). von Windhuk: W. Michaelsen, 18. I. 1911.

5. Windhuk: W. Michaelsen, 29. IV.—. V. 1911 (2 Ex.).

6. Bahnstrecke bei Ke etmansh o op; Watter Kraner, 1910/11.

7. Usakos; W. Michableex, 22. IV._-22. YI. 1911 (13 Ex.).

8. 1) kawango,zwischen $19^{\circ} 11.21^{\circ} 30^{\prime}$ istl. Lg.; v. ZAstrow, 1912/13(3 Ex.).

9. Richoboth; K. Wegelebex, 1913.

\begin{tabular}{|c|c|c|c|c|}
\hline No. & $S q$. & $\begin{array}{l}\text { Zahl der } \\
\text { Riicken- } \\
\text { sehuppen- } \\
\text { kiele }\end{array}$ & $\begin{array}{l}\text { Supra- } \\
\text { labialia } \\
\text { vor dem } \\
\text { suboculare }\end{array}$ & $\begin{array}{l}\text { Breite des hellen } \\
\text { seitenbandes }\end{array}$ \\
\hline $\begin{array}{l}1 \text { a. } \\
\text { b. }\end{array}$ & $\begin{array}{l}34 \\
32\end{array}$ & $\begin{array}{l}3 \\
3\end{array}$ & 5 & $\begin{array}{c}1 / 2+1+1 / 2(-1) \\
1+1\end{array}$ \\
\hline e. & & & 5 & $\ddot{3}$ \\
\hline 2. & $3 s$ & 3 & i) & \\
\hline 3. & 40 & 3 & (i & \\
\hline 4. & 35 & 3 & 5 & \\
\hline $\begin{array}{l}5 a . \\
\text { J. }\end{array}$ & $\begin{array}{l}2+4 \\
34\end{array}$ & $\begin{array}{l}3 \\
3\end{array}$ & $\begin{array}{l}5 \\
5\end{array}$ & $2+1 / 2$ \\
\hline 6. & 34 & 3 & $6-5$ & $1 / 2+1+1+2$ \\
\hline 7. & $\begin{array}{l}34(9 \mathrm{Ex} .) \\
3 .)(9 \mathrm{Ex} .)\end{array}$ & $\begin{array}{r}3 \text { (9 Ex.) } \\
3-5 \text { (2 Ex. } \\
3-7 \text { (2 Ex.) }\end{array}$ & $\begin{array}{l}5(11 \mathrm{Ex} .) \\
(i-5(1 \mathrm{Ex} .) \\
5-4(1 \mathrm{Hx} .)\end{array}$ & $\begin{array}{c}1 / 2+1+1 / 2(\mathrm{Ex} .) \\
2+1 / 2(1 \mathrm{Ex} .) \\
1+1 / 2(1 \mathrm{Ex} .) \\
1 / 2+1 / 2(2 \mathrm{Ex} .)\end{array}$ \\
\hline $\begin{array}{l}\text { sa. } \\
\text { b. } \\
\text { c. }\end{array}$ & $\begin{array}{l}: 34 \\
: 34 \\
34 \\
34\end{array}$ & $\begin{array}{l}: 3 \\
3 \\
: 3 \\
3\end{array}$ & $\begin{array}{l}5 \\
5 \\
5 \\
5 \\
5\end{array}$ & $\begin{array}{l}\text { liiiekenzone } \\
\text { sehr hellbrann, } \\
\text { mit sclwwarzen } \\
\text { und gelblichen } \\
\text { Piinktehen, } \\
\text { niclit deutlich } \\
\text { von den hellen } \\
\text { seitenband } \\
\text { (1 } 1 / 2 \text {-2) abge- } \\
\text { grenzt. }\end{array}$ \\
\hline
\end{tabular}

Färbung und Zeiehnung

Dunkle Bänder nit hellen Ocellen, ähnlich Chalides ocellatus. Lnterseite bei b dumliel getüpfelt, mit Längslinie auf der Hinterlälfte des Bauches; Bauchzeichnung bei a undeutlich, verwaschen.

Kehle stark, Bauelı schwach dunkel getleckt.

Dunkle Bänder nit Ocellen. Kehle stark, Kehle spärlieh grau gefleckt.

Dunkle Bänder ohne Ocellen. Unterseite einfarbig. Seitliches helles Lïngshand undeutlieh.

líehle und lianch dunkel gefleckt.

Dumkle Bänder mit Ocellen, Interseite dunkel gefleckt.

Dunkle Binder mit Oeellen, Untesseite sehwarz bespritzt.

Dunkle Bänder ohne Ausnahme mit Gcellen. Interseite in verseliedenster Weise dunkel gezeichnet: z. I3. ganze Unterseite spärlich grau punktiert; ganze Unterseite ziemlich dicht grau gefleckt; nur liehle gran getleckt; Banch mit gratuer Längsmittellinie; Bauch mit schwarzen Punkten usw.; Koptoherseite bei helleren Exemplaren auf liraunem Grunde sehwarz und w if getleckt. 


\section{Mrabuia sulcata Ptrs.}

Boclexirer, Cat. Liz. III, p. 206. - Werier, Fs., p. 3.45, Taf. VIII., Fig. 10, 10 a u. b. Hewtt, Ann. Transvaal Mus., II, 1910, p. 94. - Nredex, I. c., p. 450. - Hewitt \& Power, p. 158.

Fundangaben: Lï deritzbucht; W. Munaelsex, 20.-24. VII. 1911. (nigra.)

Wind hu k: WV. Michaelsex, 29. IV.-8. V. 1911 (serstriata).

Neudamm, $42 \mathrm{~km}$ (1.No. von Windhuk; W. Michaelsex, 10.-15. V. 1911 (subnigra, serstriata).

Ton Niedex auch für Kuibis erwähnt.

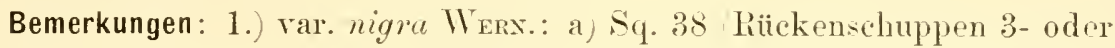
unsmmmetristh 4 kielig.) Frontonasale vorn halbiert, rom Frontale getrennt. suboculare links über dem 6.-8., rechts über dem 4. u. 5. (5. sehr lang, $=5 .+6$.) supralabiale.

b) S.q. 36. (Rüickenschuppen 5-, teilwrise bkiclig.) Frontonasale vom Frontale getrent. Linkes Parietale mit dem Interparietalo trilweise verschmolzen. Suboculare auf dem 5. und 6. Supralabiale.

๑.) var. subnigra Wers.: Sq. 40. (Rüickenschuppen 3 kielig, am Rande entsprechend den Kielen zackig). Frontonasale mit Frontale in Kontakt. suboculare iber dem 5.-7. Supralabiale. - Oben hellbraun, Kehle schwarz, Brust schwarz, woib gefleckt, Bauch, Vorder-und Hinterbeine und schwanz unterseits weiß, schwarz gefleckt (Schwanzregenerat einfarbig weiß). (Iberseite der schnauze, auch Hals und Torderricken mit wenigen dunklen Flecken: Kopfseiten schwarz.

3.) var. serstriatu Boc: a) Sq. 36 (Riickonschuppen 3 kielig). Frontonasale und Frontale in Kontakt. Interparietale mit deutlichem Parietalauge. $5-4$ (4. sehr lang) Supralabialia vor dem den Lippeurand erreichenden Suboeulare. Kopfschilder symmetrisch dunkel gezeichnet. Kéhle und Bauch weiß, fein dunkel getüpfelt.

b) šq. 36 (Riickenschuppen 3 kielig, nur spurweise Andeutung von Außenkielen). Frontonasale und Frontale in Kontakt. 6-5 Supralabialia vor dem den Lippenrand erreichenden subnculare. Untersite anfarbig.

E. ist sehr bemerkenswert, dab diese 3 Varietänn nicht nur soweit bisher bekannt, nicht durch Tberoänge verbunden sind und sogar am selben Fundorte vorkommen Neudamm: subnigra. serstriata). Es wär noch fostzustellen, ob sie in diesem Falle nebeneinander und unter denselben Lebensverhältnissen leben oder sich doch gegenseitig ausschlieben. Nach Power sollen die schwarzen Tiere $\sigma^{\top}$, div gestreiften of sin: nath dem mir von dem Koll. Scmutze vorliegenden Material erseheint mir dies nicht seh glaubwïrdig. 


\section{Mabuia acutilabris Ptrs.}

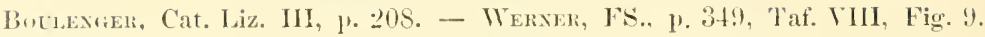

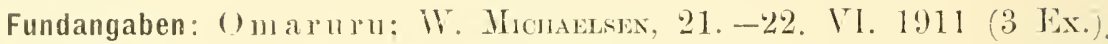
Usakos: IV. Mumansw, 22. IT.-22. YI. 1911 (9) Ex.).

Bemerkungen: Dirse in allen wesentlichen Mrrkmalen scher bestandiga und schon nach der charaktoristischen Zeichmog leicht erkennbare Art entspricht anscheinend biologisch ganz der Scapteira cuneirostris unter den Lacertiden von Deutsch-siidwestafrika. Dir 'Zahl der Schupuemeihen betrigt 32, die liickrnschuppen sind nutwerer gleichstark dreikielig, oder es ist der Mitielkiel schwächor als dio soitlichen, oder er tohlt ganz. Das suboculare liogt anf dom 4., 5., 6. oder atuf dem 5. nud 6., ansmahmswaise auf dem 4 . und 5. Supralabiale.

liei einem Exemplar ist das Frontalo qure in win gröberes vorderes Grekiges und ein kluinures linteres lingliches (rochteckiges) stohildchen gorialtom.

\section{Lygosoma Gray.}

\section{Lygesoma Smmaleralli Smith.}

Budlextieli, ('at. Liz. III, 1. 307 ; Ann. S.Afr. Mns., V/9, Nr. 16, p. 486. - Whater, SF., 1. 350. - HewitT \& Poweli, p. 159.

Fundangabe: (irootfontein; Loxkexbers 1911 (5 Exomplare).

Bemerkungen: 1.) Grïbtes Exemplar $77+49 \mathrm{~mm}$ (Schwanz rogeneriert). Entfornumg der Selnatuznspitze vom Vorderbrinamsatz 22/3 mal in der vom Torder-zum Hinterlorinansatz enthalten (bei den folgenden Exemplaren kurz: "Entf. $22 / 3$ " bezeichnet). Sif. 26 ( auch bei allen folgenden Exemplaren). 4. Kehe sterts dentlich linger als 3. Sutur zwischen Nasale und Supranasale unvollstiindig, nach rorn ïber das Nasenloch nur etwas hinauserehend. Oberseite hellgraubraun, in der vorderom himpfhäfto Schmpenrinder otwas dunkler; in dor hinteren tritt auf dor liasis jeder Felmper ein dunkler Fleck anf, der sich auf den folgenden sehuppen immer meh vergribert; anch das Solnwanzogenerat ist so guzeichnet und vom basalstumpf mu schwierig abzugrenzen. Timmpferitun, hintrester Teil des Banches und sichwauzuntersoite auf gelblich weifen Grunde dnokel getiipfolt.

2.) Jänge 5.5 $+80 \mathrm{~mm}$ (Schwanz vollstandig). Nasale vom supranasale volktaindig gotremnt. Entf, $21 / 3$. Bauch und S'chwanzuntersesite mit Ausnahum der spitze njelet dunkul getiipefolt.

3., 4., 5.) Jïngere 'lier. Nasal rom Sulranasale mollständig getremnt.

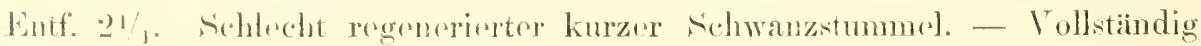

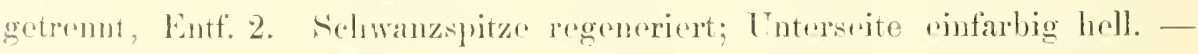

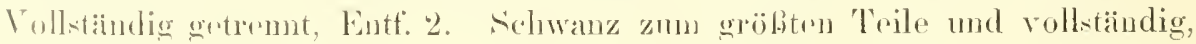


fast unkentlich regeneriert, unterseits dunkel punktiert, sonst L'nterseite einfarbig.

Auffällig ist bei dieser surie folgendes: rrstens, daß die schnanze bei den jüngeren Tieren noch höher, stumpfer ist, als bei den erwachsenen, bei denen sie niederoedrickt und namentlich in dor Kehlgegend ganz flach ist: ähnlich wie bei Scincus; zweitens dab dis Hinterbeine wälnend der postembryonalen Entwicklung immer weiter von den Vorderbeinen abrïcken, wodurch die Gestalt immer gestreckter, schlangenähnlichor wird. Thnliches kann auch bei Chalrides beobachtet werden.

\section{Sepsina Boc.}

\section{Sprsina amyolensis boc.}

Barboza de bucage, Herpétologie d'Angola et du Congo, Lisbonne 1s95, p. 53̈: Jorn. Ac. Sci. Lisboa. I. 1866, p. 6i3, Taf. I, fig. 1, 1a-d.

Fundangabe: Grootfontrin; IV. Mrandesex, X. VI. 1911.

Bemerkungen: Ein Exrmplar von Grootfontein, das sich von der lieschreibung von Bocate durch die gröfere Zahf von schulpenreihen 26 anstatt 24), von einem Exemplar meiner Sammlung aus Angola (aus dem Mus. Lissabon) unwesentlich auch in dur Färbung unterscheider. Diess Art ist neu tür l)eutsch-Sudwestafrika, ron wo anch die Gattung noch nicht bekannt war.

Entferumg von der Sichnanzenspitzo zum Vorderbeinansatz $3^{3}{ }_{4}$ mal in der rom Vorder- zum Hinterbein rnthalten; Vorderbein so lang wir die Entfernung ron der Sclmauzenspitze zur Angenmitte, Hintroein so lang wie Entfernung, von Fichnauzenspitze bis zum Hinterrande des 7 . (letzten) Supralabiale.

()berseite hellbraun mit schmalen grauen Längslinien (dunkle Schuppenseitenränder); Kopf mit EinschluB der Parietalia grau, dunkl'r als der Rücken. Unterseite gelbichweif.

Kopfrumpflänge $8.5 \mathrm{~mm}$; Vorderbein 5-5, Hinterbein $9 \mathrm{~mm}$ lang.

\section{Acontias Cuv.}

\section{Acontias meleagmis $L$.}

Botlexger, Cat. Liz. III, p. 427. - Weraer, SF., p. 351. - Hewitt, Ann. Transtaal Mus., II, 1910, p. 96.

Fundangaben: 1. Okahandja: G. Fock, 1910 (8 Fx.).

2. Ebenda: Giauer, 1911,1 Ex. .

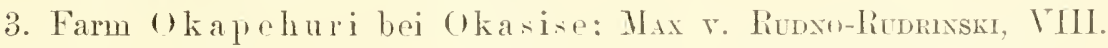
bis LX. 1911 ( 7 Ex.). 
4. Farm ()tjituezu bei Neudamm; ('a. 46 kun NO. von Windhuk; W. Michaelsex, 13. V. 1911 (1 lix.).

Bemerkungen: Schuppemeilıen: 6 mal 16 (Okahandja 1, 2); 10 mal 18 ()kapeluuri, ()tjiturzu, Okahandja 1), 1 mal 20 (Okapehuri).

\section{Acontirs: limeatus Ptrs.}

Borlexger, ('at. Liz. III, p. 428. - Weknel, SF., p. 351. -- Hewt', p. 96.

Fundangaben: Bahmstrecke bei Ke etmanshoop: WALTER Lramer. $1910 / 11$.

Ein Exemplar mit 4 dorsalen lieihen dunkler Punkte anstatt Lingslinien.

Geiab-Rivior bei stolzenfols am Oranje-Flub; H. Thousex, V. 1913.

Ein großes Exemplar (190 mm lang).

\section{Rhiptoglossa. \\ Chamaeleontidae. \\ Chamaeleon L. \\ Clumaleteon dilepis Leach.}

Botlexges, Cat. Liz. 1I1, p. 450. - Werker, Zool. Jahırb. Syst., XV, 1902, p. 339 ; Tierreich, Lief. 27, 1911, p. 13; SF., p. 352. - Lanipe, p. 179. - Неwtt \& Power, p. 159.

Fundangaben: 1. Okalıand ja; G. Fock, 1910 ( $\sigma^{\prime}$; 1 우 j.).

2. Windhuk; Wutrke, 1911 ( $($ ) $)$.

3. Farm Paulinenlof; ca. $36 \mathrm{~km} \mathrm{().} \mathrm{von} \mathrm{Windhuk;} \mathrm{Frl.} \mathrm{Hulle-}$ MANy, I.-V. 1911 (우).

4. Windhuk; Busch, 1911 (2) 오 $f$ ).

5. Usakos; M. Michaelsen, 22. IV.-22. VI. 1911 (q j.).

6. Neudamm, 42 km ON(). von Windhuk; W. Micuablsex, 10.-15. V. 1911 (f j.).

7. Farm ()kapehuri bei ()kasise; Max v. Remo-kunziski, VIII.-IX. 1911 (б j.).

8. Okawango, zwischen $19^{\circ}$ u. $21^{\circ} 30^{\prime}$ istl. Lg.; v. Zastkow, 1912 bis 1913 if).

Bemerkungen: Bei dem gröBeren of aus Windluk (4), das $130+125 \mathrm{~mm}$ miBt, sind dir (Jocipitallappen deutlich ronrinander getrennt (Roperi). Das P von Farm P'anlinenhof hat Birr von $12 \times r \mathrm{~mm}$ in den ovidukten. Bei dem laar aus ()kahandja ist folgendes zu bomerken: l)ie spärlichen hellen Flockrn in oberen limmptelrittel sind in der Fairbung deutlich verschieden von den hallen Seitonbinden in unteren Drittel; diese sind weißlich, die 
Schuppen in gröBeren Gruppen angeordnet, die durch tiefe Furchen voneinander getrennt sind.

Von Lampe aus Rietmond und Karibib erwähnt.

\section{Chamaeleon mamaguensis Smith.}

Boltexger. Cat. Liz. III, p. 462. - Weraer, Zool. Jahrh. Syst., XV, 1902, p. 369, Taf. 16, p. 40, fig. 14; SF., p. 353. - Bullexcier, Ann. S.Afr., V/9, Nr. 16, p. 493. - Lampe, p. 152.

Fundangaben: S'wakopmund: Jacoss 우 ad.

Lii deritzbucht; Baumgart 1911 (f ad., getrocknet).

Ton Lamp: aus Obib am (Oanje River genannt.

Bemerkungen: Rïckenhücker 13, bezw. 15 (1: gröBerr): Länge dus swakopmund-Fxemplares $125+83 \mathrm{~mm}$, des Lïderitzbucht-Exemplares $125+105 \mathrm{~mm}$.

\section{Ophidia.}

\section{Typhlopidae.}

\section{Typhlops Schn.}

\section{T!llhtols muceuso Ptrs.}

Botleager, Cat. Sn. I, p. 46.

Fundangaben: Okawango, zwischen 190 und $21^{0} 30^{\prime}$ östl. Lo.; rox KAstrow, 1912-1913.

Gro otfontein: Ltakexberix, 1911.

Okahandja: (i. Fock, 1910 (3 Exemplare).

B rackwater. $20 \mathrm{~km} \mathrm{N.} \mathrm{von} \mathrm{Windhuk:} \mathrm{W.} \mathrm{Micuaersex,} \mathrm{23.} \mathrm{V.} 1911$.

AuBer von Grootfontein wird die Art ron ștersenelo (p. 12) auch ron Gobabis erwähnt.

Bemerkungen: Ton den Okahandja-Stiicken ist das grïßte $320 \mathrm{~mm}$ lang. der Durchmesser 24\% 11 al in der Gesamtlange enthalten. Schuppen 34-36 um die Rumpfmitte.

Oberseite dunkelbraun mit kleinen gelben Fleckin und Längsstricheln. die dadurch entstehen, dab Längreihen ron schuppen auf kurze strecken gelb gefärbt sind. Unterseite meist einfarbig gelb.

Das Exemplar von Brackwater ist lialbwiichsig, seine Schnauzenkante weniger scharf als bei den Erwachsenen. Oberseite unegehäBig hellgrau und schwarz gefleckt, Unterseite einfarbig gelblichweiß.

Das (1kawango-Exemplar ist ihnlich, aber wenig schwarz gefleckt.

Das Stiick ron Grootfontein ist stark eingetrocknet und rerkrimmt. und die Bestimmung daher nicht sicher. 


\section{Glauconiidae. \\ Glauconia Gray. \\ Glanconia Iabialis sternf:}

Stenxem, sli. Ges. naturf. Fr., Berlin, 1908, p.92; Mitt. Zool. Mus. Berlin, V, 1910, p. 54. Fundangabe: Ts $11 \mathrm{meb}$ : W. Michaelsex, 13.-19. VI. 1911.

Ein Exrmplar, $106 \mathrm{~nm}$ lang, Durchmesser $1 \mathrm{~mm}$.

Ton Sterseme (p. 14) für 1)utjo angegoben.

\section{Boidae. \\ Python Daud. \\ Python anchictae Bocage. \\ Tafel [lI, Fig. 1, $1 \mathrm{a}$ und b.}

Bocatie, Herpéthologie d'Angola et du Congo, Lisbonne 1895, p. 73, Taf. IX, fig. 1, a-c.

Fundangabe: Ababis: (). Müller, 1910.

Bemerkungen: Ton dieser anscheinend iiberaus seltenen Art, ron der hisher seit 27 Jahren) auBer den drei f)riginalexemplaren aus Ca tu mbolla iu Angola krine weiteren brkannt geworden sind, liegt ein zwar otwas verletztes, aber im allgemeinen sonst gut erhaltenus ơ von $128 \mathrm{~cm}$ Gesamtlänge (Schwanz $15 \mathrm{~cm}$ ) ror.

Fs ist das gröfte bekannte Exemplar dieser Art, und ich zweitle nicht daran, dab es sich hien wio bei dem nahe rerwandten Pythou regius um eine $/$ woroform handult. An diese Art rinnert die Kopfzeichunng, die tiofen hostral- und Oberliprengruben, der in der Mitte auttallund dicke Kïrper, wälıend dir limmpfzeichnung riel Alnnliclıkeit mit derjenigen von I'ython silotes rar. variegata aufweist.

Schuppentormel: Sq. (i1, V. ${ }^{4 / 4}+260$, 1. 1. Sc. ${ }^{54} / 54+1$.

Aupralabialia 14-15 idas 7. u. 8., brzw. 8. u. 9. unter dem Auge); 15 Augenkrauzehildehen, dis supra- und praeocularen am gröhten; $1+2+2$ vereröberte Lornalia: Intrmasalia doppolt so lang wie breit; Praefrontalia obenso lang wie breit, unregehnäfig: ebenso wie die Internasalia in der Jittellinis dureh eine sichildehenreihe getronnt.

Die Zeichnung der (tberserite ist durch die Abbildung (Taf. VII, Fig. 1) genïgend wiedergegebrn: die Farben sind hollbrann, gelblichweib und scliwarz.

\section{Colubridae.}

Boodon D. B.

\section{Boorlone lineretos DB.}

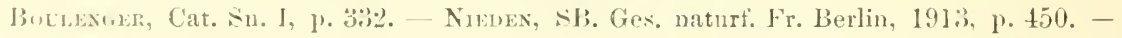

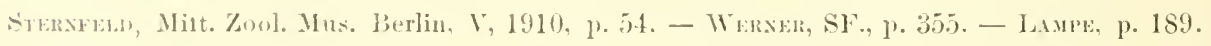


Fundangaben: Frootfoutein: Luxkerbeix, 1911: IV. Michaelsex. 7.-11. NI. 1911.

Okah andja; C. Fock, 1910; Gater, 1911.

Farm Okapehuri bei Okasise: Max r. Rewo-Renzissis, VIII. bis IX. 1911.

Farm Paulinenhof, ca. $36 \mathrm{~km}$ (). von Windluk, an den Anas-

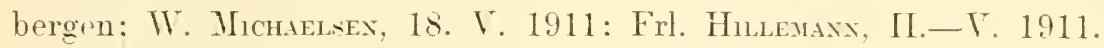

IV ind huk: Bisch 1911.

Wird von Stelixem für Okahandja, Gobabis, ( ranjefluß, ron Niedex für Kuibis, ron Laspe für liietmont und Windhuk angeführt.

Bemerkungen: Zahlreiche Exemplare, dir ich durchwegs dieser Art zurechne; zur Beibehaltung der Art B. mentalis Grus. sehe ich ebensowenig rinen Grund wio Sterreld. Das gröbte Exemplar ist 73 cu lang (Achwanz $10 \mathrm{~mm}$ ) und lat pine Maus im Magen.

Von diesen sind 2 nit 25, 9 mit 27 und 5 mit 29 schuppenreihen: 5 Exemplare haben beiderseits 1 I'raeoculare, 7 beiderseits 2, 3 auf piner ceite 1, auf der anderen 2) Pracocularia.

\section{Lycophidium DB.}

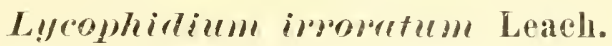

Bollexger, Cat. Sn. I. p. 340. - Werner. SF., p. 355. - Sterafeli, Mitt. Zool. II us. berlin. 1910, p. 51 (capense). - Lasie, p. 159 (capense). - Hewtтt d Powel, p. 161.

Fundangaben: 1. (trootfontein: Ltakexerix, 1911 ( $\sigma^{7}$ u. f).

2. Okalhandja: (r. Fock 1910 (o u. Q ).

Von Stersele für Windhuk. Gobabis und Grootfontein prwähnt.

Bemerkungen: 1.) o T. 177, sc. $37 / 37+1$, ㅇ T. 189, sc. $29 / 29+1$.

z.) o T. 176 , sic. $36 / 36+1$, q T. 187 . s.c. $27 \cdot 27+1$.

1.) Seitenschupen mit hellgraum spitzenfleck oder am Pauchrande) hellgrauem Hinterrande; Bauch- und Schwanzschildtr hinten hellgrau gesïumt.

2.) Kopf oben grau, dicht dunkel getiipfelt. 1'ntrseite (o) gelblichweib mit großen dunklen Flecken; ( $f$ grau mit unrogelmaBigen golblichen Flecken. schuppenspitzen grauweib c), Subcaudalia grau, hinten weib getleckt (ㅇ.. Länge des of to $0+j 0 \mathrm{~mm}$.

Das Lycophidim ron Doutsch-Siidwestafrika wird ron StTERxFen zu capense gestellt. Ich tinde keinen Lnterschied der westafrikanischen stücke von irroratum. 


\section{Pseudaspis Cope. \\ Psemedespis reme L.}

Boclexier, Cat. Sn. I, p. 373. - Werner, SF., p. 356. - Lampe, p. 191. - Sternfetd Mitt. Zool. Mus. Berlin, V, 1910, p. jt.

Fundangaben: 1. Nakop-Rivier zwischen Nonidas und Goanikontas: Herlyx, $1910\left(\sigma^{\top}\right)$.

2. Farm ()kapelurj bri Okasise: Max y. Runo-Runzissi, III.-IX. $1911\left(\sigma^{7}\right)$.

3. 4. Ukawango, zwischen 190 n. $21^{\circ} 30^{\prime}$ istl. Lg.: r. Zastrow, 1912 bis $1913\left(\sigma^{7}, q\right)$.

5. Farm Paulinenh of, ca. $36 \mathrm{~km}$ (1. von Windhuk; Frl. Huldemaxx, I.-V. 1911 (Jumgos).

6. Sandfold, ca. $60 \mathrm{~km}$ SO. von Grootfontrin; Lunkexbers (Junges).

Von strempele aus Gobabis erwihnt, von LAsue aus Rietmond und Kakatskupp.

Bemerkungen: 1.) S.'. 27. V. 187, Sc. 59/59+1; 'Trmporalia $2+4,3+4$.

Lichtbram, jode Schuppe an der Spitze dunkelbram. Unterseite gelb, Schwanzunterseite, hintere Hälfte gran gewälkt; Kehle graugrün gefleckt. Länge $1260 \mathrm{~mm}$, Schwanz $235 \mathrm{~mm}$.

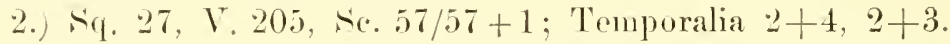

Helloranbraun mit schwarzen Schujpenspitzen, gelblichweißen Flocken und cinzelnen schwarzen Schuppenränderu. Länge $900 \mathrm{~mm}$. Schwanz $160 \mathrm{~mm}$.

3.) o S. . 27, Y. 194, S.. 61/61+1; Temporalia $2+4$.

Oberseite hellgelburam mit langwelligem Zickzackband, älnnlich wie bei lipera ammodytes.

4.) Q S.1. 27, V. 206, Sc. $53 / 53+1$; T'emporalia $2+4$.

Hellgraubram, einfarbig, jed. Schuppe an der änersten Spitze selwwarz. Ventralenhinteräinder dunkelgrau.

5.) Bri dieser sehön gezuichneten Jugendform sind die Rïekenflecken ron drus seitlichen durch rine oft unterbrochene gelblichwribe Längslinie getrennt.

6.) Wir vorige, aber die helle Längslinie vollständig in Flecken aufgelïst. Rïckenflecken bei beiden Exemplaren, von einer hellen Querlinie lialbiert, stellenwoise (wenigstens am Nacken) rin Zickzackband bildend.

\section{Micaëla n. gen.}

Diagnose: Kopf niedrergedriickt, nicht rom Riumpf abgesetzt. Schnauze weit vorspringend. mit selır deutlicher lsorizontaler Kante, auf der Unterfäche mit breiter Längsfurche. Nasenloch klein, im vorderen Teile eines ganz gereilten Nasalr. Auge klein, mit runder l’upille. Keiue Internasalia, Fron- 
tale sehr groß. Supraocularia sehr klein. Parietalia schmal, nur auf kurzer Strecke in Beriihrung miteinander. Kein Loreale. Rumpf langgestreckt. rund, sclıwanz kurz, gegen das Ende wenig verschmälert, dieses abgerundet. Oberkieferzähne 3, weit getrennt, nach hint'n an Gröbe rwas zunehmend. Unterkieferzähne klein, weit getrennt. Sichuppen glatt, in 17 Längsreihen. Anale geteilt. Subcaudalia paarig.

\section{Hicaёla permasuta n. sp.}

'Tafel VII, Fig. 2, 2) a $11.2 \mathrm{~b}$.

Fundangabe: Deutsch-sidwestafika, Farm Otjituezu bei Noudamm, ea. $46 \mathrm{~km} \mathrm{No.} \mathrm{von} \mathrm{Windhuk:} \mathrm{W.} \mathrm{Michanesen,} \mathrm{13.} \mathrm{V.} 1911$.

Beschreibung: Rostrale groß, oben und unten gleich lang, I'orderrand parabolisch, Hinterrand eine sehr stumpfe spitze bildend, durch die Praefrontalia, dir breiter als lang sind und miteinander eine sehr kurze sutur bilden. rom Frontale getrennt. Dieses ist 23/2 mal so lang wie der yon oben sichtbare Teil des Rostrale, nicht ganz doppelt so lang wie breit, achteckig, in Kontakt mit P'raefrontale, Praeoculare, Supraoculare und Parictale. Ein langes, 5eckiges Praeoculare, in Kontakt mit dem hinteren Nasale; ein selur kleines Postoculare. Fechs supralabialia, die beiden ersten ganz, von den übrigen die untere Hälfte auf der Unterseite des Kopfes golegen, das 3. und 4. am Auge, das 5. am größten, das 6. klein. Ein sehr großes Temporale, zwischen Parietale und 5. Supralabiale eingekeilt. Symplyysiale klein; erstes Paar von sublabialen in Kontakt: zweites Paar klein, drittes sohr grob. Vorderes Paar von Kinnschildchen sehr klein und schmal, hinteres winzig klein, fast ganz in der Kinnfurrhe verborgen, so dab das 3. Paar von Unterlippenschildehen median in Kontakt zu sein scheint. Tentralia 209, Fubcaudalia 18 Paare.

Oberseite purpurschwarz, äußere Schuppenreihe gelb, die $2-3$ nächsten Rrihen dunkel wit gelben Rändern. Unterseite hellgelb mit unregelmäBigen spärlicheu dunklen Flecken. Torderrand der Subcaudalia dunkel. Rostrale unten ebensu dunkel wie oben. Supralabialia gelb, etwas dunkel gefleckt.

Totallänge $580 \mathrm{~mm}$ : Schwanzlänge $32 \mathrm{~mm}$; Durchmesser $9 \mathrm{~mm}$.

Bemerkungen: Diese Achlange, wohl der interessanteste Reptilfund der Michancsexschen Expedition, steht der Gattung Prosymna nahe, unterscheidet sich aber durch die geringe Zahl von Zähnen, die anch nach hinten an Größe nicht autrallend zunehmen: ferner durch die vertikale Nasalsutur, das Fehlen der Internasalia, den langgestreckten Körper, stumpfen Fichwanz und die runde Pupille.

24 Michaelsen, Deutsch-Südwestafrika. 


\section{Prosymna Gray. \\ Prosymna Sundevalli Smith.}

Boullenger, Cat. Sn. II, p. 247. - Werker, SF., p. 357.

Fundangabe: O kahandja: G. Fock, 1910. (var. bicittate W Wrx.).

Bemerkungen: Ein Exemplar, 296 mm lang (Schwanzlänge 21 mı); V. 180 , se. 22 Paare.

Ein schwarzer Fleck iiber jedem Auge, in der Mitte vor der hinteren Spitze des Frontale, sowie linter jedem Parietale; an diese die beiden Längsbinden des Rïckens anschliebend, die je $1 / 2+1+1 / 2$ Schuppenreihen breit, braun, mit weißen S'chuppenrändern sind. Rïcken zwischen den Binden mit spärlichen dinklen Fleckehen.

\section{Prosymua bergeri Lindh.}

Jixphols, Jahrb. Nassau. Ver. f. Naturk. Wiesbaden, Jahrg. 55, 1902, p. 57.

Fundangabe: Usakos; W. Michaelsex, 22. IV._22. VI. 1911.

Ein Exemplar dieser seltenen Art, die erst aus Riotfontein nach den Typen bekannt ist.

Bemerkungen: Das Exemplar hat die Schuppenformel: A. . 15, V. 150, Se. 48/48+1. Supralabialia 7, das 4. und 5. an Auge (bei den Typen 6, das 3. und 4. am Auge) Kopfoberseite braun, pin dunkelbraunes Querband am Nacken, vorn und hinten weiß begrenzt (das vordere weiße Band erreicht den Hinterrand der Parietalia). Obersoite bleichbrann, mit weißen Punkten, hinten noch heller, einfarbig braun. Unterseite weiß. Ein dunkelbrauner Fleck unter dem Auge.

Gesamtlänge $147 \mathrm{~mm}$, davon $27 \mathrm{~mm}$ auf den Sichwanz entfallend, aliso anscheinend $\sigma$.

Tabelle der Prosymma-Arton. Die gegenwärtig bekannton Prosymma-Arten lassen sich wie folgt unterscheiden (mit Zugrundelegung der Tabelhr Bolluencens):

I. Schuppen glatt.

A. Zwei Internasalia:

a. Ein Prarfrontale; zwei vordere Temporalia überninander

1. Sumderalli Sintri.

b. Zwei Pracfrontalia; nur ein vorderes Temporale

2. Greigerti Moce.

B. Fin einzig's Interuasale:

a. Shehnauzemrand abgerundet; Subcaudalia 19-29 Paare

3. variabilis WERx.

b. Schnauzenrand kantig:

ж. Frontale stioBt vorn an das Auge ... 4. Bucagei Bunar.

3. Frontale vom Auge durch Praroculare getrenut: 
$\alpha^{\prime}$ Zweites und drittes Oberlippenschild berührt das Auge; ein Postoculare . . . . . . . 5. meleagris Reixn.

$\beta$ 'Drittes und viertes oder viertes und fünftes Oberlippenschild berülirt das Auge;

$\alpha^{\prime \prime} 19-34$ subcaudalenpaare

$\alpha^{\prime \prime \prime}$ Nur ein Postoculare; zwei Paare vom Kinnschildchen 6. ambigua Boc.

$\beta^{\prime \prime \prime}$ Zwei oder drei Postocularia; ein Paar von Kinnschildern ...... 7. transraalensis Henrtт.

3" $3 S-50$ subcaudaleupare

$\alpha^{\prime \prime \prime}$ Stirnschild meln als halb so breit wie der Kopf

8. Bergeri Linoh.

$\beta^{\prime \prime \prime \prime}$ Stirnsehild weniger als halbmal so breit wie der Kopf

9. frontalis PTrs.

[I. Schuppen gekielt ............ 10. Jani Biaxc.

\section{Tarbophis Fleischm. \\ Tarbophis semiannulatus Smith.}

Boulexger, Cat. Sn. III, p. 51. - Werker, SF., p. 35S. - Sternfeld, Mitt. Zool. Mus. Berlin, V, 1910, P. 55. - LAM1'E, p. 198.

Fundangaben: 1. Wind huk; Buscre, 1911 ( $\sigma^{\prime}$ ) (von LAmes von dorther erwähnt).

2. Windliuk; W. Mrcuaelsen, 29. IV.-8. V. 1911 (Junges Tier).

3. Usakos; W. Michaelsex, 22. IV._-2. VI. 1911 (Junges Tier).

4. Rehoboth; K. Wegeleben (Junges Tier).

AuBerdem von Goba bis und $\mathrm{K}$ e etma ns ho o p bekannt (ATERneld).

Bemerkungen: 1.) o su. 19, V. 2.23, A. 1, se. $64 / 6 t+1$.

Supralabialia 8 (3. 4. 5. am Auge); Temporalia $2+3,2+3$;

50 schwärzliche Rückenflecken, Grundfarbe weißlich.

2.) Sq. 19, V. 225, A. 1, sce.70/70+1.

Supralabialia 8 (3. 4. 5. am Auge); 3 Postocularia; 68 dunkle Querbinden (davou 18 auf dem Schwanz); von diesen Querbinden sind manche nur auf eine Körperlälfte beschränkt und alternieren in unregehmäßigen Zwischenräumen; so steht die 4.-15., 29.--34. Halbbinde abwechselnd.

3.) Sq. 19, V. 244, A. 1, Ne. $65 / 65+1$.

Supralabialia 9 (3. 4. 5.): 2 Postocularia: 75 dunkle Querbinden (daron 20 auf dem Schwanz). In der linteren Rumpfhälfte und auf dom schwanz stehen schmälere und blassere Querbinden in dor Mitte zwischen den übrigen. 
Die beiden anselesinend wenig iiber die 1. Häutung hinubergekommenen Jungen sind 285 bezw. 242 nmm lang.

4.) Sq. 19. Y. 220, A. $1 / 1$, Se. $6969+1$.

Supralabialia 8-9 (3. 4. 5.); 2 Postucularia: Temporalia $2+2,2+3$. 58 dunkle Rückenflecken, davon 15 auf deun Schwanz.

\section{Trimerorhinus Smith.}

\section{Trimerorhinus tritaeniatus Gthr.}

Borlexger, Cat. Sn. 1II, p. 139. - Werier, SF., p. 35S. - Strixfeld, Mitt. Zool. Mus. Berlin, $v, 1910$, p. 55.

Fundangaben: O kaliandja: C. Fock, 1910 ( $\left.\sigma^{*}\right)$.

Farm utjiturzu bei Neudamm, ca. $46 \mathrm{~km} \mathrm{No}$. ron Windhuk: W. Michaelsen, 13. V. 1911 ( ( ).

Farm P'aulinenlof an den Anasbergen, ea. $36 \mathrm{~km}$ o. ron

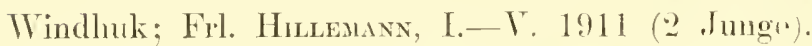

Brackwater, $20 \mathrm{~km} \mathrm{N.von} \mathrm{Wind} \mathrm{hnk;} \mathrm{W.} \mathrm{Mrchasisen,} \mathrm{23.} \mathrm{Y.} 1911$ (Jung).

()kaliandja; (inuer, 1911 (2 Junge).

Auberdem von Gobabis, Grootfontein, Grob-Namaland, Ka la hari bekannt ('Mternfelo).

Fine in allen Merknalen selır bestiindige und leicht kenutliclıe Art.

\section{Rhamphiophis Ptrs.}

\section{fincemphophis multimaculatus Smith.}

Bollewier, Cat. An. I11, p. 148. - Nieven, SB. Ges. naturf. Fr. Perlin, 1913, 11.450. --

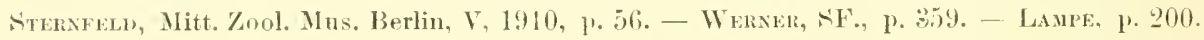

Fundangaben: Balustrecke bej Kretuanshoop; Watwe Krauer. $1910 / 11$.

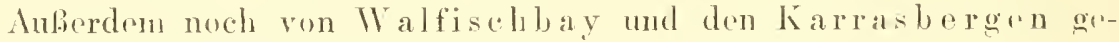

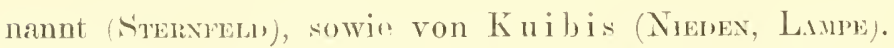

Bemerkungen: $q$ sig. 17. Y. 155 , Se. $38 / 38+1$.

Praecularia $1-2$, P'ostocularia $3-2$, Temporalia $\frac{1}{1-1}+4,2+3$.

Sublabialia 5. (Hosamtlinge 284 mo (Schwanz 38).

Fälonng blïnlichaschgrau, Flecken rötlichbranu, die Riickenflecken

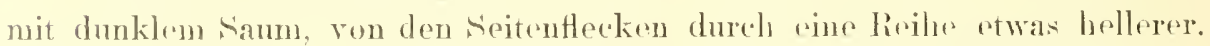
blimlichrr, dunkel gesiumntor Flecken setrennt; dunkle Interorbital- und l'ostorbitalbinde vorhanden. 


\section{Dispholidus Duvernoy.}

\section{Jispholidus tyllus Smith.}

Bollexger, Cat. Sn. III, p. 157. - Werxer, SF., p. 363. - Sterxeeld, Mitt. Zool. Mus. Berlin, V, 1910, p. 57.

Fundangaben: 1. Okahandja; G. Fock, 1910 ( $\left.\sigma^{7}\right)$.

2. Farm Paulinenhof an den Auasbergen, ca. $36 \mathrm{~km} \mathrm{O.} \mathrm{von}$ Windhuk: Frl. Hullemaxs, I.-V. 1911 (Junges Tior).

3. Grootfontein; Lunkenbein, 1911 (2 Junge).

Stennele führt diese schlange aus Go babis und Windhuk an

Bemerkungen: 1.) đ von $117 \mathrm{~cm}$ Kopfrumpflänge mit 184 Ventralen. Temporalia 1+2, Supralabialia 7 (3. 4), Sublabialia 4. Färbung braun.

2.) Graubraun, Nacken mit breiten dunkelbraunem Längsband, das nach hinten almählich verblaßt, Kopfoberseite braun, Oberlippe gelblichweiß. Im Magen junges Chamaeleon dilepis.

3. a) Kopf oben braun, ()berlippenschilder weißlich, ein dunkler Punkt am Hinterrande des 3.-5. Supralabiale. Nackenlängsband schwarz, nach hinten zu grau verblassend; Ventralenrand mit schwarzen Flecken.

b) Keine dunklen Oberlippenpunkte. Nacken weniger dunkel, weißlich punktiert. Ventralenseitenränder ohne Elecken.

\section{Thelotornis Smith.}

\section{Thelotornis Kinflandi Hall.}

Bollexger, Cat. Su. III, p. 185. - Steraffel1, Mitt. Zool. Mus. Berlin, V, 1910, p. 56.

Fundangaben: Grootfontrin; Lunkenbers, 1911.

Bisher aus Gobabis bekannt (Sterseren).

Bemerkungen: Oberseite grau. Ein Interorbitalband aus dunklen Punkten gebildet über die hintere Hälfte der Supraocularia; ebensolche Punkte au der medianen Hälfte der Parietalia. Ein braunes, dunkel gesäumtes Postorbitalband. Medianes Postparietale ebenso.

\section{Psammophis Boie. I'scemmophis notostictus Ptrs.}

Boulesger, Cat. Sn. III, p. 156; Ann. A. Afr. Mus., V/9, N1. 16, p. 513. - Hewitt, Rec. Albany Mus. Grahanıstown, Vol. 2, Nr. 4, 1912, p. 265. - Sternfel1, Mitt. Zool. Mus. Berlin, V, 1910, p. 56. - Werxer, SF., p. 360. - Laspe, P. 200.

Fundangaben: 1. Lü deritzbucht; W. Michaersen, 20.-24. VII. 1911 (jung).

2. Ste ehoim; Benrenos, VI. 1911 (ㅇ und jung). 
Außerdem Rietmond und Kuibis (LAmpr); Karrasberge, Gobabis, Outju. Warmba d (Fternero).

Bemerkungen: 1.) Hinterkopf mit dunklen, viereckigen Flecken, die nur die Seitenränder der Parietalia freilassen. Zwei grobe runde helle Flecken dicht nobeneinander an der Parietalnaht; zwei dunkle Längsbinden am Nacken.

2.) Zeichnung vorn ganz typisch, hinten mit 3 gelben Längslinien. Kehle und Innenrand der Fublabialia grau gezeichnet.

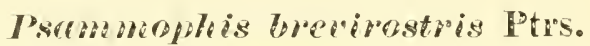

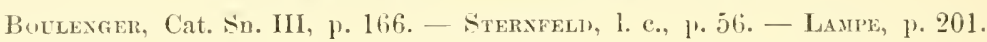

Fundangaben: 1. Gro otfo ut e in; Lunkexbern, 1911 (우).

2. Okaw an go; r. Zastrow, 1912/13.

Erst aus Gobabis (Stemanfeld) und der Namib-Wiste (Lampe) bekaunt.

Bemerkungen: 1.) V. 177, A. $1 / 1$, Nc. $106 / 106+1$, Temporalia $1+2$.

Oberippenschilder dunkel punktiert, mit kleinen Ringfiecken o.

()berseite dunkelgrau, Schwanz hellbraun. Unterseite grünlichweiß, Ventralenseitenränder mit dunklem Fleck.

2.) T. 169, A. $1 / 1$. Sic. $80 / 90+\ldots$, Temporalia $\frac{1}{1+1}+3,2+2+3$.

Rostrale, Internasalia und l'raefrontalia gelblich, obenso Nupralabialia. Uberseite sonst dunkelgrau, Schwanz hellbraun. Tentralenhinterränder hellgrau.

Dadurch, dafo das obero Postnasale nicht länger als das untere ist, und daß das Praeoculare vom Frontale dentlich getrennt bleibt, läßt sich disse Art von fircatus leicht unterscheiden, ganz abgesehen von der Breite des Frontale. Es ist also eine Vereinigung beider Arten nicht angezeigt.

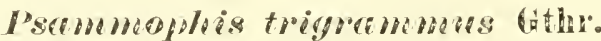

Bollexger, Cat. Sn. II, p. 159. - Sterkfeld, Mitt. Zool. Mus. Merlin, V, 1910, p. 56. - LAMPE, P. 201.

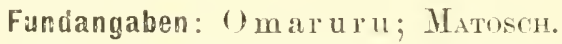

Durch den Nachwois des Vorkommens dieser Sichlange bei Re hbock

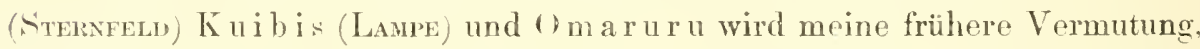
daf sie für Deutsch-süuwestafrika irrtümlich angegeben worden sei, hinfällig.

Bemerkungen: Ein Exemplar von $640+405 \mathrm{~mm}$ Länge, also Schwanz auffallend lang; dem entspricht auch die ungewöhnlich hohe Zahl der Fub(audalia. V. 189, Ace. $150 / 150+1$. Temporalia $2+2$; hintere Kinnschilder viel selimäler und $1 \frac{1}{2}$ mal so lang wir vordere. 6. Nupralabiale so lang wie $4 .+5$. 
Oberseite einfarbig hellgraubraun, nach hinten heller, mehr gelbbraun Unterseite mit hellgrauem Mittel- und weißem Seitenfeld (bis zur Mitte der äußersten schuppenreihe hinauf).

\section{Psammophis furcatus Ptrs.}

Bollexger, Cat. Sn. III, p. 164. - Hewitt, Rec. Albany Mus. Grahamstown, Vol. 2, Nr. 4. 1912, p. 269. - Sternfeld, 1. c.. p. 56 (sibilans). - Werder, SF., p. 361. - LaMpe p. 201.

Fundangaben: Okahandja; GaUer, 1911; G. Fock, 1910.

Bahnstrecke bei Keetmansh o op: Walter Kraner, 1910/11.

Bemerkungen: Das größte Exemplar, ein ơ von Okahandja, mißt $640+315 \mathrm{~mm}$; anch ein zweites o ist noch $950 \mathrm{~mm}$ lang.

Sterrfeld hält diese Art für identisch mit sitilans L.; ich kann mich ebenso wie Hewrt dieser Ansicht nicht anschließen. Der Habitus und die Kopfzeichnung erinnert rielmehr an Schokari Rss. Ich kann mir nicht vorstellen, daß eine Schlange mit der Hinterkopfzeichnung des sibilans (Querflecken) mit einer Art mit Längsstreifung der betreffenden Region identisch sei. Tiehmehr läßt sich zeigen, daß beide Zeichnungsformen verschiedenen Psammophis-Gruppen eigentümlich sind, was ich vielleicht später einmal ausführlicher dartun werde. Daher stimme ich anch Boruexger nicht bei, wenn er srine $P$. Leightoni hierher rechnet. Mir liegt ein Fxemplar dieser letzteren Art, das zweite aus Deutsch-südwestafrika bekannte, vor:

\section{Psrmmophis Leightomi Bhngr.}

Tafel TII, Fig. 3 und 3 a.

I'roc. Zool. Soce London, 1902 l, 1. 126, Taf. XII. - LAsHe, p. 201 (furcatue).

Fundangaben : Siwakopmund; JAcoes.

Ton LAupe aus der $\mathrm{Namieb-Wüste} \mathrm{genannt.}$

Bemerkungen: Sq. 17, T. 179, A. 1,1, Ne. 114/114t1; 1 Praeoculare, 2 Postocularia,

Frontale mit dem Praeoculare eine breite Sutur bildend,

Temporalia $2+2+3, \frac{1}{1+1}+3$. Nupralabialia $8(4.5)$ : sublabialia 4 die vorderen Kinnschilder erreichend. hintere vollständig getrennt. Länge $935 \mathrm{~mm}$, schwanz $235 \mathrm{~mm}$.

Oberseite hellgelbbraun, mit 3 Reihen schwarzbranner Flecken, ron denen die medianen quer rechteckig und durch helle, gelbliche Zwischenräume voneinander getrennt sind. Unterseite einfarbig weiß. Kopfzeichnung sehr charakteristisch; hinterer Teil der supraocularia und des Frontale hell, eine Mförmige Zeichnung bildend; eine dunkle Wförmige Zeichnung anf 
den Parietalen, deren Hinterenden freilassend, aber anf das hintere obere Temporale übergreifend; 22 runde dunkle Flecken dicht an der Parietalnaht ganz vorn.

Das Exemplar stimmt in der \%eichnung in den wesentlichen Punkten gnt mit der Abbildmg Bovlexgers ïberein, nur die Unterseite ist verschieden, doch kommen Variationen der Unterseite gerade bei Psammoplis häufig vor.

\section{Naia Laur. \\ Nain flark Merr.}

Botlexger, Cat. Snakes III, p. 376. - Werder, SF. p. 364. - Lampe, p. 203. - HewitT \& PuWEr, p. 164.

Fundangaben: Liideritzbucht: C. Masger.

Aus Rietmont, Auas und Kuibis dureh Laspe erwälnnt.

Bemerkungen: Ein junges Tier, Siq. 21 (Hals 22), V. 201, A. 1, Sc. 55/55+...

Postocularia 2-3; Temporalia $1+1$. Rostrale fast so lang wie sein Abstand rom Frontale; dieses fast viereckig (Hinterecke sohr stumpf). Oberseite hellgelbbraun, Unterseite hellgelblich, 8.-24. Ventrale dunkel (violettbraun). - Im Magen eine Agane.

\section{Nreia nigricollis Rhdt.}

Borlextier, Cat. Snakes III, p. 378; Ann. S.Afr. Mus., V/9, Nr. 16, p. 519. - Stenxield, Mitt. Zool. Mis. Berlin, T, 1910, p. 57. - Werxer, SF., p. 364. - Laupe, p. 203.

Fundangaben: 1. und 2. Okahand ja: G. Fork, 1910.

3. und 4. Nïrdliches Fiandfeld zwischen Löwen-Omuramba und Owangowa-Voldt; v. KAstrow, 1912.

Bekannt von Gobabis, Windhuk (Átersfent) und Kuibis (LAme).

Bemerkungen: 1.) ad. Si. 23,21 ; T. 204, A. 1. Sc. $66 / 66+1$.

Länge $1380 \mathrm{~mm}$, Sichwanz $285 \mathrm{~mm}$.

Kopf und Nacken schokoladobraun, (Wberseite sonst etwas heller brann, mit undeutlichen schmalen gelblichen Querbinden. Hals schwarzbraun (dis erstrn 16 Ventralen), dann abwechsehnd gelblich und braun gobändert.

2.) jung; (zerschlagen). Temporalia $2+4$.

Kopf und Hals (eine Kopfliange weit braungrau, dann gelblich mit zahlureichen winkeligen granbraunen querbinden: 20 vordere Ventralia schwarz; hintere Kinnschilder gelblich.

3.) S. 24,23, Y. $188, \Lambda .1$, se. $60 / 60+1$.

()berseite: Kopt hellbraun, sonst hellgran; Untorseite woib; dunkel sind die Ventralia: 10-11, 17-21, 26-27, 31, 34.

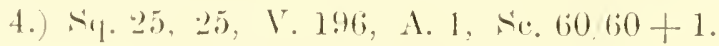

Färbung wie voriges Eximplar: dunkel sind die Ventralia: 12-13, 
16-21, 25--27, 31, 38. (Man beachte die ziemlich große Cbereinstimmung in der Breite und Entfernung der dunklen Ventralquerbinden beider Exemplare!)

Labialia und Temporalia z. T. schmal schwarz gesäumt.

\section{Aspidelaps Smith.}

\section{Aspiclelaps lubricus Laur.}

Bollexger, Cat. Sn. III, p. 390. - Werxer, sF., p. 365. - Sternfeld, Mitt. ZooI. Mus. Berlin, V. 1910. p.57. - LAMre, p. 204.

Fundangaben: Farm Paulinenh of an den A u s bergen, ca. $36 \mathrm{~km}$ O. von Windluuk; Frl. Hili.emaxi, I. - T. 1911 ( (

2. Bahnstrecke bei Keetmanshoop; Walter Kramer, 1910/11 (f f).

3. Klein-Wind huk: W. Michaelsex, 1911 (ㅇ).

Weitere Fundorte: Gobabis, Lïderitzbucht Śtersenes), Rietmond (LAnipe).

Bemerkungen: 1.) $\sigma$ : Schätzungsweise $550 \mathrm{~mm}$ lang. Sq. 19, 1. 157, A. 1, c. $3434+1$.

Kopf und Hals oben ganz schwarz. Srmphysiale und Kinnschilder gelb, schwarz gesäumt; 6 von vorn nach hinten immer schmäler werdende schwarze Querbinden auf den Ventralen: die folgenden nur durch kleine Flecken angedeutet; mediane subcaudalsuturen schwarz. Oberseite grau mit undeutlichen dunklen ( uerbinden.

Der ron oben wichtbare Teil des Rostrale so lang wie sein Abstand rom Frontale.

2.) 오 (halbwüchsig): i. 19: V. (wegen scoliose in der hinteren Kürperregion und Zusammenschiebung der V. nicht zählbar); $5.28 / 28+1$.

Kopf und Hals schwarz; rordere Querbinden der Oberseite breit, nach hinten schmäler werdend: 3 schwarze (puerbinden auf der Unterseite des Halses. die folgenden schmäler, grau, undentlich.

3.) \& (klein): s.q. 19, T. 151, A. 1, s.e. $36 / 36+1$.

Kopfzeichnung ungefähr wie meine Abbildung Fig. 1t. (1)erseite sonst grau mit schmalen schwarzen (querbinden, Kehle weib, schwarze Querlinie hinter dem zweiten Kinnschilderpar; 9.--10., 13.-34. Tentrale ganz oder (hintere teilweise schwarz; a uf den folgenden Ventralen größere oder kleineru schwarze Flecken, die hintersten ganz weib, schwanzunterseite etwas schwarz gefleckt.

\section{Viperidae. Bitis Gray.} Bitis arietans L.

Bollexger. Cat. Sn. III, p. 493; Ann. S. Afr. Mus., T/9, Mr. 16, p. 522. - Weraer. SF., p. 366. - Lampe, p. 206. - Sterafelu, Mitt, Zool. Mus, Berlin, T, 1910. p. j7. 


\begin{tabular}{|c|c|c|c|c|c|c|c|c|}
\hline Fundangaben: & Geschlechit & $\therefore$ s. & Ventral. & $\begin{array}{l}\text { Sub- } \\
\text { candal. }\end{array}$ & $\begin{array}{l}\text { Supra- } \\
\text { Ialoial. }\end{array}$ & $\begin{array}{l}\text { Sub- } \\
\text { orbital- } \\
\text { reihen }\end{array}$ & $\begin{array}{l}\text { Augen- } \\
\text { kranz- } \\
\text { schild- } \\
\text { clien }\end{array}$ & $\begin{array}{l}\text { Prae- } \\
\text { nasal- } \\
\text { schild- } \\
\text { chen }\end{array}$ \\
\hline $\begin{array}{l}\text { Liide ritabuelit, } \\
\text { C. MAxtiER. }\end{array}$ & $\sigma$ ad. & 34 & 138 & $30 / 30+1$ & $14-15$ & $t-4$ & $14-14$ & 1 \\
\hline $\begin{array}{c}\text { X eudamm, } \\
42 \mathrm{kmONO} \text {. von } \\
\text { Windhuk; } \\
\text { W. Micustasix, } \\
\text { 10.-15. V. 1911. }\end{array}$ & $\sigma^{\prime} \mathrm{i}$ & 34 & 137 & $30 / 30+1$ & $16-15$ & $t-3$ & $14-14$ & 2 \\
\hline $\begin{array}{c}\text { TS m meb; } \\
\text { W. NICHAELALX, } \\
\text { 13.-19. VI. 1911. }\end{array}$ & $\sigma^{\prime} \mathrm{j}$ & 36 & 136 & $31,31+1$ & $11-15$ & $3-3$ & $16-15$ & 2 \\
\hline $\begin{array}{c}\text { Usakos; } \\
\text { W. Nichatsen, } \\
\text { 22. IV. 22. VI. } 1911 .\end{array}$ & of hw. & 34 & 140 & $18 / 18+1$ & $15-15$ & $1-4$ & $14-14$ & 1 \\
\hline $\begin{array}{l}\text { Okaluandja; } \\
\text { G. Fock, } 1910 .\end{array}$ & o hw. & -35 & 134 & $2121+1$ & $16-16$ & $4-4$ & $13-14$ & 2 \\
\hline $\begin{array}{l}\text { Sandfeld; } \\
\text { JAcols. }\end{array}$ & f. i. & 35 & 144 & $19 / 19+1$ & $15-16$ & $3-3$ & $14-14$ & 1 \\
\hline 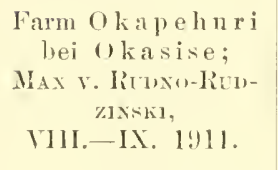 & o i. & 36 & 139 & $23 / 23+1$ & $14-14$ & $3-3$ & $13-13$ & 2 \\
\hline
\end{tabular}

Auberdem: Gobabis, liehoboth (Sternmon), Rietmo ud (Lampe).

\section{Bitis Peringme!l lingr.}

Botlexger, Cat. Sn. III, p. 495. - Nienex, AB. Ges. Naturf. Fr, Berlin, 1913, p. 450 . Werakr, ,F., 1. 366, Taf. VI, Fig. 4 .

Fundangaben: Swako pmund; JAcors.

lVird von Nieves aus Kuibis rrwihnt.

Bemerkungen: $1 \mathrm{Ex} .225 \mathrm{~mm}$ lang, Schwanz $15 \mathrm{~mm}$.

Sy. 26, I. $1391 / 2$, Sc. $19 / 19+1$; Supralabialia $12-12$, Interorbitalreihen 8, Suborbitalroilın 4-4, Augenkranzschildchen 12-13; Internasalschuppen 2, Pracuasalschuppen 2.

Das Exrmplar untersheidet sich in keiner Weise vou allen übrigen, die ioh bishre gesehen habe und ist rin nener lorweis dafür, daß diese Art von 13. heraldice boc. spezifisch verschiodon ist.

\section{litis rormotat.}

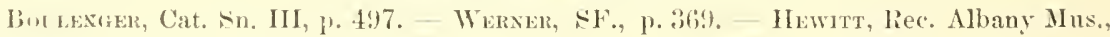
Vol. II, 1912, p. 27\%. - Lamp', 1. 206.

Fundangabe: I, ii de ritzbuelit; C. Haxger, 1911 (오, $\mathrm{N}_{\mathrm{r}}$. 2. 11. 3.); II. 1912 (vordere Hillte eines Tieres: Nr. 1). 


\begin{tabular}{|c|c|c|c|c|c|c|c|}
\hline & $S q \cdot$ & $\mathrm{V}$ & Sc. & $\begin{array}{l}\text { Supra- } \\
\text { labialia }\end{array}$ & $\begin{array}{l}\text { Augen- } \\
\text { kranz }\end{array}$ & $\begin{array}{l}\text { Subocular- } \\
\text { reihen }\end{array}$ & Färbang n. a. Bemerknngen. \\
\hline $\begin{array}{c}\text { 1) rordere Hältte } \\
\text { eines Tieres. }\end{array}$ & 27 & ? & ? & $12-13$ & $15-14$ & $3-3$ & $\begin{array}{l}\text { Oberseite liellgra, Flecken } \\
\text { vorn dunkler, hinten helles } \\
\text { rotbranu, weiBlich gesäumt. } \\
\text { Augenbrauenhörner rechts } \\
\text { wenig verschieden, links } \\
\text { eines besonders lang. Im } \\
\text { Magen Reste von Jachy- } \\
\text { dactylus Bibronii. }\end{array}$ \\
\hline 2) ㅇ. & $29 ?$ & 143 & $?$ & $13-13$ & $16-16$ & $3-4$ & $\begin{array}{l}\text { Oberseite hellaschgrau mit } \\
\text { dunkelbranngranen Flecken. } \\
\text { diese mit weißlichem sanm. } \\
\text { Hörner ziemlicl gleich lang. }\end{array}$ \\
\hline 3) 오. & 29 & $1 \pm \frac{4}{x}$ & 28 & $13-?$ & $15-?$ & $3-?$ & $\begin{array}{l}\text { Oberseite hellgrinlichgrau, } \\
\text { Flecken olivengrïn, nicht } \\
\text { heller gerändert. Von den } \\
\text { Hörnern eines jederseits } \\
\text { stark verlingert. }\end{array}$ \\
\hline
\end{tabular}

\section{Bitis catclatis Smith.}

Botlexger, Cat. sn. III, p. 498. - Werxer, SF., p. 367. - Hewtt, 1, c., 1. 279. LAMPE, p. 206.

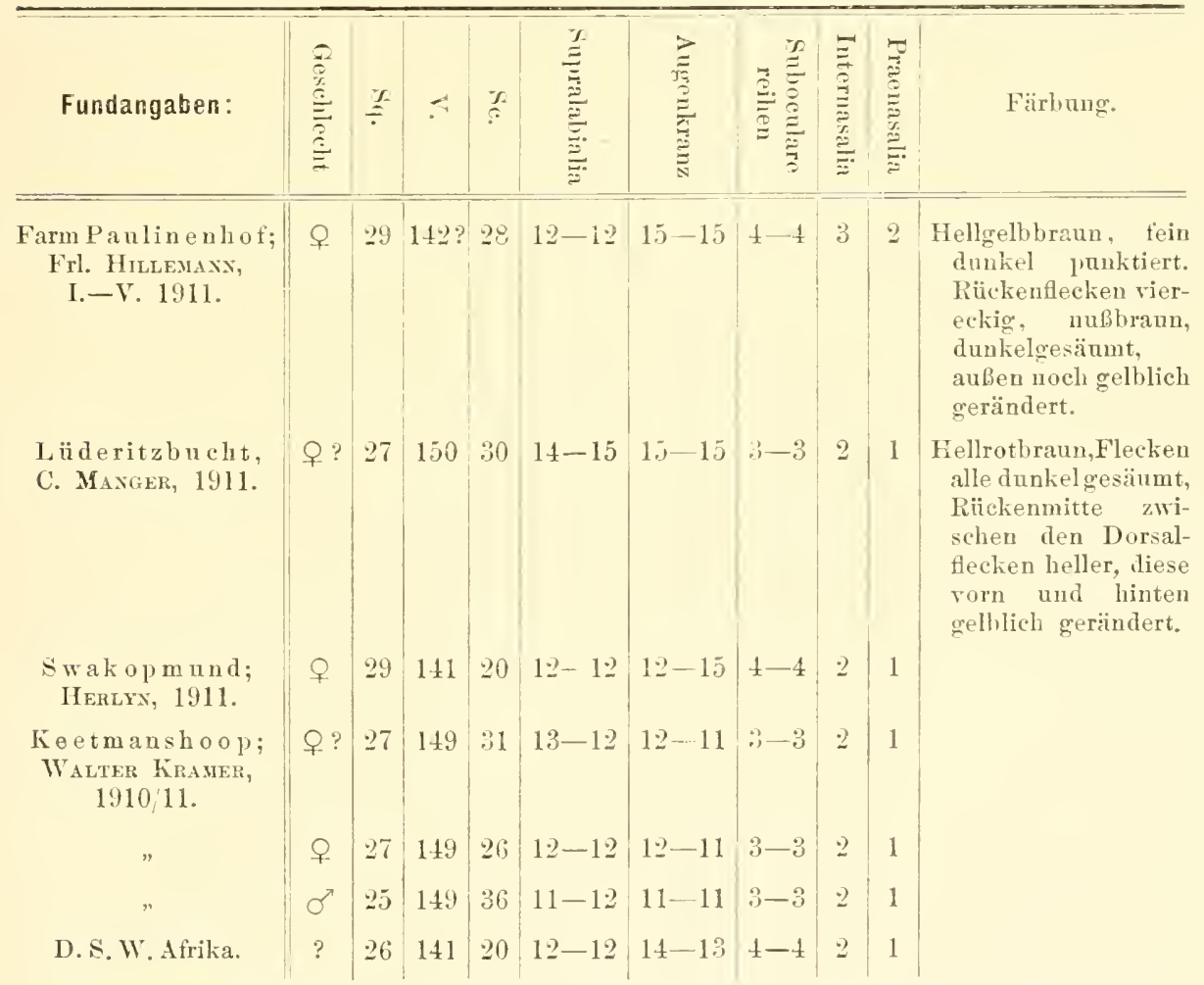

Lampe erwähnt die Art auch ron Rietmond, Kuibis und B erseba. 


\section{BATRACHIA.}

\section{Ecaudata.}

\section{Dactylethridae.}

Xenopus Wagl.

\section{Tenopus laceis Daud.}

Burlexter, Cat. Batr. Sal., 1882, p. 456. - Wender, SF., p. 291. N Nedex, SB. Ges. nat. Fr. Berlin, 191\%, p. 452. - Hewtт \& Power, p. 174.

Fundangaben: Okahandja: (r. Fock 1910, (S Ex.); W. Michaelsex, 27.—-2. IY. 1911 (1 erw., 2 halbw.).

Neudamm, ea. $42 \mathrm{~km}$ ONO. von Windhuk; W. Micnamlsex, 10.-15. V. 1911 (2 Ex., erw. u. jung, und in felsigen Wasserlöchern hinter der Neudammer Kuppe 7 Larven und Junge).

Groutfontein; W. Michaelsex, 7.-11. VI. 1911 (3 Ex., 2 erw., 1 jung).

Windhuk; W. Mímaelsex, 20. IV.-8. V. 1911 (1 elw.).

Usakos; W. Michaessix, 22. IV.-22.VI. 1911 (1 halbw.).

Farm Paulinenhof an den Auasberaen, ca. $36 \mathrm{~km}$ O. von Windhuk; W. Michaelsen, 18. Y. 1911 (2 eben verw. Ex.).

Farm Voigtsland anden Bismarckborgon, ea. $38 \mathrm{~km} \mathrm{O.} \mathrm{von}$ Windluuk: W. Miciaelsex, 16.-19. V. 1911 (2 junge Larren).

Farm ()tjituru bei Noudamm, (a. $46 \mathrm{~km}$ No. von Windhuk: IV. Minhelsex, 13. V. 1911 (ב Junge).

Nenes führt die Art für lielooboth an.

Bemerkungen: Das größte Exemplar, vou Okahandja, ist $72 \mathrm{~mm}$ lang. Fäbung hell- bis dunkelbraun, meist einfarbig, ein Exemplar grob dunkel marmoriert. Die Larven und Jungen von Neudamm sind in den verschiedensten Entwicklungsstadion (1 zwoiberinge Larve ${ }^{1}$ ), 3 virebeinige Larven mit langen Tentakeln, 1 mit kurzen T'entakoln, I Junges mit S'chwanzstummel, I vollkommen verwandelt); dir Jumgen von Otjituezu haben etwa 1 cm lange Stummelscluwänze. Da die beiden Larven ven Nendamm und Voigtsland seler jung sind und sicher in Mai die Eihüllen verlassen haben, so seheint die ganze Yrrwandlung innerhalb der ersten drei Wochen des Mai vor sich zu gehen.

1) Entsprechend der in (Chars-(ikobsex, Lehrb. d. Zoologie, Il. Antl., 1910, p. 816 . Fig. S52, reproduzierten Bus schen ligur. 


\section{Bufonidae. \\ Bufo Laur. \\ Bufo regularis Reuss.}

Boclexcer, Cat. Batr. Sal, 1852, 1. 298. - Welaxer, SF., 1. 291. - Hewtt, Rec. Albany Mus., II, Part 3, p. 216 ff. - Niedex, 1. c., p. 452. - Hewitt \& Power, p. 172.

Fundangaben: 1. Okahandja: G. Fоск, 1910 (ㅇ).

2. Tsume b; IV. Mrehaelsex, 13.-19. VI. 1911 (字).

3. u. 4. Windhuk: W. Micmaelsex, 20. IT.-8. V. 1911 (2 qq).

Bemerkungen: Die vier Exemplare unterscheiden sich in Färbung, Bosehaffenheit der Haut, Länge des 1. Fingers, Größe und Form des Tympanums nicht unwesentlich: auf die Länge des 1. Fingers als Tnterseheidungsmerkmal von den beiden verwandten Formen B. Grunti und angusticeps ist gar nichts zu geben, denn bei beiden erstgenannten Exemplaren ist er nicht länger als der zwoite. Nachstehend die Resehreibung:

1.) Okahandja-Fx. $77 \mathrm{~mm}$ lang. Parotoiden deutlieh, länger als Entfermung von Schnauzenspitze zum Tympanum-Torderrand. 'Tarsometatarsalgelenk erreicht das Tympanum. Ober- und Lnterseite deutlich warzig. Färbung hell lederbraun, Oberseite mit dunkelrotbraunen, dunkel geränderten Flecken.

2.) Tsumeb-Ex. $57 \mathrm{~mm}$ lang. Parotoiden kaum vortretend. Tympanum kreisrund, fast $2 / 3$ Augendurchmesser. Tarsometatarsalgelenk erreicht den Augenhinterrand. Oberseite glatt, Unterseite dicht gerunzelt, aber nicht granuliert oder warzig. Färbung der ()berseite helloran mit rotbramen, dunkel gesäumten Flecken, Unterseite wrib.

3.) Windhuk-Ex. $60 \mathrm{~mm}$ lang. Tymplanum nur 1/2 Augendurchmesser. Parotoiden so lang wie Entfernung der Schnauzenspitze von der Augenmitte. Tarsometatarsalgelenk erreicht die Augenmitte. Oserseitr fast glatt, namentlich Riucken. Unterseite dieht gerunzelt, nicht warzig. Oberseite hellgraubraun mit rotbraunen, dunkel aingefaßten Flecken (die gröBten beidersrits von der Mittellinie); Unterseite gelbbraun.

4.) Windhuk-Ex. $58 \mathrm{~mm}$ lang. Tympanum "2/3 Augendurehmesser. Parotoiden so lang wie Entfernung der Sehwanzspitze rom Augenhinterrand, 'Tarsometatarsalgelenk erreicht den Augenhinterrand. ()berseite glatt, Unterscite gerunzelt. Dunkelgrau mit rotbraunen, schwarz umgrenzten Flecken, die grïßten jederseits von der Rückenmitte; Unterseite heller grau.

Man sieht, daß die vorliegenden Exemplare, nebeneinandrr gelegt, leicht Anlaß bieten würden, sie für artverschieden zu halten. Dio beiden Exemplare mit kurzem ersten Finger lasseu sich aber ron B. Grunti dureh 
div viel schlankeren Finger und längeren Hinterbeine unterscheiden, die zwei anderen, die wie das ron Tsumeb uberseits glatt sind, kömnen von B. regularis trotzd'm nicht abgrtrennt werden, da solche glattrückige Exemplare auch sonst im Vrerbreitungsgebiete der Art beobachtet werden.

\section{Engystomatidae.}

\section{Braviceps Merr.}

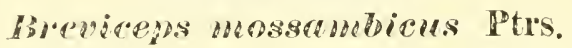

Peters, Arch. f. Nature., 1855, p. 58. - Bovlengke, Cat. Batr. Sal., 1882, p. 177. Whreli, SF., p. 293. - Hewitt, Rec. Albany MIus., II, Part 3, p. $212 \mathrm{fi}$.

Fundangaben: Farm Neitsas, Bez. Grootfontein; G. Fock, 1907.

Farm Ukapehuri bei Okasise; Max r. Rumo-Runzixskr.

Okahandja; G. Fook 1910 .

Bemerkungen: Das ersterwähnte Exemplar ist mit $55 \mathrm{~mm}$ das gröbte. Kärper (bei allen dreien) stark aufgebläht. Kehle mit awei Fleckenlängsbinden, die eine helle Mittelzone freilassen (vergl. den am gleichen Orte gefangewen, gleichfalls grabenden und aufgeblähten I'yricephalus Ruddi mit gleicher Kehlzeichnung). Eine feine helle Rückenmittellinie. Rücken mit großen bräunlichweißen symmetrischen Flecken, die dunkel gesäumt, von einer lateralen Reihe runder, großer Flecken dureh eine rotbraune Zone getrennt. Diese Flecken sind seitlich und nach unten durch einen dunklen breiten Saum begrenzt, der gegen den Bauch zu in rotbraun und schlieblich in schwarz übergelit und weib getiipfelt ist. Kopf rotbraun mit kleinen schwarzen Flecken.

Das zweitgenannte Exemplar $(45 \mathrm{~mm})$ ist ahnlich gefärbt wie voriges, aber Rücken und Geitevflecken mehr rütlichbraum, die sicitenzone nicht rotbraun, sondern violettgrau. Kopf rotbraun, ungefleckt.

Das 3. Exemplar ist halbwüchsig, dem vorigen ahnlich gezeichnet, aber nicht so lebhaft gefärbt. Schnauze gelbbraun; ein dunkles Querband zwischen den Augen, dahinter ein helles.

Bei allen dio typisch" Zeichnung der Koptseiten.

\section{Ranidae.}

\section{Rana L.}

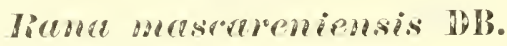

Boelexgke, C'at. Batr. Sal., 1) 52.

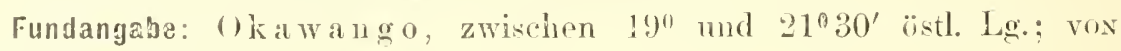
YASTROW, $1912 / 13$. 
Bemerkungen: 2 우우, das größere mit breiter, heller Rïckeubinde. Tibiotarsalgelenk erreicht den rorderen Augeurand. Anscheinend neu für Deutsch-Südwestafrika, sonst im ganzen siddlichen und tropischen Afrika bis Igypten und die algerische Sahara verbreitet.

\section{Terute fuscignela DB.}

WERER, SF., p. 259.

Fundangaben: Farm Otjituezu bei Neudamm, ca. $46 \mathrm{~km} \mathrm{No.} \mathrm{von}$ Windhuk: W. Mrehaelsen, 13. V. 1911.

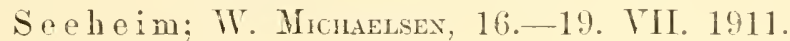

Nur Larren.

Bemerkungen: Die große Kaulquappe ron Otjituezu mit $30+54 \mathrm{~mm}$ lang. Der obere Hautsaum reicht bis zwischen die Augen; er ist auf dem Rïckrn dick, lederartig. Färbung der Oberseite hellgraubraun; Kehlgegend fein dunkel gefleckt. - Hinterbeine ganz ungleich, das rechte anscheinend ron Grund aus regeneriert; beim linken mit anscheinend rerstïmeltem Fub und unvollständig regenerierten Zehen ist der Oberschenkel $6 \mathrm{~mm}$ lang und $4 \mathrm{~mm}$ dick, das rechte ist in ganzen nur 5 mm lang, aber gut ausgebildet. Dio (1brrlippenzähnchen stehen in einer einfachen Reihe, Unterlippenzähnchen $=$ =

Die kleine Kaulquappe, $1 j+50 \mathrm{~mm}$, sehr ähnlich der Larre ron Berseba (Werner, Fig. 3 ist oben hellgrau, Schwanz gelblich. braun gefleckt, unten weif, Schwanz einfarbig hellgelb. - Der lange schwanz (iiber dreifache Kopfrumpflänge) ist charakteristisch für die Art; bei dem grofen Exemplar ist das Ende geschwumpt, der Schwanz daher kïrzer.

Mehrere grobe dunkle Laren row Ssire am Omurambo-0 matako (Landmesser Hextscuec I II. 1909 mit der Lippenzahnformel = gehören wohl auch hierher, sind aber sehr schlecht erhalten.

\section{Pyxicephalus Tschudi, Nieden.

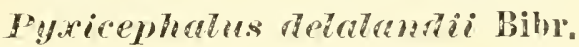

Bollextier, Cat. Batr. Sal., 188*2, p. 31 (Ran a): - Werner, SF, p. 298. - Hewtt, Rec. Albany Mus., II, Part 3, p. 203. - Nienex, 1. c. p. 451. - Hewtt \& Powel, p. 169.

Fundangaben: Grootfontein; W. Michaelsex, 7.-11. VI. $1911\left(\sigma^{\top}\right)$.

Okah andja; iV. Michaflsex, 27.-28. IV. $1911\left(\sigma^{7}\right)$

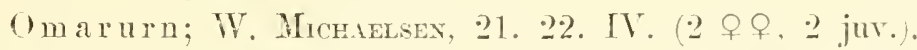

Teufels ba ch, $26 \mathrm{~km}$ siso. ron Okahandja: W. Micmaelsex, 1. M. (q).

Farm Otjituezu bei Neudamm, ea. $46 \mathrm{~km} \mathrm{NO}$. ron Windhuk:

W. Michaelsen, 13. Y. 1911 (juv. u. Larve).

Ton Nienex ans Rehobotls und Kuibis erwähnt. 
Bemerkungen: (Obwolil nieht auffallend warzig, doch von der folgenden Art gut untersclieidbar.

\section{P'yxirephalus matalensis Smith.}

Bollexger, Cat. Batr. Sal., 1852, p. 30 (Rana) - Hewitt, l. c., p. 203.

Fundangaben: Bahnstrecke bei Keetmanshoop: Wattek Kiramer, $1910 / 11$.

Diese Art ist neu für Deutsch-Siidwestafrika, bisher von X atal, Zululand und Transraal bekannt.

Bemerkungen: Ein o von $40 \mathrm{~mm}$ Lainge. Haut der Oberseite vollkommen glatt. Tarsometatarsalgelenk erreicht dio Schnanzensjitze. Färbung sehr dunkel, wohl infolge Formolkonservierung.

\section{I"yxirephalus Inuldi Blngre.}

Boclexger, Proc. Zool. Soc. London, 1907, p. 480, Taf. XXI1, Fig. 1. - Hewitt, Ann. Transvaal Mus., III, 1!11 1, p. 52 (= omatu Ptrs.). - Hewtt \& Power p. 168.

Fundangaben: Farn Noitsas, Boz. Grootfontein: Gr. Fuck, $1907\left(\sigma^{\top}\right)$.

S'wakopmund, Strand: E. O. Mïller (jung.).

Diese Art ist glcichfalls nexu fïr Deutsch-siidwestafrika. Da alle Pyaicepludu-Arten rine grabende Lebonsweise führon, also sehr verborgen leben, so kïnnen solche, die nicht solur luäufig sind, anch in rielbesuchten Gegenden lange Zeit unbemerkt bleiben. Teh erinnere hier an die bekanntr ähnlich lebende heimische Knoblanchkröte, Pelobutes fosens, die anßerhallo dre in Masser verbrachten P’arungszeit wohl anch dort, wo sio sehr häutig ist, nur äuberst solten aufgefunden wird.

Bemerkungen: l'as $\sigma$ ist ein sohr schönos Exemplar von 56 mm Länge, in allen wesentlichen Punktrn mit Bonlensers Abbildung pines of ron Beira ïbereinstimmond, nur sind die dunklen bänder der ()berseite niclit ganz schwarz, sondrun dunkel gerändert und gefleckt. die ledle pueplinie zwischen

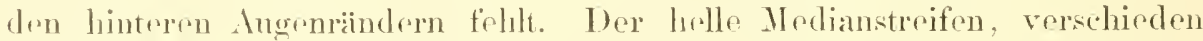
ron der sonstigen hellrötlichlorannen frundfärbung, weist eine rigentïnliche asclorane Firbung auf und ist in der sacralgegend unterbrochen. Ein orober unsymmotrisclier Fleck in dersolben Färbung, zwischen sacralgegend nnd After sotzt sich nach hinten in das lotzte Stiick des Mordianstreifens fort.

Finger sehe kurz, am Girunde durch dicke spambaiute verbunden,

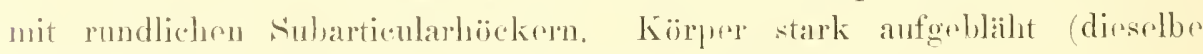
Fiahokeit des Aufhlasens besitzt anch l'. adsperses 'T'scu.'). 
Das $18 \mathrm{~mm}$ lange, augenscheinlich (wie die Form des Mundes beweist) cben in Verwandlung begriffene. Jungtier, das ziemlieh stark eingetrocknet ist, läßt sich an der Kehlzeichnung gut als zu dieser Art gehörig erkennen. Riickenzone rotbraun, olne dunkle Bänder, Seitenzone dunkel.

\section{Arthroleptis Smith. Arthroleptis Schebeni Nieden.}

SB. Ges. naturf. Fr. Berlin, 1913, Nr. 10, p. 451.

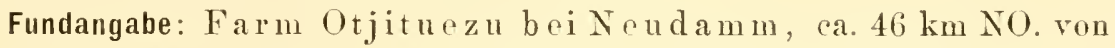
Windliuk; W. Michatsisv, 13. V. 1911 (5 Junge und 4 Larven).

Diese bisher von Klein $\mathrm{N}$ auas in der Kalalıari und von Relo both bekannte Art, die dem A. Lightfooti BLxFr. 1) an näehsten zu stehen scheint. liegt nicht in erwachsenen Exemplaren vor; die Beschreibung ergibt aber die völlige Übereinstimmung mit obiger Art.

Bemerkungen: Ich benutze als Hauptuntersuchungsobjekt das größte Exemplar von $16 \mathrm{~mm}$ Länge.

1. Finger kürzer als der 2.; Zunge olne mediane Papille. Schnauze so lang wie der Augendurehmesser, am Ende abgerundet; Schnauzenkante kaum bemerkbar. Interorbitalraum mehrmals breiter als ein oberes Augenlid. Tympanum nicht unterseheidbar. Finger und Zehen an der Spitze nicht angeschwollen; deutliches Sehwimmhautrudiment zwischen den Zehen. Subartikulhöeker sehr deutlieh; ein innerer und ein äuBerer Metatarsalhöcker; kein Tarsaltuberkel. Tarsometatarsalgelenk reicht bis zum Augenvorderrand: Tibia deutlich kïrer als der Fuß, $2 \%$ der Gesamtlänge gleichkommend. Eine starke Falte vom Augenhinterrand zum Vorderbein. darunter eine ebensolehe vom Mundwinkel zum Vorderbeinansatz. Oberseite helloran mit kreisrunden oder elliptischen, dunkel gesäumten grauen Fleeken: die rom Irundwinkel naeh hinten zieliende Falte weiBlich, diese Färbung bis unter das Auge fortgesetzt, hinter diesem nach oben und unten dunkel begrenzt; Oberlippe dunkel punktiert. Kehle gelblieh mit dunklen Punkten; Banch weiß mit größeren schwarzen runden Flecken. Hinterbeine rötlichgelb, fein rotbraun getïpfelt.

Es ist möglich, daß diese Art nach erfolgter Verwandlung nieht mehr viel wäehst, da auch Boulexger für A. Lightfooti $16 \mathrm{~mm}$ als Gesamtlänge angibt, ohne zu bemerken, ob es sich um ein Jungtier handelt. Bei dem mir vorliegenden Exemplar ist dies aber außer Zweifel. Von den mitgefangenen Larven (eine zweibeinige mit kurzen Glicdmaßen, eine mit

\footnotetext{
1) Aun. S.Afr. Mus., V/9, No. 16, 1910, p. 538.
} 
langen, eine 3 - und eine 4 beinige) gohören die meisten gewiß hierher, wie sich aus den langen, bis zum Grunde freien Zehen ergibt; diese führen dann aazu, auch die eine kurz-zweibrinige hierher zu rechnen, die $14+24 \mathrm{~mm}$ lang ist und eine Lippenzahnformel $=$ erkonnen läßt.

Da auker den von mir (SF., p. 286) aus Dentsch-Südwestafrika verzeichneten 6 Batrachier-Arten noch zwei von Ninden (Arthroleptis Schebeni und Crssince senegulensis), ferner zwei von Boulwnaer (Ruppia marmoruta RAPr von Otjimbora, Damaraland, und $R$. sugillutu Cope ebendaher), schlioBlich Pysicephulus nutulensis und Ruddi jetzt von mir angeführt werden, so hat sich seit 1910 die Zahl der Arten auf 12 erhöht, also verdoppelt, und zwar gohören alle neu hinzugokommenen Arten zu den Raniden, die jetzt $75 \%$ der Batrachierfauna bilden.

\section{Figurenerkliirung. \\ Tafel VII.}

Fig. 1 Python anchietue Bocars; ganzos Tier, ca.

1 a Kopf von oben.

16 Kopf von der Srite.

Fig. 2 Micuëlu pernusute n. sp.; ganzes Tier, ca.

2 "Kopf von der Seite.

2b. Kopf von oben.

Fig. 3 Psummophis Leightoni Bungr.; ganzes Tier, ca.

3 " Kopf von oben, ea. 


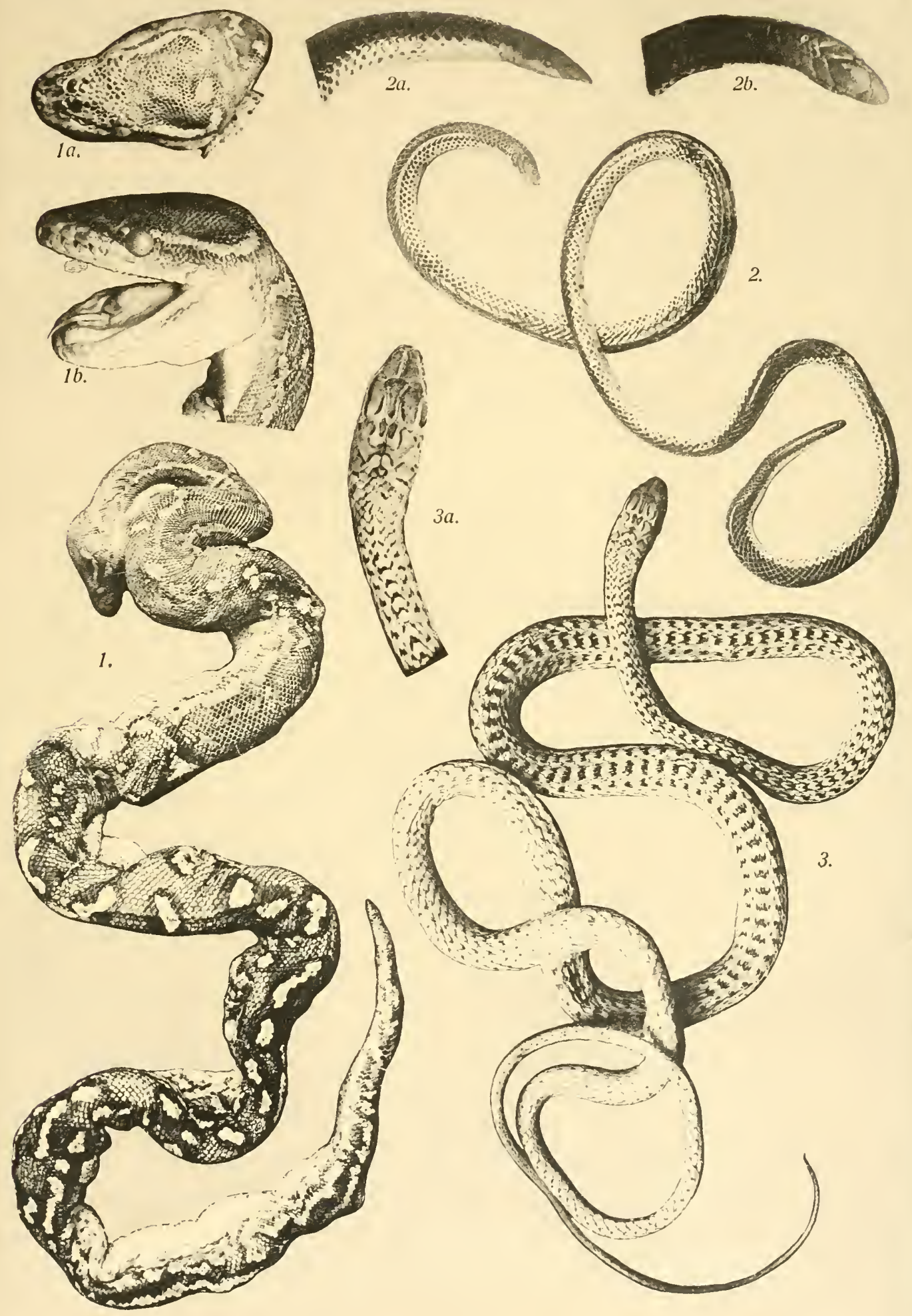





\section{Nematodes}

ron

\section{G. Steiner (Thalwil-Zürich).}

Mit 26 Truttiguren. 

Das Untersuchungsmaterial zu dieser kleinen Arbeit hat mir in liebenswïrdiger Weise Herr Professor Dr. W. Michancsex in Hamburg überlassen; Pr soi an dieser Stelle meines besten Dankes versichert. Das Material ist ron ihm selber auf der Hamburger Dentsch-sïdrestafrikanischen Studienrejse im Jahre 1911 gesammelt worden; alles war in Alkohol konserviert. Einige Gläser mit Schlamm aus Wasserlïchern und Kuhtränken habe ich sclbst durchsucht; freilebende Nematoden waren darin merkwïrdig spärlich vorhanden. Die außerordentliche Wasserarmut des Untersuchungsgebietes ist wohl wenigstens zum Teil die Ursache dieses Verhaltens.

Lisstow ${ }^{1}$ ) hat bereits früher die ersten Nematoden aus Deutschs üd wostafrika beschrieben, mit Ansnahme einiger freilebender mariner Arten alles Parasiten: es sind die folgenden:

Heterakis schebeni v. Lisstow.

", poculum r. Lixstow.

Physaloptera brevicanda r. Lixsтow.

Oryuris polyoon v. Lisstow.

. curvela Ritoolphi.

Asceris feroc Fhrexba. u. Hempr.

„. sparoidum Diesing.

Physaloptera paradora v. Lisstow.

, $s p$.

Spiroptera s".

Oryurie Hagellum Ehrexbg. 11. Hempr.

Enoplus bisetosus v. Lixstow.

, macrolaimus v. Lisstow.

Oncholaimus spiralis r. Lnssow.

Euchromadora afieana v. Insstow.

Thoracostoma sp.

1) Lixstow, O. v. Neue Helminthen aus Deutsch-Siidwestafrika in: Centralbl. f. Bakteriologie, Parasitenkunde u. Infektionskrankheiten. 1. Abt. Orig. Bd. 50, p. 448.

Lixstow, O. v., II. Helminthes in: L. Scluultze, Forschungsreise Bd. 1. Jenaische Denkschriften. Bd. XIII, p. 19, Taf. IV. 


\section{Teptosomitum s\%.}

Cyatholaimus \& $\%$.

Durch musere Intrestehung wird diess Listr, soweit dir Land- und

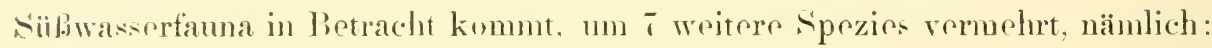

Trilobus pelluritus Bastrax.

Monohystrme paluelicola ne Max.

,. Lothrioluima 11. sp).

Morylaimes merenaster n. sp.

Actinolaimu. mirhaelsemi n. sp.

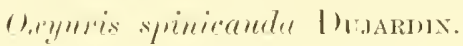

lermis damarensis 1 . sp.

Dir marinen spezios werden in den gloichzoitig orscheinenden Boi-

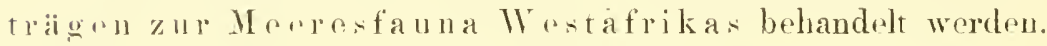

lie jorsten in oben stchender Liste aufgefuilurten Arten sind Siibwasserberohner, dir Cleyuris spinicauda ist Ganz-Parasit, dir Mermes damamensis wohl wis simtliclur Mremithiden zoitweiser Parasit.

\section{Geographisches.}

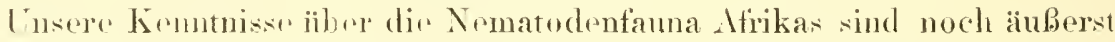
diirttig. Obgleich die freilubenden Nematoden zu den häufigsten und ver-

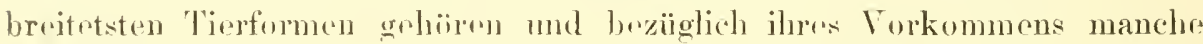
Thulichkrit mit des Protozoen habon. sind sir bis heuter ron der Forschung ganz stiefmiitrerlich behandelt worden. Besser kamen selson die parasitischen Nematoden weg: speriell fïj Afrika sind sir besser bekannt als

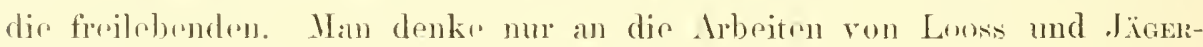

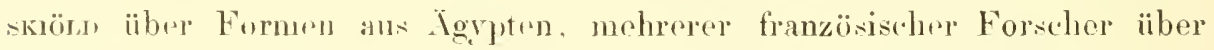
Formen ans Agire ete. ote. Eint Anzahl dieser Parasiten sind kosmopolitisch verberitot: andore, die an rine bestimmte Tierart gubunden sind, trilen vielfach die Verbereitung ilurer Trigere.

Bozïglich dor goographischen Verbreitung der bis jetzt in Afrika beobacheteren treilebenden Tromatoden grstattor das folgende doch schon ein

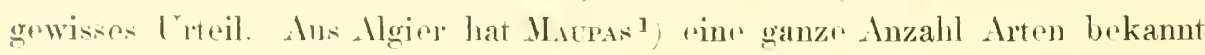
gomarlst, meist Finhnisluwoluner, dic zum groben Teil anch in Europa vorkommoen odop dort roransichtlich nocls werden gofinden werden. Ans

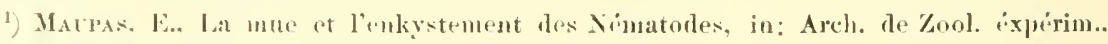
:) Vol. 7, $189 !$.

Modes th formes de reprodurtion des Nimatodes; ibid. \$3), Vol. \$, 1900. 


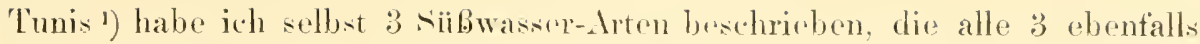

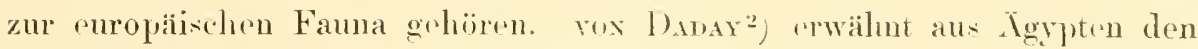
Dorylaimes superbus ne Max, rine kosmopolitische Form, und aus Deutseh-

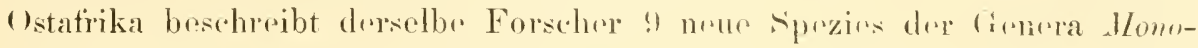

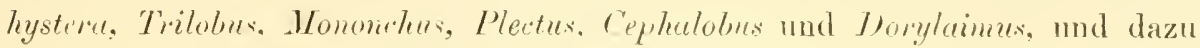

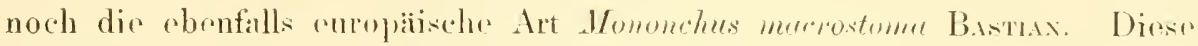
sämtlichen Grenera sind kosmopolitisch vorloreitet. Von don Komoren habe

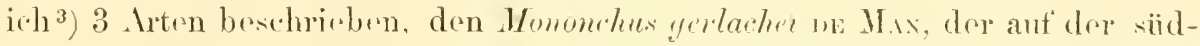
lichen Erdhälfte verbreitet zn sein seheint, den /roryluimus pureus. dar anch

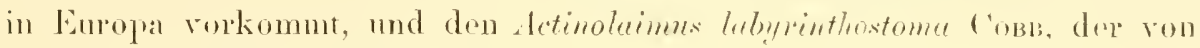
den Fidchi-Inseln bekannt ist ${ }^{4}$.

1) Strixel, G., lieiträge zur geocraphischen Verbreitung freilebender Veniloden. Kool. An\%. IBd. XlVI, 1, 311. 1916.

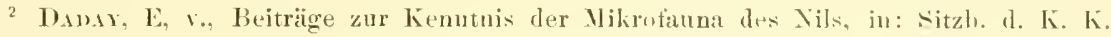
Mkad. 1. Wiss. Wien. Mathem.-naturw. Klasse, Vol. 119, 1910.

- Untersuchungen iiber die sübwasser-Mikrotauna Hentsch-0ntatrikas, in: Zonlogica. Tol. 23. 1910.

3) Sisle l. c., Nr.2.

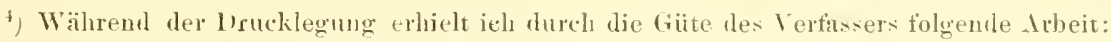

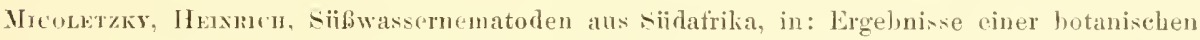
Forschungseise nach Deutsch-1)stafrika und siidafrika Kapland, Natal mud Rhodesien': in: Denkschr. d. K. Akad. d. Wirsenseh. Ẅjen. Math.-nat. Kilasse. Bd, 92, p. 1-23, 'T"at. $1-4,1915$.

In dieser Arbeit werden 13 Arton freilebender Nematolnn beshrieben, die sich aut 9) Genera verteilen. Zwält Arten entstammen 2 verschiedenen stellen des Sambesi, wine Art dem batkens River bei Port Elizabeth in Ka band. E sind die folgenden:

Alerimess prinitimes In: Max.

Honohystere enelyarion DE MAX.

, simitis Bitranus.

Tribubes gracilis MAsTIAX

Pectus sambesii MicnLetzKr.

Diplogasteroides afirumus MйLET\%K.

Mononchus ep.

"hromatora monohystere Mn'ustzas.

Dorylaimes stamalis Dr.

, bastiani Bitsenu.

., flacomacelaters V. Lissiow.

. macroluinus de MAx.

Tylenchus africanus Micoletzri:

Es ist dies eine interessante Ergänzung zu den bereits vorliegenden Funden; $\checkmark$ Arten von den 12 sind ebenfals in Europa natgewiesen, 4 davou durelı E. v. H.usv leveits friiher auch in Atrika. Jedentalls ist die Zahl der europaischen Komponenten an freilehenden siibwassernenatoden in dor Fauma Afrikis nicht unbetrüchtlich. 
1)io 5 oben erwihnten freilobenden spezies ans Dentsch-Siidwestafrika gehören obenfalls kosmopolitischen Genera an, Trilobus pellucidus und Monohystera paludicola sind vermutlich iiber die ganze Erde verbreitet.

Die vorstehenden Daten bozichen sich in der Hauptsache auf Siibwasserbewohner. Ob die tropischen Laterit- und Urwaldbïden mit ihron fouchtwamen Detrituschichten eine spezifischr. Nematodenfauna beherbergen, ist erst noch zu erforschen: ich halte es aber fü̈ sehr wahrscheinlich.

J)as aber, glaube ich, steht heute schon fest, dab die Grnera der freiJobenden Nematoden kosmopolitische Verbreitung haben und gewif auch rine große Zahl von spezies. Ot) sich fïr andere spezies begrenzte Verbreitungsgebiete ergeben, läit sich beim hentigen stande dieses Forschungszwoigus noch keineswegs beurtrilon. Dir freilebenden Nematoden vorhalten sich tiergeographisch den Protozoen äuberst ähnlich.

Was schließlich noch dic Memithiden betrittit, ist schon länger bekannt, daß sie abenfalls kosmopolitische Verbreitung haben. Vertreter des Genu Mermis sind ans allen krdteilen beschrieben worden. speziell aus Afrika wurden durch v. Lixstow I) Mermis preemetura v. Lixst. und Mermis acrididomm $v$. Luss. aus Madagaskar, Mermis quedripurtita v. Lisst. aus Réunion, Mermis africuna v. Lasst. und Memis incolute r. Lixst. aus Togu und der merkwïrdige spinifer füllebomi v. Lsxst, sowir Pseudomermis

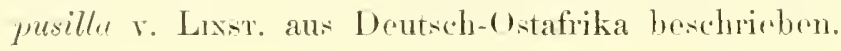

\section{Systematisches. \\ Genus Trilobus Bastian. \\ Trilobus pellucidus Bastian.}

('l'irxttig. 1 11. 2.).

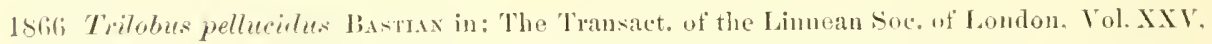
1. 100, Pl. IX, tige. 2:2, 24.

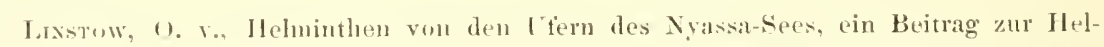
uinthen-Fanna von Sïd-Afrika, in: Ienaische Keitschr. t. Naturwissensch., Bd. 35, 1901, p. 409.

Das Genus Mermis, in: Arell. f. mikroskop. Anat, lik. 3̈, 11. 14\%.

- Gordiden und Mernithiden des K. Zoul. Museums in lierlin, in: Mitt. aus d. Zool. Muserum in berlin, Bd. HI, 1). 2.1. 
1573 Trilobus gracilis Bast. ex parte, Bütschli in: Nova Acta der Ksl. Leop.-Carol. Deutschen Akad. d. Naturforscher, Bd. XXXY1, p. 53, Taf. XX, fig. 21il.

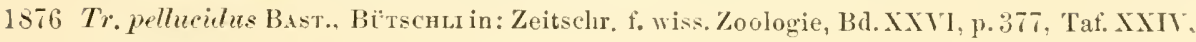
tig. $10 \mathrm{a}-\mathrm{d}$.

$1880 \mathrm{~T}$. leptosoma dE MAx in: Tijdschr. d. Nederl. Dierk. Vereenig., Deel V, p. 30.

1851 Tr. pellucidus Bast., de MAx in: Tijdschr. d. Nederl. Dierk, Vereenig. Deel V, p. 140-142:

lsst $T r$ pellucidus Bast, DE MAN in: Die frei in der reinen krde und im süß. Wasser leh. Nematod. d. niederländ. Fauna, 1). 76 , Taf. XI, fig. 44.

1597 Tr. pellucidus BAst., E. $v$. DADAY in: Resultate d. wiss. Erforschung d. Plattensees. Bd. II, p. 98.

1598 Tr. pellucidus Bast., E. y. DandY in: Zool. Jahrb., Abt. f. syst., Geogr. u. Biol. d. Tiere, Bd. 10, P. 110.

$1900 \mathrm{Tr}$. pellucidus BAst., Zscnokкe in: Die Tierwelt d. Hochgebirgseen, 1 r. ş-9)1.

1901 Tr. pellucidus Bast., Plotxixofe in: Ber. bi.l. siißwasserstation d. Naturforseh. Ges. St. Petershurg, Vol. 1, 1. 246 .

1904 Tr. pellucidus Bast., E. v. DADAY in: Zool. Jahrh.. Abt. t.. Srat.. Geogr. 11. Biol. d. Tiere, Bd. 19, p. 46.

1907 Tr. pellucidus Bast., J. G. 12E Max in: Annales de Biologie lacustre, Tome 1I, p. 16.

1909 Tr. pellucidus BАsт., Jü̈ERsiö̈d in: Die sïßwasserfanna Deutschlands, heransgegeb. v. Prof. Dr. Braner, Heft 15, p. 17, fig. 21.

1910 Tr. pellucidus Bast., E. $x$ Danar in: Zoologica, Bd. 23. p. th.

$1911 T \%$ pellucidus Bast, DrtLexsex in: Vidensk. Meddel. tra den naturh. Foren. Kobenhavn Bd. $63,11.234$.

1913 Tr. longicaulus r. Lixstow, Ilofuïxer in: Revne Snisse de Zoologie. Vol. 21, p. 618 Pl. 15 , fig. 7 et 8 .

1913 Tr. pelluridus Bast, Mnoletzky in: Sitz. d. Kaiserl. Akad. d. Wiss. in Wien. Math. nat. Klasse, Bd. CXxil, Abt. 1, p. 3.

1913 Tr. pellucidus Bast, Bhackexnofe in: Abl. Nat, Ver. Bremen, Bad. Xxil, p. 284.

1914 Tr. pellucidus Bast. Mucoletzky in: Zool. Jalırb., Abt. f. Syst., Geogr. u. Biologie der Tiere, Bd. 36 , 1. 438.

1914 Tr. pellueilus Bast., Steñer in: Arch. t. Hydrobiologie u. Planktonkunde, Hd. 1X. 1. 260.

1914 Tr. pellucidus Bast., Mexzel. in: Arel. f. Naturgeselı, Bd. S0, Abt. A., p. \$2.

$1914 T r$ pellucidus Bust., stmpaxsir in: Recherches sur la faune der Nématodes libres du Bassin du Léman. Thẻse de l'Lniversité de Genève, p. 28.

1915 Tr. pellucidus Bast, Hormüxer n. Mexzed in: Revne Suise de Zoologie, Tul. 23. 1. 159.

$1915 \mathrm{Tr}$ pellucidus Bast, Mrcoletzix in: Mitteil. d, Naturwis.. Verein. f. Steiermark. Jahır. 1914, Bd. 51. p. ?.

Fundangaben: Grootfontein, zwischen Algen: IV. Mrchaelsex, †.-11. Juni 1911.

Weitere Verbreitung: Ton zahlreichen stellen aus fast ganz Eu ropa bekannt; außerdem noch ron Afrika, nämlich rom Kilinandjar"u (rox DADAY 1910).

Torliegend 1 reifes Wribchon mit 3 Eiern und 1 jugendliches Ties. 
Bemerkungen: Das vorliegunde erwathene Weibchen besali folgende

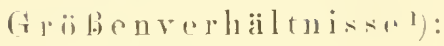

\begin{tabular}{|c|c|c|c|}
\hline Gexamtlänge & 2,340 & 11111 & $r_{i} 0.3 \bar{t} \mathrm{~mm}$ \\
\hline Osophaguslaingo & $(0,409$ & . & $\mathrm{F}_{2} 0.443 \quad \ldots$ \\
\hline schwanzlängs & 0,281 & . & \\
\hline ( iröbtr. Dickr. & 0,067 & $"$ & $\%=35$ \\
\hline licke am Iftor & 0.040 & , & $\beta=5,7$ \\
\hline 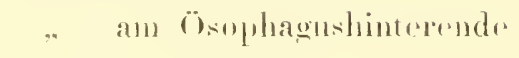 & 0.058 & .. & $\ddot{\imath}=8.3$ \\
\hline$"$ am Koppo & $0,0.3 \cdot 2$ &. & $v=42 \% / n$. \\
\hline
\end{tabular}

Jas Tier hesitzt riur ziomlich intronive hranngolbe Färbung, die ich bri europäischen Formon nir gesehen habr. Kudem ist die auf die äuBerste

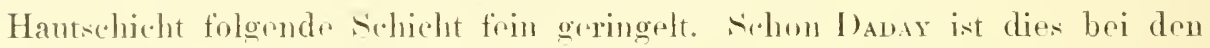
Excmplaren rom Kilimandjaro und Brarkexune bei solehen aus der Lm-

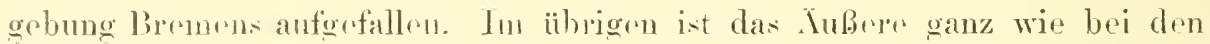
"uropaischen Exemplaron heselattin. Dir submedianen Burstenteihen sind sehr deutlich. Auch die Koptborsteu sind normal ansgebildet: das Seitenorgan hat vou dor. Flähe gosolen dine schwach wale Form, und zwar so,

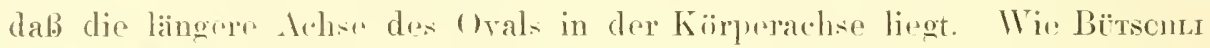
und ne Max schon ansfïhrten, tragen dis 6 schwachen Lippen 10 feine Papillehen. je enbmedian und eines lateral. bir Abbildung. dir Hofrëxxek

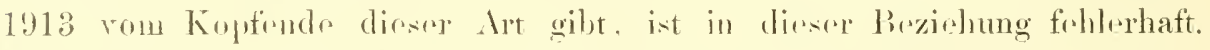

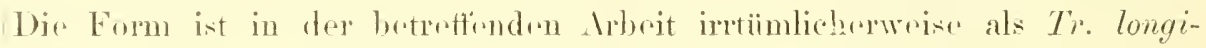

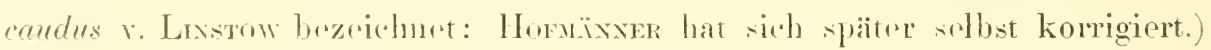
Da vorlirgande Exemplar besab nnmittrlbar hinter der trichterförmigen

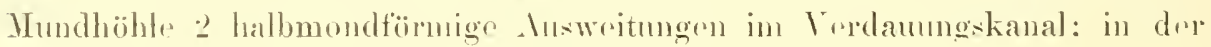
vorderen sohien oins kleino kngolign Vordickmng zu s.in.

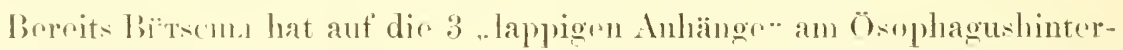

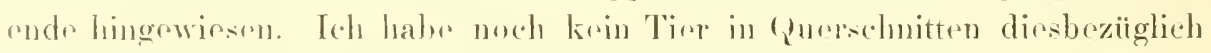

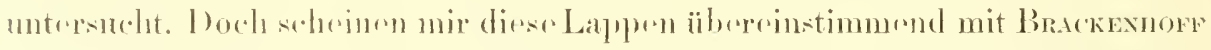

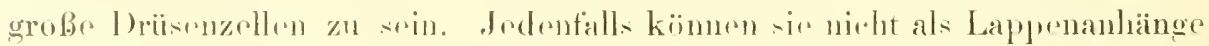

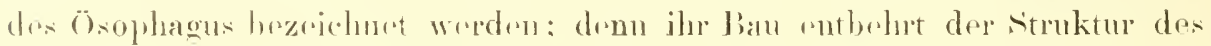

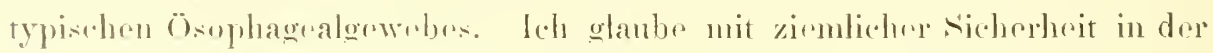

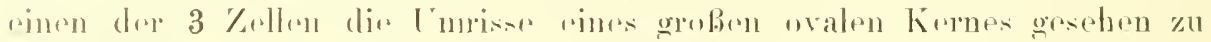

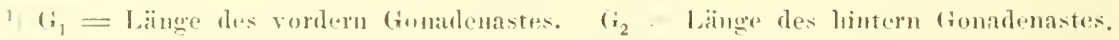

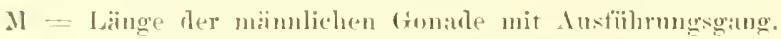

$I_{1}=$ Läinge des vordern IIoden. $I_{2}-$ Länge des hintern Huden.

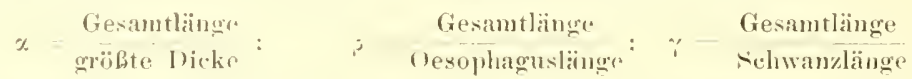

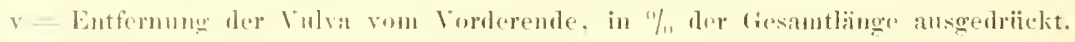


haben (Vergl. Texttig. 1). Würde sich dies bestätigen, so hätten wir es wohl mit 3 I)rüsenzellen zu tun. Fïr Trilolues und pinige Monohy terese, dir solche Drïsenzellen am Ösophagushintrende busitzen. ist woder ein Porus rxcreturius noch irgend etwas wie Seitenkanäle nder Ventraldriistn beobarbtet worden. Haben wir es hier vielloicht mit diesen homologen Grobilden zu tum :

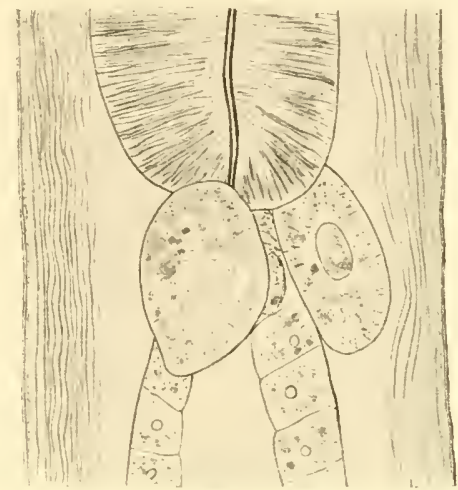

Fig. 1. Trilobus pellucielus BAst. Körper an der ïbergangsstelle

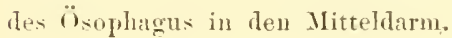
lerer. 360 .

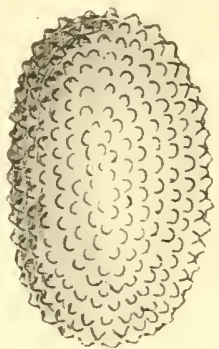

Fig. 2. Tritobus pelluridus His.t. Ansicht eines Eies.

Vergr. 1;00.

Eimr bemorkenswerte Eigenschaft habe ich anberdem noch an den Eiern des rorliegenden Wribehons beobachtet. Lirse busaben namlich alle eine mit Reihen spitzkroelfiimiger Warzen bedrekte. Obertächr. (Vergl. Textfig. 2.) l)iese Frscheimung habe ich an europäischen Vertretern der spezies bis heute nicht beobachtet, noch erwihnt irgend oin anderer Forscher dieselbe. Es ist drshalb gut mäglich, dab das rurliegende Exemplar von Grootfontein rinre afrikanischen Varistät zuguhör, die dureh warzig beschater Eior ausgezeiclunet ist.

\section{Genus Monohystera Bastian.}

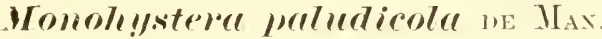

$188+$ Womohystera paluticola we Max in: Die frei in der reinen Erde und im sidben Wasser lebenden Sematoden der niederlïndischen Fanna. Leiden, p. 37. Tat. II. fig. 7.

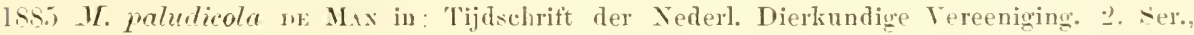
Deel 1. 1. 1s.

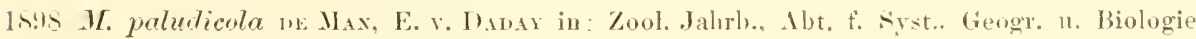
der 'Tiere, Bs. 10, p. Is.

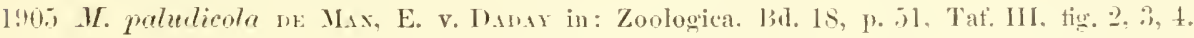




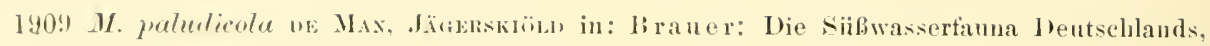
Ileft 15, 11. 11, fig. 11.

$191:$ H. pratudicola ne Max, Mcoterzk in: Internat. Rev. d. gesamten Hydrobiol. n. Hydrographie. Biol. suppl., VI. Ser., p. 2 und p. 11.

1!13 M. paluticola DE MAx, Miculetzkx in: Nitzungsber. d. Kais. Alad. d. Wiss. in Wien. Math.-Natum. Klasse, Bd. CXXII, Abt. 1.

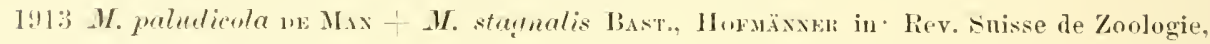
Vol. 21, ए. (;0!).

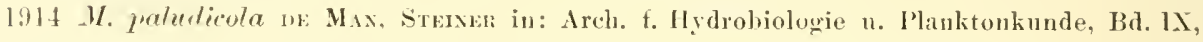
1). 260 .

1914 If. paldelicola ut Max, Mnconatzis in: Zoolog. Jahrb. Abt. f. Ayst., Geogr. u. Biol. d. Tiere, Bd. 3ti, [1. $41 \%$.

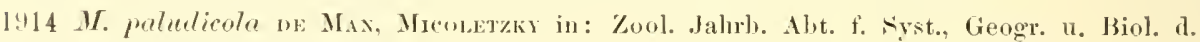
Tiere, Bd. :35, p. $25 \%$.

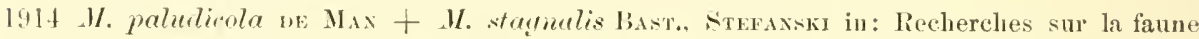
des Nématodes lihres dı Bassin du Lúman. 'Thése de l'Lniversité de Genéve, p. 17.

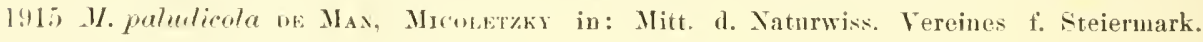
Jahrg. 1914, 13d. 51, 1.2.

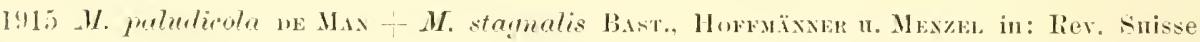
de Zonlogie, Iid. 23 , p. 123.

Fundangaben: Grootfontrin, zwischen Mgen. W. MIrnatsex: 7. bis 11. Juni 1!!11.

Weitere Verbreitung: Von zahlreichen sitellom ans Mittol- und Ust-

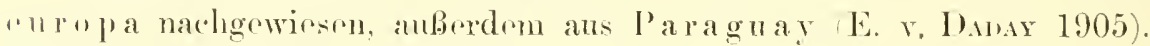

Vorliogend 2 Exomplare, 1 f und 10 .

\begin{tabular}{|c|c|c|c|c|c|c|c|}
\hline \multirow[t]{2}{*}{ Bemerkungen: } & \multicolumn{6}{|c|}{ Gräbenvorhältnisse: } & \multirow[b]{2}{*}{$\sigma^{\prime}$} \\
\hline & q & & o & & क & & \\
\hline livsamtlainge & 0.785 & $m m 1$ & 0,760 & mm! & $x=$ & 27 & 26,2 \\
\hline Osophaguslängo & 0.144 & .. & 0.144 & " & $\beta=$ & 5.4 & 5.3 \\
\hline F́chwanzläng. & 0.126 & $"$ & $(1,112$ & $"$ & $r=$ & $(i, \ddot{-})$ & 6,8 \\
\hline (iröbtr D)icke & $0,02 !$ &, & 0,029 & ,. & $r=$ & $6: 3.31 / 10$ & \\
\hline Wicko an After & 0.014 & 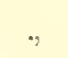 & 0,019 & , & & & \\
\hline . am ():ophlagus- & & & & & & & \\
\hline linterende & 0,025 &. & 0,025 & , & & & \\
\hline .. am Kojifi. & $(1,01:$ & , & $0,01: 2$ &, & & & \\
\hline
\end{tabular}

I)ies rntepricht zienlich genau den Messungen an mitteleuropäischen

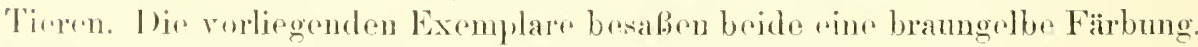
Dis sitenorgane lagen bei beiden Tirren dem Koffrorderrand ganz nahe.

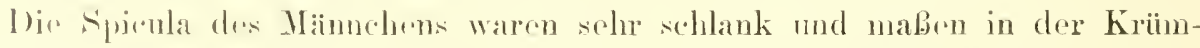

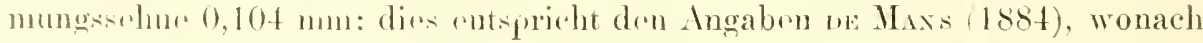

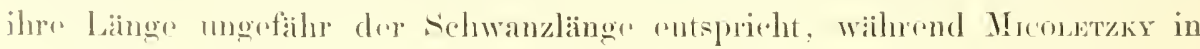


d.:n Ostalpen Tiere fand, bei denen die Spicula nur ungefähr halbe Schwanzlänge erreichten. Hofmäxsen \& Mexzel und auch Stefaxski vereinigen M. stagmulis BAst. und $\boldsymbol{H}$. puludicola DE MAx gegen die Prioritätsregeln zu M. puludicola: doch lassen sich die beiden Arten, wie Micoletzkr schion ausführt, namentlich beim Mämchen, aber auch beim Weibehen gut unterscheiden. Jedenfalls aber miifte die Sammelspezies M. stagnalis Bast. heifen.

\section{Womohystera bothriolaima n. sp.}

(Textfig. 3-5.)

Fundangabe: Grootfontein, zwischen Algon. W. Mlchaelsex; 7. bis 11. Juni 1911.

Vorliegend 1 jugendliches Exemplar ohne jede Geschlochtsanlage.

Äußeres.

Gesamtlänge

Osophaguslänge

Schwanzlänge

Giöbte Dicke

Dicke am After Grïbenverhältnisse.

" am O):ophagus-

$$
\text { hinterende } 0,031 \%
$$

, am Kopfe 0,016 ,

$$
\begin{array}{ll}
1.048 \mathrm{~mm} & \%=26,2 \\
0,187 . & \beta=5,6 \\
0.119 . & \gamma=8,8 . \\
0,040 . & \\
0,025 \quad, &
\end{array}
$$

Körpergestalt: eher etwas plump: wio aus der Mabtabelle ersichtlich, verjiingt der Kärper sich rom Ösophagushinterende nach vorn um ungefïh die Hälfte. Der Schwanz ist verlängert, verjüngt sich kegelfirmig, endigt stumpf gerundet.

Färbung am Vorderende nur schwach, an der hinteren Körperhälfte stark braungelb.

Ha ut nur düm, die äberste schicht fein geringelt.

Körperborsten mit Ausnahme des Kopfendes nur ganz vereinzelt, lang und frin. Vor der Schwanzpitze submedian je aine kurze, steife borste.

Papillen scheinen zu fehlen.

Längsw ïlste. seitenfelder breit: Medianfelder schmal.

$$
\text { Seitenmombranon nicht beob- }
$$
achitet.

Ko pfende nicht abgesstzt (rergl. 'Textfig. 3).

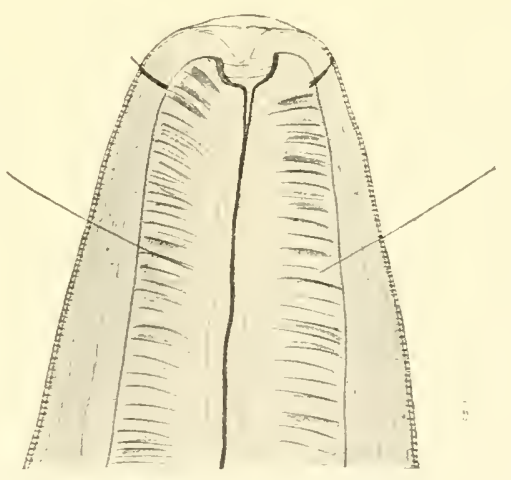

Fig. 3. Monolustera bothrio-

laimu n. sp. Kopfende. Vergx. 900. 


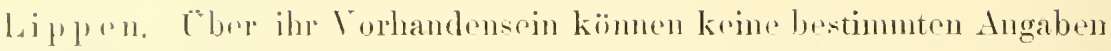
gemaleht wordon, woil dem Kopfvorderrand rino nicht zu entfernende Kappe fremdrop substanz anflagepte. Imuserhin glaube ich die L'mrisse schwach

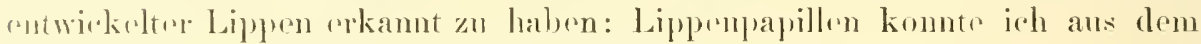
elerehen cimnde obenfalls nicht beobachten.

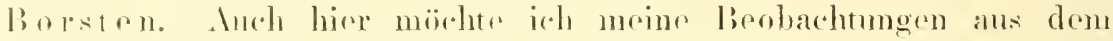

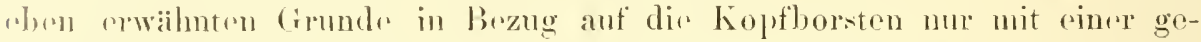
wissen limerve wirdergeben. Es scheinem nur 4 submediane, kurze Kopfborsten rorhanden zu sin (rergl. Texttig. 3 11. 4).

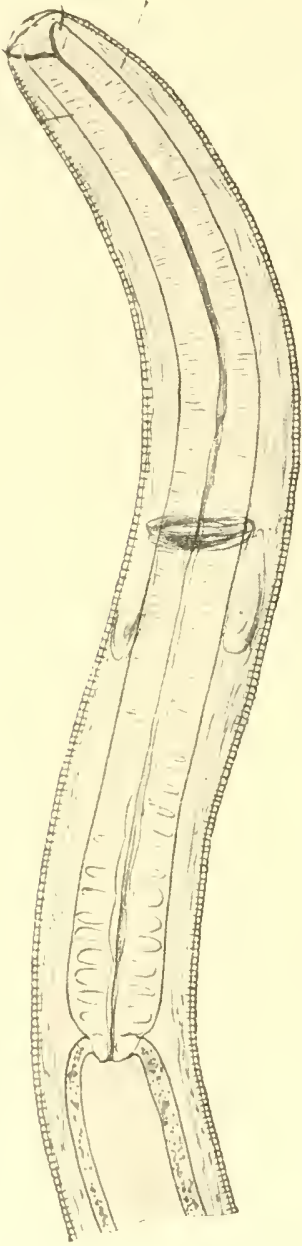

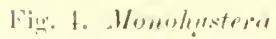
luthrivlaimer 11. sple

linerlerendr. liner. : :i)6. Mreiter hinten beobachtete ich aubordem sichor noch + lange. frino sublateralborstrn. durch die

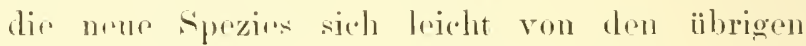
Virtrotem der Gattung unterscheiden läßt.

Die soitrnorgano scheinen zwischen den riguntlichen Kopfloustrin und diesen langon sublateralborsten zu liegen und ovale oder vinlleicht sugar kroismudr Form zu haben. In dor Fläche komnte ich sio nirht brstimmt erkomen, wohl aber waren sir in Protil als schwache Hacho Vertirfingen kenntlich.

Innere Organe. Jir II ndh $i h_{1}$ la erscheint inn optischn Längsichnittr als Haches, kolchförmiges Grübrhen mit verdicktrn Wäinden.

bor (O) inchem or nach lintru nur wong rodedickt ist. El

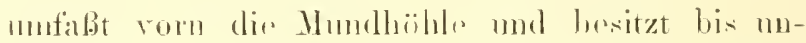

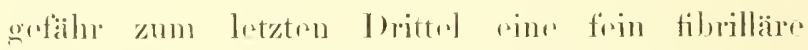
Muskulatur: am lotaten l) rittel abor benbachtet uan zwischon den Fibrillen quere Finlagerungen von das Licht stäker brochendem Gowolur. Dic G)ophagualintima ist mor sehwach verdickt.

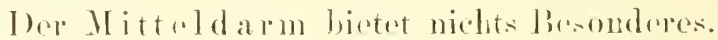

Eine dorsal von der Cbereangestelle des Mitteldaress in den Enddam liegonde \%elle ist ver mutlich als lierotaldriise zu dentem.

II

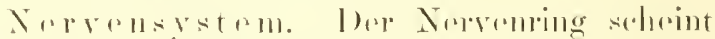

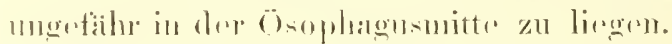

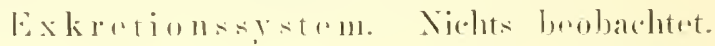


Scellwanz d riisen rorhanden, vermutlich aus 3 größeren und 2 kleineren Zollen bestehend. Ein Driisenausfïhrungsiohrchen habe ich nicht beohachtet, wohl infolge mangellafter Konservierung des Exomplars.

Bemerkungen: (Obgleich mir nur ein rinziges. nicht goschlechtsreifes Exemplar vorlag, beschreibe ich das Tier als neur spezies. da es wohl nicht schwer ist, dasselbe auch in rrwachsenen, geschlechtsreifen Individuen wiederzuerkennen. Ich möchts in dieser bozichung bresonders auf die eigonartige Schwanzform, dic geringelte $\mathrm{Haut}$ und auf den Bau des Vorderendes, nawrontich auch auf dir 4 sublateralen feinen Halsborsten hinwrisen.

\section{Gen. Dorylaimus Dujardin.}

\section{Dorylaimus merogaster 11 . sp.}

(Texttig. 6-12.)

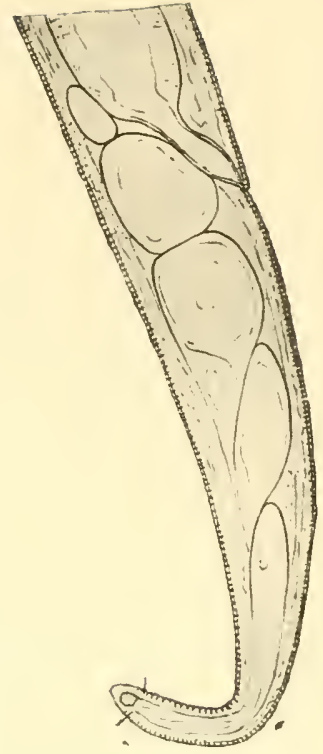

Fig. D. Momoherstern

lenthrolaima n. s.1. schwanzende. Vergr. 30ti.

Fundangaben: Farm ()tjiturzu bei Noudamm, $66 \mathrm{~km} \mathrm{NO}$. IV ind huk. zwischen Sïßwasseralgen: WV. Michaelsex, 13. Mai 1911.

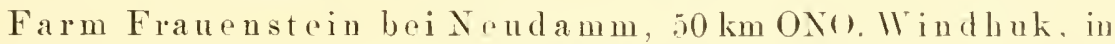
einem Toich mit grünen Pflanzen: W. Mchaessex, 13. Mai 1911.

Windhuk, zwischensiißwasseralgen; W. Mucnabusex, 20. 2.2. Mai1911.

Grootfontein, zwischen süßwasseralgen; $\mathbb{W}$. Michatesen, 7. bis 11. Juni 1911.

Vorliegend 6 Exemplare, $4 \sigma^{7}, 1$ f und 1 jugendliches Tier.

Äußeres.

Gesamtlänge

Ösophaguslänge

Schwanzlänge

Größte Dicke

Dicke am After

am Osophagus-

hinterende 0,088

am Kopfo

$G_{1}$

$\mathrm{G}_{2}$

Gröbenverhältuisso.

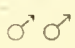

$\mathrm{mm} \quad \mathrm{mm} \quad \mathrm{mm} \quad \mathrm{mm}$ jugendl. Ind.

$$
\begin{array}{ll|l|l}
3,988 & (3,205-4.457) & 4,741 & 2,088 \mathrm{~mm} \\
0.948 & (0,925-1,044) & 0.882 & 0,551 \quad .
\end{array}
$$$$
\begin{array}{l|l|l}
0,0405(0,032-0,047) & 0,396 & 0,133,
\end{array}
$$$$
0,094(0,086-0,10-))\{n=40,117 \quad 0,054
$$$$
0,0.59(0,058-0,060)\}^{11=4} 0,076
$$ 
MI

$\mathrm{H}_{1}$

$\mathrm{H}_{2}$

\section{$-7,762$}

0.727

0,605 $\{n=1-$

jugendl. Ind.

$40,5 \quad 38,7$

3,8

15.7

l is Alkoholkonservierung hat vermutlich diese Zahlen etwas beceinflußt, da simtliche Tiere schrumpfungen anfwissen.

K ïr pergestalt fadenfürmig, beim Weibehen der schwanz verlängert,

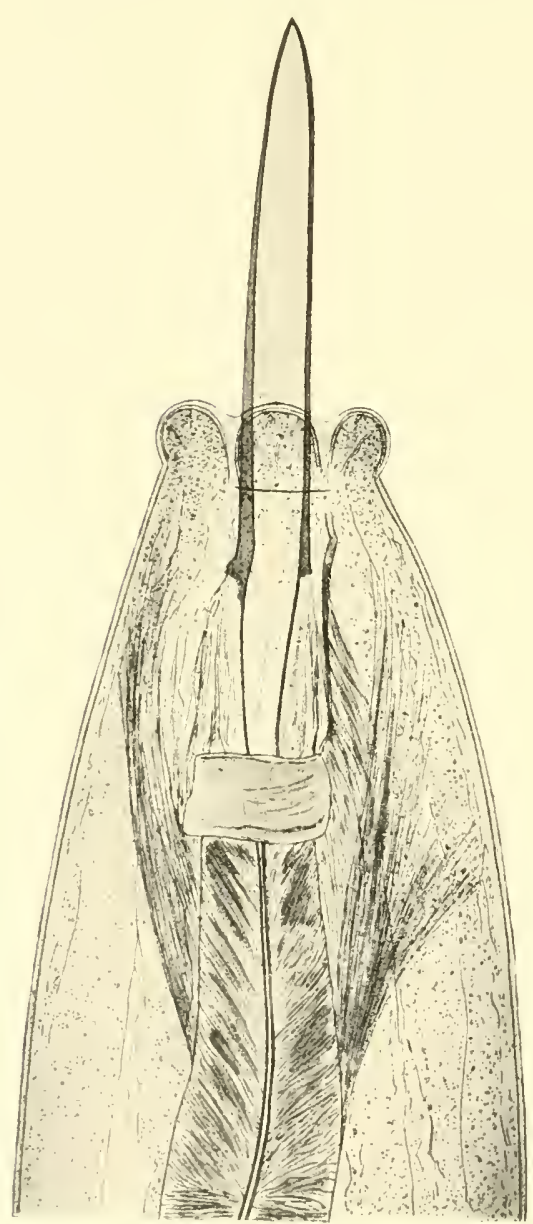

Fig. 6. Ionvlaimus meroutretor n. sp. Kopfende. Veror. 116. allmällich verjüngt und fadenförmig endend, beim Männchen das Sichwanzende stumpf gerundet; dir Verjüngung nach den beiden kïrperenden zu ist am besten aus den oben angeführten Dickenmessungen am After, Ösophagushiuterende und am Kopfe ersichtlich.

Fä r bung. Haut livalin, sonst braungelb.

Ha ut glatt, whe Borsten und. ausgenommen das Kopfende und das männliche Schwanzende (siehe diese). ohne Papillen. Buim Weibchen schien mir die Hant viel dickor zu sein als bei den Minnchen, namentlich am Hinterande des Kiirpers.

Sritenfeldrr bis 25,2 "u breit. hell, von 2 Reihen in der Flächs rechteckiger Zellen gebildet. S eitenmembranen fehlen vollständig.

Medianfolder nicht beobachtet, wemn vorhanden, so dünn, daß sic an Totalprijparaten nicht zu sehen sind.

Kupfende durch eine seichte Einschnïrung rom Körper geschieden: Lipper sohr deutlich kugelig gerundet. verhaltnismäbig grofo: ihre Kahl wie gewiihnlich 6. J'apillon auf den 
Lippen so klein, daß sie nur mit starken Linsensytemen zu rkennen sind: vermutlich sind 2 Kreise vorhanden, jeder mit je 6 Papillen, die

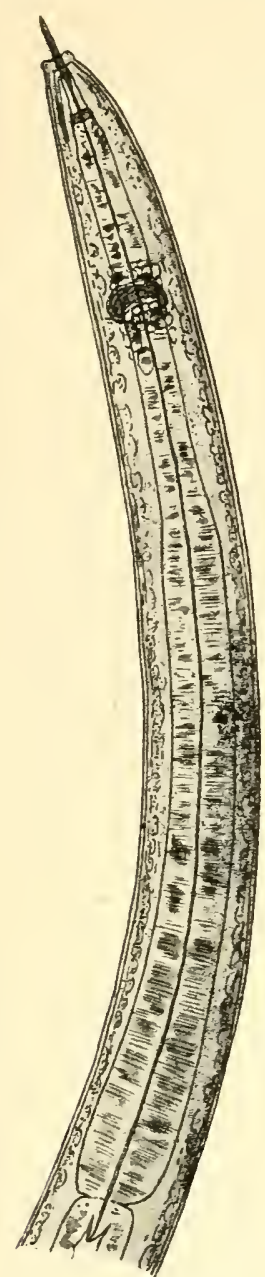

Fig. 7. Dorulaimu: merogaster n. sp. Vorderende. Vergr. 5 s. sich nur ganz wenig ïber dir Lippenoberfläche vorwölben. Der hintere Papillenkreis liegt am AuBenrand der Lippen, der vordere an der Peripherie de. Vorderrandes.

Die s'eitenorgano sind in seitlicher Lage des Tieres oberflächlich nur als quere Linien zu erkennen. die gleich hinter den Lippen liegen.

Innere Organisation. II $u=-$ kulatur polymyarisch.

I) arm. Mundhijhle eng. dünnwandig, nur im hintersten Abschnitt mit ein oder zwei ringartigen Verdickung'n: diese Verdickungen kïunen anch dis Form eines kurzen liihrenstückes haben, wie ich dies bei einem der Tiere vorfand und in Texttig. 6 dargestellt liabe. Es handelt sich hier wie bei zahlreichen Durylaimi $\quad$ Im 50 genannte Gleit- oder Fiilurungsringe für den Uundstachel. Dieser ist kräftig und deutlich ron der Osophagusintima abgesetzt. die nur diinn ist. Osophagus schon am
Vorderende krïftig muskulös,

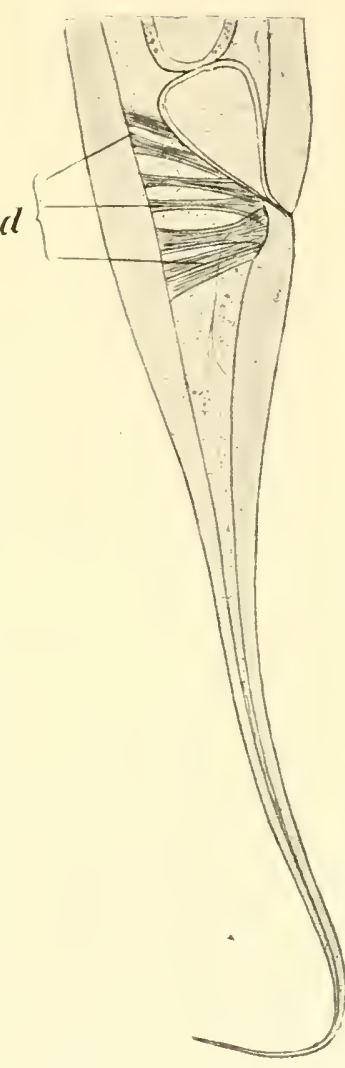

Fig. S. Dorylaimus meromaster n. sp. Schwanzende des $q$. Vergr. 132.

d- Dilatatores ani. nach hinten anschwellend und

dicker werdend, sudaß er an dir Cbergangstelle zum Mitteldarm sehr dick und kräftig ist. Das Anschwellen nach hinten ist ein ziemlich allmähliches; nur ungefähr am Ende des ersten Drittels seiner Länge sicht man ein plötzlich etwas stärkeres Anschwollen. Tou der Bewegungsmuskulatur des Mundstachels sah ich dorso- und ventromedian oder submedian große kräftige Protraktoren. 
In der Ebergangsstell. vom Vordır- zum Mittrldarm sind auben an der trennenden Einschnürung 2 oder $3 \mathrm{kl}$ cine Zollen anfgelagert.

l) Mittoldar rerbält sich beim Männehen wie bei den typischen Dorylami: or ist in eimen vordopen braungelt, gefirbten und einen hintern. farblosen prärectalen Alselnnitt gesondert, und zwar nicht blob dureh eine

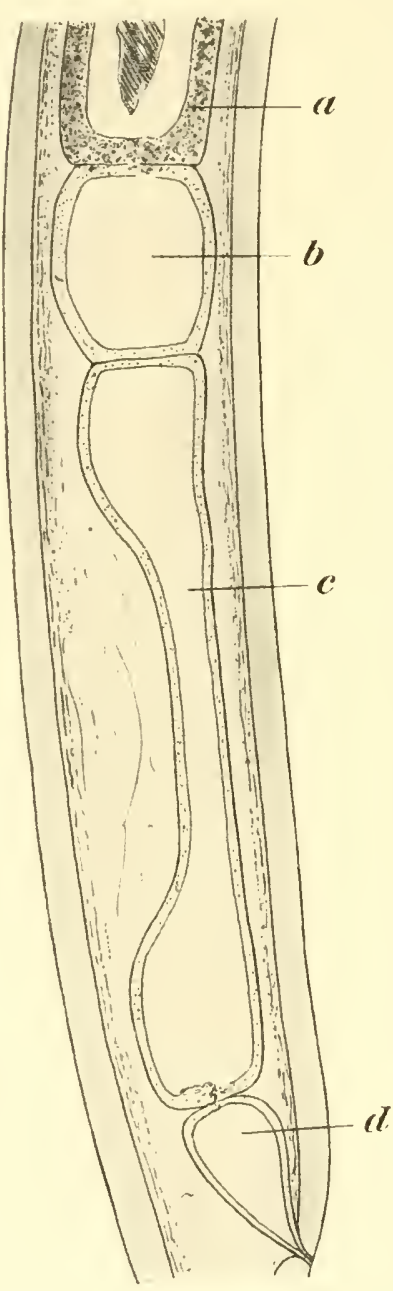

Fig. ?.

Einschnïrung, sondern dureh rine doppelto Wand (siche Textfig. 11). Bei dem einzigen orwachsenen Wreibclien, das nir vorlag. beobachtetr ich num eine interessante besonderheit, dir wohl als Inomalie zn denten ist; der prärectale Mbschnitt war hier noch inmal geteilt in sin vorderes 0,076 inm langes Stïck und einon hintern $0,300 \mathrm{~mm}$ langen $\mathrm{Ab}$ schnitt. Bride waren farblos und hoben sich schom dadurelı rom braungelben eigentlichen Mitteldarm ab. 1).r J)arm wrist hier also eine

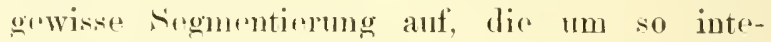
ressanter ist, als dir tronnenden Wände doppelt sind Texttig. 9. Bei den Männchen hatte das l'rïroctum eine Länge von $0,472-0,497 \mathrm{~mm}$.

l)as licetum war nur beim Weibchen gut zu erkomnen, blasig aufgetrieben und dümwandig. Während ich beim Jännchen in der. Recetalgegend zahleriche vermutlich nervïse \%ellen beobachterte, komnte ich beim Weibehen koine solchen auftinden. Dir Analmuskulatur des Mannchens besteht aus zwoi in spitzem Winkel zu einander wirkenden Dilatatores: der ainu streiclit schiref, der andere senkrecht zur Kiirperachse. (V'rol. Texttig. 12.) Das Weibchen verhält sich atuch in dioser Bezielunng eigenartig. Es ist näullich kein einheitlicher Dilatator ani vorhanden, sondern jedorsoits eine ganzo

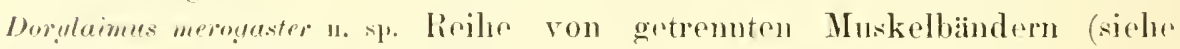
L'racectumn und Rectum des f. Textfig. 8).

Verogr. 132.

$a$ - Mitteldarm, 7 - vorderer pratruetaler, c - hinterer praterectalier Abschuitt, d licetum.
Nervensystom. Der Noprenring liogt verhälnismäige weit vorn (rergl. Textfig. 7). Der Cosophagus ist in seiner Nähe von zahlprichen, wohl norviisen \%ollen mantelartig nm- 
schlossen. I Jie oben bereits kurz berïhrten großkernigen Zellen in der Umgebung des männlichen Rectums sind sehr wahrscheinlich anch nerviiser und nicht driisiger Natur.

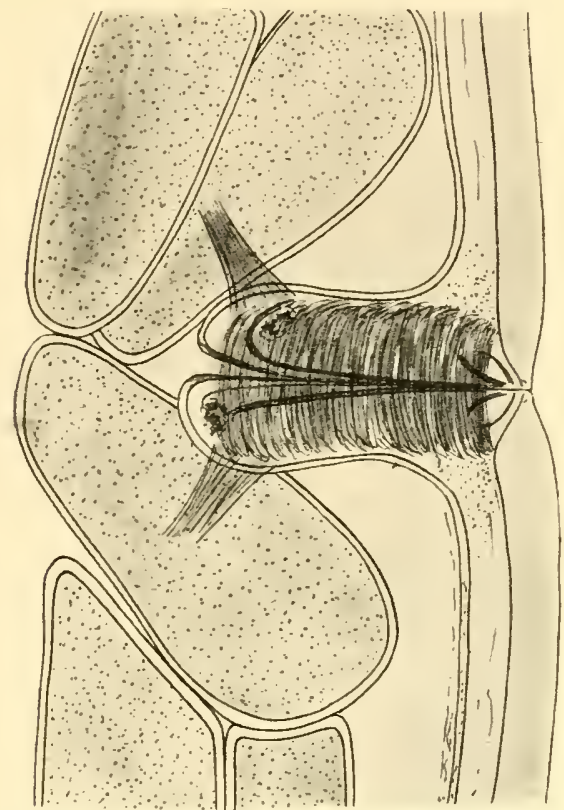

Fis. 10. Dorylaimus merogaster n. s]. Vulva- und Vaginalgegend des $f$. Vergr. 600.

$$
\text { Mrabliche Geschlechts- }
$$
organe. Sie sind paarig, aber asrmmetrisch, indem der rordere Gronadenast etwas kiirzer ist als der hintere. Die rinen queren spalt bildende Vulra liegt bedentend vor dor Kärpermitte und fuihrt in rine V'agina nit kräftiger zirkulärer Muskulatur (vergl. Texttig. 10) . Nahe an der Ubergangsstelle in die Lteruswande glaube ich zwischen die zirkulären Muskelfasern eingelagert jederseits j" eine klrine Drïsenzelle geveluen zu haben. Iie Vagina besitzt -7 Miehaelken, Deutsch-Siidwestafrika.

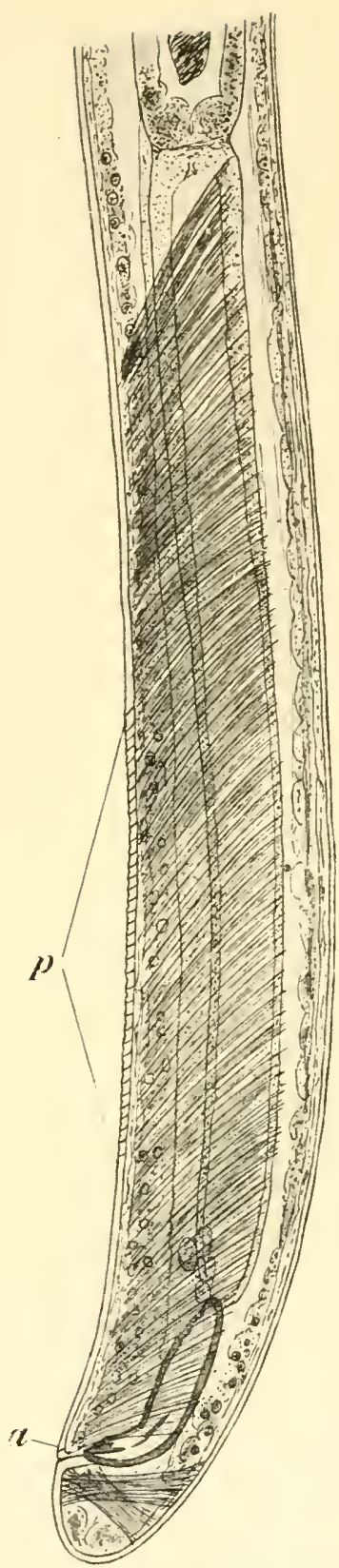

Fig. 11. Dorglaimus merorrester 11. sli Hinterende des 7 mit Praerectum und Bursalmuskulatur. Vergr. 182. $\mu$ - praeanale Papillenrıilie, $a$-Analpapille. 
aubredem noch viel bandartige Muskehn, die schicf zur Kïrperarhse liegen (rorgl. Textig. 10\% Timutlich dienen dieselben beim Durehgang der Eier zum wonigstens teilweisen Öfinen des inneren Vagina-Endos oder damn blob zum Fostlalten desselben, und die Uterusmuskulatur öftnet dis Vagina durch küiftiges Durchdrücken dor Eirer. Letztere sind dünnnnd glattschalig und sehr lang: sie waren säntlich ungofurcht: ich zählte in

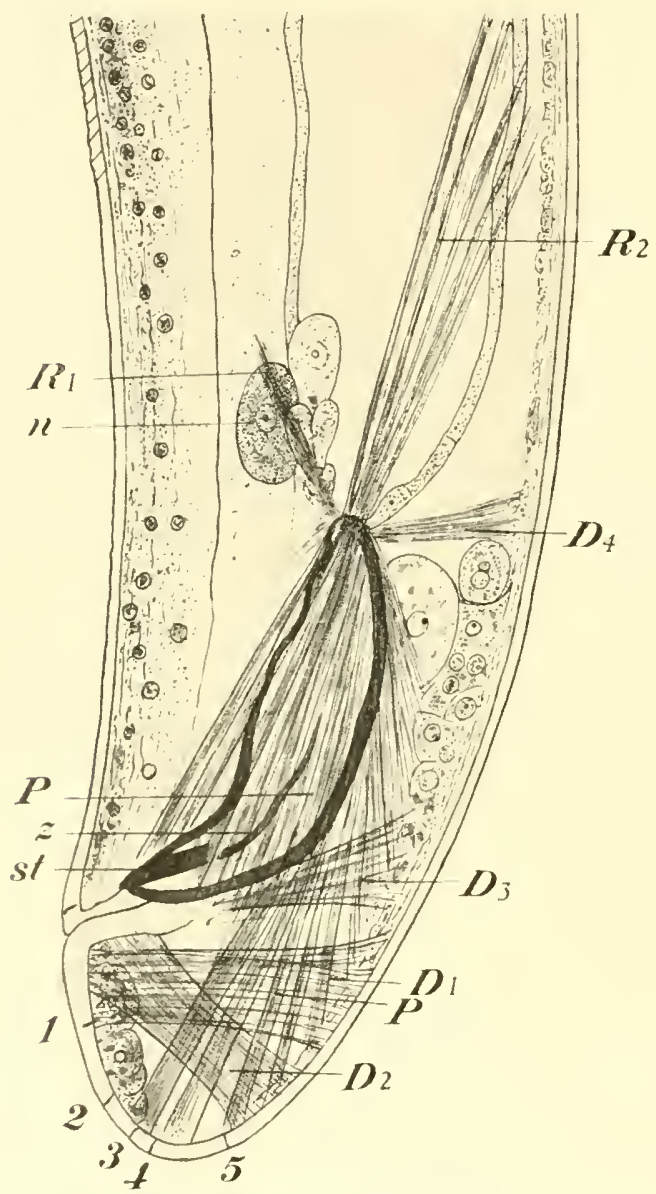

Hig. 12. Mormlaimu: meromaster n. sp.

Kofudationsapparat des $\sigma$. Vergr. 360.

и-Zellen, vermulich nerviser Natmr, li, Retractor yiculi minor, $I_{2}$ - lictractor spiculi major, I' - Protractores spiculorum, $I_{1}$ - Dilatator rectus ani, $I_{2}$ bilatator obliquus ani, /, - Muskel fraglicher Wirliung, /) vermutlich nit ilem Rectum in Beziehung stehemolar Muskel, st - alkossorisches stiick, $\hat{x}$ - zentrale Verstiolimmeleiste, 1 5. postanale Papillen. jedem Lterusast deren 4. Der Cterus entlielt auferdem noch eine Unmenge lïuglicher spermatozoen.

MännlicheGeschlechtsorgane. Dor Hoden ist, wie iiblich, paarig: der eine ist nacls vorn ansgestreckt, der andere zuritekgeschlagen: der samenleiter ist eng und schmal. Dit spicula sind krä̈ttig, ziemlich phump, vermutlich mit zentraler Vorstälkungsleiste. lic akzensorischen stiucke sind nur selumal und sehwer zu sehen, wie iibrrhanpt die spieula, da sie von einem ganzen Muskelmantel eingeschlossen sind. Die Bewroungsmukulatur dieser sireula ist ziemlich kompliziert; als Protractores wirken rine ganze Anzahıl ron Muskeln, die die Spicula umschliefen (vergl. Truttig. 12). Ein Teil derwelben sertzt ant proximalen lindre rines jeden spiculums an und heftet sich dann fast in Afterhiohe an dere Hant fest, und zwar in breiter Flacher vou der ventralen sublaterallinie bis nalı zur dorsalen ILedianlinie. Writere Muskelliundel greifen anf der borsalmite der spicula 
an und sind im Inneru der schwanzspitze festgeheftet. Als hetractoreswirken zwei verschiedene Muskeln: der eine, als Retractor major zu bezeichnen, greift am proximalen spicnlumEnde an, streicht schief dorsahärts nach rorn und leftet sich nahe der dorsaten submedianlinie an. Der andere, als hetractor minor zu bezeichnen, greift am glrichen spiculum-Endr an, zicht aber ventralwärts schicef nach vorn und heftet sich in der ventralen Sublaterallinie an. Er ist viel sehwächer als der listractor major und dient wohl nur zur Korrektur der Bewegung des letzteren. SchlieBlich soi noch erwähnt, daßich in der Nähe dos proximalen spiculnu-Endes, aber innerhalb descelben, cinen dorsalwärs ziehenden Muskel sah, der aber unparig zu soin schien und vermutlich nicht mit dom Kopulationsapparat, sondern mit dem Rectum in Beziehung stcht. Im Zusammenhang mit dem männlichen (ieschlechtsapparat stehen 61-1;3 Bursalmuskelpaare, dis vor dem After joderseits von der ventralen submedianlinie zur dorsalen sublaterallinie ziehen. Sie wirken als Flexores candac und sind den Nännchen sämtlicher 1)oryaimi eigen, aber nichtsdestoweniger von violen Forschern als schirefo streifung der Haut beschrieben worden. An männlichen schwanzende sind sowohl präanale als postanale Papillen vorhanden. Vor dem After liegt die isoliert stehende Inalpapille und weiter rorn noch rine ventromediane Rrihr von 35-3!) feinen, enggedrängton Papillen; sic sind ihrer Kleinheit wegen nu bei genau lateraler Lage des Tieres, also im Protil, deutlich zu selen: dir ventrah Medianseite rrscheint dann, soweit die Papillen gehen, leicht gewellt. Die Papillenreihe begiunt etwas ror den inneren Fipula-Enden vorgl. Textfig. 11 n. 12). Am schwanze sind chenfalls einige fuine Paprillun vorhanden (rorgl. Abb. 12).

Bemerkungen: Her Dorylimus mevorfester gehört zu junev Gruppe der Dorylaimen, bei der dir Weibchen rinen verlïngerton, fadenförmigen, die Mänchen "inın kurzen, stumpf gerundeten schwanz besitzen, also zur

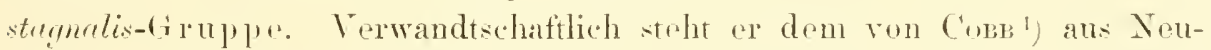
serland beschriebrnen lomglaimus nocae seulandiue sehr nahe: letzterer, der in ungefäh $107 \mathrm{~m}$ Tiefo im Taupa-fore gefunden wurde, hat aber eine ganz anders gebaute Lippenregion: ,the lip region being neithre contracted nor rxpanded. There appear to be six rery inconspicuous lips each bearing a single minnte papilla. The width of the head may he gauged by the fact that the lip region is about twice as wide as the spear." Auch in andern Figensehaften wrichen die Formen von einander ab: so ist der Darm bei 7). novere seculudice dunkel gefirbt, das Prarrectum nicht so

1) Com, N. A., Freeliving fresh water New Zealand Nematodes. Proc of the Cambridge Philos, Society, Vol. XII, p. $363,1904$. 
lang wir bei unserer Art, die Größe beträchtlichre 6,7 mm und $6,36 \mathrm{~mm}$ ), die Zahl der präaualen Papillen beim Männchen nur 29 nsw. Leider belegt Corks soine Beschrobung nicht mit Abbildungen, was selor zu bedauern ist, da daun leichter ein endgültiges Verteil zu gebon wäre. Auch der von mir') beschriobeno Dorylaimes yaussi. der leider unr noch inn Männchen bekaunt ist, besitzt grobr M̈lnlielıkeit mit der vorliegenden neuen spezies. Doch ist anch bei diesem die Lippenregion anders gebant, der Copplagus erst von der. Mitte an verdickt, das Tier viol kleiner $\left(\sigma^{7} 2,380 \mathrm{~mm}\right.$ lang) und dor sclnwanz otwas anders geformt. l)agegen sind Zahl (38), Lage und Ban der prï- und postanalon Papillın bei don Männchen der beiden Arten fast völlig ibereinstimmend. Wir mïsen noch abwarten, bis das

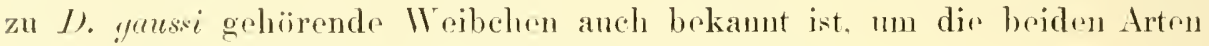
noch besser umschreiben und abgronzen zu kinmon.

\section{Gen. Actinolaimus Cobb.}

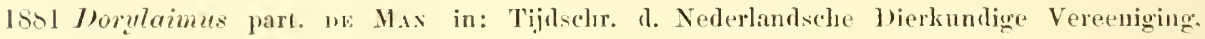
Deel $\mathrm{Y}, \mathrm{l} .100$.

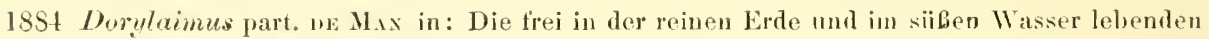
Nematoden der niederlänlischen Fanna, 1. 190.

1899 Dorulumus part. N. A. Coms in: Macleay Memorial Volume, Departement of Agriculture.

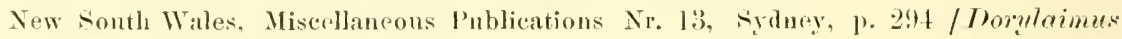
balurinthostoma].

$18: 47$ Morylaimus part. E. $\because$. DAnAy in: Resultate der wissenschaftlichen Erforschung des Plattensees, Bd. 2, p. 106 / Thonluimus inarolaimes].

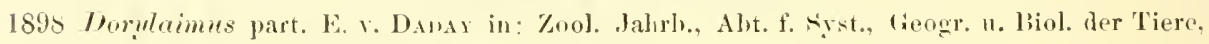
BA. 10, 1. 12.; Dorenlaimus macrolnimus/.

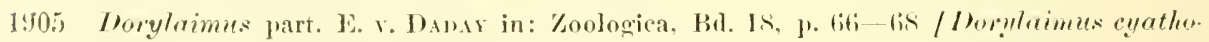
laimese und I). tripapillates.].

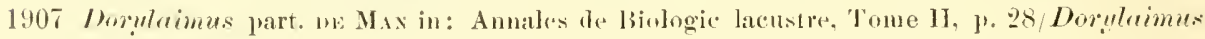
macroluimes.

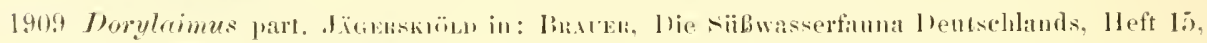
p. +2 /). macrolaimets/.

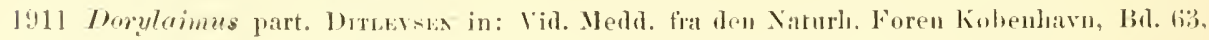
p. 249 / (1). marnoluimes/.

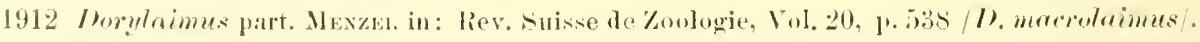

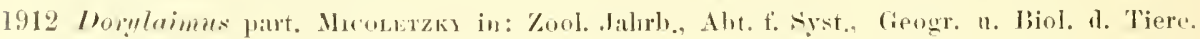

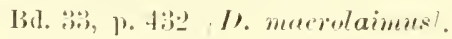

1918 Actimolrimus ('us, in: Journal of the Mashington Academy of seienees, Vol. 111, 1. t34.

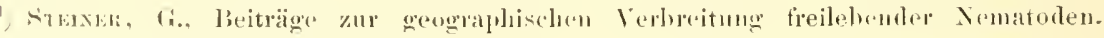
Zoolog. Anzeiger Bł. XI.11. 1. :201. 1916. 


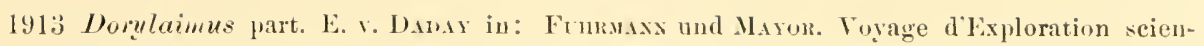
tifique en Colombie Mém. d. I. Soc. neuchâteloise des sciences naturelles, Vol. V, 1. 666 /D. macolaimus].

1913 Dorylaimets part. Bвакихниp in: Abh. d. Nat. Ver. Bremen, Bd. XXII, 1. 310 [D. macrolaimus].

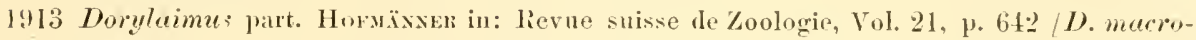
laimus].

1914 Dorylaimus part. Mrcoletzis in: Zool. Jahrb., Aht. t'. Ayst., Geogr. n. Biol. d. Tiere, Bd. 36, 1. 524 7D. macrolaimus].

1914 Dorylaimus part. Mexze1, in: Areh. i. Naturgesch. Achtzigster Jahrg., Abt. A, p. 74. [1). macrolaimus].

1914 Dorulaimus part. StEFAsкK in: Recluerches sur la faune des Nématodes libres du Bassin In Léman. Thèse de l'Université de Genève, p. 56 [D. macrolaimus].

1914 Dorylaimus part. Mroletzks in: Zool. Jahrb., Abt. f. Syst., Geogr. u. Biol. d. Tiere, Bd. 35, p. $270 / \mathrm{Il}$. macrolaimus/.

1915 Dorylaimze part. Hornixser \& Mexzei in: Rev. Suisse de Zool., Vol. 23. p. 205 (D). macrolaimus/.

1915 Dorylaimas part, Mroutzks in: Ergehnisse einer botanischen Forschungsreise nach Deutsch-Ostafrika und siidafrika (Kapland, Natal und Rhodesien) in: Denkschr. d. K. Akar. d. Wiss. Wien. Mathen.-nat. Klasse, 92. Bd., p. 19.

1916 Actinolaimus stEixen in: Zool. Anzeiger 13d. 46,1 . 32s.

Typus: Actinolaimns macrolaimus (LE MAx).

Diagnose: Körper schlank, fadenförmig, Schwanz beim Männchern stets, brim Wribchen seltrn stumpf gerundet, meist fadenförmig verlängert. Seitenfelder stets vorhanden, breit, Medianfelder, wenn vorhanden, nur schmal: Haut ungeringelt, glatt. Kopfende nie mit Borsten, wehl aber mit gröBeren oder kleineren Papillen. Scitenorgane eine enge, quero spalte bildend. Lippen rudimentär. Um den Mundeingang meist ein oder zwei peristomale Chitinringe. Stets aine deutlichrgeräumige II undhöhle mit rippenartigen Verdickungen oder melireren Zähnen und cinem kraftigen Mundstachel, dor diedirekte Verlängorung des Osophagealrohros darstellt. Osophagus kräftig muskulös, meist mit einem diinnern vordern und rinem otwas dickern hintern Abselınitt.

Muskulatur polymyarisch. Nervensystem mit ringförmigem Kentralorgan. Exkretionssystem unbekannt. Weibliche Geschlechtsorgane paarig, nit zurïckgeschlagenen Ovarien. Hoden ebenfalls paarig: Spicula plump, gebogen; akzessorische Stïcke klein, meist lanzettförmig. Tor dem After zahlroiche präanale Papillen, die in sine einfache Reihe oder zu Gruppen geordnet sind.

Bemerkungen: Ich schliebe mich in der generischen Sonderung dieser Gattung dem Vorgehen ('uBs's an, der sie 1913 von /oryluimus abgetrennt hat. Fichon de MAx, der bripits 2 hierher gehörunde Arten beschrieben 
hat, rereinigte sie zu riner besonderen Gruple der Dorylaimi, die rr mit folgenden Worten charakterisierte: „Dorylaimen mit gewöhulichem, nicht nadelfömigem Stachel, bei wel $\cdot$ hem di" Mund ̈̈ffnung in ein seh. weitrs Vostibulum fiihrt, das bis an die Stachelmembran von einer dicken Chitinwand begrenzt ist." Ich habe bisher folgende V'ertreter des Genus aus eigener Anschaumg kinnen gelernt:

Actinoluimus macrolaimus (1, Max)

rotundicanda (DE MAX)

labyriuthostoma (Coss)

und dir vorliegende Art und bin zur Überzengung gekommen, daß wir es hier mit rince natiirlichen (iruppe verwandtsehattlich eng zusammengehöronder Formen zu tum haben. Das Vorhandensein einer derart ruchgestalteten eigentlichen Mundhöhle liefort rin Merkmal, das für die systrmatisehe sonderung der Gattung hochwertig genug ist, unsomehr als bri andern Gruppen freilobender Nematoden viel geringerwertigr Eigenschaften zur Anfstellung neuer Ciattungen hrrangroogen wurden. Ich möchte nur an die Crenera Chromadore, Spilophore, Hypodontolaimens, Achromadora rinnern. Daßs das bis jetzt ïbliche Genus Morylaimas anch einigo geschlossenere Formengruppen momschlob. hat Cors richtig erkannt und bereits einige derselbon als neue fienera abgetrent. Freilich gehören alle diese Genera phylugenetisch zusammen und werden wohl später bejun Ausbau des Nematodensystrms zu ainer Fanilie vereinigt werden.

Verwandtschaftlich schließt sich das Genus Actinolaimus am nächsten an einige langschwänzige Dorylaimi an, nämlich an die strgualis-Cruppe.

Von den jetzt bekamenten Actinolaimi scheinen die rorliegende und A. ryatholaimus (v. I) Ausv) dir primitivsten zu sein, wenigstens in Bezug auf den Bau dro. Inndhöhle: an sie wiïden sich set. macrolaimas (DE MAN), A.t. rediutus ('овв und Act. labyrinthostoma (Сове) anschließen: Act. tripapillatus (v. WADAY) schlie.Blich zeigt den kompliziertesten Bau rou allen und ist phyletiscele vermutlich dir jüngste Furm. Act. rotumdicanda (DE MAx) abre nimmt wieder rine etwas gesonderte stellung ein, indem hier dre peristonalo Ringkanal völlig fehlt. Es ist aber sehr gut mïglich, daß dies die primitirste Form ist. Nur ist es dann rinigemaßen unverstandlich. wie dir hier kräftigen zahnartigen Bildungen der Mundhöhle sich wieder zurieckgebildret hätten zu den doch schwachen und mehr Ausstïlpungen der Mundhöhlrnwand darstellenden Zähnen bei A.t. michaelseni n. sp. und Act. ryatholaimus.

[Ther dir Funktion der Actinolaimon-II undhöhle liegen noch keine Brobachtumgren ror: daf sic nicht zur Aufnahmo resp. zum Durchleiten 
von Nahrung dient, scheint mir auf der Hand zu liegen, da sic keine sichtbare Verbindung mit dem Ösophaguskanal hat; diese Aufnahme findet sicher durch das Stachellumen statt, und dieses stellt eigentlich die primäre Nundhöhle dar. Sehr wahrseheinlieh spielt die Actinolaimen-II undhöhle eine Rolle beim Festheften des Torderendes an den auszusaugenden Gegenstand, seien as nun Algenfäden oder andere ptlanzliche oder tierische Körper. Die preristomalen Chitimringe dienen dann wohl zur V'ersteifung des Saugnapfos, die \%ähne vielleicht auch zum Ritzen und zum Einspritzen vou Verdaungsiskreten in die aufzumehmende Nahrung.

Geographisch ist dio Gattumg iiber die ganze Erde rerbreitet. Act. rotumelicande und Act. macrolaimus') sind ans En o pat, letztere durch DaDAr auch aus $\mathrm{Kol} 11 \mathrm{mb}$ ien bekannt: Aet. labyrinthostomu wurde von Cons ant den Fijdschi-Inseln und ron mir anf drn K omoron. Act. radiatus ron

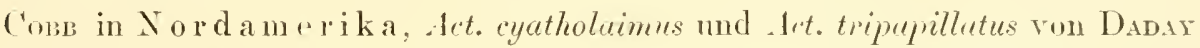
in Paraguay gefunden. und num kommt der unten beschriebeno A.t. mirhaelseni ans Deutsch-siidwestafrika nuch dazu.

\section{Actinglaimels michaelsemi n. sp.}

l'extfig. 13-17.)

Fundangabe: Windhuk, zwischen Niibwasseralgen: IV. MunaEsis, 20.-2.2. Mai 1911.

Farm Fraurnstoin bei Neudamm, 50 km ()NO. Windhuk. zwischen Nïßwasseralgen: W. Michaelsex, 13. Mai 1911.

Vorliegend 4 Exemplare, 2 geschlechtsprife Irinnchen und 2 jugondliche Exemplar.

\section{ÄuBeres.}

Gesamtlinge

0 ) sophagusläinge

Schwanzlänge

Gröbte Dicke

Dicke am After

am Osophagus-

hiuterende

am Kopfi:

$\%$

j

$\gamma$
Gröbenrer haltnisse.

$$
\checkmark \text { jureniles Tier jur. Tier }
$$

$$
2,736 \mathrm{~mm} \text { 1,73.5 } \mathrm{mm} \quad 1.677 \mathrm{~mm}
$$$$
0,644 \quad 0,457 \quad, \quad 0,414 \text {. }
$$

$0,022 \quad, \quad 0,133 \quad, \quad 0,194 \quad$.

$0,044 \quad, \quad 0.034 \quad, \quad 0,036$

0,036

0,044

0,022

60

1) Actinolaimus macrolaimus (DE MAN wurde von Mrobetzkr (191.) anch im inmbesi oberhall, der Faille gefunden. 
Das zweitr Mänmehen konnte ich leider für diese Messungren nicht berücksichtigon, da das hintore Körperende derart aufgerollt war, dab ein Messon nicht gut möglich war.

K ï rporgosta It fadenförmig, schr schlank, rom Ösophagushinterende nach vorn um rtwa $1 / 2$ verjüngt. Im schwanzende zeigen die ansgewachsunen Männchen von den beiden jugendlichen Tieren einen bemerkenswerten Intersehied, indem beide nur cinen sehr kurzen, stumpef gerundeten

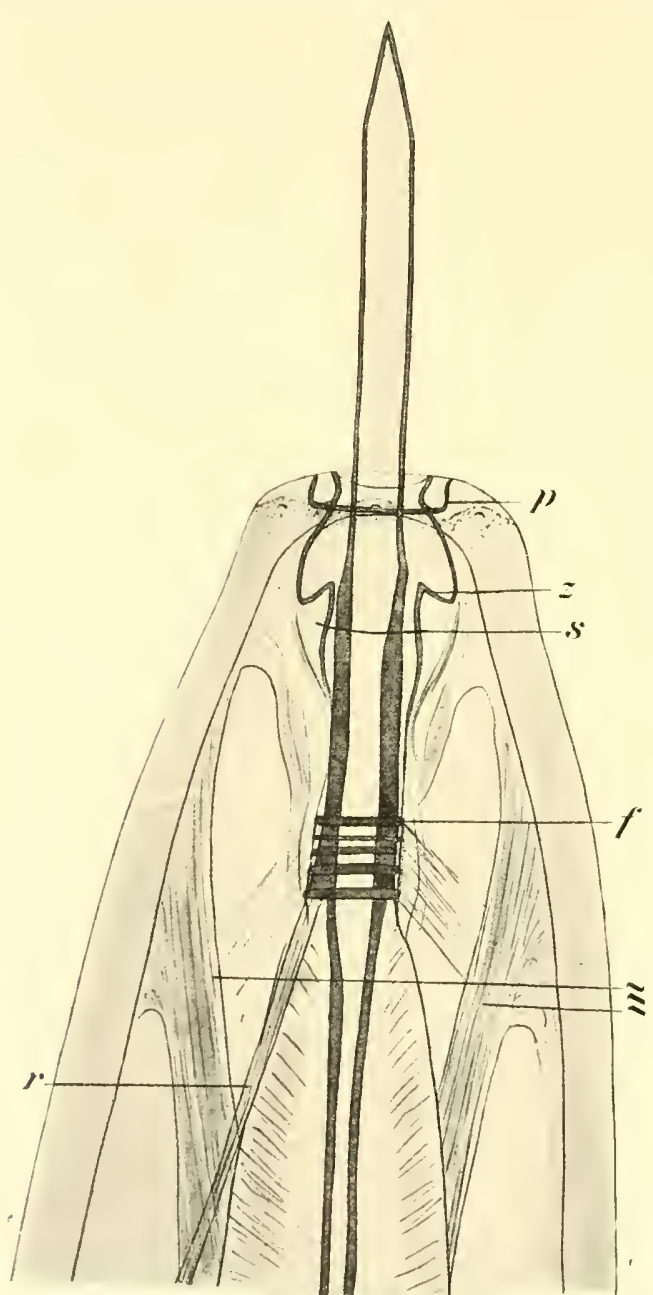

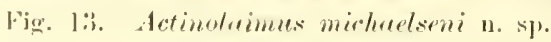
Kopfende. Vergers. $1: 30$.

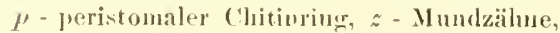

$s$ - Scitenorgan, $f$ - Fiihrnugs- oder Gleitring,

me-Protractoren des Mundstachels, " - Retractur des Mundstacliels.
Schwanz besitzen, während er bei beiden jugendlichen 'Tieren vorlängert ist und fein fadenförmig endet. Vermutlich besitzt das Wribchen anch in "rwachsenen Kustande sinen dreart verlängerten Schwanz, und selor wahrscheinlich das Männchen bis zur lotzten Häutung obenfalls, wie dies fïr den nahe vorwandten Actinolaimes marrolaimus (DE Max) zulerst durch Dothaysex nachgewiesen wurde.

F a rbung scluwach bramgollb bis hyalin.

Haut glatt und borstenlos, $3-t$ le dick, deutlich aus 3 sichichten brstehend.

Papillen nur am Koptconde (siche dirsess) und am männlichen Hinterende siche dieses).

Längswiilste. Diesieitenfralder sind $18 \mu$ breit: Zellen konnte ich an densolben nicht rrkemen; sie sind stellonwrise reich an Lakunen und enthalten rinc das Licht stark brechende, vermutlicle fettartige substanz ill grober Menge. Mrodianfolder konnte ioh an derr 
'Totalpräparaten keino auftinden: sind solche vorhanden, so sind sie sulp schmál. Sreitrnmambran an fehlen völlig.

Kopf vom Kïrper durch schwache Verjüngmg leicht abgesetzt, voru breit gerundet. Lippen fehlon rollständig. Papillen sind 6 rorhanden, je submedian und latreral eine; sio sind so kloin, dab sir anch bei Anwendung starker Systeme (Komp) Ok. 18. Apochr. Tmm. 2 mm) nur sehwer zu sehen sind. Borsten fehlon rollständig. Seitrnorgane ähnlich wie bei Actinolaimus mucrolaimus rine "nge, linienfimmig". "Lure Spalte: bei dem rinen Männchen lag sir in der Hähe der spitze der Mundzähne, bri dem andern (siehe 'lextfig. 13) etwas witer hinten.

Innere Organisation. I) arm. Wir bei allen Actinolaimi ist auber dem Mundstachel noch eine geräumige Mundhïhle vorhanden. I)er Mundringang scheint ziemlich weit zu soin. Rings um denselben läuft in linwebre sin nach dem Kopfvorderrande wenigstrens scheinbar offener prepistomaler lingkanal. Soine Winde sind verdickt: im Qureschnitt hat er ungerähr die in 'Trextig. 13 dargestelle Form. Seine Bedentumg ist noch rin Ratsel; vermutlich dient er bei sangendrer Nahrungsanfnahmo zum Abschlieben und

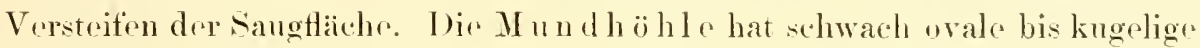
Form: ilure Wände sind kaum etwas verdickt, aber mit Kailmon rersehen. Diese Zähne sind aber nicht massive ('hitingebilde. sondern spitze, nach vorn gerichtete Vorstiilpumgen dor Mundhöhlenwand, ähnlich wip sir zahlreiche Oncholaini, aber auch andrer Nematodengenera besitzen. Es schien wir, dab nur je dorso- und ventromodian ein solchor Kahn vorhanden sit. also in ganzen 2. Mit starken Linsinsystrmon glaube ich gesoluen zu haben, daf diese Zähne an der spitze ron einor feinen Ottinung durchbuhrt sind; doch wöchte ich dies nicht als endgitlig xicher hinstrellen. Der Mundstachel ist kräftig: ror der Insatzstelle des Ösophagus ist dir den Stachel umgebende Wand nit ringartigen Verdickungen versehen; bei einom Exrmplar sah ich nur eine solche Vurdickung, bei rinem andorn (siche Textfig. 13) deren 4 oder 5: sir waren hier anch rerselueden stark. Liese linge luaben wohl dic Bedentung von Glirit- oder Fiihrungsringen beim Vorstoben des Mund-

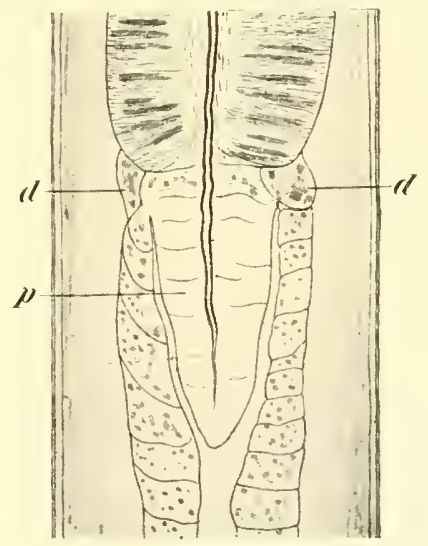

Fig. 14 .

Artinolaimus michuelseni n. sp. Körperabschnitt am İbergang des Ösophagus in den Mitteldarm. Vergre. 400.

, - vermutliche Drïsenzellen, $P$ ius Mitteldarmlumen vorspringender Gewebspfropt epithelialer Natur. 
stachels: ron ihnen sal ich schief nach hinten foime Fasern ziehen, die ich nur als Mnskelfibrillen deuten kamu, dir zur besserm Befestigung der Ringr dirnen.

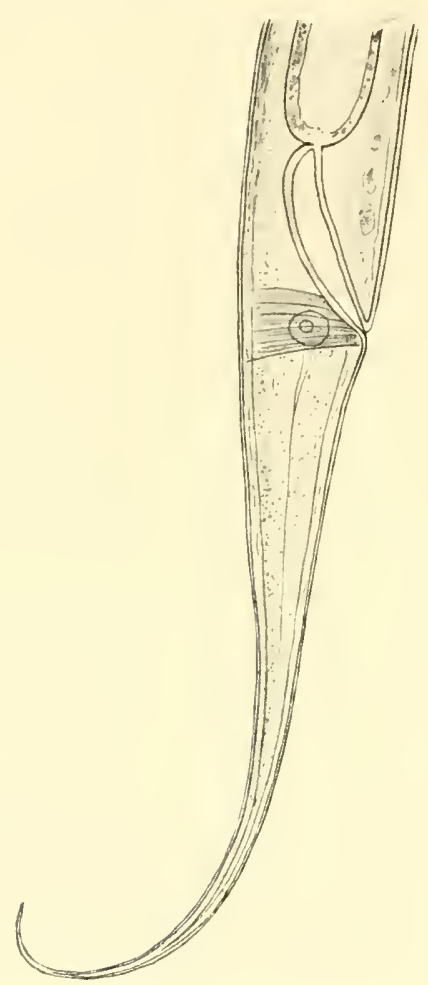

Fị. 15.

Artimulaimus micherelseni $\mathrm{n}$. sle. schwanzende eines jugendlichen. vielleicht weilulichen Tieres.

Vergr. 306i.

Der ()sophagus ist sriner ganzen Läinge nach kräiftig tibrillär: ar verdickt sich ungerähr in der Mitte plïtzlich otwas stärker, nimmt aber ron da an bis zum Hinterende gleichmäBig noch an loick! zu. Die das Osophageallumen auskleidende Intima ist vorn kräftiger als hintrus.

b) Mittrldarm hat schwach braungelbe 'Tönung und ist in zwoi Abschnitte getrennt: dem an seinem hintrrn Ende ist rin rtwa 300 p langer, hrllu, prïrectaler Teil dentlich rom vorderen Mitteldarm getrenut.

Das Rectum hat ungefälur die doppelte Länge des analen Kïrperdurchmessers.

M nskulatur polymyarisch. An dieser Strelle soi anch noch anf die Bewegungsmuskulatm des Mundstachels hingewirsen, von der ich in Nbb. 13 dargestellt habr, was sich bei lateraler Lago dos Tiores seloen lick. Jederseits modian odre virlloicht submedian ist ein krätiger Protractor. Ton den Retractoren konnte ich nur ainen einzigen submodian liegenden wahmohmen, der nur schmal und bandartig int (vergl. Texttig. 13).

$$
\text { Noryemsystem. Der Nepreming }
$$

way bei dru gemessenen, ansgrwachsenen

Männcluen (1,151 mm vom Vorderende entfornt; or ist breit und umkreist das Osophaguspoler schicef, sodab der ventralo hand weiter hinten liegt als dor dorsale.

Exkretionssystem unbekannt.

sichwanzdrïson fehlen.

II ännliche Geschlechtsorgaue. Hoden farrig, dor rine nach vorn, der andere nach hinten ausgestreckt, 0,274 mm lang: das blinde Ende des vorderen ist $1.871 \mathrm{~mm}$ vom After rntfernt. Iie spienla sind plump, schwach gebogen, an proximalen und distalen Ende spitz gerundet.

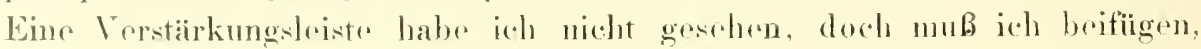


daß die spicnla nur undeutlich zu sehen waren, indem Bursalmuskulatur und seitenfolder sie vordeckten und die Boobachtung rrsehwerten. Dir akzessorischen Stiicke schienen mir kurz und lanzottförmig zu sein. Ton der Bowegungsmuskulatur des Spicularapparates konnte ich den lietractor spiculi erkennen, der rom proximalen spicuhm-Ende schief nach vorn dorsosubmedian zog. Der Protractor spiculi hat ebenfalls dic gewolnte Lage: er greift dorsal an den sipicula an und heftet sich an der Schwanzriickenwand fest. Auferdem waren noch zwei weitere Muskelpaape zu sohen, dir ich als Dilatores ani dente; der einc greift an der inneren Wand des Anus an, der andere gleich linter demselben: sie wirk'n in spitzem Winkel zu rinander. Eigentümlich verhalten sich dir präanalen Papillen: die Analpapille liegt nmmittelbar vor dom After: in etwa 11, facher fpiculumlänge weiter vorn steht dann rine Cruppe von 7 l'apillen eng beieinander: hierauf folgen in grijberen Abständon zwei isolierte und dann wioder ane Gruple von 6 anggedräingten Papillen (siehe Trextig. 16): in ganzen haben wir also 16 puäanals Papillon. di" Analpapille mitgerechnet. Tie ventrale Köperwand ist an den stellen der zwai Papillengruppen rorgewölbt.

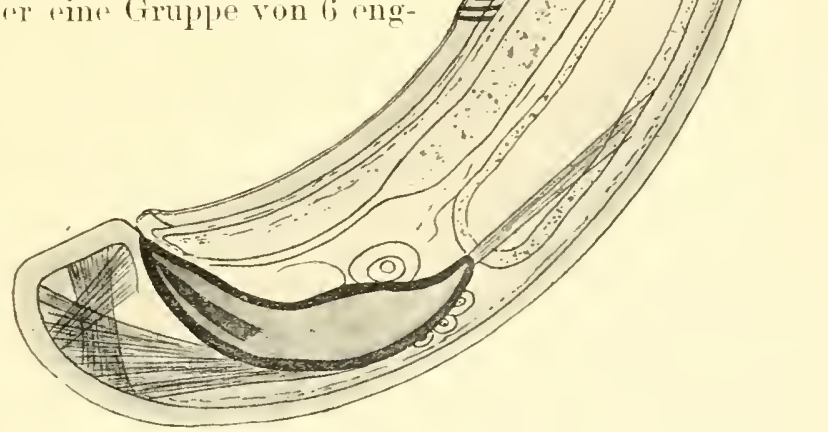

Fig. 16. Actimolaimes michat.seni и. sp. Schwanzende des $\sigma^{7}$. Tergr. 306.

Die Bursalmuskulatur reicht atwas vor die rorderste Papillengruppe: dir Kahl der Muskeln ist suwer zu bestimmon; vermutlich sind es 52 bis 56 Paare.

Bemerkungen: Artinolaimes mirhuelseni steht Actinolaimus cyatholuimes v. DADAY) [siehe sub Gonus 1905] sehr nahe. Boi letzterer Art ist aber das Koptende verbreitert und besitzt nach der Beschreibung Davars zwei peristomale Chitinringe; die Mundhöhle hat viel stärker chitinisierte Wändr. dam sind die Thiere vid plumper. und der schwanz ist doppelt so lang; beim Männclien sind die präanalen Papillen nicht zu truppen, sondern 
zu ciner gleichmäbigen Reihr goordnet, und jodes sprembm ist in der Mitte ventral tiof ausgeschnitten. DaDAY zeichnet in der beigegebenon Figur des männlichen schwanzendes keine Analpapille ein und orwalnt nichts von ciner soldhen. Ist diesclbe ihm otwa nntgangen oder fehlt sie tatsaichlich?

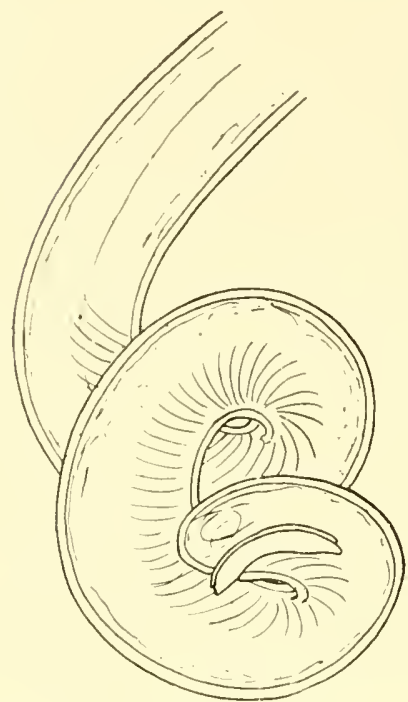

Fig. 17.

Wie bereits erwähnt, war das Hinterende bei drum ainem der vorliegenden Mämnchen so weit die Bursalmuskulatur reichter, ringerollt: wahrselueinlich habun sich wälıend der Agonic die Bursalmuskeln kontrahiert und so dieses Einrolleu brwirkt; gleichzeitig waren die spicula teilweise vorgestoben (sieho Texttig. 17). Dies seheint meino Varmutung zul bestätigen, daf- die Mainnchen der Dorylaimi und ihrer Verwandtru bei dor Kopulation das Sclowanzende $\mathrm{nm}$ das Wribchen rollen, und zwar soweit die Bursalmuskulatur reicht, während der ïbrige Körper wach irgend einer Richtıng absteht. Es wäre dies rinn Kopulationsstellung. die ganz von drejenigen der Rhabdiditen. () xyuren etce abweichen würde, wo das Actinolames michaelsemi u. sp. männliche Schwanzende sich dor Vulva rinfach
schwanzende des eingerollten $\sigma$. anheftet und mit Hilfr einre Bursa und KittVergr. 15\%. substanzen fiestgehalton wird.

\section{Gen. Oxyuris Rudolphi.}

\section{().rymois spinicamata Dujardin.}

('loxtfig. 1s-23.)

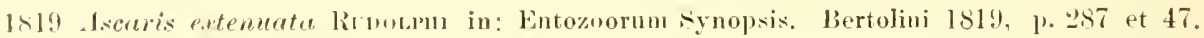

154. Oenuris spinicamda l) Mamux in: Ilistoire naturelle des Helminthes ou vers intestinaux, 1. $14: 3$.

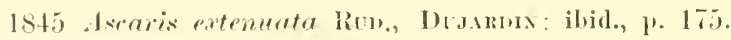

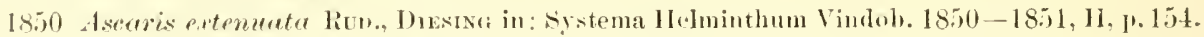

1850 Asaris acanthara Diesna in: Fystema Helminthum Vindol. Il, P. $18 \mathrm{S.}$

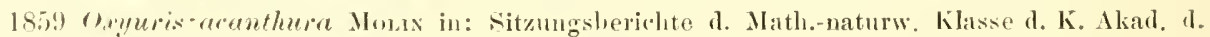
Wiss., Wien, Bd. :3, 1. 18, Taf. J. tig. 1-7.

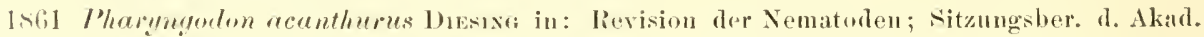
Wiss., Wien, Math.-nat. Klasse, Mal. 42.

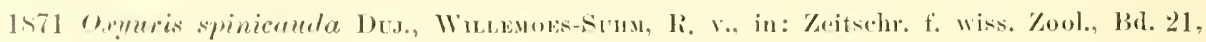
1. Ist;. Tat. XII, tig. $1-6$ u. S. 
157 Pharyngoton aranthuru. Dus., Lisstuw, O. in: Compendinn der Helmintbologie, p. 192 แ. 193 .

1983 Pharyngodon acanthurts Dies, Drasche, R. r., in: Verhandl. d. k. k. zoologischbotanischen Ges. in Wien, Bd. 32, p. 118, Tat. 9, tig. 12 и. 13.

1883 Pharymodon acanthurus Dies., Lixstow, O. V., in: Arch. f. Naturgesch., Jahrg, 49. Bd. 1, p. 297 .

1859 Tharyngodon aranthurus Diks., Lxistow, O. v., in: Compendium der Helmintlologie. Sachtrag p. 65.

1909 Oryuris spinicauda Dr.., Lxsтow, O. v., in: Brater, Die sïßwasserfauna Dentsch. lands, Heft 15, p. 70, fig. 57 .

Fundangabe: Windlun (Wirt unbekannt); W. Mrenaelsex, 19. April bis 8. Mai 1911.

Weitere Verbreitung: Europa, Nordafrika, Turkostan.

Wirte: Lacertilier und Wolge.

Torliegend ein einziges weibliches Exenplar olun Eirr.

Äußeres.

Gräßen rorhältnisso:

$\begin{array}{llll}\text { Gesamtlänge } & 1,696 \mathrm{~mm} & \alpha=9,8 \\ \text { Gsophaguslänge } 0,317 \quad, & \gamma=5.3 \\ \text { Schwanzlänge } & 0,551 \quad . & \gamma=3.1 \\ \text { GröBtr Dicke } 0,173 \quad, & \mathrm{v}=1,1,9 \% \text {. }\end{array}$

Färbung: Haut schwach brangelb. Feitenfolder holl. Osophagu dunkel, Darm hell.

K̈̈rpergestalt plump, nach vorn von der V'ulva an stark verjüngt. das Kopfende ziemlich spitz gurundet: Schwanz an der Basis breit. dam plötzlich stumpf gerundet und in einem langen, fadenförmigen Fortsat\% auslaufend. An letzteren beobachtete ich nur eino einzige kleine Borste. Normalerweise soll aber dieser Fortsatz mit zahlreichen kurzen Borsten besetzt sein. Möglicherweise sind sie bein vorlingenden Exemplar abgerbrochen (rergl. Texttig. 18).

H a ut ohne Borsten und Papillen, aber mit sethr deutlicher Ringrohng und feiner Langsstreifung. D) Ringelung greift aber nicht anf die seitenfelder iiber: die die Ringel trennende Furche ist scharf. Gregen das Hinterende wird die Ringelung schwächer und ist an der sichwanzbasis nur undeutlich; dre fadenförmige schwanzanhang ist gar nicht geriugelt: dagegen ist dir Haut an seiner Basis deutlich rerdickt.

Längswïlste: Śritenfelder breit; sie tallen durch ilur Helligkeit auf und heben sich deutlich von den angrenzenden, geringelten Hantabschnitten ab. Sie beginnen hinter dem liopfende und endigen an dir Ansatzstelle des fadenförmigen Áchwanzabschnittes. An der vorderen Körperhälfte erheben sich auf diosen Sritenfeldern knoten-, wulst- mond zahnartign 
Vudickungen, die quer über den Feldern stohen oder einen seitenmombranartigen, scharf markirten liand bilden (vergl. T'oxttig. 19). Diese Bildungen werden nach hinten nirdriger und verschwinden fast ganz; nur der hand rinuert an eine unregelmäBig ausgebildrte und ausgeluchtete Seitenmembran vergl. 'Textfig. 20). Nach dem Kö̈perinnern hin verbreitern sich dir sicitenfelder um melır als das doppelte: ilır hand scheint durch die Haut durch und begleitet den :inkern seitenfeldrand in einem gewissen Abstande (vergl. 'Tuxttig. 18, 19, 20). If dianfelder sind obenfalls rorhanden: doch kann ich ïber ihren lian nur mitteilen, dab sie nach innen kraiftig vorspringende IViilstr bilden.

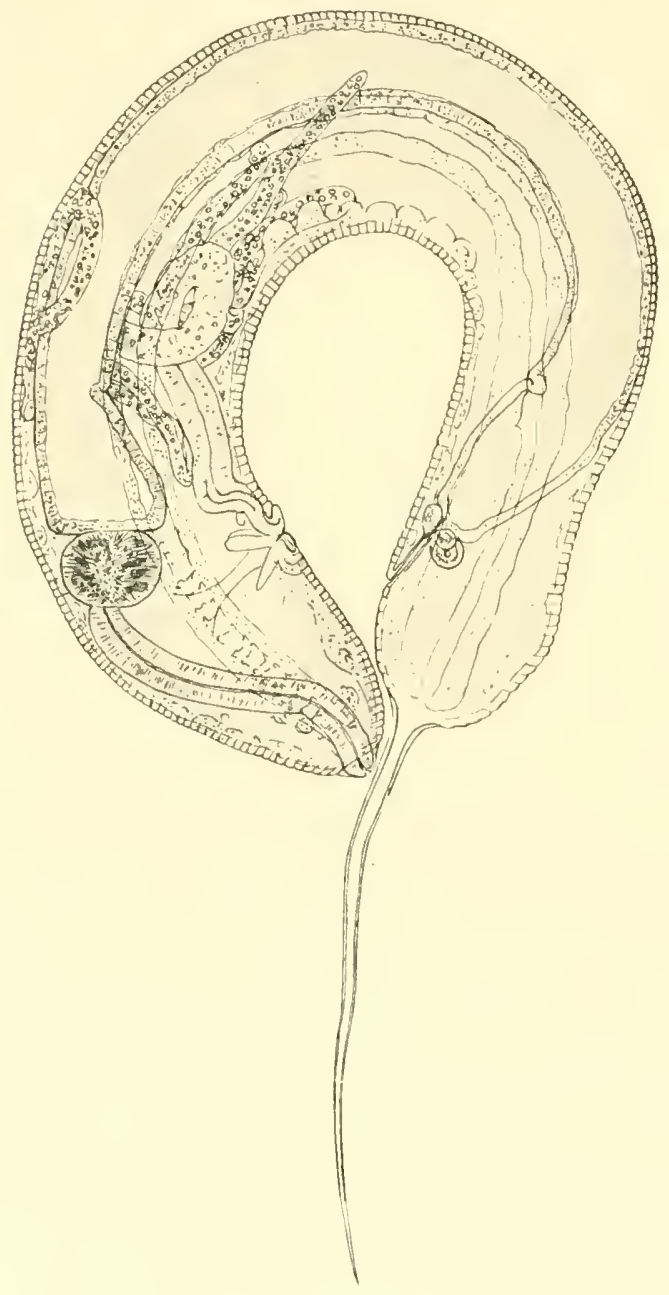

lig. 1s.

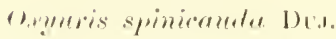

(iosautansicht des Tieres vou dre seite. Veror. 2:31.

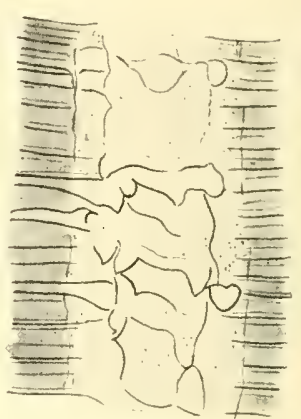

Fig. 1:1.

Orumeis spinicauda DCJ. Ansieht eines seitenfeldes

an Vorderkiorper.

veror. 306.

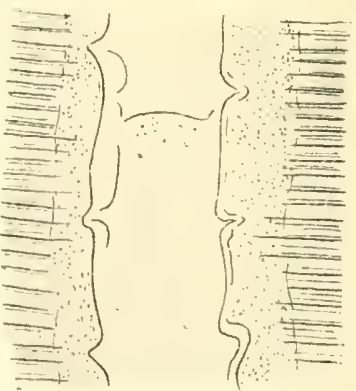

Fig. 20.

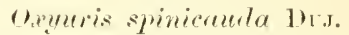
Ansiclit eines scitenfeldes vor Aem After. Vereses. BOR. 
Kopfende spitz gerundet (rergl. 'l'exttig. 21). Kopflborsten und -papillun habe ich nicht beobachtet. Die Zahl der Lippon scheint 6 zul sein.

\section{Innere Organisation.}

Darm. Mtundhijhle nur klein, grïbchenförmig, olır besondere ('hitinberaffinung; sie wird rom Osophagusgewebe mufabt. (Osophagus ein gleichmäßig dickrs,

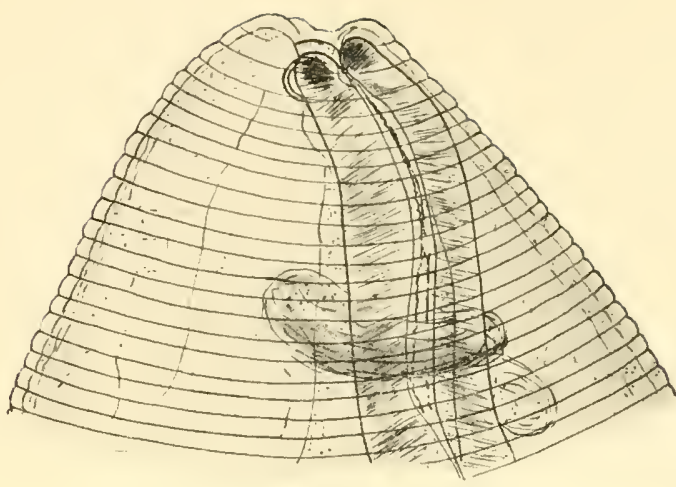

Fig. 21. Osmeris spinicauelu DC.J. Koptende. Vergr. 306. zylindrisches Rohr, das am

Hinterende eincu groben, kugelrunden bulbus trägt: ummittrolbar ros dem Bulbus ist eine dontliche Einschnörung. Bubus und zylindrisches Rohr mit kräftig tibrillärer Muskulatur. In Bulbus sind zwischen den Muskelfasern I) rïsenzellen eingolagert. 1)ie Intima des zelindrischen liohres ist nicht besonders rerdickt; im liubus ist oin dreiziptliges, ziemlich weites Lumen zu sehen mit kräftig verdickten $W_{\text {änden }}$ (Texttig. 2.). Mittoldarm sehon an Vorderende breit. Zollen desselben in der Fläche pulyenal (Trexttig. 23), im optischen Laingsochnitt rochteckig: Kollinhalt granuliopt.

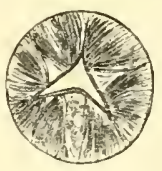

Fig. 22. Ommeris spinicaurla JuJ. Optischer Querschnitt durch den Inulbus. Tergr. 340 .

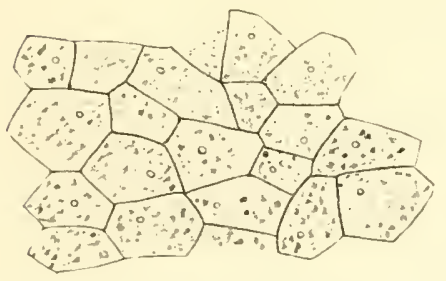

Fig. 23. Oxuntris spinicauda Dro. Mitteldarm-Zellen von der Fläche. Vergr. 306. licetum an der liasis mit vermutlich 5 Drïrenzollen, ron denen die dorsale die gröbtr zu sein scheint.

Juskulatur typiseh mrromyarisch.

Nerronsystom. Mubur dew nur wenig hinter dem Kopfinde gelogenon Nervenring nichts boubachtot.

Exkretions ystem nieht beobachtet.

Weibliche lioschlechtsoleane. Vulva dem Vorderendir sehr genähert, ror dem Beginn dos Mitteldarms golegon: die Vagina scheint zweiästig z1 sein. J)ie () varien sind auberordentlich lang und in viele Windungen geschlmaen.

Bemerkungen. Wir schon bemorkt, habe ich dis Torstrn am fadenformigen 
Schwanzanhange niclst beobachtet: Lassow bemerkt aber l. 1. 297, dab bei den Exrmplaren der Sammlung Feurscuexas dieselben zum gröbtron Toil abgefallen seinn, sodaß dic Annahum auf der Hand liegt, dirselben wïrdon bej den vorliegenden Exemplare aus demselben (irunde firlen.

There don Wirt des vorliegenden Tieres kann ich keine Angaben

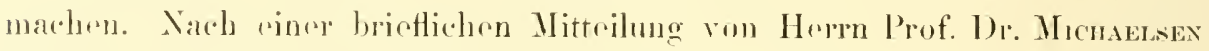
handelt os sich hïelst wahrecheinhich um rin Tier, das mit Kotanswurt (beim

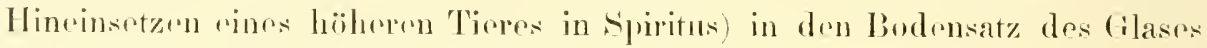
geraten ist. Ms Wirt könne mur ein licptil uder ein Froseh in Frage kommen: dies wärde den Angaben älterer Forscher enteprechen.

lufolge der oft sehe stummatischen liagnosen früherer Nematodenforsclee ist as hente vielfach selor sehwierig, parasitische Numatoden zu bestinumen. lch bin durchaus nicht iiberzengt, dab alle die furmen, dic bisher und anch hior als synonym mit ceryneis spinicande low. betrachtet worden, wirklich zu rin und derselben spezies gehiiren. Würde sich br-

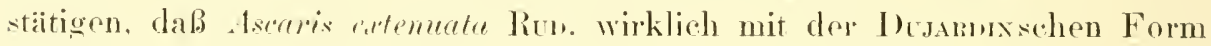

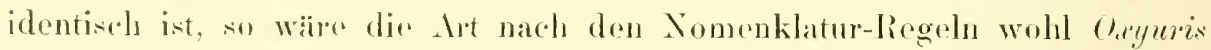

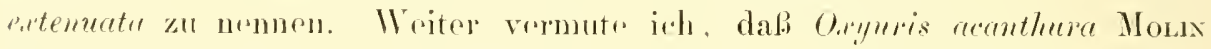
gar nicht hiorher geheirt oder doch einu abweichende Variout darstellt: die Vulva liegt bui derselben bedentend hinter don Vorderonde des Mittel-

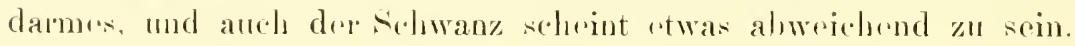

\section{Gen. Mermis Dujardin 1842.}

\section{Wermis damuremsis n. sp.}

Tixttig. $24-2(j)$.

Fundangabe: Airootfontoin: IV. Murnesen, 7.-11. Juni 1911.

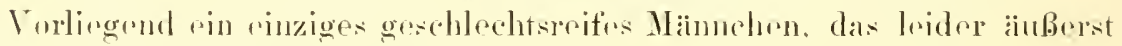

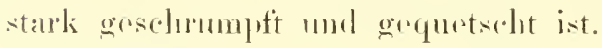

Äंußeres.

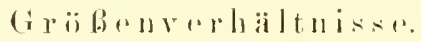

\begin{tabular}{|c|c|c|c|}
\hline (ivsantutlänge & 11,600 & $111 m$ & $x=90$ \\
\hline Ösophagus]änge & $?$ & & $j=?$ \\
\hline Schwanzläng口 & 0.28 & , & $=4$ \\
\hline (iroibte l)icke & 0.129 & .. & \\
\hline liekr an Kopte & 0.0665 & ,. & \\
\hline
\end{tabular}

J)iss. Ifalin siod natiolich durch dir Alkoholkonscrviorung breinflubt,

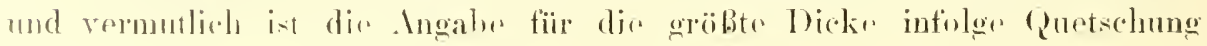


zu groß, trotzdem ich zum Messen einen Kïpperabschnitt auswählte, der nicht goschrumpft schicn.

K ör p ergestal t fadenfirmig; Schwanz etwas verlängert, stumpf kegelfïmig gerundet, Kopfinde leicht verbreitert. Der Kïrper des vorliegenden Tieres war in viele Windungen geschlungrn, was die Untersuchung ziemlich schwierig gestaltete.

Färbung hyalin, ganz loicht ins braungelbe getönt.

Ha ut glatt, ohne Längs- und Querstreifen und ohne Krouzfaserung. liorstin fehlend.

Papillen auf' das Kopt- und mäinnliche Schwanzende beschränkt. (Niehe dieve unten!)

Lä ngsw ïlste. Was diese betrifft, miichte ich nuch kein endgïltiges Lrteil fällen, da der Erhaltungszustand des Tieres es bedingt, daß mir eventurll vorhandene schmälere Längswïlste entgangen sind. Ich habe nur sicitenfeldיr beobachtet, dir $34-36 \mu$ breit und, wie mir schien, am Torderende schwach dorso-sublateral verschoben sind. Dieso Seitenfelder seheinen ans zwoi Zellreihen zu bestehen.

Kopfende ganz schwach verbreitert und rom breit gerundet. Lippen seheinen zu fehlen. Es sind $b$ Kopfjapillen vorhanden, die sich nur ganz wenig über die Oberfläche vorwölben und spitzkogelförmige Form haben (vergl. Texttig. 24, 25). J cinc Papille lingt lateral und submedian. Die scitrnorgan" sind $83 \mu$ rom Vorderende entfernt: von der Fläche gesehen, habun sie rundovalo Form (vergl. Textfig. 24). im optischen Längsschnitt sind es flache Becher (rol. Texttig. 25) mit stark verdicktem Boden. Es schien mir, als ob die Seitenorgano ganz leicht dorso-sublateral verschoben soien: denn es gelang mir nicht, beide Organ gleichzeitig genau in Protilansicht zu bringen: oder ist violleicht eino leichte Schumpfung die Ursacho dirser Erscheinung?

Innere Organisation. Darm. Der Mundeingang ist ein enges Rohr mit schwach verdickten Wänden und fiihrt direkt in den Ösophaguskanal, dessen Intima etwas stärker verdickt ist. Die genaue Länge des Osophagus konnte ich leider nicht feststellen, vermutlich erreicht er nngefähr 1/6 der Körper-

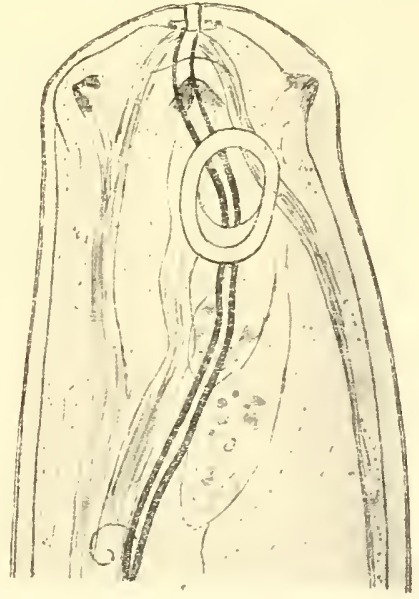

Fig. 24.

Mermis damarensis n. sp. Kopfende, lateral gesehen.

Vergr. 306. 28 M i chaclsen, Deutseh-Südwestafrika. 


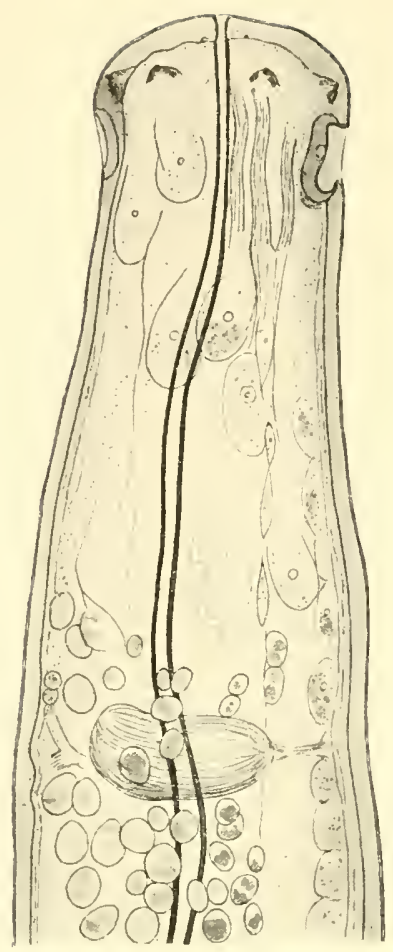

Fig. 25.

Mermis damarensis n, sp. Vorderende, dorsal gesehen. Vergr. 406 .

länge. Der Fettkörper war noch fast intakt und reichte bis nahe zum Nervenring nach vorn; "r besteht aus großen Kellen mit zahlreichen fettglïnzenden Kugehn.

Muskulatur. Körpermuskulatur gut entwickrelt, von polymyarischem Typus.

Nerrensystem. Von diesem konnte ich bloß das Zentralorgan, den $0,216 \mathrm{~mm}$ rom Vorderende entfornten Nervenring, deutlich erkennen.

Exkretionssystem nicht beobachtet. Mänuliche Geschlechtsorgane. Der Hoden scheint paarig zu sein; der eine ist gorade nach rorn ausgestreckt, der andere zuriekgeschlagen. l)ie parigen spicula (vergl. Texttig. 26) sind (0,250 $\mathrm{mm}$ lang und am distalen Ende rentralwärts gebogen; sie sind sehr schlank. Die Bewegungsmuskulatur, soweit sic zu crkennen war, ist auf der Textfig. 26 dargestellt. Die Bursalmuskulatur reicht ron der Schwanzspitze bis vor das vordere Ende der Papillenreilen. Es sind 3 soleher Reihen vorhanden; die mittlere, mediane, ist doppelt und bildet rinen kräftig vorgewölbten Wulst, der an der schwanzpitze beginnt und bis weit ror den After geht, 1)ir beiden seitlichen, submedianen Papillemreilien sind viel lockerer: hier zähllte ich hinter dem After 10 und vor demselben 11 Papillen, dic isoliert oder in Gruppen zu 2 und 3 stehen. Bei dirsen fehl aber jede Wulstbildung.

Bemerkungen: Bis heute and berrits über so Mrrmithiden-spezies beschrioben worden, leider rine grobe Kahl dersellben selhr ungenïgend, sudaf w ijfters kanm möglich soin wird, dioselben wieder zu erkennen. Dis vorstrlende Beschreilung ist leider auch unvollständig, aber doch so, daßs die spezies von jedrun lieobachter wird identifiziert werden können. Wäre jeh der Dabarschen Genera-Einteilung gefolgt, so lätte ich wohl ein neues Gemu schatfen miissen. Mit liücksicht auf die nicht sichere Feststellung der Zahl der Längswiilste, die im Danarschen System das wichtigste Moment sind, mubte ich ron vornherein davon albshen. Clbrigens zweifle ich mit Hacmener sehr an der \%weckmäBigkejt und verwandtschaftlichen 


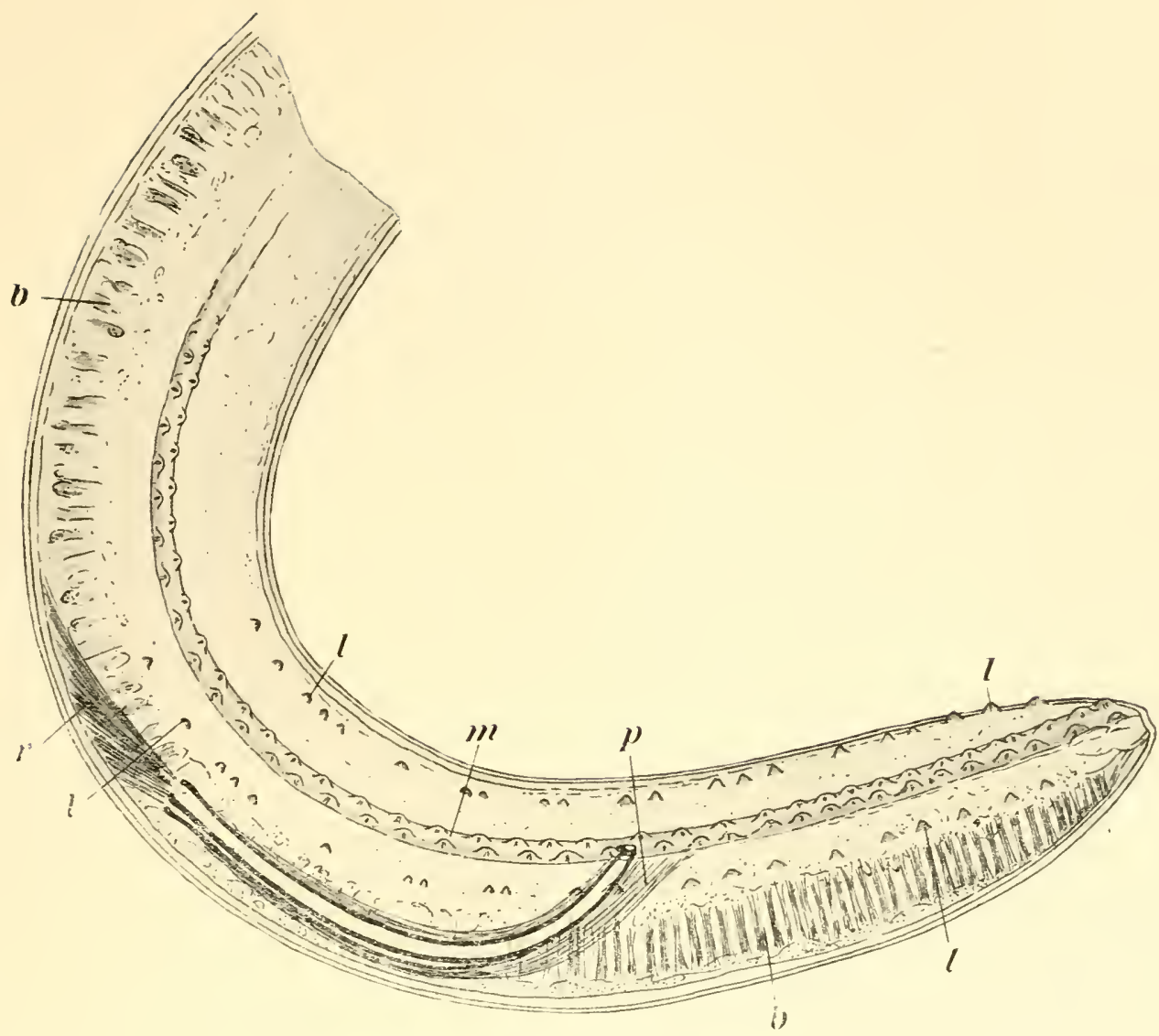

Fig. 26. Mermis damarensis n. sp. Scliwanzende eines $\circlearrowleft$. Vergr, 132.

l. subuediane Papillenreihe. $m$ - vactromedianer Papillenwulst, $b$ - Bursalmuskulatur, $r$ - Retractores spiculorum. $p$ - Protractores spiculorum.

Berechtigung der Einteilung Dabays. Die vorliegende Form mag deshalb vorläufig zum Grnus Mermis gerechnet werden, bis ein reicheres und bessel erhaltenes Material erlaubt, die Frage ihrer srstematischen Stellung endgïltig zu entscheiden.

Leider kann ich keine Angaben über den Wirt unserer spezies machen; das Tier wurde in süßwasserschlamm gefunden. 



\title{
Hymenoptera V: Apidae ron
}

\author{
H. Friese (Schwerin i. M.).
}

Mit einer Tafel. 

Durch die Hamburger Studienreise nach Deutsch-Südwestafrika, welchro Herr Prof. Dr. W. Michaelsex im Jahre 1911 ausführte, erhielten wir das langersehnte weitere Material an Bienen (Apidue) aus dortiger ưgend. Vereint mit dem bisher bekannten, hauptsächlich den Ergebnissen der. Forschungsreise vou Prof. Dr. Leonu. Scuultze (vergl. daruber: Friese. Bienen Afrikas, Jena 1909), und den Sammelergebnissen von Hauptmann Volkmaxs in Grootfontein und H. Rautanex in Ondonga, gestattet uns dieso dem Hamburger Zoologischen Museum einverleibte Michasesexsche Sammlung eine gute Trbersicht iiber den Bestand der wilden Bienen in unsorer Kolonic.

Das wasser- und blütenarme Land hält naturgemäß eine erfolgreiche Vorgleichung mit den reichen Bestanden in Kapland, Transvaal, Rhodesia und Natal nicht ans, bietet uns aber mancherlei Erscheinungen und Inpassungen von Farbe des Haarkleides und der Lebensdauer (z. P. lange Puppenruhe), wie eben extreme Lebensbedingungen sie hervorbringen (lange Trockenzeit). Neben weibgrau behaarten Wüistenformen,

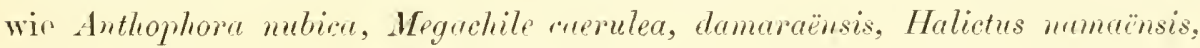
treten lokal auch recht bunt behaarte Bienen auf, die als Beispicle von Kontrastfarben gelten kömnen, wie Megaclile muillowe, bullata, Xylocopa inconstans ( $q$ ). mossambica $(f)$, Anthophora plumipes a. a., die aber in ihr'm schwarzen Kleid mit weiBen oder gelben Querbinden sehr wohl das Frkanntwerd'n in dortiger Landschaft ersehweren können. Daueben kommen auch einfarbig schwarz behaarte oder rotgelb behaarte Arten (Meyarkile cerleres, $\boldsymbol{W}$. fulce u. a. vor, deren Verwandte im übrigen Afrika die charakteristische rotfilzige Beliaarung der Abdomen tragen (Megachile combustu bombiformis, tithonus, cognuta).

Die Mehrzahl der siddwestafrikanischen Bicnen-Arten sind aber kloine unscheinbar behaarte Formen, die zum 'Teil kaum noch an „Bienen“ erinnern, wie z. B. die Allodape- und Ceratinu-Arten und Malictus. 
Wemn trotz der mnginstigen Lebensbedingungen fiir Bienen voch so Arten aus don meisten Bienen-Giruppen zusammengebracht wurden, bei finem Grsamtbrstande von fast 900 Arten $i m$ tropischen Afrika, so ist vielleicht anzunehmen, daß cinstmal, in früheren Erdperioden, günstigere Brdingungen für die Entfaltung des Bienenlebens vorhanden gewesen sind und wir daher in dem heutigen Bestand der Fauna ron I)rutsch-siidwestafrika nur noch die Ubberbleibsel - die Restbestande - rinstiger Blütezeit zul sehen haben, was ja anch mit der Armut an Individurn iiburomstimmen würde. Jedenfalls ist die Zahl der Arten im Vorhältnis zur Individunnzahl nach den bisherigen Befunden als sohr grob zu bezeichnen.

Besonders spärlich sind anch die Vertreter der Śchmarotzerbienen aufgefunden, nur Crorise und Coelioxys sind in 5 Arten bekannt geworden. Dagegen fehlen Epeolus, Nomede, Omachtes ganz: anch diese Erscheinung würde in der kümmerlichen Lebensfristung der Wirtbienen (Sammelbienen) ihre Erklärung finden können.

Cber die Lobensweiso diesur Bienen wurd. erst sehr wenig bekannt: auch aus dem ibrigen Afrika fehlen Angaben hierüber fast ganz. Es ist daher mit Fronden zu begrüßen, dab unsere Forscher einge Xylocopu-Nester (Holzbirne) mit Larron und Puppen in Rhicims-standen mitbrachten, wie auch rinige pigrobe, an Zweigen angeklebte Wollnexter der Wollbiene Serupis denticulutu und als besonders wertwollen Fund dir Larven von Allodrepe sp. ?, die haufenweise in Höhlungen ron PHanzenstengeh ohne besondere Zellabteilungen leben und wie die Honigbiene (Apis) von der Mutter gefüttret werden; jedenfalls trägt die einsam lebende Mutterbirne nach und nach Pollen und Nektar als Larvenfuttre für dir Brut hrobed vergl. Nr. 31 in Abschuitt II). Auch das Vorkommen einer Trigona-Art istachellose Honigbience ist bemorkenswort.

Was die Verwandtschaft der Bienen-Arten ron H)entsch-siidwestafika zn den Nachbargebieten betrittt, so liegt diese bei den Formen aus Rhodesia und Kapland; die \%uwanderme diirfe darnach wohl ron ()sten oder siiden rrfolgt sein. Mit den nördliclen Grobieten von bontsoh-südwestafika dürftrn sich kanm besondope Verwandtseluaftsinion zioloen lassen.

$$
\text { S.hworin, don lt. Mairz l!ndi. }
$$




\section{Liste der Apidae Deutsch-Siidwestaffikas $\left.{ }^{1}\right)$.}

\section{Proapirlae, Urbienen.}

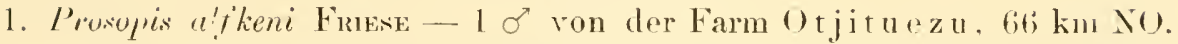
ron Windhuk. am 1:3. Mai 1911 Hiegond, Mrunelsex log. siehr Abschnitt [I].

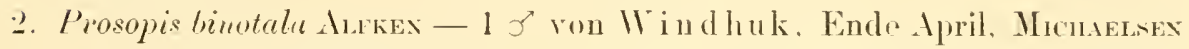
log. (siche Ibsclinitt II).

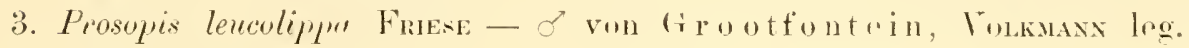
(sieho Ibschnitt II).

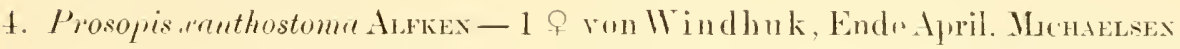
leg. (siohe Ahselnitt II).

\section{B. Prodilegidar, Beinsammler.}

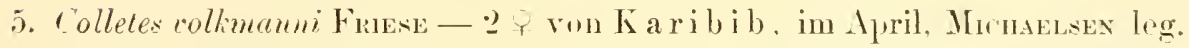
6. Colletes mutatsis Friese - I o von der Farm (1) tjituezu, $66 \mathrm{~km} \mathrm{No.}$ von 11 indlı k, am 13. Mai 1911 Hiegend. Michaelsex log.

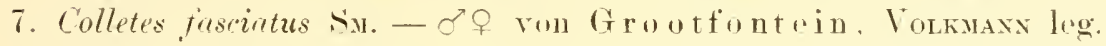

ऽ. Colletes testaceipes Friese - $\bigcirc$ ron der Prinzen-Bai, Scuurze leg. und rou Groottontein, Volknax leg.

9. Colletes rufotilialis Friese - $\sigma$ ron tirootfontain. Vunkmax leg.

10. Colletes colkmanni Friese - of von Grootfontein, Touksaxix leg. 11. Colletes reullis Friese - f ron Grootfontein. Toukuax leg.

12. Malictus duplocinctus n. sp. - - P von () kalıandja, im Mai Hiegend. Dichalisex leg. Nioho Abochnitt II!

13. Halictus michuelseni n. sp. - 4 q von Okahandja, im April Hiegrnd Jichatesex leg.

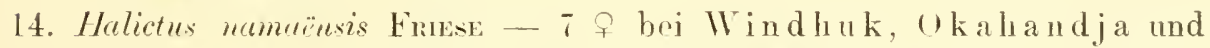
Noudam metangen, im Mai Hiegend. Michaecsis leg.: $\sigma$ q anch ron liooibank im Mai und von der Prinzenbai, Sentuze leg. Das Minnchen in der Form rar. untematus n. var. ron Windhuk, Michaessex leg. (siehe Abschnitt II).

15. Halietres arenicole n. sp. - - - rom nördlichen siandtuld zwischen Löwen-Omuramba und Owangowa-Veld, r. Kastrow ling: 1 q von Grootfontein, Vosksaxi leg. siehe Abrchnitt II.

1) Diejenigen Arten, welche in Frass, Bienen Afrikas, 1911. Jeni, nicht enthalteu sind, nuter anderen die nenen Arten, werden im Abschnitt II unter den gleichen Iummern irörtert. 
16. Halictus windlinkeusis n. sp. - 2 우 4 o von Windhuk, im Mai fliegend. Mrchatusex leg. (siehe Abschnitt II.

17. Halives nitidiusculus K. var. niveolivetus n. var. 오 von der Farm Otjituezu, $66 \mathrm{~km}$ NO. von $W$ indlıuk, am 13. Mai, Michaelsex leg. (siohe Abschnitt II).

18. Halictus atrorimidis Cam. - 1 ㅇ von Ka ribib, Ende April, Mrchaelsex leg. 19. Halictus (Nomioules) fasciutus Friese - jo von Rooibank, in Mai fliegend, Schuttze leg.

20. Somia junodiella n. sp. - 2 $\sigma^{7}$ von $\|^{r}$ indhuk, Ende April, Michaelsix log. (siehe Abschnitt II .

21. Nomia mebripes Fulse - 1 o von Windhuk, 29. April 1911, Muchaelsex leg. (siehe Abschuitt II).

2:. Nomia fulvipes Fmese - I $\sigma$ ron $\mathrm{h}$ a ribib, Ende April, Mrcmaersex leg. (siehe Abschnitt II).

23. Nomia tridentutr var. digitretn Fruese - 1 o aus dem Landexmuseum zu Windhuk').

24. Nomin anthidioides GEsst. - var.? - 1 f ron K arjbib, Ende April, Micilatisear leg.

25. Nomia seutellaris SAcss. var. meculuta Fuese - 1 우 ron G rootfontein, Tolkmaxy leg.

26. Nomia Hacofasciuta Friese - ron Grootfontein.

27. Poecilomelitta Havida Friese - 2 우 von Grootfontein, Volkmaxi, Irg. (siohe Abschnitt II).

28. Poecilomelita fuliginosa Fness - 2 우 von Grontfontein, Toukmax log. siehe Abschnitt II .

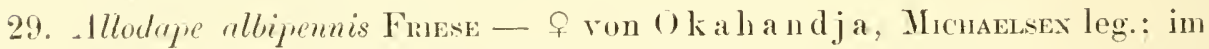
April, und nördlichess sandfeld zwischen Lïwen-Omuramba und Owanguwa- Veld; v. Kastrow, leg., 1912. Ferner von Ke etmanshoop, im Angust 1905, Scuutze leg., und von Grootfontein, Volkuax leg., brkannt geworden.

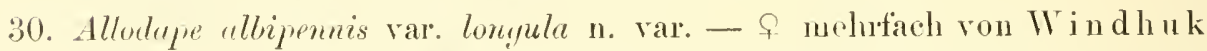
vom 29. April bis S. Mai, Hiegend: 2 anch von Usakos. in April, Michaelses leg. (s. Abschinitt II.

31. Allodape lertipemis Bmaxs - 1 f von Wind huk, Ende April, fliegend, Michaneser leg.

32. Allodrpe sp.? - an 20 Larven einer der griißten .1llodupe-Arten (wir

1) Diese Hymenoptera aus dem Landesmuseum zu Windhuk sind dem Hamburger Zoolugischen Museum im Instaushe gegen andere sachen ibergchen worden. 
1. luteipennis und 1. rufocinctu Fr. rom Kapland) von der Farm Neitsas bei Grootfontein, Fock leg., 1907 (siehe Abschnitt II). 33. Ceratina lativentris Friese - o o ron Usakos, im April, of ron Okahandja, Ende Mai, Michaersex leg.

34. Ceratina lunata Friese - 1 우 ron Usakos, in April, Michaelsex leg. 35. Xylocopa metitursis Lep. - 1 \% von der Farm Okosongomingo, a m klein en Waterberg, Thousex leg.; 1 ㅇ ron () tjikoto, $20 \mathrm{~km}$ IV. von Tsumeb. im Juni, Mrlmaelsex leg.

36. Sylocopa lugubris Gerst. - 2 ㅇ 1 б von der Farm Ok os o $\mathrm{ng}$ o mingo a m kleinen Waterborg. Thomsex leg.: 1 q ron $\mathrm{Lsakos,} \mathrm{im}$ April, Milhaelsex leg.

37. Xylocopa stuhlmanni KoнL -1 ㅇ aus dem Landesmuseum zu Windhuk. 38. Xylocope senior VAcH. — q mehrfach von Okahandja, Windhuk. Ts u meb, März-April, 1 o von Karibib, Mrchaelsex leg.: 3 우 $1 \sigma$ von der Farm Okosongomingo am kleinen Waterberg. Thomsex, leg.; 1 f von Grootfontein. r. Kastrow leg.; f auch aus dem Landesnuseum Windhuk.

39. Xylocopa cutira L. var. mossambice Gribon. - 3 우 ron Wind huk, im Mai: 7 o ron $\mathrm{K}$ aribib, im April; 1 q ron $\mathrm{N} e \mathrm{udamm}$, im Mai, Michaelsex leg; 1 f ron Rehoboth, Megedebex leg. Auch ein Nest in einer Rhicinus-Staude mit Larven und Puppen von Karibib. Michaelsex leg.; ferner von Rooibank, im Mai und BersebaBethanien, im August 1905, Finutze leg. (siehe Abschnitt II).

40. Syloeopa inconstans Sx. - größte Bienenart in Sïdwest-Afrika, 오 schwarz mit weißhaarigem Brustgürtel, 2t mm lang. - jof ron Tsumeb, Karibib und Okahandja, im April, fliegend: $3 \sigma^{7}$ ron $\mathrm{Karibib}$, ebenfalls im April gefangen, Michaelsex leg.: 2 으응 ron der Farm Okosongomingo am kleinen Waterberg. Thomsex leg. siehe Abschnitt II).

41. Xylocopa tuberculireps Friese - C 으 ron Grootfontein, Vombars leg. 42. Meliturgula minima Friese - O von Grootfontoin. Volknasx leg. siche Abschnitt II).

43. Mermiglossa mía Friese - J von Grootfontein, Volksaxi ling. (siehe Abschnitt II).

44. Tetralonia junodi Friese - $\sigma$ P ron Groot fontein, Volkmaxi leg. (siche Abschnitt II).

4.). Tetralonia pulverosa Friese - 1 ㅇ von $\mathrm{K}$ a ribib, Ende April, Hliegend. Michatesan leg. (siehe Abschnitt II

46. Tetralonia michaelseni n. sp. - 1 o von Windhuk. Antang Mai. Michaelsex leg. (siehe Abschnitt II). 


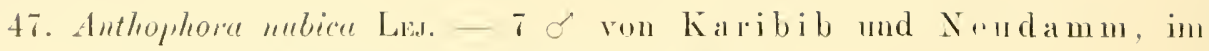
April und Mai Hiegend, Mrumaelsex leg.

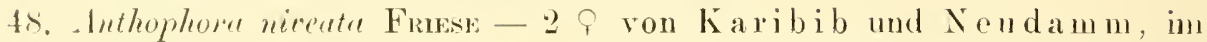
April und Mai fliognd, Monatses log.; anch von Liideritzbucht, wn sir im Dezember die Blïten von Mesembrianthemum gymnocladum momflogen, of von Kortmanshoop, August, Semulaze log.

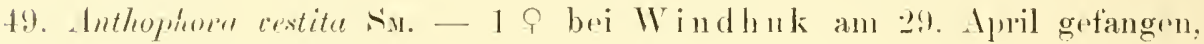
Michatisex log.

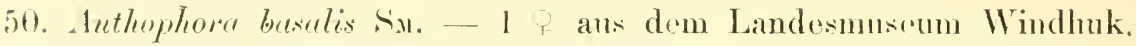

51. Anthophore plumipes IF. - Eino weitrorbreitete Art, ron Abessinion bis Kapland und rom sonegal bis D) clagoa-bai, auch ron (trootfontein erhalten, Vommaxx leg.

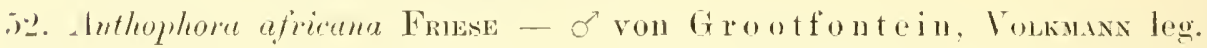
53. Inthophora relutind Funse - + G ron Liideritzbucht. am 3. De-

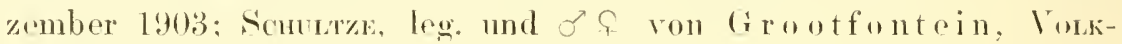
mixi leg.

\section{('. Melectince, corlioxymat, Schmarotzerbienen.}

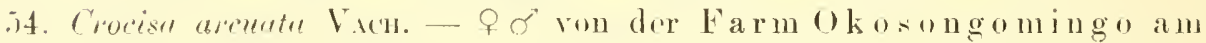
kleinen Watroborg, Tuomsex leg., in Juli 1912; 1 defektes o ams dem Landesmusemm Windhuk und 1 g vom Undonga; liautaxes leg.

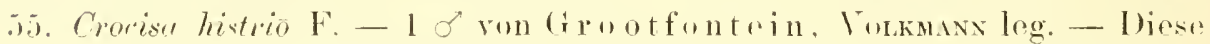
Art trite nur lriatiger auf in Ibessinien und geht bis nach Lndien.

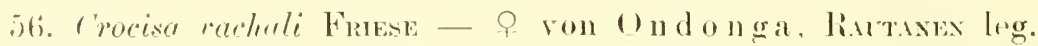

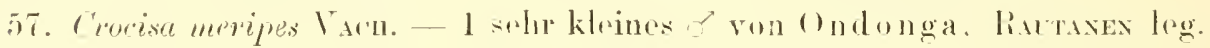

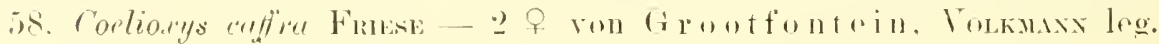

\section{D). Grastrile!fidne, Banchsammler.}

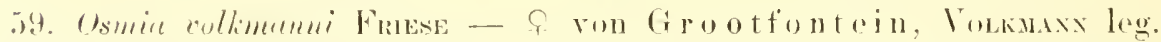

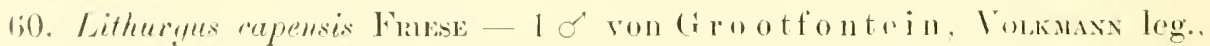
sonst häutiger in Kapland bei Willowmore, Basutu Land, ann Ilex River, Hiregt im Novermber and I)zember siolar Abschnitt II.

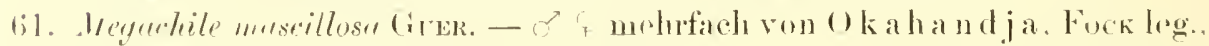
und aus dron Landesmusenm Windhuk.

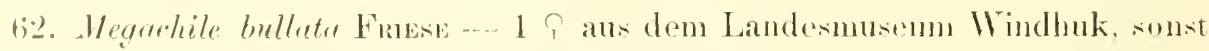
vom Lapland Sinithtield) bekannt geworden (siohe Abschnitt II.

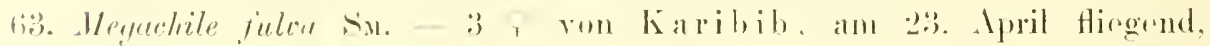
Mhomenas leg. 
64. Megarlite merulen Finese - 1 f von $\mathrm{K}$ aribib. am 23. April, Micha-

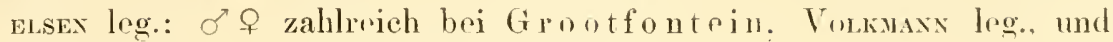
besonders in der Kalahari-Wüstr, srructze leg.

65. Megarhile wahlberri Fruese - f von Grootfontoin, Tommaxi leg. Dir Art wurde von $\mathrm{N}$ (iami beschrieben und auch bri Lehututu (Kalahari) mohrfach von sicururze gesammelt.

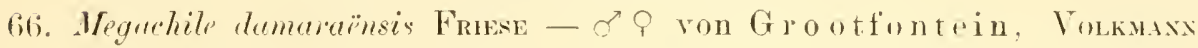

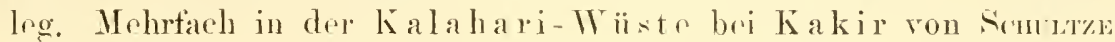
gesammolt.

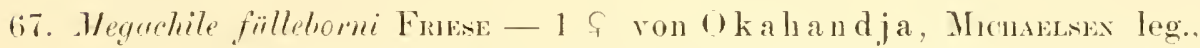
am 25. Mai: in Afrika weit verbreitete und auffallend braun beharete Art, su im Kapland, Nyassaland. Ost-Afrika, Sudan bis Abessinien.

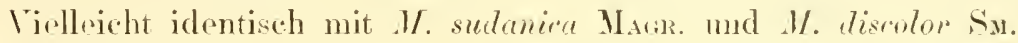

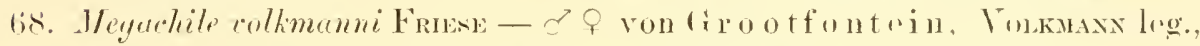
anch im Kapland, Transval bis Ost-Afrika.

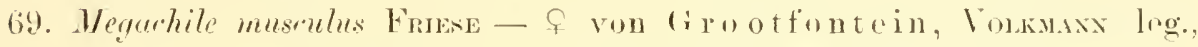
und ron kl. Namaland bis Gokiep rergl. Abschnitt II.

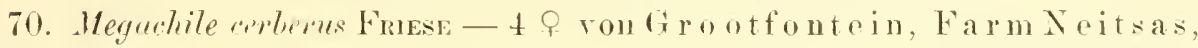
Fock leg., und alls dem Landesmmsemm Windhuk. Fine große ganz schwarz buharte Art, dir mir uoch ron Grootfontrin. Ondonga und Bengurla vorliegt. Finn typisch sidwestafrikanische Form.

71. Megarlite perniriosa Fuene -- 1 o rou Okahandja, Fock lrg.. sonst von Transvaal und dem kapland bekannt geworden.

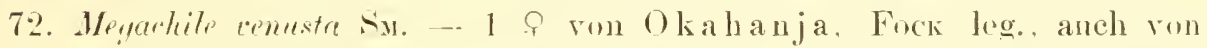
Grootfontein: Volkuxx, log. Hätigur im Kapland und in Ostafrika. 73. Megrachile aratiosa GEsst. - 2 f ron Karibib, Ende April Hiegend. Mnnalusex, leg., ron Rowibank. im Mai 1905, Fonutze leg.: sonst in Transvaal und in Ostafrika häntiger.

74. Megurkile windhukiand n. sp. - 1 f ans dem Landssmusemm Windhuk (sieh" Abschnitt II).

75. Megachile funebris sis. - 1 G ron dur Farm Okosongomingo am kloinen Waterbero, im Juli 1912, Fnonsex leg.: 1 q von Odonga: Raltavex leg.; häntig in Ostafrika und anch noch anf Narienhof, Insul im Ukerewe-sien, ('oxkads leg.

7i. Meguchile cinctiventris n. sp. - 1 f ron Grootfontoin, Toumax leg. (siehe Abschnitt II).

77. Megachile alborufir n. sp. - G von Ondonga, Ravaxex leg. wiehe Abschnitt Il).

78. Anthilium vollmanni Friese - o 우 ron Grootfont ein. Volkmanx leg., auch bei Strinkopf im Ḱl. Namaland von scurutze gesammelt. 
79. Ton Serapis demliculatu su. wurden 2 fast faustgroße Nester aus geschabter Pflanzen- Wolle, die an Dornzweigen bofestigt waren, mitgebracht (siehe: Abschnitt II). Gro otfoutein, Luxkexben leg. (Jus. Hamburg).

\section{E. Sociale Ipiden.}

s0. Trigona bererii Ginus. var. albotasciata n. var. - 5 Arbeiter $(G)$ von Tsumob, Otjikoto bei T'sumeb und Farm Toigtsland, O. von Wind huk im Mai und Juni, Michaelsex leg.; bei G ro ot fo ntein von Volkux gesammolt (siehr Abschnitt II).

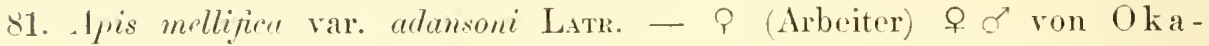
h a n d ja. Fock und Micnaelsex, log.; ferner P (Arbeiter) von Usakos, 21. April, von Windluk, 29. April bis 8. Mai, von Toufelsbach bei Okahandja, 1. Juni, von Brakwater, 23. Mai, von Otjikoto bei Tsumeb, 16. Jumi, von Grootfoutein, 7.-11. April, von Neudamm, 10.-15. Mai, Mrthuelsex leg.; f auch ron der Farm Neitsas bei Grootfontoin, Fock leg. Die 4 Weibchen (우) zeigen ein fast rotes Abdomen, sind sonst aber solr abgenutzte Exemplare, of und of waren wohl nwch nicht näher beschrieben (siehe Abschnitt II).

\section{Erörterung bezw. Beschreibung von neuen und weniger bekamnten Ipten bezw. Yestern.}

Dieser Abschnitt bringt hauptsichlich Erörtorungen ïbre die deutschsïdwestafrikanischen Apiden-Arten, die in meiner Arbeit "Bienen Afrikas, Jena 1909", noch nicht aufgeführt sind, vor allem also die Beschreibungen dox in den nou bearboiteten Ausbeuten enthaltenen neuen Arten. Ich füge die Beschreibung ringer neuer Arton aus benachbarten liebieten, sowie riniger noch unbekannter Nester hinzu.

I)ir Nummern der Art-Übersehriften des Abschnitt II entsprechen den Nummern der Liste, die den Abschnitt I dieser Arbrit bildet.

\section{Prosopis alfieni Friese.}

1913. Pr. a. Fnisse, of in: Zool. Jahrb., Syst., V. 35, p. 583.

1913. Pr. a. Friese, ơ in: Deutsch, ent. Zeitschr., p. 574.

1914. I'r. a. Alfikex, ơ $\sigma^{\prime}$ in: Deutsch. ent. Zeitschr., p. 194.

Der Pr. atriceps Fasse or tauschend ahnhlich, aber Kopf, Thorax und siegment 1-2 grob punktiert, Antennenschaft einfach.

б. Schwarz, fein und sparsam weiß behaart, fiesicht bis über die Antrmenbasic gelloweib, deutlich und grob punktiert, Antennen sehr lang, 
braun, erreichen das scutellum, schatt einfach und schwarz, Geibel unten heller braun. Kopf und Thorax grob runzlig punktiort, etwas glänzend, Collare schwarz, aber dicht weiß behaart; Area grob längsrunzlig, aber kaum gegen die Ungebung abstechend, Segment 1-2 grob und dicht, fast rumzlig punktiert, etwas gläzend, mit feiner Fransconbinde auf den Endrïndern, 3--6 äußerst fein und kaum auffallend skulpturiert. Tentralsegmente fast glatt, glänzend. Beine schwarz, mit golben Knien und Tarsen, Tibie I ganz gelblich. Flïgel hyalin, Adern und Tegulae schwarzbraun, Tegular rorne mit gelbem Flrek. L. $4 \frac{1}{2} \mathrm{~mm}$, Br. $1 \mathrm{~mm}$.

Alfkex gibt an:

오. $5 \mathrm{~mm}$ lang. Schwarz. Pronotum. Mesonotum ror dem Schildehen, Hinterränder des ersten, zweiten und dritten Hinterleibsringes weib gefilzt. Auch die Hinterränder der übrigen Hinterleibsringe zeigen spuren weißer Haare. Kopf lïnglichrund, nach unten rin wenig rersehmälert. Wangenanhänge deutlich. C'lyeus höher als breit, dicht und ziemlich stark punktiert. Stiruschildehen und Wangen etwas zerstrenter punktiert, letztere ungefleckt, Gesicht also einfarbig schwarz. Stirn und Scheitol glïber und zerstreuter punktiert als der Clypeus. Augenfurchen kurz, die Höhe des oberen Augenrandes kaum erreichend. Wangen schmal. Fühlergeißel unterseits bramnrot. - Mesonotum dicht und grob runzlig punktiert, an den Seiten neben den Flïgelschiippehen wie die Schultrpbeulen hinten schwach weib gefilzt. Mesopleuren ziemlich dicht punktiest. Mesosternum flach muldenförmig eingedrückt, etwas glänzend, zerstreut punktiert. Fichildchen grob und mäbio dicht punktiert. Hinterschildchen matt, fein runzlig punktiert und abstehend behart. Metapleuren sehr foin und dicht punktiert. Mittelfeld dos Mittelsegments glänzend, grubig vertieft, hinten foin und scharf gerandet. - Erster und zweiter Hintrrleibsring dicht und grob runzlig punktiert, die ïbrigen Ringe mit kaum erkenubarer Skulptur. Banchringe glänzend, Hinterränder sehwach rötlich durchscheinend, zerstrent punktiert. Beine sehwarz, nur dir Klauen rot. Flügel glashell, Stigma schwarzbraun, Flügelschiippchen braunschwarz, vorn gells gefleckt.

o. $4 \frac{1}{2}-5 \frac{1}{2} \mathrm{~mm}$ lang. Dem \& sehr ähnlich. Schwarz. Clypeus, Stirnschildchen, Wangen bis über die Fühlerwurzeln hinaus gelb, die Gesichtszeichnung also ähnlich wic bei der paläarktischen P. pictipes NiL. Fühlerschaft einfach, nach der spitze hin kaum breiter, schwarz; Geißel rot, oben gebräunt. Kopf ziemlich dicht und grob punktiert. Stirn, Ścheitel Imd Schläfen abstehend weiß behaart. Schlïfen schmal. Wangenanhang kurz. - Pronotum dicht weib behart. Mesonotum und schildchen grob punktiert. Mittrlfeld des Mittelsegments fein und zerstreut gerunzelt, hinten 
scharf gorander. - Erster und zwriter Hinteresibsring solu grob runzlig punktiont. dere orste mit dentlicher, der zwrite mit undentlichor sehmalor wrißer Haarbindo am Hinterande; dir äbrigon linge kaum rekennbar skulpturiert. Bauchringe glänzend, ohme Auscichnungen. Vorderschienen vorn oder ganz, Mittel- und Hinterseluenen an Gimde ma an der Spitze, Tarsen mit Ausnahmo der bramen Endglioder weif. Fliigel glashell, Schüippohen braun, vorn golb.

Eino durch die agenartig grobe Punktierung der boiden ersten Hinterloibsinge ansgezeichnetr Art. - Bulawayo, 1 f $6 \sigma-28$. Sept. 1912. Iriot,1) leg.

Von mir untersucht aubor $2>d$ rom Bulawayo ans dem RlodesiaMus(rum):

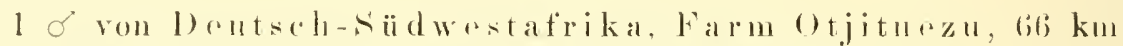
NO. Vou Windlınk, an 13. Mai 1911 Hirgend, Mromanisen leg.

\section{$\therefore$ I"rosopis bimotata Ilfk.}

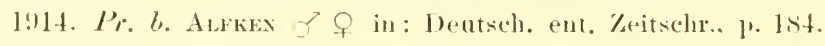

Alrkex gibt iibor dirse Art an:

o $5 \frac{1}{2} \mathrm{~mm}$ lang. Schwarz, Kopt rund, breitre als lang. Clypens seler fein lodrartig germozelt und anberdem mäbig dicht nit Nabolpunkten besetzt. Wangon zerstrent, Stirnsehildchen, Stim und scehoitol dichter punktiert. Achläion mäßig broit, dicht und foin runzlig punktiort, grauweib bolıart. Augrenfurchen undeutlich, lang, otwas nach den inneren Nebenaugen hin gebogen. Wangenanhänge, ()berlippe, ()berkicfer, untore Fpitze der Wangen, Clypens mit Ansnahme der Basis und des Spritzenrandes und der untere Teil dos stirnschildelens rot. Wangen mit rinem rundlich derockigen, oben in eiuen strich rerlautendon gelben Fleckon. Füluler rot, Gribel oben gebräunt. - Pronotum rot, rom golb gostreift. Sichulterbulen rot.

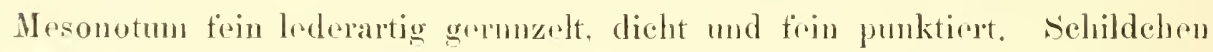
gläinzond, zerstreut und stark punktiert, an Hinterrande soitlich mit jo oinem gelbweißen Flecken. Hinterschildehen matt, zirmlich dicht runzlig punktiert. Mrsopleuren tein und maifig dicht punktiort. Mittelfeld des Mittelsergments glïuzend, ziemlich stark gribchrenartig gerunzelt, hinten schwach gorandet. Seiten des Mittelsegnents dicht körnig punkticrt. Hinterleib fast natt, stwas sridenartig glanzend. Erster Ring fast ohne skulptur, bei starker Vorgröberung ist eino auBerordentlich feino und dichte Qurriefung und aine selu foime Punktierung zu erkrmnen; dir ijbrigen Ringe auBerordentlich dichl und fein punktiert. Basis, Sriten und Linterseito des arsten Ringes rot, anberdem ist ror dom Hinterrande ein versehwommener roter Streifon 
zı erkemnen. Seiten dos ersten Ringes am Hintrrande mit cinem weißen Filzflecken, die iibrigen Ringe an Hinterrande mit Spuren ron Filzbinden. Beine rot, Fersen und Hüften mehr oder weniger gebräunt, Pasis der Hiuterschienen gelb. Flïgel leicht getribt, Adern und Fliigelmal schwarzbraun, Schüppchen rot, rorn gelb.

Diese Art ist der mir nur nach der Beschreibung bekannten P. mugrettii Vicu. selur ähnlich, unterseheidet sich aber ron dieser durch den roten Clypeus md das unten ebenso gefleckte stirnschildehen. Bei $P$. magrettii

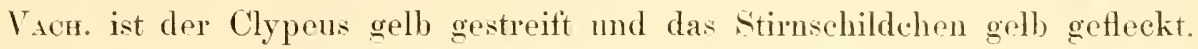
Auch tinde ich in der Beschreibung der $P$ '. magrettii dir eigenartige nabelartige Punkticrung des C'lypens nicht erwähnt. Fuese gibt in seiner Beschreibung der $P$. mugrettii, Archiv f. Naturgesch. 1911, P. 132, an, dab dor erste und zweite ling des Hinterleibes seitlich mit weißen Haarfransen versehen sind. Dies ist ein Irrtum. Vachal schreibt, daf nur der erste Ring rine breite, breit unterbrochenr Haarbinde trägt.

Kapland, Titenhage, 1 kx. 16. Okt, 1896 . H. Braux leg.

․ $5 \frac{1}{2} \mathrm{~mm}$ lang. Dem f sehr ähnlich. Oberkiefer rot, am Grunde gelbwrib gefleckt, Clypeus, 2 große dreieckige, die Fühlerwurzeln iiberragende Wangentlecken, Stirnschildehen und Pronotum gelbweib. Schildehen am Hintrende wie beim of mit 2 kleinen gelbweißen Flecken, in der Mittr tiof grubig eingedriickt, glänzend, zerstreut punktiert. Sehläfen und Lntersite des Thorax kurz abstehend grauweib behart. Frster Hinterleibsring rot, in der Mitte rerdunkelt, seitlich am Hinterrande, wie auch der zweite ling weils getilzt. Bauchringe einfach. Fïhler, Flïgelschiippchen, Schulterbrulen und Beine mehr oder weniger rot, erstere oben gebrainnt. Hinterschenkel und Hinterschienen verdunkelt. Alle Sehienen und Fersen am Grunde weiß gefleckt uder geringelt.

1) eutsch-sia dwestatika, Ir indhuk, 29. April bis S. Mai 1911, II. Michaelsex leg. $1 \mathrm{Ex}$.).

Rhodesia. Kimberloy lingls. 26. April 1912, G. Inxom leg. (l Ex.. Type).

\section{Proxopis leucolippa Friese.}

191:3. Pr. l. Funse, o in: Zool. Jahrb., syst. V. 3., 1. 58 .

191:3. Pr. l. Fmenk, o in: Dentsch. ent. Zeitschir., 1. 574.

1914. Pr. 1. LlfFkex in: Deutsch. ent. Zeitschr., p. 191.

Wir I'r. longula Frisse, aber der schwarze Antemensehaft rorn weibgalb, Antenne anffallend dick und gekerbt arscheinend, ('alli hum. nnd Trenlae weibgelb.

?) Michaelsen, Deutsch-Sidwestafrika. 
o. Schwarz, Kopf und Thorax fast runzlich punktiert, matt, Gesicht gelbweif, auch zwischen den Antennen weit nach oben reiehend, Mandibel, Labrum und Antennenschaft vorn gelbwriß. Antenne rot, nur der Schaft hinten schwarzbraun, Antennenglieder stark gerundet, daher die Antenne gekerbt arscheinend. Collare dicht weibtilzig, Tegulaehälfte hinten weiß. Abdomen matt, Segment 1-2 deutlich und ziemlich grob punktiert, $3-7$ äußerst fein skulpturiert. Ventralsegmente äuberst foin skulpturiert matt. lieine sehwarzbraun, Tibien und Tarsen gelbweiß, Tibie mitten melar odre wrniger sehwarz geringelt. Flügel hyalin, Adern und Tegulae schwarzbrann, Tegulae vorn gröbtentrils weif. L. $41 / 2$ 1m, Br. 1 mm.

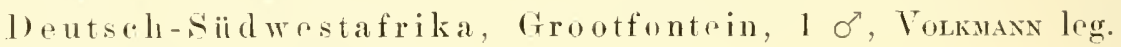

Alfken sagt iiber diese Art:

б. $4^{1 / 2}-5 \mathrm{~mm}$ lang. Schwarz. Oberkicfer bis auf die dunkle Spitze, (1) brolippe, ('lypeus, Stirnsehildehen, Wangen, Fïhlerschaft und erstes Geißelglied unten, Scluulterbeulen hintrn, Fliignlschiippehen vorn, Knie, Tordershienen bis auf ainen schwarzon Fleck hinten, Basis und spitze der Mittelund Hintershionen und die Tarsen mit Ansnalmue der letzten Glieder golb. Fiihlergoißel rot, obon cin wonig rordunkolt. Kopf lïnglichrund, nach unton rin wenig rerschmälert. Wangenanhänge fohlond, Clypeus. Stirnshildehon und Wangen zerstreut und fein, Wangen gröber punktiert. Schläien solur schmal, - Pronotum weiß gefilzt. Mesonotum gläizend, mäBig dicht und grob, schildchen zerstreuter punktiort. Mittelfeld des Mittelsegments fein und unregolmäBig gerumzelt, frin und scharf umrandet, auch hinten fein gerandet. - Hinterleib sehr schmal, erster und zweiter IIinterleibsring ziemlich stark und mäßig diclit punktiert, mit Spuren weißur Brefilzung: die iibrigen línge kaum erkennbar skulpturiort. Banchringe glinzend, ohne Anszeichnung, an den Hinterrändern schwach hell durchschoinend.

Mit $P$. Hovisentum nahe verwand, bei der abor ()berlippe und (Oberkiefer schwarz gefübt sind; vor allem in der Punktierung des ersten und zweiten Hinterleilsringws damit ïbereinstimmend.

Bulawayo, lilodesia, 28. IX. 12, (i. Anom, log. 2 Explo).

\section{Mrosopis renthostoma Iltk.}

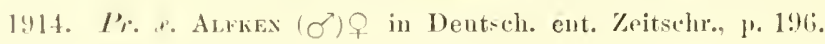

Ansex sagt iiber diese Art:

f. 41/4-43/4 mm lang. Schwar. Kopf pund, otwas länger als breit.

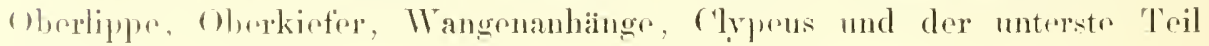


der Wangen und der schläfen rot. C'ypeus auBerordentlich fein längsgerieft und außerdem mäbig dicht und fein punktiert. Stirnschildchen ebenfalls mäßig dicht, Stirn und Scheitel dichter und feiner, Schläten noch feiner punktiert. Augenfurchen kurz, die Hïhe des oberen Augenrandes nicht erreichend. Fïhlergeißel oben braun, unten hellrot. - Pronotum schwarz, hinten nit schmaler grauweißer Halsbinde, srine Torderecken spitz vortretend. Mesonotum sohr fein lederartig gerunzelt und auferdem ziemlich stark und dicht punktiert. Schildehen zerstrout punktiert. Mittelfeld dos Mittelsegments mit einigen gribchonartigen Vertiefungen, hinten scharf' gerandet. - Hinterleib fast matt, schwach seidenartig glänzend, auBerordentlich fuin (schwer erkenubar) lederartig gerunzelt. Endränder besonders seitlich schwach eingedrückt. Erstrr Ring seitlich am Hinterrando weiß gefilzt, die iibrigen Ringe am Hinterrande mit einzelnen weißen Härchen. Buine schwarz, Knie, Tarsen und Vorderseite der Vorderschienen ein wenig grbräunt. Fliigel glasholl, Adern und Stigma schwarzbraun. Schüppehen brannschwarz, vorn gelb.

Eine an den rotgefärbten Mundteilen leicht zu crkennende Art. In der Gestalt des Kopfes ist sie der paläarktischen I'. aracilicornis $\mathrm{F}$. Mon. ähnlich und im system vielleicht neben sie zu stellen.

Kapland, Sunday-Rivar, 10. April 1896, H. Brauxs leg. (1 Ex.).

1 f ron Windhuk, Ende April, Mrumelsex leg.

Ton .J. Bequanterhielt Alfkex (; f, welche am 10. VII. 11 bei Bukama, Belgisch-Kongo, an den Blüten von Acaciu Bequaesti on W. saugend gefangen wurden, und 1 f von II funga, Belgisch-Kongo. 3. XII. 11.

Als o dürte das wie nachfolgend von Alskex beschriebene Exemplar anzusolien soin, das J. Beutaer am 20. Okt. 1911 bei stanleyville, Bolgisch- K o n g o, fing:

5 mm lang. Dem fählich, aber das Mesonotum grob runzlig punktiert. Mundteile, C'lypeus, Stirnschildehen, Wangen und Beine schmutzig braunrot, Schienen, Schenkel, Schenkehringe und Hüften mehr oder weniger dunkel. Clypeus höher als breit, ziemlich grob runzlig punktiert. Fühler dunkelrot, obrrseits, die letzten Glieder auch unterseits gebräunt. Augen groß, Gesicht nach unten verjüngt. Mittelfeld des Mittelsegments ziemlich grob gerunzelt, hinten sehwächer gerandet als beim o. Skulptur des Hinterleibes wie beim f. Endränder der Ringe stark eingedrückt und glänzend. Erster ling seitlich mit schwacher weiber Endfranse. Bauchringe einfach, ohne Höcker, hier und da mit einem Punkte besetzt, letzter und vorlotzter Ring ein wenig rot gefarbt. 
Ich konnte untersuchen 1 Stück ron:

Dentseh-siidwestafika. Windhuk, Ende April, Monaensiax leg. ( 1 f.)

\section{1\%. Halictus deplocinctus n. sp. I.}

Wie 11. michaelseni, aber grïßer und Segment 2-5 an der Basis und am Endrand weiB befilzt.

ㅇ. Schwarz, weiß bchaart, Kopt' und 'Thorax fein runzlig punktiert, Clypeus einzeln grob punktiert, mit fast glattem, gowulstetem Endrand, Antenne schwarz, unten braun, 2. Gépelglied so lang wie das 1. und viel länger als das 3., Area höckerig gerunzelt, mit scharfom Rand, Metanotum weißfilzig. Abdomen fein runzlig punktiert, Segment 1 nur an der Basis weißfilzig, 2-5 an der Pasis und am Endrand weif befilzt, mehr oder weniger bindonartig, 5 woib bohaart, anch die Seiten der resten Analfurche. Ventralsegmente lang weiß gefranst, mit bartragenden Punkten, sonst wie bei H. mirhuelseni. L. $9 \mathrm{~mm}, \mathrm{Br} .3 \mathrm{~mm}$.

Dentsch-siidwestafrika, Okahandja, im Mai Hiegend, Munablasen leg. (1 f).

Aller Wahrscheinlichkeit nach gohiiren H. mirhelseni und H. duplorinctus in das Subgen. Pulellapis, was abor erst nach Bekanntwerden der betr. Männchen zu antucheiden ist.

\section{Halictus michaclseni n. sp. f.}

Don II. leucosomirus K. vou Europa :ilnlich, aber Bohaarung rom weiß 11. anderes.

क. Schwarz, weib belıart, Koplf und Thorax dicht rumzlig punktiert. C'lypeus cinzeln und gröber punktiert, Endrand lang gelblich gofranst, Antenue schwarz, unten gelbbraun, 2. Geißolglied $=1$, aber etwas länger als :3. Mesonotım fast diclıt punktiert und matt, mit ringedrïckter Mittellinie, scutellum punktiert, otwas glänzend, Metanotum und Area liöckrrig punktiert, etwas glänzend, bei beiden der Hinterrand scharf erhaben und herroptrectend. Abdomen foin runzlig punktiort, Sogment $1-4$ mit weißbefilzter Basis und hramer, fein punktierter Endhälfte, 5 mit braun behaarter Analfurche. Ventralsoguento braun mit haartragenden Punkten, lang woißlich belaart, Riandor golbhäutig. Brino selwarzbraun, gelblich brhaart. Scopa grelblich, 'Tarsengliod 2-5 rotgelb, Calcar rotgotl. Fliigel hyalin. Adern und Tegulae gelbbraun. L. T1/2 nn. Breste 2 mm.

1) rutsch-Sïdwestafikika, Okahandja, im April Hiegond,

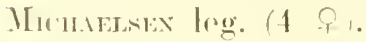




\section{Halirtus mamaënsis Friese.}

1909. И. n. Flake o $\sigma^{\top}-$ Bienen Afrikas, p. 142.

Diese von der Walfischbai und Priuzenbai (sidllich der L ï der itzbucht) beschriebene Art wurde in zallheichen 아 bei W in dhuk. ()kahandja und Neudamm von Michascsex gesammelt. Die Tierchen Hogen im Mai. Durch die weiBfilzige Behaarung kennzeichuen sie sich als echte Wüstentiere; $2 \sigma$ weichen durch dir Antennenfarbe von den typischen Exemplaren ab.

var. antematus n. var. - $\sigma$, Antennenschaft vorn golb und alle Geißelglicder unten gelb, Mesonotum feiner und ziemlich dicht punktiert. L. $6 \mathrm{~mm}$.

Deutsch-Siid westafrika, Wind huk, $\left.\left(\mathrm{l} \sigma^{\top}\right)^{1}\right)$, Michaelsex leg., (inotfontein $\left(1 \sigma^{\pi}\right)$ Volkmaxy leg.

\section{Halictus arenicola n. sp. f.}

Dem $H$. nitidiusculus var. niveuhirtus ähnlich, aber Antenne unten rotgelb, Fligel stark milchig getrübt, Tarsenglied 2-5 gelblich.

․ Schwarz, weiblich behaart, Kopf und Thorax fast matt, ohne erkennbare skulptur, Stirnschildehen und clypeus glänzend, mit einzelnen groben und flachen Punkten, Antenne schwarzbraun, unten rotgelb, 2. GeiBelglied $=1$ und etwas länger als 3. Mesonotum und scutellum matt infolge sehr feiner Skulptur, etwas Hach gedrickt, mit deutlichen Vorderecken, Metanotum dicht weiß befilzt, Area grob netzartig gerunzelt, Runzeln autliegend (bei niveohirtus fein runzlig punktiert.) Abdomen schwarzbraun, fein skulpturiert, etwas glänzend, die braungelben Endrainder dor segmente linienschmal. Ventralsegmente lang weiBlich behaart. Beine schwarzbraun, weißlich behaart, Scopa weißlich, ('alcar golblich, Tarsenglied 2-5 gelblich. Flügel dick milchweiß getriibt, Adern braun: 'T'egular braun mit gelber' Hinterhälfte. L. $51 / 2-1 ; 10 m$, Br. 11/2 $\mathrm{mm}$.

Nördliches șandeld zwischen Lijwon Omuramba und Owangowa-Veld, r. Kastiow leg. (1 ff, Grootfontein, Volkmax leg. $(1 f)$.

\section{Halivtus mimthuliensis 11 sp. $\sigma \circ$.}

Dem H. minutissimus K. von Europa sehr nahestehende Art, aber Mesonotum sehr fein quergerunzelt mit ganz wenigen größeren Punkten, Abdomen fast ohne skulptur, of mit ganz schwarzer Nundgegend.

I) In der Sammlung des IIamburger Museums nicht vorhanden. 
9. Schwarz, kurz weißlich behaart, Kopf und Thorax fein runzlig punktiert, Clypeus gröber punktiert, Antenne schwarz, unten braun, 2. Geißelglied kürzer als das 1. und etwas länger als das 3., die folgenden viel breiter als lang. Mesonotum äuBerst fein quergerunzelt, mit ganz einzelneu groben Punkten, Area selur fein gerunzelt, mit schwachen Längsrunzeln. Abdomen fast ohne Skulptur, glänzend, Segmentrander gelblich, durchscheinend, Analfurche gelblich behaart. Ventralsegmente braun, abstehend gelblich bchaart. Beine ganz schwarz, gelblich bohaart, Scopa weißlich, Calcar rotgelb. Flïgel ganz schwach gotribt, Adern und Tegulae brann. L. $3 \frac{1}{2}-4 \mathrm{~mm}, \mathrm{Br} .1 \frac{1}{\mathrm{t}} \mathrm{mm}$.

$\sigma$ - sehr lang gestreckt, sehmal und dadureh besonders von II. minutissimus $\sigma$ abweichend, sonst wis 9 . auch Kopt sant Mundgegend ganz sehwarz. weiß behart, Antrnne sehwarz, ?. Geißolglied $=1$, aber viel kiirzer als 3., das dritte und folgende viel länger als breit. Beine ganz schwarz, nur Calear gelblich. Fliigel schwach getrübt, Adern und Tegulae sehwarzbraun. L. $41 / 2 \mathrm{~mm}$, Br. $3 / \mathrm{t} \mathrm{mm}$.

Deutsch-siidwestafrika, Windhuk, am 8. Mai 1911 gufanger, Michaelsex leg. ( 2 of und $4 \sigma^{\prime}$ ).

\section{1\%. Halictes nitidinsculus var. miveohirtus 11 . var. G.}

f. Wie H. nitidiusenlus, aber die Behaarung rein weiß, auch Beino weiß brhaart und Scopa weib. Area fein runzlig punktiort. L. $5 \mathrm{~mm}$. Br. $1 \frac{1}{2} \mathrm{~mm}$.

Deutsch-siidwestafrika, Farm otjituezu, 66 km NO. von Windluk, 우 13. Mai 1911, Michaelsex leg. (1 우).

Mit dieser Art vermehrt sich die Zahl der gemeinsamen Arten zwisclsen Kapland und der Paliaarktik um rine weitere, die sich also den folgenden anreiht:

Nomioides pulchellus Sonck, und $N$. fiesciatus Frimse.

Melitte dimidiatu var. copensis Friese.

Anthophora quadrifaseriata we Visi.

Meractile venusta Sis.

Coeliou'ys ufira. Lis.

\section{Nomiat junodiella 11 . Sp.}

(olim N. junodi, nec Steganoms (Nomia) junodi Grus.

D) $N$. parce Kons von Nordost-Ostafrika nahestehend, aus der Ver-

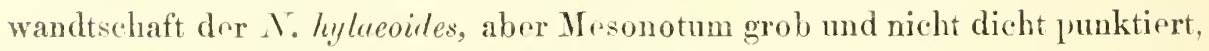
etwas glänzend, $\sigma$ mit golben Tarsen, Ventralsegment 4 dicht gelbfilzig. 
․ Schwarz, gelblich behaart, Kopf und Thorax runzlig punktiert. Gesicht dicht gelbtilzig behaart, Anteune schwarzbraun, unten rotbraun. Mesonotum grob und tief punktiert, olıne Runzeln, Area fein längsrunzlig. glänzend, mit matter Umgebung. Abdomen sehr fein runzlig punktiert, mit glatten segmenträndern, Segment 1-2 nur seitlich breit gefranst, 3-j mit breiten gelben Fransenbinden, 6 kahl und rotbraun. Tentralsegmente sehwarzbraun, matt, lang gelblich gefranst. Beine schwarzbraun, gelblich behaart, Calcar gelb, Tarsen III stark verbreitert, Metatarsus breiter als die selur schmale Tibir, innen goldgelb behaart, Penicillus lang und rorstehend. Fliigel mit getribtem Rande, Adern golbbraun, 'Tegulae sehr grub. braun, breit gelbweib gerandet. L. $7 \mathrm{~mm}, \mathrm{Br} .2 \mathrm{~mm}$.

o - langgestreckt, Kopf grobrunzlig, punktiert, Anteme lang, erreicht das Thoraxende, 2. Geißelglied $=3$. Ventralsogment 2 schwach ausgerandet, 4 dicht gelb befilzt, is kunkav, jederseits bebüschelt, 'Tarsen verlängert, suhr diinn und rotgelb. L. $8 \mathrm{~mm}$, Br. $2 \mathrm{~mm}$.

오 $\sigma^{7}$ mehrfach von Rikatla (Delagoa-Bai), Kapland und einzeln anch ron Harar in Abessinien.

Doutsch-siidwestafika, Windluk, 29. April 1911, Micnaessex $\operatorname{leg}(2 \sigma)$

\section{Nomia hylacoides Gerst. f.}

1857. N. h. Gerstafkele, $\sigma$ in: Ber. Ak. Berlin, 1. 46.2.

1909. N. h. Fruese, o - Bimen Afrikas, p. 156.

1909. N. andree Vacmas i. 1. nach 10 in der Coll. linaxs.

f. Dem o ähnlich, aber viel breiter gebaut, Kopf und Thorax gedrängt punktiert, glänzend, Gesicht breit runzlig punktiert, matt, fast kahl, Antemnc braun, 2. Geißolglied länger als 3. Rand des Mesonotum weißfilzig, Mrtanotum weif brhaart, Area fein längserunzelt. Abdomen brauu bis schwarzbraun foin runzlig punktiert, aber glänzend, Segment $1-2$ jederseits weiß gofranst, 3-4 iiberall foin weißtich gefranst, 5. gelblich behaart, 6. rotgelb, gelbtilzig. Ventralsegmente rotbraun mit gelbhäutigen Rändern, runzlig punkticrt und ziemlich lang, aber sparsam weißlich behaart. Beine braun, weib behaart, 'Tarsen III stark verbreitert, Mctatarsus breitel' als Tibie, mit mächtigem Endpinsel (Penicillus) bewehrt. Flügel hyalin, mit breitem braunem Endrande, Adern und Tegulae braun. L. 6 mm, Br. 2 mm.

$$
\begin{aligned}
& \sigma=61 / 2 \mathrm{~mm}, \text { Br. } 1 \frac{1}{2} \mathrm{~mm} \text {. } \\
& \text { Deutsch-()stafika, Tanga }(2 \sigma, 3 q) \text {, } \\
& \text { Britisch-Ostafrika, Mulango (1 } \sigma) \text {, } \\
& \text { Delagoa-Bai, Rikatla }\left(1 \sigma^{\top}\right) \text { Juxon leg. }
\end{aligned}
$$




\section{Domin linmermensis 11 sp. $\sigma$.}

IVie $X$. hylueoides (iEss'r. aber kleiner, Kopf und Thorax dicht mul fein germuzelt, ganz matt, Segment 1-3 erkennbar punktiert, glänzend.

б. Schwarzbraun bis schwarz, frin weiblich behaart, Kopf und 'Thorax frin und ganz dicht gerunzelt, durchaus matt, (iesicht gelbfilzig, Antenm. schwarzbraun, lang, rreicht das segment 1, 2. Crubelglied $=3$. Ränder des Mesonotum, das Metanotum und dir Thoraxsciten weibtilzig, Area nit 6 Längsrippen, Abdomen fein punktiert, glänzend, S'egment 1-3 jedersoits woib gofranst, 4-(i undentlich punktiert, mit ganzen Fransenbinden, 6 bis 7 mit rotem Endrand, weib bohaart. Ventralsogment $1-3$ fein punktiert. glänzend, 4 mit erlabencr. mattrer Basalplatte, 5. ausgerandet, jederseits gehiickert. lieine schwarz, Tarsen gelblich, Calcar weib, sonst Beine weib bohaart. Flïgel hyalin, mit breitem bramen Endrand, Adern und 'Trgular braun. L. $5-6 \mathrm{~mm}, \mathrm{Br}^{\mathrm{r}}$ 1-1/4 $\mathrm{mm}$.

Kamerun, Viktoria (2 o ), Station Jaundr, $800 \mathrm{~m}$ hoch (1 d).

\section{Somire mama n. sp. $T$.}

1) ar I. hylacoides (iers's. ähnlich, aber Sugment 1 nicht langgestreckt. lrroitre als lang, Kopf und 'Thorax schwach rrzgrün glänzend, dïnn gelbfilzig behaart, Femur und 'Tibie III sehwach verdickt.

o. Kopf und Thorax schwach erzgriin, diinn gelbfilzig behaart, fein runzlig punktirert, fast matt, Gesicht dieht gelbfilzig, Mandibrende rot, An-

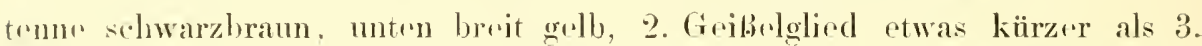
Mrsonotum foin dicht punktiert, etwas glainzend: Pronotum und Metanotum ganz dicht gelbfilzig, am Jesonotum und Feutellum nm die Ränder, Aroa foin lingsonzlig, durch rtwas Glanz von dor Imgebung abstohend. Abdonern dielst runzlig punktiert, matt, mit glatten, glanzonden, braunen und ringers-lnürton Endräindurn, Segment 1-2 jederseits breit gelblich gefranst. 3 - 5 mit ganzon gelbon Fransenbinden, $6-7$ rotgolb, gelblich behart. Ventralsognente braun, gelbhäutig gerandet, firin rumzlig punktiert, gelb bofilzt, "was konkar, 5 jedersoits gehöckert. Beine schwarzbrann, 'l'arsen gallylich, auch Calcar, Frmm IIl schwach krulenartig rerdickt, Tibie III nhenfalls mit verbroitertem Ende, imnen mit stumpiem Endzahn, davor mit Ausrandung. Flïgel gotriibt, mit bramem Endrand. Adern und Tegulare gelbbramn. L. 6 nmm, Lir. 1/2 nmm.

1) lagua-Bai, likatla, Jrop leg. 
Bestimmungstabelleder Nomia-Arten aus der Gruppe

$$
\text { T. hylaeoides GEnst. }
$$
$1\left\{\begin{array}{l}\text { Beine III einfach - } 2 \\ \text { Beine III verdickt, Tibie III innen mit Endzahn, davor nit } \\ \text { Ausrandung - } \\ \text { N. nena Fr. }\end{array}\right.$

$2\left\{\begin{array}{l}\text { Tarsen gelblich gefärbt }-3 \\ \text { Tarsen schwarz gefärbt, Mesonotum runzlig punktiert, matt. - } \\ \text { L. } 9-10 \mathrm{~mm} \text {. para Kont. }\end{array}\right.$

$3\left\{\begin{array}{c}\text { Ventralsogm. } 4 \text { dicht gelb befilzt }-4 \\ \text { Ventralsegn. } 4 \text { mit erhabener, kahler und matter Basalplatte. } \\ \text { L. } 5-6 \mathrm{~mm} .\end{array}\right.$

Mesonotum Hach und gedrängt punktiert. matt. Segm. 1'deutlich und frin punktiert, etwas glänzend. - L. $6 \frac{1}{2} \mathrm{~mm}$.

$4 \begin{cases}N \text {. hylapoides Gerst. } \\ \text { Mesonotum grob und gestuchen, dentlich punktiert, glänzend, }\end{cases}$ Segm. 1-3 dicht runzlig punktiort, matt. - L. \& mm. I. junodiella Fr.

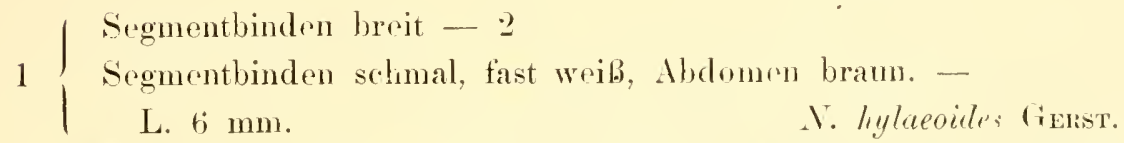

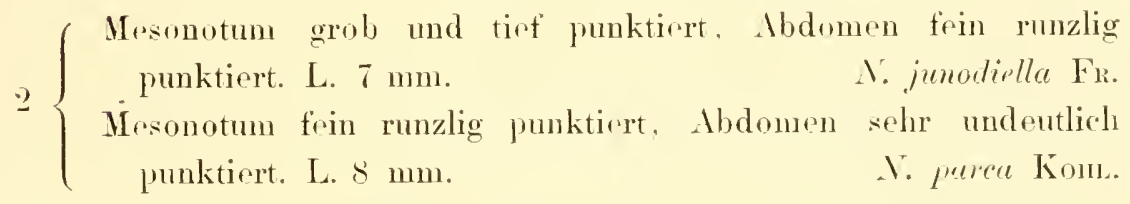

\section{?1. Nomia mbripes Frases.}

1914. N. r. Frifesk, of in: Deutsch. ent. Zeitschr., p. 632.

In der Form dor $N$. mennicentris ähnlich, abor segment $1-5$ mit hellen Fransenbinden. Beine fast ganz rot, III nur schwach bewehrt.

o. Schwarz, dicht gelbbraun behaart, Kopf und Thorax dicht rmzlig punktiert, ganz matt; (iesicht dichtbürstig behaart, ('ypeus kurz, daher Kopf viel breitor als lang. Antenne schwarz. Scutellumgegend fast brann behaart, Area nicht auffallend. Mittelsegment mit einzolnen groben Punkten, schwach glänzend. Abdomon dicht gelblich behaart und dicht runzlig punktiert, segment 1-5 auf den Endräudern mit gelben Fransenbinden, 3-5 auf der segmentscheibe mit einem erhabenen Höckerwall, 6 rot gefübt, 7 rerborgen, seitlich rotgelb bebiischelt. Ventralsegmente braun mit breiten 
blaßgelben Raindern, einzeln und grob punktiert, 4 ausgerandet mit '2 starken nach hinten konvergierenden Kielleisten, 5-6 konkav, einfach gekielt und rot. Brine rotgelb, an der Basis und auch das Femur trilweise noch schwarz, Femur IIl verdickt, fast halbkugelig, Tibie III dreikantig, verbreitert, nach innen und vor dem Ende stumpf, aber eckig verlingert. Flïgel gelblich mit breitem braunem Rande. Adern und Tegulae gelb bis gelbbraun. L. $9 \mathrm{~mm}$, Br. $3 \mathrm{~mm}$.

Dentsch-Sï dwostafirika, Windluk, 29.9. April 1911, MıchaelSEx leg. $(1 \sigma)$.

Deutsch-0stafrika. Kigonsera $\left(4 \sigma^{\prime \prime}\right)$.

Kapland, Willownore, im Dezember Hiegend.

\section{Nomia fubipes Frusis. ó.}

1914. N. f. Frime, or in: Deutsch. ent, Zeitschr., p. 634.

Genau wie $N$. burorum gebildet, aber viel kleiner und weiblich behaart: Mesonotum auch sparsaner punktiert, glänzend; Abdomen fein und zerstrent punktiert, glanzend, 3-5 mit dem eigenartigen Höckerwall; Femur III verdickt, am Endr und unten mit dentlichen /ahn. Flügel heller, L. 8 mm Br. 는 $11 m$.

Vielleicht nur var. von $N$. burorum:

Deutsch-siidwestafrika, Karibib, Ende April 1911, Menuessex leg. $\left(\begin{array}{ll}1 & 0\end{array}\right)$.

siidafrika, Willowmore, Botharille und shilourane, im De-

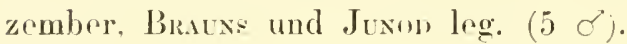

\section{Gen. Poecilomelitta Friese.}

1913. I'. FHase, in: Deutsch. ent. Zeitschr., 1.574.

1913. I'. Fruese, in: Zool. Jahrb., Sept., v. 35, p. 585.

P'oecilomelitte ist rine Gattung fast unbehaarter Bienen, die lebhaft an die kleinen sïdamerikanischen Arten von Camptopoeum erinnern, abrer 3 Cubitalzollen aufweisen und kurze Mundteile wie Amdrena haben und so den stark gelbgezeichneten Arten vom Subgenus Epimethea (I'anurginus) nalie stehen.

f. Kïrper ziemlich breit, besonders das Abdomen, welehes viel breiter als der Thorax ist. Fliigel kurz, erreichen kaum das 5. Śegment, Radialzelle langgestreckt, abgestutzt mit dentlichem Anhang, Endo also vom Flïgelrande entfernt liegend, mit 3 Cubitalzellen, dir erste so groß wie dir 2. 11. 3., die 2. am kleinsten, 2. Cubitalquerader nach auben ausgerbogen, 
Discoidalqueradern mitinden etwas vor der 1. und 2. Cubitalquerader (beide Arten stimmen darin nicht gonau überein).

Mundteile kurz, einfach 1), Zunge kurz, dreirckig, Labialpalpen nicht sichtbar. Maxillarpalpen 6 gliedrig, sehr dünn, alle Glieder fast gleich lang. Maxille kurz, breit und lappenförmig. Antenne wie bei Camptopoeum kurz mit langem Schaft, Scopa sehr dïnn und sparsam, Tibie und Metatarsus. cinfach, nicht verbreitert: Srogment 6 mit breiter, dreieckiger, kalıler Analplatte wie bei Andrena. L. $6 \frac{1}{2} 2^{-6} \mathrm{~mm}$, Br. d. Abdom. fast $2 \mathrm{~mm}$.

sii dwestafrika.

\section{2\%. Poerilomelita Harida Friese.}

1913. I'. f. Frusse, $Q$ in: Deutsch. ent. Zeitschr., p. 574.

1913. P. f. Friese. f in: Zool. Jahrb., Sept., v. 35, p. 586 .

Wie Camptopoen Hariventre Friese ron Argentinien, aber VorderHiigel mit 3 C'ubitalzellen und kurzen Mundteilen (Andrena).

오. Gelb bis colblich, Kopf und Thorax sohr dicht, fast runzlig punktiert, matt, Kopf viel breitur als lang (ca. $1^{1 / 2}-1^{3 / 4}$ ), Gosicht gewölbt, Clypeus ca. 2 mal so breit wie lang, vorn ausgerandot, in drr gewölbten Ausrandung sitzt das rotgelbr. Labrum, Mandibel rotgelb. Fehwarz sind nur: dre hintere Kopfrand. - breite zackigo Streifen ron diesen über das seitliche Ocel, zur Antennenbasis, forner 2 lïngliche, rertiefte, riereckig" Flecken zwischen diesen zackigen Stroifen und dem inneren Augenrand. Intenne rotgelb, oben braun. Schafi voru breit gelb und 1/3 der Antennenlänge ausmachend. Jesonotum schwarzbraun mit 4 golben Längsstreifen. Scutellum gelb, mitten mit dreieckigem, schwarzem Fleck, ebenso die Basalzone der Area schwarz und grob gerunzelt. Abdomen mit schwarzbrann'n klecken. Abdomen schr dicht und foin runzlig punktiort, matt, nur seitlich und dem Ende zu lang behaart, segmentr an der Basis mehr oder weniger schwarzbraun, auf Segment 1 mit 3 rundlichen Flocken, 5-6 lang, rotgelb befranst, 6 mit großer, kahler, dreieckiger Inalplatte. Ventralsegmente zerstretit punktiert, glänzend. mit melır weniger großen braunen Flecken, schwach rotgelb gefranst. Beine gelb, Coxa, Trochanter und Femurbasis dunkelbraun, Femur II nach unten scharf gekantet, Scopa dïnn, weißlich. Flügel hyalin, Rand kaum getrübt, Adern und Tegulae gelblich. L. $61 / 2-7 \mathrm{~mm}$, Br. des Abdoms fast $2 \mathrm{~mm}$.

Deutsch-sid westafika. Grootfontein, Tolkyax leg. (2 우)

1) Soweit bei den getrockneten und stark defekten Exemplaren noch erkennbar. 


\section{Poceilomelitia folliginosa Friese (f).}

191: I'. f. Friese, $f$ in: Deutsch. ent. Zeitschr., p. $57 t$.

191\%. P. f. Friess, f in: Zool. Jahrb., Syst, v. 35, p. 5ST.

In Form und Gröbre wis $P$. Harida, aber ohne golbereichnungen. rinfarbig, schwarzbraun.

․ S'chwarzbraun bis braun, schwach weiBlich behaart, Kopf und Thorax sparsam punktiert, glinzend, Kopf breiter als lang (1/t), Clypeus sparsam und gröber punktiort, in der Ausrandung vorn sitzt das Labrum, welehes vorn breiter als hinten, sonst aber gerundet viereckig ist. Antenne fast hellbraun; Area fein pmuktiert, fast runzlig, nicht abstechend gegen dir Umgelsung. Abdomen frin punktiert, gläzend, Srgmente mut breiten, fast glatten, häutigen Endräindern, Segment 5 lang, rotgelb behaart Analplatte (6) breit, dreieckig und kahl. Ventralsegmente obenfalls fein punktiert, 4-5 lang gelbbraun behaart. Beine schwarzbraun, gelblich behaart, Scopra diinn und gelblich, Motatarsus schr sehmal, nur $2 / 3$ der 'Tibienbreite rrreichend, nach oben in doruartigen Haarschopf ausgezogen. Fliigol hyalin, Adern und Tregulae golblich. L. $(i 1 / 2-7 \mathrm{~mm}$, Br. d. Abdom. fast $2 \mathrm{~mm}$. Doutsch-sïdwestafrika, Grootfontein, Y Immax leg ( 2 )

\section{Allodeque albipennis var. Iomgulle n. var. ․}

․ Wir A. allipemis, aber kloinor und langgestreckter, dor weibe (resichtsfleck kleiner und bei rinzelnen Exomplaren rudimentär werdend Antrune mohr dunkelbrann, ('alli hum. weib mit braunem Vorderfleck. Fliigel milchig gotriibt, Stigma bran mit weißer Seheibe, Tegular weiß mit braunem Scheibentleck. L. 4 mm, Br. $3 / 4 \mathrm{~mm}$.

Dentsch-südwostafrika, Windhuk. vom 29. April bis 8. Mai

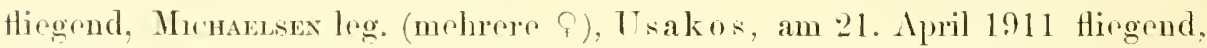
Mr'maensex leg. (- f).

\section{3:. Hllorlope sl. :', Larven mit Pseudopodien. Tafel I'III, Fig. 5a-d.}

Hom Musem Hamburg verdanko ich die Einsichtnahne ciner Anzahl fubloser Larven in Alkohol von der Farm Neitsas im Brzirk Grootfontein Doutseh-sidwestatika), die sich als Bienenlarven erwiesen und zur Gattung - lllodape gehörten, dis Cemetime ong verwandt ist. Vor 10 Jahron erhielt

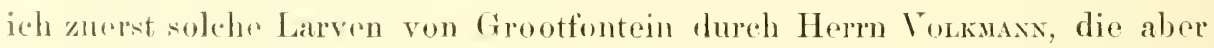
zu sines kleineren Art gohörtin und wegen arger Kusanmensehrumpfung sich nicht zum Abbildon oignetron. J)arauf sah ich woiteros und gut kon- 
serviertes Material 1905 in einer Senclung von Dr. Bracxs in Willowmore (Kapland), das von Arow (iutscri in Jena mustrihaft gezeichnet wurde und zu den mittelgroben Arten Lllodape crivita Br. und A. fmugens Br. gehörte. Dariiber wird Herr Dr. Bratss selbst referieren, da er die Larren in ihren Besonderleiten lebend beobachtete. (Man rergl, auch: \%, für syst. Hymenopterologie u. Hipterologie [Konow] 1902 vol. 2. p. 379 u. 380 [bei Encondylops zum SichluB]. anch ahgedruckt in: Fruese, Bienen Afrikas, 1909. p. $20 \pm[$ Jena $]$ ).

Tie groben Larven ron Neitsas bis (rootfontein (Taf. V'lll, Fig. Ju-d) sind gelbweiß von Farbe. wie alle Bienenlarven, und zeichenen sich durch die starke Verbreiterung der mittleren Segmente aus, der Köruer ist deprimiert und zeigt oben und unten deutliche Abplattung, hat also nichts ron der sonst bei Bienonlarren vorherrschenden zrlindrischen Form mit den vorn wie hinten leichten Zuspitzungen. Die offenbar stark zusammengezogenen Larven (durch Alkohol) haben noch eine Länge von 10 mm und eine Breite einschlieblich der abstehenden scheinfiiße (Pseudopodien). ron $\uparrow$ mm. Die vorspringenden Psendopodien des sechsten serements mexsen $1^{1}{ }_{2} \mathrm{~mm}$ in der Länge wir in der Breite.

L)as (erste) Kopfsegment ist rundlich und zeigt infolge winzig kleiner. anliegender, dunkler Driisenborsten eine bräunliche Farbe, trägi ferner vorn ? rudimentïre braun Kioferwiilste, dis etwas nach dor Tentrakeite zu liegen: die forgenden segnente -2-4 zeigen keine Besonderleiten anßer den kleinen jederseits auftretenden Hautwïlsten, und erst das fünftes segment zeigt ein GrïBerwerden, ain Anschwollen dieser Sestenwiilste. Das sechste. siebente und achte segment tragen dann jederseits am seitenrande - grobr blasenfömige Ausstiilpungen, dis am sjebenten segment am grïbten sind und hiere obige Mafe von 1\%, mm Länge und Breite ereichen: das siebentr und achte segment besitzt auberdem an der Ventralseite und dem Seitenrande zu jederseits eine etwas kleinere Ausstiilpung der Haut, dir ca. $1 \mathrm{~mm}$ Gröbe und bicke erreicht. Das nennte und zehnte segment besitzen jederseits wis das siebente und achtr 3 blasenformige Fortä̈tze der Hant, aber von viel sehmalerer Gestalt, so daß sie bei 1 mm Länge nur 1/2 wm l)icko erreichen und daher als wirklich. Fïße erscheinen, und zwas reihen sich diese Psendopodien auf segment 9 und 10 derart, dafo sie in der verlängerten Linie der 2 Reihen Psondopodion von siegnent und 8 , sowir der Tentralhöcker liegen. Sogment 11 ist rinfach und abgerundet.

Jiese Answïchse, dio sehon durch ihro Inordnung don Gorlanken an fubartige Oroane hervorrufen, sind blasenartige Anstiilpungen der äuferen 
Haut und enthalten wie alle Chitinplatten an drr Innenseite eine nuskulöse Felicht ak Auskleidung und Terdickung; der Innenraum des Fortsatzes s.heint hobl zu sein. Genaure Strukturverhälnisse lieben sich bei dem ungehärteten und anch geschrmmpten Materialo nicht klarstellen.

Bemerkenswert dürtte die verschiedene Form der Scheinfiiße am sechsten bis achten Segment und am neunten bis zohnten Sogmont sein, rrstere sind mehr halbkuglig, Gebilde und scheinen sich den grwölunlichen Hïckem und duswächsen an den Seitenrindern unserer Bienenlarven anzureilien, die Analfüfr (neuntes bis zehntes Segment) sind dagegon besondere Gobilde, lang und diinn, fast von zylindrischer Gestalt.

Die Figuren geben leider die Form der Scheinfübe nicht tadellos wieder, da während des Photographierens die ans dem Alkohol heransgenommenen und festgeklebten Larven naturgemäi eintruckneten und die Endın der ScheinfüBe einstiilpton, daher wie saugnajpfo aut' den Abbildungen erschrinen.

Das olfte segment (letztes) der Larve ist oinfach gerundert und zeigt ventralwails rine kleine Vertiefung, die wohl als Afteröffnung anzusprechen ist, doch miissen hieribrr noch genaucre Untersuchungen an lobendem Materiale abgewartet werden.

Sollte bei der Allodepe-Larve eine Defakation während der Zeit der Nahrungsantnahme stattinden, so häten wir ein Lnikum in der Welt der solitïren Bionen zu verzeichnen, da bisher alle bekannten Bienenlarven dir Defakation erst vor den Rubrzustands dor Larve nach Vollendung der Nahrmgsaufinahme rollbringen. Da aber nach Brauss-Willowmore die - Hllodape-Larren von der Mattrobiene (und anderen ? ?’) gefüttert werden, rine Aufspoicherung des zum Auswachsen nötion Futtervorrates in der ron der Mutter zu sehliobenden Birnenzelle nicht stattfindet, so wäre also in der Defikation der Larven auch eine Abweichung rom gewöhnlichen Custande nicht ausgeschlosinn.

Inter den 20 Larren betinden sich nur :3 halbwüchsige ron ca. 7 bis \& mm Lảnge ror und 3 Fliegenlarven.

Hentsul - siidwestafrika, Farm Noitsas beiGrootfontein, Fink leg. 1907 .

Nach der croblo dor Larve haben wir es hier mit der gröbten bisher noch unbeschriobenen Art zu tun, dir sich den Formen Alluelape rlypeata

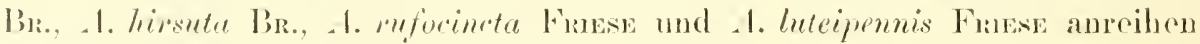

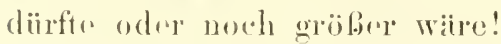

Grenanere Notizen äbres don Fundort liegen leider nicht ror, doch

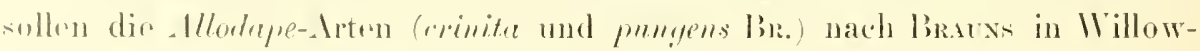


more (Kapland) beri lort Elizabeth das ganze. Jahr hindurch dort nisten und auch im Juni (das ist Winter) an schönen Tagen ausfliegen und sammeln, da eine Wintrrflora dort blüht. Die $200 \mathrm{~km}$ von Willowmore (das hoch liegt) bedingen trotz der Nähe oinen oklatanten Klimauntersehied, teils durch die Nähe des (1zeans, teils durch dio niedrige Neereshöhe im Verhältnis zu Willowmore. Fernor schreibt Bratxs mir im Brief: ..Am Standund Nistort finder sich aine Creme-artige Liliacee, doren Blüten im Sommer abgeschnitten und zum Verkauf angeboten werden (: Freesia). In den vorjährigen abgeschnittenen Blïtenstengeln, deren Mark leicht auszuhöhlon ist, finden sich die Nester von Allodape und Cerotina." Nach einer spätoren Notiz ron Brudss soll Allodupe eine primitive Nostanlage haben und diese in marklıaltigen trockrnen Bliitenständen ron Aloë, Liliacren, Akaziendornen, in trockenen Rubus- und Rosa-Zweigen u. a. anlegen. Hoffentlich hören wir nun bald ausfïhrliches von diesem erfolgreichen Forseher.

\section{Iyloropa catima var. mossambire Grib. und}

\section{I. incomstous Sm.}

Tafel VIIL, Fig. $1 a$ und $b$.

Nester in alten Rlicims-standen. Wie die Figuren la und $b$ der. Taf. IIIl zeigen, sind die ottenbar alten Stämme der Rhicinus-stauden ${ }^{1}$ ) durch Anbohren von außen (Fluglichor) und Ausbohren vou innen zu Nestern hergerichtet. Die purwände, die die einzelnen Zellon abteilen, sind aus den beim liau geschabten Holzspänen mit speichel gemischt hergerichtet. Die unteren 3 größeren Zellen dos geöffineten Stammstückes (Fig. 1a) diirten von Nylocopa inconstans lerriileren weil gröbere Zellen) und die 3 oberen dieses Stammstiickes von $X$. caffra var. mossumbica (weil kleinere zellen). Jedenfalls sind diese beiden Artun nach der Buzeichnung des Museums-Materiales aus den Stauden, die 40 und $50 \mathrm{~cm}$ lang und hohl sind, auch verschiedene writere Fluglïcher zeigen, mit versehiedenen Larven, Puppen und Sc.hmarotzern (E Schlupfwespen und Milben) herausgeholt worden.

Deutsch-sidwestafika, Karibib, an 23.-26. April 1911, Michancsex leg.

1) Es sind blattluse, vollständig vertrocknete, vorjührige standen. 


\section{Weliturgula minima Friese $\sigma$.}

1912. Y. m. Friese, of in: Archiv f. Naturg. 1. 188, fig. 8.

Wie Meliturga clevicomis gebaut, aber durch ihre Kleinheit und rinfarbig schwarzen Kïrper auffallend.

6. Schwarz, lang weiblich behaart, Kopt und 'Thorax punktiert, etwas glinzend, Kopf' viel breitrr als dor Thorax, Augen sehr grofo, $2 / 3$ des Gesichtes ansmachend, innepe Orbitae nach linten und nach vorn anseinandergehend, wir )(. Clypeus gelb, vorn doppelt so breit wie lang; Labrum schwarzbraun, körnig punktiert, lang behaart: Antenne gelbbraun, keulenförmig, Grißel unten gelb, 2. GeiBelglied lang $=3+4$. Mesonotum zerstreut punktiert, mit fast glatter, glänzender Scheibe, Area frein gerunzelt, ganz matt. nimmt die ganze hintere 'Thoraxwand ein. Abdomon matt, zerstreut junktiert und überall selır fein quergerunzelt, mit etwas Erzschimmer, segment $1-4$ mit breitem, brannem, noch friner skulpturiertem Endrand, 6 - 7 lang weiblich behaart, 7 . joderseits mit kleinem Dorn am Eude. Ventralsegmente glänzend, golbbraun gefranst, punktirrt, 6 vor dem Endrand eingedrïckt, 7 glatt, mit rot gerandeter orhabener Endplatte. Beine scbwarzbraun, weißlich behart, alle Tarsen und C'alcaria gelb. Flügel milchig gotrübt. Adern blaßgelb, Tregular gelbbranu. L. 7 мm, Br. 2 mus.

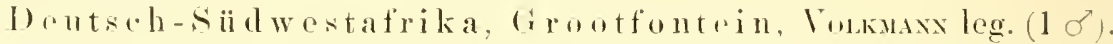

Ich erhielt dies of zusanmmen mit Mermiglossa mfa (q) zur selben Zeit

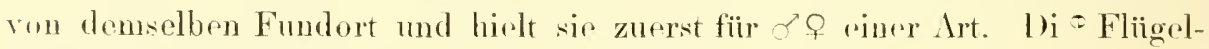
hildung zwang mich jodoch zu einer Tremung beider.

\section{Gen. Mermighlossa Friese.}

1912. M. Freme, in: Archiv f. Natmrg. p. 188.

Mermiglossa ist pine kleine Meliturya nit 2 Kubitalzellen im VorderHiigel und feinen fadrufïrmigen Mundtrilen.

Kïpler breit, Louf grob, Hach, beeiter als der Thorax, Flizgol reroichen das Abdomenendo, Radialzelle grob, mit dem kude weit rom Fliggelrande entfernt liegend. mit großer Anhangszellr, 2) Kinbitalzellen, dir. fast gleich grof sind, die "2. Kubitalzelle nimmt beide loiscoidalqueradern anf, und zwar gleich weit vom der 1. und 2. Kubitalyuerader.

Mundteile lang, wfinhar hochentwickelt und diftienziort, Kunge und Maxillon lang, fackenförmig, oproichen zuräckgalegt das Thoraxende, div J'aster sind leider bej dem getrockunten Exemplar nicht rekembar.

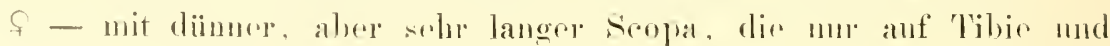


Metatarsus beschränkt ist, Metatarsus nur $2 / 3$ der Tibienbroito erreichend nnd außen in eine sclıräge Spitze auslaufend. L. $8 \mathrm{~mm}$.

Inı System linter Meliturgula einzuschalten.

Nur 1 Art bisher.

Sii d a frika.

\section{Memmiglossa rufu Friese}

1912. M. r. Friese, ㅇ in: Archiv f. Naturg. p. 189, fig. 9.

Wie Meliturya clavicornis gebaut, aber viel kleiner, Abdomen rot.

ㅇ. Sclwwarz, kurz weiBlich behaart, Kopf breiter als der Thorax und breiter als lang, Kopf und Thorax fein punktiert, glänzend, innere Orbitae parallel verlaufend, Clypeus stark vorgewölbt, tief ausgerandet, hufeisenförmig, in der Ausrandung sitzt das braune, poliert glänzende Labrum, das gewölbt ist, länger als breit und am Ende gerundet erscheint: Antenne braun, keulenfiirmig, 2. Geißelglied wenig länger als 3.; Mesonotum und Scutellum gleichmäßig deutlich punktiert, Area scheint glatt (?) und gliinzend zu sein (hier durch lange mit Pollen besetzte Behaarung verdeckt). Abdomen rot, deutlich punktiert, schwach beliaart, Sogmentränder von $1-4$ gelbhäutig und fein quergerunzelt, 5-6 lang rotgelb beborstet, 6 mit dreieckiger, kahler, rotbrauner Analplatte. V'entralsegmente rotbraun, mit einzelnen groben Punkten dem Endrande zu, Ränder häutig und gelbbraun, 6 konkav, mit glatter Scheibe und Endrand. Beine schwarzbraun, weiBlich behaart, Tarsenglied 3-5 gelbbrann, Calcar rotgelb, Scopa dünn aber lang, nur auf Tibie und Metatarsus beschränkt (und auf die hintere Thoraxwand), Metatarsus auBen in schräge Spitze ausgezogen, sonst aber viel $(2 / 3)$ schmaler als die Tibie. Flügel schwach getrübt, Adern bleich, Tegulae rotbraun. L. $8 \mathrm{~mm}$, Br. $21 / 2 \mathrm{~mm}$.

Deutseh-Sii dwestsfrika, Grootfontein, Volkman leg. (1 우).

\section{Tetralomia jumodi Friese.}

1909. T. j. Friese, o in: Bienen Afrikas, p. 259.

1911. T. j. Friese, 우 in: Zool. Jahrb., Syst, v. 30 , p. 656.

ㅇ. Wie eine große T. tenuifasciata, aber weißlicl behaart, nur Mesonotum oben gelbbraun, Clypeus mit erhabener Mittellinie und grob runzlig punktiert, vor dem Endrande mit eingedrückter Rinne, Mandibelende rotgelb. Abdomen fein punktiert, Segment 2-4 mit breiten, weibfilzigen Binden an der Basis, 5-6 gelbtilzig, mitten braunfilzig. L. 14 mm, Br. 5 mm. 
$\sigma^{\prime}$ - zeigt mitten am Femur III nach linten cinen kleinen Zahn, der einen langen, oft verklebten und spitzen Haarpinsel träigt (= Species('harakter!).

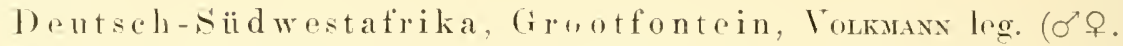

siidafrika. Rondrboseh und ()$^{\circ}$ okiep, ium september ( $q$ ),

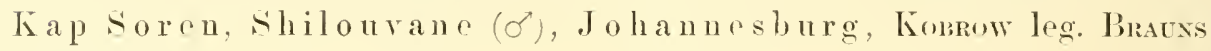
ded. $\left(\sigma^{\prime}+\right.$ ).

\section{Tetrefomire pulverosire Friese.}

1911. T. p. Friese, of in: Zool. .lahırh., Syst. v. 30, p. 658.

T. pulverosa fällt dureh das rigenartig befilzte Abdomen auf. es erinnert an T. pollinose Ler. (Sïd-Europa).

‥ Schwarz, gelbbraun behaart, Kopf und Thorax dicht runzlig punktiert, matt, Clypeus am Vorderrand mit broiter, gelber Binde, auch Mandibelbasis ist gelb geffeckt, Mandibelende rotgolb: Antenue schwarzbraun, unten rotbram, 2. Goibelglied $=3+4$. Thoraxrïcken matt, dicht gerunzelt und dicht, fast rotgelb bohaart, Area grob gerunzelt, mit seichter Mittellinie. Abdomen punktiert, Punkte groß aber Hach, Segmontrinder bram, Segment 1 am Endrand, 2-4 dicht und kurz rotgelb brfilzt, wis bestäubt, 4 molı graufilzig. 5 schwarz befilzt mit weißem Endrand, 6 dunkel. Ventralsegmente dicht graugelb, schwarzbraun behaart. Brino schwarz, gelblich behaart, Tarsen mehr dunkel behart, foopa wriblich, auf Motatarsus innen schwarzbran, Penienllus schwarzlıran, Calcar schwarzbran. Flügel fast hyalin, nit kaum dunklerem Findrand. Adern schwarzbraun, Tegulae scherbengelh. L. 1 i $11 m$, Br. 4 mm!

of wie of, aber Clypeus fast ganz gelb, Antennen rot, lang, orrechen das Aldomenende, gekerbt erscheinend (Glieder sind gobogen), mur Sehaft und die 3 letzten Glieder schwarz, 2. Geibelolind sehr kurz, so lang wie 1 $=$ P'edicellus), Abdomen auf Segment $1-2$ golbbram befilzt, sonst weißfilzig. Beine schwarz, gelblich belaart, Femur III unten in der Mitte mit mächtig('m, aber stumptim Dorn. V'entralscomente fast kahl, letzter infolge tirfer Mittelfurche an Ende 2dornig. L. $10 \mathrm{~mm}, \mathrm{Br}_{2} \mathrm{I}_{2} \mathrm{~mm}$.

Doutsch-siidwestafrika, Karibib, Fude April Hiegend, Menaensen log. (1 1 , $)$.

Nord-Transval, Shilouvano, Juxon log. (ơ 0 ).

\section{Tetralonia mirhaelsemi n. sp. $\sigma$.}

Wir $T$. salicarice Lep. (Mittelumopa), aber Gesicht schwarz, Antenne kurz, cresicht nur Thuraxende. 
б. Schwarz, gelbbraun behaart, Kopf und Thorax runzlig punktiert, glänzend, Gesicht lang und dieht weiß behaart, Mandibelınde gelb, Clypeus kurz, viel breiter als lang, Antennen schwarzbraun, unten braun, erreichen das Thoraxnde, 2. GeiBelglied wenig länger als 1.; Area fein runzlig punktiert. fast matt. Abdomen fein und dicht runzlig punktiert, fast matt, Segmentränder breit, braun, Segmont 1 an der Basis lang, weiblich behaart, 2.-5. Segment an der Basis dieht weißtilzig, 6 dicht gelblich befilzt, jederseits spitz gezahnt, 7. braun, abgestutzt, konkar mit aufgebogenem Rand. Ventralsegmente zerstreut punktiert, glänzend, vor dem gelbhäutigen Endrande lang weißlich gefranst, $5-6$ mitten eingedrüekt, 6 glatt, stark glänzend, mit erhabenem, gelbborstigem Endrande. Beine sehwarzbraun, gelblich behaart, Calcar braun. Fliigel hralin, Adern braun, 'Tegulae hellgelb. L. $8 \mathrm{~mm}$, Br. $3 \frac{1}{2} \mathrm{~mm}$.

Deutsch-siidwestafika, Windhuk, Anfang Iai 1911 fliegend, Michaelsex leg. ( 1 o.)

\section{Tetralomia obscmiceps 1. sp. б".}

Der T. michaelseni ähnlich, aber Clypens etwas verlängert, Ifsonotumscheibe fein quergerunzelt, mit einzelnen großen und Hachen Punkten, Antenne kürzer, erreicht nur das sicutellum.

ơ. Schwarz, gelblich behaart, auch Gesicht, Clypeus vorgewölbt, dicht runzlig punktiert, Mandibel rotbraun, Antenne braun. unten gelbbraun, sehr kurz, rreicht nur das Sentellum, 2. Geißelglied wenig länger als das 1. Mesonotumscheibe fein quergerunzelt, mit einzelnen großen flachen Punkten. Abdomen fein punktiert, wenig glänzend, mit breiten, braunen Endhälften der Segmente, Endrand gelbhäutig, Segment 1 lang gelbbraun behaart, 2-3 mit weibfilziger Basalbinde, 6. jederseits gezahnt, †. rot abgestutzt, Ventralsegmente fein punktiert, glänzend, mit breiten, gelbhäutigen, glatten Räudern, gelblich gefranst, 5 jederseits der kahlen Vitte mit braunem Haarbüschel, 6 rotbraun mit tiefer Mittelfurche. Beine braun, gelbbraun behaart. Calcar gelblich, Tarsen I und II merklich verlängert, Klauenglied gelblich. Flügel hyalin, Adern braun, Tegulae gelbbraun. L. $9 \mathrm{~mm}, \mathrm{Br} .31 / 2 \mathrm{~mm}$. Deutsclu-Ostafrika. Ma dibira, Hatruger leg. ( $\left.\sigma^{7}\right)$.

\section{Tetsalonia rileatlä̈nsis n. sp. $\sigma$.}

Wie $T$. obsemiceps, aber größer, Segment 2-6 mit weißfilziger Basis, Beine II und III weiß behaart. Tentralsegment j jedersits schwarz bebüschelt. 
c. Schwarz, weiblich behaart, Kopf punktiert, glainzend, Clypeus runzlich punktiert, Mandibelende gelb, Antenne sehr kurz, erroicht nur die Mitte des Mesonotum. 2. Geibelglied $=3$ und $4 \mathrm{mal}$ st lang wie 2, Thorax dicht runzlig punktiert, glänzend, Arra grober gerunzelt und matter. Abdomen dicht rumzlig punktiert, mit brauner segmenthalfte, die foinor skulp)tiert ist, Endrand der Fegmente glatt und gelblich, Segment 2 an dor Basis und ror dem Endrande mit weiber Filzbinde, 3-6 anf der Mitte resp. ganz weiB befilzt, 6 jederseiti gezahnt, 7 koukar, rot mit aufgebogenem

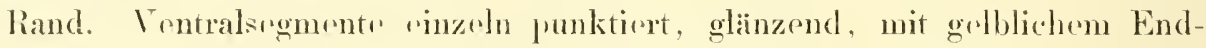
rande, 5-6 konkar, 5 jederseits schwarz beloischelt, 6 rotbran, jederseits am sicitemande mit kielartigem Mrulst. Beine swhrarz, weil. boborstet, II und III Buimpar mit verlingerten Tarsen. III mit gekriimmtom Metatarsus, ('alcar rotbraun. Flägol gelblich gotrïbt, Adern schwarzbraun, 'Tegular golbbrann. I. 10 111m, Irr. 4 mm.

1) elagoa-Dai, Rikatla, Juxon log. 1 d abgatlogonl.

\section{Osmeire st1.:" (mossaira n. sp.)}

Tafil YIII. Fig. 2." nnd b.

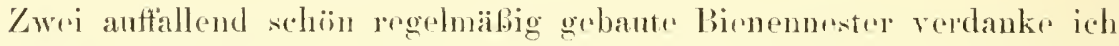

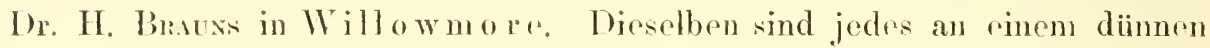
Stengel allein gemauert, und zwar aus braunew Harzstoff', desson Beschaffenheit derart ist, als wenn er flitissig verwandt wörde and erst nachleer an dor Luft rintrocknete. Dir ! resp. 6 Zollen liegen rings $m$ den Stengel herum. Nach Fertigstollung drer Yollen, die ans reiner brauner Harzmasse

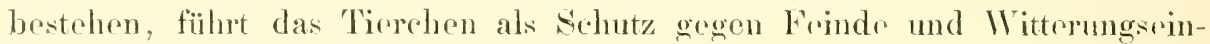
Hiisse noch dincen l'anzer ans lauter kleinen steinclen von 1-2 Q pradratmillimeter Fliche mu die fertigen \%ellen hormm. Wie Steine bestelen ans Quarzit und sind ron weißer und roter Farbe; zwisehen den Strinchon quillt dio hier schwarzoriine Harzmasse hervor: das Nust gloicht tiauschend einem 'lerazzo- oder Mosaik-(iebildr. Thr ziomlich gleich grobun streinchen werden kunstgerecht aneinandergefïgt nud mit dem schwargriinrm Mörtel verbunden, sodalo nach auben rine ganz rbene Fläebe olene nennenswerte lorspringe cutsteht. Was (ianze macht einen iubrest soliden Eindruck ron grober Frestigkeit, Widerstandskraft und auch ron Schönhest. Dio Griblor mibt bei dem rinen Nrest: $16 \times 17 \mathrm{~mm}$ boi $1.5 \mathrm{~mm}$ I)urehmesser, bri dem zweitun: $11 \times 13$ bri $10 \mathrm{~mm}$ Intrehmesser.

I ber Banmeistor ist noch mbekannt, doch tinden wir bishere nur bei der Gattung (Somia Ankliingr zu solcher Baukunst, hoffentlich golingt dinu orfulgreiclun Entelocker des Nesters auch noch das Auffinden des Maurerincisters! 


\section{Lithurgus capensis Friese.}

Tafel VIII, Fig. 6.

Von Lithuryus rapensis, einer Steinbienenart, erhielt ich mehrfach vou Ir. H. Bratxs ans der l'mgebung seines Wohnortes Willow mor" (K apland) die Nestre, welche sie dicht gedrängt in dir Käferbohrlöcher alter Baumstämme anlegen. Lis werden besonders die ron den Buren importierten Pappelbäum. berorzugt, deren Holz weicher ist und auch von der Birne zernagt werden kanu. Wie stark solche alte I'appelbäume durch die Biene zugerichtet werden kïnnen, zaigt Fig. of dur Taf. YIII, wo Flugloch bei Elugloch liegt und Röhre neben Röhre verläuft. Das Holzstiick stanmt von Willowmore und lialst die meist von oben Flugloch nach unten verlaufenden Gänge erkonn'n, die dam durch Querwände von Holzmehl and Speichel von der Biene (f) zellenartig abgeteilt werden. Jedo Zelle (11-12. mm lg.) wird mit Pollen (zur Hälfte) und dem Bionenei versehen und dann durch Querwand abgesehlossen. Der Deckul bildet dann gleich den Boden der folgenden Zelle. Daneben diurften aber auch noch wie bei anderen . Irten dieser Gattung Vorratsöhhren nach oben (rom Flugloch aus) gebohrt werden, wohinein die Lithrigns-? Polle n als Vorrat für Zeiten der Not vorläutig anfspeichern, un bei ungünstiger Trachtzeit doch ihre begonnenen Banten zn Ende führen zu künnen. (Man vol. darüber anch: Furse, Bienennest mit Vorratskammorn. in: Yatschr. f. wiss. Insektenbiologie. 1905. r. 1. 1. 118.

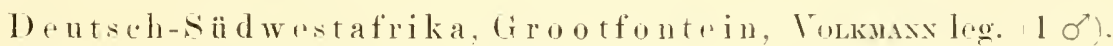

Kapland, Willowmor", Kapstadt. Hoxriror.

Basuto-Land.

Rihodesia.

Anch in den Sammlungen vom Kap-Musenm und Rhoderia-Mnseum vorlianden.

\section{6\%. Megachile bullata Friese.}

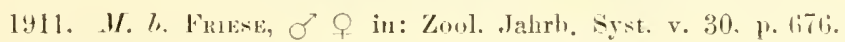

Der 11. etripes Fruese ron T'ransvaal verwandr, aber kloiner und ror allem schmaler, im of mit wulstig aufgebogenem l'lypeusendrand und kräftigem Stirnhäker, o mit zackigem Endrand des Sugments 6, 'Taren I verbreitert und waib.

f. Schwarz, stellenwoso typisch schnoreweiB behaart, Koplf und Thorax dicht runzlig punktiort, matt, wie $M$. atripes, clypeus etwas vorlangert, abgostutzt, mit stark gewulstetern aufgebogonem Rande. Stirnschildchen mit großem, 
zweibeuligem Höcker, (iesicht weiß behaart, ebenso der 'Thorax, besonder's an den seiten und an der hinteren Thoraxwand lang weiß bebüschelt. Abdomen undeutlich und unregelmäbig punktiert, Segment 1 -2 lang schnerweiß behaart, 3-4 fast kahl, 5-6 kurz schwarzborstig, scopa rot, auf 5 rotbraun, 6 schwarzbraun. Beine schwarz, kurz schwarzbraun behaart, 'T'arsen braun behaart, Calcar braun. Flügel hyalin, mit scharf alogesetztem braunem Endrand (bei $M$. utripes mehr als dio Flügelhälfte braun), Adern und Tegular schwarzbraun. L. $13 \frac{1}{2}-14 \frac{1}{2} \mathrm{~mm}$, Br. $3 \frac{1}{2}-4 \mathrm{~mm}$.

of und $f$. Gesicht unbeweht, lang anliegend weiß behaart; Thorax sparsam skulpturiert, etwas glänzend, Segm. 1 ganz, 2--3 an den Seiten, 4 am Rande, 5-6 kurz und diinn rotgelb beborstet, 6 gerundet, mit gezacktem Endrand, 7 auf der Ventralseite als kurze Spitze sichtbar; Ventralsegmente braun, lang, düinn weißlich gefranst, punktiert, glänzend. Beinu braun, weib behaart, Coxa I mit stumpfem, kurzem Griftel, Tarsen I stark rerbreitert, weißgefïbt, nach hinten lang weiß gefranst, 'Tarsen 11 braun, auch weißlich bebiischelt, Metatarsus etwas verbreitort, dann schräg abgestutzt, gelbbraun behaart. Flïgel gebräunt, Hintertlïgel tast hyalin. L. 14 mn, Br. $4 \mathrm{~mm}$.

Deutsch-siidwestafrika, ans dem Landesmusemm zu Windluk ( $f$ ). Oranje-Kolonie, Smithfirld, Hat.-Riv.

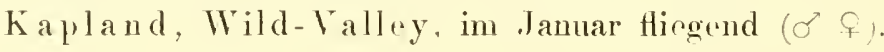

\section{Hegachile (chaticontoma) musrulus Friese f.}

1913. H. m. Friese, of in: Zool. Jal rb. Frat. r. :0, p. 592.

IVie Chalicodoma y'yrenair" Ler. (Europa), aber Alukomen fast rinfarbio lang grau behart. Analsegment 2 teilig und sternit 6 mit rrhabenem. glatten, halbkreisförmigem Rand vor den Ende.

f. Arhwarz, lang grau belhaart, Kopf und Thorax mehr graubraun behart, Nobengesicht aber schnerweib belıart. Kopf und Thorax dicht rmalig punktiert, fast matt, ('lypeus vorgezogen, gerundet und schwarz kremuliert, Mandibel stumpf gzähnig: Antenne schwarz. 1. Cieibelglied fast $=2+8$. Arra sohr foin gremzelt, matt. Abdomen lang und weiblich grau behart. Sogment $4-5$ am Rando mit längeren, abstrhenden, roten Borstrn,

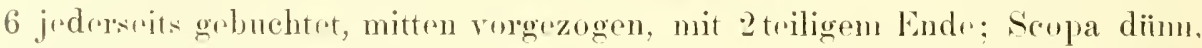
rotgolb. Ventralsegmontr sohr grob punktiort, Analsegment mit glattrm.

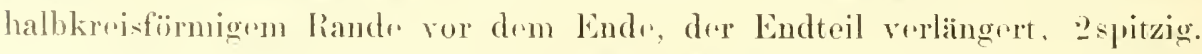
boine sclowarz. Tarsen rot, rotgell, hehaart, C'alcar rot. Tilinendr der Beine III 
auch rot. Flügel stark getriibt, Adern scluwarzbraun, 'Tegulae rotgolb. L. $13 \mathrm{~mm}, \mathrm{Br}, 41 / 2 \mathrm{~mm}$.

Deutseh-Südwestafrika, Grootfontein. Tolkxax leg. (2 q). Ka pland, Ookiop in Kl. Namaland, im September fliegend.

\section{j4. Megachile uinathukiama II. sp. Ғ.}

Der $1 \%$. caerulea sehr ähnlich, aber kleiner, Abdomen schwarz, Basis und Endrand der s'egmente weißlich befilzt, of Scopa ganz rotgolb, o Endglied der Antenne etwas verbreitert, Beine II und III schwarz.

f. Schwarz, weiBlich behaart, Kopt und Thorax fein und dicht runzlig punktiert, matt, dic Punkte aber meist gut erkennbar, Gesicht gelblich bchaart, Clypeus kurz, abgestutzt, mitten mit einigen Hückerchen, Antenn' schwarzbraun, 2. Geißelglied $=3$. Mesonotum sparsam und kurz gelblich behaart. Abdomen schwarz, auch Segment 1, 2-4 mit schwach grünlichem Schimmer. 1 sparsam und länger behaart, 2-5 mit schmalen, gelblichen Fransenbinden und weißfilziger Basis, 6 grautilzig nit braunbefilzter Endhälfte. Seopa rotgolb, Ventralsegmente sonst grob punktiert, mit schmaler weißbefilzter Basis, dis durch die rotgelben scopahare durchscheint. Beine schwarzbraun, Femur II und III braun, kurz weib behart, Metatarsus plattgedrückt, von Tibienbreite, Tibie III dreikantig und verdickt, C'alcar rot. Flügel mit getribtem Rande, Adern schwarzbraun, Tegulae braun. L. 12 bis $13 \mathrm{~mm}$, Br. $4 \mathrm{~mm}$.

c) - d.m ơ ron M. coemea täuschend ähulich, aber kleiner, Autenno länger, Endglied etwas verbreitert. Thorax und Segment 1 weißlieh behaart, Beine II und III schwarz, Beine I mit rotem Femur und roter Innenseite der 'Tibie, Tarsen weiß, vabreitert, ron Tibienbreite. mit weiber' Beborstung nach hinten, die Borstenhaare mit rotgelber Endhälfte. L. 12 bis $12 \% 2 \mathrm{~mm}, \mathrm{Br} .4 \mathrm{~mm}$.

Deutsch-siidwestafrika, aus dem Landesmuseum zu Windhuk $1 f$. Grootfontein, Vol.kuax leg. $(2) 1 \sigma^{\circ}$.

\section{Hegachile niveofasciata Friese und Verwandte.}

Wie Cruppe der Megachile niveofasciata Friese aus Siidafirika zeigt uns ein auffallendes Beispiel, wie sich Formen abzweigen. Iuberlich fast ganz gleich - nach dem Aussehen - nur in Gröbe otwas abweichend. bieten uns dir 4 Formen bei genauerer Lntrsuchung doch auffallende Abreichungen, die offenbar infolge extremer' Witterungsverhälnisse und 
dadurch bedingter verinderter Lebensweise hervorgebracht und festgehalten wurden. (Mandibel-Bildung - Scopa-Farbe).

Megachile niveofascinta wurde von mir 1904 in d. Zeitschr. f. syst. Hym. Dipt. vol. 4, 1. 336 nach einem Pirchen von Willowmore, Kapland, das ich Horm Dr. H. Brauss verdanke, beschieben. Die Tierchen Hogen dort in Dezembres. Man rergl. anch: Fuese, Bienen Afrikas; Jena 1909, P. 376 .

Vorwg lasse ich die analytische Bestimmungstabelle folgen, darauf div Beschreibung der nowen Jiten:

\section{오.}

1 | Mandibol ganzrandig -2

Scopa woib, Ventralsegmente schwarz, Mesonotum dicht runzlig punktiert, schwarzbraun behaart, Clypeus mitten abgestutzt, schwarz, grob runzlig punktiert. L. $12 \mathrm{~mm}$, Br. $4 \mathrm{~mm}$.

1\%. niveofasciata Fr.

Scopa rotgelb, Ventralsegmente rot, mit weißen Fransenbinden, Mesonotum dicht punktiert, weißlich behaart, Clypeus gerundet, mit rotgelbem Endrand, der grob krenuliert, sonst der Clypus weitläutig punktierí gerunzelt, L. $10 \mathrm{~mm}$, Br. $3 \mathrm{~mm}$.

H. cinctiventris 11 . sp.

Mesonotum firin rumzlig punktiert, rtwas glämzend, gelblich behaart, Scopa rotgelb, Vontralsegmentr rot mit weißen Cilienbinden und schwarzbramer Basalhälte. Mrotatrsus fast von 'libienbreitr. L. $10 \mathrm{~mm}$, Br. $3 \mathrm{~mm}$. M. alborufa n. sp.

$:\{$ Mesonotum grob rumzlig punktiert, Irsonotum wie Oberseite des Lopfes bram behaart, Scopa weiß, I'entralsegmente schwarz, besondere Cilienbinden nicht autfallend, Metatarsus viel schmaler als die 'Tibir. L. $11 \mathrm{~mm}$, Br. $31 / 2 \mathrm{~mm}$.

\section{1. albopilose $11 . \mathrm{s}$.}

Dir dazn gohïrigun or liogen bis anf M. niceofasciate noch nicht vor, sir alloin wordon iibre die detinitive Irtabgrenzung don Aussehtag goben.

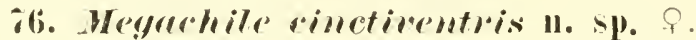

P. Schwa\%, woil. behant, Kopt' und 'Thorax dicht punktiont, weib brhaart, Mandibel ganzandig, wie bei M. niveofesciate, Clypens germendet, mit rotgelben Endrand, sonst weitlaiutig runzlig punktiert, der Endrand grob

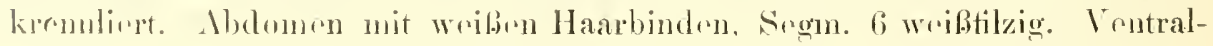


segmente rot. mit weiben Fransenbinden, dir durch die rotgelbu seopa durchscheinen. Beine rot. Flïgel hyalin. L. $10 \mathrm{~mm}$, Bs. $3 \mathrm{~mm}$.

Dontsch-Sii dwestafika, Grootfontein. Volkuxx leg. (f).

\section{\%. Hegachile alborufia n. sp. ค.}

‥ Nichwarz, weiß behaart, Kopf und Thorax foin runzlig punktiort, etwas glänzend, oben gelblich behaat, Mandibel spitz, am Endes schwach

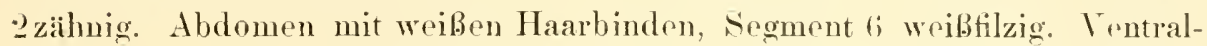
segmente rot, mit weißen C'ilimbinden und schwarzbraner Basis, scopa rotgelb. Beine rot. Metatarsus fast ron 'Tibienbreite. Flïgel hỵalin. L. $10 \mathrm{~mm}$, Br. $3 \mathrm{~mm}$.

Deutsch-siodwestafika, Ondonga, lictuxes leg. (P).

\section{Megachile albopilosid n. sp. f.}

f. Schwarz, weiß behaart, Kopf und Thorax grob rumzlig punktiert. matt, Mandibel spitz, an Ende schwach 2zähnig; Mrsonotum und Kopfoberseite braun behaart. Abdomen mit wriben Haarbinden, Segment i; weibfilzig. Ventralsegmente schwarz, scopa weiß, die Cilienbinden der Sogmente nicht auffallend. Beine rot, Metatarsus viel schmaler als die 'libie. Flügel hyalin. L. $11 \mathrm{~mm}$, Br. $3 \frac{1}{2} \mathrm{~mm}$.

Kapland, Kapsta dt, Kenharm leg. ( $f$ ).

\section{Serapis renticulatu Sm.}

'Tafel VIII, Fig. 3 und 4 u-c.

Nister von Grootfontein durch Luxkexber gesammelt und dem Hamburger Musrum durch Mrchaessex ïbermittelt. Das Nost besteht aus einer graufilzigen, melr als eigroben Masse, wie StтAdewax bereits 1897 in seinel Notiz ,Hymenopt." (Dentsch-(Ostafrika) exwähnte. Es ist an einem diunen Stengel ron Federkielstairke befestigt, d. h. dis eine Nestwand unfaßt den Stengel in seiner ganzen Ansdeluung. Đie Gröfe schwankt zwischen j und $6 \mathrm{~cm}$ Lainge und zwischen 3 und $4 \mathrm{~cm}$ in Durchschnitt. Das Gewicht ist shlur goring und betrug 4--5 gr. Das pine Nest saß an einem Dornzweig ( $\therefore$ Fig. 3), w wurde aufgeschnitten und zeigt eine Anzahl Zellen von 8 bis $10 \mathrm{~mm}$ Länge und 5-6 mm Breite, die Zwischenränme der einzelnen Zellen sind ebenfalls mit der granen Filzmasse angefïllt, sodaB jede einzelne Zelle ganz davon umhïllt ist. Die grauen Filzhaare schaben die Tierchen offenbar von stark behaarten Pflanzen (Blättern) ab, wie es unsere Wollbienen (Anthilium) in Europa ebenfalls tun, und verarbeiten sie zn der Filzmasse, 
die eine außerordentlich zïhr Beschaffenheit hat, sich schwer schneiden und noch sehwerer zerreißen läßt. Die Zallen liegen ziemlich unregelmäßig, wie man os auch in der Abbildung deutlich erkennen kann, die das Nest mitten durehgeschnitten und auseinandergebogen zeigt. Immerhin sind 2 Reihen Zollen, von denen das cine Polende nach dem Zweigende zeigt, zu untersehoiden. Diese in Pflanzenwolle grebetteten und ganz cingehüllten Zellen 'nthalten jetzt nur noch Pollenreste, Facees und einen braunhäutigen, fast durchsichtigen Cocon, der von der Serapis-Larve gesponnen wird; es sind bei dem durehsehnittenen Nest 5 Zollen sichtbar $(=10 / 2)$, das ganze Nest diurfte 12 bis 15 ziemlich großr. Zellen boherbergen.

Der eigentliche Zellenhaufen zeigt abor noch als weitere Umhiillung eine ziemlich gleichmäBig geschichtete $4-5 \mathrm{~mm}$ dicke Wand von reiner P'flanzenwolle als Schutzhiille gegen die Wittrung und Schmarotzer Schlupfwespen). Der bau dïrfte folgendermaßen verlaufen: Nach Auswahl des botr. Stengels befestigt die Mutterbiene (오 kleine Wollpatzen, die sie in 2-3 mm groben Packchen von den betr. Blättern abgeschabt hat, an den Stengel mit Hilfe ihrer Speichelsekrete (die in der Bienenwelt ein. mannigfaltige Rolle spielen) und baut so die rrste Kellhöhle auf; nach Glättung und speichelung der Immenwand wird der Pollenballen eingetragen, dor die Kelle etwa zur Hälfte anfüllen wird, darauf legt die Biene ein Ei und schließt die Zelle mit Wollpatzen ab. Nach guter Umhiillung mit Pflanzenwolle folgt daneben dann der Bau der 2. Kelle usf. In meinen Bionon Afrikas (1909) finder sich auf der 'Tafel Il, Fig. 15 und 15 a rine kolorierte Abbildung des Wollnestes von Authidium truncatum auf einem Palmblatt, auch im Durchsehnitt mit dem Pollenballen und dem banenden ․ Zum S'chlusse, nach Tnterbringung dor Dutzend Zellen, werden alle iußren Unebenhoiten noch mit Wolle ausgefüllt, geglättet und die gleichmäbige Dicke ron 4-5 mm Wollschicht als AbschluB herumgelegt, wodurch das mehr als eigrobe Nost wong auftallendes zeigt, sodab es von den meisten Mensehen übersohen werden dürfte. Nach einem grölocen laitraum, in welchem sich die aus dem Ei schliipfende Larve an dem aufgespeichorten Pollen genährt hat und ausgewaclsen ist, was in 20 bis 25) 'agen vor sich gehen dürftr, wird der Cocon von der Larve gesponnen, und nach weiteren 8 Tagen begimnt die L'mwandlung der Larve in dir P’uppo (Chrysalide), in welchem Stadium dann Dürre wie Feuchtigkoit, Kälte wir Hitze ohne Schaden rrtragen wird. Bei guinstiger Witterumg und für Südwestafrika wohl bei günstigen Ernährungsverluältuissen (hier also nach der Regenzoit) verlasson die jungen Bienchen den Cocon und die weife Wollumbüllung, inden sie sich mit ihren Kiefern durch- 
nagen und durchzwängen, um das Freie zu gewinnen. Das Flugloch (vielleicht auch mehrere) befindet sich oben der Zweigspitze zu.

Die Nahrungspflanze der Serapis-Biene ist ebenso wir die Pflanzenart, welche die Wolle zum Nestbau liefert, noch nicht bekannt geworden. Die Biene ist iiber Ost- und Siidafrika verbreitet, lobt noch am Kilimandjaro und bei Willowmore im Kapland, fernor bei Mulango, Kigonsera. Malange, Usambara, Zanguebar und Bali.

Im Kapland kommen noch 2 etwas kleinere, aber sonst älnliche Arten ror: S. firesei bei Willowmore und S. mpipes bei Kradock; eine virute Art lebt in Kamerun, ist aber noch nicht beschrieben.

\section{so. Trigona beccarii var. abbofasciata 11. var. ㅇ.}

Wie Tr. becearï Grm. von Eritrea, aber Flecken und Binden auf Segment $1-6$ sehr breit, deutlich und elfenbeinweiß, anch die \%eichnungen des Kopfes wie Thorax auffallend hellgelb. Thoraxbehaarung heller, grolblichgrau. L. 5-5 $2 \mathrm{~mm}$, Br. $2-2 \frac{1}{2} \mathrm{nmm}$.

Doutsch-Sid westafrika, T'sumeb und Otjikoto bei Tsumeb, 13.-19. Juni 1911, Michaelsen leg. (5 야:

Farm Voigtsland, (). von Windhuk, 6.-19. Mai, Mucuelasex leg. (2 ㅇ).

Grootfontein, Tolkutx leg.

Fïr Deutsch-Siidwestafrika sind dies die mil bekannt oewordenen südlichsten Fundorte für Trigona-Arten; sir liegen ungeführ unter $18^{\circ}$ östl. Läinge und $19^{\circ}$ südl. Br., während der bisher südlichste Fundort fiur Trigone in Afrika ron der Kalkpfanne Koa unter 2.50 südl. Br. und $25^{\circ}$ östl. Länge bekannt geworden ist; ss handelt sich un die Trigona clypeatu Fruese, die von Hern Prof. L. Scichutze dort auf eines Narzissenart = Buplune sp.? mehrfach gesammelt wurde. Weiterer sidlicher Fundort für Trigona-Arten ist Bulawayo in Rhodesia, wo Trigona braunsi KonL und Tr. clypeata var. zebra Friese mehrfach gefunden wurden. (Rhodesia-Mus. (r. Arxold leg.). Bulawayo liegt unter dem 30.0 sidl. Br. und 25.0 östl. Länge.

\section{Apis mellifice valo arlamsomi Latr. for.}

오. Kopf und Thorax schwarz, seutelhm rot bis braun, Abdomen rotgelb, Segmentrand $2-5 \mathrm{meh}$ weniger braum bis schwarzbraun gefärbt, 6 ganz schwarz. Beine mehr weniger rotgelb. L. $15-16 \mathrm{~mm}$.

$\sigma$ - mit schwarzem Scutellum und kaum ron echien 4. mellifica o abweichend. Abdomen schwarz, Segmente 1-4 mitten am Endrandr mehr 
weniger breit gelb bandiert, Abdomenende und Gesicht gelblich behaart, Clypeus fast ganz gelblich gefärbt. L. $14 \mathrm{~mm}$.

Deutsch-Sïdwestafrika, Okahandja und Farm Neitsas boi Grootfontein, Fock leg. ((').

Delagoa-Bay, Rikatla, Juxod log. (q).

Transvaal, Shilouwane ( $\left.\sigma^{\prime}\right)$.

Deutsch-Ostafrika, Lukuledi.

Britisch-Ostafrika, Ikutha.

Auch vom Stanley river (?) vorliegend.

\section{Figurenerklïrung.}

Tafel VIII.

Fig. 1. Nylocopa cuffra var. mossambica Grib. und X. inconstans S. von Karibib. a. der Läng» nach aufgeschlitztes Stammstück einer vertrockneten Rhicims-Staude mit Nestern von $X$. caff'ra var mossambica (die 3 kleineren oberen Zellen) und $X$. inconstans (die 3 größeren unteren Zellen); $b$. Stammstiick einer vertrockneten Rhicinus-Staude mit 2 Fluglöchem von Xylocopa, dabei 2 오 von $X$. caffre var. mossambice. Natürl. Gr.

Fig. 2. Osmia sp. ? (O. musaica n. sp.) ron Willowmore in Kapland. Zwri Nester. Vergr. 2.

Fig. 3. Serapis denticulata Sx. von Grootfontein.

Ein der Länge nach aufgeschnittenes und auseinandergeklapptes Nest. Vergr. $3 / 2$.

Fig. 4. Serapis denticulate SM. von Grootfontein.

$a$. ein vollständiges Nest, $b$. ein 오, $c$. ein $\sigma$. Natïrl. Gr.

Fig. 5. Allodape sp. von Grootfontein.

4 Larven, $a$. Dorsalseite, $b$, Ventralseite, $a$ von der linken Seite, d. voln vorn. Vergr. $11 / 3$.

Fig. 6. Lithurgus ecpensis Friese von Willowmore in Kapland. Nester in Käfreohrlöchern alter Baumstämme. Vergr. $5 / 4$. 

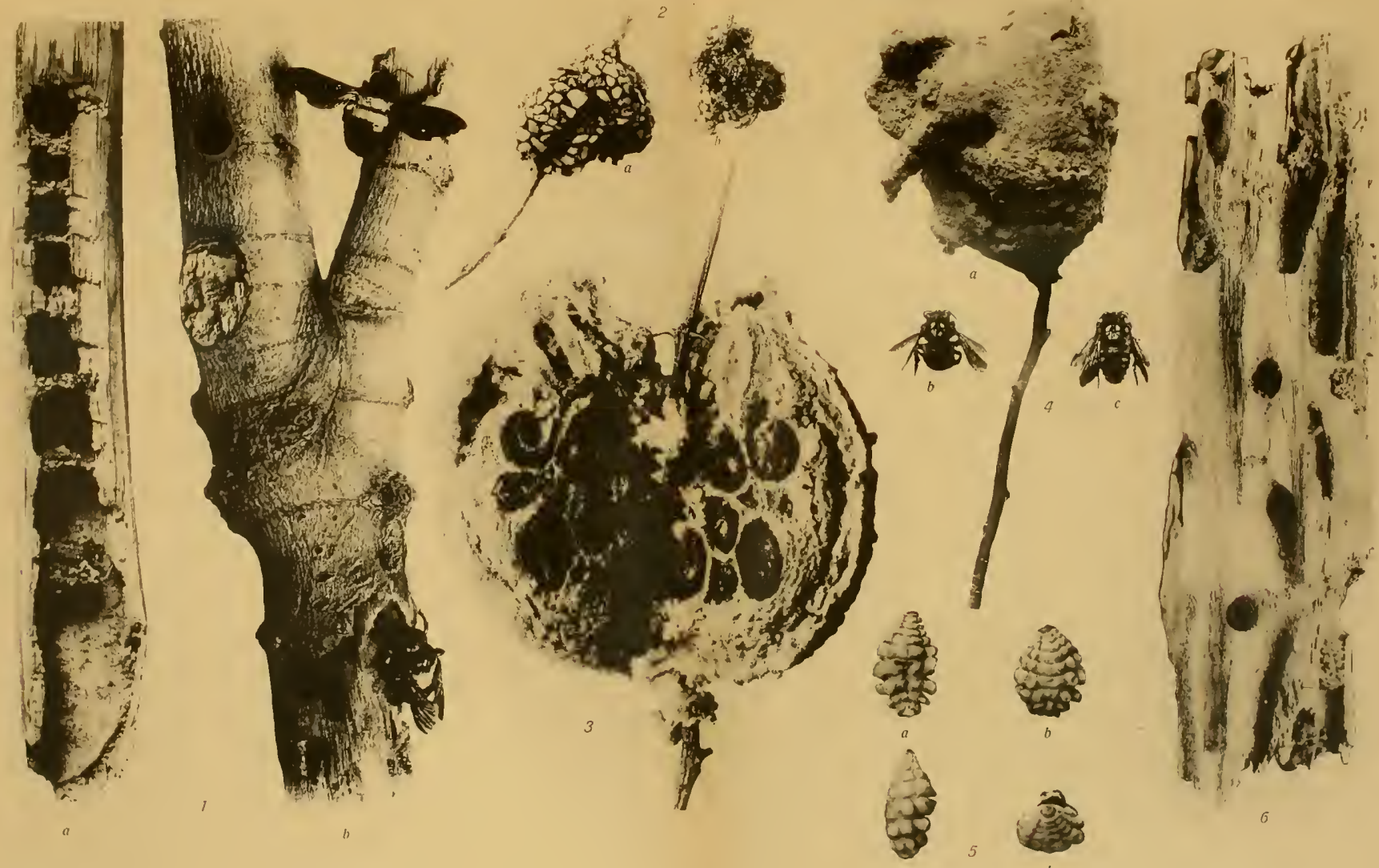



\section{Beiträge zur Kenntnis}

der

\section{Land- und Süßwasserfauna Deutsch-Südwestafrikas}

Ergebnisse der

Hamburger deutsch-südwestafrikanischen Studienreise 1911

Herausgegeben

von

\section{W. Michiaelsen (Hamburg).}

\section{$+$}

\section{Lieferung 1.}

\section{Vorwort.}

W. MICHAELSEN (Hamburg), Reisebericht mit 15 Abbildungen im Text und 1 Kartenskizze.

K. KRAEPELIN (Hamburg), Bryozoa mit 1 Tafel.

Y. SJÖSTEDT (Stockholm), Isoptera mit 1 Tafel und 2 Abbildungen im Text.

C. VAN DOUWE (München), Copepoda mit 1 Tafel und 1 Kartenskizze im Text.

K. KRAEPELIN (Hamburg), Shorpiones und Solifugae mit 6 Abbildungen im Text.

W. MICHAELSEN (Hamburg), Oligochaeta mit 1 Tafeln, 1 Abbildung und 6 Kartenskizzen im Text.

Alle Rechte vorbehalten.

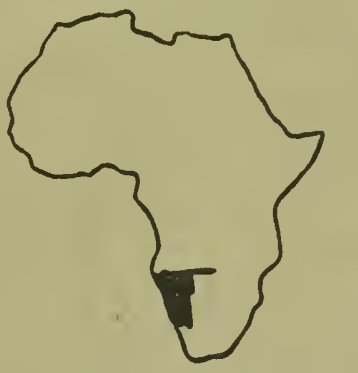

HAMBURG

L. FRIEDERICHSEN \& CO.

(Dr. L. \& R. FRIEDERICHSEN)

1914. 




\section{Verlag von L. Friederichsen \& Co., Hamburg.}

Gleichzeitig mit den „Beiträgen zur Kenntnis der Land- und Süßwasserfauna Deutsch Sudwestafrikas, Ergebnisse der Hamburger deutsch $\sim$ südwestafrikanischen Studienreise 1911 " beginnen in Lieferungen zu erscheinen:

\section{Beiträge \\ zur Kenntnis der Meeresfauna Westafrikas}

\section{herausgegeben von \\ Prof. Dr. W. Michaelsen, Hamburg.}

Zusammen mit den von Prof. Michaelsen in dem Küstenmeer von Deutsch-Südwestafrika erbeuteten Sammlungen, werden in obigem Werk die großen und wertvollen Sammlungen der Herren Kapt. Carl Hupfer, Prof. Richard Greeff und Dr. Arnold Schultze von der westafrikanischen Expedition des Herzogs Adolf Friedrich zu Mecklenburg, sowie verschiedene andere kleinere Sammlungen verarbeitet. Sie erstrecken sich über das Gebiet von Kap Verde bis zur Muindung des Oranje-Flusses.

Ergebnisse der Hamburger Magalhaensischen Sammelreise I892/93. Herausgegeben vom Naturhistorischen Museum zll Hamburg. 3 Bände. I896-1907. I636 S., II I Fig., 45 Taf. u. 3 Karten. M. 92.50.

Ehrenbaum, E.: Ueber Fische von Westafrika, besonders von Kamerun. (Sonderdruck aus dem »Fischerboten«, im Druck).

Fischerbote, Der. Zeitschrift für die Interessen der Hochsee-, Küsten- und Fluß fischerei, auch der Fischerei in den Kolonien. Herausgegeben vom Fischereidirektor H. Lübbert und Prof. Dr. E. Ehrenbaum in Hamburg. Vl. lahrgang 1914, jährlich M. 8. - .

Garrett, Andrew: Fische der Südsee, beschrieben und redigiert von Dr. Albert C. L. Günther. 3 Bände in $4^{\circ}$. 515 Seiten und 180 meist farbige Tafeln. 1873-1910. M. 540.-.

Waibel, Leo: Lebensformen und Lebensweise der Tierwelt im tropischen Afrika. Versuch einer geographischen Betrach tungsweise der Tierwelt auf physiologischer Grundlage. (Sonderdruck aus Mitteilungen der Geographischen Gesellschaft in Hamburg Band XXVII) 75 S. und I Karte. 1913. M. 3.-.

Weigold, Hugo: Lebensweise und wirtschaftiche Bedeutung der deutschen Seemőven (Sonderdruck aus dem »Fischerboten«) 3r S. u. ir Abb. M. I.50. 


\section{Beiträge zur Kenntnis}

der

\section{Land- und Süßwasserfauna Deutsch-Südwestafrikas}

Ergebnisse der

Hamburger deutsch-südwestafrikanischen Studienreise 1911

Herausgegeben

von

W. Michaelsen (Hamburg).

\section{Lieferung 2.}

GY. SZÉPLIGETI (Budapest), Hymenoptera I: Braconidae.

G. ENDERLEIN (Stettin), Hymenoptera II: Archihymenidae mit 1 Tafel und 1 Abbildung im Text.

J. J. KIEFFER (Bitsch), Hymenoptera III: Serphidae (Proctotropidae).

G. ENDERLEIN (Stettin), Hymenoptera IV: Ichneumonidae mit 6 Abbild. im Text.

N. ANNANDALE (Calcutta), Spongillidae with 1 plate.

J. WEISE (Warmbrunn), Coleoptera I: Chrysomelidae und Coccinellidae.

H. BICKHARDT (Kassel), Coleoptera II: Histeridae.

M. PIC (Digoin), Coleoptera III: MLalacodermata et Bruchidae.

P. LESNE (Asnière), Coleoptera IV: Iyctidae.

CH. KERREMANS (Brüssel), Coleoptera V: Buprestidae.

I. MOSER (Berlin), Coleoptera VI: Cetonidae.

Alle Rechte vorbehalten.

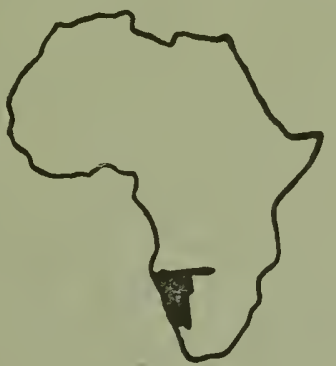

HAMBURG

L. FRIEDERICHSEN \& CO.

(Dr. L. \& R. FRIEDERICHSEN) 
Von den „Beiträgen zur Kenntnis der Land- und Sïßwasserfauna Deutsch-Siidwestafrikas, Ergebnisse der Hamburger deutsch-südwestafrikanischen Studienreise 1911 ist außer vorliegender Lieferung bisher erschienen:

Lieferung 1. 182 Seiten mit 24 Abbildungen im Text, 8 Kartenskizzen und 4 Tafeln. 1914. M. 12.-.

(Inhalt: Michaelsen, Reisebericht; Kraepelin, Bryozoa; Sjöstedt, Isoptera; van Douwe, Copepoda; Kraepelin, Skorpiones und Solifugae; Michaelsen, Oligochaeta). 



\section{Verlag von L. Friederichsen \& Co., Hamburg.}

Gleichzeitig mit den „Beiträgen zur Kenntnis der Land- und Sußwasserfauna Deutsch-Südwestafrikas, Ergebnisse der Hamburger deutsch-súdwestafrikanischen Studienreise 1911 " erscheinen:

\section{Beiträge}

\section{zur Kenntnis der Meeresfauna Westafrikas}

\section{Prof. Dr. W. Michaelsen, Hamburg.}

Zusammen mit den von Prof. Michaelsen in dem Küstenmeer von Deutsch-Südwestafrika erbeuteten Sammlungen, werden in obigem Werk die großen und wertvollen Sammlungen der Herren Kapt. Carl Hupfer, Prof. Richard Greeff und Dr. Arnold Schultze von der westafrikanischen Expedition des Herzogs Adolf Friedrich zu Mecklenburg, sowie verschiedene andere kleinere Sammlungen verarbeitet. Sie erstrecken sich über das Gebiet von Kap Verde bis zur Mündung des Oranje-Flusses.

Bisher erschienen:

Lieferung I. 84 S. m. 2 Porträts, I2 Abb. im Text, 2 Kartenskizzen u. 2 Taf. 1914. M. 6. - .

Ergebnisse der Hamburger Magalhaensischen Sammelreise $1892 / 93$. Herausgegeben vom Naturhistorischen Museum zu Hamburg. 3 Bände. 1896- 1907. 1636 S., 1 II Fig., 45 Taf. u. 3 Karten. M. 92.50.

Ehrenbaum, E.: Uleber Fische von Westafrika, besonders von Kamerun. (Sonderdruck aus dem »Fischerboten«, im Druck).

Fischerbote, Der. Zeitschrift für die Interessen der Hochsee-, Küsten- und Flußfischerei, auch der Fischerei in den Kolonien. Herausgegeben vom Fischereidirektor H. Lübbert und Prof. Dr. E. Ehrenbaum in Hamburg. Vl. lahrgang 1914, jährlich M. 8. - .

Garrett, Andrew: Fische der Südsee, beschrieben und redigiert von Dr. Albert C. L. Gunther. 3 Bände in $4^{\circ}$. 515 Seiten und 180 meist farbige Tafeln. 1873-1910. M. 540.-.

Waibel, Leo: Lebensformen und Lebensweise der Tierwelt im tropischen Afrika. Versuch einer geographischen Betrachtungsweise der Tierwelt auf physiologischer Grundlage. (Sonderdruck aus Mitteilungen der Geographischen Gesellschaft in Hamburg, Band XXVII) 75 S. und I Karte. I913. M. 3. - .

Weigold, Hugo: Lebensweise und wirtschaftiche Bedeutung der deutschen Seemõven (Sonderdruck aus dern "Fischerboten«) 31 S. u. II Abb. M. 1.50. 


\section{Beiträge zur Kenntnis der}

Land- und Süßwasserfauna

\section{Deutsch-Südwestafrikas}

Ergebnisse der

Hamburger deutsch-südwestafrikanischen Studienreise 1911

Herausgegeben

von

W. Michaelsen (Hamburg).

Lieferung 3.

Max Bernhauer (Horn in Niederösterreich), Coleoptera VII: Staphylinidae.

Fr. Werner (Wien), Reptilia und Amphibia, mit 1 Tafel und 1 Abbildung im Text.

Alle Rechte vorbehalten.

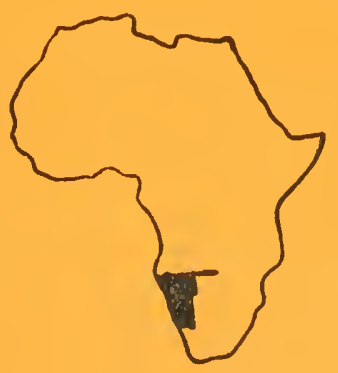

HAMBURG

L. FRIEDERICHSEN \& CO.

1915.

Prinled in Gormany 
Von den ..Beiträgen zur Kenntnis der Land- und Siißwasserfauna Dentsch-Siidwestafrikas, Ergebnisse der Llamburger dentsch-siidwestafrikanischen Studienreise 19116 ist außer vorlingender Lieferung bisher erschienen:

Lieferung 1. 182 Seiten mit 24 Abbildungen im Text, 8 Kartenskizzen und 4 Tafeln. 1914. M. 12.-.

(Inhalt: Michaelsen, Reisebericht; Kraepelin, Bryozoa; Sjöstedt, Isoptera; van Douwe, Copepoda; Kraepelin, Skorpiones und Solifugae; Michaelsen, Oligochaeta).

Lieferung 2. 125 Seiten mit 7 Abbildungen im Text und 2 Tafeln. 1914. M. 8.-.

(Inhalt: Szepligeti, Hymenoptera I: Braconidae; Enderlein, Hymenoptora II : Archihymenidae; Kieffer, Hymenoptcra III : Serphidae (Proctotropidae); Enderlein, Hymenoptera IV : Ichneumonidae; Annandale, Spongillidae; Weise, Coleoptera I: Chrysomelidae und Coccinellidae; Bickhardt, Coleoptera II: Histeridae; Pic, Coleoptera III: Malacodermata et Bruchidae; Lesne, Coleoptera IV: Lyetidae; Kerremans, Coleoptera V: Buprestidae; Moser, Coleoptera VI: Cetonidae. 



\section{Verlag von L. Friederichsen \& Co., Hamburg.}

Gleichzeitig mit den "Beiträgen zur Kenntnis der Land und Süßwasserfauna Deutsch-Sudwestafrikas, Ergebnisse der Hamburger deutsch-südwestafrikanischen Studienreise 1911" erscheinen:

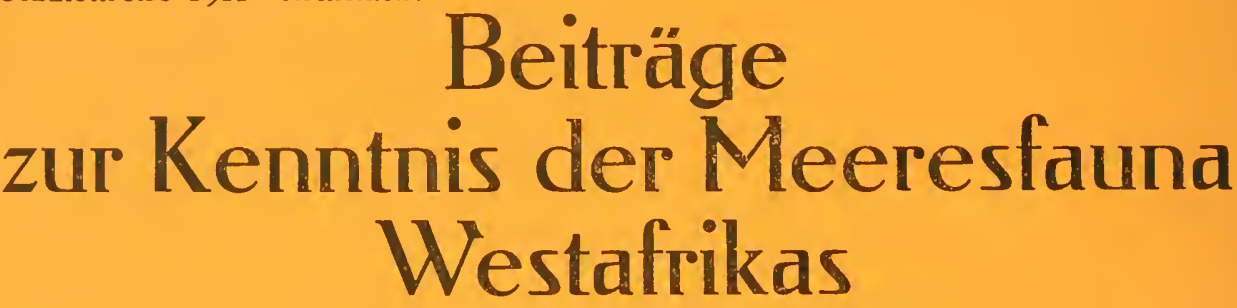

herausgegeben von

\section{Prof. Dr. W. Michaelsen, Hamburg.}

Zusammen mit den von Prof. Michaelsen in dem Küstenmeer von Deutsch-Südwestafrika erbeuteten Sammlungen, werden in obigem Werk die großen und wertvollen Sammsungen der Herren Kapt. Carl Hupfer, Prof. Richard Greeff und Dr. Arnold Schultze von der westafrikanischen Expedition des Herzogs Adolf Friedrich zu Mecklenburg sowie verschiedene andere kleinere Sammlungen verarbeitet. Sie erstrecken sich über das Gebiet von Kap Verde bis zur Mündung des Oranje-Flusses.

Bisher erschienen:

Lieferung I. 182 S. m. 24 Abb. im Text, 8 Kartenskizzen U. 4 Taf. 19r4. M. 12. -

》2. 234 S. m. 13 Tafeln. 1914. M. 20.-.

” 3. 200 S. m. 4 Tafeln und 4 Abb. im Text. 1915. M. 18.-.

Ergebnisse der Hamburger Magalhaensischen Sammelreise I892/93.

Herausgegeben vom Naturhistorischen Museum zn Hamburg. 3 Bände. 1896-1907 I636 S., I I I Fig., 45 Taf. u. 3 Karten. M. 92.50.

Ehrenbaum, E. : Uleber Fische von Westafrika, besonders von Kamerun. (Sonderdruck aus dem »Fischerboten«, im Druck).

Fischerbote, Der. Zeitschrift für die Interessen der Hochsee-, Küsten - und Fluß fischerei, auch der Fischerei in den Kolonien. Herausgegeben von Fischereidirektor H. Lübbert und Prof. Dr. E. Ehrenbaum in Hamburg. VIl. lahrgang 1915. lährlich M. 8. - .

Garrett, Andrew: Fische der Südsee, beschrieben und redigiert von Dr. Albert C. L. Günther. 3 Bände in $4^{\circ}$. 515 Seiten und 180 meist farbige Tafeln. 1873-1910. M. 540.-.

Waibel, Leo: Lebensformen und Lebensweise der Tierwelt im tropischen Afrika. Versuch einer geographischen Betrach tungsweise der Tierwelt auf physiologischer Grundlage. (Sonderdruck aus Mitteilungen der Geographischen Gesellschaft in Hamburg, Band XXVII) 75 S. und I Karte. 1913. M. 3.- .

Weigold, Hugo: Lebensweise und wirtschafliche Bedeutung der deutschen Seemöven (Sonderdruck aus dem »Fischerboten«) 31 S. u. 1 I Abb. M. 1.50. 


\section{Beiträge zur Kenntnis der}

\section{Land- und Süßwasserfauna Deutsch-Südwestafrikas}

Ergebnisse der

Hamburger deutsch-südwestafrikanischen Studienreise 1911

Herausgegeben

von

W. Michaelsen (Hamburg).

Lieferung 4.

G. STEINER (Zürich-Thalwil), Nematodes, mit 26 Abbildungen im Text.

W. FRIESE (Schwerin i. M.), Hymenoptera V: Apidae, mit 1 Tafel.

$\overline{\text { Alle Rechte vorbehalten. }}$

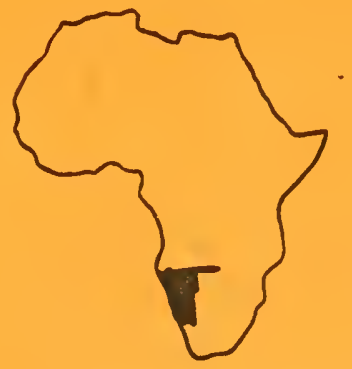

HAMBURG

L. FRIEDERICHSEN \& CO.

1916.

Printed in Germany 
Von den "Beitrïgen zur Kenntnis der Land- und Siißwasserfauna Dentsch-Suidwestafrikas, Ergebnisse der Hamburger deutsch-siidwestafrikanischen Studienreise $\mathbf{1 9 1 1 6 5}^{6}$ ist außer vorliegender Lieferung bisher erschienen:

Lieferung 1. 182 Seiten mit 24 Abbildungen im Text, 8 Kartenskizzen und 4 Tafeln. 1914. M. 12.-.

(Inhalt: Michaelsen, Reisebericht; Kraepelin, Bryozoa; Sjöstedt, Isoptera; van Douwe, Copepoda; Kraepelin, Skorpiones und Solifugae; Michaelsen, Oligochaeta.)

Lieferung 2. 125 Seiten mit 7 Abbildungen im Text und 2 Tafeln. 1914. M. 8.-.

(Inhalt: Szépligeti, Hymenoptera I: Braconidae; Enderlein, Hymenoptera II: Archihymenidae; Kieffer, Hymenoptera III: Serphidae (Proctotropidae); Enderlein, Hymenoptera IV : Ichneumonidae; Annandale, Spongillidae; Weise, Coleoptera I: Chrysomelidae und Coccinellidae; Bickhardt, Coleoptera II: Histeridae; Pic, Coleoptera III: Malacodermata et Bruchidae; Lesne, Coleoptera IV: Lyctidae; Kerremans, Coleoptera V: Buprestidae; Moser, Coleoptera VI: Cetonidae).

Lieferung 3. 66 Seiten mit 1 Abbildung im Text und 1 Tafel. 1915. M. 4.-.

(Inhalt: Bernhauer, Coleoptera VII: Staphylinidae; Werner, Reptili a und Amphibia.) 



\section{Verlag von L. Friederichsen \& Co., Hamburg.}

Gleichzeitig mit den »Beitrăgen zur Kenntnis der Land- und Süßwasserfauna Deutsch-Súdwestafrikas, Ergebnisse der Hamburger deutsch-südwestafrikanischen Studienreise I9II" erscheinen:

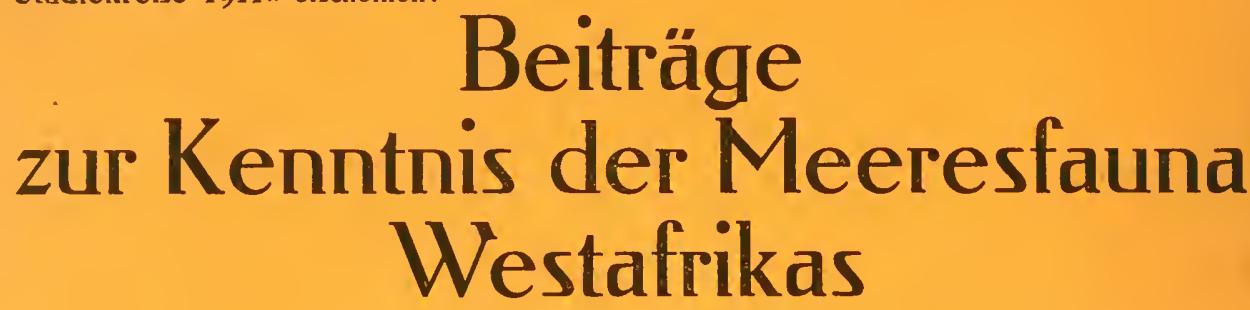

herausgegeben von

Prof. Dr. W. Michaelsen, Hamburg.

Zusammen mit den von Prof. Michaelsen in dem Küstenmeer von Deutsch-Südwestafrika erbeuteten Sammlungen, werden in obigem Werk die großen und wertvollen Sammsungen der Herren Kapt. Carl Hupfer, Prof. Richard Greeff und Dr. Arnold Schultze von der westafrikanischen Expedition des Herzogs Adolf Friedrich zu Mecklenburg, sowie verschiedene andere kleinere Sammlungen verarbeitet. Sie erstrecken sich über das Gebiet von Kap Verde bis zur Mündung des Oranje-Flusses.

Bisher erschienen:

Lieferung I. 182 S. m. 24 Abb. im Text, 8 Kartenskizzen u. 4 Taf. 1914. M. 12.- .

》2. 234 S. m. 13 Tafeln. 1914. M. 20. - .

" 3. 200 S. m. 4 Tafeln und 4 Abb. im Text. 1915. M. 18.-.

Ergebnisse der Hamburger Magalhaensischen Sammelreise 1892/93. Herausgegeben vom Naturhistorischen Museum zu Hamburg. 3 Bände. 1896-1907 1636 S., 111 Fig., 45 Taf. u. 3 Karten. M. 92.50.

Ehrenbaum, E.: Uleber Fische von Westafrika, besonders von Kamerun. (Sonderdruck aus dem »Fischerboten«).

Fischerbote, Der. Zeitschrift für die lnteressen der Hochsee-, Küsten- und Flußfischerei, auch der Fischerei in den Kolonien. Herausgegeben von Fischereidirektor H. Lübbert und Prof. Dr. E. Ehrenbaum in Hamburg. Vll. lahrgang 1915. lährlich M. 8. - .

Garrett, Andrew: Fische der Südsee, beschrieben und redigiert von Dr. Albert C. L. Günther. 3 Bände in $4^{0}$. 515 Seiten und 180 meist farbige Tafeln. 1873-1910. M. 540.- .

Waibel, Leo: Lebensformen und Lebensweise der Tierwelt im tropischen Afrika. Versuch einer geographischen Betrachtungsweise der Tierwelt auf physiologischer Grundlage. (Sonderdruck aus Mitteilungen der Geographischen Gesellschaft in Hamburg, Band XXVIl) 75 S. und i Karte. 1913. M. 3.- .

Weigold, Hugo: Lebensweise und wirtšchaftliche Bedeutung der deutschen Seemőven (Sonderdruck aus dem "Fischerboten«) 31 S. u. I I Abb. M. I.50. 







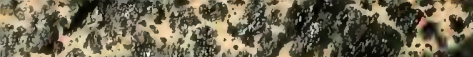

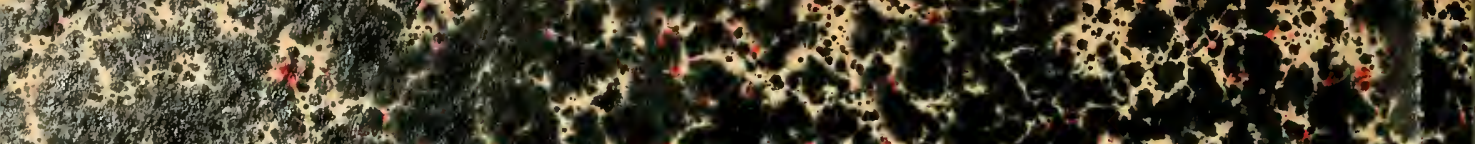
4.

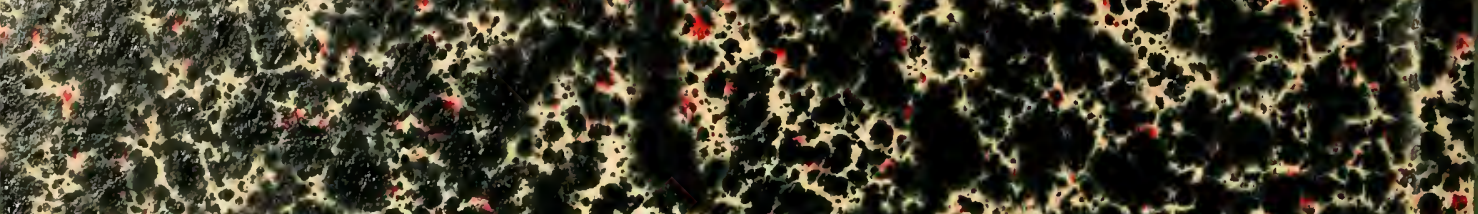

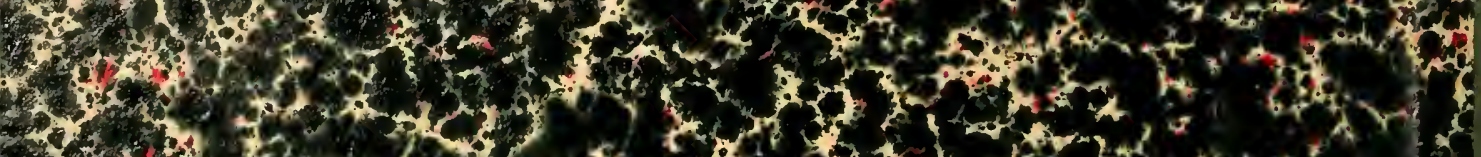

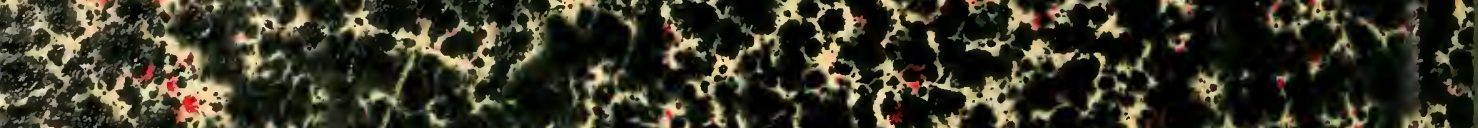
2.

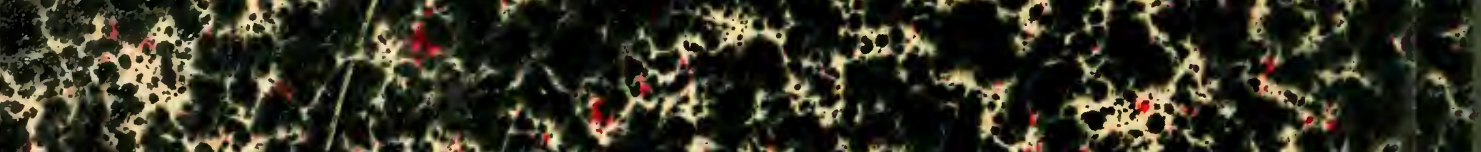
2. 3.

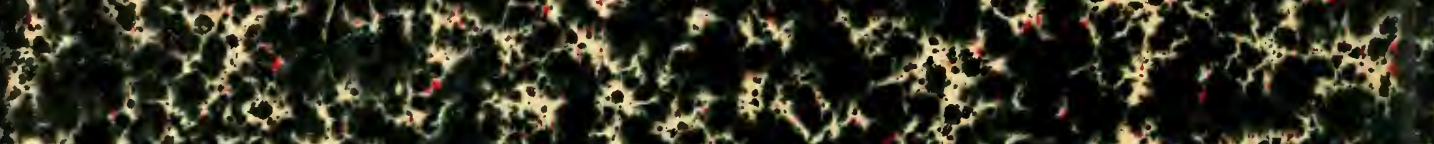
2 .

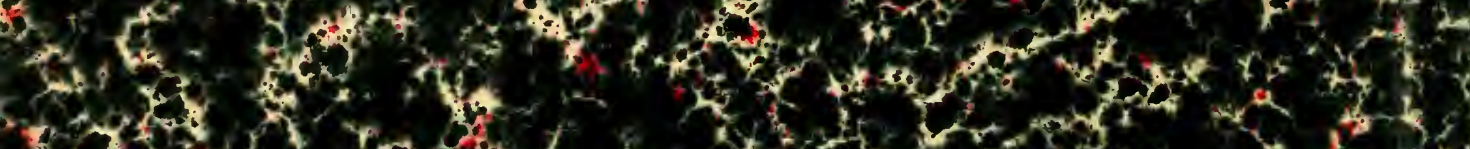

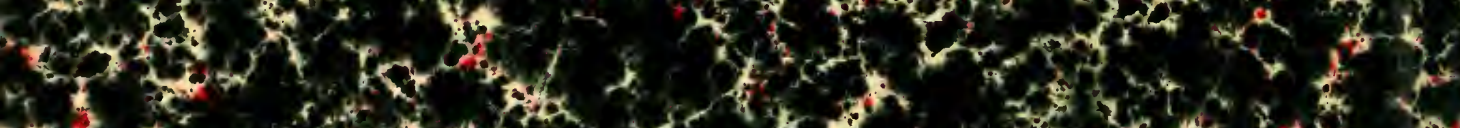
2.

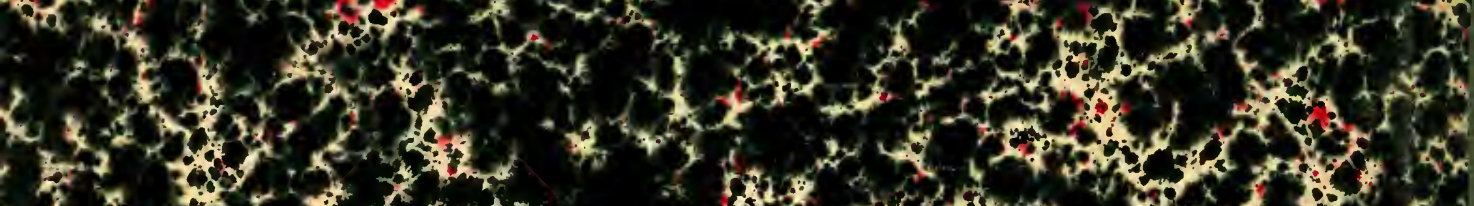

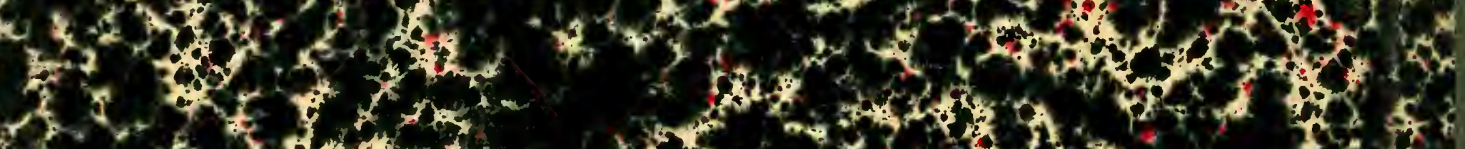

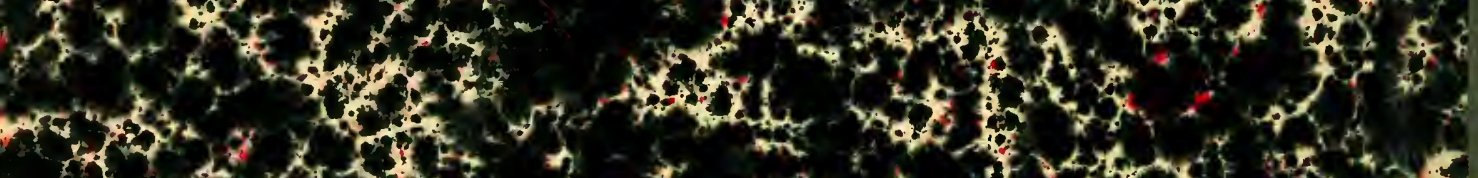

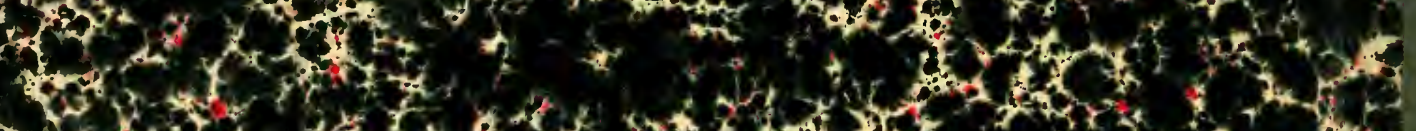

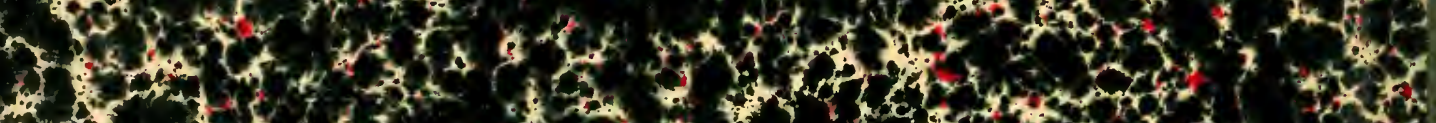

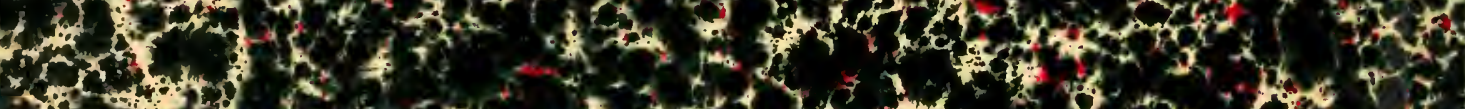

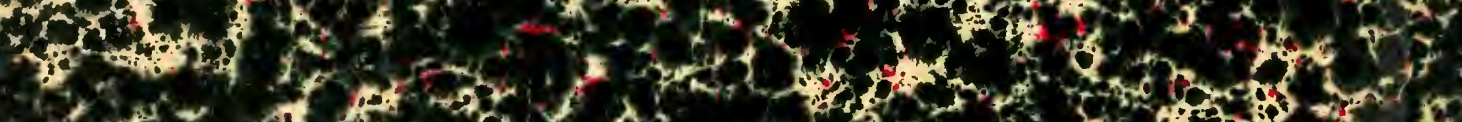

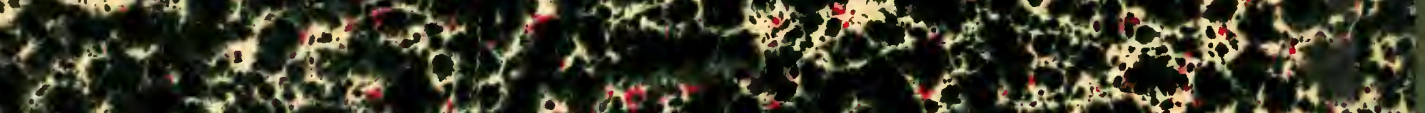

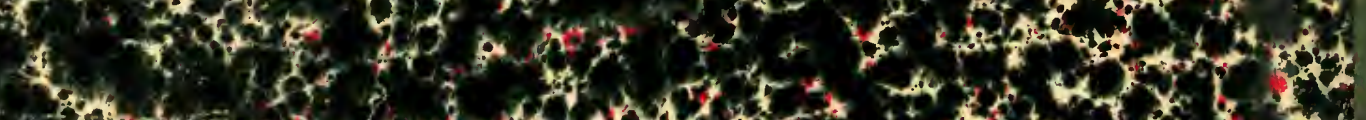

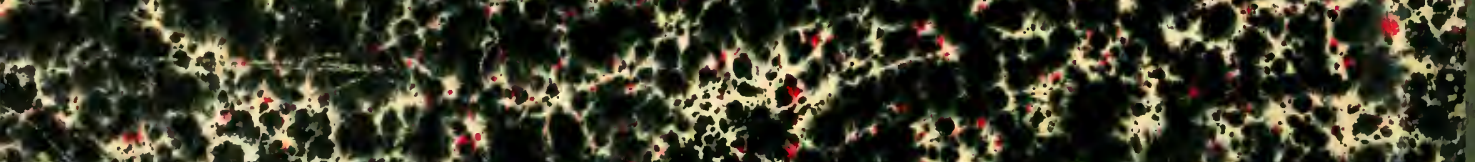

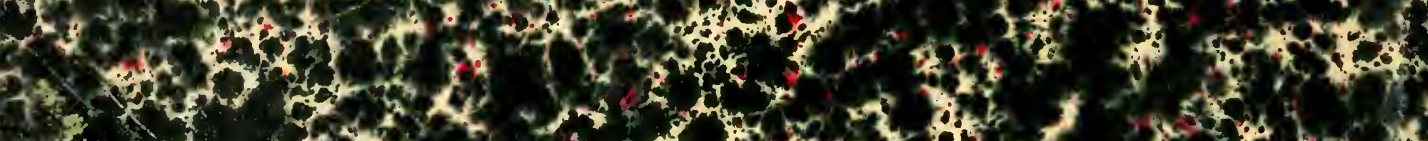
(1)

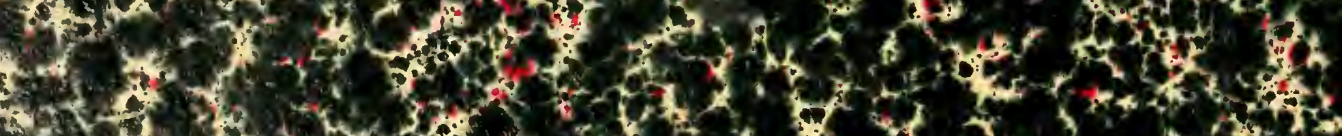

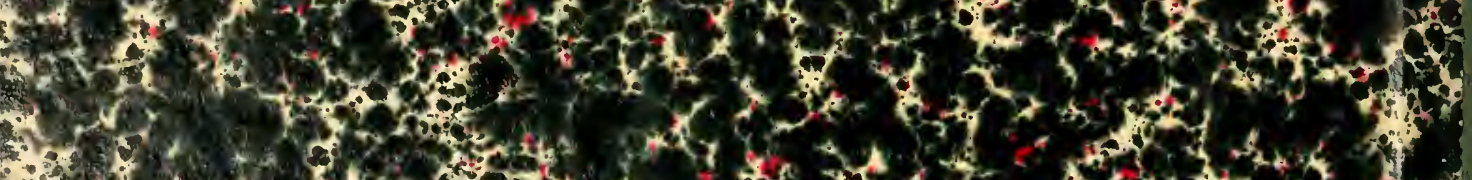

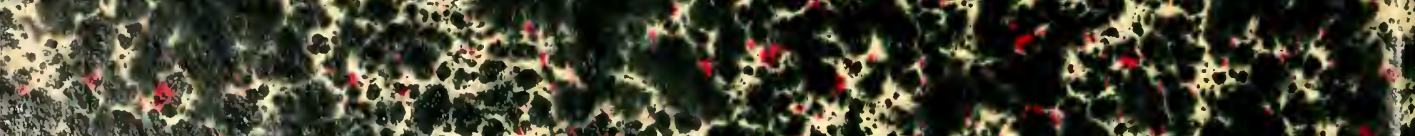

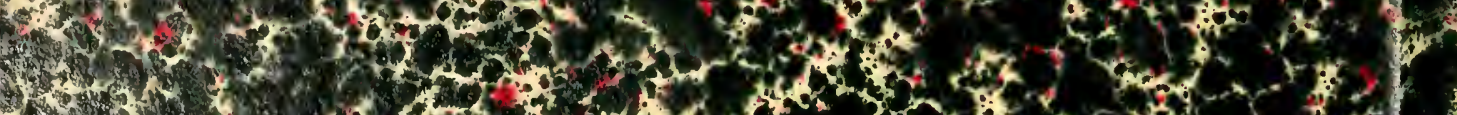

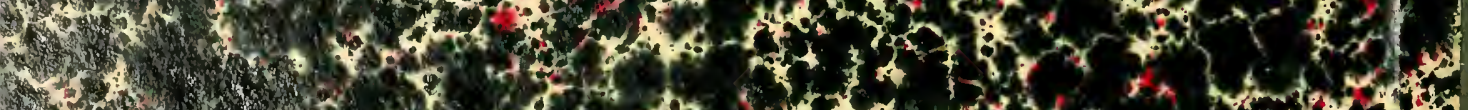

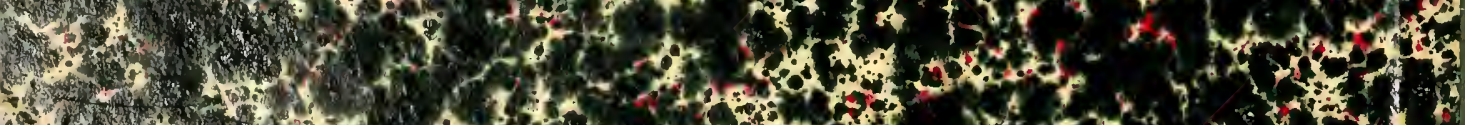

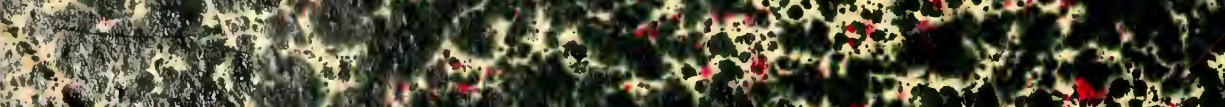

